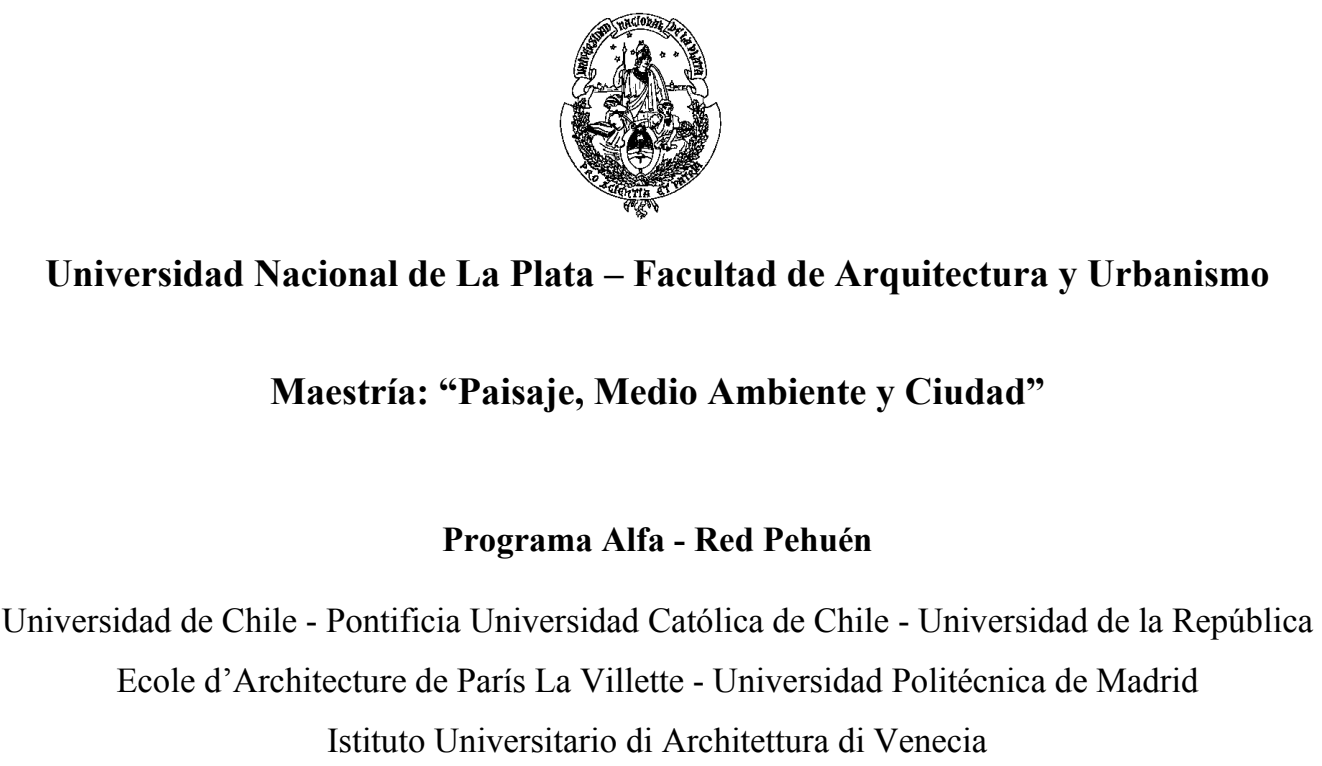

Istituto Universitario di Architettura di Venecia

$<<$ Tesis para optar por el grado de Magíster $>>$

\title{
EL PAISAJE COSTERO COMO FACTOR DE INTEGRACIÓN
}

EL PROYECTO HIDROELÉCTRICO YACYRETÁ Y LAS TRANSFORMACIONES DEL PAISAJE EN LAS ZONAS URBANO-COSTERAS DE LAS CIUDADES INVOLUCRADAS, EN EL PERIODO 2005-2010.

Presentado por: Carlos Alberto Fulco

Director: Fernando Alfredo Tauber - Dr. Arquitecto UNLP

La Plata, diciembre de 2011 

Agradecimientos

Un agradecimiento especial al Arq. Oscar Thomas, Director Ejecutivo de la Entidad Binacional Yacyretá, por haberme permitido realizar este esfuerzo de investigación, e indagar los archivos y la documentación hasta aquí, en gran parte inédita sobre el Proyecto Hidroeléctrico Yacyretá.

En el ámbito laboral de Yacyretá, a Raúl Leyton, Mauricio Perayre, Nelson Simões, Héctor Roncati, Carlos Basaldúa, Daniel Maxit, Miguel Angel Almirón, Marcelo Cardinali, Rodolfo Sténico y Leticia Ortiz Ibáñez, que han colaborado orientando la búsqueda y análisis de información, y por el material propio brindado.

También especialmente, a Norberto Levinton, por el aporte bibliográfico, de material edito e inédito de sus investigaciones en marcha, y por la orientación brindada para encauzar los aspectos históricos de la región que ha sido objeto de estudio de esta investigación.

En la Universidad Nacional de Misiones, al Prof. Dr. Leopoldo Bartolomé, del Programa de Posgrado de Antropología Social, y al Dra. Ana Gorosito de la Facultad de Humanidades y Ciencias Sociales.

En la Facultad de Arquitectura y Urbanismo de la UNLP, en particular en la Maestría Paisaje, Medio Ambiente y Ciudad, a mis profesores, con una mención especial a Gustavo San Juan y Leandro Varela, que han orientado mi formación en esta temática del paisaje y en la búsqueda de información.

A mi familia, Alejandra, Débora y Camila, por su paciente comprensión y apoyo durante el largo tiempo que me ha demandado esta apasionante investigación. Y una dedicatoria muy especial a mi madre, y a la memoria de mi padre. 



\section{ÍNDICE}

RESUMEN 7

PARTE I: EL CONCEPTO DE PAISAJE EN UN TERRITORIO TRANSFORMADO POR UNA GRAN OBRA DE INFRAESTRUCTURA HIDROELÉCTRICA

CAPÍtUlo I: LA DIMENSIÓN DEL PAISAJE EN EL CONTEXTO DE LAS GRANDES OBRAS DE

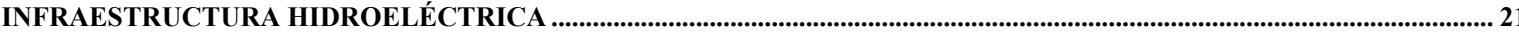

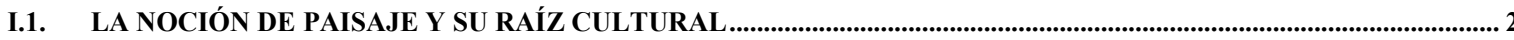

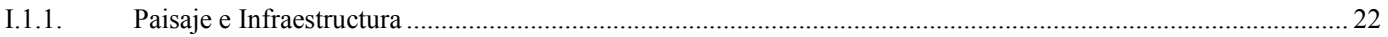

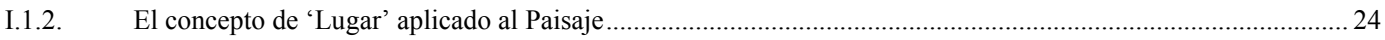

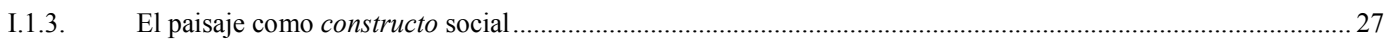

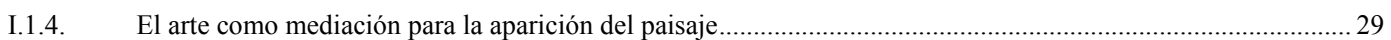

I.2. EL PAISAJE COMO DISCIPLINA PARA ENTENDER LA OBRA DE INGENIERÍA ENRAIZADA EN SU ENTORNO. 31

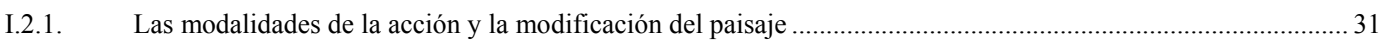

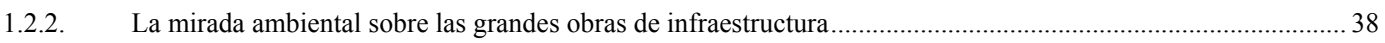

1.2.3. Algunas alternativas para un proyecto hidroeléctrico a gran escala................................................................39

I.3. LAS GRANDES OBRAS DE INFRAESTRUCTURA HIDROELÉCTRICAS EN EL CONTEXTO DE LA EVOLUCIÓN DEL DEBATE INTERNACIONAL EN TORNO AL VÍNCULO ENTRE MEDIO AMBIENTE Y

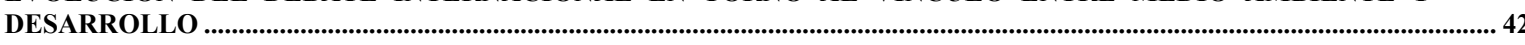

I.3.1. Expansión de la frontera económica y uso irrestricto de los recursos naturales ...............................................43

I.3.2. Década de 1960: el surgimiento del movimiento ambiental ........................................................................ 47

I.3.3. Década de 1970: consolidación del movimiento ambientalista ........................................................................49

I.3.4. Década de 1980: internacionalización del debate ambiental ........................................................................50

I.3.5. Década de 1990: el camino hacia el eco-desarrollo ...........................................................................................52

I.3.6. Década de 2000: hacia un desarrollo gestado localmente ..................................................................................5

CAPÍTULO II: LA EVOLUCIÓN DEL PAISAJE EN LA CUENCA DEL ALTO PARANÁ: DE LA REGIÓN HISTÓRICA GUARANÍ A LAS GRANDES TRANSFORMACIONES TERRITORIALES .

II.1. DESARROLLO HISTÓRICO REGIONAL: la pervivencia de una Región Cultural

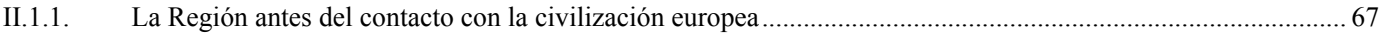

II.1.2. La Región en el contexto del primer contacto con la Cultura Europea (1515/1603)............................................... 72

II.1.3. Los Pueblos-Ciudad Jesuíticos (1604/1767): la noción de una Región Cultural ................................................. 76

II.1.4. La Región en el período de formación e institucionalización de los Territorios Nacionales (1769/1882): el tránsito

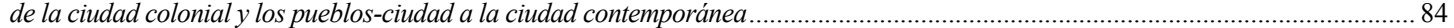

II.2. LA REGIÓN HOY: La Cuenca del Plata y los Proyectos Hidroeléctricos.................................................................................... 92

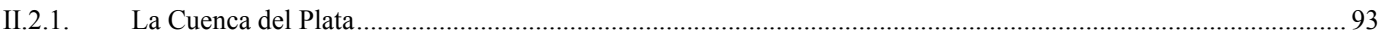

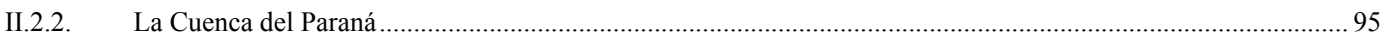

II.2.3. Aprovechamiento Hidroeléctrico de la Cuenca del Plata ............................................................................... 98

II.3. ASPECTOS CONCEPTUALES Y CRITERIOS PARA UN ANÁLISIS Y UNA REFLEXIÓN HISTÓRICA SOBRE EL PAISAJE

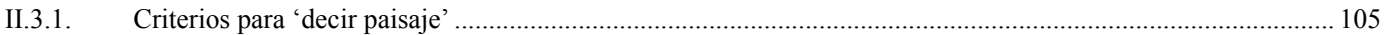

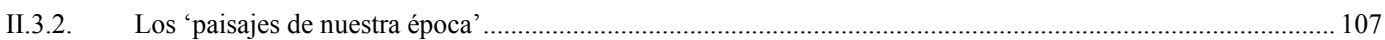

II.3.3. De la obra al concepto: principales elementos del Paisaje .............................................................................. 109 
PARTE II: HACIA UNA GESTIÓN SUSTENTABLE DEL PAISAJE EN EL CONTEXTO DE LAS TRANSFORMACIONES URBANO-TERRITORIALES DERIVADAS DE LA EJECUCIÓN DE YACYRETÁ EN LAS ZONAS URBANO-COSTERAS

CAPÍTULO III: CONSIDERACIONES ACERCA DEL PROCESO DE RECONFIGURACIÓN DEL PAISAJE EN EL AREA DE IMPLANTACION DE YACYRETÁ

III.1. EL PROYECTO HIDROELÉCTRICO YACYRETÁ

III.1.1. Yacyretá: evolución de los hechos que definen el proyecto y la transformación del paisaje .......................................... 114

III.1.2. Principales elementos que operan la transformación del paisaje ................................................................... 125

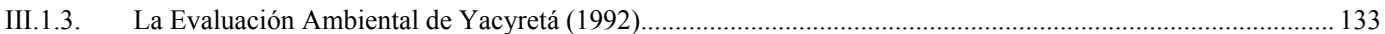

III.2. EL PAISAJE EN EL EMBALSE Y EN LAS CUENCAS INTERIORES

III.2.1. El Embalse de Yacyretá: la transformación del paisaje a escala microregional ............................................. 136

III.2.2. Subembalses: la transformación del paisaje a escala local ............................................................................ 138

III.3. EMBALSE, SUBEMBALSES Y CIUDAD: las Zonas Urbano-Costeras

III.3.1. El área de Posadas, en Argentina.

III.3.2. El área de Encarnación, en Paraguay

III.3.3. Las implicancias de la Obra sobre su área de implantación y los instrumentos de gestión territorial como basamento del proyecto Paisaje....

III.4. LAS MEDIDAS DE MITIGACIÓN Y LOS PROYECTOS DE RECONFIGURACIÓN TERRITORIAL

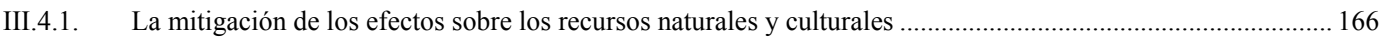

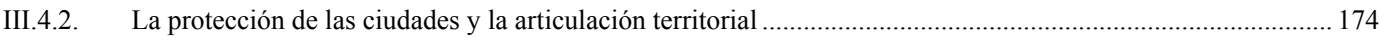

III.4.3. La planificación como estrategia para la terminación de Yacyretá............................................................. 177

CAPÍTULO IV: EL PAISAJE COSTERO Y LAS TRANSFORMACIONES EN LAS CIUDADES INVOLUCRADAS POR YACYRETÁ, ENTRE LOS AÑOS 2005 A 2010 181

IV.1. APROXIMACIÓN A LA NOCIÓN DE PAISAJE A PARTIR DE 'LA ACCIÓN’

IV.1.1. Interpretación del Proyecto como Paisaje a escala ‘Territorio' '.................................................................. 183

IV.1.2. Interpretación del Proyecto como Paisaje a escala 'Área'

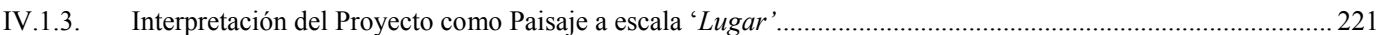

IV.2. DEL PROYECTO A LA REFLEXIÓN: Hacia un Modelo de Gestión del Paisaje

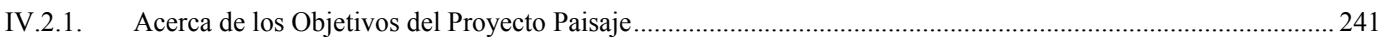

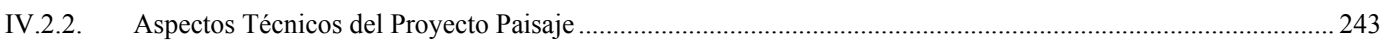

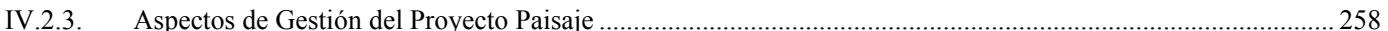

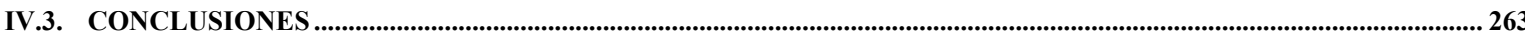




\section{EL PAISAJE COSTERO COMO FACTOR DE INTEGRACIÓN}

El Proyecto Hidroeléctrico YaCyretá y las transformaciones del Paisaje en las

\section{ZONAS URBANO-COSTERAS DE LAS CIUDADES INVOLUCRADAS, EN EL PERIODO 2005-2010}

Palabras Clave: PAISAJE / INFRAESTRUCTURA - INTERFASE COSTERA / LUGAR / RESIGNIFICACIÓN DESARROLLO SOSTENIBLE / GESTIÓN.

\section{RESUMEN}

La tesis analiza la dimensión que alcanza la noción de paisaje en el contexto de un territorio transformado por una gran obra de infraestructura hidroeléctrica, como es el caso del Proyecto Hidroeléctrico Yacyretá (PHY), profundizando el análisis en el paisaje costero de las ciudades involucradas, en el período junio de 2005 - julio de 2010, dado que en ese quinquenio se consolidan las transformaciones de las zonas urbano-costeras que son el objeto específico de esta investigación.

De tal forma, dicha investigación identifica el escenario en el que se sitúa el objeto de estudio, reconociendo el concepto de paisaje dentro de un ámbito territorial transformado por la construcción de una gran obra de infraestructura (Yacyretá), considerando en ese recorrido, cómo ha sido la evolución histórica de la región dónde dicha obra se inserta, y el estado de un abanico de variables 'externas' al proyecto, como el contexto internacional en el que se desarrolló y expandió el apoyo y financiamiento a este tipo de obras; las implicancias de las nociones de desarrollo y sus correspondientes imperativos dominantes por los que pasó el proyecto desde su concepción a inicios de la década del 60, hasta la actualidad; las diversas miradas sobre el controvertido tema de las transformaciones derivadas de la construcción de una gran obra de infraestructura hidroeléctrica y su impacto; y, un conjunto de variables 'internas', como las características e impactos propios del proyecto; los escenarios, tendencias y desafíos, que orientaron el propio proceso de terminación de Yacyretá; y las posibilidades que ofrece una visión integral desde la noción de paisaje como proceso proyectual, para definir pautas y estrategias de planificación y gestión participativa del territorio transformado.

El análisis de estas variables, ha permitido verificar que puede encauzarse una gestión del paisaje, a partir de sus interfases costeras, principalmente las urbano-costeras localizadas tanto sobre el embalse del río Paraná, como en los subembalses de los arroyos urbanos, dónde la planificación y gestión participativa como proceso, se muestra como una componente del discurso reciente de marcada vigencia, y como insumo indispensable para orientar la '(re)conciliación' entre cultura y naturaleza como objetivo, teniendo al desarrollo sustentable como camino a transitar y meta a alcanzar, en un contexto de corresponsabilidad socio-institucional.

En suma, el caso de las zonas urbano-costeras como ejemplo tangible de los procesos de transformación natural-cultural de ese territorio, verifica en líneas generales el fenómeno de reconfiguración de la ciudad y del territorio, y permite revisar con precisión los aspectos específicos para una gestión holística de un 'nuevo paisaje', que debe ser aprehendido por el conjunto social. 


\section{INTRODUCCIÓN}

El desarrollo de la Tesis comprende "[...] una indagación sobre esa relación esencial del hombre con la naturaleza que es el construir" (Aguiló, 1999:13), y para ello, la misma se estructura a partir de una introducción, dónde se define el objeto de estudio, la perspectiva de análisis y la metodología de investigación, que se desarrolla en dos partes: En la primera, se indaga sobre el estado de la cuestión de aquellos aspectos que condicionan y contextualizan el objeto de estudio, delimitando el marco teórico-conceptual que, respecto de una cierta posición asumida con relación a las variables paisaje e infraestructura, permite explicar los alcances de la ruptura del proceso histórico de su consolidación, entendido como síntesis de la relación naturaleza y cultura, por efecto de la construcción de un proyecto a gran escala (en este caso hidroeléctrico). En tanto que en la segunda parte, se enfoca el análisis de las transformaciones del paisaje derivadas de la construcción del Proyecto Hidroeléctrico Yacyretá (PHY), profundizando la noción de paisaje como proyecto, en las zonas urbano-costeras de las ciudades directamente intervenidas dentro del proceso de terminación de Yacyretá.

\section{Objeto de Estudio}

El objeto de estudio de esta investigación es la gestión del paisaje transformado por efecto de la construcción de una obra de infraestructura hidroeléctrica a gran escala, como es el caso del Proyecto Hidroeléctrico Yacyretá (PHY), profundizando el análisis en las zonas urbano-costeras de las ciudades involucradas, en el quinquenio comprendido entre el mes de junio de 2005, al mes de julio de $2010 .{ }^{1}$

Considerando la particularidad del objeto de investigación conformado por un territorio cuyo paisaje no ha sido transformado por un proceso derivado del lento devenir histórico, sino que ha sido modificado por la construcción de una gran obra de infraestructura hidroeléctrica, para definir el objeto de estudio en profundidad, fue necesario establecer un conjunto de puntos de referencia que se precisan y delimitan en la primera parte de la investigación.

Por una parte, ¿qué dimensión alcanza la idea de paisaje en el contexto de un territorio transformado por una gran obra de infraestructura hidroeléctrica?, ¿cómo es la raíz cultural de esa noción de Paisaje?, ¿es esta noción de paisaje la disciplina más adecuada para entender la obra de ingeniería enraizada en su entorno?, ¿cómo ha sido la irrupción de estas grandes obras de infraestructura en el mundo?, ¿cómo ha evolucionado su apoyo o su crítica en el contexto del debate internacional en torno al vínculo entre me-

\footnotetext{
${ }^{1}$ El periodo seleccionado está relacionado con la efectiva consolidación del proceso de terminación del Proyecto Hidroeléctrico Yacyretá, a partir del inicio de las obras; si bien dicho proceso, fue sustanciado con la aprobación en el mes de febrero de 2004 del Plan de Terminación Yacyretá (PTY) por las Altas Partes Contratantes, conformadas por los respectivos gobiernos de la Repúblicas de Argentina y del Paraguay; por el Acuerdo de Ministros y el Compromiso de Financiamiento asumido en abril del mismo año por el Gobierno Argentino; y por la aprobación, en septiembre de 2004, de los Acuerdos establecidos, en la Quinta Reunión de Alto Nivel (Va. RAN), entre los Gobiernos de ambos países, el Banco Internacional de Reconstrucción y Fomento o Banco Mundial y el Banco Interamericano de Desarrollo, realizada en la sede central de este último, en Washington DC, EEUU.
} 
dio ambiente y desarrollo?, ¿cómo pensar en este caso la relación 'cultura-naturaleza' como potencialidad -paisaje- y no como ruptura?, ¿cómo ha sido la evolución del paisaje en la Región?

Y por otra, ¿es posible que las transformaciones derivadas de la construcción de una gran obra de infraestructura -en nuestro caso, hidroeléctrica- puedan ser compatibilizadas con el objetivo de desarrollo sustentable?, ¿cuáles son las principales consideraciones acerca de la configuración del paisaje de las cuencas interiores y del paisaje urbano en su área de influencia?, ¿cómo inciden las medidas de mitigación y los proyectos de reconfiguración territorial?, ¿qué dimensión alcanza la idea de gestión sustentable del paisaje en el contexto de las transformaciones urbano-territoriales derivadas de la terminación de Yacyretá, en los sectores urbano-costero de las ciudades afectadas?

La búsqueda de respuestas a estas preguntas fundantes, permite señalar que el objetivo general de la tesis es dilucidar si es posible -una vez consolidada la decisión de construir una gran obra de infraestructura hidroeléctrica como Yacyretá- identificar, desde la noción de paisaje, pautas de gestión que contengan la idea de 'reconciliación' entre naturaleza y cultura como objetivo, y el desarrollo sustentable como meta a ser alcanzada, en un contexto de corresponsabilidad socio-institucional, tomando el caso de las áreas urbano-costeras de las ciudades intervenidas, en el quinquenio comprendido entre el mes de junio de 2005, al mes de julio de 2010, por ser éste el período dónde se materializa la transformación del paisaje costero de las siete ciudades directamente afectadas por Yacyretá.

También se reconocen como objetivos específicos:

- Identificar y analizar los escenarios en los que se situó el objeto de estudio, dando cuenta de los postulados sobre los que se fomentaron el desarrollo de grandes obras de infraestructura desde su concepción hasta nuestros días, desde una cierta posición asumida con relación a las variables paisaje e infraestructura;

- Explicar los alcances de la ruptura del proceso histórico de conformación del espacio, por efecto de la construcción de un proyecto a gran escala (en este caso hidroeléctrico), describiendo y analizando la evolución del paisaje en el contexto histórico-regional de referencia;

- Analizar y describir las transformaciones del paisaje derivadas de la construcción de Yacyretá y sus efectos sobre la naturaleza y la cultura; el conjunto de medidas de mitigación y los proyectos de reconfiguración territorial;

- Evaluar el área de estudio, a fin de identificar escenarios de intervención y criterios de actuación para el proyecto paisaje, en las zonas urbano-costeras.

Por lo tanto, puede observarse que el sumario de la Tesis describe el alcance de la investigación y su organización con relación al estado de la cuestión de aquellos aspectos que condicionan y contextualizan el objeto de estudio, tanto en lo referente a las variables paisaje e infraestructura, al contexto internacional en el que se desarrolló y expandió el apoyo y financiamiento de grandes obras de infraestructura, a las transformaciones derivadas de la construcción de un proyecto hidroeléctrico a gran esca- 
la, al desarrollo sustentable, al proceso histórico y a las características ambientales del área de estudio; como en cuanto al análisis de las transformaciones del paisaje derivadas de la construcción de Yacyretá, al conjunto de medidas de mitigación y obras de reconfiguración territorial, así como a la noción de paisaje como proyecto, en las zonas urbano-costeras de las ciudades involucradas, con particular atención sobre las cuencas interiores de los arroyos urbanos.

Para delimitar el estado de la cuestión en las dimensiones teórico-conceptuales, ecológiconaturales e histórico-culturales, la primera parte de la Tesis se estructura en dos capítulos.

El Capítulo I delimita el marco teórico-conceptual con relación a las variables paisaje e infraestructura, a partir de destacar la raíz cultural de la noción de paisaje desde una reflexión sobre "[...] la acción en el concepto de paisaje [...], como momento sensorial o perceptivo, que es consustancial a la misma idea de paisaje [...] y como archivo histórico de la acción del hombre." (Aguiló, en Maderuelo, 2006: 213). En una segunda instancia, analiza la incidencia de las obras de ingeniería civil sobre la naturaleza, en particular de las represas hidroeléctricas, dado que "[...] su especificidad esencial, lo que les da su razón de ser y las distingue de las demás obras, es su vinculación a los accidentes particulares del terreno, con vistas a su superación" (Aguiló, en Maderuelo, 2006: 216), procediéndose a identificar las principales variables afectadas por un proyecto hidroeléctrico, sus conflictos determinantes y las potencialidades derivadas de esa transformación. Estos apartados permiten encuadrar la tercera instancia de este capítulo, que analiza los postulados sobre los que se fomentó el desarrollo de grandes obras de infraestructura, para lo que se indaga sobre el contexto internacional en el que se desarrolló y expandió el apoyo y financiamiento a este tipo de obras, analizando y describiendo las implicancias de las nociones de frontera económica (década del 60); protección ambiental (década del 70); manejo de los recursos (década del 80); eco-desarrollo (década del 90) y ecología profunda, (década de 2000) y sus correspondientes imperativos dominantes, que en sus extremos han pasado de la óptica de explotación irrestricta de los recursos naturales como medio para satisfacer las necesidades de consumo de la sociedad, hasta la más reciente de eco-topia anti crecimiento.

El Capítulo II se enfoca en el análisis del ámbito regional dónde se inserta Yacyretá, delimitando el caso de estudio desde una perspectiva histórica de la estructuración del territorio y de la evolución del paisaje en el contexto regional. En el primer apartado se analiza la evolución de la denominada región histórica guaraní (Levinton, 2007) en términos de paisaje; identificando en estos términos, los principales hechos históricos vinculados con las características del medio, en particular del río como límite, frontera, comunicación y aprovechamiento, junto a la evolución de los distintos 'tipos' de asentamiento desde el período guaraní, pasando por los pueblos-ciudad de la época jesuítica y hasta la ciudad contemporánea (Cambas, 1962; Cortiñas, 2000; Lins Ribeiro, 2003; Levinton, 2007; Snihur, 2007). En tanto que el segundo apartado del capítulo analiza la irrupción de los emprendimientos hidroeléctricos en la Cuenca del Río de la Plata y las transformaciones derivadas de su construcción. Finalmente, en el tercer apartado se realiza una reflexión que conjuga criterios teórico-metodológicos 
(Berque, 1995 y 2006; Roger, 2007; Donadieu, 2006; Nogué, 2007), procediéndose a identificar los aspectos conceptuales para una reflexión histórica sobre el paisaje regional y cuáles son los principales elementos de ese paisaje que son transformados por proyectos hidroeléctricos a gran escala.

Establecido el estado de la cuestión sobre los aspectos conceptuales y sobre la región de referencia, la segunda parte de la investigación se aboca a describir y analizar el Proyecto Hidroeléctrico Yacyretá y sus efectos sobre el territorio y el paisaje y se aborda, en una segunda instancia al paisaje como proyecto, a fin de verificar si, desde esta noción, es posible orientar las bases de una modalidad de gestión del paisaje transferible, sobre el complejo escenario de un territorio transformado, mediante la interacción de criterios estético-ecológicos, de producción urbano-territorial y de participación socio-institucional.

En tal sentido, en el primer apartado del Capítulo III se realiza un análisis de situación del PHY, que permite indagar sobre los procesos que relacionan las decisiones de su construcción (Lins Ribeiro, 2003; Levinton, 2010) y los principales elementos que definen la modificación del paisaje (EBY, 1992.a, b y c; $2002^{\text {a }}$; 2004 y 2006). Esta mirada global sobre el proyecto, orienta el contenido del segundo apartado, destinado a entender sus efectos sobre la naturaleza y la cultura; su funcionamiento y la transformación del paisaje; las modificaciones de la cuenca principal y de las cuencas interiores; en tanto que en el tercer apartado, se analiza su incidencia sobre la ciudad, sus actividades y las personas (EBY, 2005), considerando las implicancias de la Obra sobre su área de implantación y los instrumentos de gestión territorial que servirán de basamento del proyecto Paisaje, que se aborda en el cuarto capítulo de esta investigación. Este diagnóstico, permite profundizar en el cuarto apartado del tercer capítulo, el análisis sobre el conjunto de medidas de mitigación (EBY, 1992/2002.a, 1992/2005, 2002.b, 2004, 2009 a y b) y sobre los proyectos de reconfiguración territorial (EBY, 2004 y 2009.a y b); acotando el tema de investigación sobre las zonas urbano-costeras de Posadas y Encarnación (EBY, 2005 a y b, 2009 a y b, Global Consultores, 2008), como medio operativo para la configuración de un nuevo paisaje.

El Capítulo IV aborda la noción de paisaje como proyecto en las zonas urbano-costeras. Para ello se plantea en el primer apartado, una aproximación a la noción de paisaje, que aún sin haber sido pensado como tal por el ente ejecutor, nos permite ensayar una lectura de las transformaciones provocadas por Yacyretá en estos términos. Dicha lectura se realiza a partir de un análisis de situación de los denominados 'recursos del paisaje' desde tres perspectivas: ecológica-ambiental, histórico-cultural y geográfico-urbanistica. Esta lectura permite orientar una valoración de esas transformaciones, a partir de tres dimensiones o escalas de interpretación que aluden a la clasificación del Sistema de Inventario del Patrimonio Mundial (TASEO): i) La macro-escala o escala Territorio; ii) La escala intermedia que incluye a las áreas de incidencia de las ciudades de Posadas (Argentina) y Encarnación (Paraguay), considerada como Área; iii) La escala urbana y de las zonas específicas de intervención, consideradas como Sitio o Lugar (UNESCO, 1986; EBY, 2004, 2005 a- b, 2006, 2007, 2009 a-b-c, 2010; Fulco, et al, 1995 y 1996; Global Consultores, 2008). En tanto que el segundo apartado presenta los instrumentos que permiten construir un cierto modelo de gestión del paisaje como proceso proyectual, analizan- 
do los antecedentes que contemporáneamente se están empleando para el manejo y gestión de paisajes, y planteando los principales aspectos conceptuales y metodológicos que pueden ser empleados en un contexto como el latinoamericano, considerando objetivos de intervención; aspectos técnicos, para analizar y evaluar -sectorial e intersectorialmente- los conflictos y potencialidades de un área de estudio que, en conjunto, permiten caracterizar, valorar y catalogar escenarios de intervención y estrategias de actuación (en términos de programas, subprogramas y proyectos emergentes) y criterios de monitoreo y evaluación; cerrando este apartado con un análisis sobre los aspectos de gestión para el proyecto paisaje (Consejo de Europa, 2000; de Bolós, 1992, Fundación CEPA, 1985 y 2005; Fulco, et al, 1993, 1995 y 1996; Tauber, 1999; Salvador Palomo, 2003; BID, 2005).

En la última parte de la Tesis se incluye un parágrafo con las conclusiones que procuran verificar, si es posible -una vez consolidada una decisión de estas características- definir pautas de gestión que permitan orientar la '(re)conciliación' entre naturaleza y cultura como objetivo y tener el horizonte de un desarrollo sustentable en un contexto de corresponsabilidad socio-institucional.

\section{Perspectiva de Análisis y Metodología}

La investigación está orientada a identificar, diagnosticar y explicar las relaciones urbanoterritoriales que surgen de la repercusión ambiental que experimenta el sistema territorial y el paisaje, como consecuencia de la construcción de un proyecto de infraestructura hidroeléctrica a gran escala, como es el caso de Yacyretá.

Para abordar los efectos de este tipo de proyectos, podemos señalar inicialmente, que hoy existe una vasta bibliografía y posturas internacionales, ya sea contrarias a la construcción de proyectos hidroeléctricos (y otros proyectos de infraestructura) a gran escala, como otras posturas que recomiendan hacerlas con alto respeto ambiental, en función de los impactos que este tipo de grandes obras generan sobre el territorio y sobre el desarrollo de las comunidades locales involucradas (Suárez, 1984; Bartolomé, 1985; Lins Ribeiro, 2003; Políticas Operacionales del BIRF y del BID, 1999/2001).

Estas preocupaciones, están fundamentadas en la necesidad de encontrar -a escala global y localmodelos de desarrollo que sustituyan la perimida noción de explotación indefinida de los recursos naturales como medio para satisfacer las necesidades de consumo de la sociedad, por otros arraigados en el concepto de desarrollo sustentable, definido por las Naciones Unidas como "crecimiento económico con justicia social y equilibrio ambiental".2

\footnotetext{
${ }^{2}$ El término desarrollo sostenible, perdurable o sustentable se aplica al desarrollo socio-económico y fue formalizado por primera vez en el documento conocido como Informe Brundtland (1987), fruto de los trabajos de la Comisión Mundial de Medio Ambiente y Desarrollo de Naciones Unidas, creada en la Asamblea de las Naciones Unidas de 1983. Dicha definición se asumiría en el Principio $3^{\circ}$ de la Declaración de Río (1992): Satisfacer las necesidades de las generaciones presentes sin comprometer las posibilidades de las del futuro para atender sus propias necesidades.
} 
Coincidimos sobre la validez de este concepto, pero la realidad nos muestra que el mundo transcurre, con excepciones, en un constante desequilibrio global y de altas (in)diferencias locales. La construcción de este tipo de proyectos no es ajena a esa realidad, entonces ¿qué sucede cuando esos proyectos se encuentran en fase de operación, o como en el caso de estudio, tienen por delante el desafío de su terminación y aún no han mitigado totalmente los impactos generados? Por otra parte, este sólo ejemplo, ¿sirve para indicar que en estos casos el desarrollo sustentable no es aún verificable sino, más bien, constituye una aspiración, pero que no debe ser abandonado, sino que debe constituirse en un horizonte de reflexión, una guía para la acción y un objetivo a alcanzar?.

En esta investigación, a través del análisis del territorio modificado, se analizan los impactos y se identifican las potencialidades del paisaje para su ordenación. El concepto 'Paisaje', con un enfoque multidimensional y transdisciplinario, aporta de esta manera el basamento conceptual para la construcción del concepto de resignificación. ${ }^{3}$ Desde lo teórico, como reflexión sobre las implicancias (ecológicas, económicas y sociales) que sobre el desarrollo local (Arocena, 1995) tiene una enorme transformación como la generada por la construcción del proyecto hidroeléctrico; y desde lo proyectual, como instrumento de valoración y ordenación a escala territorial, que permite orientar el planteo de un proceso de gestión del paisaje como proyecto sustentable y transferible a otros territorios involucrados por transformaciones de características análogas a las aquí analizadas. ${ }^{4}$

El paisaje del espacio transformado por la obra, se convierte así en producto de una particular significación de la interacción de los conceptos de naturaleza y cultura, en su dimensión espaciotemporal, que dentro de un enfoque específico de desarrollo sustentable, requiere del aporte de las ciencias ambientales y territoriales -en ámbitos relativos a lo ecológico, lo económico y lo socioinstitucional- y la verificación del supuesto de investigación en un lugar determinado. Desde esta perspectiva, el proyecto paisaje recurre a una estrategia de gestión de sus interfases ${ }^{5}$ costeras, como "teatro de experimentación para el desarrollo sustentable", ${ }^{6}$ actuando como inductor de nuevas relaciones de integración entre naturaleza y cultura de un territorio modificado.

\footnotetext{
${ }^{3}$ En el sentido de encontrar aquellos valores y significados socio-culturales persistentes; así cómo, a especificar nuevos valores que puedan ser apropiados por la comunidad. De tal forma, podemos entender "la resignificación como la puesta al día de la relación entre la parte de un signo que puede hacerse sensible o significante y la parte ausente o significado." (Ducrot / Todorov, 1974 (1972): 122).

${ }^{4}$ Nos referimos a la posibilidad de hacer tangible uno de los objetivos del Programa MaB de UNESCO, en el sentido de "propender a la expansión de los beneficios de un área natural y culturalmente protegida al resto de territorio".

${ }^{5}$ El concepto de interfase fue definido por Valerio Giacomini (1980/83) para Roma, en el marco del Programa MaB, UNESCO y desarrollado por la Fundación CEPA, para el Proyecto de Ecología Urbana del Sistema Urbano Pampeano para UNESCO, (CEPA 1983/85) y aplicado también por el autor, en 3 proyectos en la Provincia de Río Negro (CFI-Fulco [dir.] 1993/96).

${ }^{6}$ Halffter; Gonzalo (1994). Este concepto fue desarrollado por el ex-presidente Comité MaB, en el Encuentro Mundial de Reservas de Biosfera, Sevilla, España.
} 


\section{El Problema de la investigación}

Tomando en consideración las reflexiones expuestas hasta aquí, es necesario señalar que la investigación permitirá demostrar, por una parte, que el Proyecto Yacyretá fue concebido hace varias décadas, sin el marco de conciencia ambiental que hoy se requiere para pensar y sin las herramientas de diagnóstico y mitigación, con que se cuentan en la actualidad para encauzar una obra de estas características, que afecta a la naturaleza (río, flora y fauna) y a la sociedad (salud, áreas urbanas, población que debe ser trasladada, etc.); en suma al paisaje que otorga carácter e identidad a un determinado lugar o región. Y por otra parte, que en su fase de terminación está cumpliendo los objetivos de esa concepción: generar energía hidroeléctrica sustituyendo el uso de combustibles fósiles con los consecuentes beneficios ambientales; contribuir a controlar las periódicas inundaciones que afectaban a las comunidades ribereñas, y realizar un aporte al desarrollo regional a través de hacer viable la navegación y el riego de las zonas rurales (EBY, 1973). Mitigar los impactos generados por su construcción, a través de la provisión de complejos habitacionales con todos los servicios y equipamientos comunitarios para relocalizar las poblaciones; la selección de sitios adecuados y el acompañamiento para reasentar en nuevos sitios totalmente equipados a la población isleña y rural; la reconstrucción del circuito comercial de la ciudad de Encarnación (EBY, 2005); la reposición de tantas hectáreas de reserva como superficie inundada; el rescate arqueológico; el repoblamiento de fauna y flora; el tratamiento de efluentes cloacales, la provisión de agua por red y la gestión de cuencas y urbana de las ciudades involucradas; la ejecución de defensas costeras y la reposición y ejecución de nuevas infraestructuras territoriales (EBY, 2002); es el cometido de su fase de terminación (EBY, 2004).

En tanto la investigación se propone abordar la problemática ambiental y cultural derivada de la transformación del paisaje, proponiendo una reflexión sobre 'los bordes' más significativos de esta intervención, que se materializa en las zonas costeras, tanto del río Paraná (embalsado) en general, como en particular, de las cuencas de los arroyos que surcan el territorio y desaguan en él. Una reflexión que aborde las posibilidades de la resignificación de estos espacios, que históricamente han sido interpretados como espacios de articulación entre los pueblos (Cambas, 1962; Levinton, 2007; Snihur, 2007). En este marco, la investigación, busca claves para una nueva articulación entre espacio, sociedad y naturaleza y se inscribe en la siguiente pregunta:

\section{¿Es posible resignificar la configuración del nuevo paisaje, a partir de recomponer la fractura} de la relación naturaleza-cultura, provocada por la construcción de una gran obra de infraestructura hidroeléctrica sobre las áreas costeras de las ciudades involucradas?

Para ello, la investigación se enfoca en el análisis de la readecuación y significación de las zonas costeras como ordenadoras de un nuevo paisaje, dado que el llenado del embalse a su cota final de diseño, representa una importante transformación en términos histórico-culturales y urbanísticos de los usos y apropiación del territorio. 


\section{Cuerpo de Hipótesis}

El cuerpo de hipótesis de esta investigación aborda el interrogante del problema, planteando que el territorio transformado por la construcción de un proyecto hidroeléctrico a gran escala como Yacyretá, implica una gran distorsión ambiental, que tiene la potencialidad de constituirse en matrices de un nuevo Paisaje, planteando como hipótesis general, que la conformación de un embalse para favorecer la generación de energía hidroeléctrica, transforma un río (ambiente líctico) en un lago (ambiente lentico), generando alteraciones tanto sobre el medio físico-natural, como sobre el espacio construido de pueblos y ciudades, modificando el paisaje y los valores culturales que sobre él operaban; haciendo necesario por tanto, su identificación y valoración, a través de una visión holística del territorio involucrado.

También se reconocen hipótesis secundarias:

- La intrusión de lenguas de agua (subembalses) sobre el territorio, a través de los arroyos que desaguan en el embalse, provocan la configuración de un nuevo paisaje interior que fragmenta territorial, física y socialmente las ciudades y centros de servicio rural.

- En el caso de estudio (ciudades y zonas costeras), esta alteración genera una fuerte modificación de las áreas centrales, derivada de la pérdida de territorio sobre la costa del río Paraná y de los arroyos urbanos, con relocalización de poblaciones y actividades costeras y una alta segregación de la periferia urbana, por efecto de los futuros subembalses.

- El paisaje como proyecto, a partir del manejo integral de las zonas costeras, asume el desafío de estructurar nuevas relaciones sinérgicas derivadas de la recuperación del territorio, en términos de recurso disponible para el desarrollo de actividades compatibles con las dimensiones ecológica, económica y social bajo el concepto de desarrollo sustentable y surge, complementariamente, como potencial estrategia de desarrollo local y regional de integración.

La investigación adquiere así una visión diagnóstica y reflexiva, tendiente a orientar una ruptura de la inercia de la planificación territorial tradicional, de carácter normativo y coercitivo, indagando sobre las posibilidades de encauzar una modalidad de gestión participativa, adaptable e inductora de una dinámica de desarrollo de carácter endógeno e integrador. Se trata de una modalidad de gestión basada en la promoción de actividades compatibles con objetivos de calidad de vida urbana y de producción hacia un manejo sustentable del territorio, que oriente la focalización y consolidación de usos públicos que alienten la integración socio-comunitaria; y que compatibilice los criterios ecológicos de conservación y desarrollo de una "[...] construcción física y mental del paisaje, entendida como una forma particular de relación entre el hombre y la naturaleza" (Silvestri y Aliata, 2001:13).

\section{Aspectos Metodológicos}

Desde el punto de vista metodológico, se recurrió a un tipo de investigación de naturaleza empírica, aplicada a un ámbito específico, en un período establecido, que ha determinado y explicado, por una parte, las múltiples dimensiones y factores que intervienen en el problema de investigación; así como por 
otra parte, ha identificado aquellas variables que permitieron orientar un proceso de intervención para las áreas costeras, abordando la complejidad socio-ambiental de las transformaciones generadas por la construcción del complejo hidroeléctrico; y desde allí, en un sentido de extrapolación de resultados -en términos de orientaciones para la gestión del paisaje-, al resto de las ciudades y territorios involucrados por Yacyretá y a otros ámbitos de características sustancialmente análogas a las descriptas.

Su alcance temporal es de tipo seccional, realizando una descripción sintética del contexto histórico, considerando en ello, los rasgos determinantes de la conformación de la Región Histórica Guaraní (Levinton, 2007), así como de las reducciones jesuíticas; de los actuales asentamientos poblacionales y del quiebre determinado por la ejecución de la presa y central hidroeléctrica de Yacyretá; pero centrando el análisis de situación en el último quinquenio (2005/10), que es dónde se han materializado las principales transformaciones en el área de intervención.

La amplitud del trabajo, se ha focalizado en un sector del área de intervención de Yacyretá: las zonas costeras, en particular, en las urbano-costeras.

La factibilidad y/o viabilidad de llevar adelante esta investigación se basa en la existencia de las fuentes bibliográficas, documentos institucionales, páginas $\mathrm{Web}$, documentos inéditos y entrevistas a actores clave; así como, en la posibilidad concreta de acceso del investigador a las mismas, para alcanzar los objetivos propuestos.

Las fuentes de información son mixtas, con análisis crítico de material bibliográfico y con trabajo de campo para la recolección de información primaria derivada de relevamientos propios, entrevistas con actores e informantes calificados, a partir de la cual se extrajo información referida a los procesos que relacionan a la población y su paisaje. Sobre el conjunto de información recogida y/o seleccionada, se aplicó un tipo de análisis de carácter cuali-cuantitativo, dirigido a:

- observar y describir el conjunto de realidades derivadas de la obra, dentro del contexto histórico y cultural en el que se desarrolla;

- inventariar, relevar y valorizar, en cada dimensión de la realidad seleccionada, las transformaciones operadas;

- explicar, es decir identificar relaciones causales, nexos de correlación entre los fenómenos y establecer correlaciones entre fenómenos aparentemente independientes entre sí.

- Ponderar los conflictos y valorar las potencialidades que permitan realizar una lectura holística e inclusiva de la realidad

- Identificar posibles escenarios de gestión del territorio modificado.

Este análisis, en su conjunto, ha permitido detectar -desde una perspectiva paisajística- los aspectos centrales del proceso de organización del espacio; su configuración como paisaje cultural y los efectos de las transformaciones producidas al entrar ese ambiente, en la compleja interrelación con el Proyecto Hidroeléctrico Yacyretá. 
Desde el punto de vista operativo, se tomaron cuatro líneas o fases de aproximación para el estudio del paisaje, directamente relacionadas con las variables de la hipótesis; que abarcan: la delimitación del marco teórico conceptual; un diagnóstico regional -escala temporal y espacial; un diagnóstico del paisaje a través de sus funciones y transformaciones; y finalmente, pautas de diseño para la gestión del paisaje costero, con sus respectivas conclusiones.

Con relación a las fuentes para acotar la noción de paisaje y su raíz cultural a partir de una reflexión sobre la acción en el concepto de paisaje y para analizar desde esta perspectiva paisajística a la obra de ingeniería enraizada en su entorno, nos hemos basado en Maderuelo (2003 y 2006), Aguiló, Martínez de Pisón y Marchán Fiz (en Maderuelo 2006), Aguiló (1999), Augué (2005), Isola (2002), Milani (2007), Nogué (2007), Gonzales Virós y Nel-lo (en Nogué, 2007), Roger (2007), Silvestri y Aliata (2001), SolàMorales (2002). Para analizar desde esa perspectiva paisajística a la obra de ingeniería enraizada en su entorno, nos hemos referido a Pichs Madurga (1994), Aguiló y Marchán Fiz (en Maderuelo 2006), Flores (1995), Miller (1994), Kiely (1999), EBY (2006, 2009b), Banco Mundial (1991), CEPAL, ILPES, PNUMA (1986), IHA (2010). Para analizar los postulados sobre los que se fomentaron el desarrollo de grandes obras de infraestructura, hemos recurrido a Aguiló (en Maderuelo, 2006), Boisier (1993), Miller (1994), Levinton (2010), Borja y Castells (1997), Pesci (1985, 1992, 1995, 1999, 2007), Tauber (2008), Pichs Madurga (2004), Kiely (1999), Maldonado (1999), Gallopín (2003), Suárez, Franco y Cohen (1984), EBY (1992, 2003, 2004), Groppa (2006), Comunidad Económica Europea (2000), UNESCO (1972), CNUMAD (1972) y otras publicaciones, como las de la Fundación Proteger, CEPAL, Banco Mundial o Banco Internacional de Reconstrucción y Fomento y Banco Interamericano de Desarrollo.

Para analizar la evolución histórica y del paisaje del área de estudio, hemos recurrido a Cambas (1962), Cortiñas (2000), Giménez (1988), Levinton (2007 y 2009ª), Maeder (1992), Meliá (1988), Micó (1975), Moguer (1985), Pastore (1972), Sepp (1973), Snihur (2007), Delvalle (1998), Velásquez (1997, 1981), Reverchon (2009), Armani (1988), Sánchez Quell (1981) y entrevistas sobre precisiones de la cultura guaraní con los doctores en antropología Leopoldo Bartolomé y Ana Gorosito de la UNaM, Argentina. Para establecer la incidencia de los proyectos hidroeléctricos en la cuenca del Plata, nos hemos basado en el Tratado de la Cuenca (1969), CICPlata (2009), EBY/CIC (1998), Lins Ribeiro (2003), y otras publicaciones institucionales, junto a entrevistas a profesionales de Yacyretá. Finalmente, para los criterios de análisis para una reflexión sobre el paisaje, nos hemos referido a Berque (1995, 2004, 2005, 2006, 2007), Roger (2007), Donadieu (2006) y entrevistas sobre precisiones del idioma guaraní con la Lic. Bárbara Leticia Ortiz Ibáñez de Paraguay.

Para analizar el Proyecto Hidroeléctrico Yacyretá, se ha considerado el Tratado de Yacyretá (1973) y otras publicaciones oficiales e inéditas de la Entidad Binacional Yacyretá (desde el año 1992 a 2010, inclusive), Levinton (2007 y 2010), Ayudas Memoria de las Misiones de Supervisión de los Bancos Mundial e Interamericano de Desarrollo (desde el año 1993 a 2010, inclusive); así como, informes internos de ejecución de las obras del Plan de Terminación de Yacyretá (PTY), dónde el autor 
de la tesis ha tenido directa participación, y se han considerado también, otras miradas y opiniones externas, principalmente, Lins Ribeiro (2003) y Global Consultores (2008) y los planes oficiales de ordenación territorial, principalmente, de carácter internacional, al Consejo de Europa (2000); de la República del Paraguay Municipalidad de Encarnación (1999 y 2006); de la República Argentina, Ministerio de Economía y Obras Públicas de la Provincia de Misiones (1957), Secretaría de Turismo de la Nación (2005), Ministro de Planificación Federal, Inversión Pública y Servicios (2008), Municipalidad de Posadas (2002 y 2010), y Municipalidad de Garupá (2010).

Finalmente, para analizar Yacyretá desde la noción de paisaje en las zonas costeras, hemos recurrido a las publicaciones de la EBY citadas en la bibliografía, otras inéditas y los informes de seguimiento de ejecución del PTY, realizados por el autor de esta investigación, y otros de UNESCO, (1986) y Global Consultores (2008). En tanto que para la definición de los instrumentos de gestión del proceso proyectual, hemos considerado a de Bolós (1992), Fundación CEPA (1985 y 2005), Fulco, et al (1993, 1995 y 1996), Tauber (1999), Salvador Palomo (2003), BID (2005), Arocena (1995), Pesci y Pérez (1995), Le Dantec (2007), Roger (2007), Fontanari (2007), Reho (2007).

\section{Observaciones}

Las fuentes de información están conformadas, inicialmente, por una bibliografía de base que ha permitido establecer una cierta posición con relación a las variables paisaje e infraestructura, sin perder de vista el contexto internacional que ha favorecido el desarrollo y financiamiento de este tipo de obras y el posterior enfoque de desarrollo sustentable que, a partir del Informe Brundtland (1987) y de los preceptos definidos en la Cumbre de Río de Janeiro (1992), han inducido un cambio de enfoque y una profunda reflexión sobre los límites del crecimiento en perjuicio de recursos naturales de lenta o difícil renovabilidad, que normalmente son afectados por este tipo de emprendimientos.

Para el desarrollo de la investigación sobre el Proyecto Hidroeléctrico Yacyretá y sobre el área de implantación, se ha recurrido a documentación histórica, complementada con documentos inéditos sobre el proyecto y a diversas fuentes de información -bibliográfica, gráfica y de producción propia dentro del ámbito laboral de Yacyretá-, que fueron seleccionadas sobre la base de criterios de pertinencia con el tema de investigación; y hemos recurrido también, a los apuntes y otros documentos de los Seminarios dictados en la misma Maestría, Paisaje, Medio Ambiente y Ciudad.

Sobre la base de estas consideraciones generales, para hacer más ágil la lectura, las fuentes bibliográficas son citadas dentro del texto del trabajo utilizando el apellido del autor, la fecha de publicación y la página citada entre paréntesis. En el caso de las páginas Web, entrevistas y citas indirectas, se mencionan la idea pero -salvo excepciones- no se transcriben textualmente y consecuentemente, no se coloca la página de referencia. Las referencias concretas se incluyen al final, en la bibliografía. 
PARTE I: EL CONCEPTO DE PAISAJE EN UN TERRITORIO TRANSFORMADO POR UNA GRAN OBRA DE INFRAESTRUCTURA HIDROELÉCTRICA 
Paisaje

Medio Ambiente y

Ciudad

Maestría 


\section{CAPÍTULO I: LA DIMENSIÓN DEL PAISAJE EN EL CONTEXTO DE LAS GRAN- DES OBRAS DE INFRAESTRUCTURA HIDROELÉCTRICA}

El Capítulo I, analiza diversos enfoques para establecer la dimensión que puede alcanzar la noción de paisaje en el contexto de un territorio transformado por una gran obra de infraestructura hidroeléctrica.

Para ello se indaga, en la primera parte de este Capítulo, acerca de la raíz cultural de esa noción, a partir de la relación que puede establecerse entre un determinado paisaje y una obra de infraestructura, analizando los conceptos de lugar, de paisaje como construcción social y del arte como mediador en la construcción de dicha noción de paisaje.

En la segunda parte se analiza la incidencia de las obras de ingeniería civil sobre el ámbito natural en el que se inserta, describiéndolas como modalidad de la acción y como momento de la conformación de un nuevo entorno, profundizando la mirada en las transformaciones que derivan de una obra hidroeléctrica a gran escala y en algunas de las alternativas que existen para encauzar su construcción.

Para vincular estas nociones a la realidad, en la tercera parte del Capítulo se analiza la evolución del debate en torno al vínculo entre medio ambiente y desarrollo en el contexto internacional, considerando principalmente las cinco últimas décadas por las que ha pasado la construcción de Yacyretá.

Pero en virtud de que el área de estudio adquiere una gran significación histórica por haber sido asiento de la antigua nación guaraní y posteriormente de las misiones jesuíticas, cuyas huellas y rasgos siguen vigentes, y considerando además que esta parte del territorio es actualmente asiento de importantes ciudades en ambas márgenes del río Paraná, resulta importante indagar acerca de si en esta región histórica ha existido una relación con el entorno, que pueda ser considerada como paisajística, recurriendo en el cuarto apartado a precisar de qué manera puede interpretarse en la actualidad las relaciones con el nuevo paisaje que surge del proceso de transformación del territorio (Berque, 1995 y 2006; Roger, 2007; Donadieu, 2006), y de identificar, en ese marco de referencia, los principales compontes del paisaje regional que son impactados y modificados por la implantación de proyectos hidroeléctricos a gran escala.

\section{I.1. LA NOCIÓN DE PAISAJE Y SU RAÍZ CULTURAL}

"El Paisaje se contempla [...] se dibuja y se describe, pero también se recrea por medio de la construcción de jardines. Más adelante, el paisaje también se piensa, llegando a reclamar la atención de los filósofos." (Maderuelo, 2006:5).

Podemos señalar inicialmente, que la noción de paisaje es en esencia una construcción cultural, como la forma que tiene el hombre de interpretar culturalmente el territorio.

"[...] Uno de sus mayores avances en civilización fue la adquisición intelectual y estética de una idea elaborada de paisaje y de relación con él, alcanzada sólo plenamente en el progreso iniciado en el Renacimiento, buscado luego esforzadamente en la Ilustración y entendido finalmente con profundidad en el Romanticismo. La idea de paisaje es una lenta y expresiva conquista de la civilización." (Martínez de Pisón, en Maderuelo, 2006: 132). 
Pero, como señala Simón Marchán Fiz:

"En nuestros días el paisaje brota sin tapujos en la encrucijada entre la naturaleza y la cultura, en una combinación de ingredientes naturales e históricos, oscilando entre la naturaleza que todavía se despliega de un modo orgánico y la fabricada [...], casi nunca se nos ofrece en su estado originario, sino como naturaleza históricamente modificada en la que penetra la acción humana por mediación del proceso civilizatorio y los dispositivos de la cultura. De acuerdo con esto, los paisajes actuales [...], se constituyen en la intersección, no exenta de tensiones, entre el paisaje natural [...] y el paisaje de cultura [...]. El hombre va dejando sus improntas y marcas en la superficie de la tierra a través del tiempo.” (Marchán Fiz, en Maderuelo, 2006: 39).

En nuestro caso de estudio esas 'tensiones' se materializan en las transformaciones derivadas de la construcción de una gran obra de infraestructura hidroeléctrica, cuyo resultado físico y sensorial, es la aparición de un nuevo ambiente. En lo natural, un tramo de 200 kilómetros de un caudaloso río es convertido en un ambiente lacustre, con la consecuente pérdida de hábitats de flora y fauna; y en lo cultural, está representado por la pérdida de territorios insulares y continentales costeros, que afectó áreas agrícolo-ganaderas y sectores urbanos, tanto en los bordes del embalse como de las cuencas hidrográficas interiores; así como también, en otros ámbitos interiores por efecto del traslado de población (nuevos sectores residenciales urbanos y periurbanos) y de actividades (nuevos espacios públicos y áreas comerciales y/o productivas), que deberán ser asumidos progresivamente como nuevos ámbitos de desarrollo para la vida individual y social.

Para interpretar esas transformaciones, vincularemos entonces la noción de paisaje a la de infraestructura (Aguiló, en Maderuelo, 2006), e indagaremos sobre el concepto de 'lugar' (Aguiló, 1999), enfrentándolo al de no-lugar (Augé, 1992), que sobre ese ambiente modificado puede tener la población directamente afectada por la obra y sus consecuencias. Pero, como la noción de paisaje, en tanto construcción cultural, resulta más abarcativa que la noción de lugar, para dilucidar si estos nuevos ámbitos y su entorno pueden ser interpretados como paisaje, analizaremos también, los conceptos de paisaje como construcción social (Nogué, 2007) y de 'artealización' de la naturaleza (Roger, 2007).

\section{I.1.1. Paisaje e Infraestructura}

Vincular la noción de paisaje a la de infraestructura como parte de las transformaciones del territorio, nos lleva a analizar "[...] las transformaciones provocadas intencionadamente, consciente aunque no siempre reflexivamente, [que] son las transformaciones culturales [...]" (Maderuelo, 2006:6), y este razonamiento, requiere explicar los cambios desde diferentes perspectivas de análisis: “[...] Frente a las transformaciones provocadas queda una herramienta: ¡pensar! Pensar el paisaje en cuanto actividad cultural en sus dos vertientes: histórica y científica." (Maderuelo, 2006: 7).

Es decir, que el paisaje puede ser interpretado desde muchas disciplinas y áreas de conocimiento y también, desde diferentes posturas ideológicas. "Esta pluralidad de enfoques nos obliga a partir de la idea de paisaje como hecho cultural, entendido como una construcción humana en un doble sentido: como constructo mental, es decir, como interpretación perceptiva y también, como una construcción 
tangible, en cuanto que esa realidad física, ese territorio, ha sido y está siendo transformado por acciones humanas" (Maderuelo, 2006: 235).

Por estas razones es que, ante una de las preguntas fundantes de esta investigación acerca del ¿por qué abordar la idea de paisaje desde los impactos y transformaciones que provoca la construcción de Yacyretá? resulta necesario señalar que, como se verá en el desarrollo de esta investigación, la región en general y el área de estudio en particular, se ha consolidado históricamente a partir de sucesivos impactos y transformaciones producto de la acción antrópica sobre un medio natural 'dominante' que, en cada momento histórico, ha debido ser 'dominado' para favorecer el asentamiento humano.

En términos generales, la historia de la humanidad determina que el hombre en comunidad, siempre ha buscado dominar la naturaleza con sentido de supervivencia y desarrollo. En la antigüedad lo ha hecho adaptándose a ella, no tanto por convicción, sino por un limitado acceso a la tecnología; quizás por esto es que, recién a partir de la Primera Revolución Industrial, esa idea de 'dominación' comienza a hacerse tangible a escalas antes inimaginables. El desarrollo de las ciudades fue rápido y caótico; las actividades urbanas y de producción fueron altamente demandantes de energía, cuya generación estuvo sustentada primero en el aprovechamiento de combustibles fósiles; más tarde en los recursos hídricos y posteriormente en el poder del átomo y más recientemente, de otros menos impactantes, como el viento y el sol. En el caso de la producción de energía eléctrica a gran escala mediante el aprovechamiento del caudal de grandes ríos y saltos naturales, se generan transformaciones, a partir de impactos que adquieren dimensiones biológicas y culturales de gran importancia; entre otros, pérdida de territorios y de diversidad biológica; desplazamiento de poblaciones rurales y urbanas con las derivaciones propias en los planos social y cultural, además de las consecuentes alteraciones de los procesos de producción y de las economías locales, que son algunas de las múltiples alteraciones que originalmente no eran consideradas al concebirse proyectos de estas características, pero que la nueva conciencia ambiental que rige en nuestros días, hace que sea de fundamental importancia ponderar, sobre todo, al analizar un proyecto aún en ejecución.

En el área de estudio veremos, en el capítulo siguiente, que el proceso de ocupación del territorio ha estado signado por diversos procesos históricos conjugados sobre la base de impactos o transformaciones derivados de la acción antrópica. Es por ello que, para poner en contexto el tema de estudio, resulta razonable analizar qué sucede cuando hay que reflexionar sobre una determinada realidad, que se ha consumado sobre la base de sucesivos impactos y que, en el caso concreto de Yacyretá, devienen tanto por decisiones tomadas respondiendo a intereses nacionales y regionales que exceden los intereses locales sin haberlos necesariamente contemplado, como así también, porque no se trata de un caso aislado, sino que es un emprendimiento que forma parte de un sistema de aprovechamiento hidroeléctrico y geopolítico de toda la Cuenca del Plata; y finalmente, porque este tipo de obras es, además, parte de una profunda discusión global que se ha profundizado a partir de la década del 70 acerca del 'hacer' o 'no hacer'. 
Vemos así, que "[...] la idea de una transformación consciente del entorno y de una interpretación de él en cuanto paisaje tiene, connotaciones históricas, económicas, sociales, políticas y aún ideológicas" (Maderuelo, 2006: 7). Por lo que resulta pertinente entonces, verificar lo planteado por Aguiló, acerca de que "[...] en estos casos frente al pensamiento o la reflexión, se trata de ver en qué forma incide la acción concreta; es decir, que se trataría de entender el paisaje desde una posición no solo diferente, sino opuesta, dónde parece inevitable una especie de dialéctica pensamiento/acción, como dos polos extremos en la manera de afrontar el conocimiento del paisaje" (Aguiló, en Maderuelo, 2006: 209). En el caso de Yacyretá, el pensamiento debe reflexionar desde lo ya actuado.

\section{I.1.2. El concepto de 'Lugar' aplicado al Paisaje}

La idea de paisaje como 'lugar' representa una 'experiencia fenomenológica cualitativa', en relación a un territorio que ha sido transformado en sus aspectos físicos, así como en las relaciones que sobre él ejercía la sociedad y principalmente en el significado que le fuera conferido por la historia. Por eso, en este contexto, dónde parece bastante difícil, apriorísticamente, concebir el 'lugar' como 'paisaje', nos resulta pertinente plantear una afirmación de Norberg Schulz como interrogante: ¿será posible, en cambio, entenderlo por referencia a las cosas concretas que constituyen el mundo, con sus interrelaciones y fenómenos particulares? (Aguiló, 1999: 19).

Como se ha señalado en la introducción, esta investigación representa una indagación sobre esa relación esencial del hombre con la naturaleza que es el construir, que en nuestro caso no aparece como una relación derivada de lo sensible, de lo leve y del lento devenir de la historia. No es la resultante de una construcción social concertada con lo local, sino más bien de una situación que, parafraseando a Arocena, ha sido impuesta desde una lógica cultural diferente a la local. En el mismo sentido y desde otra lógica, Aguiló señala:

"Sobre lo natural, crecido espontáneamente, se dispone aquello que posee corporeidad y ha sido diseñado deliberadamente [...]. El hombre [...] inserta en lo natural un orden deliberado que responde a un propósito [...]. Es a conjunción de lo natural y lo construido es experimentada como lugar cuando se tiene conciencia de los significados alli acumulados por el uso." (Aguiló, 1999: 13)

Por eso, siguiendo conceptualmente al mismo autor, podemos señalar que cualquier construcción sólo puede entenderse conjuntamente con el entorno que la acoge y le da gran parte de su carácter y que, sin la inclusión simultánea de lo construido, no puede entenderse ni la estructura, ni la función, ni los cambios del paisaje. Es en este sentido que esta investigación profundiza en el concepto de lugar, entendido como una consecuencia de esa relación dialéctica entre cultura y naturaleza.

"[...] En esa manifestación del habitar que es el construir, el puente permite el paso [como la represa permite superar el salto de agua] y, al hacerlo, revoluciona el sistema de relaciones preexistentes y altera el significado del territorio. Para entenderlo, hay que aproximarse al mundo de lo natural y lo construido con singular rigor, y considerar el papel de la historia y lo irracional en la conciencia del lugar. Se trata [en suma] de entender la actividad de construir 
como una forma esencial de estar en el mundo e incidir en el ámbito profundo de la transformación del emplazamiento en lugar, por razón de lo que allí se construyó.” (Aguiló, 1999: 14).

Para Aguiló la comprensión de estos lugares resultantes de una intervención a gran escala es fundamentalmente existencial, porque está ligada a las experiencias espaciales sentidas en determinadas localizaciones que nos atraen y que, de alguna manera, nos hace sentir dentro de algo vivo y envolvente. Por eso resulta interesante reflexionar sobre su esencia, origen, estructura y propiedades, como "[...] un entramado racional que permitirá aprovechar mejor el posterior estudio detallado de algunos lugares particulares" (Aguiló, 1999: 15); y en ese sentido, se enfoca esta investigación.

Ahora bien, llegado a este punto, es necesario no perder de vista lo ya señalado, acerca de que un proyecto hidroeléctrico genera enormes transformaciones sobre la naturaleza (gea, flora y fauna) y sobre la cultura (territorio, poblaciones que deben ser trasladadas a otros sitios, actividades económicas, productivas y servicios, etc.); por lo tanto, uno de los aspectos más complejos a enfrentar en este tipo de emprendimientos -quizás, por ser el más tangible para la población-, está relacionado con las transformaciones que afectan los ámbitos urbanos; tal como ocurre con Yacyretá, que modifica territorios costeros y ambientes interiores de cuatro ciudades en Paraguay (Encarnación, Cambyretá, San Juan del Paraná y Carmen del Paraná) y tres en Argentina (Posadas, Garupá y Candelaria), con afectaciones menores en otras ciudades, islas y territorio rural costero. Por estas razones, resulta importante entender de qué manera puede enfrentarse este tipo de situaciones a la hora de reflexionar sobre el paisaje, particularmente del paisaje urbano, ya sea de una ciudad en su conjunto o de un sector que ha sido transformado por la obra, porque aún cuando las acciones de mitigación de los impactos socioambientales y las soluciones previstas para encauzar esas modificaciones aparezcan como técnicamente apropiadas, en el imaginario colectivo, esos 'nuevos lugares' pueden ser interpretados como espacios residuales, sin significado, constituyéndose, al menos inicialmente, en una suerte de 'no-lugares'.

Augé describe los no-lugares a partir del mismo concepto de lugar, en particular, del lugar antropológico, que lo define como aquel espacio común al etnólogo y a aquellos de los que habla y lo expresa como una suerte de "doble invención" en cuyo origen existe una realidad que le provee su materia prima y su objeto. Este concepto está vinculado con lo existencial planteado por Aguiló, ya que incorpora la subjetividad de la mirada externa, por lo cual, para poder caracterizarlos, Augé indica que estos lugares tienen por lo menos tres rasgos comunes: son identificatorios -a la vez espacial y social, constitutivo de la identidad individual-, relacionales -de los elementos que lo conforman- e históricos, dado que el lugar lo es a partir del momento en que -conjugando identidad y relación- se define por una estabilidad mínima. Además expresa que para la descripción de un lugar, pueden aplicarse las nociones de itinerarios, como recorridos que pasan por un cierto número de fronteras y límites; de intersección, como ámbitos informales de reunión e intercambio; de centro, como espacios institucionales y de monumento, como la expresión tangible de la permanencia. (Augé, 2005: 49 a 69). 
Parece razonable pensar entonces, que el 'lugar antropológico' conforma un espacio con símbolos evidentes que definen una identidad individual y social, determinada por las relaciones entre ellos y por la historia que los une; y que se hace tangible en los caminos, cruces, hitos y monumentos que definen el nombre y de alguna manera el significado del lugar.

Es a través del contraste con la noción de lugar antropológico, promovido a la categoría de 'lugar de la memoria', cuando Augé introduce el concepto de no-lugar:

"Si un lugar pude definirse como lugar de identidad, relacional e histórico, un espacio que no puede definirse ni como espacio de identidad ni como relacional ni como histórico, definirá un no lugar" (Augé, 2005: 83).

Son el producto de lo que el autor denomina la 'sobremodernidad', constituyendo

"[...] un mundo... prometido a la individualidad solitaria, a lo provisional y a lo efimero, al pasaje” (Augé, 2005: 84).

Pero también se leen en términos de 'espacio': de transporte o circulación (autopistas, áreas de servicio de gasolineras, aeropuertos, etc.); de consumo (hipermercados, hoteles, etc.) de comunicación (pantallas, cables, cartelera de las rutas y autopistas, etc.). Por eso no resulta sencillo definir el límite y la diferencia:

"[...] un no-lugar existe igual que un lugar: no existe nunca bajo una forma pura [...]. El lugar y el no lugar son más bien polaridades falsas: el primero no queda nunca completamente borrado y el segundo no se cumple nunca totalmente: son palimpsestos donde se reinscribe sin cesar el juego intrincado de la identidad y de la relación." (Augé, 2005: 84).

Desde aquella subjetividad impuesta por la mediación de 'la mirada', este concepto nos permite interpretar que cada lugar puede ser un no lugar; por eso, un espacio transformado por los procesos de ejecución de una obra de infraestructura, que no considere en forma adecuada las mencionadas relaciones obra-entorno y los proceso de adscripción de significados, puede ser sentido como un 'no lugar'.

"Cuando las aplanadoras borran el terruño [...] o cuando se instalan 'alóctonos', en el sentido más concreto, más espacial, se borran, con las señales del territorio, las de la identidad" (Augé, 2005: 54).

Para enfrentar esta dualidad, Aguiló propone que una primera aproximación al concepto de lugar puede elaborarse por medio del estudio de sus 'componentes' (el medio físico, las actividades de la gente y el significado) y de las 'relaciones' que existen entre ellos, y que son en esencia, las que hacen surgir el sitio: el proceso de ajuste entorno-obra y el proceso de adscripción de significados. Posteriormente, propone analizar las propiedades del sitio en términos de estructura espacial y carácter, con especial atención a los atributos de pertenencia y genius loci (o espíritu del lugar), con el propósito de formar una especie de entramado que sustente el estudio de su evolución en el tiempo: de los sitios, de su vitalidad y de los riesgos que los amenazan (Aguiló, 1999: 19 y 233). ${ }^{7}$

\footnotetext{
${ }^{7} \mathrm{Al}$ concepto de sitio o lugar se han acercado filósofos, geógrafos y arquitectos preocupados por el espacio y por la relación del hombre con su entorno. Entre los pensadores sobresalen Martin Heidegger, Merlau Ponty y Gaston Bachelard (a quiénes debiera sumarse Tetsuro Watsuji). Entre los geógrafos, Edward Relph y Yi-Fu Tuan. Entre los arquitectos, Christian Norberg Schulz, Kevin Linch y Spiro Kostof. (Aguiló, 1999: 18).
} 
Esta aproximación, reforzada con los conceptos que se exponen a continuación, representan los ejes de la segunda parte de esta investigación; de forma tal que, evitando la abstracción, nos permita comprender a estos nuevos sitios como sistemas abiertos y como fenómenos reales y diversos, integrados a partir de nuevos significados derivados de la experiencia del paisaje, cuyo desafío está en desarrollar las herramientas de gestión, para (re)construir socialmente su significado.

\section{I.1.3. El paisaje como constructo social}

Resulta evidente que la temática paisajística y el paisaje como sujeto de análisis e intervención, debe ser interpretado desde una perspectiva interdisciplinar, o más bien transdisciplinar, de característica abierta e innovadora, favoreciendo la inclusión de diversas miradas: filosófica, técnica, científica y también la del habitante, administrador y/o usuario, que como conjunto de actores, contribuyan a una 'construcción social' de esta mirada sobre 'el país', porque "[...] el paisaje puede interpretarse como un producto social, como el resultado de una transformación colectiva de la naturaleza y como la proyección cultural de una sociedad en un espacio determinado.” (Nogué, 2007: 11).

Ahondar el análisis sobre esta reflexión nos resulta de fundamental importancia en el caso de esta investigación, habida cuenta que -como se ha mencionado al inicio del acápite anterior- el caso de estudio no es 'el resultado de una transformación colectiva', sino que es producto de decisiones que reportan a intereses de lo que José Arocena denomina una 'lógica' cultural diferente a la 'lógica' de los intereses locales ${ }^{8}$ consolidando una nueva configuración territorial. El primer interrogante que nos surge, es: ¿estamos, además, ante la presencia de un nuevo paisaje?

Si seguimos el razonamiento de Nogué, que nos indica, que: “[...] Las sociedad humanas han transformado a lo largo de la historia los originales paisajes naturales en paisajes culturales, caracterizados no sólo por una materialidad (formas de construcción, tipos de cultivos), sino también por los valores y sentimientos plasmados en el mismo [...] conformando lugares que encarnan la experiencia y las aspiraciones de los seres humanos [...]" (Nogué, 2007: 12); seguramente, es una pregunta, a priori, difícil de responder y surgen en consecuencia otros interrogantes.

Y si aceptamos también el planteo del mismo autor acerca de que: “[...] los paisajes se construyen socialmente en el marco de un juego complejo y cambiante de relaciones de poder, esto es, de género, de clase, de etnia... de poder en el sentido más amplio" (Nogué, 2007:13), entonces aparecen nuevos interrogantes: ¿Podemos considerar que la 'lógica de lo regional', es parte de la 'lógica de lo local'? y en consecuencia, esa transformación i““[...] esconde una nueva estética, una nueva concepción del espacio y del tiempo, un nuevo paisaje" (Nogué, 2007: 20), que hay que aprender a leer para hacerlo

\footnotetext{
${ }^{8}$ Nos referimos a la noción planteada por José Arocena (1995), acerca de que el sistema socio-territorial está formado por un conjunto de sectores que intervienen en el proceso de desarrollo del área en cuestión, interactuando en el territorio desde sus distintas Lógicas específicas. Citado en la bibliografía.
} 
visible? Si esto es así ¿Qué categorías, qué claves interpretativas nos permitirían leer hoy el paisaje de la transformación? Además, si el paisaje“[...] es un concepto fuertemente impregnado de connotaciones culturales y puede ser interpretado como un dinámico código de símbolos que nos habla de la cultura de su pasado, de su presente y tal vez también la de su futuro" (Nogué, 2007: 21): ¿Qué nuevos significados aportará al conjunto social esta nueva configuración urbana-territorial que se convierte en parte de la 'cotidianeidad'?

Si bien no resulta sencillo 'leer' una intervención de la escala de Yacyretá como 'nuevo paisaje', el mismo Nogué nos acerca al respecto, alguna orientación:

"[...] La legibilidad semiótica de un paisaje, esto es el grado de decodificación de sus símbolos, puede tener mayor o menor dificultad, pero está siempre ligada a la cultura que los produce. Si la cultura es concebida como un sistema de significaciones vehiculadas como un conjunto de mediadores y de representaciones, el paisaje juega un papel esencial en tanto que contribuye a la objetivación y a la naturalización de la misma: el paisaje no sólo refleja la cultura, sino que es parte de su constitución. Y es por ello mismo -y sobre todo- un producto social” (Nogué, 2007: 21).

De ahí el interés de analizar el paisaje resultante de esta forma de transformación del territorio y en particular de la ciudad, para saber si es posible -en términos análogos a los expuestos por Itzíar Gonzales Virós para la arquitectura- "[...] interpretar y participar en la [re]construcción social del paisaje, [...añadiendo] a los trazos visibles aquellos que son invisibles. Añadir [en suma] a la realidad evidente la realidad latente [...]" (González Virós, en Nogué, 2007: 167); seguramente, a partir de una nueva sensibilidad, que debiera ser compartida con los actores sociales locales.

Entonces, si damos por cierto el planteo de Oriol Nel-lo, acerca de que "[...] la ciudad, por su naturaleza, pertenece a la categoría de paisajes que pueden ser concebidos y sentidos, pero no pueden ser vistos [...]" (Nel-lo, en Nogué, 2007: 184); el proceso de reinserción de la población isleña y costera en nuevos ámbitos rurales y urbanos, en el largo período de ejecución de Yacyretá, requiere, análogamente a lo expuesto con relación a la noción de lugar, una reflexión sobre la ciudad. Una ciudad, que está viendo transformados sus 'bordes' costeros y que con el progresivo llenado del embalse a su cota de diseño, está viendo escindido algunos de sus barrios por efecto del ingreso de lenguas de aguas (subembalses), y consecuentemente, verá modificados tantos sus flujos de materia y energía, como principalmente de información y verá, en suma, modificadas sus relaciones y sus significados.

Esta particular situación potencia, de alguna manera, el propio carácter fragmentario de la experiencia urbana contemporánea, que "[...] contribuye a hacer invisible el paisaje urbano y comporta que, para cada uno, la ciudad no exista más que a través de una selección de lugares" (Nel-lo, en Nogué, 2007: 187). Es por ello, que podemos coincidir con este autor, al decir que:

"[...] la ciudad es un paisaje oculto latente, por razones de tres órdenes: en primer lugar, su propia configuración nos impide que cuando estamos en ella, podamos capturarla con la mirada; en segundo lugar, el uso parcial y segregado del espacio urbano al que nos vemos abocados los ciudadanos induce visiones fragmentarias y sesgadas; y, finalmente, la sensación de riesgo que entraña en muchos casos la experiencia urbana [por las diferencias sociales en el 
uso del espacio] inhibe la curiosidad y fomenta la ocultación. Por todo ello la ciudad es paisaje latente." (Nel-lo, en Nogué, 2007: 190)

Pero, lo que habrá de verificarse en esta investigación es el segundo argumento de su hipótesis, ya que "[...] en la actualidad, la ciudad es ante todo un proyecto de futuro, un paisaje existente sólo en ciernes." (Nel-lo, en Nogué, 2007: 190); y sobre todo, considerando que esa nueva configuración urbana se encuentra en ejecución, que "[...] el carácter todavía invisible del paisaje de la ciudad futura no menoscaba en absoluto su belleza, al contrario, quizás la ensalza.” (Nel-lo, en Nogué, 2007: 195).

\section{I.1.4. El arte como mediación para la aparición del paisaje}

Señalábamos con anterioridad, que para encauzar las acciones de (re)construcción de la ciudad, principalmente en sus zonas costeras, por el efecto del llenado del embalse de una represa hidroeléctrica, debiera atenderse no ya las nuevas formas, sino más bien, las nuevas relaciones y los nuevos significados que deberán confrontarse con la mirada de las comunidades involucradas, a fin de enfrentar los impactos de las modificaciones generadas por la obra. Indicábamos también, que: forma física, relaciones y significado, tienen que ver con la noción de lugar y con el sentido de identidad. Ahora bien: ¿tienen que ver también con la noción de paisaje? Alain Roger sostiene que, un paisaje nunca es reductible a su realidad física (los geosistemas de los geógrafos, los ecosistemas de los ecólogos, las trasformaciones territoriales de los ingenieros, arquitectos y urbanistas, etc.).

La transformación de un país en paisaje supone siempre una metamorfosis, una metafísica, entendida en el sentido dinámico. En otros términos, el paisaje nunca es natural, sino siempre 'sobrenatural' (Roger, 2007:13), y para que esto suceda, indica, debe existir necesariamente una mediación. Es en tal sentido que Roger sitúa al paisaje ‘a medio camino' entre ‘el naturalismo ingenuo' y 'la intervención divina', definiéndolo como 'humano y artístico'; y afirmando que:

"El arte constituye el verdadero mediador, el 'meta' de la metamorfosis, el 'meta' de la metafisica paisajística [... que]; se opera según [...], retomando una palabra de Montaigne, una 'artealización' [...]”' (Roger, 2007: 14).

Vemos así, que Roger habla de operar en sentido artístico y distingue "[...] dos modalidades de la operación artística, dos formas de intervenir en el objeto natural o [...], de artealizar la naturaleza. La primera es directa, in situ [sobre el terreno]; la segunda, indirecta, in visu, por mediación de la mirada" (Roger, 2007: 21). Esa mediación de la mirada es lo que le permite plantear la siguiente reflexión:

"[...] un lugar natural sólo se percibe estéticamente a través del Paisaje, que, así pues, realiza en este ámbito la función de artealización. [...] La naturaleza es indeterminada y sólo el arte la determina [del mismo modo]: un país no se convierte en paisaje más que bajo la condición de un paisaje, y esto, de acuerdo con las dos modalidades, móvil (in visu) y adherente (in situ), de la artealización. [...] El país es, en cierto modo, el grado cero del paisaje, lo que precede a su artealización, tanto si esta es directa (in situ) o indirecta (in visu).” (Roger, 2007: 22-23). 
Parece bastante claro que cuando Roger nos habla del paisaje, nos está hablando de 'lugar'; o mejor del genius loci, ${ }^{9}$ que otorga sentido al lugar, que expuesto a la mediación de la mirada, se manifiesta como paisaje. Apoyándose en Maurice Barrès indica que:

"Hay lugares que sacan el alma de su letargo, lugares envueltos, bañados de misterios, elegidos [...] ¿De dónde viene el poder de estos lugares? [...] ¿Quiénes son [...] los genios silenciosos de esos lugares? [... para Roger] esos buenos genios no son ni naturales ni sobrenaturales, sino culturales. Si frecuentan esos lugares es porque habitan en nuestra mirada y, si habitan en nuestra mirada, es porque nos vienen del arte. El espiritu que respira aqui e 'inspira' estos sitios no es otro que el del arte, que, por medio de nuestra mirada, artealiza el país en paisaje" (Roger, 2007: 25 y 26);

Adhiriendo de esta forma al punto de vista de Agustín Berque, quién sostiene que "en sí mismo, el genio del lugar no existe" (Berque, 1996: 187). Por eso quizás, Aguiló hace referencia a la importancia del sentido del lugar, indicando que: "[...] los significados atribuidos a elementos del entorno y a su configuración espacial son innatos o tienen profundas raíces culturales que enraízan con civilizaciones muy remotas" (Aguiló, 1999: 243) y para explicarlo, se apoya en las relaciones que surgen de articular las 'cinco categorías fundamentales del conocimiento concreto de la naturaleza', desarrolladas por Norberg-Schulz: ${ }^{10}$

"La primera está constituida por las fuerzas naturales [...].

La segunda categoría de conocimientos es la abstracción de orden cósmico sistemático, de un flujo natural de los acontecimientos [como el ciclo solar o las crecidas de un río...].

La tercera es el carácter de ciertos elementos del paisaje natural [como la montaña o el agua como elementos sagrados de varias culturas...].

La cuarta es la luz, siempre considerada como un componente fundamental de la realidad al provenir del sol [...].

Por último, el tiempo que marca el ritmo de los fenómenos naturales y encadena las estaciones [...].

Las cosas y el carácter están más relacionadas con la tierra, mientras que el orden cósmico y la luz lo están con el cielo. Por otra parte, las cosas y el orden son de naturaleza espacial, pero el carácter y la luz se refieren a la atmósfera general del lugar.

El tiempo es la dimensión de la constancia y del cambio, y hace partícipes a los otros de una realidad viva." (Aguiló, 1999: 243 a 245). ${ }^{11}$

Siguiendo este razonamiento, nos resulta necesario dejar planteado el siguiente interrogante: ¿es cierto que existe un paisaje natural y un paisaje cultural, o simplemente existe paisaje?

${ }^{9}$ La idea de genius loci surge en la antigüedad, no sólo griega, para llegar hasta Shaftesbury, Fénelon, Rollin, Watteau, Marivaux, Montesquieu, Voltaire y Diderot, y volver a proponerse en Kant y Goethe. [...] Genius loci es, en la cultura moderna y contemporánea, una idea gracias a la cual, la naturaleza infunde en el artista el propio ingenium; y es también teoría de la naturaleza que imita al arte ingenuo.” (Milani, 2007: 150).

${ }^{10}$ Norberg-Schulz, Christian, 1979. Genius loci. Paessaggio, Ambiente, Architettura. Electra, Milano, Italia.

${ }^{11}$ Lo que pretende verificar esta investigación, es si “[...] esta 'doble articulación' -artealización in situ y in visu, por una parte y, país y paisaje, por otra- [permiten enfrentar...] eficazmente las reducciones de que es habitualmente víctima el paisaje: reducción 'geográfica' a los geosistemas, reducción 'ecológica' a los ecosistemas [... que constituyen] las debilidades y las contradicciones del naturalismo.” (Roger, 2007: 202). 


\section{I.2. EL PAISAJE COMO DISCIPLINA PARA ENTENDER LA OBRA DE INGE- NIERÍA ENRAIZADA EN SU ENTORNO}

Para explicar los dos rasgos fundamentales de la relación del hombre con el paisaje, Miguel Aguiló, ${ }^{12}$ propicia realizar "[...] un doble acercamiento, desde las modalidades de la acción y desde los momentos de la formación del concepto" (Aguiló, en Maderuelo, 2006: 216). En el primer caso, para recoger lo actuado por el hombre sobre su mundo y en el segundo caso, para acercarse al momento sensorial o perceptivo que es consustancial a la idea de paisaje.

Sobre la base de esta argumentación emplearemos una analogía, a través de la cual, explicaremos de qué forma un emprendimiento hidroeléctrico a gran escala se inserta en su entorno, generando su transformación. En este sentido se aborda, en primer término, la explicación de los principales elementos que definen la obra enraizada en su entorno, a fin de explicar desde la misma 'modalidad de la acción', de qué forma se producen las principales modificaciones de ese entorno. En la segunda parte se explica sintéticamente, la cronología histórica de la generación hidroenergética, a fin de poder percibir inicialmente, de qué forma se ha insertado progresivamente el debate sobre sus ventajas e impactos sobre el medio físico para conseguir los objetivos de la acción, que ha estado signado, a escala global, por el "[...] proceso de internacionalización del debate en torno al vínculo entre medio ambiente y desarrollo, que tiene importantes dimensiones políticas, económicas, tecnológicas, sociales, ambientales y humanas" ${ }^{13}$ (Pichs Madruga, 2004: 4). En tanto, en un tercer acápite, se identifican los elementos más significativos de 'la obra' y 'del entorno' que, con la ayuda del concepto de lugar y a través de la mediación del proyecto, serán profundizados en el Capítulo IV, para verificar si efectivamente estamos en presencia de un nuevo paisaje.

"Con ello, la obra de ingeniería puede ser abarcada de un modo más amplio, que incluye la radicación en la naturaleza, su vinculación con el mundo, y su evolución en el tiempo, como factores básicos de acumulación de sentido.” (Aguiló, en Maderuelo, 2006: 217).

\section{I.2.1. Las modalidades de la acción y la modificación del paisaje}

Para abordar el significado de esta reflexión sobre el paisaje desde la acción, es decir, desde el 'construir', Aguiló destaca a la ingeniería civil como la técnica más representativa, dado que la obra de ingeniería no puede ser comprendida al margen de la naturaleza: se construyen puentes para salvar ríos u obstáculos naturales y una presa no tiene sentido sin su cerrada. En efecto, indica, no se puede hablar de una particular estética de la ingeniería civil sin considerar, desde el instante inicial, el 'locus' como componente esencial de la obra. Lo que les da su razón de ser a estas obras es su vinculación a los accidentes particulares del terreno, con vistas a su superación. Por eso resulta imprescindible conocer los procesos

\footnotetext{
${ }^{12}$ Ver, en tal sentido, el apartado I.1. Paisaje e Infraestructura, de esta tesis.

${ }^{13}$ Tema, éste, que se aborda en el apartado siguiente.
} 
naturales porque además de condicionar el dimensionamiento de las obras, la acción debe producirse con la mínima alteración de lo natural para no hipotecar el futuro (Aguiló, en Maderuelo, 2006: 216).

Desde otra perspectiva, Simón Marchán Fiz también plantea que habría que resaltar las extraordinarias aportaciones de la ingeniería actual en el paisaje, en la misma dirección de las obras del Land Art, argumentando que estas obras de arte representan hitos en donde la naturaleza circundante no sólo es su enclave ambiental, su sitio específico, sino que es incorporada como parte de la obra de arte, despertando el interés hacia la naturaleza y actuando como un imán en el paisaje, fomentando su apreciación en un doble sentido: perfeccionando las cualidades estéticas de la naturaleza y mejorando las éticas, es decir, el arte como 'improvement’ (Marchán Fiz, en Maderuelo, 2006: 43).

Por su parte, Aguiló expresa que, por esa vinculación esencial con el entorno, la incidencia de las obras de ingeniería sobre la naturaleza puede analizarse a muy diversas escalas, desde la geografía, hasta el diseño. Pero sostiene que la disciplina más adecuada para entender la obra de ingeniería enraizada en su entorno es el paisaje, porque su carácter comprensivo de lo natural y lo construido proporciona un enfoque integrador sobre el resultado de esa conjunción que es el ambiente, que pude ser entendido como:

"[...] el conjunto de circunstancias físicas (o factores fisicos) que rodean a los seres vivos: Este concepto puede extenderse más allá de los factores del medio natural, para incluir también las circunstancias sociales, culturales y económicas de los grupos humanos, lo que amplía el significado de la definición original y, al mismo tiempo, la hace más flexible. En este sentido el ambiente abarcaría a todos los sistemas en que es posible la vida, dado que el hombre forma parte de la naturaleza, depende de ella para la supervivencia y, a su vez la modifica con sus actividades, en ocasiones de manera irreversible. Por lo tanto el concepto de 'ambiente' es distinto del concepto 'ecología', aunque ambos están relacionados" (Flores, 1995:32 y 33).

Por eso Aguiló señala también que con la ayuda del concepto de lugar se puede introducir la dimensión humana, tanto en sentido histórico como emocional. De esta manera, la obra de ingeniería puede ser abarcada de un modo amplio, que incluye su radicación en la naturaleza, su vinculación con el mundo y su evolución en el tiempo, como factores básicos de acumulación de sentido (Aguiló, en Maderuelo, 2006: 217). De tal forma, indica, que "[...] el interés estético de los paisajes creados, dependerá del acierto formal del diseño (Aguiló, en Maderuelo, 2006: 218) 14 y seguramente, de la forma en que el resultado sea interpretado por la sociedad.

Bajo esta perspectiva de análisis, resulta imprescindible entender entonces, cuales son los significados de las transformaciones que derivan de una obra hidroeléctrica a gran escala.

"[...] En los sistemas hidroeléctricos a gran escala se construyen elevadas presas a través de ríos grandes para crear grandes embalses [...] el agua acumulada se deja fluir a través de conductos a velocidades controladas, impulsando turbinas y generando electricidad." (Miller, 1994: 506)

\footnotetext{
${ }^{14}$ Para completar este concepto Aguiló indica que los tipos más conspicuos en el paisaje son las presas para retener el agua; los puertos para el abrigo de los barcos; los caminos para unir ciudades; los túneles para atravesar el terreno; los puentes para salvar obstáculos. Casi todos ellos, presentes en Yacyretá.
} 
Este tipo de proyectos causan cambios ambientales irreversibles sobre grandes áreas geográficas $\mathrm{y}$, por lo tanto, tienen el potencial para causar impactos importantes, en virtud de lo cual, ha aumentado la crítica a los mismos, en particular en las últimas cinco décadas. Los críticos más severos reclaman que, como los beneficios valen menos que los costos sociales, ambientales y económicos, es injustificable construir grandes represas; en tanto que otros sostienen que se puede, en algunos casos, evitar o reducir los costos ambientales y sociales a un nivel aceptable, al evaluar cuidadosamente los problemas potenciales y la implementación de las medidas correctivas. Por eso resulta necesario esbozar cuáles son las principales implicancias de estas obras.

\section{I.2.1.1. Las transformaciones que genera una obra hidroeléctrica}

George Tyler Miller Jr., señala que las obras para generar energía hidroeléctrica, presentan varios inconvenientes. En primer término, indica que los costos de construcción de los sistemas a gran escala son elevados y sus embalses inundan extensas regiones, ${ }^{15}$ y que ello repercute, en general, en la modificación y/o destrucción de hábitats de la vida silvestre, en la reducción de la fauna íctica por efecto del corte de la migración natural de los peces aguas arriba para el desove, en la necesidad de desplazar poblaciones y puede disminuir la fertilización natural de tierras con aptitud agrícola en los valles situados aguas abajo de la presa. Afirma por otra parte, que sin un adecuado control del uso de la tierra, los sistemas a gran escala pueden incrementar la erosión del suelo y que la contaminación del agua, por efecto de sedimentos provenientes de zonas cercanas y aguas arriba del embalse, puede ir reduciendo progresivamente la vida útil efectiva del embalse (Miller, 1994: 507).

Estudios encargados por la misma Entidad Binacional Yacyretá (EBY), para encauzar medidas orientadas a garantizar la calidad del agua del embalse, ponen el acento en estas cuestiones:

"Mundialmente la acción antrópica ha provocado una serie de perturbaciones en el funcionamiento de los ecosistemas fluviales (Petts \& Greenwood, 1985; Petts et al. 1993). Una de las mayores interferencias está relacionada a la acumulación de grandes volúmenes de agua en represas, modificando el comportamiento de los rios y de las áreas circundantes. El ecosistema lacustre así formado puede ser conceptuado como una ambiente ecológicamente complejo y heterogéneo (Araujo-Lima et al. 1995) siendo considerado un híbrido entre ríos y lagos (Margalef, 1983; Esteves, 1998).

La mayoría de las alteraciones observadas en las características del agua de un río, en función de su represamiento, es consecuencia de la disminución de la velocidad de la corriente, o sea en la transformación de un ambiente lótico en uno lenítico o semilenítico, causando una discontinuidad longitudinal en las características fisicas, químicas y biológicas del río. Modifica también el régimen de caudales, la estructura fisica del hábitat y el funcionamiento ecológico (Prenda et al., 2006)

Además de estos cambios, los recursos hídricos en general y los embalses artificiales en especial, están amenazados por la contaminación, tanto antrópica como natural. La pérdida de calidad de las aguas, incide directamente en las posibilidades de uso del recurso. Es por eso, que

${ }^{15}$ El área de influencia de una represa se extiende, en general, desde los límites superiores de captación del reservorio hasta zonas de estero, de costa y aún del mar. Incluye la cuenca hidrográfica y el valle del río aguas abajo de la represa. 
se deben conocer los procesos y características físicas, químicas y biológicas que se dan en todos los sistemas naturales o artificiales como asi también en la cuenca de drenaje, lo que constituye una herramienta importante para gestionar adecuadamente el recurso, para estar en condiciones de darle uso óptimo y seguro, básicamente cuando se desea lograr un proceso de desarrollo sostenible. (EBY, 2009.b: i)

Vemos así, que la base de las transformaciones territoriales, parten de la transformación del sistema hidrológico, que se manifiestan en el flujo, calidad, cantidad y uso del agua, en los organismos bióticos y en la sedimentación de la cuenca del río represado, factores estos, que requieren especial atención.

“[...] Pueden aparecer en el embalse problemas de contaminación, análogos a lo que sucede con los lagos naturales, estuarios y mares, dónde [...] con frecuencia, la dilución es menos efectiva que en las corrientes, debido a que estos cuerpos de agua contienen frecuentemente capas estratificadas que tienen poco mezclado vertical.

La estratificación también reduce los niveles de oxígeno disuelto, en especial en la capa del fondo. Además [...], tienen escasa fluencia, lo que reduce la posterior dilución y reposición de oxígeno disuelto [...]. ${ }^{16}$ Por tanto [...], son más vulnerables que las corrientes, a la contaminación por nutrientes vegetales, petróleo, pesticidas y sustancias tóxicas que pueden destruir la vida del fondo y matar peces [...].

La eutrofización ${ }^{17}$ derivada de los cultivos agrícolas por adición de fosfatos y nitratos, como resultado de actividades humanas, es un problema grave [...].

Durante la temporada cálida, esta sobrecarga de nutrientes produce crecimiento denso de vegetales, como algas, cianobacterias, lirios acuáticos y lenteja de agua.

El oxígeno disuelto en la capa superficial de agua cerca de la costa y en la capa del fondo, es agotado cuando mueren masas grandes de algas, que caen luego al fondo y son descompuestos por bacterias aeróbicas. Esto puede matar peces y otros animales acuáticos que consumen oxígeno [...]." (Miller, 1994: 672).

Los mismos estudios realizados para Yacyretá, indican que además, un represamiento “[...] genera [perturbaciones] y modificaciones de la calidad aguas abajo, dependiendo no sólo de la calidad de agua del propio embalse, sino también de la modalidad de erogación de las mismas [... y que por el conjunto de estos factores asociados], la magnitud o intensidad de los distintos problemas de calidad de agua en un embalse están estrechamente vinculados al 'Tiempo de Retención Hidráulico del Embalse' (volumen / caudal), es decir, el tiempo medio que el agua es retenida en el cuenco lacustre [... indicando que], a mayor tiempo de permanencia hidráulico los problemas de sedimentación, acumulación de componentes tóxicos y desarrollo de algas y micrófitos serán también mayores.” (EBY, 2006: 11).

El gráfico $\mathrm{N}^{\circ} 1$ muestra las relaciones existentes entre factores asociados con el recurso agua en una represa, que generan efectos ambientales no deseables.

\footnotetext{
${ }^{16}$ La depuración y cambio del agua en los lagos y depósitos artificiales grandes puede tomar de 1 a 100 años, en comparación con los varios días a varias semanas que toman las corrientes” (Miller, 1994: 672).

${ }^{17}$ Miller aporta dos definiciones: “eutroficación: cambios físicos, químicos y biológicos que tienen lugar después que un lago, un estuario o una corriente fluvial de flujo lento, reciben nutrientes vegetales, en su mayor parte nitratos y fosfatos por la erosión natural y los escurrimientos desde la cuenca circundante, y eutroficación cultural: sobre-enriquecimiento de ecosistemas acuáticos con nutrientes vegetales (sobre todo nitratos y fosfatos) a causa de actividades humanas tales como agricultura, urbanización y descargas desde plantas industriales y plantas de tratamiento de aguas negras" Miller, 194: 813).
} 


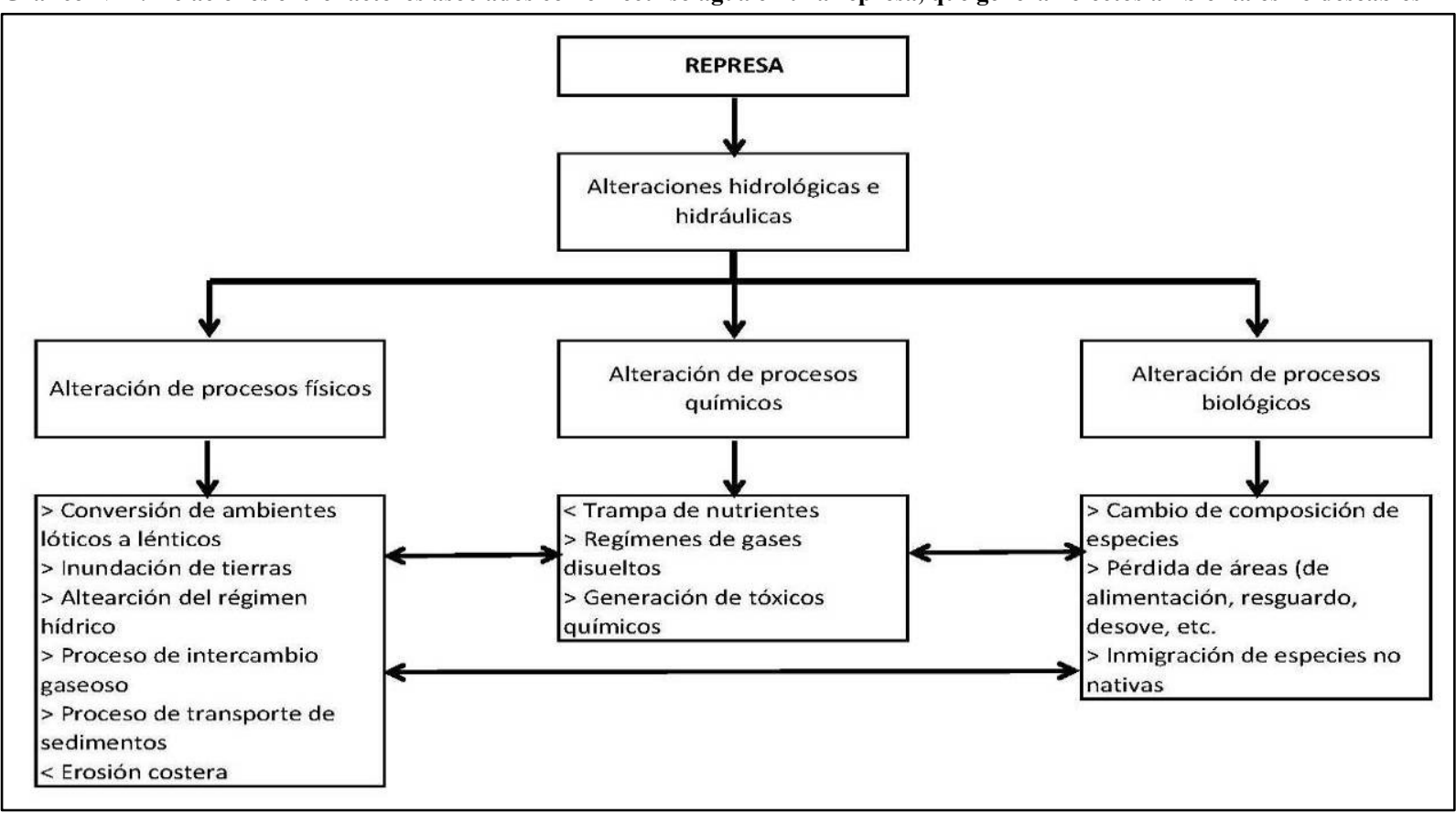

Fuente: Programa de Calidad de Agua del Embalse Yacyretá, (EBY, 2006: 12). Modificado de Bizer, J. R. 2000.

De lo expuesto puede observarse entonces que, al represar un río y crear un lago, se cambia profundamente la hidrología y limnología del sistema fluvial, y se modifica consecuentemente, el entorno territorial y el paisaje preexistente.

\section{I.2.1.2. Beneficios que aporta una obra hidroeléctrica}

Además de permitir un desarrollo para la región de influencia sobre la base de la generación de energía hidroeléctrica, que es su finalidad principal, la construcción de represas y reservorios, usualmente, se planifican para uno o más de los siguientes propósitos complementarios: para controlar las inundaciones; para proveer un afluente de agua confiable y de buena calidad para el riego y el uso doméstico e industrial; y también (como en nuestro caso de estudio), para favorecer la navegabilidad a través de esclusas de navegación que superan obstáculos geológicos como saltos naturales (en nuestro caso, los Saltos del Apipé).

También, las mismas represas pueden favorecer la generación de alternativas para las actividades que tienen el potencial para causar impactos negativos mayores. Por ejemplo, la energía hidroeléctrica es una alternativa para la energía termoeléctrica a base del carbón u otro combustible, o la energía nuclear. En materia hidroenergética, Miller afirma lo siguiente:

"La hidroenergía tiene una producción energética neta moderada a elevada, y costos de operación y mantenimiento bajos. Las plantas hidroeléctricas rara vez necesitan ser cerradas, y no producen emisiones de dióxido de carbono u otros contaminantes del aire atmosférico durante su operación. Sus embalses tiene una vida útil, dos a diez veces la vida de las plantas térmicas nucleares y de carbón. Las grandes presas también ayudan a controlar inundaciones y proporcionan un flujo regulado de agua de riego a áreas situadas corriente debajo de la presa." (Miller, 1994: 507). 
Otros ejemplos, corresponden a la intensificación de la agricultura a través del riego, que puede reducir la presión sobre los bosques, los hábitat de fauna y otras áreas no aptas para la agricultura; o bien, aguas abajo de una presa puede potenciarse una industria de pesca y facilitar también, la producción agrícola, que en algunos casos, pueden compensar las pérdidas sufridas en estos sectores como resultado de su construcción.

Estas grandes obras de infraestructura generan también otro tipo de efectos benéficos, derivados de lo que se denominan 'obras complementarias', que son aquellas destinadas a salvaguardar sectores del territorio que aguas arriba de la central son afectados por la conformación del embalse principal o de los subembalses que se generan en los arroyos afluentes; y que aguas abajo, son afectados por el cierre que consolida el represamiento para generar el embalse.

De tal forma pueden contarse las 'obras de protección ambiental' que protegen las costas insulares y continentales de la inundación, recuperando ámbitos naturales y urbanos con espacios recreativos y/o de conservación de la naturaleza; 'obras de reposición' de infraestructura vial y de equipamientos socio-comunitarios, que aportan a una mejor articulación local y regional; 'obras de ampliación urbana y/o de nuevos proyectos rurales', destinados a relocalizar aquellos sectores de las poblaciones costeras afectadas por el llenado del embalse; y principalmente, 'obras de saneamiento', que aportan los servicios de tratamiento de efluentes cloacales y de provisión de agua potable, básicos para garantizar la calidad de vida de la población y la del agua del embalse y sus afluentes.

También existen otros efectos positivos complementarios, determinados, entre otros, por la conformación de áreas de reserva natural protegidas que compensen en tipo y superficie a los territorios inundados; así como, por los aportes en equipamiento y en nuevas capacidades de gestión destinados a las organizaciones gubernamentales y aún no gubernamentales locales, encargadas de prestar los servicios básicos -principalmente de salud, educación, asistencia y desarrollo socio-comunitario y seguridad-, que normalmente van más allá de la población directamente involucrada en un proyecto de estas características, para extender sus beneficios a la población en general, con alcance regional.

En términos generales puede señalarse así que, este conjunto de obras y acciones, contribuyen por una parte a mitigar los impactos negativos de la obra y por otra, a conformar nuevos ámbitos (naturales, sociales y culturales), que pueden favorecer el desarrollo de nuevas relaciones en diversas escalas de interpretación y que, a través de 'la mediación de una nueva mirada', pueden contribuir también a la construcción de una cierta 'noción de paisaje'.

Para ampliar el detalle de este conjunto de afirmaciones, el cuadro $\mathrm{N}^{\circ} 1$, rescata una sistematización de los impactos negativos potenciales y de las medidas de atenuación o mitigación que normalmente se implementan en este tipo de emprendimientos. 


\begin{tabular}{|c|c|c|}
\hline & IMPACTOS NEGATIVOS POTENCIALES & MEDIDAS DE ATENUACIÓN O MITIGACIÓN \\
\hline \multicolumn{3}{|c|}{ DIRECTOS } \\
\hline \multicolumn{3}{|c|}{\begin{tabular}{l|l}
1 & Efectos, ecológicamente negativos, de la construcción:
\end{tabular}} \\
\hline & $\begin{array}{l}\text { 1.1. } \\
\text { contaminación del aire y del agua como resultado de la construcción y de la } \\
\text { eliminación de los desperdicios; }\end{array}$ & 1.1. control de la contaminación del aire y agua; \\
\hline & 1.2. erosión del suelo; & $\begin{array}{l}\text { 1.2. } \\
\text { ubicación cuidadosa de los campamentos, edificios, excavaciones; canteras, depósitos } \\
\text { de basura y desechos; }\end{array}$ \\
\hline & \begin{tabular}{l|l} 
1.3. & destrucción de la vegetación, problemas de saneamiento y salud en los \\
campamentos de construcción.
\end{tabular} & 1.3. $\mid$ preocupaciones para reducir la erosión; reclamación de la tierra. \\
\hline 2 & Dislocación de la gente que vive en la zona inundada & $\begin{array}{l}\text { Reubicar a la gente en un área adecuada, entregar compensación en especie por los recursos } \\
\text { perdidos, proveer servicios adecuados de cuidado sanitario, infraestructura y oportunidades } \\
\text { de empleo. }\end{array}$ \\
\hline & $\begin{array}{l}\text { Pérdida de terreno (agrícola, bosques, pastos, humedales) a causa de la inundación } \\
\text { para formar el reservorio. }\end{array}$ & $\begin{array}{l}\text { Ubicar la represa de tal modo que se reduzcan las pérdidas, disminuir su magnitud y el del } \\
\text { reservorio, proteger las áreas de igual tamaño en la región para compensar las pérdidas. }\end{array}$ \\
\hline 4 & Pérdida de propiedades históricas, culturales o ascéticas a raíz de la inundación. & $\begin{array}{l}\text { Seleccionar el sitio de la represa o reducir el tamaño del reservorio para evitar pérdidas, } \\
\text { recuperar o proteger el patrimonio cultural. }\end{array}$ \\
\hline 5 & Pérdida de tierras silvestres y hábitat de la fauna & $\begin{array}{l}\text { Localizar la represa o disminuir la magnitud del reservorio para evitar o reducir la pérdida, } \\
\text { establecer parques compensatorios o áreas reservadas, rescatar a los animales y reubicarlos. }\end{array}$ \\
\hline & $\begin{array}{l}\text { Proliferación de las hierbas acuáticas en el reservorio y aguas abajo, impidiendo la } \\
\text { descarga de la represa, los sistemas de riego, la navegación y la pesca, y mayores } \\
\text { pérdidas de agua por transpiración. }\end{array}$ & $\begin{array}{l}\text { Limpiar la vegetación lignosa de la zona del reservorio antes de inundarla (eliminar los } \\
\text { alimentos), disponer medidas para controlar la maleza, cosechar la vegetación para compost, } \\
\text { forraje o biogas, regular la descarga del agua y manipular los niveles de la misma para } \\
\text { desalentar el crecimiento de la maleza. }\end{array}$ \\
\hline \multirow[t]{3}{*}{7} & \multirow[t]{3}{*}{ Degradación de la calidad del agua del reservorio } & 7.1. Limpiar la vegetación lignosa de la zona del reservorio antes de a inundarla; \\
\hline & & 7.2. Limitar el tiempo de retención del agua en el reservorio; \\
\hline & & \begin{tabular}{l|l} 
7.3. & Instalar salidas a diferentes niveles para evitar la descarga del agua sin oxígeno.
\end{tabular} \\
\hline \multirow[t]{3}{*}{8} & \multirow[t]{3}{*}{ Sedimentación del reservorio y pérdida de su capacidad de almacenamiento } & \begin{tabular}{l|l}
8.1 & Controlar el uso de la tierra en la cuenca hidrográfica (prevenir, especialmente), la tala \\
de los bosques para agricultura);
\end{tabular} \\
\hline & & \begin{tabular}{l|l}
8.2 & $\begin{array}{l}\text { Implementar actividades de reforestación y/o conservación de suelos en las cuencas } \\
\text { hidrográficas (efecto limitado); }\end{array}$
\end{tabular} \\
\hline & & \begin{tabular}{l|l}
8.3 & $\begin{array}{l}\text { Eliminar, hidráulicamente, los sedimentos (lavado, corrientes de agua, liberación de } \\
\text { corrientes de alta densidad) }\end{array}$ \\
\end{tabular} \\
\hline & $\begin{array}{l}\text { Formación de depósitos de sedimento en la entrada del reservorio, creando un efecto } \\
\text { de contracorriente, e inundando áreas aguas arriba. }\end{array}$ & Lavado del sedimento, corrientes de agua \\
\hline 10 & Lavado del lecho del río, aguas debajo de la represa. & $\begin{array}{l}\text { Trampa para liberar el sedimento (p.ej. lavado del sedimento, corrientes de agua) para } \\
\text { aumentar el contenido de sal del agua liberada. }\end{array}$ \\
\hline 11 & Reducción de la agricultura de los terrenos aluviales (recesión). & $\begin{array}{l}\text { Regular la liberación de agua de la represa para duplicar, parcialmente, el sistema natural de } \\
\text { inundación. }\end{array}$ \\
\hline 12 & Salinización de los terrenos aluviales & Regular el flujo para reducir el efecto \\
\hline 13 & Intrusión del agua salada al estero y aguas arriba & Mantener un caudal mínimo, por lo menos, para impedir la intrusión \\
\hline 14 & $\begin{array}{l}\text { Interrupción de la pesca en el río, debido a los cambios en el flujo, el bloqueo de la } \\
\text { migración de los peces, y el cambio en la calidad y limnología del agua. }\end{array}$ & $\begin{array}{l}\text { Mantener un flujo mínimo, por lo menos, para la pesca, instalar gradas para los peces y otros } \\
\text { medios para que puedan pasar, proteger los sitios de desove, implementar acuacultura y } \\
\text { desarrollar la pesca en el reservorio como compensación. }\end{array}$ \\
\hline 15 & Se agarran las redes de pesca en la vegetación sumergida del reservorio & Desbrozar, selectivamente, la vegetación antes de la inundación \\
\hline 16 & Aumento de las enfermedades relacionadas con el agua & \begin{tabular}{|l|l|}
16.1 & Diseñar y operar la represa para reducir el hábitat del vector
\end{tabular} \\
\hline & & \begin{tabular}{|l|l|}
16.2 & Controlar el vector \\
\end{tabular} \\
\hline & & \begin{tabular}{|l|l|}
16.3 & Emplear profilaxis y tratar la enfermedad \\
\end{tabular} \\
\hline 17 & Demandas opuestas en cuanto al uso del agua & $\begin{array}{l}\text { Planificar el manejo de la represa dentro el contexto de los planes regionales de desarrollo; } \\
\text { distribuir el agua equitativamente entre los grandes y pequeños agricultores y entre las } \\
\text { diferentes regiones geográficas del valle. }\end{array}$ \\
\hline 18 & Trastorno social y reducción del nivel de vida de la gente reasentada & $\begin{array}{l}\text { Mantener el nivel de vida, asegurando que el acceso a los recursos sea, por lo menos, igual a } \\
\text { lo que se perdió; proveer servicios sanitarios y sociales. }\end{array}$ \\
\hline 19 & Degradación ambiental debido al aumento de presión sobre el terreno. & \begin{tabular}{|l|l}
19.1 & $\begin{array}{l}\text { Seleccionar el sitio de reasentamiento para evitar que se supere la capacidad de carga } \\
\text { de la tierra. }\end{array}$
\end{tabular} \\
\hline & & \begin{tabular}{|l|l|}
19.2 & $\begin{array}{l}\text { Aumentar la productividad o mejorar el manejo de la tierra (mejorándola para la } \\
\text { agricultura, pastoreo o silvicultura) para que pueda soportar una población más } \\
\text { grande. }\end{array}$ \\
\end{tabular} \\
\hline 20 & Trastorno/destrucción de los grupos indígenas y tribus & $\begin{array}{l}\text { Evitar el desplazamiento de personas no asimiladas, culturalmente; donde esto no sea posible, } \\
\text { reubicarles en un área que les permita mantener su estilo de vida y costumbres. }\end{array}$ \\
\hline 21 & $\begin{array}{l}\text { Aumento de humedad y neblina, localmente, creando un hábitat favorable para los } \\
\text { vectores insectos de las enfermedades (mosquitos tsetsé). }\end{array}$ & Controlar los vectores \\
\hline 22 & $\begin{array}{l}\text { Migración incontrolada de la gente hacia el área, gracias a los caminos de acceso y } \\
\text { líneas de transmisión. }\end{array}$ & $\begin{array}{l}\text { Limitar el acceso, implementar desarrollo rural y servicios de salud para tratar de reducir el } \\
\text { impacto. }\end{array}$ \\
\hline 23 & $\begin{array}{l}\text { Problemas ambientales como resultado del desarrollo que facilita la represa } \\
\text { (agricultura con riego, industrias, crecimiento municipal). }\end{array}$ & $\begin{array}{l}\text { Implementar planificación integral en toda la cuenca para evitar el uso excesivo, abuso y uso } \\
\text { incompatible de los recursos terrestres acuáticos. }\end{array}$ \\
\hline EXTEF & ERIORES & \\
\hline 24 & $\begin{array}{l}\text { Mal uso de las tierras de las áreas de captación sobre el reservorio, produciendo mayor } \\
\text { sedimentación y cambios en la calidad del agua. }\end{array}$ & $\begin{array}{l}\text { Incluir en la planificación del uso de la tierra, las áreas de la cuenca hidrográfica que se } \\
\text { encuentren encima de la represa. }\end{array}$ \\
\hline
\end{tabular}

Fuente: Ecología y Medio Ambiente (Miller, 1994: 376).

El PAISAJe COSTERo COMO FACTOR de INTEgRaCión

El PROYECTO HidRoELÉCTRICO YACYRETÁ Y LAS TRANSFORMACIONES DE LAS ZONAS URBANO-COSTERAS

DE LAS CIUDADES INVOLUCRADAS, EN EL PERIODO 2005 - 2010 


\subsubsection{La mirada ambiental sobre las grandes obras de infraestructura}

Los problemas derivados de la construcción de grandes obras de infraestructura, motivaron la realización de estudios preventivos, denominados genéricamente de evaluación ambiental, cuyo propósito es asegurar que las opciones de desarrollo bajo consideración sean ambientalmente adecuadas y sustentables, y que toda consecuencia ambiental sea reconocida pronto en el ciclo del proyecto y tomada en cuenta para su diseño.

Esta nueva conciencia, con relación a los efectos de las grandes obras, derivó en la creación de normas y procedimientos que aparecieron a finales de la década de 1960 en la legislación de los Estados Unidos y se extendió después a la de otros países con el nombre genérico de 'environmental impact assessment' (EIA), traducido al español, como evaluación de impacto ambiental.

En 1979, comienzan a ser considerados los impactos ambientales de los grandes embalses en Brasil, dónde los estudios ambientales estuvieron dirigidos, principalmente, a elaborar planes de mitigación en la fase de llenado de los embalses. Con estos mismos criterios se realizó en 1992 la Evaluación Ambiental de Yacyretá, con el proyecto en plena ejecución desde 1983.

De acuerdo con el 'Libro de Proyecto Ambiental' (Volúmenes I, II y III), publicado por el Departamento de Medio Ambiente del Banco Mundial, la Evaluación de Impacto Ambiental (EIA) es, en esencia, un procedimiento administrativo que sirve para identificar, prevenir e interpretar los impactos ambientales que producirá un proyecto en su entorno en caso de ser ejecutado, con el fin de que la administración competente pueda aceptarlo, rechazarlo o hacerlo modificar. Este procedimiento jurídico administrativo se inicia con la presentación de una memoria resumen por parte del promotor, sigue con la realización de consultas previas a personas e instituciones por parte del órgano ambiental, continúa con la realización de un Estudio de Impacto Ambiental a cargo del promotor y su presentación al órgano competente; se prolonga en un proceso de participación pública y se concluye con la emisión de la Declaración de Impacto Ambiental, por parte del Órgano Ambiental de competencia, en el área de implantación del proyecto.

Dado que la EIA se refiere siempre a un proyecto específico ya definido en sus particularidades, tales como: tipo de obra, materiales a ser utilizados, procedimientos constructivos, trabajos de mantenimiento en la fase operativa, tecnologías utilizadas, insumos, etc., estos procedimientos fueron evolucionando hasta la construcción de una nueva herramienta de gestión ambiental, denominada Evaluación Ambiental Estratégica (EAE).

Este término refiere a la Directiva (2001/42/CE) de la Unión Europea, que fuera originada al respecto del planeamiento territorial y el desarrollo regional. La misma se constituye en una serie de análisis de los impactos ambientales sinérgicos o acumulativos de las políticas, planes y programas que permite poner condiciones adelantadas que deben ser incorporadas en las acciones específicas. 
En su mayor parte una EAE es realizada con anterioridad a que la correspondiente EIA sea emprendida. Esto significa que la información sobre el impacto ambiental de un plan podrá ir descendiendo 'en cascada' a través de los distintos niveles de toma de decisiones y ser usada en una EIA en un estadio posterior.

A partir de la década del 90, estos procedimientos fueron encauzándose hacia una forma de evaluación que permite extraer conclusiones, con relación a la conveniencia de realizar un determinado proyecto de gran escala, o un plan de desarrollo. Esta nueva metodología es conocida con el nombre de Evaluación Ambiental Regional (EAR), que está conformada por estudios ambientales que se realizan cuando existen propuestas de varias actividades de desarrollo en una región determinada.

Este cambio de enfoque en la mirada ambiental resulta de gran utilidad para definir el área natural de estudio; para seleccionar modelos de desarrollo entre distintas alternativas; para identificar impactos ambientales acumulados o cruzados (entre proyectos simultáneos en la misma zona) y para definir medidas para evitarlos o atenuarlos; para identificar procesos de interacción ambientales o conflictos entre varios proyectos en los cuales los impactos de un proyecto podrían reducir los beneficios de otros; para formular criterios a ser incluidos en los proyectos particulares permitiendo la identificación de áreas sensibles; y para seleccionar los sitios y lineamientos de planificación del uso de la tierra (Banco Mundial, 1991; CEPAL/ILPES/PNUMA, 1986).

Este tipo de estudio sirve además para identificar vacíos de información, para definir programas de seguimiento y control ambiental y para distinguir los instrumentos políticos e institucionales que permitan orientar objetivos de desarrollo sustentable en la región en análisis.

\subsubsection{Algunas alternativas para un proyecto hidroeléctrico a gran escala}

Una de las premisas de esta investigación es la de contribuir, desde la perspectiva paisajística, a la discusión global sobre la construcción de este tipo de emprendimientos, que se profundizará en el apartado siguiente, en este caso, a través de lo que podemos denominar la mediación del proyecto (Marchán Fiz, en Maderuelo, 2006: 51), entendida como instrumento para articular diversas miradas convergentes sobre el controvertido tema de las transformaciones derivadas de la construcción de una gran obra de infraestructura hidroeléctrica y sus impactos.

Para introducirnos en este aspecto, Gerard Kiely señala, con relación a las responsabilidades que deben enfrentarse ante la definición de un proyecto hidroeléctrico, lo siguiente:

"[...] Tradicionalmente, los ingenieros pudieron ejercer su profesión sin tener que atender a la ética ambiental [...], era aceptable diseñar una carretera o cambiar el curso de un río, basándose en las condiciones técnicas y económicas [...]. La práctica de la ingeniería ambiental hoy en día requiere que nos ocupemos de estos asuntos. La legislación nos exige preparar un Informe de Impacto Ambiental (IIA) antes de la fase de diseño de un proyecto. Es en esta fase cuando debemos ocupar- 
nos de la cuestión ética ambiental. La ética ambiental se preocupa de la actitud de las personas hacia otros seres vivos y hacia el medio natural (Vesilind et al., 1994) ${ }^{18}$ " (Kiely, 1999: 9).

Por eso en la actualidad, es necesario analizar sobre una variedad de alternativas para decidir el diseño y manejo de los proyectos de las represas.

En este sentido podemos citar a modo de ejemplo las siguientes consideraciones:

$\square$ se puede evitar o diferir la necesidad de construir la represa, reduciendo la demanda de agua o energía, aplicando medidas de conservación, mejorando la eficiencia, sustituyendo los combustibles, o restringiendo el crecimiento regional;

$\square \quad$ es posible evitar la necesidad de construir una represa, cuyo propósito principal sea el riego, ampliando y/o intensificando la agricultura de los terrenos aluviales del río, o fuera de la cuenca hidrográfica;

$\square \quad$ se puede investigar la posibilidad de ubicar el proyecto en un rio que ya tenga una represa, diversificando sus funciones;

$\square \quad$ se debe ubicar la represa propuesta, de tal manera que se reduzcan al mínimo los impactos negativos y sociales;

$\square \quad$ es posible ajustar la altura de la represa, el área inundada, el diseño y los procedimientos de operación, para reducir los impactos ambientales negativos;

$\square \quad$ se pueden instalar varias represas pequeñas en vez de una grande.

En cuanto a los aspectos de manejo de este tipo de grandes proyectos, la modalidad de administración resulta esencial. De tal forma, un organismo descentralizado, que tenga la responsabilidad de administrar el proyecto de la represa, es una de las figuras más utilizadas. Esta institución es en general responsable de: recolectar los datos de base; construir y manejar la represa; producir un plan maestro para el uso del agua que contiene las estrategias para regular el reservorio; coordinar el control de los vectores de las enfermedades; planificar el suministro de agua potable en el área involucrada y la instalación de equipos para el tratamiento del agua.

Otro aspecto, que generalmente se incluye en la gestión operativa, es el de articulación interinstitucional. Esto tiene por objetivo asegurar la calidad del agua del embalse y de los subembalses a partir de una adecuada cooperación intersectorial, como por ejemplo, un consejo o comité de manejo de la cuenca del río, para concertar y/o coordinar políticas y acciones, con los organismos gubernamentales que sean responsables por la agricultura, la pesca, la forestación, los pastos y ganadería, la salud, la fauna, el turismo, la planificación territorial e industrial y el transporte.

Pero también tiene que ver con la educación, la salud -en particular para el control de la contaminación y de los vectores de las enfermedades- y con las cuestiones sociales, vinculadas principalmente con el desplazamiento involuntario de poblaciones y con la selección y adaptación a los nuevos sitios de asentamiento y reinserción de esas comunidades.

${ }^{18}$ VESILIND, P. A. PEIRCE J.J, and WEINER, R.F. 1994. Environmental Engineering, 3rd edn, Butter-worthHeinneman, Oxford. 
En los grandes proyectos hidroeléctricos, los aspectos de gestión operativa de articulación interinstitucional, se fortalecen con asistencia técnica y capacitación interna y externa. De tal forma, los Paneles de Expertos Internacionales, de carácter asesor en temas de seguridad de presas y de operación; de medio ambiente y/o de reasentamiento, proveen las guías de manejo y, también, las instancias de capacitación donde sea necesaria.

Finalmente, tanto en sus fases de construcción como de operación durante la vida útil de la represa, es esencial el monitoreo de factores críticos tales como:

lluvia;

volumen de agua almacenada en el reservorio;

volumen anual de sedimento que se transporta al reservorio;

calidad del agua a la salida de la represa y en algunos puntos a lo largo del rio (como salinidad, $p H$, conductividad eléctrica, turbiedad, oxígeno disuelto, sólidos suspendidos, fósforo, nitratos);

generación de sulfuro de hidrógeno y metano en la represa;

muestreo limnológico de la microflora, hierbas acuáticas y organismos bénticos;

evaluaciones de la pesca (especies, poblaciones, etc.) del río y del reservorio;

fauna (especies, distribución, números);

cambios en la vegetación (cubierta, composición de especies, tasas de crecimiento, biomasa, etc.) de la cuenca hidrográfica superior, la zona debajo del reservorio y las áreas aguas abajo;

aumento de erosión en la cuenca;

impactos en las tierras silvestres, la especies o las comunidades de plantas de especial importancia ambiental;

salud pública y vectores de las enfermedades;

migración de la gente hacia el área y fuera de ella;

cambios en el estado económico y social de las poblaciones reasentadas y la gente que permanece en la cuenca.

De todas maneras, la nueva mirada ambiental que debe aplicarse hoy sobre un proyecto de tales características, indica que todas estas alternativas debieran alimentar ex-ante los estudios para realizar una Evaluación Ambiental Estratégica (EAE), que determine la conveniencia o no de encauzar un proyecto hidroenergético.

Es en este sentido, que actualmente la misma International Hydropower Association (IHA), marca la necesidad de realizar un análisis de Sustentabilidad a escala regional, basado en aspectos de evaluación institucional, socio-ambiental y económica o de mercado.

En términos específicos, la IHA, adopta una metodología de evaluación estratégica de sustentabilidad, a partir del análisis e identificación de nueve tópicos, que son considerados por en el denominado Protocolo de Etapa Temprana: 1) Necesidades demostradas; 2) Opciones de evaluación; 3) Políticas y Planes; 4) Riesgos políticos; 5) Capacidad Institucional; 6) Aspectos técnicos y riesgos; 7) Aspectos sociales y riesgos; 8) Aspectos ambientales y riesgos; 9) Aspectos financieros, económicos y riesgos. 


\section{I.3. LAS GRANDES OBRAS DE INFRAESTRUCTURA HIDROELÉCTRICAS EN}

\section{EL CONTEXTO DE LA EVOLUCIÓN DEL DEBATE INTERNACIONAL EN TOR- NO AL VÍNCULO ENTRE MEDIO AMBIENTE Y DESARROLLO}

Hemos señalado con anterioridad el concepto de que, para pensar el paisaje transformado por la acción humana en cuanto actividad cultural, es necesario hacerlo en sus vertientes: histórica y cientifica (Maderuelo (2006: 7), pero también puede intentarse una posible aproximación al 'paisaje de la acción', desde un enfoque más dialéctico y menos descriptivo, con la mención estricta de unos cuantos episodios concentrados en un solo paisaje. Eso permite un menor alejamiento del concepto respecto a los hechos particulares, dado que aquél surge como visión o destilado de la acumulación de éstos (Aguiló, en Maderuelo, 2006: 218).

Esta forma de aproximación nos resulta apropiada para reseñar los principales acontecimientos que definieron la ejecución de complejos hidroeléctricos a gran escala a nivel mundial y particularmente de Yacyretá, en el contexto de la evolución del debate internacional en torno al vínculo entre medio ambiente y desarrollo; para lo cual, parafraseando a Aguiló, se incluyen unas notas o episodios independientes, a modo de destellos fugaces de diferente voltaje pero suficientemente intensos como para iluminar una porción de la realidad que se escudriña, sin apropiársela ni explicarla pero contribuyendo a mantener un cierto resplandor para acercarse a ella (Aguiló, en Maderuelo, 2006:218).

Es por eso, que nos resulta necesario analizar de qué forma ha evolucionado en las cinco últimas décadas el concepto de desarrollo y su implicancia sobre el ambiente, analizando los paradigmas y los imperativos dominantes de cada década, que permiten explicar y entender 'el porqué' de las adecuaciones del proyecto en su largo período de ejecución.

Cuadro No 2: PARADIGMAS DE DESARROLLO Y AMBIENTE

\begin{tabular}{|c|c|c|c|c|c|}
\hline PARADIGMA & $\begin{array}{l}1960 \\
\text { FRONTERA } \\
\text { ECONOMICA }\end{array}$ & $\begin{array}{l}1970 \\
\text { PROTECCION } \\
\text { AMBIENTAL }\end{array}$ & $\begin{array}{l}1980 \\
\text { MANEJO } \\
\text { DE RECURSOS }\end{array}$ & $\begin{array}{l}1990 \\
\text { ECO. } \\
\text { DESARROLLO }\end{array}$ & $\begin{array}{l}2000 \\
\text { ECOLOGIA } \\
\text { PROFUNDA }\end{array}$ \\
\hline Imperativo dominante: & Progreso infinito & $\begin{array}{l}\text { Contradicción } \\
\text { entre ecologlay } \\
\text { crecimiento }\end{array}$ & Sustenlabilidą̧ & $\begin{array}{l}\text { Co-desanrolo } \\
\text { humano y natural }\end{array}$ & $\begin{array}{l}\text { Ecotopla } \\
\text { Anticrecimiento }\end{array}$ \\
\hline $\begin{array}{l}\text { Relaciones entre } \\
\text { hombre y naturaleza }\end{array}$ & $\begin{array}{l}\text { Antropocentrismo } \\
\text { muy fuerte }\end{array}$ & $\begin{array}{l}\text { Antropocentrismo } \\
\text { tuerte }\end{array}$ & $\begin{array}{l}\text { Antropocentrismo } \\
\text { moditicado }\end{array}$ & Ecocentrismo? & Biocentrismo \\
\hline Conflictos dorninarxes & $\begin{array}{l}\text { Kambre } \\
\text { Pobreza } \\
\text { Catástróes Naturales }\end{array}$ & $\begin{array}{l}\text { Especies en peligro } \\
\text { Cortaminación }\end{array}$ & $\begin{array}{l}\text { Recursos degradados } \\
\text { Pobreza } \\
\text { Crecim. poblacional }\end{array}$ & $\begin{array}{l}\text { Cambio global } \\
\text { Incertidumbro } \\
\text { ecollogica }\end{array}$ & $\begin{array}{l}\text { Colapso de los } \\
\text { ocosistemas }\end{array}$ \\
\hline Grandes temáticas & $\begin{array}{l}\text { Explotación } \\
\text { infinita de kos } \\
\text { recursos naturales }\end{array}$ & $\begin{array}{l}\text { Ecologfay } \\
\text { externalidades } \\
\text { econcmicas }\end{array}$ & $\begin{array}{l}\text { Interdependencia } \\
\text { econónica-cotogica }\end{array}$ & $\begin{array}{l}\text { Simbiosis } \\
\text { Economla ecologiza- } \\
\text { da y sisternas sociales }\end{array}$ & $\begin{array}{l}\text { Vueha a fa } \\
\text { naluraleza }\end{array}$ \\
\hline $\begin{array}{l}\text { Regimen prevaleciente } \\
\text { de propiedad }\end{array}$ & $\begin{array}{l}\text { Privat. capitalista o } \\
\text { Nacional marista }\end{array}$ & $\begin{array}{l}\text { Privatización } \\
\text { dominante }\end{array}$ & $\begin{array}{l}\text { Legislación mundial } \\
\text { global de protección }\end{array}$ & $\begin{array}{l}\text { Global } \\
\text { y local }\end{array}$ & $\begin{array}{l}\text { Privado y público } \\
\text { articulados por } \\
\text { la conservación }\end{array}$ \\
\hline ¿Quión paga? & El Estado & $\begin{array}{l}\text {-impuestos } \\
\text { fiscales }\end{array}$ & $\begin{array}{l}\text { - Contaminadores } \\
\text { pagan }\end{array}$ & - Tasas ambiontales & $\begin{array}{l}\text { - Costos ambientales } \\
\text { integrados }\end{array}$ \\
\hline $\begin{array}{l}\text { Resporsables del } \\
\text { desartoto y el } \\
\text { gerenciamiento }\end{array}$ & $\begin{array}{l}\text { Propielarios } \\
\text { individ. y el Estado }\end{array}$ & $\begin{array}{l}\text { Desarrollo } \\
\text { descorntralzzado } \\
\text { Mlanejo contralizado }\end{array}$ & $\begin{array}{l}\text { Interposición } \\
\text { intersectorial e } \\
\text { interjurisdiccional }\end{array}$ & $\begin{array}{l}\text { Imovaciones } \\
\text { institucionales } \\
\text { privado-público }\end{array}$ & $\begin{array}{l}\text { Amplia descen- } \\
\text { tralieación pero } \\
\text { diseño integrado }\end{array}$ \\
\hline $\begin{array}{l}\text { Conceptos } \\
\text { fundamentales }\end{array}$ & $\begin{array}{l}\text { Mecanicistas } \\
\text { pero creativa }\end{array}$ & $\begin{array}{l}\text { ldeologla de } \\
\text { la abundancia }\end{array}$ & $\begin{array}{l}\text { - Integración de } \\
\text { los lactores sociales }\end{array}$ & $\begin{array}{l}\text {-Nueva conciencia } \\
\text { pública giobal }\end{array}$ & $\begin{array}{l}\text { - Orgánica pero no } \\
\text { crealiva } \\
\text {-Cómo reducir la } \\
\text { población? }\end{array}$ \\
\hline
\end{tabular}

Fuente: Revista A/MBIENTE No 74, p. 27 
$\mathrm{Al}$ respecto, "El Dr. Roger Amisial, experto de OEA delegado ante el CIDIAT de Venezuela, ha desarrollado [a inicios de la década del 90] una síntesis de las doctrinas y tendencias que orientaba a los organismos de cooperación" (Pesci: 1992: 26).

\section{I.3.1. Expansión de la frontera económica y uso irrestricto de los recursos naturales}

"Hacia fines de 1880, en pleno apogeo de la revolución industrial, el paradigma de desarrollo a escala mundial, estaba basado en el criterio de expansión de la frontera económica y del uso irrestricto de los recursos naturales" (Miller, 1994: 41). Pero de todas maneras, en Europa comenzaba la preocupación por el crecimiento desmedido de las ciudades y por los serios problemas de contaminación y salud, derivados de la falta de saneamiento y de tratamiento de los efluentes urbanos e industriales. "En tanto que en EEUU, surgía el primer movimiento conservacionista, preocupado por el aumento de la deforestación y el agotamiento de la vida silvestre en todo el país” (Miller, 1994: 42).

Ese enorme crecimiento imponía una gran demanda de electricidad, cuya generación se basaba fundamentalmente en la utilización del carbón mineral, “[...] pero en 1880, se construye la primera central hidroeléctrica en Northumberland, Gran Bretaña, ${ }^{19}$ aunque su expansión se produjo recién a principios del siglo XX, y hacia la década de 1920, las centrales hidroeléctricas ya generaban una parte importante de la producción total de electricidad." (Miller, 1994: 42).

En tanto en el área de estudio, hacia fin del siglo XIX ya se hablaba de los Saltos del Apipé en el Paraná y del Salto Grande en el río Uruguay como accidentes de un mismo sistema hídrico. ${ }^{20}$ Se decía que el río Paraná se vinculaba con el río Uruguay a través de los Esteros del Iberá y el río Miriñay. Por ello ambas caídas de agua fueron estudiadas en conjunto en numerosas oportunidades. Ya iniciado el siglo XX, hacia 1903, una ponencia presentada ante la IX th Internacional Navigation Congress comenzó a juntar el tema del mejoramiento de la navegación en los Saltos del Apipé, con la producción de energía hidroeléctrica (Levinton 2010: 89) y durante 1912 el ingeniero francés Maurice Mollard propuso al Congreso de la Nación Argentina la utilización del Salto Grande, con un dique de 17,5 m. de altura que atravesaría perpendicularmente el río Uruguay con una longitud de $2.200 \mathrm{~m}$., con dos usinas eléctricas y un canal para navegación con esclusa (Levinton, 2010: 92).

El 24 de julio de 1919, el Presidente argentino Hipólito Yrigoyen ordenó la realización de los estudios para el aprovechamiento de la energía de los Saltos del Iguazú y del Salto Grande del río Uruguay, que los ingenieros Francisco Mermoz y Humberto Gamberale, efectuaron entre 1920 y 1921. El

\footnotetext{
${ }^{19}$ El nacimiento de la energía hidráulica se produjo por el desarrollo del generador eléctrico, seguido del perfeccionamiento de la turbina hidráulica.

${ }^{20}$ Levinton señala además, que la Argentina ya contaba con Centrales Eléctricas desde 1886, en la ciudad de La Plata, con diques desde 1888, el de San Roque en la Provincia de Córdoba y con Centrales Hidroeléctricas desde 1897 (Casas Bamba en la Provincia de Córdoba). (Segovia, F. / Corthell, E. L., 1902: 30, en Levinton, 2010: 89).
} 
resultado de la medición de caudales no resultó económicamente satisfactorio para su aprovechamiento y por eso se les encargó, en forma complementariamente, el estudio de los Rápidos del Apipé sobre el Río Paraná (Levinton 2010: 92). Esto deriva en el primer hecho significativo a nivel institucional, el $1^{\circ}$ de febrero de 1926, con la firma en Washington DC (EEUU), del 'Protocolo Argentino-Paraguayo' relativo a la utilización de los Saltos de Apipé, que establecía la utilización del lugar del salto en jurisdicción común, a cambio del derecho para el Paraguay de adquirir hasta el 7,5\% de la producción total (Levinton 2010: 93), siempre que "[...] para la utilización de las caídas se instalasen obras en territorio paraguayo." (Debernardi, 1996: 308).

En Argentina entre 1920 y 1930 se produciría una gran concentración de los servicios públicos de electricidad de procedencia térmica. Pero desde algunas regiones con reales posibilidades potenciales de beneficiarse con una explotación hidroeléctrica se insistía en el tema. Para esta época la industria norteamericana tenía un gran auge en los sectores de la química, el petróleo, la electricidad, los automotores, la metalurgia y la construcción. Por su parte Argentina también experimentaba un indudable crecimiento pero, entre otras cosas, la cuestión energética era muy vulnerable a las fluctuaciones de la economía mundial (Levinton, 2010: 93). Para Brasil, dentro de la órbita de influencia de los Estados Unidos, la industrialización pasó a ser el factor clave del desarrollo, en tanto que la Argentina, fuertemente ligada a Europa y sobre todo a Gran Bretaña, entraba en un período de estancamiento económico, especialmente por la declinación del modelo agroexportador. Durante la década de 1930, la crisis del capitalismo mundial produjo un gran retroceso de las actividades económicas y por ende una gran concentración de los mercados internacionales. ${ }^{21}$

En la Argentina recién en esta década la industria, que se localizaría en el Gran Buenos Aires, comenzaría a convertirse en uno de los sectores impulsores del crecimiento económico del país. (Levinton, 2010: 95). De otro forma, podemos señalar en general, que:

“Antes de la Segunda Guerra Mundial la noción de 'desarrollo' era muy cercana a la de 'civilización' y se entendía más vinculada al grupo cultural y social que alcanzaba un país dado que a la economía". (Mattelart, 1998 y 203, en Tauber, 2008: 50).

En la región, durante el período correspondiente a la segunda guerra mundial, se abre una nueva etapa de desarrollo. El Brasil, siempre apoyado por los Estados Unidos, expandía el proceso de sustitución de importaciones y el crecimiento energético, mientras que los demás países de la Cuenca del Plata estaban en una situación más diletante. Sin embargo -sobre la base de los estudios de Gamberale y Mermóz- el 13 de enero de 1938, se firmó un Acta que se instauró como el Protocolo inicial entre

21 "El inglés John Maynard Keynes fue el economista más influyente a partir de sus críticas al liberalismo y su concepción de la importancia del Estado a través de políticas activas. Publicó en 1936 su Teoría general de la ocupación, el interés y el dinero. Estas concepciones influyeron decisiones como la 'New Deal' de Roosevelt que implementó la intervención estatal realizando obras públicas. Una demostración de ello fue la Tennessee Valley Authority que emprendió la realización de grandes represas hidroeléctricas ayudando al crecimiento de una región agrícola del sur de los Estados Unidos" (Levinton, 2010: 95). 
Argentina y Uruguay para el aprovechamiento del Salto Grande. A inicios de la década del 40, las exportaciones de bienes primarios y secundarios (cemento, aparatos eléctricos y productos químicos y farmacéuticos) de Argentina hacia el Brasil aumentaban sustancialmente en forma temporal y Paraguay, recién en esta década tenía disponibilidad de energía eléctrica para el consumo público. Hacia 1943, la Argentina creaba la Dirección Nacional de Energía, con el objetivo de implantar y explotar centrales eléctricas en el país (Levinton, 2010: 95-96).

A nivel internacional se creaba en 1945 el Fondo Monetario Internacional (FMI) con gran predominio de Estados Unidos (Levinton, 2010: 96), y en ese mismo año, con la conclusión de la Segunda Guerra Mundial, cambia el paradigma de desarrollo, por la necesidad de reconstruir a los países afectados por ese desgraciado episodio bélico.

"El concepto de desarrollo cambia en la segunda posguerra (Sunkel y Paz, 1970) y tiene su ejemplo institucional más claro en las Naciones Unidas, que en su Carta fundacional, firmada en la Conferencia de San Francisco de 1945, se compromete 'a emplear un mecanismo internacional para promover el progreso económico y social de todos los pueblos' (UN, 1945, Preámbulo) y mantiene esa línea en sus Comisiones Regionales, muy en particular a través de la Comisión Económica para América Latina y el Caribe-CEPAL-“(Tauber, 2008: 50).

Este mecanismo de promoción contribuyó a la recuperación de esos países y, en materia de desarrollo, impulsó el uso en forma irrestricta de los recursos naturales. Dentro de ese contexto internacional, se promovió la ejecución de innumerables emprendimientos hidroeléctricos para favorecer el crecimiento económico. Al respecto, el mismo Tauber, señala:

"A partir de ese momento y durante más de dos décadas, el concepto de desarrollo fue fundamentalmente económico, fundamentado sobre el trípode abundancia de recursos naturales -y energéticos-, aumento de la productividad del trabajo y presencia del Estado de Bienestar -o Estado desarrollista-; asociado al crecimiento y medido por la evolución del PBI o del PBI per cápita (Sunkel y Paz, 1970). [...] Esta concepción economicista del desarrollo, apuntada a la cosificación del concepto, por sobre la multiplicación de capacidades sociales para integrarse al mundo sin perder identidad, colonizó incluso el discurso latinoamericano del momento" (Tauber, 2008 51).

En este periodo de pos-guerra, en Argentina se crearía en 1945 la Administración Nacional del Agua y en 1946 las Centrales Eléctricas del Estado. En tanto, el 3 de diciembre de ese año, se creaba la Comisión Técnica Mixta de Salto Grande (CMT) por un Convenio Argentino-Uruguayo. El gran problema de esos días era el déficit energético. Por su parte la economía brasileña mantenía un ritmo acelerado de crecimiento económico (con una media del 7,1\% del PBI) y en Paraguay, dónde según Debernardi sólo una parte de la ciudad de Asunción tenía servicio eléctrico regular, se creaba el 22 de noviembre de 1948 la ANDE -Administración Nacional de Electricidad- (Levinton, 2010: 97-98).

"La situación del Cono Sur debía entenderse en el conjunto de los países. El Presidente Perón quería modificar el status único de nación agro exportadora de la Argentina, como le estaba haciendo exitosamente Brasil, con una política sustitutiva de importaciones. Esta política se articulaba con una expansión de las actividades existentes mediante la utilización intensiva de la mano de obra [...] aumentos salariales [...] y expansión del mercado interno [...]. Para lograr 
lo enunciado tenía que desarrollarse un mayor potencial energético. [...] Uno de sus propósitos era el de llevar a cabo la realización de Yacyretá." (Levinton, 2010: 98-99)

Bajo la presidencia del Gral. Juan Domingo Perón, el Primer Plan Quinquenal (1947-1951) definía que el desenvolvimiento de la economía estaría supeditado a la racional utilización de los recursos energéticos aún inexplorados y, en particular, de los hidráulicos porque el agua era la única fuente de energía que se renovaba a sí misma. En concordancia con esto, el 27 de abril de 1948, se iniciaron los trabajos de relevamiento para Salto Grande, y en 1949 se organizó la Dirección Nacional de la Energía que tuvo a su cargo la instalación de centrales hidroeléctricas y termoeléctricas.

"La explotación de las fuentes de energía desaprovechadas fue uno de los objetivos fundamentales del gobierno. Se terminaron varios diques en Tucumán, Mendoza, Santiago del Estero, Catamarca, Río Negro y otras provincias. Las obras de mayor trascendencia fueron El Nihuil en Mendoza; los Molinos en Córdoba; Florentino Ameghino en Chubut; Las Pirquitas en Catamarca y La Florida en San Luis. El plan contemplaba la realización de once centrales termoeléctricas y de 45 centrales hidroeléctricas incluyendo 4.500 kilómetros de líneas de transmisión. De cualquier manera el Presidente Perón debió sortear dos crisis energéticas en 1949 y en 1952 [...]" (Levinton, 2010: 99)

La segunda mitad de la década de 1950 estuvo caracterizada en la región por el impulso de los proyectos nacionales y binacionales. En la Argentina, el Segundo Plan Quinquenal (1953-1957) de la presidencia del Gral. Perón, contemplaba una progresiva y completa electrificación del país con énfasis en la utilización de los recursos hidroeléctricos. De tal forma, en abril de 1953, se hizo un estudio comparativo entre los aprovechamientos del río Paraná en Apipé y del río Uruguay en Salto Grande, y en 1954, se preparaba un anteproyecto del Apipé. Mientras tanto en el Paraguay, el uso masivo de la energía eléctrica recién comenzaba a difundirse, y en Brasil, la aceleración del crecimiento, con epicentro en la industria, exigía un desarrollo en infraestructura y servicios para los que las ciudades brasileñas no estaban preparadas (Levinton 2010: 101).

"Fuldner decía que 'en el Brasil se proyectaban en 1954 [...] obras hidráulicas por un valor de 500 millones de dólares. En la Argentina esta cifra no era ni el 5 por ciento' y su conclusión era que 'el atraso en esta materia se paga caro' (Fuldner, 1956: 7). Al respecto, mencionaba que no existía ningún anteproyecto terminado para los 'Rápidos del Apipé' ni para Salto Grande, que habia que actualizar los estudios realizados por Mermoz y Gamberale." [...] Por otro lado, consideraba que debía tener prioridad el aprovechamiento de los Rápidos del Apipé porque realizándose primero el desarrollo del Paraná se podrá desviar un importante caudal de las crecientes normales del Alto Paraná al río Uruguay, cuyo régimen con respecto a los estiajes era inverso al del Alto Paraná. [...] Por último, insistía, que únicamente el río Paraná podía suministrar un volumen de energía eléctrica de suficiente magnitud para cubrir la mayor parte del déficit." (Levinton, 2010: 101-102)

En 1955, un golpe de Estado derrocaba al Gral. Perón de la presidencia en Argentina.

"En 1956 se organizó un Comité Popular Pro Represa de Salto Grande y se constituyó el Movimiento Internacional Pro-Aprovechamiento Hidroeléctrico del río Uruguay. [...] Por su parte el Almirante Rojas en 1957 afirmaba, como repitiendo las consignas del peronismo, que 'el Plan de Restablecimiento Económico - el llamado Plan Prebisch-asigna a la energía eléctrica 
y su desarrollo una misión primordial (...) la solución del problema está en la hidroelectricidad [...]” (Levinton, 2010: 103).

Pero el hecho de mayor significación se producía a fines de la década: "El 23 de enero de 1958, se celebró el Convenio entre Argentina y Paraguay para la creación de la Comisión Mixta Técnica Paraguayo- Argentina del Apipé [CMT]. El objetivo era realizar el estudio del aprovechamiento de la energía hidroeléctrica pasible de ser producida debido a los rápidos y el mejoramiento de la navegabilidad en el paso por los mismos. [...] El 1º de mayo de 1958 asumiría [el Dr. Arturo] Frondizi la Presidencia de la Nación Argentina y la CMT sería ratificada el 16 de junio.”22 (Levinton 2010: 23).

En suma, como hemos señalado en párrafos anteriores, hacia la década de 1920, las centrales hidroeléctricas ya generaban en el mundo, una parte importante de la producción total de electricidad.

"En la década del '50 se multiplicaron los proyectos hidroeléctricos en el mundo. En esta época comenzaron a estudiarse más en profundidad los proyectos de Itaipú y Yacyretá. [...] Cuando Brasil decidió hacer Itaipú ya tenía una infraestructura eléctrica de 16.700 .000 kilovatios de los cuales 12.438.000 [74,5\%] eran de procedencia hidroeléctrica” (Levinton, 2010: 151).

Pero es sobre la base de sus ventajas comparativas que, a partir de la década de 1960 y durante casi dos décadas, se fomentaron financieramente en el mundo la construcción de este tipo de grandes obras de infraestructura hidroeléctrica.

\section{I.3.2. Década de 1960: el surgimiento del movimiento ambiental}

Esta década, que consolida el paradigma de expansión de la frontera económica, estuvo particularmente marcada por el debate en torno a varias publicaciones difundidas internacionalmente, que llamaban la atención sobre algunos de los problemas ambientales más preocupantes en esos años (Pichs Madruga, Ramón, 2004: 4).

En 1962, la bióloga Rachel Carson publica La primavera silenciosa (Silent Spring), que describe la contaminación del aire, agua y vida silvestre por el uso ampliamente extendido de los plaguicidas lentamente degradables como el DDT. Este libro ayudó a ampliar el concepto de la conservación de los recursos para incluir la preservación de la calidad del aire, el agua y el suelo. ${ }^{23}$ De tal forma, entre 1965 y 1970, la surgente ciencia de la ecología recibió amplia difusión por los medios de comunicación. Al

\footnotetext{
${ }^{22}$ Levinton afirma que de todas maneras, esta medida no tendría efecto inmediato, debido a que la cuestión del aprovechamiento hidroenergético no era prioritaria en ese momento porque se pensaba en la posibilidad del autoabastecimiento argentino en base al petróleo. (Levinton 2010: 23).

${ }^{23}$ Miller acota, que "La respuesta pública sin precedente al libro de Carson fue el principio de lo que ahora se conoce como movimiento ambientalista en Estados Unidos. El tercer movimiento de conservación nacional de los recursos empezó durante el breve gobierno de John F. Kennedy (1961-1963). Estos esfuerzos se ampliaron bajo la gestión presidencial de Lyndon B. Johnson (1963-1968). En 1964, el Congreso aprobó la Ley de Vida Silvestre. Autorizó al gobierno a proteger áreas de tierra pública no desarrolladas, como parte del Sistema Nacional de Vida Silvestre.” (Miller, 1994: 48)
} 
mismo tiempo, las divulgaciones de biólogos como Paul Ehrlich, Barry Commoner y Garrett Hardin, ayudaron al público a enterarse de las alteraciones del crecimiento de la población, el uso de los recursos y la contaminación. También durante ese periodo, varios acontecimientos reseñados por los medios de comunicación aumentaron la difusión de problemas derivados por ejemplo, de los contaminantes en el aire de Nueva York; de la espuma producida por el extenso uso de sustancias no biodegradables en ríos y arroyos; o de la contaminación con petróleo, como lo ocurrido en el río Cuyahoga (Miller, 1994: 48).

Puede señalarse además que, dentro de ese contexto, el imperativo dominante de progreso infinito comenzaba a tambalear, cuando el economista inglés Dudley Seers, fuertemente inspirado en el pensamiento de Gandhi, incorpora en la agenda a la pobreza, el desempleo y la desigualdad, como los temas a mejorar o superar en un proceso de desarrollo y los considera incluso prioritarios al crecimiento de la renta per-cápita." (Seers, 1963, en Tauber, 2008: 52).

"Es precisamente en esos años cuando comienza a difundirse el paradigma de la protección ambiental, que suponía el uso de tecnologías de la fase final o 'al final del tubo' para controlar la contaminación una vez que esta se había producido, además de abogar por la utilización preferente de mecanismos administrativos o regulaciones legales para enfrentar el deterioro del entorno. Cabe apuntar, además, que bajo este enfoque, no se fomentaban los vínculos entre la protección del medio ambiente y las políticas de desarrollo; es decir eran considerados como objetivos por separado." (Pichs Madruga, 2004: 5).

Sin embargo, para los proyectos hidroeléctricos, en este período se valoraban más los impactos positivos de la generación de electricidad para fomentar el desarrollo, en función de los bajos costos de operación y mantenimiento y aún de las postergadas promesas de desarrollo local y regional, que los negativos sobre el ambiente las comunidades locales afectadas por su construcción.

Dentro de la región de análisis, Brasil -tal como hemos analizado- ya había iniciado un amplio desarrollo de emprendimientos de estas características que se expandió en esa década a partir de la creación de grandes empresas de economía mixta como la Centrais Elétricas de Minas Gearis (Cemig / 1955), Furnas Centrais Elétricas SA (1956) y ELETROBRAS SA (1961).

“En 1964 se entregó el Informe Técnico-Económico-Financiero producido por la CMT considerado por los autores como anteproyecto de la Represa de Yacyretá Apipé” (Levinton, 2010: 153). En tanto que "el 12 de febrero de 1967 se creó la Comisión Mixta Técnica Paraguayo-Brasileña [...]" (Levinton, 2010: 154) para el proyecto hidroeléctrico Itaipú (el más grande en generación a nivel mundial), el 20 de julio de 1967 se concretaba el "[...] intercambio de Notas Reversales para continuar los estudios sobre el aprovechamiento de la energía hidráulica y el mejoramiento de la navegación del río Paraná a la altura de las islas Yacyretá-Apipé" (Levinton, 2010: 107).

Hacia 1968, la Comisión Interministerial Binacional establecía el cronograma de las obras de Salto Grande, fijando el primer semestre de 1974 para el comienzo de las mismas, e indicando que la Central Hidroeléctrica entraría en funcionamiento en 1979. Ambas fechas serían cumplidas. 
En el caso de Yacyretá, la publicación de un proyecto para el denominado Complejo Hidroeléctrico Apipé-Iberá-Salto Grande por la Comisión Nacional de la Cuenca del Plata, mostraba que todavía no había ningún esquema totalmente aceptado por el Paraguay y la Argentina. Por ello, Paraguay, asistido técnicamente por el Brasil, el 16 de diciembre de 1968, inauguraba oficialmente la usina de la represa del Acaray, la más importante obra de ingeniería construida hasta ese momento en el Paraguay (Levinton 2010: 157).

“[...] Hacia 1969, en la Argentina el 87\% de la potencia eléctrica instalada era de origen térmico, mientras que la hidroelectricidad participaba con el 13\% restante." (Levinton 2010: 157-158).

\section{I.3.3. Década de 1970: consolidación del movimiento ambientalista}

Esta década -cuyo paradigma fue la protección ambiental y su imperativo dominante una suerte de contradicción entre ecología y crecimiento-, está caracterizada por lo que puede denominarse "[...] la organización de la corriente ambientalista, a partir de la creación de agencias o departamentos gubernamentales dedicados a la investigación de los problemas ambientales en casi todos los países capitalistas desarrollados [...]" (Pichs Madruga, 2004:5) y por una creciente demanda social. ${ }^{24}$

"En 1972, se celebró en Estocolmo (Suecia) la Conferencia de Naciones Unidas sobre el Medio Ambiente Humano y se fundó el Programa de Naciones Unidas sobre Medio Ambiente (PNUMA), ${ }^{25}$ y se publicaron los estudios auspiciados por el Club de Roma sobre 'Los Límites al Crecimiento ${ }^{26}$. Paralelamente, el embargo de petróleo por la OPEP, ${ }^{27}$ en 1973, y la caída de la producción en Irán en 1979, condujeron escasez y bruscas alzas en el precio del combustible entre 1973 y 1981" (Miller, 1994: 49).

Es por ello, que entre 1975 y 1980, el debate en torno a los problemas ambientales devino en un movimiento ecologista, que tuvo su centro principal de atención en el tema energético. Este debate entre energía y medio ambiente tuvo amplia repercusión internacional a partir de 1979, al ocurrir el accidente de la planta nuclear de Three Mile Island, Pennsylvania, EE.UU” (Pichs Madruga, 2004: 6).

${ }^{24}$ El 22 de abril de 1970 tuvo lugar la primera festividad anual llamada Día de la Tierra, en Estados Unidos. Cerca de 20 millones de personas en más de 2.000 comunidades salieron a las calles para exigir mejor calidad ambiental. ${ }^{24}$ (Miller, 1994: 49-50).

${ }^{25}$ La Declaración de Estocolmo sobre el Ambiente Humano incluía 26 principios y 109 recomendaciones para la actuación ambiental. Tenía una gama muy amplia en la protección del entorno e incluía apartados tan diversos como la protección de los bosques y la calidad del agua en ríos, lagos y mares.” (Kiely, 1999: 16). Este Programa fue uno de los primeros promotores del criterio de ecodesarrollo, como intento de incorporar objetivos culturales, sociales y ecológicos en el concepto de desarrollo. De esta forma se dotó a los esfuerzos y debates en el terreno ambiental de una base institucional. (Pichs Madruga, 2004:5).

${ }^{26}$ Estos estudios preveían que de continuar sin cambios las tendencias de crecimiento de la población mundial, la industrialización, la contaminación, la producción de alimentos y el uso irrestricto de los recursos naturales, en un período de 100 años se alcanzarían los límites al crecimiento del planeta; proponiendo una rápida modificación de estas tendencias y el establecimiento de normas de estabilidad ecológica y económica, que permitiesen alcanzar el equilibrio global de crecimiento cero. Según Pichs Madruga (2004:5), una de las críticas más aguda que tuvo este estudio y que ejemplifica esa contradicción entre ecología y desarrollo, provino de la Universidad británica de Sussex, que consideró que las conclusiones subestimaban al progreso tecnológico.

${ }^{27}$ Organización de Países Exportadores de Petróleo, del Tercer Mundo, constituida en Bagdag el 14 de septiembre de 1960, por Arabia Saudita, Irak, Irán, Kuwait Venezuela. Para profundizar este aspecto, consultar Pichs Madruga, Ramón 2004“Petróleo, energía y economía mundial (1964-2004)”, en "Los últimos 40 años de la economía mundial”, CIEM, Documento de Trabajo 09/04, Vol. II, pp. 24-43, La Habana, Cuba. 
Previamente -entre otras importantes medidas de protección ambiental- en 1977, el presidente James Carter creó el Departamento de Energía, advirtiendo que Estados Unidos y otros países industrializados debían desarrollar una estrategia energética de amplio alcance. ${ }^{28}$ (Miller, 1994: 50).

Esta situación derivada de la crisis internacional del petróleo, fue justificando ampliamente la difusión y fomento de la generación de energía hidroeléctrica, como alternativa a la termoelectricidad, por parte de los organismos multilaterales de crédito -como el Banco Mundial y el Banco Interamericano de Desarrollo-, representando esto también, una de las razones que fundamentó la firma el $1^{\circ}$ de mayo de 1973 del Tratado de Itaipú entre Brasil y Paraguay (cuya obra dio inicio el 25 de noviembre de 1974), y 13 de diciembre, el Tratado de Yacyretá entre Argentina y Paraguay (cuya obra se iniciará recién en 1983), que representarán los dos mayores emprendimientos hidroeléctricos de la región. ${ }^{29}$ En 1979, Salto Grande (construido entre Argentina y Uruguay) comenzaba a generar electricidad.

\section{I.3.4. Década de 1980: internacionalización del debate ambiental}

Con tales precedentes, entre 1981 y 1986, transcurre una etapa en la que se profesionaliza la conciencia ambientalista y se aprecia un creciente interés parlamentario en relación con el deterioro ambiental, que se canaliza por la vía de numerosos partidos políticos -'verdes'- principalmente en el viejo continente y por la actividad de numerosas organizaciones no gubernamentales (ONG), que surgen al calor del debate sobre el medio ambiente. ${ }^{30}$ (Pichs Madruga, 2004: 6): Esa profesionalización se ve materializada en lo que Roger Amisial denomina 'el paradigma de manejo de los recursos'.

En tanto, Miller caracteriza este período en EE.UU, como de continuación de la controversia y alguna marcha atrás, indicando que desde 1981, la presidencia de Ronald Reagan, atacó las principales leyes ambientales y de conservación del país, impugnadas por fuerte oposición en el Congreso, malestar público y demandas legales por las organizaciones ambientalistas y conservacionistas, cuyo número de miembros aumentó notablemente en este período. El efecto de los '8 años de Reagan' fue retardar el ímpetu de la protección ambiental y la conservación de los recursos. En vez de avanzar, las or-

\footnotetext{
${ }^{28}$ Según Miller, la mayor parte de los esfuerzos de los EE.UU para encarar el final de la era del petróleo barato, fueron debilitados por la derrota de Carter y la saturación temporal de petróleo en la década de 1980. Estos acontecimientos enviaron un falso mensaje a muchos consumidores y funcionarios electos, en el sentido de que la conservación de la energía y la búsqueda de sustitutos del petróleo, ya no eran de alta prioridad.

${ }^{29}$ La segunda razón sobre la decisión de construir Yacyretá está íntimamente relacionada con el análisis geopolítico de la influencia del Brasil sobre el Paraguay y el noreste de la Argentina, particularmente las provincias de Misiones y Corrientes." (Lins Ribeiro, 2003: 81).

${ }^{30}$ A partir de esta década se han hecho más evidentes algunos de los problemas ambientales de alcance internacional, tales como el agotamiento de la capa de ozono, el efecto invernadero, la pérdida de la diversidad biológica, la contaminación urbana, el tráfico transfronterizo de desechos peligrosos, la contaminación de los mares, océanos y zonas costeras y el deterioro ambiental asociado a las condiciones de subdesarrollo y pobreza en que vive la tres cuarta partes de la población mundial (Pichs Madruga, 2004:6); abriéndose también el debate sobre los impactos que generan las grandes obras de infraestructura hidroeléctrica sobre el medio ambiente y la sociedad, principalmente en aquellas localizadas en los países subdesarrollados.
} 
ganizaciones ambientales y de conservación gastaron mucho tiempo y dinero luchando contra un vigoroso intento oficialista de retroceso (Miller, 1994: 50-51).

En el contexto regional, “[...] el 7 de julio de 1981, el Banco Mundial autorizó el préstamo 1761RA para las Obras Civiles Principales" (Levinton, 2010: 248) de Yacyretá, que después de esto estuvo prácticamente paralizada durante dos años.

En 1982, la Argentina entraba en guerra con Gran Bretaña. "La guerra de las Malvinas paralizó totalmente la actividad de la EBY. En el mismo año [...] se precipitó una crisis financiera internacional que se expresó en cesación de pagos de la deuda pública de México. Esto llevó al corte del crédito privado internacional para toda la región, forzando a los países deudores a recurrir a los organismos multilaterales de crédito" (Levinton, 2010: 251).

En tanto que el 3 de diciembre de 1983 recién daba comienzo la construcción de Yacyretá, ${ }^{31}$ el 17 de diciembre Brasil inauguraba Itaipú, con el "[...] primer giro mecánico de la $1^{\circ}$ Unidad Generadora" (Levinton, 2010: 116).

"En noviembre de 1984, el gobierno argentino, acosado por la severa crisis que se desencadenó a partir del 82, sólo atinó a asumir el proyecto [Yacyretá] en un virtual estancamiento, lo que no ayudó a contener el drenaje de divisas que exigía mantener las villas permanentes levantadas en la zona de obras." (Diario 'La Nación', 22/11/92).

El debate ambiental cobra mayor fuerza a partir de mediados de la década del 80. En octubre de 1984, convocada por la Asamblea General de Naciones Unidas, se reúne por primera vez la Comisión Mundial sobre Medio Ambiente y Desarrollo (World Commission on Environment and Development), con la finalidad de establecer una agenda global para el cambio (a global agenda for change), partiendo de la convicción de que es posible para la humanidad construir un futuro más próspero, más justo y más seguro, publicando en abril de 1987, sobre la base de este enfoque, su informe 'Nuestro Futuro Común' (Our Common Future), ${ }^{32}$ planteaba la tesis del desarrollo sostenible, definida como aquel desarrollo que permite satisfacer las necesidades del presente sin comprometer la habilidad de las futuras generaciones para satisfacer sus propias necesidades, obteniendo un crecimiento económico basado en políticas de sostenibilidad y expansión de la base de recursos ambientales.

Sin embargo, Pichs Madruga, señala con acierto, que en este contexto de internacionalización del debate ambiental, "[...] los países desarrollados han insistido en el tratamiento por separado de los problemas del medio ambiente y del desarrollo [... desviando] la atención internacional hacia aquellos

31 “El 10 de diciembre de 1983 asumió Raúl Alfonsín como Presidente [Constitucional] de la Argentina. [...] Al retirarse del poder el gobierno militar dejaba una herencia económica poco menos que catastrófica: el país se hallaba en plena recesión, con una desocupación creciente, una inflación del 400\%, una deuda externa de 46.200 millones de dólares (casi el 70\% del PBI) y sin reservas internacionales" (Levinton, 2010: 259).

${ }^{32}$ También conocido internacionalmente como 'Informe Brundtland', por el nombre de la doctora Gro Harlem Brundtland, que encabezaba la Comisión Mundial sobre Medio Ambiente y Desarrollo. 
temas ambientales que son de su interés, sin tener en cuenta debidamente los objetivos y prioridades de las naciones subdesarrolladas." (Pichs Madruga, 2004:8). ${ }^{33}$

En abril de 1989 se concreta en Yacyretá la “[...] habilitación del Vertedero Principal para el desvío del brazo principal del río Paraná" (Levinton, 2010: 118) y el 9 de julio, luego de una nueva crisis económica-financiera en Argentina, asume su primera presidencia el Dr. Carlos Saúl Menem. Para ese año, la energía de las plantas hidroeléctricas proporcionaba el 20\% de la electricidad en el mundo y el $6 \%$ de la energía comercial total. Los hidrosistemas proporcionaron prácticamente toda la electricidad en Noruega, el 74\% en Suiza, 67\% en Austria y 50\% en los países subdesarrollados (PSD). Ya se ha desarrollado gran parte del potencial hidroeléctrico de América del Norte y de Europa, pero África ha aprovechado sólo el 5\% de su potencial hidroeléctrico, América Latina, el 8\% (a excepción de Brasil, cuya matriz energética ya superaba el 80\% de generación hidroeléctrica), y Asia, el 9\%. Muchas plantas o centrales hidroeléctricas a gran escala están en planeación o desarrollo en Brasil, China, India y otros PSD (Miller, 1994: 507).

\section{I.3.5. Década de 1990: el camino hacia el eco-desarrollo}

Sobre esta nueva conciencia pública global, apoyada en los objetivos de alcanzar el paradigma de eco-desarrollo, sobre el imperativo dominante de co-desarrollo humano y natural y sobre unas relaciones cultura-naturaleza determinadas por una suerte de ecocentrismo, los ambientalistas advierten que debían hacer de los años 90 una nueva década del ambiente (un decenio verde), que debiera ir más adelante que lo realizado hasta ese momento, y que este nuevo despertar ambiental, requeriría de un fuerte liderazgo nacional y mundial por parte de los Estados Unidos, por ser el país más rico del mundo y el más grande contaminador, usuario y derrochador de los recursos.

De tal forma el 22 de abril de 1990, se celebró el vigésimo 'Día de la Tierra' ${ }^{34}$, cuyas principales metas fueron, llegar a las minorías y a los pobres que luchan diariamente por la sobrevivencia en todo el mundo; hacer que la gente esté consciente de la diferencia que sus acciones podrían tener en el sostenimiento y conservación de la Tierra: actuando localmente y pensando mundialmente, resumido ello en su lema: ‘¿Quién dice que usted no puede cambiar el mundo? Y finalmente, convencer a todos para que hagan de cada día el 'día de la tierra'.

\footnotetext{
${ }^{33}$ Es sobre la base de estas ventajas comparativas y de los imperativos dominantes de la época, que a partir de la década de 1960 y durante casi dos décadas, se fomentaron en el mundo la construcción de grandes obras hidroeléctricas, que como se explicara en el apartado anterior: "En 1989, [...] proporcionaban el $20 \%$ de la electricidad y el 6\% de la energía comercial total en el mundo [...]." (Miller, 1994: op.cit.).

${ }^{34}$ Miller, estima que participaron 200 millones de personas en 141 países de los 7 continentes, constituyéndose en la demostración mundial más grande de la historia (Miller, 1994:51).
} 
Para ejemplificar esta postura, resulta esclarecedor, el planteo de Miller:

Agenda para la Conservación y Sostenimiento de la Tierra en los años 90 y después:

Tratar de los problemas ambientales y de recursos que afrontaremos no será fácil o poco costoso. Implicará mucha controversia y requerirá que hagamos transacciones y cambios significativos en nuestra visión del mundo, los sistemas políticos y económicos, y los estilos de vida.

Las acciones especificas que los ambientalistas creen que son necesarias para ayudar a conservar la tierra, se exponen y describen en todo este libro.

El énfasis al paso de remediar la contaminación a prevenirla [...]; de la disposición de los desechos, a evitarlos y reducirlos; de la protección de las especies a la del hábitat; y del uso creciente de recursos a la conservación acrecentada de ellos.

Se necesitará usar los sistemas económicos y políticos existentes para recompensar las actividades económicas de conservación de la Tierra y desalentar las que dañen. Debemos reconocer que la codicia económica a corto plazo, eventualmente conduce al perjuicio económico y ambiental a largo plazo.

Tendremos que permitir que sanen las partes del mundo que hemos dañado; ayudar a restaurar las áreas severamente lesionadas, y proteger las áreas silvestres restantes contra cualquier forma de desarrollo destructivo. Los gobiernos tendrán que cooperara para tratar de resolver un cúmulo enorme de problemas ambientales y de recursos de tipo regional y mundial [...].

Encontramos nuestra casa-Planeta Tierra-provisto óptimamente de agua potable, buen suelo para cultivar alimentos y aire limpio para respirar. Por lo menos debemos dejarla en tan buenas condiciones como la encontramos, si no es que mejor." (Miller, 1994:51).

Pero cabe hacer explícita aquí la advertencia de Tomás Maldonado, acerca de que:

"Si se olvida, por ejemplo que el riesgo es transnacional, podemos terminar aprisionados en un ambientalismo que no mira más allá del propio país, de la propia región, ciudad o barrio. [... El mencionado] eslogan ambientalista 'pensar globalmente, actuar localmente', lleva a una visión distorsionada de la realidad. Ocuparse de problemas próximos es acertado, pero deja de serlo cuando olvidamos de ver los lazos estrechos que existen entre los problemas que nos son próximos y aquellos que nos son lejanos. [...] Si no se puede prescindir de un eslogan, mejor sería reproponerlo en los siguientes términos 'pensar y actuar local y globalmente'. La convergencia entre pensamiento y acción, entre lo local y lo global, es en este punto una cuestión improrrogable." (Maldonado, 1999: 20).

Por eso, podemos coincidir que el desarrollo sostenible debe ser analizado en el contexto de un debate más amplio acerca del desarrollo (Pichs Madruga, 2004: 9), porque la sostenibilidad, o mejor, el objetivo de desarrollo sostenible, se encuentra entre los conceptos más ambiguos y controvertidos de la literatura y parece ser evidente que su búsqueda exige integrar factores económicos, sociales, culturales, políticos y ecológicos (CNUMAD, 1992), y exige tener en cuenta al mismo tiempo, los aspectos locales y los globales, y la forma en la que se relacionan recíprocamente. (Gallopín, 2003: 7). Pero, Pichs Madruga sostiene al respecto, lo siguiente:

"[...] A pesar de su ambigüedad, el concepto de desarrollo sostenible asume que los objetivos de desarrollo económicos y sociales del desarrollo deben ser definidos en términos de sostenibilidad. Tomando como puntos de partida los [mencionados] conceptos de desarrollo sostenible (Comisión de Naciones Unidas sobre Medio Ambiente y Desarrollo) y desarrollo humano $(P N U D)$, pueden identificarse tres dimensiones básicas e interrelacionadas del desarrollo, que constituyen aspectos complementarios de una misma agenda: sostenibilidad económica, social $y$ ambiental. Por tanto, con un enfoque integral, el desarrollo sostenible debe ser definido como un proceso multidimensional, que debe ser 'sostenible' en términos económicos, sociales y am- 
bientales; y donde cada una de estas dimensiones constituye una condición necesaria aunque no suficiente para la sostenibilidad." (Pichs Madruga, 2004:9).

Por otra parte, Gerad Kiely, señalaba que los problemas ambientales no hacen caso de los límites geográficos, como quedó bien ilustrado por el accidente de Chernobyl de 1986. ${ }^{35}$ (Kiely, 1999: 11), y resume las herramientas de gestión para enfrentar esos problemas, explicando que las leyes ambientales evolucionan para cubrir zonas mayores e incluso regiones continentales con la misma legislación, como en el caso de Estados Unidos donde la normativa ambiental federal se aplica a todos los Estados, ${ }^{36} \mathrm{o}$ en la Unión Europea, dónde la Comisión de la UE en Bruselas fija normas para toda Europa (Kiely, 1999: 12). Además, en el ámbito internacional destaca dos Acuerdos: la mencionada Declaración de Estocolmo (1972) y la Declaración de Río (1992), que aspiraba a alcanzar un Acuerdo global en un cierto número de asuntos clave: cambio climático, biodiversidad, bosques tropicales y desarrollo sostenible. La conferencia produjo dos importantes convenios: uno sobre cambio climático y otro sobre la biodiversidad, así como la Declaración de Río que establece los principios básicos para orientar la política ambiental y de desarrollo, y la Agenda 21, un plan a largo plazo para integrar ambiente y desarrollo. (Kiely, 1999: 16).

Por esta época, mientras que Itaipú, el 6 de mayo de 1992, con la entrada en operación de la $18^{\text {a }}$ Unidad Generadora, permitía que la Central Hidroeléctrica alcanzara su potencia máxima de 12,6 millones de kW" (Levinton, 2010: 119), Yacyretá se debatía entre algunos avances y continuas reprogramaciones de sus obras principales. En tanto que el $1^{\circ}$ de agosto se realizaba el cierre de las tomas de las unidades generadoras para permitir la remoción de la ataguía de protección, el 28 de julio de ese mismo año, un Acta de Acuerdo entre la EBY y ERIDAY UTE, modificaba el Cronograma de Yacyretá, fijando el $1^{\circ}$ de septiembre de 1994 como límite máximo para la puesta en operación de la Unidad Generadora $\mathrm{N}^{\circ} 1$, mientras que el 4 de septiembre, se formalizaba el 'Tercer Convenio de Propietarios' entre los Gobiernos de Argentina y Paraguay con el Banco Mundial (Levinton, 2010: 119). Coincidentemente, en este período comenzaban también, las polémicas ambientales sobre el proyecto:

"Dentro de dos años, cuando ingrese en funcionamiento, más de 50 mil habitantes de la zona deberán reubicarse y dónde hay un río, el Paraná, se estancará un inmenso lago cargado de enfermedades y amenazas" (Suplemento Verde de 'Página 12', 6/9/92).

De todas maneras, el 14 de agosto de 1992, la EBY -por Acuerdo con el Banco Mundial- ya contaba con un Informe de Evaluación Ambiental (EBY, 1992.a), del que derivaron, como principales medidas de mitigación y compensación, "[...] el Plan Maestro de Manejo Ambiental (PMMA) y el Plan de Acción para el Reasentamiento y la Rehabilitación (PARR), como parte integral del Proyecto Hidroeléctrico Yacy-

\footnotetext{
${ }^{35}$ El accidente de la planta nuclear de Chernobyl, ocurrido en Ucrania en 1986, puso nuevamente en un primer plano los problemas de la contaminación atmosférica transfronteriza y el debate sobre energía y medio ambiente (Pichs Madruga, 2004:6).

${ }^{36}$ Sin embargo, Miller señala que en 1989, George Bush llegó a la presidencia, prometiendo ser un ambientalista, pero en 1992, los alcances ambientales de Bush eran mixtos y, con frecuencia, carecían de la muy necesaria acción vigorosa y el liderazgo nacional y mundial que había prometido (Miller, 1994:51).
} 
retá, con el fin de salvaguardar y mejorar la calidad de vida de las poblaciones afectadas y proteger el patrimonio histórico y cultural, el ambiente y los recursos naturales del área de influencia inmediata del Proyecto" (BID, 1994: Anexo A: 1). Estos programas, fueron aprobados por la EBY, en octubre, por Resoluciones del Comité Ejecutivo №2044/92 y del Consejo de Administración № 494/92 (EBY, 1992 b y c), y con el objeto de consolidar y ejecutar el PMMA y el PARR, el 26 de enero de 1994, la República Argentina suscribe con el Banco Interamericano de Desarrollo (BID) el Préstamo No 760/OC-RG, orientado a financiar el denominado "Programa de Medio Ambiente y Reasentamiento" (BID, 1994).

Paralelamente, la obra principal de Yacyretá siguió su curso. El primero de junio de 1993, se inauguró la Esclusa de Navegación, mientras que el 16 de julio, se concretó la privatización del sistema de transporte de energía eléctrica de alta tensión en la Argentina (Transener S.A.). En diciembre, se efectuó el control de los Vertederos para la operación del embalse y recrecimiento de las crestas, el $1^{\circ}$ de febrero de 1994, se dio inicio al recrecimiento de las crestas de ambos Vertederos; el $1^{\circ}$ de junio, comenzó el llenado del embalse a Cota 76 msnm, para dar inicio a las pruebas de generación de energía y se concretó también, la terminación de las Presas de tierra a cota 86,00 msnm. El 2 de septiembre, se inauguró la Central Hidroeléctrica de Yacyretá con la puesta en operación de la $1^{\text {a }}$ Turbina, o Unidad de Generación (UG No 1 ) y se inició así la generación a cota reducida (76 msnm). El 8 de noviembre se ponía en marcha comercial la UG N² 2, el 20 de enero de 1995 la UG N 3, el 27 de febrero la UG $\mathrm{N}^{\circ} 4$, el 3 de mayo la $\mathrm{UG} \mathrm{N}^{\circ} 5$ y el 28 de julio la UG $\mathrm{N}^{\circ} 6$ (Levinton, 2010: 122).

Por otra parte, y en consonancia con los acuerdos alcanzados por las máximas autoridades nacionales de ambos países, el gobierno argentino inició distintos cursos de acción para incorporar la gestión privada en Yacyretá, destinada a la concesión de los servicios de operación y mantenimiento de la Central y a la ejecución y financiamiento de las obras y compromisos faltantes. En este camino, el 23 de noviembre de 1995 se formaliza el denominado 'Protocolo de Esquema para la Participación del Capital Privado en el Proyecto Yacyretá' (rechazado posteriormente, en 1996, por las Cámaras Legislativas de Argentina y Paraguay). En diciembre, se desató la crisis financiera de México, con su denominado "Efecto Tequila", que impactó negativamente en la región y también en Yacyretá, y en 1996, el Gobierno argentino suspendía el financiamiento del proyecto, en cumplimiento de las restricciones impuestas al gasto público, por las metas fiscales comprometidas con el FMI. Su consecuencia en Yacyretá: la paralización de las denominadas 'Obras Complementarias'.

Dentro del contexto de las polémicas que desataba la ejecución de Yacyretá y los efectos del embalse y de las lluvias en el área de influencia del proyecto, llevó a que en marzo de 1995, la ONG paraguaya SOBREVIVENCIA, presentara ante el BIRF y BID, denuncias invocando perjuicios sobre las familias y sobre el medio ambiente, que tendrían su origen en Yacyretá. Tales presentaciones motivaron que se diera curso a una investigación, a efectos de analizar la eventual falta de cumplimiento de las políticas operativas por parte de los equipos de supervisión de los Bancos. Si bien esta investigación desestimó gran parte de las denuncias sociales y ambientales, los Bancos recomendaron convocar 
a un Panel de Expertos, denominado 'Cinta Azul', que efectuó recomendaciones para la gestión del PMMA y del PARR, que fueron incorporadas a la ejecución del Programa Base (Levinton, 2010: 122).

De tal forma, en 1997, la EBY acordó con el Banco Mundial (BIRF) medidas para mitigar el impacto de la permanencia prolongada a la cota $76 \mathrm{msnm}$, a lo que adhiere posteriormente el Banco Interamericano de Desarrollo (BID), dentro del marco establecido por el denominado 'Programa Base', que promovió una reasignación de recursos de la misma Entidad Binacional Yacyretá:

"[...] con el fin de realizar la desocupación y tratamiento ambiental del área comprendida entre las cotas 76 y 78 msnm y ejecutar las obras básicas de saneamiento, necesarias para mejorar las condiciones ambientales y evitar problemas de contaminación y calidad del agua de las ciudades de Posadas y Encarnación. Dentro del marco de implementación del Programa Base aprobado a inicios del año 1997- se relocalizaron todas las familias ubicadas en la mencionada franja costera y se realizó el tratamiento sanitario de las zonas liberadas." (EBY, 2003: 12).

Pero la falta de recursos económicos, privó a la EBY de poder efectivizar las correspondientes expropiaciones de las tierras y con ello la imposibilidad de controlar las zonas liberadas, lo que llevo a que sean nuevamente ocupadas por otras familias, en condiciones análogas a las relocalizadas.

También en el plano regional e internacional, las polémicas sobre los impactos de los proyectos hidroeléctricos se iban acentuando. En marzo de 1997, se firmaba la Declaración de Curitiba (Brasil) y se declaraba al 14 de Marzo como el 'Día Mundial de Acción contra las Represas y por los Ríos, el Agua y la Vida' en el marco del '1er. Encuentro Internacional de Afectados por Represas', dónde se indicaba que:

"[...] la proliferación de grandes represas sobre los ríos del planeta es un mal sólo comparable a la multiplicación de centrales nucleares desde la segunda posguerra hasta Chernobyl, y dónde los habitantes desplazados por represas construidas en lugares tan distantes como el río Narmada en la India, el Tocantins, afluente del Amazonas, el Malibamatso, en Lesotho, y Yacyretá en el Paraná, habian testimoniado el desarraigo, la desocupación, la enfermedad y la pobreza que traen las grandes represas a las poblaciones locales" (Fundación PROTEGER, 2009).

Durante la semana del 14 de marzo se desarrollan actividades en todos los continentes reclamando por los ríos libres, y por la reparación y restauración de los daños sociales y ambientales ocasionados por las grandes represas. ${ }^{37}$

En abril de 1997 (derivado del encuentro internacional de Curitiba), con el auspicio del Banco Mundial y de la Unión Mundial para la Naturaleza (IUCN), representantes de distintos intereses se reunieron en Gland, Suiza, para discutir cuestiones muy controvertidas relacionadas con las grandes represas, a la luz de un informe del Banco Mundial. El taller de trabajo reunió a 39 participantes procedentes de distintos gobiernos, el sector privado, instituciones financieras internacionales, organizaciones

\footnotetext{
${ }^{37}$ Sobre el tema existe un libro emblemático: "Ríos Silenciados - Ecología y Política de las Grandes Represas" de Patrick McCully (1996), que analiza las razones económicas, históricas y sociológicas que circulan por debajo de los argumentos con que se propagandizan las mega-represas. Un fragmento de la introducción del libro expone: "No existen dudas de que el apogeo de las represas ha llegado a su fin. Lo que no implica que no se construyan más represas ni que todas las represas existentes deban ser demolidas; pero significa que se han construido demasiadas. Más allá de los cantos de sirena está emergiendo un nuevo orden para los ríos y la gente que depende de ellos". (Traducción: Fundación PROTEGER, www.proteger.org.ar.).
} 
de la sociedad civil y personas afectadas. Una de las propuestas que se adoptó en la reunión fue que todas las partes trabajaran juntas para constituir la Comisión Mundial de Represas cuyo mandato consistiría en: "revisar la eficacia de las grandes represas para promover el desarrollo y evaluar alternativas para el aprovechamiento del agua y la energía; formular criterios aceptables internacionalmente y guías y normas, donde fuera adecuado, para la planificación, diseño, evaluación, construcción, funcionamiento, inspección y desmantelamiento de represas" (BIRF, 1997).

En mayo de 1998, comienza su labor la Comisión Mundial de Represas (CMR), bajo la Presidencia del Prof. Kader Asmal, entonces Ministro de Forestación y Recursos Hidrológicos de la República de Sudáfrica. Sus miembros fueron seleccionados para representar una diversidad de regiones con diferentes perspectivas y con intereses afectados por las represas. La CMR menciona que los beneficios derivados de las inversiones realizadas en represas han sido crecientemente cuestionados.

Con este marco internacional, Yacyretá transitaba dentro del contexto de permanencia prolongada en la cota $76 \mathrm{msnm}$, habiendo acordado con los Bancos adecuaciones a las acciones socio-ambientales. Pero la Obra Principal cumpliría el cronograma de ejecución. De tal forma, el 7 de julio de 1998 se pusieron en marcha las 20 Unidades Generadoras, que a esa cota reducida permitían que la Central Hidroeléctrica generara sólo al 60\% de su capacidad (1.350 MW); y en septiembre de ese año, se declaraban finalizadas las tareas constructivas de la Obra Principal de Yacyretá.

El 29 de diciembre de 1998, la EBY aprobó el 'Programa de Desbordes de Arroyos' (PDA), destinado a relocalizar 3.000 familias afectadas por las inundaciones producidas por el fenómeno climático 'El Niño', que en diciembre de 1997, afectó severamente a Posadas y Encarnación.

"El PDA fue elaborado por la EBY y acordado con los Bancos, ${ }^{38}$ para cooperar con los gobiernos locales, adelantando la solución relocalizatoria de las familias que residen en áreas del futuro embalse de Yacyretá, que se ven constantemente afectadas por crecientes extraordinarias y desborde de los arroyos urbanos (que aceleran el proceso de degradación ambiental), comprometiendo las condiciones de habitabilidad en una significativa franja urbana de las ciudades de Posadas (República Argentina) y de Encarnación (República del Paraguay) [...], el PDA no representa una intervención independiente, es parte y se rige por los procedimientos del PARR, proponiendo una secuencia relocalizatoria que amplía el procedimiento inicial de programación de las acciones de traslado por cotas de afectación (76; 78 y $83 \mathrm{msnm}$ ). El mismo incorpora una componente de "vulnerabilidad socio-ambiental" para la definición de áreas prioritarias de atención y población objetivo y la adhesión al mismo por parte de la población involucrada es de carácter voluntario." (EBY, 2003: 12)

También en materia ambiental se produjeron cambios, a partir de la creación del 'Programa Marco de Actividades Ambientales Recurrentes', que incorporó como garantía ambiental en la gestión del PMMA, los costos de los programas de monitoreo, mitigación, control y manejo de los cambios ambientales generados por el embalse. (EBY, Resolución CE N 4004/99).

${ }^{38}$ El Programa Desborde de Arroyos (PDA) fue aprobado por Resolución N 900 del Consejo de Administración de la Entidad Binacional Yacyretá, de fecha 29 de diciembre de 1998. 
A finales de la década de los noventa, las primeras potencias productoras de electricidad eran Canadá -con un $60 \%$ de su electricidad proveniente de centrales hidráulicas- y Estados Unidos. En todo el mundo, la hidroelectricidad ya representaba aproximadamente, la cuarta parte de la producción total de electricidad, y su importancia siguió en aumento y los países en los que se constituye en la fuente de electricidad más importante son Noruega (99\%), Zaire (97\%) y Brasil (96\%) que lidera este tipo de producción en Sudamérica.

El tema de los costos versus los beneficios obtenidos se convirtió en una preocupación pública, debido a la creciente experiencia y conocimiento de los resultados y las consecuencias de las represas. La oposición comenzó a crecer, motivada por la investigación y la información respecto a los impactos de las represas sobre la gente, las cuencas hidrográficas y los ecosistemas, así como por los datos sobre sus resultados económicos. En una primera fase, el debate y la polémica estuvieron centrados en represas específicas y en sus impactos a escala local. Pero gradualmente estos conflictos locales se convirtieron en un debate más general que acabó siendo global.

Figura $N^{\circ} 1$ : BENEFICIO Y COSTO DE LA REPRESA DE ASUÁN

\begin{tabular}{|c|c|c|}
\hline 3 & 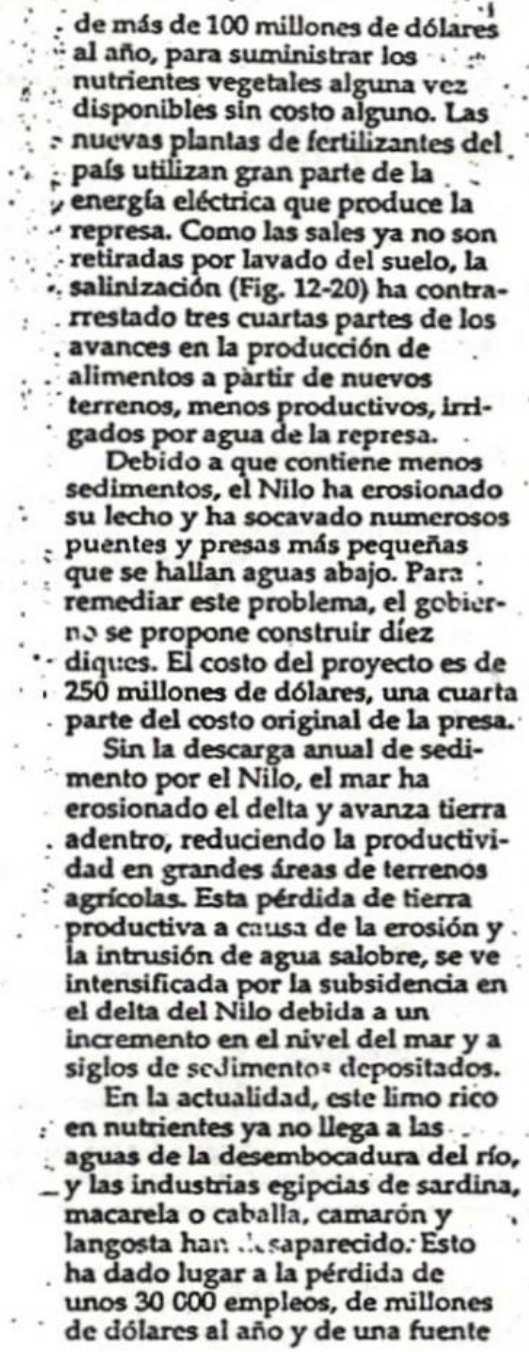 & 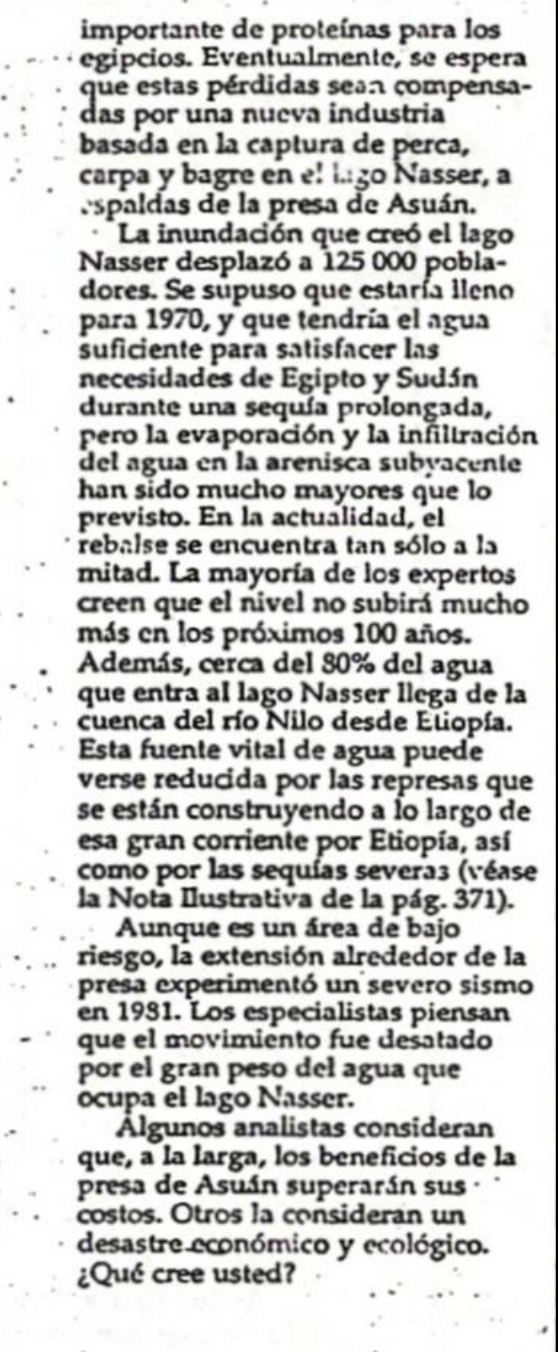 \\
\hline
\end{tabular}

Fuente: Ecología y Medio Ambiente (Miller, 1994: 376). 
De todas maneras, cabe señalar que un balance de lo acontecido en la escala mundial en los años transcurridos desde la Conferencia de Naciones Unidas sobre Medio Ambiente y Desarrollo (1992), pasando sobre la Cumbre de Desarrollo Sostenible de Johannesburgo (2002), revela que el acelerado deterioro ambiental ha coincidido con la erosión aún mayor de la escasa voluntad política de los países desarrollados para contribuir a la solución de los problemas ambientales. Un análisis integral de la relación entre medio ambiente y desarrollo debe tomar en consideración la deuda ecológica del mundo desarrollado y la persistencia de un entorno de subdesarrollo, pobreza y deterioro ambiental, que afecta a las tres cuartas partes de la humanidad. ${ }^{39}$ (Pichs Madruga, 2004: 14).

\section{I.3.6. Década de 2000: hacia un desarrollo gestado localmente}

Puede señalarse que en los 90, el neoliberalismo alcanzó su apogeo con la aplicación de las políticas dictadas por el denominado 'consenso de Washington' ${ }^{40}$ Sin embargo, dicho cóctel de medidas estuvo lejos de obtener los resultados que perseguía. Antes bien en muchos países (como en los latinoamericanos) la situación social se agravó tanto que terminó socavando el propio crecimiento económico que se pretendía apuntalar (Groppa, 2006: 42).

En noviembre de 2000, se publicaba el informe final de la CMR, "Dams and Development: A New Framework for Decision-Making" (Represas y Desarrollo: Un Nuevo Marco para la Toma de Decisiones). El mismo, indica que los dos polos principales del debate ilustran la gama de opiniones respecto a la experiencia del pasado en materia de grandes represas.

Una perspectiva se centraba en la diferencia entre los beneficios prometidos y los resultados alcanzados. La otra ve los desafíos del desarrollo del agua y la energía desde una perspectiva de 'construcción nacional' y de la asignación de recursos. Sus defensores sostenían en cambio, que las represas han dado buenos resultados, que son una parte integral de las estrategias de desarrollo del agua y la energía en más de 140 países y que, salvo excepciones, han proporcionado una variedad esencial de servicios hídricos y energéticos. Los oponentes sostienen que existen opciones para satisfacer las necesidades de agua y

\footnotetext{
${ }^{39}$ Por un lado, los patrones de desarrollo seguidos por los países industrializados han ocasionado los mayores daños al ecosistema, sobre todo si se analiza el deterioro del medio desde una perspectiva histórica. Estos países que sólo cuentan con el $25 \%$ de la población total, controlan las cuatro quintas partes del ingreso mundial, y consumen el $75 \%$ de los recursos naturales que se comercializan: $70 \%$ de la energía, $75 \%$ de los metales y $85 \%$ de las maderas, entre otros (Pichs Madruga, 2004:14). Por otro lado, la pobreza ha sido identificada como uno de los principales obstáculos para un desarrollo ambientalmente seguro ya que la mayoría de los pobres $(60 \%)$ viven en áreas ecológicamente vulnerables (Pichs Madruga, 2004:15).

${ }^{40}$ El 'Consenso de Washington', derivó de un documento de trabajo (1989, 'What Washington Means by Policy Reform', traducido como 'Lo que Washington entiende por Política de Reformas') elaborado por John Williamson para una conferencia organizada por el Institute for International Economics, que incluyó una lista de diez políticas disciplina fiscal, reordenamiento de las prioridades del gasto público, reforma impositiva, liberalización de las tasas de interés, tasa de cambio competitiva, liberalización del comercio internacional (trade liberalization), liberalización de la entrada de inversiones extranjeras directas, privatización, desregulación y derechos de propiedad- pensadas originalmente para los países de América Latina, pero con los años se convirtió en un programa general.
} 
energía que a menudo han sido ignoradas a pesar de ser mejores, más baratas y benignas; como por ejemplo, los sistemas descentralizados de suministro de agua y energía en pequeña escala, el aumento de la eficiencia en el suministro y en los usos finales, o el manejo de la demanda; argumentando que, frecuentemente, se ha escogido construir represas cuando otras opciones podrían alcanzar esos objetivos a un costo inferior, o brindar los beneficios de un desarrollo sustentable y más equitativo.

El debate pasaba así, de ser un proceso local de evaluación de costes y beneficios, a ser un proceso en el que las represas en general, son el foco de un debate global sobre las estrategias y las alternativas del desarrollo. Por eso, el informe plantea que la decisión de construir una gran represa raramente es hoy en día solo una decisión local o nacional.

En este contexto, las preocupaciones ambientales inmediatas de los países desarrollados difieren considerablemente con relación a las de los países subdesarrollados. Mientras que en los estados industrializados lo que está en peligro es la calidad de vida; en las naciones subdesarrolladas lo que se defiende es el derecho a la vida y, por tanto, las principales preocupaciones ambientales de este segundo grupo de países están relacionadas con el problema tan acuciante como la calidad del agua y la protección del suelo (Pichs Madruga, 2004:16).

Mientras tanto, Yacyretá seguía con la implementación del PDA y dentro de un contexto de falta de financiamiento, buscaba alternativas para avanzar en su construcción. El 15 de mayo de 2000, los Presidentes de ambos países impulsaban la ejecución de las acciones sociales, medioambientales y las obras necesarias para dotar a Yacyretá de su máxima capacidad energética.

En tanto que el BID, con acuerdo del BIRF, promovía la realización de Reuniones de Alto Nivel (RAN), convocando a las más altas autoridades nacionales de ambos países vinculadas al Proyecto, a la EBY y a los funcionarios de la administración de ambos Bancos. En las denominadas RAN I y RAN II, se acordó dar atención a los afectados por la permanencia prolongada del embalse a cota 76 msnm, a los procesos para la terminación del Proyecto y a la solicitud de los Bancos para crear un mecanismo de resolución de conflictos, que atendiera las quejas y reclamos de la población afectada por el Proyecto. El 28 de febrero de 2001, en cumplimiento de los acuerdos alcanzados en la RAN III, la EBY presentó a los Bancos el 'Plan de Infraestructura Social y Medio Ambiental para culminar el llenado del Embalse de Yacyretá (PISMA).' El mismo no fue aprobado por falta de financiamiento, y el 21 de noviembre, en la RAN IV, la EBY, argumentando la difícil situación económico-financiera que atravesaba la región y en especial la Argentina, planteaba la conveniencia de encomendar la ejecución del PISMA a un inversor privado a través de una licitación pública internacional.

Pero el 20 de diciembre, se desencadena una severa crisis institucional en la Argentina, que culmina en la renuncia del Poder Ejecutivo Nacional. 
Luego de un complejo proceso de sucesiones presidenciales, las nuevas autoridades del gobierno argentino, presidido por el Dr. Duhalde, iniciaban en 2002, un severo proceso de ajuste de toda la economía, con la caída del sistema monetario basado en la Convertibilidad. También, se nombraban nuevas autoridades en la EBY. El 23 de mayo, se modificaba en su objeto el Contrato de la Consultora CIDY, estableciéndose en su punto Octavo que "las partes confeccionarán un plan de acción que precise el alcance de los servicios a prestar por el Consultor, su cronograma de ejecución y la valorización de los mismos", y con la colaboración de la Consultora y técnicos de la EBY, el 30 de junio, se presentaba a los Bancos (BID y BIRF) el 'Plan Estratégico Yacyretá para la terminación del Proyecto (PEY’ 2002)', que sólo contaba con recursos remanentes del Préstamo BID 760/OC-RG.

Con esa disponibilidad de recursos, la EBY promovería las licitaciones públicas internacionales para: a) los Complejos Habitacionales de Carmen del Paraná (PY) y Fátima (Garupá, AR), destinados a familias a ser relocalizadas hasta cota final; b) la Planta de Tratamiento de Efluentes Cloacales, Sistema de Desagües Cloacales, Estaciones Bombeo y Ampliación de la Red de Abastecimiento de Agua Potable, para Encarnación (PY); c) las Obras de Protección del Valle del Arroyo Aguapey (canal principal, estructura de control y presa de cierre). El PEY, planteado sobre la base del PISMA, sobrellevó casi sus mismos defectos, en especial el de no contar con financiamiento para las obligaciones de contrapartida (para la expropiación de los inmuebles y el resto de las obras y acciones no financiadas con el Préstamo vigente del BID).

También la EBY aprobaría el 21 de agosto, la actualización del PMMA, por las Resoluciones del Comité Ejecutivo No 5117/02 y del Consejo de Administración No 1306/02. ${ }^{41}$

Pero además, el 5 de mayo de ese año, la ONG paraguaya FEDAYIM (Federación de Afectados por Yacyretá de Itapúa y Misiones), presentó ante el BIRF y BID, nuevas denuncias invocando también, perjuicios sobre la vida de las familias y sobre el medio ambiente, con origen en Yacyretá. Tales presentaciones motivaron que se diera curso a una investigación análoga a la de 1996, a efectos de analizar la eventual falta de cumplimiento de las políticas operativas por parte de los equipos de supervisión de los Bancos. ${ }^{42}$

El 25 de mayo de 2003, luego de la profunda crisis socioeconómica de 2001 y de la lenta pero sostenida recuperación acaecida durante 2002, la República Argentina inicia una nueva gestión de gobierno bajo la Presidencia del Dr. Néstor Kirchner y el 14 de junio se inicia también un nuevo período gubernamental en la República del Paraguay bajo la presidencia de Nicanor Duarte Frutos.

\footnotetext{
${ }^{41}$ El PMMA actualizado contempla la adaptación a diferentes escenarios, según la posible operación a diferentes cotas de embalse y el manteniendo de un esquema organizacional a través de mecanismos de ajuste y actualización de los programas y actividades (EBY, 2002.a)

${ }^{42} \mathrm{Si}$ bien esta investigación también desestima gran parte de las denuncias sociales y ambientales, los Bancos efectuaron recomendaciones para la gestión de los respectivos programas (PMMA y PARR), que fueron incorporadas al Plan de Terminación de Yacyretá (PTY, 2004) a la actualización del PARR (2006).
} 
En julio, asumen nuevas autoridades en la EBY, que en Argentina continúan hasta el presente. La mejora que ya había experimentado el país y la región y la consecuente necesidad de energía para apoyar ese proceso de desarrollo, llevó a los gobiernos, a formalizar nuevos Acuerdos sobre Yacyretá. ${ }^{43}$ De tal forma, el 17 de diciembre se Reformula el Proyecto: los Presidentes de Argentina y Paraguay emiten una Declaración Conjunta en la que ratifican el interés de ambos gobiernos de concluir el Proyecto, así como de proseguir con las tratativas tendientes a ajustar el Tratado.

Respecto de la terminación de Yacyretá, acordaron definir un plan de obras y acciones imprescindibles para elevar el embalse; la Argentina se comprometió a financiar u obtener y garantizar el financiamiento.

En esa misma fecha, los Cancilleres de ambos países suscriben un Memorando de Entendimiento en el que acuerdan conformar un Grupo de Trabajo de diálogo y negociación, sobre diversos aspectos pendientes del Tratado de Yacyretá y el 29 de diciembre, el Grupo de Trabajo presidido por los Ministros de Obras Públicas y Comunicaciones de la República del Paraguay y de Planificación Federal, Inversión Pública y Servicios de la República Argentina, firman un Acuerdo, que en su numeral 4.4 instruye a la EBY a presentar las obras y acciones necesarias para terminar el proyecto.

En este período, y hasta finales de año, se procede a la relocalización de 2.474 familias en ambas márgenes del río Paraná.

El 9 de febrero de 2004, se rescinde el Contrato de CIDY por Resolución del Consejo de Administración de la EBY Nº1519/04. El 04 de mayo, los Ministros firman un Acta de Acuerdo, donde establecen: a) las bases para lograr que la EBY sea una empresa rentable y eficiente; b) terminar el proyecto por medio de elevaciones parciales del embalse; c) iniciar las obras financiadas con fondos del Préstamo BID 760-OC-RG; d) desafectar a la EBY de la Res. No 406 del PEN y reponer las acreencias; e) instruir a la EBY a dar cumplimiento del Acuerdo. El 11 de mayo el Gobierno Argentino incorpora a Yacyretá al Plan Energético Nacional, y entre los días 9 y 10 de septiembre, se realiza la RAN V donde los Gobiernos de Argentina y Paraguay, junto a la EBY, presentaron a los Bancos (BID y BIRF), los Acuerdos y el Plan de Terminación de Yacyretá (PTY) ${ }^{44}$

\footnotetext{
${ }^{43}$ Paralelamente, el 13 de noviembre, se suspende el Contrato de CIDY por Resolución del Consejo de Administración de la EBY $\mathrm{N}^{\circ} 1504 / 03$, lo que representa un cambio de rumbo fundamental en la gestión de la EBY, que pasará a depender de sí misma, sin apoyo de un Consultor externo.

${ }^{44}$ El Plan de Terminación de Yacyretá (PTY), fue aprobado el 27 de mayo de 2004 por Resoluciones del Comité Ejecutivo $\left(\mathrm{N}^{\circ}\right.$ 5752) y del Consejo de Administración $\left(\mathrm{N}^{\circ} 1503\right)$, fue refrendado el 31 de agosto, por Acta Acuerdo de los Ministerios de ambos Países, ratificada por Decretos $\mathrm{N}^{\circ} 3386$ de la Presidencia de la República del Paraguay y No 1189 del Poder Ejecutivo Nacional de la República Argentina. El PTY, comienza a implementarse a mediados de septiembre, con el objetivo de liberar las áreas comprometidas por el embalse y por las obras de protección y reposición; realizar la compra de las tierras afectadas por la elevación de la cota del embalse y de aquellas necesarias para la construcción de obras de viviendas y de infraestructura; compensar la superficie de las tierras a inundar con la formación de reservas ecológicas; realizar las obras necesarias, como caminos y puentes, la recomposición de la trama urbana de las ciudades afectadas y la protección del valle del arroyo Aguapey con un
} 
En mayo de 2005, se sustancia el proceso de terminación de Yacyretá, con el llamado a dos grandes Licitaciones (una en cada país), para las obras faltantes, pero también la EBY actualiza el Plan de Acción para el Reasentamiento y Rehabilitación (PARR), para atender en forma adecuada a cada familia involucrada en ese proceso de terminación. ${ }^{45}$

"En la ejecución del PTY, primeramente, se vinculó en forma inescindible el aumento de la producción energética con la terminación de la construcción de las viviendas de todas las familias afectadas, se completó la infraestructura de saneamiento, educación (con escuelas y comedores), de salud (con Centros Periféricos, Hospitales y Atención Ambulatoria), recreativas y deportivas, y se tomaron también, medidas de importancia para crear nuevas condiciones laborales para esa población.

Este accionar, permitió intensificar el proceso relocalizatorio de las familias y llegar a la cota 78 msnm en abril del 2006 con una potencia promedio de $1.487 \mathrm{MW}$, rompiendo así, el status quo de 12 años de permanencia prolongada en la cota $76 \mathrm{msnm}$. [...]

Pero además, la ejecución del Plan de Terminación Yacyretá, ha permitido cumplir los siguientes hitos de recrecimiento del embalse: a cota 78 msnm, en abril de 2006; a cota 78,5 msnm, en junio de 2008; a cota 80 msnm, en diciembre de 2009 y a cota $81 \mathrm{msnm}$, en octubre de 2010; luego de asegurar en ambas márgenes la infraestructura social y el saneamiento urbanoambiental.

En la práctica esto implicó que la potencia media de la Central, pasara de $1.350 \mathrm{MW}$ en 2004, a 2.243 MW en 2010: un crecimiento del 65\%." (Thomas, 2010.b: 5-7)

¿Pero qué sucedía a nivel mundial? En sentido general, el balance del período post-Río confirma que a escala mundial, la solución a los dilemas económicos, sociales y ambientales que enfrenta la humanidad a inicios del nuevo milenio, supone el diseño de estrategias de desarrollo sostenible que

canal y una presa; relocalizar el circuito comercial de la zona baja de la ciudad de Encarnación y relocalizar las familias faltantes, con los correspondientes programas de adecuación a los nuevos sitios de reasentamiento y rehabilitación socio-económica (EBY, 2004). En noviembre, se da inicio al proceso de "Verificación de Familias Urbanas" (VAU 2005) en ambas márgenes del Proyecto, con el objetivo de conformar el padrón definitivo de familias a ser atendidas en el marco del PTY.

${ }^{45}$ La 'Actualización del Plan de Acción para el Reasentamiento y la Rehabilitación (PARR)', fue aprobada por la EBY, junto al 'Listado de Jefes (as) de Hogares identificados en la Verificación de Áreas Urbanas (VAU 2005)' a través de las Resoluciones CE N ${ }^{\circ} 6813 / 05$ y CA N N $^{\circ} 1787 / 06$ y CE N ${ }^{\circ} 6913 / 05$ y CA No 1788, respectivamente. El PARR actualizado, responde a los requerimientos de las políticas operacionales de los Bancos (BIRF y BID), atendiendo particularmente a los compromisos derivados de la RAN V. En términos generales, los principales temas son: a) amplía el cuadro de beneficiarios al conjunto de la población registrada en el VAU 2005; b) abre la posibilidad para aplicar otras alternativas de soluciones relocalizatorias, como apoyo al traslado e indemnización asistida; c) instituye un proceso de consulta y participación, un plan de comunicación social y un mecanismo de atención a reclamos y controversias; d) mantiene los instrumentos de control externo del plan (monitoreo y evaluación independiente). En términos operacionales, instituye dos sub-planes operativos: Plan Operacional de Reasentamiento (POR) y Plan de Rehabilitación y Apoyo Social (PRAS), que incluye además, un programa de apoyo a las Instituciones Públicas para garantizar el funcionamiento de los servicios básicos y comunitarios por un período de hasta dos años a partir de la implementación de los nuevos servicios y/o equipamientos comunitarios construidos por la EBY. En tanto que el Listado de Jefes (as) de Hogares identificados en la Verificación de Áreas Urbanas (VAU 2005) realizadas en las zonas necesarias para el recrecimiento del embalse de Yacyretá hasta su cota de diseño, en las ciudades de Posadas (AR), Encarnación, Cambyretá y Carmen del Paraná (PY), define los procesos administrativos para la divulgación, consolidación y cierre definitivo del padrón de Familias a ser atendidas en el marco de las políticas relocalizatorias definidas en el PARR. 
reconozcan la necesaria integración entre los problemas económicos, sociales y ambientales, como dimensiones que se complementan y refuerzan entre sí.

Desde una perspectiva de largo plazo y con un enfoque integral, el crecimiento económico resulta incompatible con rezagos en términos de equidad y calidad ambiental. (Pichs Madruga, 2004: 22), lo que explica el concepto de eco-topia anticrecimiento que Roger Amisial determina como imperativo dominante de la década. Quizás por eso, distintas corrientes del pensamiento procuran abordar el problema del desarrollo desde otras perspectivas. Octavio Groppa, lo sintetiza señalando:

"Stiglitz (1998) propone que más que hablar de planes de desarrollo es mejor hacerlo en términos de estrategia. Las estrategias de desarrollo apuntan a una transformación de la sociedad, reconociendo sus ventajas comparativas dinámicas, pero también haciendo hincapié en los aspectos procedimentales, como la participación y la consecuente apropiación de las políticas. Las estrategias no pueden desconocer las singularidades de los distintos contextos. De aqui la importancia de incluir en el análisis del desarrollo y la pobreza temáticas como el capital social, la cultura o las instituciones, mediante enfoques interdisciplinares (Harris, 2000).

Otro exponente de la política de las estrategias, D. Rodrik (2005), sostiene que es preciso hacer lugar a 'políticas de desarrollo que se alejan de las ortodoxias dominantes del momento' [...]. Rodrick tiene presente que el mercado está imbricado en un conjunto de instituciones ajenas a él. Al respecto, cree que es posible reconocer algunas que le sirven de sostén. Menciona: a) un razonable respeto a los derechos de propiedad [...]; b) instituciones regulatorias [...]; c) instituciones de estabilización económica [...]; d) instituciones de seguridad social [...]; e) instituciones de manejo de conflictos [...].

Una estrategia de desarrollo supone distintos niveles en los cuales se manifiesta, desde el sector privado, el público, el desarrollo de comunidades, las familias y finalmente, el de los individuos (Stiglitz, 1998: 24-27). Se amplía así la noción de desarrollo entendido meramente como acumulación de capital fisico y humano. Por tanto, su definición debería considerar no sólo la perspectiva de los grandes agregados -macroestructural-, sino incluso el nivel local, los desarrollos peculiares al interior de un gran marco, las instituciones, así como el impacto sobre las subjetividades [...]." Groppa (2006: 42-43).

Vemos así que, tal como lo señala Fernando Tauber, las propuestas contemporáneas de desarrollo tienden a aumentar la importancia y necesidad del planeamiento participativo como instrumental fundamental para orientar el futuro (Tauber, 2008: 55 a 58). 


\section{CAPÍTUlO II: LA EVOLUCIÓN DEL PAISAJE EN LA CUENCA DEL ALTO PA- RANÁ: DE LA REGIÓN HISTÓRICA GUARANÍ A LAS GRANDES TRANSFOR- MACIONES TERRITORIALES}

El segundo Capítulo tiene el objetivo de analizar cómo ha sido el proceso histórico de estructuración del territorio dónde se inserta Yacyretá, y de explicar, desde las variables paisaje e infraestructura, los alcances de la ruptura de ese proceso de conformación de un determinado paisaje, entendido como síntesis de la relación cultura-naturaleza, por efecto de la inserción de obras de infraestructura hidroeléctrica a gran escala. Es por ello, que para determinar el estado de la cuestión en esta dimensión de análisis, se realiza una delimitación del caso de estudio desde una perspectiva histórica de la estructuración del territorio, orientada a interpretar la evolución del paisaje en el contexto regional, procediéndose a identificar las principales variables afectadas por un proyecto hidroeléctrico, sus conflictos determinantes y las potencialidades derivadas de su transformación.

Para ello se indaga, en la primera parte del Capítulo, la evolución de la denominada región histórica guarani (Levinton, 2007) y se analizan, también, los distintos tipos de asentamientos que corresponden a cada período: el guaraní, cuando se trataba de un territorio único; el de contacto con la civilización europea, pasando por la aldea de la encomienda, las reducciones franciscanas y los pueblosciudad de la época jesuítica y, posteriormente, durante el período de formación, institucionalización y ocupación de los territorios nacionales, hasta la conformación de las actuales ciudades (Cambas, 1962; Armani, 1988; Cortiñas, 2000; Snihur, 2007; Levinton, 2007 y 2009.a; Reverchon, 2009).

La segunda parte del Capítulo, establece una relación entre los imperativos desarrollados en el apartado I.3 del Capítulo I y la materialización de los proyectos hidroeléctricos en la Cuenca del Plata -como representación actual de la región histórica- y, en particular, en la Cuenca del Paraná, dónde se inserta Yacyretá (Lins Ribeiro, 2003; CIC/Plata, 1969, y otras publicaciones de las páginas oficiales de las empresas hidroeléctricas, entre otras, Itaipú, Salto Grande y Yacyretá).

Pero en virtud de que el área de estudio adquiere una gran significación histórica por haber sido asiento de la antigua nación guaraní y posteriormente de las misiones jesuíticas, cuyas huellas y rasgos siguen vigentes, y considerando además que esta parte del territorio es actualmente asiento de importantes ciudades en ambas márgenes del río Paraná, resulta importante indagar acerca de si en esta región histórica ha existido una relación con el entorno, que pueda ser considerada como paisajística, recurriendo en el tercer apartado a precisar de qué manera puede interpretarse en la actualidad las relaciones con el nuevo paisaje que surge del proceso de transformación del territorio (Berque, 1995 y 2006; Roger, 2007; Donadieu, 2006), y de identificar, en ese marco de referencia, los principales compontes del paisaje regional que son impactados y modificados por la implantación de proyectos hidroeléctricos a gran escala. 


\section{II.1. DESARROLLO HISTÓRICO REGIONAL: la pervivencia de una Región Cultural}

El análisis de este aspecto resulta particularmente importante para enfocar el caso de estudio de la investigación en virtud de que la evolución del paisaje de la región -dominado por la presencia de la selva inaccesible, imponentes saltos y grandes cursos de agua- siempre estuvo signado por la presencia del hombre, que fue ocupando las costas de los grandes cursos de agua y de sus afluentes definiéndose, a partir de allí, la transformación del territorio.

Pero también resulta importante por la pervivencia, principalmente en Paraguay, de rasgos de la cultura guaraní que resultan necesarios de ser interpretados. En primer lugar se destaca la presencia del idioma. Al respecto Alberto Armani afirma: “[...] Hoy la cepa guaraní constituye la mayoría de la población de Paraguay y su lengua disputa al español la primacía [...]” (1988: 9). Paraguay es un país bilingüe, el guaraní forma parte de la estructura educativa formal en todos sus niveles y además, muchas de las costumbres locales, en particular de los pequeños asentamientos humanos, mantienen rasgos identitarios propios de esa cultura histórica, que ha ocupado casi todo Sudamérica.

Yendo a los orígenes, los estudios de Aníbal Cambas nos muestran que dicha cultura ha ocupado extensos territorios, que van desde el Caribe a la Pampa y del Atlántico a la Cordillera, comprendiendo las tres cuartas partes del área de nuestra América. En esta extensa región -y generalmente en zonas caracterizadas por la presencia de la selva y los grandes ríos- han vivido densos núcleos indígenas formando una verdadera confederación de pueblos, que ofrecen rasgos coincidentes en cuanto a su lengua, sangre y cultura, a los que genéricamente se los ha denominado como "Complejo Guaranítico" (Cambas, 1962: 2). Sin embargo, el mismo autor, nos señala:

"Hay todavia mucha duda para la ubicación etnológica regional, como ocurre por ejemplo con los indios guayaquies, guayanáes y kainganges [...]. No obstante [...], a los integrantes de ese gran Complejo Guaranítico de América del Sud, podemos dividirlos en tres grupos [...]: La Caribe, la Tupí, y la Guarani propiamente dicha, ocupando el norte antillano la primera; el centro y Sudeste de Brasil la segunda; y el Sud brasileño, el Este y el Sudeste de Paraguay y parte del Litoral Argentino la tercera, todo dicho en términos generales." (Cambas, 1962: 3).

De la evolución de esta última, en términos culturales y territoriales, vamos a ocuparnos particularmente en este análisis. Al respecto, el mismo autor, expresa que la denominación apropiada para identificar la zona alto paranaense, dónde se radicaron estos pueblos de la nación Guaraní, es "Provincia Arqueológica del Alto Paraná" (Cambas, 1962: 7). ${ }^{46}$

Pero, a los fines de poder referenciar el área de estudio a ese contexto cultural desde la noción de paisaje, nos resulta pertinente hacerlo, especialmente, desde el concepto desarrollado por Norberto Levinton de región histórica, dado que como lo explica el autor, esta categoría "[...] implica una definición de los elementos configurantes: el territorio, la relación del mismo con el grupo humano habi-

\footnotetext{
${ }^{46}$ Cambas, expresa que esta denominación fue acuñada en el seno de la Junta de Estudios Histórico de Misiones y confrontada con las visiones de científicos como Maintzhusen, Frenguelli, Palavecino y Meghín.
} 
tante y el seguimiento de la evolución y transformación [a fin de verificar si aún existe una cierta] coexistencia de dichos elementos como proveedores de identidad". ${ }^{47}$ (Levinton, 2007: 11).

\section{II.1.1. La Región antes del contacto con la civilización europea}

En este período, se destaca “[...] la conformación de una identidad cultural esencial [...]. La organización del espacio previa al contacto con los misioneros, de aldeas desperdigadas, supuso vinculaciones interétnicas entre los grupos indígenas, un carácter identitario de ciertos espacios comunes y la noción de límite fijada por los accidentes rocosos del Apipé". ${ }^{48}$ (Levinton, 2007: 11).

El mismo Levinton, señala que -según los estudios arqueológicos que se han desarrollado hasta el momento-, antes de la llegada de los españoles, en la Cuenca del Plata existía una estructura organizativa configurada por la interacción de diversas comunidades, basada en acuerdos interétnicos que delimitaban áreas por afinidades culturales y necesidades de supervivencia. Este análisis concuerda con lo expuesto por Cambas, acerca de que el grupo étnico más numeroso era el de los tupí-guaraníes y de estas parcialidades era la mayor parte de los habitantes del Alto Paraná.

Las relaciones entre sí de estos grupos semisedentarios, estaban determinadas por una suerte de respeto devenido de conductas tradicionales, quizás fundadas en relatos míticos, que garantizaban la convivencia, diferentes a las normas sociales por las que se regían los europeos.

"Los guaranies llegaron [... a esta región] entre los años 900 y 1000. Venían de la gran región amazónica en busca de la mítica Tierra Sin Mal. La migración masiva se estima que comenzó hacia el año 2000 A.C. [...].

Guerreros por naturaleza, los guaranies poseían una tradición agrícola desarrollada y manejaban también los secretos del arte de la cerámica. El grupo se mantenía unido por una compleja organización social y por una lengua, el 'aveñeé', que los identificaba como etnia frente a los demás pueblos aborígenes.

Escudados en su fuerte identidad [...], marcharon en busca de la tierra prometida hacia la Cuenca del Plata. Los guiaba una concepción cosmológica que se constituyó en un verdadero motor de sus movimientos migratorios [...]. Pero cuando los guaranies ingresaron a las cuencas de los ríos Uruguay y Paraná, la región ya estaba habitada [...por] pueblos cazadoresrecolectores de una cultura paleolítica [...].

Los grupos guaranies lograron imponerse [...] rápidamente. Después eligieron para vivir las orillas de los grandes ríos, sobre todo el Uruguay, el Paraná, el Paraguay y sus afluentes, mientras que los grupos preguaraniticos [...] quedaban recluidos al interior del territorio, aislados en las zonas selváticas." (Snihur, 2007: 15).

\footnotetext{
${ }^{47}$ La hipótesis de Levinton señala que la relación mega proyecto-territorio-comunidad, ha contribuido a la reconfiguración de la región histórica, que representa un área geográfica que tuvo una importante consustanciación con los grupos humanos habitantes del territorio, lo que le permite plantear la posibilidad de cierta pervivencia de elementos culturales, que son inherentes también al paisaje.

${ }^{48}$ Precisamente es sobre los Saltos de Apipé, donde se localiza la Central Hidroeléctrica Yacyretá, que marca una profunda transformación del paisaje natural y cultural, dada por el sentido de límite que alcanzaba en sentido histórico para la Cultura Guaraní y también para los actuales habitantes.
} 


\section{II.1.1.1. Rasgos de la Cultura Guaraní}

Los guaraníes, desarrollaron un amplio dominio del territorio, a partir de una fuerte identidad definida por un objetivo mítico: llegar a la tierra sin mal. Se supone que no existieron migraciones masivas sino de parcialidades que, forzadas por la falta de recursos, avanzaban en la búsqueda de nuevos ámbitos para el asentamiento, que los adecuaban por la metodología agro-técnica del rozado.

Estos grupos irrumpieron en la Cuenca del Plata como un pueblo invasor frente a otros pueblos que ya estaban asentados en la zona. Se caracterizaban por poseer una lengua, una alta organización familiar y comunitaria, y también, una gran belicosidad.

'Los guaranies se llamaban a sí mismos 'avá', un concepto que encerraba la idea de 'Hombre' y también los identificaba lingüisticamente y culturalmente como grupo. Por contraposición, todas las otras poblaciones eran llamadas 'guaya' o 'tapii' (esclavo). Detrás de esta concepción subyacía la conciencia de una superioridad étnica, frente a las demás poblaciones preexistentes en la región. Una autoestima que se cimentaba en un concepto de 'superioridad' y que se proyectaba en su sometimiento del desconocido, [...] que podia manifestarse hasta en la apropiación del otro a través de la antropofagia.

Los guaranies habitaban en casas comunales [...], reunidas en torno a un espacio abierto [que...] constituían un poblado o teko'á. [...] La mujer tenía un rol fundamental en la crianza de los hijos, en las tareas agrícolas, en la elaboración de la cerámica [...] y en la danza ritual de las ceremonias religiosas. La red de parentesco estructuraba toda la sociedad guaraní y generaba las pautas sociales, habitacionales, económicas y políticas del grupo.

La dirección y administración del teko'a estaba a cargo de un Consejo de Ancianos y de un jefe o tuvicha cuya autoridad, [...] en periodos de enfrentamientos bélicos, adquiría un carácter absoluto [... pero] no era impuesta [...]. Si el tuvicha no atendía los reclamos de la población, ésta podía abandonarlo y buscar otro jefe. [...] Las ceremonias se realizaban en el opy o casa de Ñande Ru, denominación que identificaba al chamán o jefe espiritual de la comunidad. ${ }^{49}$ (Snihur, 2007: 16)
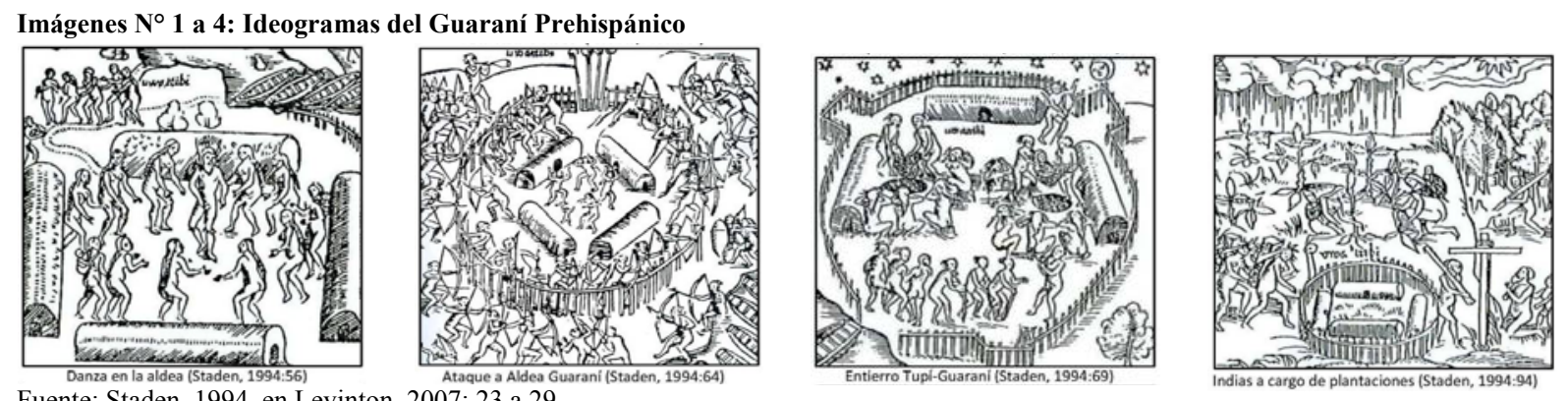

Cambas afirma que la identidad mantenida por sobre tan dilatada área, ofrece la conclusión de que los pueblos de esa nación respondían a un estado cultural definitivo, formal y con perfil propio, asentado en factores que fijaban su indiscutida individualidad étnica, racial y lingüística (Cambas, 1962: 5).

\footnotetext{
${ }^{49}$ El autor, destaca que uno de los factores de poder, tanto del Tuvicha como del Ñande Ru era la oratoria, dado que para el guaraní 'la palabra' pronunciada encerraba un poderoso misterio creador y, por lo tanto, quién la poseía tenía el 'Poder'. La religiosidad en el guaraní era una experiencia viva y su manifestación principal se daba a través de la 'danza-oración'. Pero también los sueños eran parte de los rituales individuales, se creía que el mundo onírico era creador de realidades y los Ñande $R u$ proclamaban sus revelaciones por medio de los sueños. Su poder llegaba hasta el mesianismo y, basados en su convocatoria y convencimiento, eran capaces de generar, inclusive, grandes migraciones.
} 


\section{II.1.1.2. El Asentamiento Guaraní}

Estos pueblos originarios nunca desarrollaron una civilización asentada en ciudades, al estilo de otras culturas prehispánicas de América, como la Maya o la Inca. Hasta el momento del contacto con la cultura hispánica, y como consecuencia del rápido agotamiento de los campos debido al método de cultivo por rozado, ${ }^{50}$ los grupos del tronco lingüístico tupí-guaraná eran semi-sedentarios (Levinton, 2009.a: 46) y si bien tenían prácticas de recolección, de cultivar maíz, cazar y pescar, esta cultura consideraba el uso de la tierra para la subsistencia, utilizando de la naturaleza sólo lo que necesitaban.

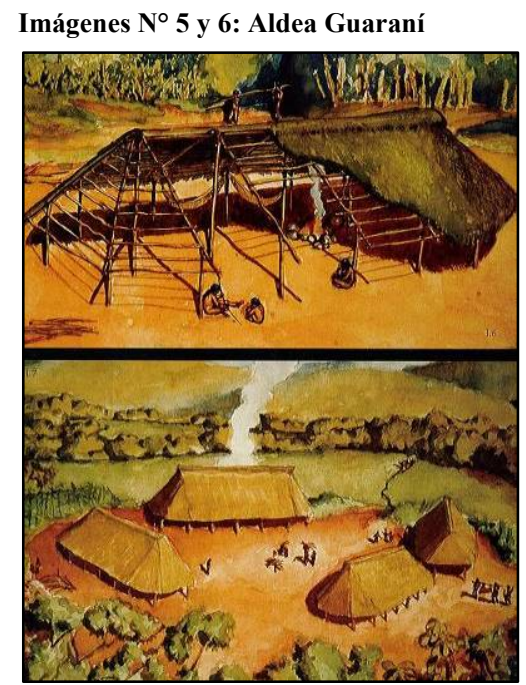

Fuente: Snihur, 2007: 21
"La radicación de estos pueblos de la nación Guarani [...], se opera en las márgenes de los ríos y riachos [...], eran canoeros, pescadores y nadadores por excelencia [...], el rio [...], el elemento primordial de su existencia." (Cambas, 1962: 7).

El esquema más común de los asentamientos o poblados guaraníes prehispánicos era la aldea, cuya denominación en guaraní es teko'a (o tekoha), que estaban conformados por casas comunales, construidas con palmas y troncos de palmera, reunidas en torno a un espacio abierto a modo de plaza y en ocasiones rodeadas de una empalizada. El elemento central dentro de cada casa comunal era el fogón comunitario. ${ }^{51}$ (Snihur, 2007: 16).

Los guaraníes evitaron emplazar sus aldeas en las zonas selváticas, en general, lo hacían en las zonas costeras de confluencia de los ríos principales -Paraguay, Paraná y Uruguay- con algún arroyo. Estas cuencas lacustres, definían el hábitat guaraní, dónde cada afluente, estero, laguna o manantial, se constituían potencialmente en el punto de radicación de un teko'a.

“En el ecosistema en que se instalaba el teko'a se producía una conjunción de dos elementos claves: el agua y la tierra. El agua implicaba la posibilidad del control del territorio y, al mismo tiempo, permitía delimitar el área de ocupación. La tierra era para la subsistencia. No era una tierra cualquiera, era aquella que se ubicaba entre el río y el límite de la selva. Era el campo o el monte, el espacio de transición. Alli se producía el continuo ciclo del rozado, la quema, la siembra y la cosecha, hasta llegar a agotar la capacidad productiva del suelo. Entonces, se producia la migración en búsqueda de un nuevo sitio, para volver a comenzar el ciclo nuevamente. Este proceso productivo generaba una asombrosa movilidad territorial. Seguian los cursos de agua, siempre en búsqueda de la mítica Tierra sin Mal”. (Snihur, 2007: 19 y 20).

Por eso, nos resulta pertinente acordar con el análisis realizado por Levinton, acerca de que otros investigadores expresan que el teko'a era mucho más que una vivienda o un conjunto de viviendas comunales. Bartomeu Meliá (1988), lo define como el conjunto casa-chacra-monte; en tanto que

${ }^{50}$ El método consistía en talar el bosque, quemar la vegetación cortada para despejar el terreno, dejar que las cenizas enriquezcan los suelos, y luego sembrar. Por esto los guaraníes son considerados agricultores semisedentarios.

51 "El fogón comunitario servía para la preparación de la comida del grupo. El fuego permanecía encendido día y noche y era tarea exclusiva de las mujeres.” (Snihur, 2008: 16). 
Bratislava Susnik (1979), la entiende como una unidad subsistencial, una fusión entre vivienda comunal, los lazos de parentesco y los hábitos de supervivencia (Levinton, 2007: 21). Agrega además, que el conjunto que formaba la aldea, podía estar conformado por 4 a 8 habitáculos alagados que tenían de 50 a 150 metros de largo y 4 a 6 metros de ancho y que la forma predomínate de las casas era el medio barril o casco de barco invertido (Levinton, 2007: 22). También resulta interesante destacar que en la aldea no existía un centro ceremonial religioso en sentido estricto, por lo general, las ceremonias se realizaban en el opy o casa de Ñande Ru (Snihur, 2007: 16). La aldea guaraní prehispánica, era siempre de carácter temporario y la relación con el monte, estaba vinculada, principalmente, al sentido de supervivencia.

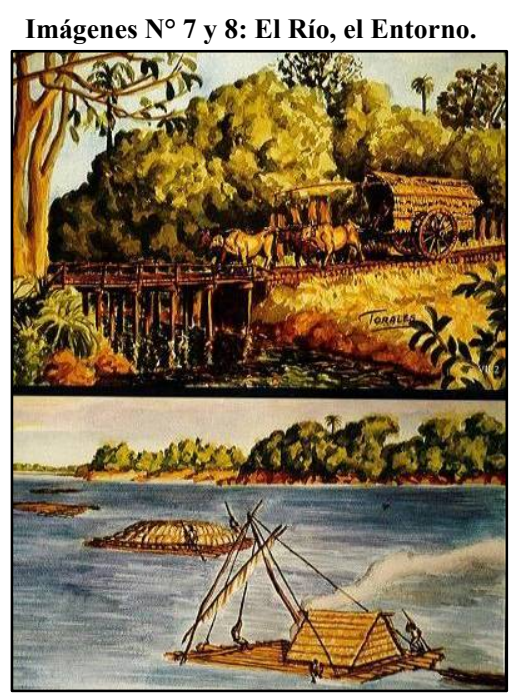

Fuente: Snihur, 2007: 109
Las selvas en galería de las zonas costeras de ríos y arroyos, eran una extensión de la casa comunal, ya que proveían tierras que una vez rozadas, era fértiles para el cultivo, dónde se instalaban las chacras. Pero además, el monte proveía de madera para las canoas, el arco y las flechas, el telar para hacer las hamacas, la miel y los frutos silvestres (Levinton, 2007: 22), y como ya hemos señalado, el espacio vital de varios grupos macro-familiares era definido con el término guará, cuyos límites estaban determinados por ríos o arroyos y montes y dentro de ese espacio, se rotaban los campos cultivados y se proveían de animales y frutos (Levinton, 2009ª 47 ).

Las diversas investigaciones realizadas en la región, demuestran que aunque la naturaleza en la zona era rica, la tierra apta para el cultivo tenía sus limitaciones.

"El sistema de rozado y quema generó un paulatino agotamiento del suelo y traumáticos cambios en el ecosistema [...]. El concepto de previsión le era ajeno a la cultura guaraní. La producción agrícola, así como el producto de la caza y la pesca, apuntaban al consumo inmediato de la comunidad. Por otra parte, la previsión no era una necesidad: el ecosistema les aseguraba la alimentación cotidiana. Si la labor agrícola no producía los frutos necesarios, siempre estaba la selva: alli abundaban los frutos silvestres y los animales [...]. El maíz y la mandioca, base de la alimentación de los guaranies [...], se elaboraban harinas que se utilizaban como complementos de todas las comidas. Con el maíz además se elaboraba la chicha, una bebida alcohólica obtenida por fermentación, que junto al tabaco y la yerba [que no se cultivaba], cumplían un importante papel en las celebraciones rituales y religiosas. "52 (Snihur, 2007: 20 y 21).

Si bien el espacio ocupado por cada tekoha se mantenía como tal por un término de 3 a 5 años antes de trasladarse a un nuevo sitio de emplazamiento (Levinton, 2009ª : 47), los mismos no estaban aislados.

"Muchas veces las comunidades compartian, hasta con otros grupos étnicos, cazaderos y lugares de pesca, yerbales o plantas de algodón silvestres. El río era el principal medio de circulación y de

\footnotetext{
${ }^{52}$ La subsistencia cotidiana implicaba una división del trabajo por sexos. El hombre era básicamente recolector y cazador, mientras que la mujer se dedicaba a las tareas agrícolas, a la elaboración de la cerámica, a la crianza de los hijos, al cuidado del fogón y a la elaboración de la comida comunitaria. (Snihur, 2007: 28)
} 
comunicación entre los grupos. No había caminos, salvo picadas de escaso trayecto que unían diferentes zonas cercanas entre sí. Los territorios constituidos por los grupos más afines [...], fueron designados por los guaranies como 'guará". 53 .(Levinton, 2007: 22).

De lo expuesto podemos señalar que, si bien esta cultura ocupó un espacio territorial muy amplio sin haber desarrollado ciudades permanentes, sino más bien 'ciudades temporales', existía en dicha cultura, una noción bastante integral acerca de la noción de región, superadora de aquella primera idea de ocupación por razones de subsistencia; vemos también, que existía una relación mítica o religiosa con el territorio, manifestada en una permanente búsqueda de 'la tierra sin mal' y hemos visto por otra parte, que esa forma de ocupación y utilización del espacio, ha determinado, por su expansión territorial, una suerte de primer gran impacto sobre el medio natural, soporte de esas actividades.

De otra forma, el conjunto teko'a (chacra y vivienda; selva y pastizal; rios y arroyos; lagunas y esteros; montes y picadas), junto al vínculo establecido por las relaciones de uso y significado, sumado a la importancia simbólica que el guaraní le otorga al idioma -basta mencionar al respecto, dos ejemplos: Paraguay, que significa 'Río del manantial del mar', ${ }^{54} \mathrm{o}$ la misma palabra 'Yacyretá' que en guaraní significa "tierra de la luna" (Lins Ribeiro, 2003: 135); o también, "Yasy-retá: el lugar donde brilla la luna" (Levinton, 2007: 5)-, conforman elementos determinantes para poder afirmar que estamos ante la presencia de una clara noción del país, en términos de paisaje.

"[...] El hábitat de los grupos indígenas semi-sedentarios de lengua guaraní tenía patrones de distribución, de sus grupos o parcialidades, en el medio físico al cual consideraban como la tierra de sus ancestros. Es evidente que, sin haber conformado una organización al estilo europeos, se puede afirmar que los indios manejaban el concepto de territorio y ciertas normas de convivencia pacifica, o no, tanto entre grupos de la misma etnia como con respecto a las relaciones interétnicas." (Levinton, 2009 a: 10).

En este sentido, podemos arriesgar a señalar también, que la conjunción de estos factores -que son consustanciales a esa noción de paisaje-, pervive aún hoy, en cierta forma, en determinadas comunidades indígenas y en los pequeños poblados rurales, principalmente, en la margen paraguaya del río Paraná.

Por eso podemos coincidir con Snihur y Levinton, cuando señalan que ya en este periodo, previo al contacto con los españoles, comienza a generarse un fenómeno cuyo impacto se proyectará hasta nuestros días, que tiene tres denominadores comunes: el hombre, la tierra y el agua.

\footnotetext{
${ }^{53}$ En general, se trataba de varias comunidades no mayores de 500 miembros cada una, que utilizaban un área por común acuerdo o por cuestiones de poderío. Cada comunidad era 'dueña' de un sector del río, pero a pesar de ello existía una continuidad tácita de la vía fluvial. Levinton señala que este concepto, representa el basamento de la noción de 'región histórica'; denominado guára, por la antropóloga Susnik (1979), que lo refiere a un conjunto de teko'a; o guará, como lo denomina Meliá (1988), relacionándolo tanto al significado de región como al de provincia, en una interpretación más abierta y sin límites demasiado estrictos (Levinton, 2007:22).

${ }^{54}$ Procede del nombre de una población indígena precolombina denominada Tavaparaguaí que vivió en el lugar donde hoy se alza la ciudad de Asunción del Paraguay. Los españoles, ante la dificultad de pronunciar la 'i' con la fonética guaraní (es la sexta vocal de este idioma), convirtieron la voz en 'Paraguay'.
} 


\section{II.1.2. La Región en el contexto del primer contacto con la Cultura Europea (1515/1603)}

La avanzada europea sobre la Cuenca del Plata comienza con el descubrimiento del Río de la Plata en 1515, por la expedición naval comandada por Juan Díaz de Solís, que tenía el objetivo de hallar la comunicación entre los océanos Atlántico y Pacífico.

"El rio descubierto, que desconcertó a los españoles por su extraordinario ancho, fue llamado Mar Dulce [...] las costas estaban habitadas. [...] Solis [...] tomó posesión de las nuevas tierras descubiertas en nombre del Rey de España. [...] -junto a ocho compañeros- desembarcaron en la costa. Un grupo de aborígenes los atacó. Sólo se salvó uno de los marineros, quien se quedó a vivir con los indígenas. El resto de la [...] expedición decidió entonces regresar a España y dar cuenta del descubrimiento y de los trágicos sucesos. El episodio, que marca el inicio de la ocupación hispánica de la gran cuenca del Río de la Plata, también signó el proceso histórico que vivirá la región. El río será usado como vía de penetración en el territorio [...] se abría como una gran puerta de acceso para que los conquistadores dominaran los ríos Paraná, Paraguay y Uruguay." (Snihur, 2007: 28).

A la desgraciada experiencia de Solís, que terminó con su vida y la de otros seis tripulantes, le siguieron otras más afortunadas, aunque el encuentro entre los aborígenes que habitaban la Cuenca del Plata con la cultura europea fue dispar, dado que se encontraron tanto con grupos hostiles, como también con grupos guaraníes con buena predisposición para entablar relaciones, asentarse y conseguir alimentos. Para estos pueblos, "[...] los españoles fueron considerados como hombres sobrenaturales. La tecnología de sus armas y la movilidad de sus desconocidos animales impactaron a los indios.” (Levinton, 2007: 22)

\section{II.1.2.1. Impacto de la irrupción de los Españoles}

Sobre la base de un nuevo concepto: la propiedad privada, inicialmente, los españoles, como en toda América, se asentaron en el territorio a partir de la fundación ciudades construidas bajo las Leyes de Indias: “[...] un hecho novedoso y hasta traumático para los grupos aborígenes” (Snihur, 2007: 40).

Pero, dadas las características seminómades de estos pueblos y, la distante y dispersa ubicación de las diferentes aldeas, ${ }^{55}$ llevó a la necesidad de tener que 'reducirlos' para poder consolidar el operativo de la conquista del nuevo territorio. Es decir que, podemos coincidir con Levinton, cuando afirma que:

"El impacto de la irrupción de los españoles produjo cambios que distorsionaron la organización indígena. El corrimiento y la distante ubicación entre sí de las diferentes aldeas de los territorios, cuyos habitantes posteriormente integraron las misiones jesuiticas-denominados del Guayrá, Tapes, Paranaes e Itatines-, fue una de las consecuencias" (Levinton, 2009a': 10)

Para este período histórico, además de entender el proceso de fundación de las ciudades, nos resulta pertinente abordar el análisis de las dos modalidades de reducción, que permitieron cumplir el objetivo de evangelizar al guaraní y convertirlo al sedentarismo:

\footnotetext{
${ }^{55}$ La antigua Provincia del Paraguay abarcaba desde el Cabo de Hornos hasta la Guyana. (Levinton, 2009: 10).
} 
"[...] la aldea guaraní a cargo del poblero, propia del régimen de la encomienda, y la reducción franciscana, con mayor preponderancia al proceso evangelizador, pero aún ligada al sistema de encomienda." (Snihur, 2007: 40).

\section{A. El proceso de Conquista del Territorio y de Fundación de Ciudades}

En 1527, Sebastián Gaboto remontó el Río de la Plata y surcó las aguas del río Paraná hasta la desembocadura del río Carcarañá, dónde fundó el Fuerte Sancti Spíritus, que constituyó el primer asentamiento en territorio argentino. Poco tiempo después las relaciones se deterioraron, y los indígenas destruyeron el Fuerte y mataron a la mayoría de los españoles.

En 1528 Gaboto, volvió a remontar el Paraná buscando oro y plata, pero los Saltos del Apipé y grupos de indígenas canoeros, que por largo tiempo se manifestaron reticentes a la presencia de los extranjeros, le impidieron continuar. Al volver por el Paraná exploró los ríos Paraguay y Pilcomayo, dónde habitaba un gran número de poblaciones indígenas

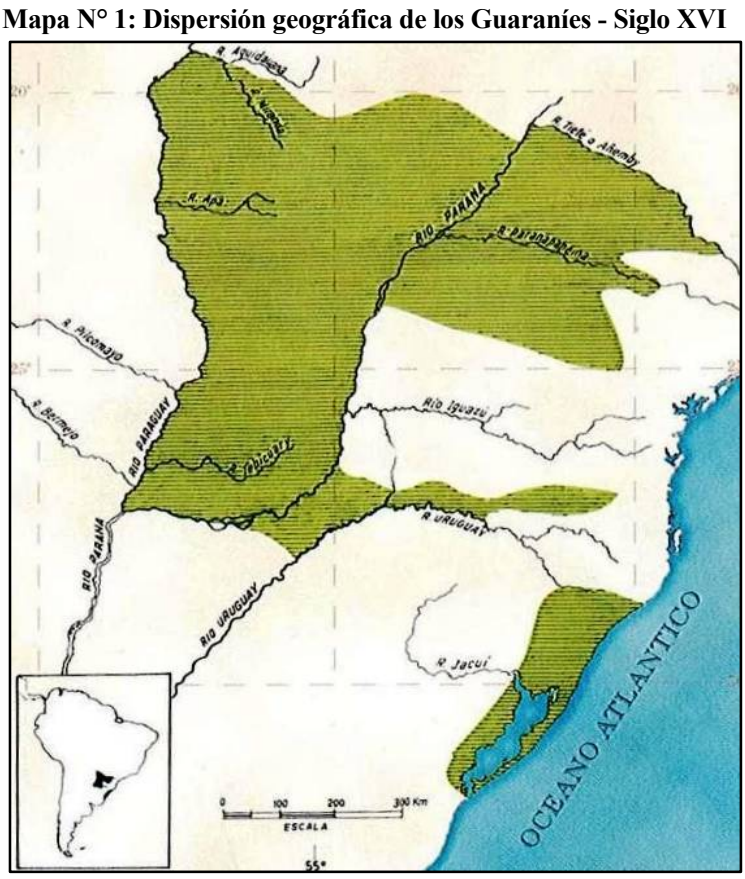

Fuente: Snihur, 2007: 24
Las muestras de oro y plata llevados a España, por las expediciones de Sebastián Gaboto y por otra comandada por Diego García (que ignoraba que Gaboto también estaba recorriendo la zona), determinaron la organización de una gran expedición compuesta por dieciséis naves, con más de 1.200 hombres, comandada por Don Pedro de Mendoza, que llegó al Río de la Palta en 1536, fundando el Puerto de Santa María de los Buenos Aires. Desde allí, los españoles volvieron a remontar el Paraná y el Paraguay, en la búsqueda de una ruta que llevara a los límites del imperio incaico, e impulsados por la falta de alimentos en Buenos Aires.

Así, en 1537, Juan de Salazar de Espinosa, fundó sobre las barrancas del río Paraguay, el fuerte de Nuestra Señora de la Asunción, cuyo desarrollo fue tal, que en 1541 impulsó la decisión de despoblar Buenos Aires y trasladar su población al nuevo asentamiento. Asunción se convirtió en el foco de expansión de la conquista y colonización española en la gran Cuenca del Plata, convirtiéndose en la llamada 'madre de las ciudades' (Snihur, 2007: 35).

"El territorio concedido por el Emperador Carlos V de España a Pedro de Mendoza era inmenso. La Provincia del Paraguay pasó a ejercer sobre el mismo pleno dominio, constituyéndose en la Provincia Gigante de Indias (entonces se creía haber llegado a las Indias occidentales hasta que Américo Vespucio demostraría que se trataba de un nuevo continente). Al norte hasta el Amazonas; al Sur más allá del Río de la Plata hasta las tierras magallánicas; al Este 
desde la línea de Tordesillas y el océano Atlántico y al Oeste más allá de los Andes abarcando 200 leguas sobre el Pacifico. Paraguay era una Provincia bioceánica." (Reverchon, 2009: 1)

Mapa $N^{\circ}$ 2: Fundaciones Españolas

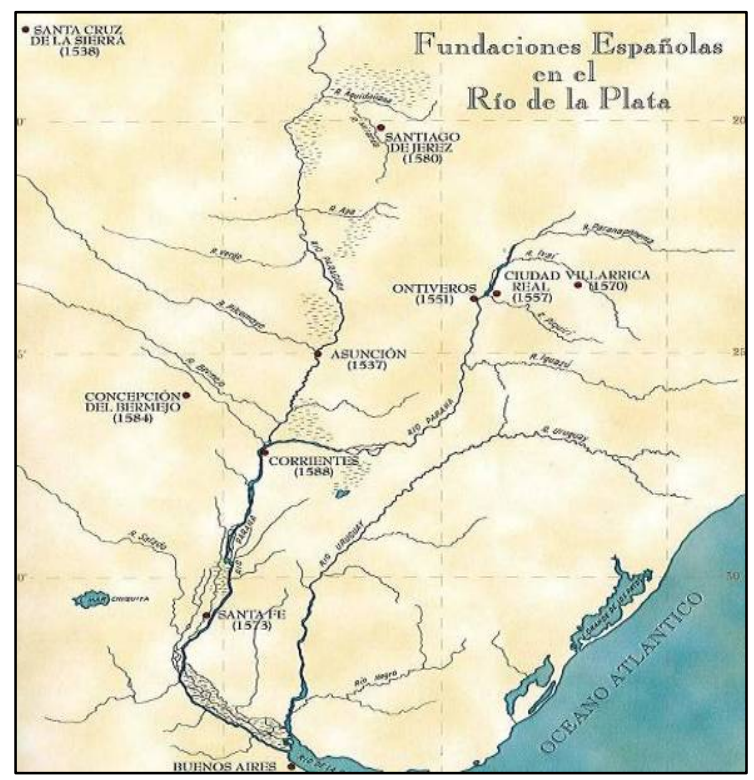

Fuente: Snihur, 2007: 29.
Diversas expediciones partieron desde Asunción para fundar ciudades en el Guairá (o Guayrá), entre otras, Ontiveros (1551), Ciudad Real (1557) y Villarrica (1570), ubicadas en sentido N-E, en función de ciertos arroyos navegables y de la existencia de mano de obra aborigen para ser afectados a trabajos rurales. Bajando hacia el $\mathrm{S}$ por el Paraná, fundaron Santa Fe de la Veracruz (1573) y Corrientes (1588). Poco antes, refundaron Buenos Aires (1580), reforzando así el recorrido fluvial que otorgó a los españoles una vía de acceso hasta Asunción.

\section{B. La Aldea Guaraní a cargo del Poblero}

Para consolidar la conquista por parte de los españoles, de ese territorio, el carácter transitorio y móvil de la aldea guaraní se contraponía al régimen económico-social impuesto por el sistema colonial de la encomienda, que necesitaba imperiosamente fijar espacialmente al aborigen y a la aldea a fin de ejercer un control efectivo sobre la población y el territorio.

"Sin embargo, la primitiva aldea guarani poseía algunos elementos que pervivirán, adaptados al nuevo orden [...], el amplio espacio abierto de la plaza, a un ámbito ceremonial preciso y las 'casas largas'. Las tecnologías constructivas utilizadas en las construcciones por los guaranies no serán descartadas. Al contrario, se implementarán plenamente en los nuevos modelos. [...] La vivienda del poblero ${ }^{56}$ y sus dependencias se constituyeron en elementos urbanos exóticos en la aldea guaraní, aunque tecnológicamente no innovaba respecto al resto de las construcciones. A esto se sumó la Capilla, como centro ceremonial cristiano, que reemplazaba al centro ceremonial guarani primigenio." (Snihur, 2007: 86).

Es por ello que, además de ciudades, los españoles junto a criollos de las ciudades de Asunción y Corrientes, fundaron en la Cuenca del Plata lo que Snihur denomina 'pueblos de indios', en el contexto del mencionado sistema de encomienda. Esta forma de reducir indígenas bajo el sometimiento ejercido por el régimen encomendero, legalizado por las 'Leyes de Indias', implicaba la difícil tarea de llevarlos del nomadismo al sedentarismo.

${ }^{56}$ El poblero fue la expresión del nuevo orden en la aldea guaraní. Su función fue controlar al poblado, asegurando su permanecía estable en un sitio determinado. 


\section{La Reducción Franciscana}

Dado que el modelo reduccional no fue efectivo para ofrecer una alternativa distinta al método de la ‘espada', se recurrió a la Iglesia, y en principio, a una orden religiosa: los Franciscanos.

"Los franciscanos tuvieron un aporte importante para reforzar la organización espacial. Prepararon pastoralmente a los cacicazgos y convivieron con los indios en los pueblos conformados por los encomenderos. Estos sacerdotes, a partir de 1580, organizaron varios asentamientos de indios guaranies ubicados en cordón alrededor de Asunción e intentaron algo similar respecto de las villas ubicadas en el camino que pasaba por el Guayrá, con destino al Atlántico." (Levinton, 2007: 24)

Los primeros Franciscanos fueron los Padres Alonso de San Buenaventura y Luís Bolaños, que ingresando a la región hacia 1575, comenzaron a predicar el Evangelio en las comunidades guaraníes que habitaban las zonas adyacentes a Asunción y a la futura ciudad de Corrientes (fundada por Juan Torres de Vera y Aragón, en 1588). La incorporación de la visión del cristianismo facilitó un mejor acercamiento y, con ello, la posibilidad de adecuar también, la forma física de ‘la Reducción':

"Siguiendo la tradición guaraní los franciscanos incorporaron al espacio de la plaza el templo, en torno al cual se distribuyeron las viviendas de los indígenas, la casa del cura y del poblero, los talleres y el cementerio. No se aprecia aún planificación y un orden de ocupación más allá de las tiras de viviendas que delimitaban la plaza. Los materiales para la construcción provenían de la propia tradición constructiva guaraní. Era un aprovechamiento muy práctico de los recursos del medio natural, como el barro, las enramadas, la paja, las maderas y las lianas." (Snihur, 2007: 86-87)

Mapa $N^{\circ}$ 3: Reducciones Franciscanas

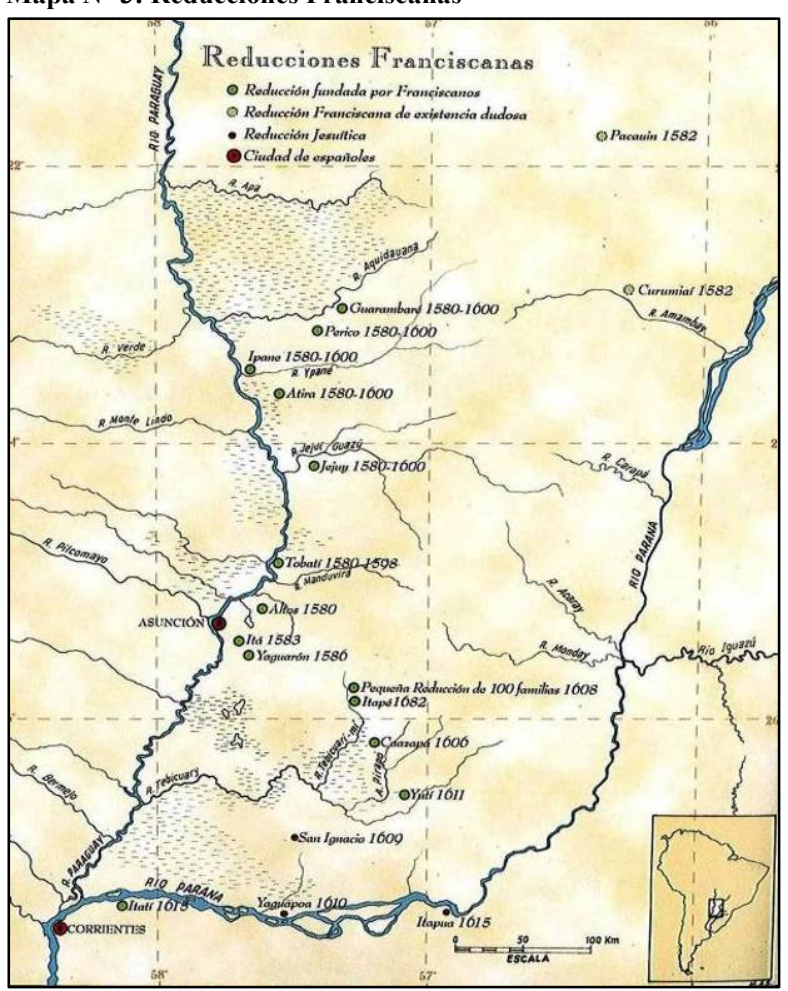

Fuente: Snihur, 2007: 42
"A partir de 1580, los Franciscanos comenzaron a fundar las primeras reducciones guaranies. Surgieron asi [...] los pueblos de Altos (1580), Itá (1585), Yaguarón (1586), Caazapá (1600), Yutí (1611) e Itati (1615), todos ellos en los alrededores de la ciudad de Asunción.

Las reducciones [...], aunque humanizaban el sistema reemplazando el 'poblero' por un sacerdote, no significaba un cambo en el sistema de sometimiento del indígena [...].

Sin embargo, "[...] la estrategia de fundar pueblos reduciendo a los indígenas al sedentarismo y convirtiéndolos al cristianismo se demostraba en la práctica como muy efectiva. El sistema permitía [...] que el poder de los chamanes quedara desprestigiado ante la doctrina cristiana $y$ ante el poder político de los caciques [...] promovido por los mismos sacerdotes.

Hacia finales del siglo XVI las rebeliones guaranies habian perdido su fuerza mística original, mientras los indigenas comenzaban a ser incorporados al sistema colonial hispánico por la vía de la evangelización masiva." (Snihur, 2007: 44).

El mismo autor explica que los límites del avance realizado por los Franciscanos, estuvo delimitado por la reducción de Itatí (en la actual Provincia de Corrientes), por el río Iguazú al N. y por el río 
Paraná, dónde hacia el E y NE, se hallaban replegadas las parcialidades guaraníes que se habían resistido tanto al régimen de encomienda, como a los Franciscanos.

\section{II.1.3. Los Pueblos-Ciudad Jesuíticos (1604/1767): la noción de una Región Cultural}

Más allá del área dominada por españoles y franciscanos, existían extensas regiones como el Guairá (o Guayrá) al N. del río Iguazú; el Tapé al E. del río Uruguay (actual Estado de Rio Grande do Sul, Brasil) y la zona al E. del río Paraná (actuales provincias de Corrientes y Misiones), que estaban ocupadas por millares de guaraníes, cuya situación durante los primeros años del S. XVII era muy compleja. Desde las ciudades de Asunción y Corrientes, se pretendía incorporarlos al régimen de la encomienda, reduciéndolos al modo de vida hispánico, y desde San Pablo se buscaba directamente 'cazarlos' para someterlos a la esclavitud en las haciendas del litoral atlántico del Brasil.

Desde esta perspectiva existía para la administración hispánica una doble necesidad de avanzar y ocupar aquel territorio que, tanto las ciudades como el método de la encomienda o las reducciones franciscanas, no alcanzaban para sedentarizar, o reestructurar la fragmentación territorial de las cuantiosas aldeas guaraníes. Por eso, ese gran proyecto, ya no estaría en manos de la Orden Franciscana, sino de la Orden de la Compañía de Jesús, y sus miembros, los 'Jesuitas'.

"El 9 de febrero de 1604, el Padre Gral. de la Compañia de Jesús, desde su sede en Roma, fundó la Provincia Jesuitica del Paraguay y nombró como primer Provincial al Padre Diego Torres Bollo. ${ }^{57}$

Creada la Provincia [...] inmediatamente los Padres de la Compañia comenzaron a predicar el Evangelio a los guaranies en una zona en la que los franciscanos aún no habian ingresado: la región del Paraná, ubicada entre los ríos Tebicuarí y Paraná. Alli, en [...] 1609 el Padre Marcial de Lorenzana fundó la primera reducción jesuítica: San Ignacio Guazú.” (Snihur, 2007: 49)

Los jesuitas fueron progresivamente, estructurando una organización del territorio indígena, articulando los adelantos europeos con los aspectos de la cosmovisión indígena que no difícultara el conocimiento de la religión cristiana, como parte de una nueva cultura basada en el 'guaraní' como lengua general (Levinton, 2009.a: 11) logrando, de esta manera, una particular integración socio-productiva y espacial de los guaraníes al sistema colonial, que fue uno de los principales logros de esta experiencia.

"Más que una cuestión politica o administrativa, lo que la organización del espacio misional jesuítico-guaraní constituyó, fue una Región Cultural” (Levinton, 2009.a: 11).

\footnotetext{
${ }^{57}$ La Provincia Jesuítica del Paraguay, estaba integrada por los territorios de los actuales países de Argentina, Uruguay, Paraguay y Chile, más la región del SE del Matto Grosso (actual Brasil). Además incorporaba los actuales estados brasileños de Santa Catarina, Paraná y Río Grande do Sul. La actual ciudad argentina de Córdoba era la sede permanente del Provincial de la Orden. La Provincia adquiriría renombre mundial por el fenómeno socio-cultural que se generó en las misiones jesuíticas. En tanto que el Guairá comprendía la región delimitada por los ríos Paraná, al W, Iguazú, al S y E, y el Tiete, al N y E. Las ciudades españolas más cercanas a esta región eran Ciudad Real y Villarrica del Espíritu Santo. El sitio era geopolíticamente clave: limitaba con los territorios portugueses y la jurisdicción de la ciudad de San Pablo, que constituía una frontera de fricción entre España y Portugal (Snihur, 2007:49/50).
} 
Para comprender en forma acabada la importancia de esta primera gran transformación del paisaje regional, nos resulta importante coincidir con Levinton, acerca de destacar que ni la geografía ni la economía condicionaron la caracterización de la integración regional. La Región Cultural estuvo compuesta por zonas de diferentes relieves, montes y pastos, dónde la imagen selvática sólo ha sido un mito historiográfico, y dada la necesidad de organizar económicamente a los diferentes asentamientos, la misma fue estructurada espacialmente en dos subregiones, en función del aprovechamiento de los ríos principales: el Paraná y el Uruguay, que fueron la ligazón de los 30 pueblos misionales ${ }^{58}$ entre sí y de cada uno de ellos con los Oficios de Misiones, que funcionaron además como dos ejes circulatorios para el transporte de la producción (Levinton, 2009.a: 12 a 15).

\section{II.1.3.1. El nuevo urbanismo de las Misiones Jesuíticas}

La configuración espacial de cada micro-región tuvo como origen la fundación del centro urbano o pueblo misionero (con traza y ejido) que fue delineado, en un principio, como una ciudad española devenida de las Ordenanzas de Alfaro emitidas en 1612 (Levinton, 2009.a: 18).

Sin embargo, desde un primer momento, comenzó a producirse una tendencia renovadora y racionalista en los trazados urbanos, que parte de una normativa surgida de un gran sentido pragmático y, al mismo tiempo, inspirada en las Ordenanzas de las 'Leyes de Indias' (Snihur, 2007: 89). Estos pueblos que, “[...] más allá de una normativa general que reglaba el aspecto espacial del urbanismo, eran creaciones de los propios curas, que en la mayoría de los casos [...], ni siquiera eran arquitectos" (Snihur, 2007: 93), estaban conformados generalmente por:

LA PLAZA O PLAZA DE ARMAS: Un espacio que podía medir hasta 1 ha. [...] El pueblo se organizaba a partir de sus 4 lados, donde además desembocaban las calles principales. Los únicos elementos en la Plaza eran el Rollo y 4 grandes cruces ubicadas en las cuatro esquinas [...].

EL TEMPLO: Generalmente se orientaba en dirección Norte-Sur, con unas dimensiones de $25 x 65 \mathrm{~m}$. [...] construidos en piedra [... o] con muros de piedra y adobes. Eran el centro de la vida religiosa de la población [...] El interior, iluminado desde las 'media naranjas' que se abrían sobre el crucero [... un] ambiente rodeado de pinturas, esculturas, retablos y molduras fantásticas, grabadas en las piedras.

EL CAMPANARIO: [...] era una estructura independiente del templo, construida con altos horcones de madera sobre una base de piedras labradas, ubicada en el patio de la Residencia [...].

LA RESIDENCIA: Se ubicaba contigua al templo y era conocidas también como Colegio o Primer Patio. Se trataba de un conjunto de habitaciones que se distribuían en torno a un patio central. Alli se encontraban las habitaciones de los padres curas, la biblioteca, la botica, el comedor, la cocina, la sala de los músicos y otras reparticiones que servían de oficinas y depósitos del pueblo. El artefacto sobresaliente en el patio de la Residencia era el reloj de sol, con el cual se organizaban los tiempos litúrgicos y laborales de los pobladores de la reducción.

58 “En 1717 había 16 pueblos del río Uruguay (uno luego disuelto) y 15 pueblos del río Paraná. Para 1731 había 15 pueblos del río Uruguay y 15 del río Paraná y en 1746, por razones tácticas, había 17 pueblos del río Uruguay y 13 del río Paraná.” (Levinton, 2009.a: 15) 
LOS TALLERES: [...] Segundo Patio. Funcionaban alli la herrería, la carpintería, la carnicería, la tahona, la fábrica de rosarios y de carretas. En ese ámbito los escultores [...], los plateros [...] y los pintores [...] realizaban sus obras.

LA HUERTA: Se ubicaba detrás del templo, de la residencia, de los talleres y del cementerio. Rodeada con un alto muro, constituía un magnifico jardín en el que predominaban los duraznos, los naranjos, los limoneros, las sidras y vegetales como las zanahorias, la lechuga, los repollos y demás verduras propias de la cocina. [...]

EL CEMENTERIO: Se ubicaba a un costado del templo, desde el cual se accedía por una de las puertas laterales. Rodeado por muros, con una puerta de acceso que daba a la plaza, su interior estaba dividido en cuatro cuarteles. En uno se sepultaba a los hombres adultos; en otro a las mujeres adultas; en otro a los niños y en el restante a los párvulos o nacidos muertos. [...]

LAS VIVIENDAS: Se organizaban por cuadras, las que estaban ocupadas por los diversos cacicazgos que integraban la reducción. Los caciques y sus familias ocupaban las casas más próximas a la Plaza. Generalmente eran las mejores al estar construidas integramente en piedra. Luego seguían tiras de viviendas compuestas de piedra y adobes; de adobes y de tapia francesa, estas últimas muy precarias. La tira de vivienda indígena rememoraba la antigua 'casa larga' comunal de los guaranies prehispánicos, aunque en el caso de las reducciones eran divididas en varias celdas o habitaciones como expresión de la imposición del modelo de familia monogámica propia del cristianismo. Cada familia poseía una sola habitación, la cual servia para todas las funciones: de día como lugar de estar y de diversas actividades, y de noche, colgadas las hamacas en las paredes, como dormitorio.

EL CABILDO: Se ubicaba en una de las tiras de vivienda que bordeaba la plaza, con la única característica distintiva de poseer amplias habitaciones que servían para las reuniones de los cabildantes. En su interior sobresalían la mesa de los cabildantes, el retrato del rey, los estandartes reales, el archivo con la documentación, los cofres en los que se guardaban las insignias y los trajes de gala de los cabildantes y un pequeño altar empotrado en la pared donde se hallaba generalmente una imagen de la Virgen María o del Santo Patrono de la reducción.

LAS CAPILLAS: Dentro de los límites del pueblo, en los accesos principales y en las zonas periféricas se hallaban dispersas un gran número de Capillas u oratorios. Eran un símbolo de la presencia continua del mensaje Evangélico en todos los ámbitos de la vida cotidiana del indígena reducido.

EL COTIGUAZÚ O CASA DE RECOGIDAS: Era un conjunto de habitaciones que rodeaban un patio central. Se ubicaban en alguno de los extremos del pueblo, generalmente cercano al cementerio. [...] En el Cotiguazú eran recluidas las mujeres cuyos maridos se ausentaban de la reducción por algún motivo, las viudas que no tenían familiares y las mujeres consideradas de vida ligera y necesitadas de corrección. La principal tarea que desarrollaban las mujeres recluidas era el hilado de la lana y del algodón.

LOS PERCHELES: Más allá del sector de viviendas se ubicaban diversos percheles o galpones pertenecientes a la comunidad. En ellos se almacenaban productos agrícolas, maderas o tejas.

LA CÁRCEL: No existía en las reducciones un edificio que cumpliera especificamente esa función. Servía como lugar de detención alguna de las habitaciones de la Residencia, alguna de las Capillas que se ubicaban fuera del pueblo, o el Cotiguazú, lugares donde los reos eran sometidos comúnmente a la pena del cepo.

LA FUENTE: En las afueras de la reducción, habitualmente a una corta distancia, se hallaba una fuente de agua que servía para el abastecimiento cotidiano de la reducción. También los pueblos poseían pozos o aljibes, localizados generalmente en el patio de los Talleres o de la Residencia, o en la Huerta. (Snihur, 2007: 97-102). 
Figura $N^{\circ} 2$ : Ntra. Sra. de la Candelaria

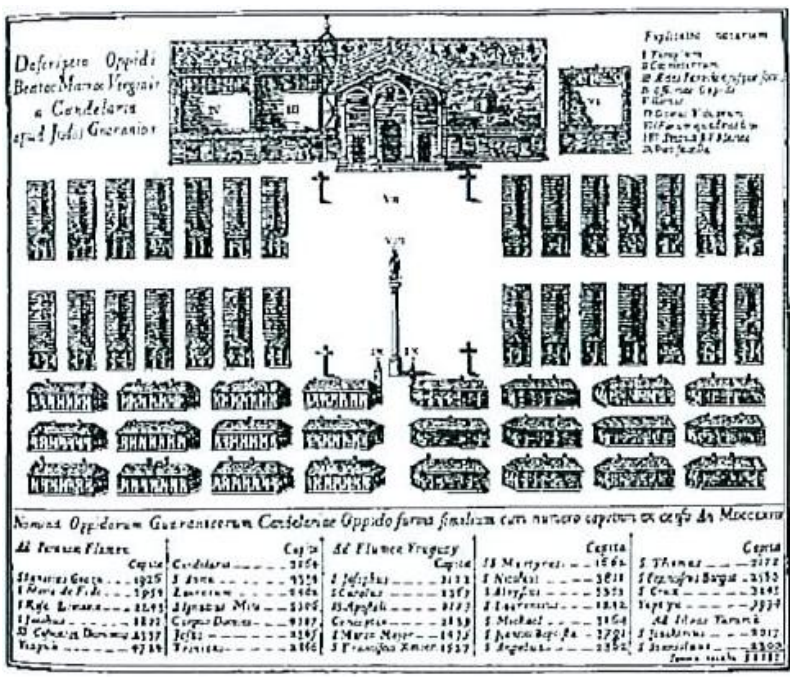

Fuente: Levinton, 2007: 41
Pero las reducciones jesuíticas, no sólo eran centros urbanos 'intramuros'. Los asentamientos presentaban una contigüidad de sus tierras para áreas urbanas, chacras y estancias y en los casos dónde se produjo una discontinuidad en las tierras de un mismo pueblo, existió continuidad del sistema misional y servidumbre de paso dada por otros pueblos (Levinton, 2009.a: 17). Además, para estructurar este territorio, proficuo de ríos y arroyos, los jesuitas recurrieron al agua (" $Y$ " en guaraní), que fue valorizada como un instrumento de ordenación del espacio.

Los ríos y arroyos también se utilizaron para la definición de los límites de los ejidos urbanorurales correspondiente a cada pueblo y para diferenciar las zonas de pasturas para alimentar los animales, de las destinadas al hábitat humano (Levinton, 2009.a: 48).

Si bien, en pocos años, los pueblos fundados por jesuitas congregaban a miles de guaraníes, la situación de aislamiento de la región del Guairá y la falta de recursos defensivos, volvieron muy vulnerables a las reducciones, frente a la voracidad del sistema colonial portugués.

"En el año 1628, los bandeirantes ${ }^{59}$ paulistas habian cruzado el río Tibajiba, ingresando de ese modo al ámbito territorial de las misiones guaireñas. [...] La población guaraní, espantada por las atrocidades cometidas por los bandeirantes, se replegaba hacia el Occidente. [...] Al culminar 1631, solamente San Ignacio Miní y Nuestra Señora de Loreto permanecian en el Guairá. Las demás reducciones habian sido destruidas [...] o abandonadas [...] ante la mirada indiferente de los encomenderos españoles de Asunción, Villarrica y Ciudad Real [...]”. (Snihur, 2007: 52-53)

El Padre Antonio Ruiz de Montoya, superior de las misiones guaireñas, decidió abandonar la región con unos 12 mil guaraníes, hacia la región ubicada entre los ríos Paraná y Uruguay. Solamente unos 4 mil indios llegaron a orillas del río Yaberbiry, dónde en el año 1632, refundaron las reducciones de San Ignacio Miní y Nuestra Señora de Loreto (en la actual provincia de Misiones).

En esta misma región el padre jesuita Roque González de Santa Cruz (primer santo paraguayo), había fundado en 1615, una reducción en la zona que actualmente ocupa la ciudad de Posadas, con el nombre de "Nuestra Señora de la Asunción de la Encarnación de Itapúa" (Snihur: 2008: 58). "Esta fundación primigenia se hallaba asentada en la margen izquierda del río Paraná, en lo que es actualmente la Ciudad de Posadas, Misiones, República Argentina." (Reverchón, 2009: 5), que poco tiempo después,

\footnotetext{
${ }^{59}$ Los bandeirantes o mamelucos, eran avezados cazadores de esclavos en tierras americanas, que se constituyeron en un factor clave en la expansión territorial portuguesa hacia el oriente.
} 
fue trasladada a la margen derecha del río Paraná (actual Encarnación, en Paraguay), fundando Encarnación de Itapúa, aunque nunca se dejó de poblar la ciudad original (actual Posadas, en Argentina).

"La Misión de Itapúa no permaneció mucho tiempo en el lugar de su emplazamiento. Diversas razones motivaron su traslado: la amenaza bandeirante, la peste, la indocilidad de los nativos, pueblo recientemente constituido todavía sin sentido de pertenencia de fácil disgregación, la conveniencia de una mayor proximidad a San Ignacio Guazú, que fue la primera reducción fundada por los Jesuitas y la seguridad necesaria para las autoridades que llegaran hasta ella, recordando la triste experiencia de Hernandarias y las pestes recurrentes. Todas ellas configuran la causa de la demora en la construcción del templo definitivo." ${ }^{60}$ (Reverchón, 2009: 7).

La Reducción de Encarnación de Itapúa se mantuvo en la parte seca del riacho de la Villa Baja por varias décadas, hasta que, debido a que se encontraba expuesta a las riadas y a las epidemias transmitidas por los mosquitos se dispuso su traslado a tres cuartos de legua al $\mathrm{N}$ en lo que es actualmente la Villa Alta emplazándose en las tierras que tuvo su centro en lo que es ahora el Colegio Inmaculada Concepción y en 1702, se iniciaron las obras de la fundación misionera en el lugar, trazándose el pueblo según las normas conocidas y poniéndose mano inmediatamente a la fábrica de la Iglesia (Reverchón, 2009: 9)

Desde esta reducción, el padre Roque González exploró la actual provincia de Misiones. En 1619 fundó Nuestra Señora de la Limpia Concepción del Ibitiracuá (actual Concepción de la Sierra, Misiones, Argentina) y frente a ésta y cruzando el río Uruguay, en 1626, fundó la reducción de San Nicolás, en territorio hoy brasileño, que constituía la antesala de la región del Tapé, que se extendía hacia el este; y dónde este padre jesuita, junto a otros sacerdotes, fundaron nuevos pueblos.

"Pero al Tapé le esperaba la misma calamidad que a los pueblos del Guairá: los temibles bandeirantes. En 1637, los ataques crecieron con una furia inusitada [...] los pueblos decidieron emigrar en la orilla Oriental del río Uruguay. Para instalarse eligieron las reducciones de Concepción y San Javier.

En este caso, y a diferencia del éxodo del Guairá, el traslado fue ordenado y por etapas. Para defender a los indígenas se realizaron acciones armadas contra los bandeirantes. [...] La nueva estrategia fue planeada por el Superior, el Padre Diego de Boroa [...].

Estas [...] acciones defensivas [...] permitieron descubrir el potencial y la destreza militar de los guaranies y el rol que podían desempeñar en la defensa del territorio [...]. Comenzó así, a pensarse entonces en la posibilidad de permitir que los guaranies de las misiones portaran armas de fuego." (Snihur, 2007: 63)

Lo antedicho y el saldo de las incursiones bandeirantes en el Guairá y en el Tapé, materializadas en pueblos forzosamente trasladados, miles de muertos, hambruna, etc., determinaron que "[...] los padres Antonio Ruiz de Montoya y Francisco Díaz Taño, en 1638, a viajar a España con el objetivo de informar minuciosamente al rey Felipe IV [...]" (Snihur, 2008: 64). Pero no fue hasta 1640, que se emitió la Cédula Real por la que se permitía que los guaraníes usaran armas de fuego para su defensa, siempre que mediara la previa autorización del Virrey del Perú.

\footnotetext{
${ }^{60}$ Sin embargo, el mismo autor señala más adelante, que: "El hecho del paso de Itapúa de la margen izquierda a la margen derecha, no está registrado por los historiadores de la época. Solo rastreando en las Cartas Anuas y los Catálogos de las Reducciones puede encontrarse alguna luz.” (Reverchón, 2009: 8)
} 
En este período se perdieron misiones tanto sobre el río Paraná, como sobre el Uruguay, dejando a merced de los portugueses las ciudades de Buenos Aires, San Fe, Corrientes y Asunción; así como muy debilitadas las defensas de los territorios hispánicos hasta el Perú; por lo cual, la Corona Española no dudó en otorgarle toda la protección y los privilegios requeridos.

Mapa $N^{\circ}$ 4: Invasões Bandeirantes

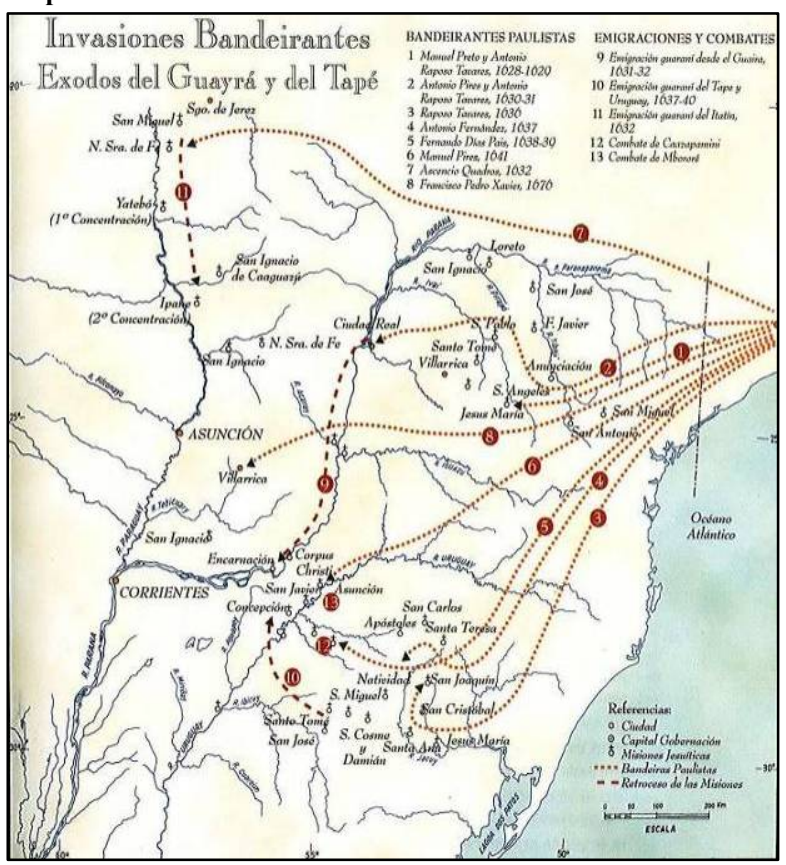

Fuente: Snihur, 2007: 79
"En el segundo semestre del año 1640 los bandeirantes, dirigidos por Manuel Pires y Jerónimo Pedrozo, abandonaron San Pablo y comenzaron su ruta a las misiones de guaranies.

Luego que la bandeira cruzara el curso del río Iguazú [estableció] un campamento sobre las nacientes del río Apeteribí [...y] siguieron su ruta hasta llegar al curso superior del rio Uruguay [...]

En el transcurso de los días 9 y 10 de marzo de 1641, los sacerdotes jesuitas, los hermanos y capitanes caciques planificaron el ataque y organizaron a un contingente de 4.200 indios para la batalla final.

El 11 de marzo, en plena Semana Santa del año 1641, los bandeirantes bajaron por el río Uruguay hacia el Mbororé. [...]

El ataque naval de los misioneros fue fulminante [...]" (Snihur, 2007: 65)

\section{II.1.3.2. Una nueva noción de desarrollo y de paisaje}

Mapa $N^{\circ}$ 5: Fundaciones Jesuíticas

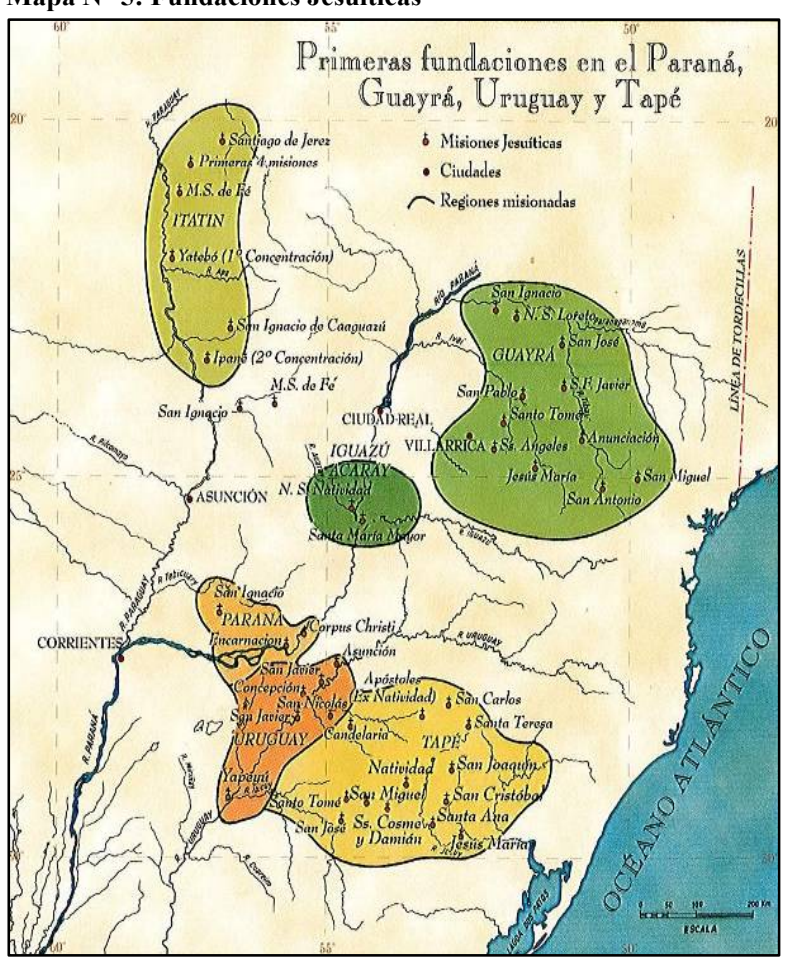

Fuente: Snihur, 2007: 71
Aquella victoria cerraba una etapa marcada por la imprecisión territorial en los pueblos misioneros y a partir de aquí, los límites y fronteras comenzaban a configurarse de manera más precisa y las misiones comenzaron a trasladarse a zonas aptas para el desarrollo de la región, principalmente donde se localiza nuestro objeto de estudio: Yacyretá.

"La expansión comenzó a producirse hacia las cuencas de los ríos Aguapey, Chimiray, Miriñay y los Esteros del Iberá. Era una zona muy atractiva al predominar en ella campos con pastos y una selva desarrollada únicamente en galerías sobre las márgenes de los cursos de agua. Un ámbito ideal para los asentamientos humanos [...] el desarrollo de la actividad ganadera y [...] la agricultura." (Snihur, 2007: 80) 
Dadas las particulares características naturales de la macro-región guaraní, el territorio de las misiones conformaba un sistema con aperturas controladas, tanto interior como exteriormente.

"Los rápidos de Apipé sobre el río Paraná, las correderas de Salto Grande sobre el río Uruguay, los saltos del Macona también sobre el curso del Uruguay, los saltos el Guayrá en el curso superior del Paraná y los Esteros del Iberá, representaban las barreras naturales que marcaban los límites del territorio de las misiones respecto al resto del mundo colonial hispánico. Los accidentes naturales facilitaban el aislamiento de las misiones y, al mismo tiempo, favorecian el estricto control de las comunicaciones desde y hacia las misiones" (Snihur, 2007: 107)

Ese contexto selvático y los accidentes naturales, favorecía el estricto control de los extraños, que contrastaba con la notable agilidad de las comunicaciones internas, favorecidas por la infraestructura construida entre los pueblos, a partir de una red de 'caminos reales' que se complementaba con el transporte fluvial que comunicaba los pueblos ribereños (Snihur, 2007: 108). De tal forma 'hacia adentro' de la macro-región, una suerte de 'red' de reducciones jesuíticas y estancias, cada una de ellas, especializadas en determinados tipos de producción, conformaban un particular urbanismo rur-urbano.

Además, uno de los principales elementos configurantes de la homogeneidad de la macro-región ha sido la concepción de hacerla evolucionar como un sistema económicamente solidario (Levinton, 2009.a; Snihur, 2007), configurando de este modo, una nueva noción del desarrollo de los pueblos y ciudades coloniales. Pero estructurando también, a partir de una nueva relación cultura-naturaleza, una verdadera reconfiguración del paisaje regional. Una suerte de concreción de 'la tierra sin mal':

"Por eso, el imaginario urbano-rural de los pueblos misioneros requirió de un paisaje realcon profusión de agua y frutas- que aportó a esas sensaciones. En las huertas, quintas, plantios y corrales, que rodeaban a la traza urbana abundaron los efectos paradisiacos aguzados por la presencia del agua y una gran cruz." (Levinton, 2009.a: 54)

De tal forma, por ejemplo, las reducciones de San Carlos y San José, se ubicaron en la naciente del Aguapey; también comenzaron a consolidarse establecimientos de estancias en la cuenca de ese río y en dirección a los Esteros de Iberá; Nuestra Señora de la Asunción de Acaraguá, fue trasladada a orillas del río Uruguay, dando origen a la reducción de La Cruz; en tanto que, Santo Tomé y Yapeyú, establecieron sus estancias en torno a esta cuenca; Apóstoles y San Nicolás se unificaron con el nombre de Santos Apóstoles Pedro y Pablo; entre otras.

Es decir que la ubicación de los asentamientos y sus respectivos territorios, destinados a la agricultura y la ganadería, fueron diagramados de tal forma que se fue delineando en el transcurso del tiempo una extensión regional continua, homogeneizada por los particulares criterios aplicados por los Jesuitas para configurar los agrupamientos humanos. Por tales motivos, más que un área administrativa, la organización del espacio misional jesuítico-guaraní constituyó, por lo innovador y lo específico, una Región Cultural. Esta área fue organizada, en forma análoga a lo que ocurría antes de la irrupción de los españoles, en función de los principales ríos y los arroyos, que se convirtieron en el medio esencial 
de ligazón entre los pueblos misioneros y de cada uno de ellos con el Oficio de las Misiones (Buenos Aires, Santa Fe, Corrientes y Asunción. (Levinton, 2007: 60).

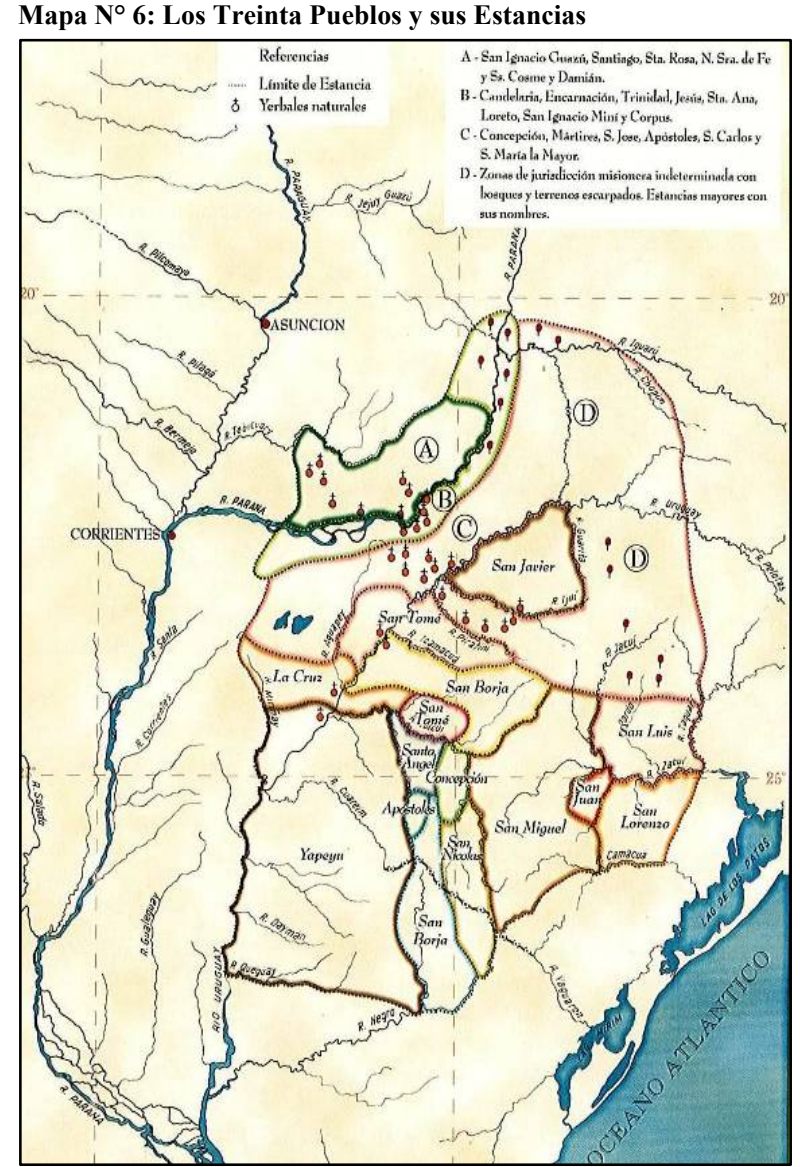

Fuente: Snihur, 2007: 131
Una vez definida la situación territorial de los pueblos ubicados entre los ríos Paraná y Uruguay, se inició una etapa de recuperación de gran parte de territorios antes abandonados y también, la fundación de nuevos pueblos-colonias.

"Treinta pueblos quedaron firmemente establecidos y consolidados con sus respectivas jurisdicciones territoriales.

En la actual República Argentina: Yapeyú, La Cruz, Santo Tomé, San Carlos, San José, Apóstoles, Concepción, Santa María la Mayor, Mártires, San Javier, Santa Ana, Candelaria, Loreto, San Ignacio Miní y Corpus.

En la actual República del Paraguay: Ntra. Señora de la Encarnación de Itapúa, Trinidad, Jesús, Santiago, Santa María de $\mathrm{Fe}$, San Ignacio Guazú, Santa Rosa y San Cosme y Damián.

En la actual República del Brasil: San Borja, San Miguel, San Lorenzo, San Juan Bautista, Santo Ángel, San Nicolás y San Luis." (Snihur, 2007: 83)

La data de fundación de estos 30 pueblos fue disímil, pero en la primera mitad del S XVIII, el conjunto de ellos ya se encontraba organizado y contenido en un espacio territorial comprendido entre las cuencas de los ríos Tebicuarí, Paraná, Uruguay, Miriñay, Negro e Iguazú. El mismo, contaba con una identidad cultural y étnica claramente diferenciada frente al resto del mundo colonial hispánico y portugués y fue definido por la Compañía de Jesús como misionero-guaraní. (Levinton, 2009.a: 8).

El Rey Carlos III dispuso, el 27 de febrero de 1767, la expulsión de los religiosos de la Compañía de Jesús de todos sus dominios, luego de que el movimiento de la Ilustración, había generado un fuerte impulso anticlerical que centró sus ataques en la Compañía de Jesús (Snihur, 2007: 169), que llevó a expulsarlos previamente de los territorios de Francia y Portugal.

A ello, se sumó por una parte, la antipatía que había generado la incorporación de los indígenas a las misiones, que los sacó del régimen de la encomienda, contribuyendo así, a mejorar la calidad de vida de los indígenas; así como también, por las fantasías que habían despertado las reducciones jesuí- 
ticas fomentadas por el asilamiento de las mismas, que favoreció la construcción de mitos y leyendas sobre la existencia de oro, tesoros y riquezas acumuladas por las reducciones.

Por otra parte, se considera que la presencia portuguesa fue otro factor determinante de esa decisión, dado que este sistema de pueblos-ciudades, representaba una valla efectiva a las pretensiones expansionistas lusitanas.

Sin embargo, “[...] En los treinta pueblos de las misiones jesuíticas de guaraníes, la expulsión recién se pudo concretar en el año 1768" (Snihur, 2007: 172). Es decir, que: "Después de ciento cincuenta y nueve años [...], los jesuitas dejaban su 'Estado' paraguayo, orgullo de la Compañía, que había destinado allí muchos de sus más valientes y preparados misioneros” (Armani, 1988: 17).

La incidencia de esta larga permanencia ha demostrado ser decisiva para salvar, junto con la lengua y la cultura guaraníes, la identidad de ese pueblo. Tal como lo señala Armani en la frase final de su libro, citando al experto en problemas lingüísticos de América del Sur Isaza Calderón:

"[...] en el Paraguay conviven con pareja importancia el guarani y el español, con la singularidad de que el paraguayo siente el orgullo de su ascendencia indigena, representada por el guaraní, y lo habla con sumo orgullo." (Armani, 1988: 216).

\section{II.1.4. La Región en el período de formación e institucionalización de los Territorios Nacio-} nales (1769/1882): el tránsito de la ciudad colonial y los pueblos-ciudad a la ciudad contemporánea

La evolución del territorio dentro del área de influencia de Yacyretá, estuvo signado por la situación de los pueblos-ciudad del sistema reduccional jesuítico, que después de la expulsión de los jesuitas y la posterior conformación de los territorios nacionales, fueron progresivamente 'vaciados de indios' y reconvertidos a ciudad.

De tal forma, sobre la margen izquierda del río Paraná, en el lugar dónde inicialmente se fundó la reducción jesuítica de Encarnación de Itapúa se fue consolidando la ciudad de Posadas (República Argentina) y sobre la margen derecha del mismo río, dónde se trasladó posteriormente dicha reducción, se consolidó la ciudad de Encarnación (República del Paraguay).

Pero, la disolución del sistema de las Reducciones no ocurrió de una vez, sino en forma gradual.

En general se ha señalado como causa primera de su decadencia la avidez de los administradores civiles, enviados en lugar de los jesuitas y de los corregidores indígenas, y también, en el cambio del sistema de administración impuesto por el gobernador de Buenos Aires, Francisco de Paula Bucarelli y Ursúa, que no tomó en cuenta que los guaraníes habían desarrollado una conciencia social ligada a un contexto políticamente teocrático y económicamente comunitario (Armani, 1998: 206). 


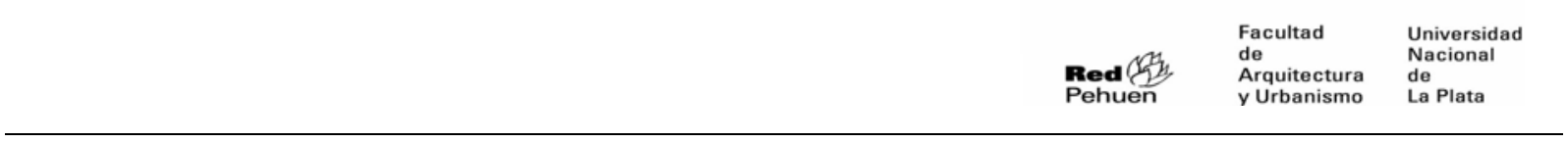

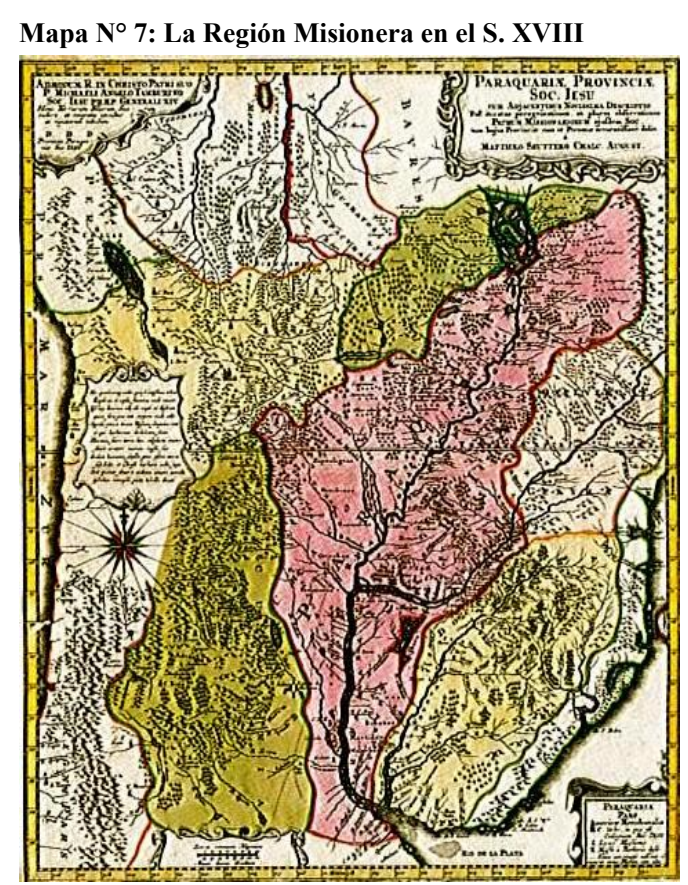

Fuente: The Library of Congress USA (Levinton, 2007:39)
Es decir, que tanto el nombramiento de esos administradores, como las nuevas medidas administrativas y las ideas económicas vigentes en la época inspiradas en el liberalismo y el capital, “[...] trajeron consigo una desestructuración del sistema territorial misionero como organización espacial. Los pueblos-ciudades perdieron conexión entre sí y dejaron de funcionar como un sistema, lo que era el fundamento de su subsistencia" (Levinton, 2007: 55), ${ }^{61}$ y progresivamente, las 'reducciones' comenzaron a ser abandonadas.

De tal forma, las ciudades fundadas por los españoles, pasaron a ser las únicas en tener predominancia sobre el territorio colonial.

En 1731, Asunción fue el foco principal de la 'Revuelta de los Comuneros' al mando de José de Antequera y Castro, una de las primeras reacciones (fallidas) contra el dominio colonial español; y hacia 1782 , se estableció en el virreinato el régimen de las intendencias.

"En 1782 entró en vigencia la Real Ordenanza de Intendentes que modificó la organización administrativa del Virreinato del Río de la Plata. Dividió su extenso territorio en ocho Intendencias y cuatro Gobernaciones Militares. Las Intendencias fueron 1) Buenos Aires; 2) Córdoba de Tucumán; 3) Salta; 4) Paraguay; 5) Potosí; 6) La Plata o Chuquisaca; 7) Santa Cruz de la Sierra (o Cochabamba); y 8) La Paz. Las Gobernaciones Militares fueron: 1) Montevideo; 2) Misiones; 3) Mojos, y 4) Chiquitos.” (Reverchón, 2009: 10)

Asunción era, en la Provincia o Intendencia del Paraguay, la única población con categoría de ciudad. La zona al sur del río Tebicuary y al este de la cordillera de Caaguazú por su parte correspondía a la Gobernación de las Misiones Guaraníes (o Provincia Subordinada de las Misiones) constituida con los restos de las Misiones Jesuíticas que pudieron quedar bajo control español.

"A diferencia de los sucedido en los pueblos de indios misioneros, el periodo entre los años 1783 y 1796 fue extraordinariamente floreciente para el comercio de las ciudades españolas." Levinton, 2007: 48)

En 1801, en los pueblos dependientes de Buenos Aires, se otorgó la 'libertad de comunidad' a los indios más destacados. Esta medida sólo causó más perjuicio a los pueblos. Durante este año los portugueses

\footnotetext{
${ }^{61}$ De acuerdo a los relatos de este autor, a diferencia de lo sucedido en los pueblos de indios misioneros, este período previo a los procesos independentistas de América del Sur, fue extraordinariamente floreciente para las ciudades españolas, dado principalmente, por la apertura comercial del sistema colonial permitida a partir de 1778, que significó un incentivo para lograr un aumento descomunal en la producción de cueros. Esto, señala, no favoreció a los pueblos indígenas, sino a la estructura de expoliación de los mismos organizada por la Administración General de Misiones (Levinton, 2007: 56)
} 
tomaron los siete pueblos de la Banda Oriental y los indios no se opusieron al cambio de dependencia (Levinton, 2007: 59). Pero con la creación en 1803, del Gobierno Militar y Político de Misiones, a cargo del Cnel. Bernardo Velazco, se consolida la supervivencia de las reducciones en torno al río Paraná. ${ }^{62}$

"Por Real Cédula del 17 de mayo de 1803 las Misiones con los treinta pueblos fundados por los jesuitas formaron una entidad administrativa y politica independiente del Paraguay y de Buenos Aires. Esta creación se hizo en base a los trece pueblos del Paraguay y de los diez y siete pertenecientes a Buenos Aires, y abarcaba un territorio que partía del río Ybycuí afluente del río Uruguay, hasta el rio Tebicuary que discurre en la actual Villa Florida de Paraguay. Fue nombrado Gobernador de Misiones Bernardo Velasco, y tres años después, lo fue a su vez Intendente del Paraguay, cargos ejercidos simultáneamente, con el título de Gobernador Militar y politico e Intendente de la Provincia del Paraguay y de los treinta pueblos de las Misiones de los indios guaranies y tapes del Paraná." (Reverchón, 2009: 10)

La política de Buenos Aires y Asunción de los años subsiguientes, no mostraron otra intención que la de reclutar indios para completar la dotación de sus ejércitos. Por ello, podemos coincidir con Levinton, cuando afirma que en esta fase del período:

"La política, llevada a cabo por la burocracia colonial, inició la desestructuración del sistema de pueblos-ciudades. Los asentamientos no podian desarrollarse en forma autónoma. El funcionamiento se basaba en la complementariedad. La relación entre los habitantes y el territorio se fue debilitando. El propio hábitat se volvió hostil." (Levinton, 2007: 60).

Cuando se produjo la Revolución de Mayo en Buenos Aires (25 de mayo de 1810), la Gobernación de Misiones y del Paraguay, a cargo de Velasco, se hallaba ocupada militarmente con efectivos en Candelaria, mientras que los pueblos de la región estaban ocupados por indios. Este aspecto, sumado a la política del nuevo gobierno argentino, orientada a dominar el territorio, terminó de definir el carácter periférico del territorio misionero. Los principales instrumentos de esa estructuración fueron 'la ciudad', que en el pensamiento de la época, originó la oposición ciudad/civilizacióncampo/barbarie (Levinton, 2007: 76) y el 'latifundio' ${ }^{63}$ que permitió, por ejemplo, consolidar el modelo agro-exportador argentino, siendo considerado por algunos autores, como la causa principal del despoblamiento de América del Sur.

En ese año la Junta de Buenos Aires comisionó al vocal Juan Manuel Belgrano, entre otras cosas, para recuperar la Provincia del Paraguay.

"Con el fracaso de sus tentativas pacificas para recuperar la Provincia del Paraguay, organizó un ejército, y vino a invadir su territorio y conquistarlo por las armas. Tomó Candelaria y luego pasó por Campichuelo sin encontrar mayor resistencia militar. [...] Belgrano llegó hasta el

\footnotetext{
${ }^{62}$ Al respecto del estado de situación de los pueblos de la región, Levinton señala: "Según Bolsi, había 12.613 indios misioneros solamente en la margen izquierda. En la margan derecha, Encarnación de Itapúa tenía 1.789 habitantes y San Cosme 890 habitantes." (Levinton, 2007: 60)

${ }^{63}$ El latifundio es una propiedad rural de gran extensión, que permite desarrollar un sistema de explotación de la tierra que reduce al mínimo el concurso humano, buscando la rentabilidad neta de la misma. Esto, empleado como proceso de reorganización del espacio.
} 
Cerro Mae y, después de vadear el Caañabe, y desde allí atacó a las tropas paraguayas el 19 de enero de 1811, siendo derrotado en toda la línea [...]"

“[...) cuando Belgrano intentaba recuperar la Provincia del Paraguay, Encarnación de Itapúa se hallaba desierta, su población después de destruir todo lo que pudiera serle útil al invasor dejando la tierra arrasada, se dirigió a tierra adentro. [...] Después de suscribir la capitulación Belgrano [...] Itapúa fue repoblada por la mayoría de sus antiguos habitantes, y pronto tendría una gran importancia como única puerta al sur de entrada y salida de personas y mercaderías del Paraguay durante la Dictadura del Dr. Gaspar Rodríguez de Francia. Muchos españoles formaban parte de su población y nativos." (Sánchez Quell, 1981: 155)

Las tropas de Belgrano fueron derrotadas el 9 de marzo de 1811 en las batallas de Tacuarí y de Paraguarí. Las tropas vencedoras asumieron una nueva identidad, y el 14 y 15 de mayo de 1811, estalló el movimiento revolucionario paraguayo, que derivó en la independencia del Paraguay. Posteriormente, "[...] en el Tratado del 12 de Octubre de 1811 suscrito entre Paraguay y Buenos Aires, el primero hizo reserva de Misiones que consideraba suya a partir de 1803.” (Reverchón, 2009: 11).

En esos años, la ciudad de Nuestra Señora de Santa María de la Asunción (actual Capital de la República del Paraguay), seguía manteniendo una fuerte hegemonía regional y durante el gobierno de José Gaspar Rodríguez de Francia (1816-1840), la mayor parte del centro de Asunción, fue demolido para rehacer la planta urbana en forma de cuadrícula.

Figura No 3: La Visita del Gobernador de Leonnie Mathis

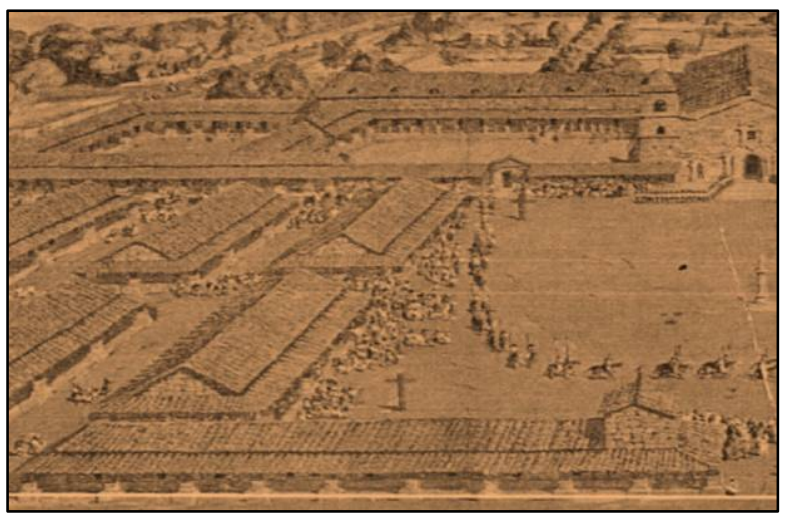

Durante ese mismo gobierno, Itapúa se constituyó en puerto de entrada y salida de personas y mercaderías del Paraguay. El transporte de esas mercaderías, con destino a Asunción y las exportables, con destino a Corrientes o Río Grande Do Sul, motivó un gran desarrollo del comercio, y favoreció el asentamiento de población estable, que se incrementó aceleradamente.

Fuente: Arrúa, 2009: 36

También en estos años Rodríguez de Francia mandó construir la 'Trinchera de San José' inaugurada en 1838 y de la cual quedan aún vestigios relativamente bien conservados, en lo que es actualmente la ciudad de Posadas (Misiones, Argentina), para resguardar la soberanía paraguaya. El Delegado de gobierno alternaba su asiento en Candelaria e Itapúa. (Reverchón, 2009: 13). El lugar era adecuado para conformar un nudo circulatorio enfrente de Encarnación y desde allí, se podían encarar los caminos hacia el resto de los pueblos misioneros (Levinton, 2007: 91)

"Muerto [Rodriguez de] Francia [en 1840], después de un breve período de anarquía, el Congreso de 1841 creó el Segundo Consulado integrado por Carlos A. López y el Comandante de Armas Mariano Roque Alonso, que de inmediato puso en marcha la reorganización de la República. El Congreso Extraordinario de 1842 proclamó la Independencia del Paraguay que ya lo era de hecho desde el 14 de Mayo de 1811, y República desde 1813." (Reverchón, 2009: 13) 
El 8 de abril de 1843, por Decreto del Consulado paraguayo la antigua misión de la Encarnación de Itapúa, fue reconocida como 'Pueblo' y fue designada además, como capital de un Departamento de $16.525 \mathrm{Km}^{2}$. El Decreto, respetaba la traza originaria, aunque no así sus edificaciones.

“[...] Artículo $1^{\circ}$ : el pueblo de Itapúa situado en la costa del Río Paraná es erigido en Villa con la denominación de su patrona tutelar, esto es Villa Encarnación.

Artículo $2^{\circ}:$ se conservará en su estado actual el arreglo de plaza y calles sin perjuicio de las mejoras que en adelante convenga hacer.

Articulo 3: en la plaza principal [Plaza de Armas] se colocará la colecturía y sus almacenes, casa de justicia, escuela de primeras letras, otras oficinas que puedan ser necesidad y uso público.

Artículo 4: el cuadro que actualmente se llama colegio se arreglará para cuartel [...].

Artículo 5०: enseguida del área de la Villa se demarcará el local para quintas también en orden de calles y cada quinta será regulada por 50 varas de frente y tras tanto de fondo [...]

Artículo $7^{\circ}$ : a continuación de las quintas se demarcará el área para las chacras y cada chacra tendrá 100 varas cuadradas dejando despejados los caminos de servidumbre comunal y labrando además de las casas y cercos para las cementeras y corral seguro para las bestias [...]. Los labradores laboriosos podrán reunir en una data de chacra hasta tres cuadras cuadradas.

Artículo $8^{\circ}$ : después de las chacras el lugar más conveniente donde hubiera pastos y aguas permanentes se marcará el ejido de la Villa de 15 a 20 cuadras de longitud (...) para el pastoreo y desahogo de los animales del servicio de la Villa, quintas y chacras.

Artículo $9^{\circ}$ : el área en general de la nueva villa para las demarcaciones de solares, quintas, chacras y ejidos se calculará con conceptos a los límites conocidos del suprimido pueblo de Itapúa con los de Jesús y el arroyo Caraguatá que será el divisor de distrito del nuevo pueblo de los naturales de Itapúa que se ha de formar en el paraje nombrado Tuparay en la costa del Paraná." (Delvalle, 1998: 29-30)

Para consolidar esa designación, los indios, antiguos propietarios de las tierras, fueron trasladados por orden superior al lugar dónde existía una antigua capilla misionera, conocido con el nombre guaraní Tuparay (hijo de Dios), configurando así, en forma incipiente, el pueblo que hoy constituye la ciudad de Carmen del Paraná (Levinton, 2007: 96).

"También fue fundado el pueblo de Carmen del Paraná y el límite con Encarnación, era el Arroyo Caraguatá. En 1848 se desmantelará el templo de la antigua Reducción de Itapúa y su madera sería utilizada para la construcción de un puente sobre el Caraguatá para unir ambas poblaciones y favorecer el intercambio comercial." (Reverchón, 2009: 13)

La situación en la otra margen del Río Paraná era muy diferente. A mitad del siglo XIX, desde el punto de vista legal la tierra misionera de la margen izquierda era institucionalmente un espacio vacío de habitantes potencialmente en litigio. Nadie tuvo en cuenta a los que deambulaban por el territorio y a los misioneros que habitaban en las áreas circundantes (Levinton, 2007: 105). El año 1852 significó para Argentina el inicio de una nueva etapa para las provincias confederadas, que empezaban a aceptar la idea de una nación. Con el reconocimiento del Paraguay como república independiente, comenzó a hablarse del río Paraná como límite natural pero no hubo arreglo definitivo entre las naciones. La libre navegación que imperaba por entonces, dejó a la región misionera nuevamente relegada, puesto que perdió importancia la comunicación entre Encarnación y San Borja. En la discusión de la Constitución 
Argentina de 1853 se incluyó la cuestión de los límites provinciales y se definió la existencia de territorios nacionales, pero el caso de Misiones no fue tratado a pesar de los pactos pre-existentes. (Levinton 2007: 109) y en 1864 la Provincia Corrientes, acercándose al territorio misionero, funda Ituzaingó, mientras que otros pueblos de indios misioneros aceptaron también, integrarse a la provincia correntina, como Loreto, San Miguel, La Cruz y Santo Tomé (Levinton 2007: 110).

Entre 1864 y 1870, se desata el mayor conflicto bélico de la historia sudamericana: La Guerra de la Triple Alianza o Guerra Grande, en la cual Paraguay luchó contra las fuerzas reunidas de Brasil, Uruguay y Argentina, que fueron apoyadas y financiadas por el Reino Unido. Paraguay, con aproximadamente 1.300.000 habitantes antes de la guerra, fue reducida a unos 221.000 luego de ella (Censo de 1871), de los que solamente unos 28.000 eran hombres. Francisco Solano López cayó muerto en el Combate de Cerro Corá y las tropas brasileñas ocuparon el país hasta 1874. Paraguay perdió gran parte de su territorio $\left(169.174 \mathrm{~km}^{2}\right)$ y fue obligado a pagar una abultada indemnización de guerra.

Sucesivas desmembraciones territoriales fueron reduciendo este vasto territorio a partir de los Tratados de Tordesillas y de San Ildefonso; la secesión de 1617 que aisló al Paraguay; la Guerra contra la Triple Alianza a cuyas resultas perdió el Chaco Central entre el Pilcomayo y el Bermejo y Misiones por el Tratado Irigoyen-Machain a favor de Argentina; y al norte el Matto Grosso que se adjudicó el Brasil por el Tratado Cotegipe-Loizaga, en virtud del reparto pactado en el inicuo Tratado Secreto de la Triple Alianza que definió la liquidación del Paraguay. Y la última, de más de $31.000 \mathrm{~K} 2$ rica en recursos naturales, sufrida a favor de Bolivia en una guerra victoriosa de las armas paraguayas. Es así como la Provincia Gigante quedó reducida a la superficie actual del Paraguay. (Reverchon, 2009: 2)

Ya antes del inicio de la 'Gran Guerra', se había interrumpido el tráfico de intercambio comercial con el Brasil. En el área de estudio, Encarnación de Itapúa entró en un periodo de absoluta decadencia y, junto con ella, cesó la ocupación de los antiguos pueblos misioneros por los paraguayos (Levinton, 2007: 97). Gran parte de los encarnacenos, se sumaron al frente de operaciones en el Ñeembucú y el resto de la población procedió a un doloroso éxodo como lo estaban haciendo los pobladores de $\mathrm{Ne}$ embucú y Misiones por orden del Gral. López. Numerosas casas quedaron abandonadas al no regresar sus propietarios y la Villa parecía muerta (Reverchón, 2009: 13).

Tras la Guerra, Paraguay había quedado devastado. La educación pública gratuita y las llamadas 'estancias de la patria', que suministraban alimentos a la población, desaparecieron. También se perdería el Paraguay pujante, la industria con talleres propios para astilleros de barcos y el primer ferrocarril de Sudamérica (Levinton, 2010: 87), que junto a la línea de telégrafos, fueron confiscados como medio de pago a la deuda de guerra. Pero, hacia fines del siglo XIX y a comienzos del siglo XX, comenzó la inmigración europea, que le imprimió a Asunción un importante cambio en su fisonomía urbana, volviéndose a reconfigurar una época de prosperidad.

En Encarnación, durante los largos y penosos años de recuperación de este período bélico, la explotación yerbatera y maderera apuntaló su economía, hasta que se le sumó el desarrollo de la agricultura y de la industria (Reverchón, 2009: 14). 
"A la postrimería del siglo XIX era una villa desaliñada, con calles surcadas por la erosión efecto de las aguas en su topografia irregular, con las secuelas de su largo abandono.

[...] La Junta Superior Gubernativa de la Villa tenía a su cargo la limpieza y el arreglo de los caminos, a mano de los obreros con palas y picos. No existían maquinarias viales todavía. El primer alumbrado público lo constituyeron faroles a petróleo que se colgaban por postes en las calles principales. El farolero los encendía al ocaso y los apagaba al amanecer. Los vehículos de transporte eran carretas para carga, y más livianos para las personas. El río Paraná era el Nilo Itapuense: toda la vida productiva dependia de sus corrientes por donde circulaban embarcaciones con los productos de la tierra y las personas.

No existían hospitales. El único médico contratado era de Asunción, y mientras duraba el contrato no podía abandonar la Villa. Los arroyos Mboi Caé y Quiteria se cruzaban sobre balsas precarias.

En 1886 se creó el Colegio Nacional que siempre funcionó en el local actual del Colegio Carlos Antonio López, frente a la Plaza de Armas. Se clausuró en 1904 a causa de una epidemia de gripe. Se restauró en 1956 y sirvió de base al Centro Regional de Educación de Encarnación. Allí se formaron Juan León Mallorquín, Tomás Romero Pereira, y fugazmente paso por sus aulas Eligio Ayala.

En la segunda década de los 1900 llegaron a Villa Encarnación las vías del Ferrocarril, enriqueciendo las comunicaciones y los medios de transporte, con un servicio de telégrafo que funcionaba en la Estación en horario diurno." (Delvalle, 1998: 34 y sgts.)

Fotos $N^{\circ} 1$ a 4: Encarnación hacia fines del siglo XIX

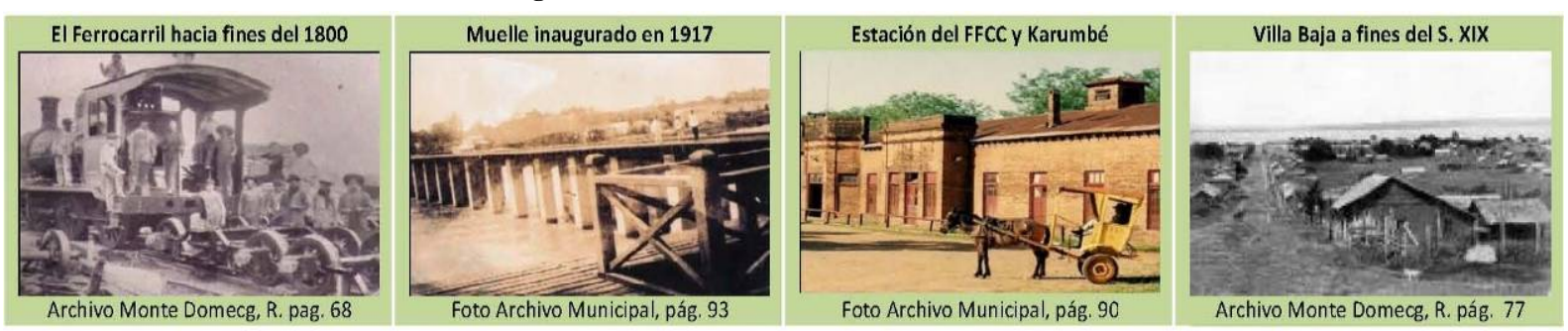

Fuente: Arrúa, 2009

En este período de pos-guerra Encarnación quedó supeditada a los cambios que se estaban produciendo en la margen argentina, donde las actividades económicas incentivaron cierto movimiento en Trincheras de San José (actual Posadas), que poco a poco, pasó a convertirse en una ciudad-puerto y también, en Ituzaingó, Monteagudo, Santa Ana, Puerto Grande y Puerto Goyena (Levinton, 2007: 115). Quizás por ello, durante largo tiempo se discutió en el Congreso Nacional Argentino, con relación a si las tierras misioneras correspondían a la Nación o a la provincia de Corrientes.

Posadas fue establecida con rango de municipio el 18 de octubre de1872 (Etorena / Freaza, 2010: 11), mientras que la Ley de Federalización de Misiones quedó aprobada recién el 22 de diciembre de 1881 y por Decreto del Poder Ejecutivo, el Coronel Rudecindo Roca fue nombrado gobernador.

“[...] La conformación del Territorio Nacional de Misiones significó la definición institucional de un espacio que se había mantenido largo tiempo con un carácter políticamente indefinido. Este espacio debía ser organizado. [...] El límite establecido entre Corrientes y Misiones dejó a Ituzaingó como población correntina, pero ésta, de cualquier manera, siempre tuvo una fuerte vinculación con Trinchera de San José (Posadas), que se convirtió, después de un tiempo, en la capital del Territorio Nacional de Misiones" (Levinton, 2007: 129)

Si bien había entusiasmo por las riquezas tan mentadas de Misiones, su desarrollo fue lento y difícil. No había caminos, faltaban puentes y transportes. La poca población era de origen criollo (brasile- 
ños, correntinos, misioneros y paraguayos) y la mayor parte de las tierras habían sido vendidas en grandes extensiones por el gobierno de Corrientes (Levinton, 2007: 118).

"La creación del Territorio Nacional de Misiones en el año 1881 puso en escena los primeros proyectos de colonización oficial y puso también en el escenario a un integrante: el inmigrante europeo o el inmigrante paraguayo y brasileño descendiente de inmigrantes europeos.

[...] Al mimo tiempo, los programas de colonización oficial imponían arbitrariamente sobre el espacio geográfico un modelo de ocupación del suelo [a través de la mensura en 'damero'] que destruía el modelo de ocupación proveniente del periodo reduccional vigente hasta ese momento." (Snihur, 2007: 232)

$\mathrm{Al}$ igual que en el periodo misionero, el río Paraná, a pesar de todo, seguía siendo la posibilidad más importante de intercambio para la región, pero el territorio, tanto en la margen argentina como paraguaya, de accidentada geografía, plagado de cursos de agua y carente de infraestructura, resultaba complicado para el progreso. La topografía fue impedimento para disponer el trazado de vías ferroviarias por la totalidad del territorio misionero argentino. En dicho Territorio Nacional, hacia 1895, había 16.334 habitantes argentinos y 16.829 extranjeros. Posadas era una localidad poco desarrollada y con pequeños asentamientos en su entorno dedicados a la actividad agrícola. (Levinton, 2007: 132 a 137).

Hacia 1918, se construyó un muelle en Encarnación, que mejoró el tráfico con la actual Posadas, que por entonces, era el principal mercado de frutos y la proveedora de productos industrializados.

"[...] El 20 de septiembre de 1926, antes de cumplir 10 años de uso, un terrible ciclón arrasó el muelle [...] El ciclón convirtió en ruinas la parte baja de Villa Encarnación, y produjo el deceso de más de 300 personas, quedando la sociedad con heridas que demoraron en cicatrizar [... que] perdura en la memoria colectiva de la sociedad encarnacena, así como la solidaria y fraternal ayuda de los posadeños, tanto que el Municipio nominó una calle con el nombre de Posadas." (Reverchón, 2009: 15)

Fotos $N^{\circ} 5$ a 8: Encarnación a inicios del siglo XX

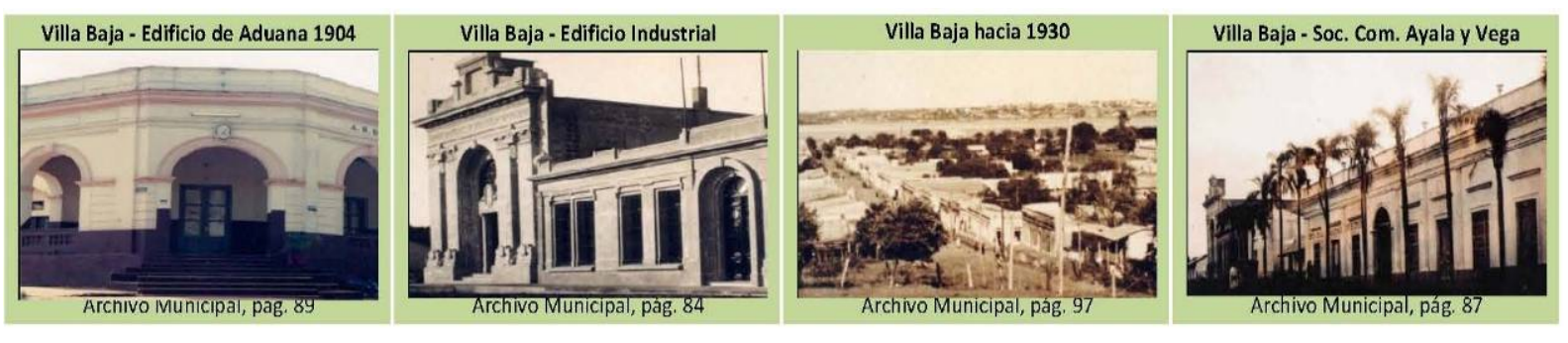

Fuente: Arrúa, 2009

El análisis de los acontecimientos históricos, vinculado a la conformación de las actuales ciudades en los territorios nacionales en formación, nos permite afirmar, coincidiendo con Levinton, que:

"[...] las trazas de los pueblos- ciudades y de las aldeas-capillas de la época jesuítica-guaraní fueron utilizadas por las diferentes políticas de reorganización del territorio misionero, tanto por los paraguayos como por los correntinos." (Levinton, 2007: 120) ${ }^{64}$

\footnotetext{
${ }^{64}$ Según Levinton, esto estuvo determinado por la localización estratégica de cada emplazamiento, con relación a la altitud respecto de su área circundante, así como a la íntima relación que tenían con los ríos y arroyos, los caminos construidos para su interconexión y la proximidad a los yerbales.
} 


\section{II.2. LA REGIÓN HOY: La Cuenca del Plata y los Proyectos Hidroeléctricos}

Para poder comprender acabadamente la situación actual de la Región Histórica o Región Cultural (ver parágrafo II.1) como área de estudio, nos resulta necesario volver la mirada hacia la escala regional, representada por la Cuenca del Plata. Esta Cuenca abarca un territorio de más de 3 millones de $\mathrm{Km}^{2}$, que por el caudal de los ríos que desaguan en el Río de la Plata constituye una de las reservas hídricas más importantes del planeta, representando además, un vasto sistema de alta diversidad biológica, determinada por la riqueza de los territorios que éstos bañan.

A los efectos del aprovechamiento de esos recursos, los Gobiernos de Argentina, Bolivia, Brasil, Paraguay y Uruguay, firmaron el Tratado de la Cuenca del Plata, que fue suscripto en Brasilia el 23 de abril de 1969, en circunstancias políticas regionales y universales muy diferentes de las actuales. Este Tratado, es considerado como 'la piedra angular' de la integración física regional, y precursor, en materia de preservación del ambiente y en la generación de una red infraestructural y de comunicaciones acordes con lo que, más de dos décadas después, sería el Mercosur.

Los instrumentos internacionales que derivaron de él, crearon y dieron funciones y competencia a distintos órganos u organismos del sistema, entre otros: Reunión de Cancilleres; Comité Intergubernamental Coordinador de los Países de la Cuenca del Plata (CIC); FONPLATA; Comité de la Hidrovía Paraná-Paraguay; Acuífero Guaraní; Comisiones hídricas bi y trinacionales.

El Tratado expresa la necesidad de aunar esfuerzos, con espíritu de cooperación y solidaridad, para lograr los propósitos señalados en la Declaración Conjunta de Buenos Aires del 27 febrero de 1967 y en el Acta de Santa Cruz de la Sierra del 20 de mayo de 1968, a partir de la acción mancomunada y la institucionalización del Sistema de la Cuenca del Plata, con el objeto de promover el desarrollo armónico y la integración física de la Cuenca y de sus áreas de influencia directa y ponderable.

Parágrafo Único: A tal fin, promoverán en el ámbito de la Cuenca, la identificación de áreas de interés común y la realización de estudios, programas y obras, así como la formulación de entendimientos operativos e instrumentos jurídicos que estimen necesarios y que propendan a:

a) La facilitación y asistencia en materia de navegación.

b) La utilización racional del recurso agua, especialmente a través de la regulación de los cursos de agua y su aprovechamiento múltiple y equitativo.

c) La preservación y el fomento de la vida animal y vegetal.

d) El perfeccionamiento de las interconexiones viales, ferroviarias, fluviales, aéreas, eléctricas, $y$ de telecomunicaciones.

e) La complementación regional mediante la promoción y radicación de industrias de interés para el desarrollo de la Cuenca.

f) La complementación económica del área limitrofe.

g) La Cooperación mutua en materia de educación, sanidad y lucha contra las enfermedades.

h) La Promoción de otros proyectos de interés común y en especial aquellos que tengan relación con el inventario, evaluación y el aprovechamiento de los recursos naturales del área.

i) El conocimiento integral de la Cuenca del Plata.

(Tratado de la Cuenca del Plata, 1969: 1) 


\section{II.2.1. La Cuenca del Plata ${ }^{65}$}

"Desde un punto de vista hidrográfico una cuenca es el área que tiene una salida única para su escorrentía superficial (UNESCO / OMM, 1992). Se trata de una región geográfica conformada alrededor del río, el emisario, como columna vertebral del sistema" (CICPlata, 2009: 1).

La cuenca del río de la Plata se abre en forma de abanico a partir de la desembocadura, abarcando gran parte del S, SE y centro-oeste de Brasil; el SO de Bolivia; gran parte de Uruguay; todo el Paraguay y casi todo el N, la mesopotamia y la pampa húmeda de la Argentina.

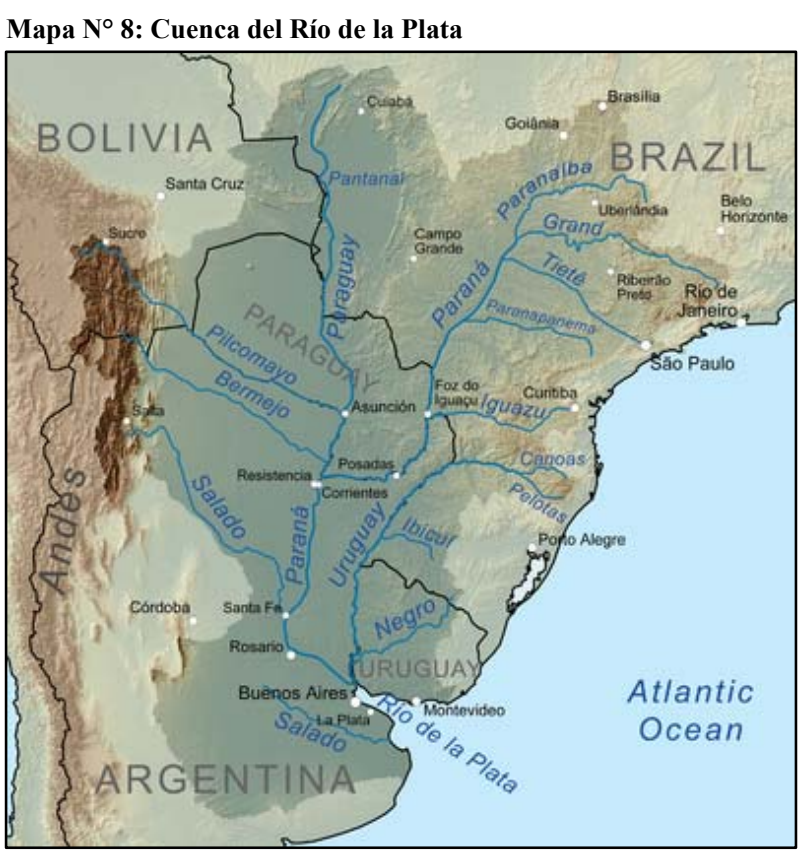

Fuente: CIC/Plata
La Cuenca del Plata es una de las más extensas del mundo con una superficie aproximada de $3.100 .000 \mathrm{~km}^{2}$, equivalente al $17 \%$ de la superficie de América del Sur. Por su extensión es la segunda después de la amazónica en esta parte del continente y constituye el área donde se concentra una importante actividad económica y la mayor densidad de población. La mayor parte de esta área de drenaje se encuentra en Brasil, donde alcanza $1.415 .000 \mathrm{~km}^{2}$, luego le sigue la Argentina, $920.000 \mathrm{~km}^{2}$, Paraguay, $410.000 \mathrm{~km}^{2}$, Bolivia, $205.000 \mathrm{~km}^{2}$ y Uruguay $150.000 \mathrm{~km}^{2}$.

El sistema hidrográfico del río de la Plata está formado por tres grandes sistemas hídricos: el Paraná, el Paraguay y el Uruguay, además del río de la Plata propiamente dicho al que vierten sus aguas algunos ríos menores. El Paraguay es afluente del Paraná, mientras que éste último se une con el Uruguay para formar el río de la Plata. Las áreas de drenaje de cada uno de ellos conforman las principales subcuencas del sistema, algunas de extensión considerable: río Paraná, $1.510 .000 \mathrm{~km}^{2}$; río Paraguay, $1.095 .000 \mathrm{~km}^{2}$; río Uruguay, $365.000 \mathrm{~km}^{2}$ y el propio río de la Plata, $130.000 \mathrm{~km}^{2}$

La región abarca desde el altiplano de Bolivia al Océano Atlántico y desde la Chapada de Parecís en el planalto, que la separa de la hoya amazónica, hasta el Atlántico, entre los paralelos $14^{\circ}$ y $38^{\circ} \mathrm{Sur}$ y los meridianos $67^{\circ}$ y $43^{\circ} 30^{\prime}$ Oeste, lo que permite advertir que existe una gran variación de características y condiciones físicas y ambientales, además de factores culturales, económicos y sociales que operan en estrecha interrelación con aquellos.

${ }^{65}$ Sintetizado conceptualmente de CIC, 1998: 3-2 a 3-7 y de http://www.cicplata.org/. 


\section{II.2.1.1. Relieve}

Desde el punto de vista del relieve sobresale el claro predominio de las llanuras, dónde se pueden considerar a grandes rasgos, dos estructuras dispuestas de $\mathrm{N}$ a S: por el E se encuentra el macizo matogrosense algo deprimido en su parte NO y al O la llanura pampeano-chaqueña, una vasta región casi plana. En medio de ambas, el umbral central, que incluye el Pantanal. El relieve con alturas más importantes se encuentra en los bordes, a lo largo del borde oriental hay un cinturón orogénico rico en yacimientos minerales y en el occidental, las sierras pampeanas y andinas.

\section{II.2.1.2. Clima}

De forma muy general se puede decir que las mayores lluvias coinciden con las nacientes de los ríos Paraguay, Paraná y Uruguay y que el registro medio anual de las precipitaciones decrece de $\mathrm{N}$ a $\mathrm{S}$ y de E a O. Las temperaturas están influidas tanto por la latitud como por el relieve, disminuyendo de N a S. El trópico de Capricornio atraviesa la cuenca desde la ciudad de São Paulo en Brasil hasta la provincia de Jujuy en la Argentina, con lo que el 40\% pertenece al cinturón tropical. En la mayor parte de la cuenca las temperaturas anuales suelen ser de más de $20^{\circ} \mathrm{C}$.

\section{II.2.1.3. Suelos}

Desde el punto de vista edáfico, la Cuenca del Plata concentra la mayor parte de los suelos con mejor capacidad de producción en América del Sur. No sólo en cuanto a la extensión actualmente en uso, sino porque muchas áreas se pueden incorporar o aumentar en su rendimiento agrícola-ganadero con el empleo de técnicas de manejo adecuadas.

\section{II.2.1.4. Recursos Naturales}

La vegetación ha constituido la base económica para el desarrollo de la región. Las grandes extensiones de pastos naturales fueron la base de la producción agropecuaria en la Argentina y Uruguay.

Los recursos forestales son importantes en el área que comprende el S de Brasil, el E del Paraguay y el NE de la Argentina, donde no sólo son más ricos sino también más explotados. Hay, además, grandes áreas en Paraguay, el oriente de Bolivia y el oeste de Brasil donde la magnitud de las posibilidades de aprovechamiento todavía no está bien determinada. La presión de la búsqueda de nuevas tierras para la agricultura, la demanda de ciertos tipos de madera, las prácticas de desmonte y quema de la vegetación han sido causa de un agudo problema de deforestación. Todos los países de la cuenca han hecho estudios en plantaciones forestales y han encarado programas de reforestación.

La producción mineral ocupa un lugar importante entre las actividades económicas de los países de la región, aunque no es un área altamente productora de minerales. Bolivia, si bien tiene dentro de la cuenca poca extensión de territorio, tiene depósitos de hierro y manganeso muy cerca de Puerto Suárez. En los bordes de la franja andina existen reservas importantes de gas y petróleo. Bolivia y la 
Argentina producen la mayor cantidad de petróleo de la región, a lo que se sumará Brasil a partir de la explotación de la nueva cuenca petrolera atlántica. En las serranías costeras de Brasil abundan además, el hierro y el carbón, y si bien algunas de las zonas más importantes quedan fuera de sus límites, de todos modos se produce una gran cantidad de minerales, que proporcionan una importante cantidad de materia prima para la industria local.

\section{II.2.2. La Cuenca del Paraná}

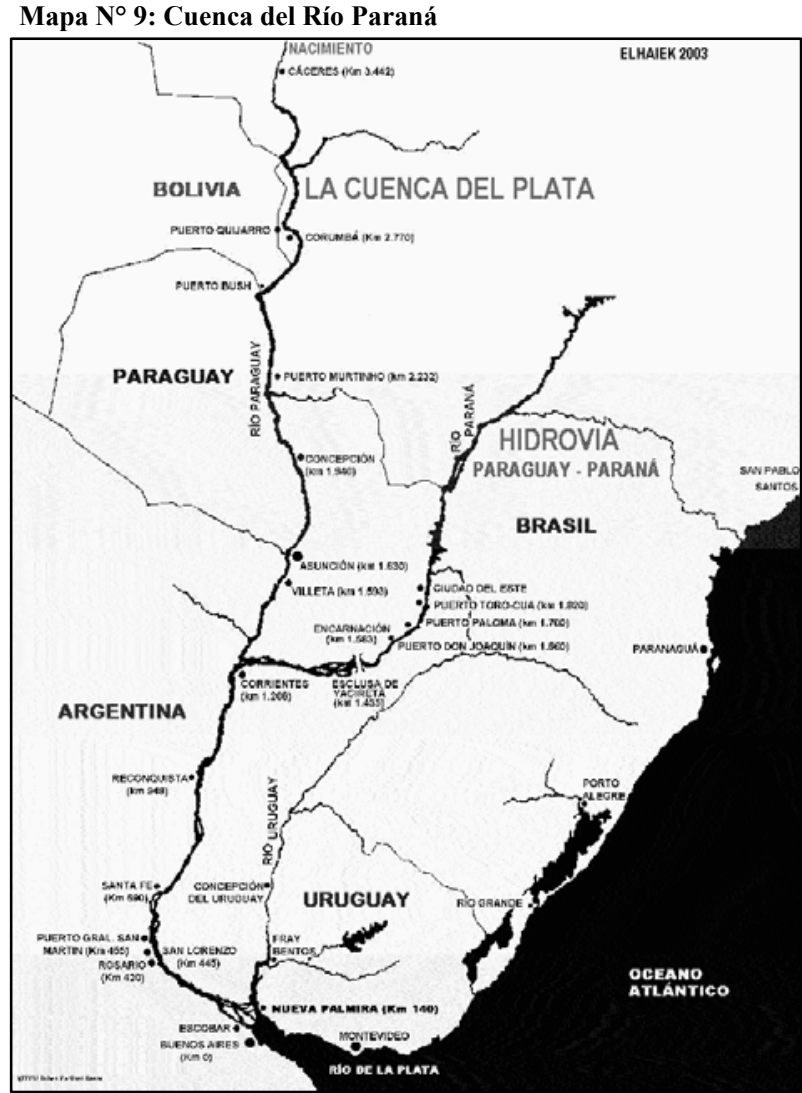

Fuente: Entidad Binacional Yacyretá.
Como se desprende de lo señalado en el acápite anterior, la cuenca del río Paraná con $1.510 .000 \mathrm{~km}^{2}$ es la de mayor superficie de la Cuenca del Plata y es a la vez, el curso más largo de dicha Cuenca, con $2.570 \mathrm{Km}$., que si se le suman los $1.200 \mathrm{Km}$. del río Paranaiba, alcanza una longitud total de $3.740 \mathrm{Km}$. de extensión. El Paraná, se encuentra también, en el noveno lugar entre los ríos que aportan su caudal a los océanos, con una descarga promedio de $14.900 \mathrm{~m}^{3} / \mathrm{fs}$. (metros cúbicos por segundo).

El río Paraná nace en Brasil, entre los estados de Minas Gerais y San Pablo, por la confluencia de los ríos Paranaíba y Grande, a los cuales aportan también otros afluentes como el Tieté, Pardo, Iguazú y Paranapanema.

Este río posee una notoria uniformidad desde el punto de vista hidrológico en gran parte del tramo que se extiende desde los Saltos de Guayrá hasta Confluencia. No obstante, los rasgos hidrológicos del Alto Paraná cambian aguas abajo a partir de los Saltos de Apipé, adoptando gradualmente las características que definen a los tramos medio e inferior como un río típico de llanura, de fondo suelto y fangoso, aguas más lentas y turbias, varios brazos y formación de islas bajas.

En su conjunto, la cuenca del Paraná representa un área de gran importancia para la vida silvestre (acuática y fauna y flora asociada) y se caracteriza por ser utilizada para la generación de hidroelectricidad. En el área de influencia directa de Yacyretá, desde su confluencia con el río Paraguay hasta la presa de Itaipú, el agua del Paraná se emplea para provisión de agua potable, fuente para la industria, riego, transporte hidrovial (materias primas y productos elaborados) y recreación (balnearios, pesca y 
náutica deportiva). Estas actividades, determinan que la misma sea receptora de efluentes industriales, urbanos y agrícolas.

Por la conjunción de estos factores, desde su nacimiento hasta su desembocadura, pueden diferenciarse tres tramos, denominados: 1) Superior o Alto Paraná (1.550 Km.); 2) Paraná Medio (722 Km.); 3) Paraná Inferior o Delta (298 Km).

\section{II.2.2.1. El Curso Superior o Alto Paraná}

Comprende los primeros $1.550 \mathrm{Km}$. del río, desde su nacimiento hasta la confluencia con el río Paraguay. En este trayecto atraviesa el macizo de Brasilia, por lo que es un río de meseta, que discurre sobre un lecho rocoso, entre barrancas que se van distanciando progresivamente entre sí. En épocas pasadas presentaba gran cantidad de saltos de agua y rápidos que han sido aprovechados, principalmente por el Brasil, para construir embalses y represas. En este tramo, sus principales afluentes son los ríos Verde, Pardo, Ivinhema y Monday, en su margen derecha y Tieté, Paranapanema, Ivaí, Piquirí e Iguazú, por la margen izquierda.

La parte brasileña de este tramo, es la más modificada por la acción del hombre, dónde la vegetación subtropical circundante ha sido reemplazada por campos dedicados a la agricultura y la cría de ganado y su valle de inundación, sumergido bajo los embalses de unas 60 represas hidroeléctricas. A partir del tramo, dónde el río se convierte en límite entre Brasil y Paraguay, y se localiza Itaipú, sobre los Saltos del Guayrá, se denomina Alto Paraná Encajonado: En la parte final de este tramo, cuando el río es límite entre Argentina y Paraguay, es dónde se localiza Yacyretá, sobre los Saltos del Apipé.

Fotos No 9 a 12: Curso Superior o Alto Paraná

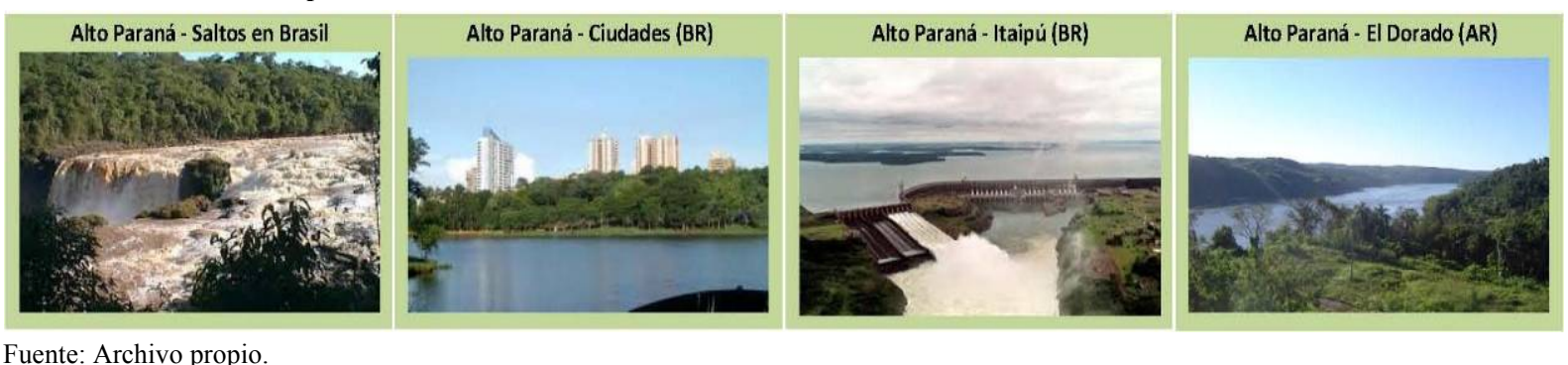

Aguas abajo de la represa de Yacyretá el río presenta una dirección hacia el oeste, ensanchándose progresivamente y ramificándose en varios canales que forman una gran cantidad de islas fluviales hasta unirse con el río Paraguay, frente a Paso de la Patria (Provincia de Corrientes, Argentina).

\section{II.2.2.2. EI Paraná Medio}

El curso medio del Paraná, o Paraná Medio, comprende unos 722 kilómetros desde la confluencia con el río Paraguay al Norte, hasta la ciudad de Diamante al Sur, donde comienza el predelta. Los principales afluentes de este tramo, son los ríos Santa Lucía, Corrientes y Guayquiraró, sobre la margen izquierda y Paraguay, Negro y Salado sobre la margen izquierda. 
Al unirse con el Paraguay, el curso del río gira bruscamente hacia el sur, a lo largo de una falla geológica ocupada por un ancho valle de inundación, convirtiéndose en un río de llanura con gran cantidad de meandros, islas fluviales y bancos de arena. En este tramo, el río es de curso lento, sobre un lecho limoso y sus aguas transportan gran cantidad de sedimentos provenientes de las estribaciones andinas fuertemente erosionadas por los ríos Bermejo, Pilcomayo y sus tributarios.

\section{Fotos $N^{\circ} 13$ a 16: Paraná Medio}
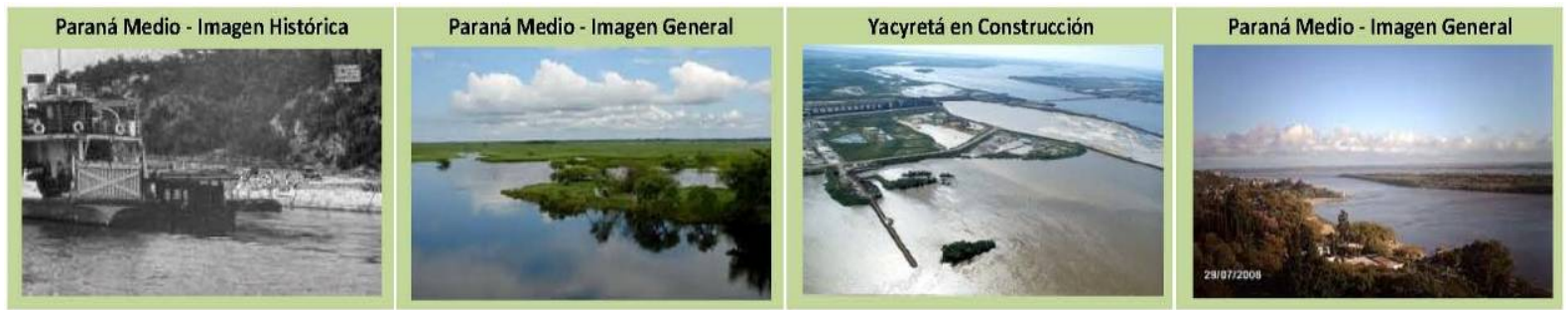

Fuente: Archivo propio.

El valle de inundación está limitado por barrancas en la margen izquierda, mientras que en la margen derecha, sus costas son bajas y anegadizas con numerosos riachos y lagunas que se inundan en época de crecientes. A partir de la ciudad de Santa Fe (Argentina), la margen barrancosa es la derecha y la baja y anegadiza, la izquierda, en territorio de la Provincia de Entre Ríos (Argentina).

\section{II.2.2.3. El Paraná Inferior o Delta}

El curso inferior del río Paraná tiene una extensión de 298 kilómetros, desde la ciudad de Diamante hasta su desembocadura en el río de la Plata.

El río sigue una dirección E-SE y su valle comprende el Predelta y Delta del Paraná (antiguamente llamado por sus pobladores originarios Carapachay, denominación que ha quedado para algunos brazos), dividiéndose en varios brazos principales: Paraná Pavón, Paraná Ibicuy, Paraná Miní, Paraná Bravo, Paraná Guazú y Paraná de las Palmas; así como en varios riachos menores que forman islas como la de las Lechiguanas.

\section{Fotos $N^{\circ} 17$ a 20: Paraná Inferior o Delta del Paraná}
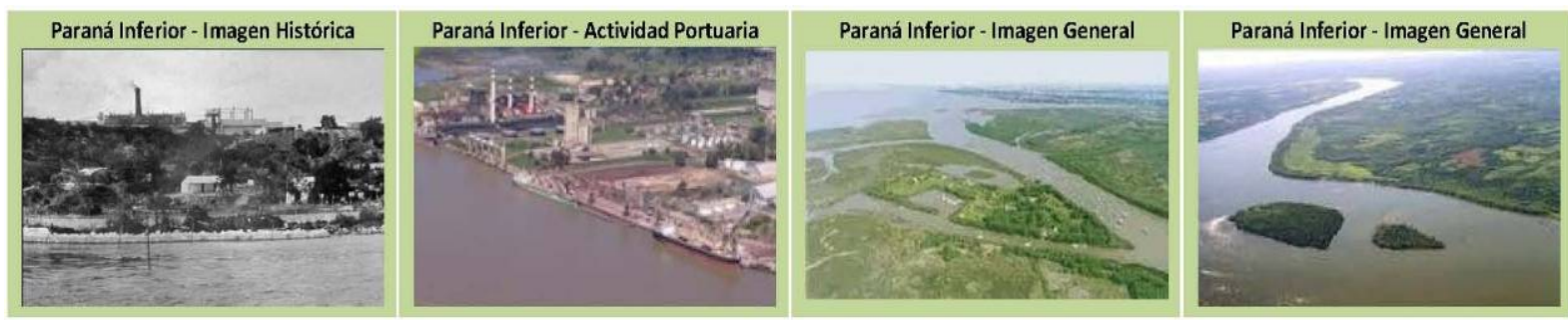

Fuente: Archivo propio.

Este tramo se corresponde con la zona más poblada y desarrollada económicamente de la Argentina, por lo que en sus riberas se encuentran gran cantidad de puertos y áreas industriales, siendo además el tramo con mayor navegación fluvial, por lo que se requiere un dragado constante del mismo. Los principales afluentes de este tramo, son los ríos Carcarañá y Luján, sobre la margen derecha y los ríos Victoria y Gualeguay., sobre la margen izquierda. 


\section{II.2.3. Aprovechamiento Hidroeléctrico de la Cuenca del Plata}

Las represas construidas en la Cuenca del Plata, abarca a la del Río Paraná y sus formadores (Paranaiba y Grande) y afluentes (Tieté, Paraná Panema e Iguazú) y a la Cuenca del Río Uruguay, que involucra a los países de Brasil, Argentina, Paraguay y Uruguay, aunque los emprendimientos hidroeléctricos han sido desarrollados principalmente por iniciativa de los dos primeros países.

Brasil posee el más amplio esquema de represamientos que se conoce en el mundo. En esta Cuenca existen 54 emprendimientos hidroeléctricos construidos y 5 en planificación.

Sobre la Cuenca del Paraná, hay un total de cuarenta (47) represas:

(5), sobre el río Paranaíba: Cachoeira Dourada, São Simão, Itumbiara, Embarcação y Cachoeira do Sertão;

(12), sobre el rio Grande: Água Vermelha, Volta Grande, Marimbondo, Porto Colômbia, Igarapava, Jaguará, Estreito, Peixoto, Furnas, Itutinga, Camargo, Salinas de Oliveira y Euclides da Cunha;

(6), sobre el rio Tietê: Nova Avanhandava, Três Irmãos, Promissão, Ibitinga, Bariri y Barra Bonita;

(6), sobre el rio Paranapanema: Capivara, Taquaruçu, Salto Grande, Rosana, Xavantes y Jurumirin;

(5), sobre el rio Iguaçu: Salto Osório, Salto Santiago, Salto Segredo, Foz de Areia y Salto Caxias;

(1), sobre el río Canoas: Campos Novos;

(4), sobre el río Para: Ilha Solteira, Jupiá, Itaipú (con Paraguay) y Puerto Primavera.

En tanto, que sobre el río Uruguay, hay cuatro (4) construidas: Itá, Machadinho, Passo Fundo y Barra Grande y quince (15) en planificación: San José, San Juan, Itapiranga, Pai Quere, Monjolinho, San Roque, Garibaldi, Chapecozinho, Santo Domingo, Perry, Nova Erechim y Passo da Cadeira, y las binacionales Garabí, Roncador y San Pedro (con Argentina).

Paraguay, posee tres represas: Acaray, sobre el río homónimo y las binacionales Itaipú (con Brasil) y Yacyretá (con Argentina), ambas sobre el Paraná.

Uruguay, posee cuatro represamientos: Gabriel Terra, Rincón de Baygorria y Constitución, sobre el río Negro y la binacional Salto Grande con Argentina, sobre el río Uruguay.

Argentina, posee dos represas binacionales: Yacyretá, con Paraguay sobre el Paraná, y Salto Grande, con Uruguay sobre el río homónimo; con otras cinco planificadas: dos sobre el Paraná: Aña Cuá y Corpus Cristi; y tres sobre el Uruguay: Garabi y Roncador, cerca de Garruchos (Corrientes) y San Pedro, cerca de Monte Caseros (Corrientes), las tres con Brasil. 
Cuadro N$^{\circ}$ 3: APROVECHAMIENTOS HIDROELÉCTRICOS EN LA CUENCA DEL PLATA

\begin{tabular}{|c|c|c|c|c|c|c|}
\hline \multirow[t]{2}{*}{$\mathrm{N}^{\circ}$} & \multirow{2}{*}{$\begin{array}{c}\text { NOMBRE DEL } \\
\text { APROVECHAMIENTO }\end{array}$} & \multirow[t]{2}{*}{$\mathrm{RIO}$} & \multirow[t]{2}{*}{ PAÍs } & \multirow[t]{2}{*}{ OPERADOR } & \multirow{2}{*}{$\begin{array}{c}\text { ALTURA } \\
\text { PRESA } \\
(\mathrm{m})\end{array}$} & \multirow{2}{*}{$\begin{array}{l}\text { VOLUMEN } \\
\text { EMBALSE } \\
(\mathrm{hm} 3)\end{array}$} \\
\hline & & & & & & \\
\hline 1 & URUGUA-I & URUGUA-I & ARGENTINA & EMSA & 90 & 1.193 \\
\hline 2 & YACYRETA & PARANA & ARGENTINA / PARAGUAY & EBY & 43 & 21.000 \\
\hline 3 & SALTO GRANDE & URUGUAY & ARGENTINA / URUGUAY & CTMSG & 65 & 5.500 \\
\hline 4 & MIRANDA & ARAGUARI & BRASIL & CEMIG & & \\
\hline 5 & NOVA PONTE & ARAGUARI & BRASIL & CEMIG & & 8.000 \\
\hline 6 & CAMPOS NOVOS & CANOAS & BRASIL & & & \\
\hline 7 & FOZ DO CHOPIM & CHOPIM & BRASIL & ELETROSUL & & \\
\hline 8 & CORUMBA & CORUMBA & BRASIL & FURNAS & & \\
\hline 9 & AGUA VERMELHA & GRANDE & BRASIL & CESP & 63 & 11.025 \\
\hline 10 & MARIMBONDO & GRANDE & BRASIL & FURNAS & 94 & 6.150 \\
\hline 11 & PORTO COLOMBIA & GRANDE & BRASIL & FURNAS & 54 & 1.524 \\
\hline 12 & VOLTA GRANDE & GRANDE & BRASIL & CEMIG & 38 & 4 \\
\hline 13 & JAGUARA & GRANDE & BRASIL & CEMIG & 60 & 450 \\
\hline 14 & ESTREITO & GRANDE & BRASIL & FURNAS & 92 & 1.400 \\
\hline 15 & PEIXOTO & GRANDE & BRASIL & FURNAS & 72 & 4.020 \\
\hline 16 & FURNAS & GRANDE & BRASIL & FURNAS & 127 & 22.950 \\
\hline 17 & ITUTINGA & GRANDE & BRASIL & FURNAS & 23 & 11 \\
\hline 18 & CAMARGOS & GRANDE & BRASIL & CEMIG & 35 & 792 \\
\hline 19 & SALINAS DE OLIVEIRA & GRANDE & BRASIL & & & \\
\hline 20 & IGERAPAVA & GRANDE & BRASIL & & & \\
\hline 21 & SALTO CAXIAS & IGUAZÚ & BRASIL & COPEL & & \\
\hline 22 & SALTO OSORIO & IGUAZÚ & BRASIL & ELETROSUL & 57 & 1.240 \\
\hline 23 & SALTO SANTIAGO & IGUAZÚ & BRASIL & ELETROSUL & 39 & 6.750 \\
\hline 24 & SEGREDO & IGUAZÚ & BRASIL & COPEL & 150 & 3.000 \\
\hline 25 & FOZ DO AREIA & IGUAZÚ & BRASIL & COPEL & 153 & 7.800 \\
\hline 26 & AMERICANA & JAGUARI & BRASIL & CESP & & \\
\hline 27 & JAGUARI & JAGUARI & BRASIL & CESP & 67 & 1.236 \\
\hline 28 & ILHA SOLTEIRA & PARANA & BRASIL & CESP & 71 & 21.060 \\
\hline 29 & JUPIA & PARANA & BRASIL & CESP & 42 & 3.680 \\
\hline 30 & PORTO PRIMAVERA & PARANA & BRASIL & CESP & 38 & 20.000 \\
\hline 31 & ITAIPU & PARANA & BRASIL / PARAGUAY & ITAIPU & 196 & 29.000 \\
\hline 32 & EMBORCACAO & PARANAIBA & BRASIL & CEMIG & 156 & 17.500 \\
\hline 33 & CACHOEIRA DOURADA & PARANAIBA & BRASIL & CELG & 26 & 470 \\
\hline 34 & CACHOEIRA DO CERTAO & PARANAIBA & BRASIL & & & \\
\hline 35 & ITUMBIARA & PARANAIBA & BRASIL & FURNAS & 106 & 17.030 \\
\hline 36 & SAO SIMAO & PARANAIBA & BRASIL & CEMIG & 127 & 12.540 \\
\hline 37 & ROSANA & PARANAPANEMA & BRASIL & CESP & 53 & 1.920 \\
\hline 38 & TAQUARUCU & PARANAPANEMA & BRASIL & CESP & 32 & 672 \\
\hline 39 & CAPIVARA & PARANAPANEMA & BRASIL & CESP & 60 & 10.540 \\
\hline 40 & SALTO GRANDE & PARANAPANEMA & BRASIL & CESP & 25 & 44 \\
\hline 41 & XAVANTES & PARANAPANEMA & BRASIL & CESP & 89 & 8.800 \\
\hline 42 & JURUMIRIM & PARANAPANEMA & BRASIL & CESP & 35 & 7.000 \\
\hline 43 & MIMOSO & PARDO & BRASIL & CEMAT & 19 & 70 \\
\hline 44 & LIMOEIRO & PARDO (SP) & BRASIL & CESP & 42 & 25 \\
\hline 45 & EUCLIDES DA CUNHA & PARDO (SP) & BRASIL & CESP & 92 & 14 \\
\hline 46 & GRAMINHA & PARDO (SP) & BRASIL & CESP & 60 & 555 \\
\hline 47 & ITUPARARANGA & SOROCABA & BRASIL & ELETROPAULO & 38 & 320 \\
\hline 48 & TRES IRMAOS & TIETE & BRASIL & CESP & 87 & 13.450 \\
\hline 49 & NOVA AVANHANDAVA & TIETE & BRASIL & CESP & & 2.720 \\
\hline 50 & PROMISSAO & TIETE & BRASIL & CESP & 54 & 7.400 \\
\hline 51 & IBITINGA & TIETE & BRASIL & CESP & 32 & 985 \\
\hline 52 & BARIRI & TIETE & BRASIL & CESP & 32 & 542 \\
\hline 53 & BARRA BONITA & TIETE & BRASIL & CESP & 33 & 2.566 \\
\hline 54 & ITA & URUGUAY & BRASIL & ELETROSUL & 103 & \\
\hline 55 & MACHADINHO & URUGUAY & BRASIL & & & \\
\hline 56 & PASSO FUNDO & URUGUAY & BRASIL & & & \\
\hline 57 & BARRA GRANDE & URUGUAY & BRASIL & & & \\
\hline 58 & ACARAY & ACARAY & PARAGUAY & ANDE & 88 & \\
\hline 59 & GABRIEL TERRA & NEGRO & URUGUAY & UTE & 51 & 8.800 \\
\hline 60 & RINCON DE BAYGORRIA & NEGRO & URUGUAY & UTE & 45 & 570 \\
\hline 61 & CONSTITUCIÓN & NEGRO & URUGUAY & UTE & 66 & 2.854 \\
\hline
\end{tabular}

Fuente: Entidad Binacional Yacyretá, CIC, 1998: 4-16. 
MaPa N 10: APROVECHAMIENTOS HIDROELÉCTRICOS EN OPERACIÓN DENTRO DE LA CUENCA DEL PLATA

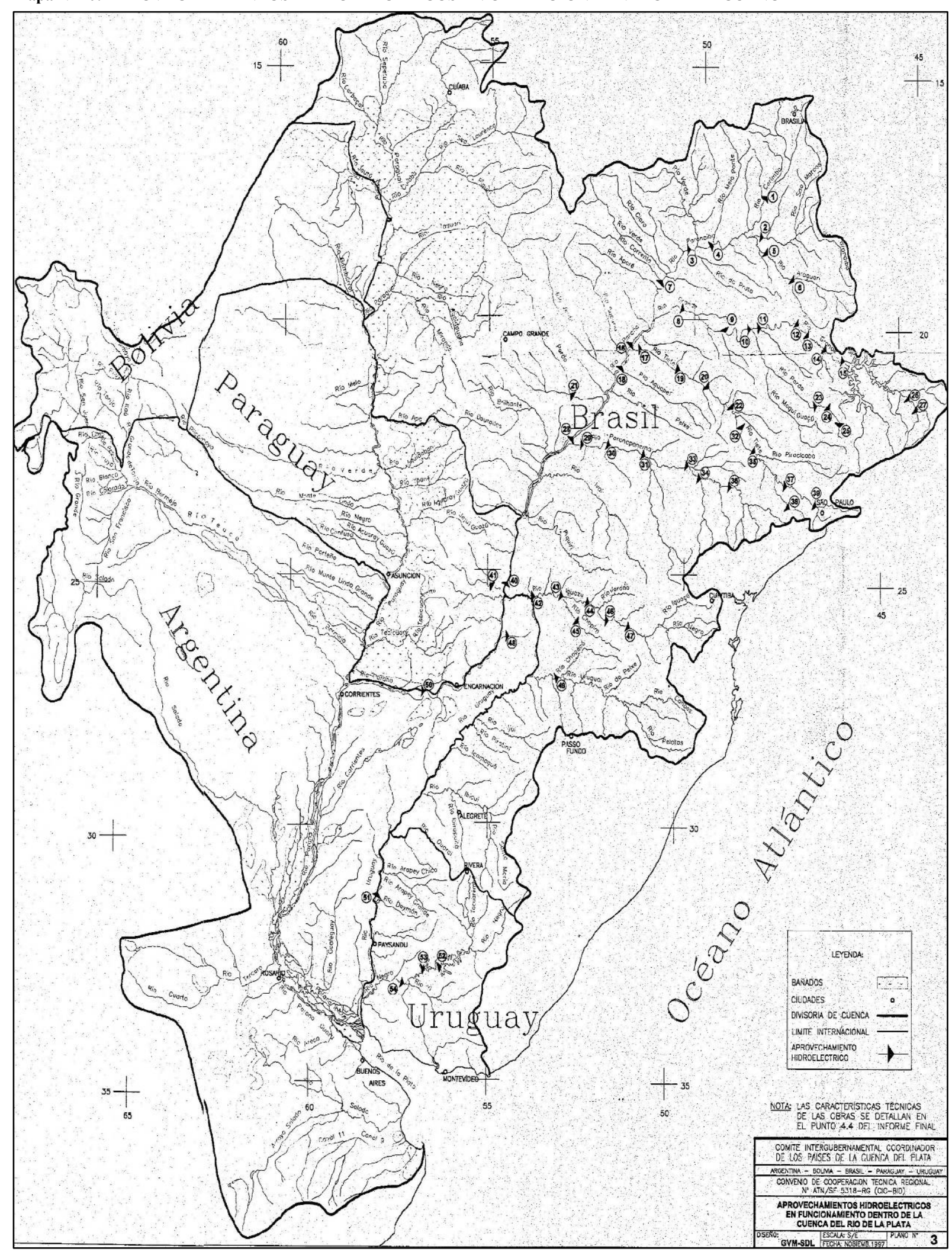

Fuente: Archivo de la Entidad Binacional Yacyretá, CIC, 1998: 4-17.

De este conjunto de represas, además de Yacyretá, algunas de las más significativas, por el tamaño de su embalse y sus consecuentes impactos, se exponen a continuación: 


\section{Represa de Ilha Solteira (Brasil)}

La Represa de Ilha Solteira es la mayor central hidroeléctrica operada por la Companhia Energética de São Paulo (CESP), la mayor del estado de Sao Paulo y la tercera más grande del Brasil. Está localizada sobre el río Paraná, entre los municipios de Ilha Solteira, en Sao Paulo y Solveria, Mato Grosso do Sul. Junto con las represas de Três Irmãos y Jupiá, compone el sexto mayor aprovechamiento hidroeléctrico del mundo, el Complejo Hidroeléctrico de Urubupungá. Su potencia instalada es 3.444 MW y cuenta con 20 turbinas generadoras tipo Francis. La central comenzó a operar en 1978.

Fotos $N^{\circ} 21$ y 22: Represa de Ilha Solteira - Brasil
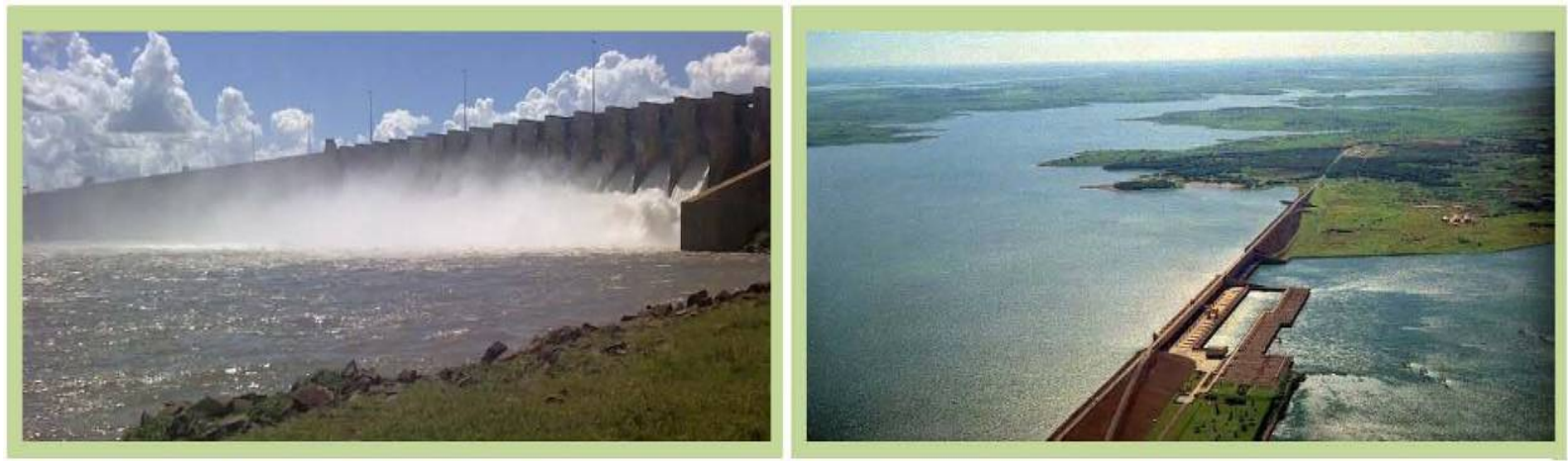

Fuente: Archivo fotográfico de la Entidad Binacional Yacyretá.

Es una central con alto desempeño operacional que, además de producir energía eléctrica, es fundamental para el control de la tensión y la frecuencia del Sistema Energético Interconectado del Brasil. Su presa tiene 5.605 metros de longitud y el embalse que genera ocupa $1.195 \mathrm{~km}^{2}$. El Canal Pereira Barreto, de 9.600 metros de longitud, comunica el embalse de la represa con el de la represa de Três Irmãos, propiciando la producción energética integrada de los 2 aprovechamientos hidroeléctricos.

\section{$\underline{\text { Represa de Três Irmãos (Brasil) }}$}

La Represa de Três Irmãos, está ubicada sobre el rio Tietê, afluente del río Paraná, cerca de la ciudad de Pereira Barreto, estado de São Paulo, Brasil. Cuenta una esclusa que facilita la navegación a lo largo de la Hidrovía Paraná-Tieté.

\section{Fotos $N^{\circ} 23$ y 24: Represa de Três Irmãos - Brasil}
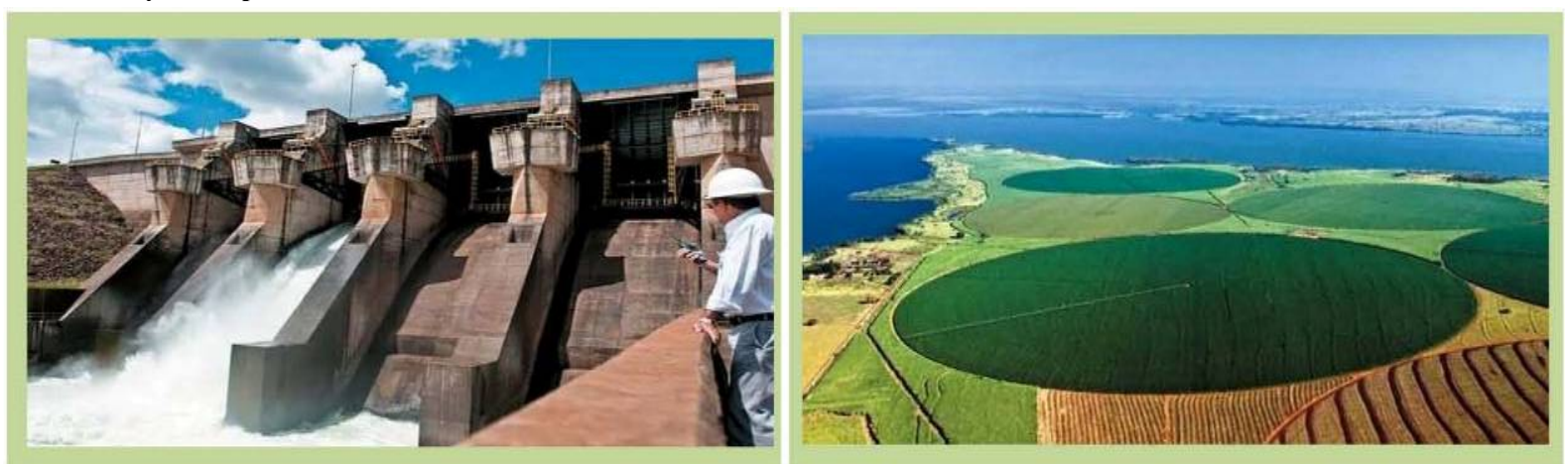

Fuente: Archivo fotográfico de la Entidad Binacional Yacyretá. 
La Central entró en operaciones en 1993, cuenta con 5 turbinas tipo Francis de 161,5 MW cada una, otorgando una potencia total instalada de $807 \mathrm{MW}$. La presa posee 3.640 metros de longitud, formando un embalse de $785 \mathrm{~km}^{2}$ de superficie.

El Canal Pereira Barreto de $9.600 \mathrm{~m}$. de longitud, comunica el embalse de la represa con el de la represa Ilha Solteira, propiciando la producción energética integrada de los dos aprovechamientos hidroeléctricos. Junto con las represas de Ilha Solteira y Jupiá conforma el Complejo Hidroeléctrico de Urubupungá.

\section{$\underline{\text { Represa de Jupiá (Brasil) }}$}

La Represa Engenheiro Sousa Dias (más conocida como Jupiá), está ubicada sobre el río Paraná, en la confluencia de este con el río Sucuriú, entre las ciudades de Tres Lagoas, Mato Grosso do Sul y Castilho, estado de São Paulo. Es la $4^{\circ}$ mayor central hidroeléctrica del Brasil.

La construcción de la represa se inicio a mediados de los '60 y se concluyó en 1974, utilizando tecnología enteramente brasileña. Construida durante la dictadura militar, la represa es bastante eficaz en términos de impacto ambiental y generación eléctrica.

Fotos N²5 y 26: Represa de Jupiá - Brasil

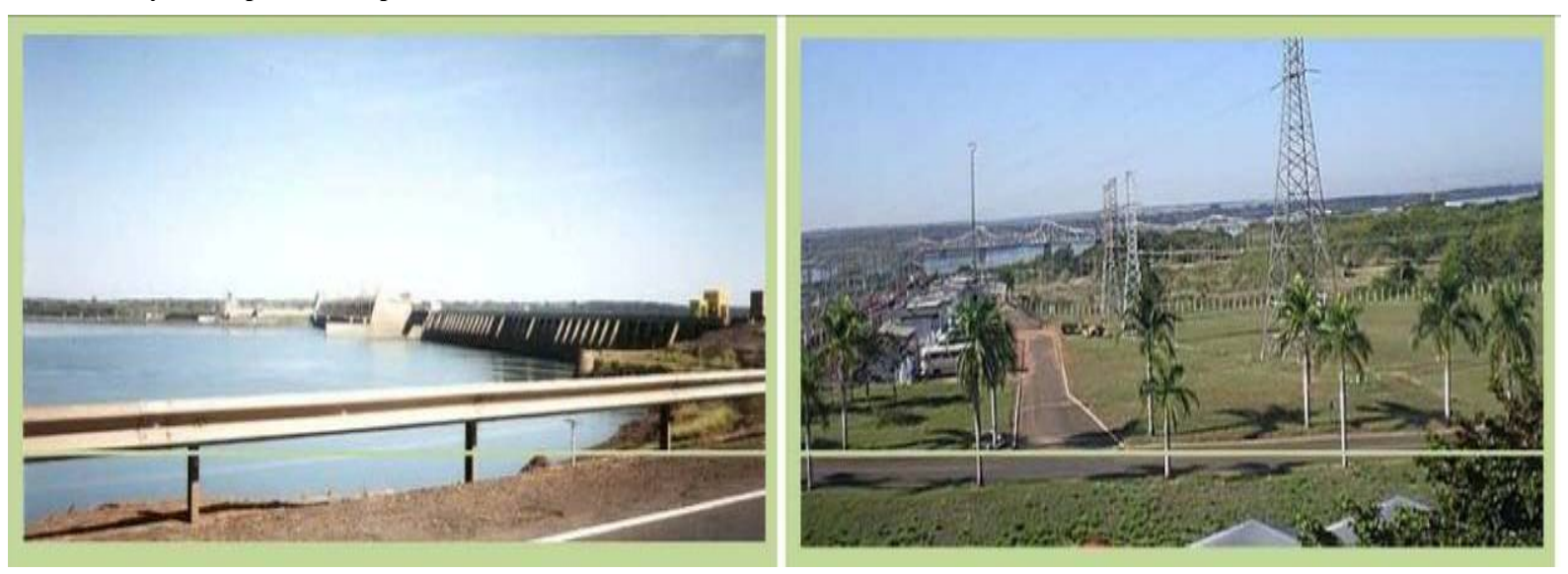

Fuente: Archivo fotográfico de la Entidad Binacional Yacyretá.

La central posee 14 turbinas tipo Kaplan, con una potencia total instalada de $1.551,20 \mathrm{MW}$, y posee además, 2 grupos de turbinas auxiliares, con una potencia de $4.750 \mathrm{KW}$ en cada uno. La presa posee una longitud de $5.495 \mathrm{~m}$. y el embalse ocupa $330 \mathrm{~km}^{2}$.

El Complejo cuenta una esclusa que permite la navegación a lo largo de la Hidrovía ParanáTietê y, tal como se ha indicado con antelación, junto con las Centrales de Ilha Solteira y Três Irmãos conforma el Complejo Hidroeléctrico de Urubupungá. 


\section{Represa de Porto Primavera (Brasil)}

La Represa Engenheiro Sérgio Motta (conocida como Porto Primavera), está ubicada sobre el río Paraná, entre las ciudades de Bataiporã, Mato Grosso do Sul y Rosana, estado de São Paulo, Brasil. Su construcción, iniciada por la Companhia Energética de São Paulo (CESP) durante la dictadura militar, es considerada uno de los más escandalosos casos de corrupción de ese país. Iniciada en 1980, su finalización estaba prevista para 1988, pero se inauguro en el año 2000, a un costo de 9.000 millones de dólares.

Fotos $N^{\circ} 27$ y 28: Represa de Porto Primavera - Brasil
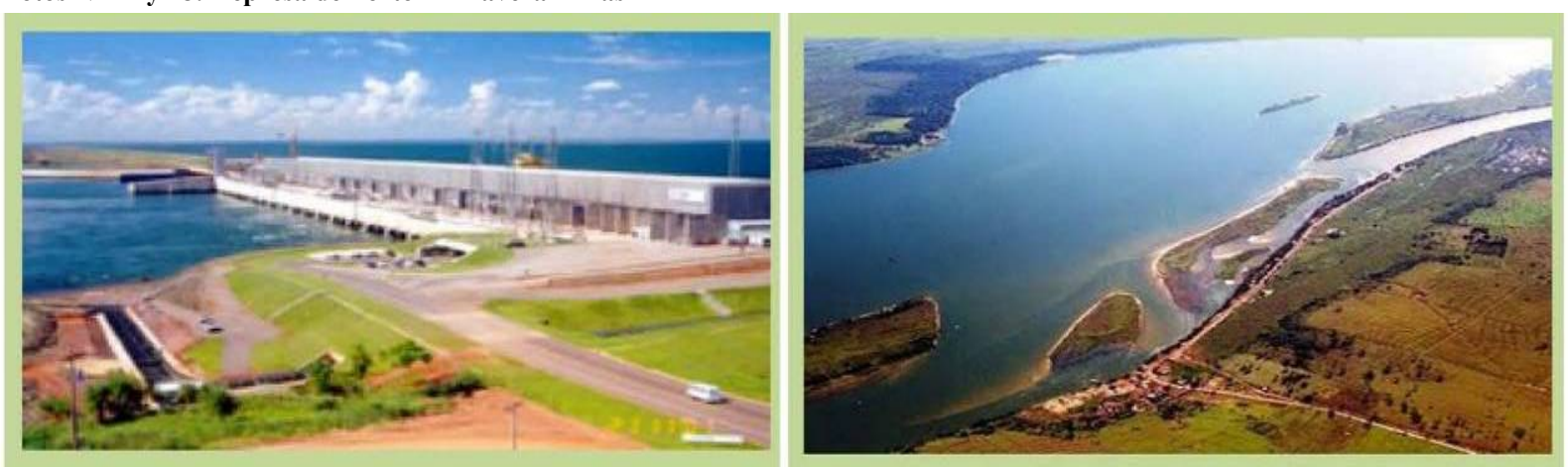

Fuente: Archivo fotográfico de la Entidad Binacional Yacyretá.

La presa tiene una longitud de 10.186 metros de longitud, y su embalse ocupa $2.250 \mathrm{~km} 2$, convirtiéndolo en el más largo lago artificial de ese país. A pesar de su tamaño, la central solo produce una media de $900 \mathrm{MW}$, sobre una potencia instalada de $1.540 \mathrm{MW}$, lo que la sitúa como la $3^{\circ}$ central hidroeléctrica más ineficaz del mundo, detrás de la represa de Balbina, en Pará, Brasil y de otra en Egipto. Cuenta una esclusa que permite la navegación a lo largo de la Hidrovía Paraná-Tietê.

\section{Represa de Itaipú (Brasil y Paraguav)}

La Central Hidroeléctrica de Itaipú («piedra que suena»), es una empresa binacional entre Paraguay y Brasil, ubicada sobre el río Paraná en la frontera entre esos países, a $14 \mathrm{~km}$ al norte del Puente de la Amistad. Es la Central Hidroeléctrica más grande del mundo, y según algunos expertos, sera difícil superarla. El área implicada en el proyecto se extiende desde Foz do Iguaçu, en el Brasil, y Ciudad del Este, en el Paraguay, al sur, hasta Guairá (Brasil) y Salto del Guairá (Paraguay), al norte.

Fotos $N^{\circ} 29$ y 30: Represa de Itaipú - Brasil y Paraguay
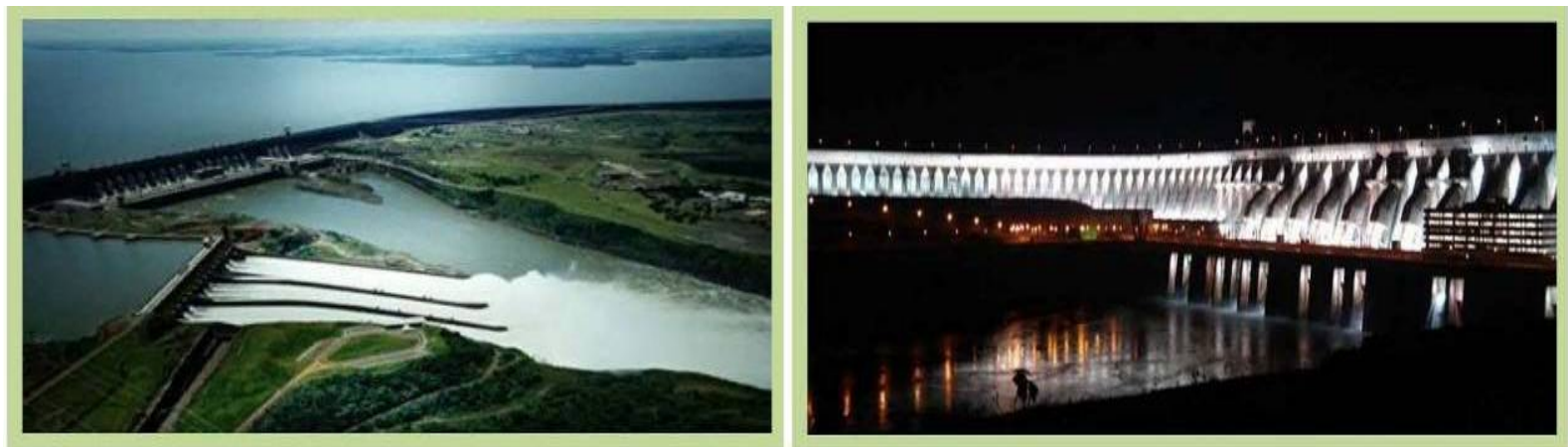

Fuente: Archivo fotográfico de la Entidad Binacional Yacyretá. 
El lago artificial de la represa contiene $29.000 \mathrm{Hm}^{3}$ de agua, con unos $200 \mathrm{~km}$ de extensión en línea recta, y un área aproximada de $1400 \mathrm{~km}^{2}$. La potencia de generación electrohidráulica instalada es de $14 \mathrm{GW}$, con 20 turbinas generadoras de $700 \mathrm{MW}$. En el año 2000 tuvo su récord de producción con 93.400 de GWh, generando el 95\% de la energía eléctrica consumida en Paraguay y el $24 \%$ de la de Brasil. La energía generada por Itaipú destinada al Brasil es distribuida por la empresa Furnas Centrales Eléctricas S.A., y la energía destinada a Paraguay es distribuida por la Administración Nacional de Electricidad (ANDE).

\section{Represa de Salto Grande (Argentina y Uruguay)}

La Central Hidroeléctrica de Salto Grande, es una empresa binacional entre Argentina y Uruguay, ubicada en el curso medio del río Uruguay, a unos $15 \mathrm{~km}$ al norte de las ciudades de Salto (Uruguay) y Concordia (Provincia de Entre Ríos, Argentina).

La Central está equipada con 14 generadores accionados por turbinas tipo Kaplan. Pose además, un vertedero central de 19 compuertas radiales de accionamiento hidráulico, con una capacidad total de evacuación de $64.000 \mathrm{~m} / \mathrm{s}$. Tiene una potencia total instalada de $1.890 \mathrm{MW}$ y su construcción aprovecha el desnivel que el río presentaba en la zona denominada 'Salto Grande'.

Fotos $N^{\circ} 31$ y32: Represa de Salto Grande - Argentina y Uruguay
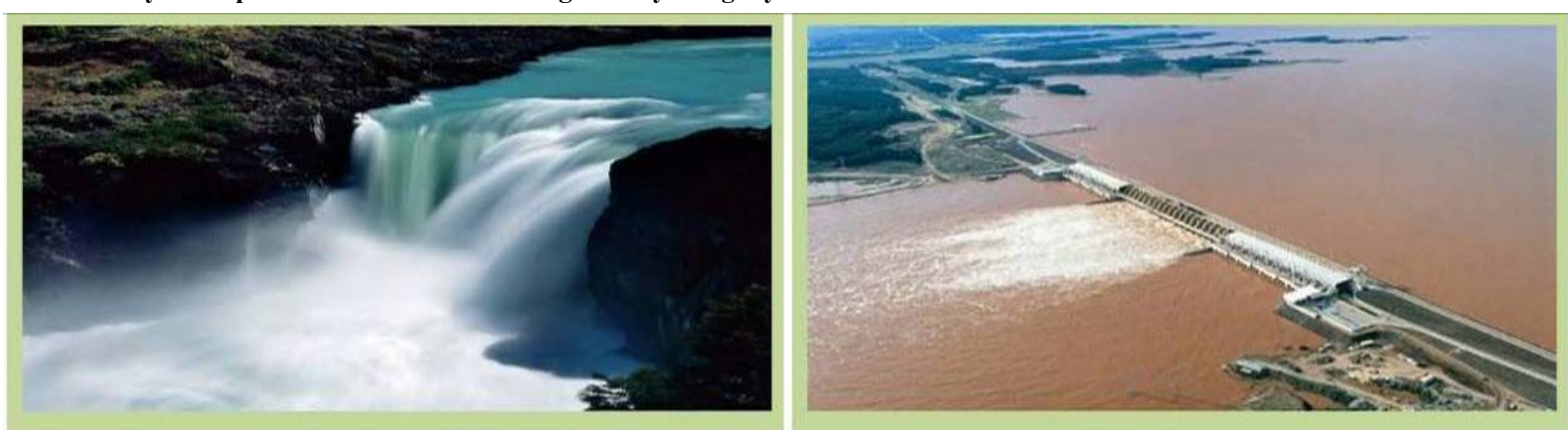

Fuente: Archivo fotográfico de la Entidad Binacional Yacyretá.

El caudal del Río Uruguay en la zona es: medio (serie histórica) $4.622 \mathrm{~m} 3 / \mathrm{s}$, máximo registrado (desde 1898) $37.714 \mathrm{~m}^{3} / \mathrm{s}(09 / 06 / 92)$ y mínimo registrado (desde 1898) 109 m³/s (03/02/45).

El embalse tiene un área de $783 \mathrm{~km}^{2}$; su volumen es de $5.000 \mathrm{hm}^{3}$; su longitud es $140 \mathrm{~km}$; su ancho máximo de $9 \mathrm{~km}$; su profundidad máxima es $33 \mathrm{~m}$. y la media $6,4 \mathrm{~m}$.; el rango normal de fluctuación anual del nivel de agua es de $0,8 \mathrm{~m}$.; la longitud de la costa de $1.190 \mathrm{~km}$. y el área de la cuenca 224.000 $\mathrm{km}^{2}$. En el coronamiento de la presa, se encuentra el Puente Salto Grande, ferroviario y carretero.

Estos ejemplos son los que demuestran la enorme transformación acaecida sobre la Cuenca del Plata, conformando con el resto de los emprendimientos hidroeléctricos, junto a la expansión de la frontera agropecuaria-forestal y el crecimiento de las ciudades-puerto, el tercer gran impacto regional, que puede denominarse como de 'reconfiguración territorial' de la región histórica. 


\section{II.3. ASPECTOS CONCEPTUALES Y CRITERIOS PARA UN ANÁLISIS Y UNA REFLEXIÓN HISTÓRICA SOBRE EL PAISAJE}

En esta parte del análisis sobre el estado de la cuestión desde la reflexión paisajística, para ser aplicada a la interpretación de un territorio que ha sido fuertemente modificado por la acción del hombre, resulta necesario recurrir a la enumeración de criterios que permitan orientar, por una parte, el análisis histórico de la región de referencia; así como, para poder dilucidar por otra parte, si ha existido una interpretación de ese territorio como paisaje, antes de la transformación y si esos criterios, pueden orientar -a posteriori de la intervención antrópica-, la identificación de un nuevo paisaje.

\section{II.3.1. Criterios para 'decir paisaje'}

Al respecto, en Les Raisons du paysage (Berque, 1995), Agustín Berque enumera [...cuatro] criterios (citados por Roger, 2007: 55 a 70), a los que el mismo Berque en "Cosmofanía y Paisaje Moderno" (Berque, en Maderuelo, 2006: 190 a 207), incorpora un quinto criterio:

"[...] 1. Existe una reflexión explícita acerca del paisaje como tal; 2. Existe una o más palabras para decir 'paisaje'; 3. Existen representaciones pictóricas del paisaje; 4. Existen jardines cultivados por placer; 5. Existe una literatura (oral o escrita) que describe paisajes o canta su belleza. [...]”" (Berque, en Maderuelo, 2006: 190).

Pero si realizamos un análisis aplicando estas condiciones en la región objeto de estudio de esta investigación, veremos que quizás sea muy difícil en nuestro contexto Latinoamericano, encontrar sociedades que cumplan con estas cinco condiciones, para ser denominadas en los términos que Donadieu llamaría como 'sociedades paisajeras'. Es por esto, que si aceptamos el planteo del mismo Berque, acerca de que cada sociedad posee sus propios términos para expresar su propia 'Cosmofanía', es decir, su realidad (Berque, en Maderuelo, 2006: 191), parece razonable entonces, plantear una tipología jerarquizada dependiendo del número de condiciones que se cumplan (Roger, 2007: 57), para establecer si una determinada sociedad es 'protopaisajera' (de grado 1, 2, 3 o 4); o totalmente paisajera (cuando cumpla las 5 condiciones).

\section{1. ¿Existe una reflexión explícita acerca del paisaje como tal?}

Dadas las características seminómades de la cultura guaraní, no se tienen registros que testimonien la lengua en forma de escritura. Fueron los Franciscanos, primero, y principalmente, los Jesuitas después, los que aportaron a estructurar el idioma en forma escrita, para aprenderlo, transmitir el evangelio, e insertar la cultura europea en las comunidades sedentarizadas en el sistema reduccional. Y es a partir de allí, que pueden recogerse expresiones vinculadas a esa noción de paisaje, derivada del 'romanticismo' que imperaba en esa época en el viejo continente.

El primer texto escrito en lengua nativa fue el "Catecismo en Guaraní" de Fray Luis de Bolaños (1588), y le siguieron “Tesoro de la Lengua Guaraní” de Antonio Ruiz de Montoya (1639); “Arte y 
Vocabulario de la Lengua Guaraní" del mismo autor (1640); "Sermones en Guaraní" del Padre José Serrano (1705) y “Catecismo y Sermones del Cacique Nicolás Yapuguaí (1724).

\section{2. ¿Existe una o más palabras para decir 'paisaje’?}

Como hemos visto en el parágrafo II.1., el guaraní le otorga al idioma una gran importancia simbólica, que puede ser demostrado con dos ejemplos: Paraguay, 'Río del manantial del mar', o la misma palabra que da nombre al Proyecto Yacyretá, del guaraní "Jasy retã, significa tierra de la luna" (Lins Ribeiro, 2003: 135), o también "Yasy-retá: el lugar donde brilla la luna" (Levinton, 2007: 5), o más simplemente, como lo denominan los lugareños 'el lugar de la luna...'

Pero existen también, algunas palabras compuestas vinculadas con la noción de 'decir paisaje', tales como: yvoty rehegua (proveniente de flores...); yvoty okaraygua (flores que bordean las costas de un territorio); ta'anga ojeguakava (imágenes que adornan un lugar, un territorio...), o ta'anga iporava (imagen bonita de un lugar...).

\section{3. ¿Existen representaciones pictóricas del paisaje?}

A excepción de representaciones de elementos de la naturaleza, no existen representaciones pictóricas del paisaje, previas al período jesuítico.

\section{4. ¿Existen jardines cultivados por placer?}

No se ha verificado la existencia de jardines cultivados por placer en la naturaleza de la cultura guaraní prehispánica. Sólo a partir del período jesuítico, puede constatarse la existencia en varios de los 30 pueblos-ciudad, de jardines y arreglos de accesos, o sitios destinados al placer, derivados seguramente, del Romanticismo naciente en Europa, por esa época.

\section{5. ¿Existe una literatura (oral o escrita) que describe paisajes o canta su belleza?}

No existe una literatura que describa al paisaje como tal, previamente al período jesuítico. Sí existen escritos posteriores sobre el paisaje escritos en guaraní por autores paraguayos que recuperan contextos de relatos, cuentos, poesías y situaciones.

Esta forma de análisis, permite establecer en los términos de Berque, si esa sociedad entendía su entorno 'en tanto que paisaje' o 'en tanto que otra cosa': “[...] Este 'en tanto que' es el modo ontológico instaurado por la relación ecumenal entre dos términos, uno de los cuales es una base universal y necesaria: la Tierra, o la naturaleza, y el otro, el Mundo, o la cultura, como interpretación contingente y singular de esta base. Este modo ontológico en-tanto-que ecumenal, es inherente a la realidad." (Berque, en Maderuelo, 2006: 191). Es decir, que aún no cumpliendo cabalmente con las cinco condiciones, podemos afirmar que esta sociedad tenía una relación con el medio en tanto que paisaje (en los términos de Berque), o bien, protopaisajera (en los términos de Roger). 


\section{II.3.2. Los 'paisajes de nuestra época'}

Los criterios esbozados en el parágrafo anterior, parecen resultar pertinentes para dilucidar en sentido histórico la existencia del concepto de paisaje, en una determinada sociedad, pero ¿alcanzan para explicar los proceso sociales del mundo actual, dominado por la ciudad, es decir, por la urbanización del territorio? Este es un aspecto importante para ser considerado a la hora de enfrentar la temática paisajística en el contexto latinoamericano y en el territorio que aborda nuestro caso de estudio.

El concepto de territorio es amplio, diverso y largamente utilizado por la geografía, pero también, su uso tiene una concepción política, y en este sentido, es considerado como el espacio físico dominado por un grupo social frente a otros o como sinónimo de Estado (especialmente en geopolítica). En la física, por ejemplo, refiere a superficie terrestre o relieve; para la ecología es sinónimo de medio natural, de entorno del ser humano en su relación con la naturaleza, y en la astronomía y tradición espacial, se lo asocia con sistemas entendidos como lugares interconectados por redes y flujos. En este caso, nos interesa abordar el enfoque empleado para el estudio del paisaje, dónde territorio es sinónimo de paisaje natural o cultural, entendido por lo tanto, como aquel sistema socio-ecológico que reúne la sociedad y el medio que ésta habita con sus significados.

Desde este punto de vista, Pierre Donadieu, indica que la visión contemporánea del sentido del paisaje demuestra que el paisaje se ha transformado en un bien público (Donadieu, 2006: 50) ${ }^{66}$ fortalecido en los países europeos por un marco institucional derivado del Convenio Europeo del Paisaje (2000) y por un marco jurídico que garantiza un 'Derecho del paisaje', por lo que el debate sobre el paisaje se ha vuelto político (Donadieu, 2006: 51). Vemos entonces las diferencias.

Por eso resulta importante verificar en nuestro contexto, que carece de esos instrumentos de gestión, aquella hipótesis de Joan Nogué expuesta en el Capítulo I, acerca de que "[...] el paisaje puede interpretarse como un producto social, como el resultado de una transformación colectiva de la naturaleza y como la proyección cultural de una sociedad en un espacio determinado.” (Nogué, 2007: 11).

Pero también resulta necesario verificarlo desde el análisis de los valores sociales que sustentan esta mirada y que Donadieu los explica como cinco sentidos, que emergen o nacen de la efervescencia social alrededor del proyecto de un mejor vivir en el mundo: la memoria más que la amnesia, la rique$z a$ más que la pobreza, la seguridad en lugar del peligro, el urbanismo en vez de la exclusión, y la identidad de los espacios en lugar de su anonimato. Cinco sentidos que constituyen 'cuatro dualidades de valores sociales' que podrían denominarse 'de la urbanidad', bajo el supuesto que la belleza de los paisajes está a veces en la base o en el fundamento de la reconquista de los territorios, pero también

\footnotetext{
${ }^{66} \mathrm{Si}$ bien Donadieu se refiere al interés que demuestra la sociedad francesa, y europea en general, por una recalificación de los territorios de hábitat y de trabajo, producidos sólo por lógicas funcionales, esta afirmación nos resulta igualmente válida como reflexión general.
} 
puede ser objeto de desacuerdos sociales, dado que la calidad de los paisajes de unos no es siempre la de otros, y por ende, el arbitraje es a veces difícil. (Donadieu, 2006: 51).

Para abordar estas cuatro dualidades sociales, Donadieu nos enfrenta a la idea que "la identidad espacial representa una apuesta social', y señala que así como la identidad de un individuo o de un grupo social corresponde a su imagen y está dotada de una designación singular, la identidad de un espacio nace de la relación de un territorio geográfico con un grupo social que lo reivindica. Esa identidad, está determinada por complejas relaciones que construyen esos espacios con la sociedad.

“Esta relación [señala], produce imágenes cuya producción, está unida a cuatro categorías de procesos: patrimoniales; económicas; de medio ambiente y territoriales. [... Categorías éstas, que] corresponden a las cuatro dualidades de valores sociales convocadas precedentemente: memoria/amnesia, riqueza/pobreza, seguridad/peligro, urbanismo/exclusión." (Donadieu, 2006: 60 a 62).

Cabe decir que, para nuestro caso de estudio resulta pertinente efectuar esta constatación crítica, a fin de poder verificar si efectivamente ha existido una cierta coherencia espacial, acompañada de una cierta sensibilidad social y de una cierta visión artística que haya hecho posible interpretar el país como paisaje, y en tal caso -ahora, que el paisaje original ha sido transformado-, si es posible, parafraseando al mismo Donadieu, reencontrar la coherencia espacial perdida, uniendo lo inteligible y lo sensible, lo funcional y lo poético.

De lo Patrimonial: Significa la necesidad de constatar si el contexto social podrá reivindicar la identidad local a partir de la memoria y el patrimonio cultural tangible e intangible de la historia del territorio y asimilar además, la lógica de otras identidades, como la turística.

De lo Económico: Implica un proceso de verificación en el tiempo, acerca de si los nuevos ámbitos urbanos, principalmente los costeros, y aun los periurbanos, consolidados con nuevas infraestructuras y equipamientos socio-comunitarios, pueden ser asimilados como productos valorizados de un nuevo paisaje.

Del Medio Ambiente: Representa el desafío de verificar si es posible en adelante, garantizar la seguridad sobre la calidad del agua, de la producción agrícola-ganadera, de los bienes civiles, de las áreas de reservas ecológicas naturales y urbanas, con criterios de corresponsabilidad y sustentabilidad.

De lo Territorial: Representa la posibilidad de verificar también, si el espacio público, el tratamiento paisajístico de los vacíos urbanos y de las infraestructuras viales, el manejo integrado de cuencas urbanas y rurales, y el conjunto de áreas de reservas naturales compensatorias, podrán ser asimilados como red de espacios abiertos a escala urbana, metropolitana y regional, constituyéndose además, como 'lugares seguros' y de fuerte integración social.

Es decir, contribuyendo a renovar las relaciones entre los habitantes y el paisaje a fin de reencontrar la urbanidad perdida, 'este arte de hacer sociedad en conjunto, nacido de la ciudad', dónde los 
nuevos lazos espaciales del territorio y de las ciudades, se ofrezcan como una promesa de lugares sociales; donde la apertura del también nuevo espacio público, se imponga al encierro de los espacios privados; donde el cruce y la mixtura tomen el paso sobre la separación de los flujos y las divisiones de la zona; donde el debate público y democrático, movilice los valores ciudadanos. En suma, donde a través del proyecto paisaje pueda anticiparse lo que va ser del territorio, para contribuir a modelar el proceso que lo produce y llegar a los estados evolutivos deseados." (Donadieu, 2006: 117).

\section{II.3.3. De la obra al concepto: principales elementos del Paisaje}

Coincidiendo con la advertencia que realiza Aguiló, acerca de que en ese tránsito de 'la cosa' (la obra) al concepto -que es conocer- se corre el riesgo de perder el contacto con 'la cosa', dado que $a c$ ción y representación son polos opuestos que la acechan, por lo que, en el modelo conceptual de paisaje vinculado a una obra de infraestructura, la representación prima el trámite de mediación y lo sublima para convertirlo en imagen y, en ese tránsito, 'la cosa' puede desaparecer en la propia apreciación. Por esto, el mismo autor afirma que, la acción sólo puede prosperar cuando se mete en la cosa y la transforma (Aguiló, en Maderuelo, 2006: 229).

En nuestro caso, 'la cosa' definida por el conjunto río, islas, selva ribereña y el territorio costero, 'desaparece' y se transforma, por su utilización como medio para conseguir 'el objetivo de la acción': generar energía hidroeléctrica, permitir la navegación y controlar las crecidas.

Sin embargo, en el modelo de paisaje la acción entra como componente del país: el conjunto conformado por la central, la presa, los tratamientos costeros, las nuevas áreas urbanas y de producción, se queda allí como parte integrante de la cosa y reaparecerá convertida en imagen para una próxima mediación. Esta reflexión nos resulta importante, dado que "[...] cualifica al concepto paisaje como territorio de la acción" (Aguiló, en Maderuelo, 2006: 231).

Es por eso, que apoyado en la distinción que hace Adorno, entre los conceptos de lo bello natural y el paisaje cultural como territorios diferentes, Aguiló señala que:

“[...] lo bello natural sería territorio de la imagen o la representación, mientras que el paisaje aparece sólo tras la acción reconocida como historia. La acción se recoge en el paisaje y es objeto de apreciación estética. [...] La sociedad ha asociado sus esquemas perceptivos y reserva lo bello del paisaje a la esfera de lo alli actuado, mientras reconoce lo bello natural como propio de la imagen contemplativa [...] Quizá, simplificando mucho las cosas, se podría concluir que, con independencia de la posible belleza de lo natural, no hay paisaje sin acción y su posible interés estético sería fruto de su historia" (Aguiló, en Maderuelo, 2006: 232). [Una historia que Yacyretá, aún está escribiendo].

En un emprendimiento hidroeléctrico a gran escala, 'la acción', determinada por 'la obra', está representada por tres conjuntos de 'elementos' que plantean nuevas relaciones y consecuentemente, nuevos significados en el territorio, para una nueva mediación que permita definir el sentido de paisaje: 
El Conjunto de Construcciones que la conforman y definen el sentido de transformación: a) las Obras Principales destinadas a la generación de energía (central de generación, presas, puentes, vertederos, esclusa de navegación y sistemas de riego); b) las Infraestructuras del Territorio (puentes, rutas, caminos y accesos); c) las Obras de Protección, tanto las costera, como las de recomposición urbana y ambiental de pueblos y ciudades.

Fotos $N^{\circ} 33$ a 36: Conjunto de Construcciones que define el sentido de la 'transformación'

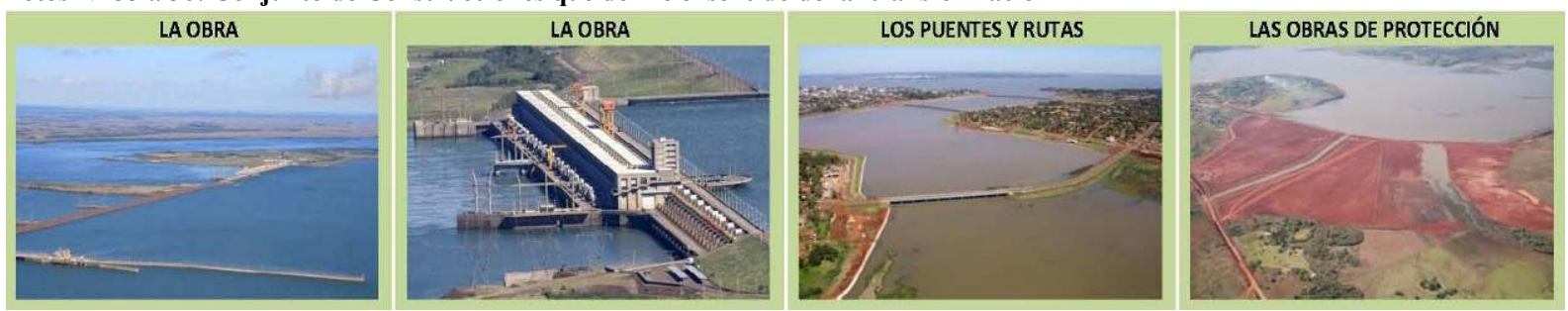

Fuente: Archivo fotográfico de la Entidad Binacional Yacyretá

El Conjunto de Elementos Culturales (tangibles e intangibles) presentes en el entorno del proyecto: a) el Hábitat Humano (el sistema de ciudades y nuevos asentamientos; los pueblos y el entorno rural); b) la Ruina; c) la Literatura, Canciones, Mitos y Leyendas.

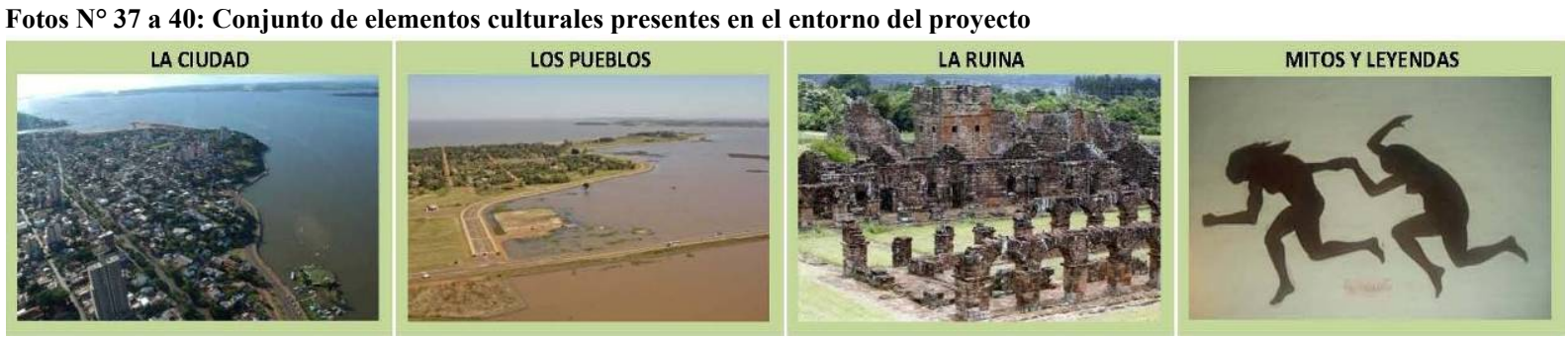

Fuente: Archivo fotográfico de la Entidad Binacional Yacyretá

El Conjunto de Transformaciones del Soporte Natural que la sostiene: a) el Agua (río y embalse; arroyos y subembalses); b) los Rápidos ('itú' o arrecifes); c) la Tierra (sabana y serranía; islas y zonas costeras; d) la Selva ('Monte' interno y costero); los Esteros.

Fotos $N^{\circ} 41$ a 44: Conjunto de transformaciones del soporte natural que sostienen 'la Obra'

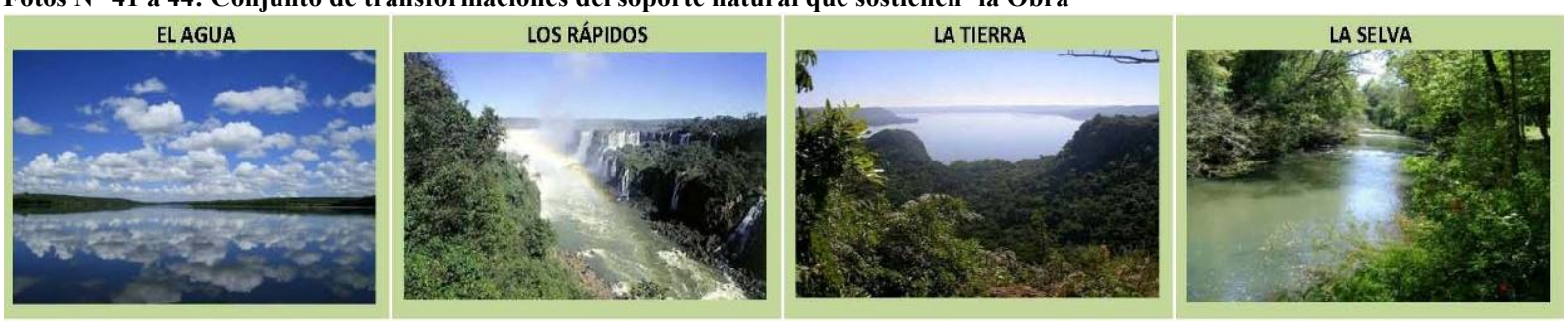

Fuente: Archivo fotográfico de la Entidad Binacional Yacyretá

Es desde esta noción de paisaje y desde distintas escalas de interpretación que, en el Capítulo IV, nos aproximaremos a identificar y describir estos elementos culturales y naturales derivados de, o transformados por la construcción de Yacyretá. 
PARTE II: HACIA UNA GESTIÓN SUSTENTABLE DEL PAISAJE EN EL CONTEXTO DE LAS TRANSFORMACIONES URBANO-TERRITORIALES DERIVADAS DE LA EJECUCIÓN DE YACYRETÁ EN LAS ZONAS URBANO-COSTERAS 



\section{CAPÍTULO III: CONSIDERACIONES ACERCA DEL PROCESO DE RECONFIGU- RACIÓN DEL PAISAJE EN EL ÁREA DE IMPLANTACIÓN DE YACYRETÁ}

La tercera parte de esta investigación, presenta una mirada detallada sobre el Proyecto Hidroeléctrico Yacyretá (PHY) en su proceso de inserción en su entorno local y regional.

Para ello se realiza inicialmente un análisis de situación, que permite describir y aportar una serie de reflexiones acerca de los hechos que, a lo largo de su historia, relacionan las decisiones de su concepción y las variaciones del proyecto junto a los impactos de su construcción sobre la naturaleza y la cultura, analizando su funcionamiento y los principales elementos que definen la transformación del paisaje, y las circunstancias históricas e instrumentos de gestión socio-ambientales derivados de la evaluación ambiental del Proyecto, realizada nueve años después de iniciada su ejecución. Esta mirada global sobre el proyecto, orienta el contenido del segundo apartado, destinado a entender sus efectos sobre la naturaleza y la cultura; su funcionamiento y la transformación del paisaje; las modificaciones de la cuenca principal y de las cuencas interiores; en tanto que en el tercer apartado, se analiza su incidencia sobre la ciudad, sus actividades y las personas, considerando las implicancias de la Obra sobre su área de implantación y los instrumentos de gestión territorial que servirán de basamento del proyecto Paisaje, que se aborda en el cuarto capítulo de esta investigación. Este diagnóstico, permite profundizar en el cuarto apartado del tercer capítulo, el análisis sobre el conjunto de medidas de mitigación y sobre los proyectos de reconfiguración territorial; acotando el tema de investigación sobre las zonas urbanocosteras de Posadas y Encarnación, como medio operativo para la configuración de un nuevo paisaje

Foto $N^{\circ}$ 45: Tratamiento Costero en ejecución - Sector Bahía El Brete - Ciudad de Posadas (Argentina)

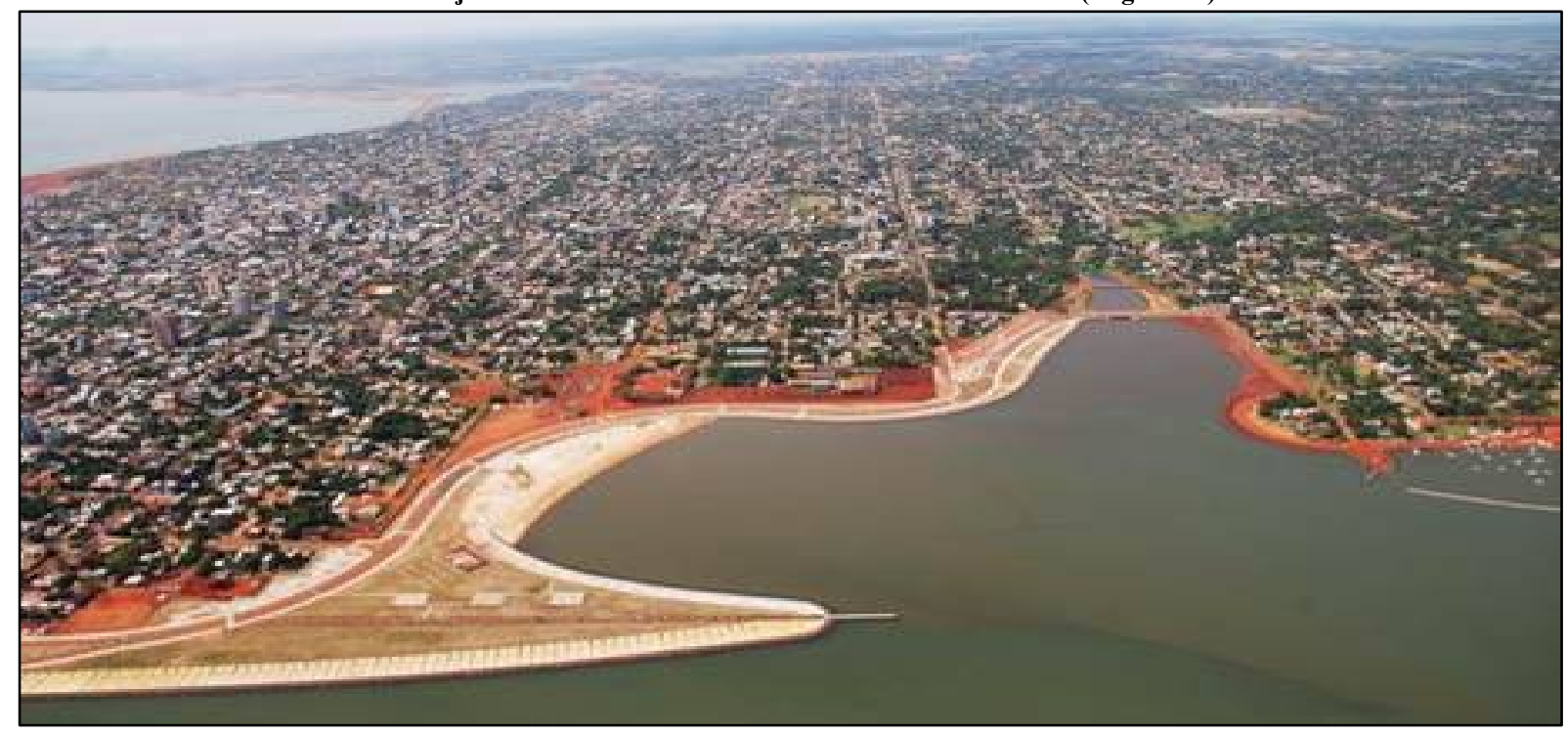

Fuente: Archivos fotográfico de la Entidad Binacional Yacyretá, diciembre de 2010.

A fin de favorecer el conocimiento e inducir la mediación de la mirada que -desde la percepción y desde una cierta posición- ayuda a construir la noción de paisaje, se recurre en este capítulo, al auxilio de gráficos e imágenes, que dan cuenta de la escala y complejidad del Proyecto y sus impactos. 


\section{III.1. EL PROYECTO HIDROELÉCTRICO YACYRETÁ}

El nombre 'Yacyretá', como otros puntos geográficos de la región, es -como ya hemos mencionado en el parágrafo II.3.1.- la denominación en idioma guaraní que le diera la población nativa a la isla en dónde se construyeron las Obras Principales del emprendimiento hidroeléctrico. La isla, de 450 $\mathrm{Km}^{2}$ de extensión, es territorio de jurisdicción paraguaya y divide al río Paraná en dos brazos, denominados Principal y Aña Cuá.

Un puente de servicio, junto a la presa principal y la misma Central construida sobre la isla, conectan a ésta con el territorio argentino, en tanto que otro puente construido sobre el brazo Aña Cuá, conecta a la isla con territorio paraguayo. El conjunto de estos puentes y la presa principal, crean una conexión física entre ambos países que, aún potencial, por no estar habilitada como tal, promueve también una percepción diferente del ambiente deltaico original.

Pero, como hemos analizado en el parágrafo II.2.3, Yacyretá representa el último eslabón de una cadena de más de 60 emprendimientos hidroeléctricos, sólo de la Cuenca del rio Paraná, cuya mayor explotación se encuentra localizada en la República Federativa de Brasil, y como veremos a continuación, su escala y complejidad técnica e institucional (de carácter binacional), han motivado complejas discusiones y demoras en su ejecución, que han trasladado su terminación hasta nuestros días, y consecuentemente, la necesidad de incorporar sucesivos ajustes al proyecto original, para adecuarlo tanto a las particularidades derivadas de su condición de binacionalidad, como a las nuevas exigencias ambientales y crediticias internacionales, como así también, a los propios conflictos y compromisos locales diferidos en el tiempo.

\section{III.1.1. Yacyretá: evolución de los hechos que definen el proyecto y la transformación del paisaje}

Como hemos adelantado en la introducción, la construcción de Yacyretá ha pasado por un largo proceso de adaptación a situaciones propias del proyecto y del área de implantación; así como por las analizadas situaciones derivadas del contexto internacional, que incidieron en los países involucrados, en la región y en el propio diseño del proyecto. De tal forma, para poner en contexto esta afirmación, resulta necesario efectuar una síntesis cronológica de los principales acontecimientos que definieron su ejecución, y con ello, las diversas posibilidades de transformación del paisaje, en su área de implantación.

Como hicimos referencia en el capítulo I (ver parágrafo I.3.1), los estudios para el aprovechamiento de los recursos hídricos de la región comenzaron mucho antes que la concreta concepción de Yacyretá, cuyos primeros antecedentes concretos, tomaron forma institucional el $1^{\circ}$ de febrero de 1926 , con la firma en Washington DC (EEUU), del Protocolo Argentino-Paraguayo relativo a la utilización de los Saltos del Apipé, y 32 años después, con la firma del Convenio del 23 de enero de 1958, dónde los Gobiernos de Argentina y Paraguay acordaron la decisión de realizar estudios técnicos tendientes a obtener energía eléctrica del Río Paraná, a la altura de las islas de Yacyretá y Apipé, y a mejorar las condiciones 
de navegabilidad de dicho río (EBY, 1958: 2) ${ }^{67}$ y sería la Comisión Mixta Técnica Argentino-Paraguaya (CMT), creada en el marco del mismo Convenio, la que tendría a su cargo la realización del estudio.

Muchas fueron las discusiones sobre las diversas trazas posibles para el cierre del río Paraná, que implicaban directamente a la cantidad de territorio a ser inundado en cada margen, principalmente en la República del Paraguay. En 1964, la CMT elevaba a consideración de los Gobiernos de Argentina y Paraguay el Informe Técnico-Económico-Financiero del Anteproyecto de la denominada 'Represa Yacyretá-Apipé' (ver parágrafo I.3.1). El mismo, describía las características excepcionales del río Paraná con un módulo de $11.794 \mathrm{~m}^{3} / \mathrm{s}$, un caudal mínimo medio mensual de $3.100 \mathrm{~m}^{3} / \mathrm{s}$, y la cota de operación era $79 \mathrm{msnm}$. Los lineamientos generales de la denominada Alternativa I, preveían la construcción de una presa frontal al río; 2 vertederos de $35 \mathrm{mil} \mathrm{m} / \mathrm{s}$, localizados sobre el Brazo Principal y el Brazo Aña Cuá del río Paraná; una Central Hidroeléctrica, formando parte de la presa frontal, constituida con 30 unidades de generación de una potencia individual de $70.000 \mathrm{KW}$ y la esclusa de navegación de $180 \mathrm{~m}$. de longitud y $30 \mathrm{~m}$. de ancho, localizada al Este de la Central. El informe consideraba que la construcción de las obras insumirían unos 8 años, estimándose que podrían iniciarse en 1972.

Plano $N^{\circ}$ 1: Traza Recta Original - CMT, 1964

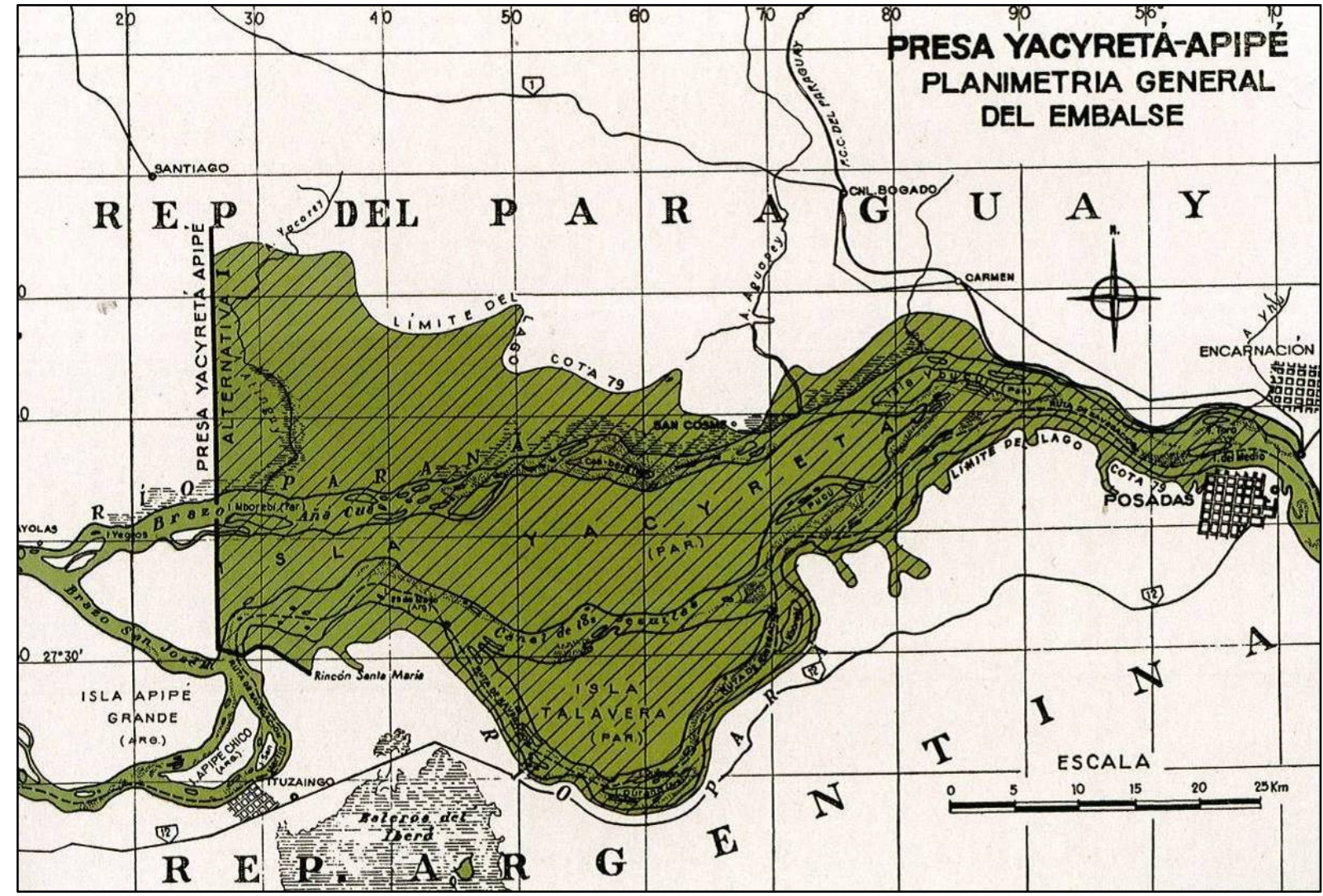

Fuente: Archivo de la Entidad Binacional Yacyretá (en Levinton, 2010: 133).

${ }^{67}$ Se refiere al Acuerdo sobre el Mejoramiento de la Navegabilidad del Río Alto Paraná y Utilización de las Caídas de Agua en Apipé, suscripto ad referéndum de los dos Gobiernos. Aprobado por Decreto 24/10/1926. 
En marzo de 1970, la CMT Paraguayo-Argentina de Yacyretá-Apipé, acordaba la precalificación de consorcios consultores para realizar la Primera Fase de Prefactibilidad sobre Yacyretá.

En junio de 1971, se hace la licitación que gana Harza, por proponer modificación clave al Proyecto de la CMT (elevación a cota $82 \mathrm{msnm}$ ). El 20 de octubre de ese año, se firmaba en Asunción del Paraguay, el Contrato entre la CMT y el Consultor HARZA, para desarrollar las denominadas Fases I y II del Proyecto y el 26 de octubre del mismo año, se formalizaba la Orden para dar comienzo al Estudio de Prefactibilidad (Levinton, 2010: 108 y 109).

Pero ya en marzo de 1972, se estaba estudiando una 'variante B', y se comenzaba a trabajar con la alternativa de operación a cota $82 \mathrm{msnm}$. El 27 de abril, se discutió el anteproyecto elaborado por la CMT que cortaba el río uniendo prácticamente con un trazado rectilíneo las poblaciones de Ituzaingó (Rincón de Santa María) en la margen argentina con Ayolas en la margen paraguaya, dónde además, el ingeniero paraguayo Debernardi, luego de todo un día y una noche de discusión, marcó en rojo sobre un plano, otras 6 trazas (Levinton, 2010: 109).

Plano $\mathrm{N}^{\circ}$ 2: Alternativas de Trazas - CMT, 1972

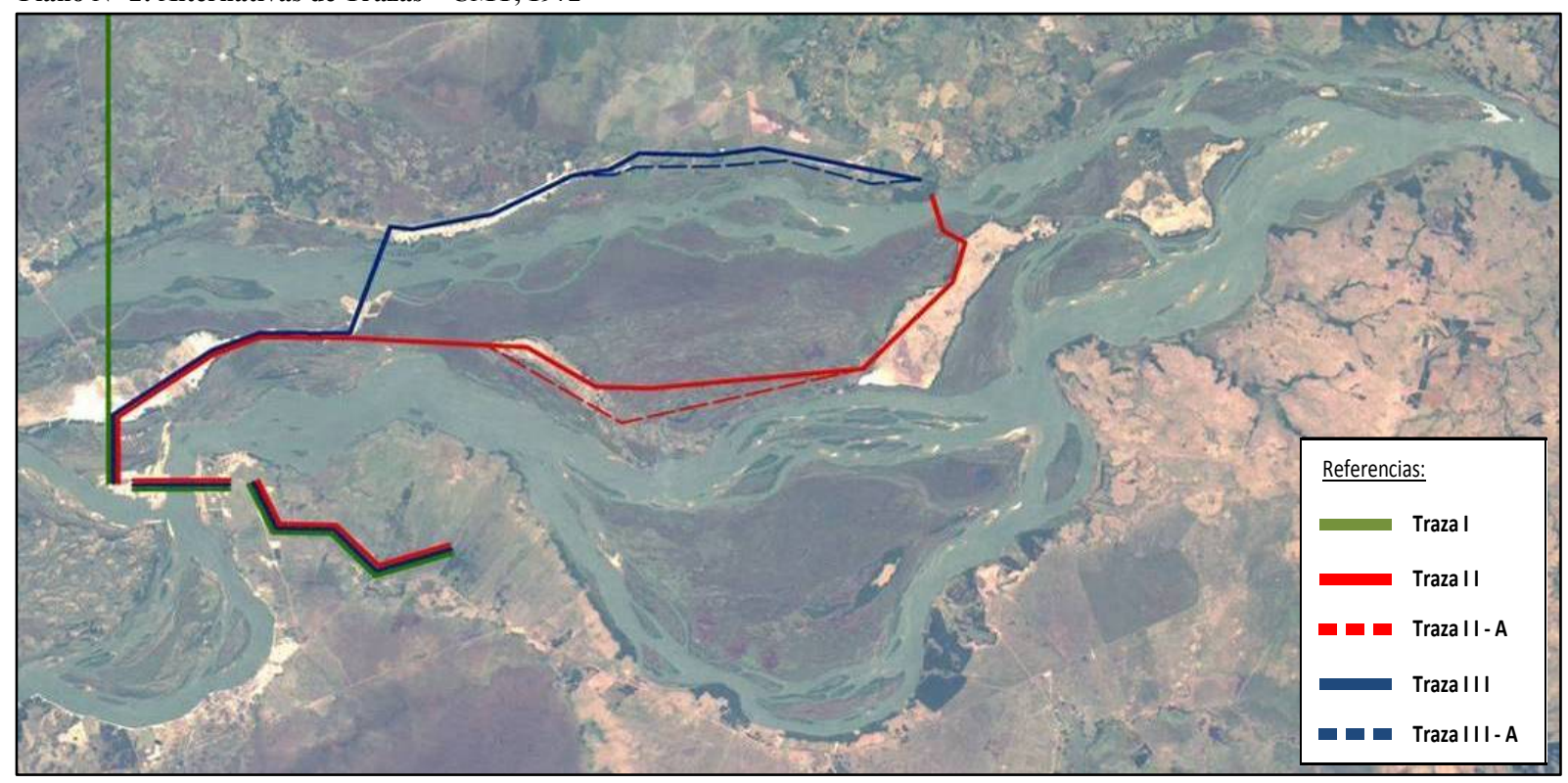

Fuente: Elaboración propia, y volcado sobre imagen de satélite de la época (sin embalse) - EBY, 2009.

El 9 de agosto de ese mismo año, en la 29a Reunión Plenaria efectuada en Buenos Aires, la delegación Argentina manifestaba que consideraba a la Traza I (o Alternativa A), como la más adecuada, en tanto, la Delegación Paraguaya optaba por la Traza II, por tener una extensión menor de territorio paraguayo a ser inundado. El 4 de octubre, Harza somete ante el Departamento Técnico, el presupuesto para realizar el llamado 'Programa Intermedio' y el 13 de octubre, dieron comienzo las tareas de campaña (Levinton, 2010: 109).

El 13 de enero de 1973, se realiza la presentación de los resultados del Programa de Acción Intermedia, que representaban estudios complementarios para seleccionar una Traza (A, B-2, Variante San 
Cosme y nueva Traza II). En junio, el Consorcio Harza y Asociados, entregaba el borrador del Informe Final con el Anteproyecto Yacyretá-Apipé. La Argentina había aceptado la Traza II propuesta por Paraguay, y por ello este país concordó en continuar con la Fase III del Proyecto a pesar de que la Traza, en ese momento, no estaba totalmente formalizada. El 6 de agosto, el Gobierno Argentino acepta formalmente la Traza II elegida por Paraguay, mediante una carta del General Perón al General Stroessner. El 12 de septiembre, el canciller Alberto Juan Vignes, comunica a su par paraguayo que la Argentina acepta la Traza II para el Proyecto de la Represa y el $1^{\circ}$ de diciembre, Harza presenta el informe Final de Factibilidad, Fase II, con la Traza II como Traza definitiva.

Un aspecto relevante en la transformación del paisaje regional, es que este proyecto generaba una gran superficie de territorio a ser inundado. Contaba con un embalse compensador de superficie equivalente al $50 \%$ de la del embalse principal, definido por $8,5 \mathrm{Km}$ de terraplenes, dónde se preveía también ejecutar una central hidroeléctrica, una esclusa de navegación, un vertedero e instalaciones para el pasaje de peces. En esta instancia, el proyecto proponía la inundación del valle del arroyo Aguapey (40 mil has.) en Paraguay, llevando el embalase principal a unos $2.000 \mathrm{Km}^{2}$ de superficie y seguía manteniendo la central principal, las 30 unidades generadoras, la esclusa de navegación y los dos vertederos, e incorporaba instalaciones para el pasaje de peces en la estructura de la Central.

Plano $N^{\circ}$ 3: Proyecto derivado de la Traza II - Harza y Asociados, 1973

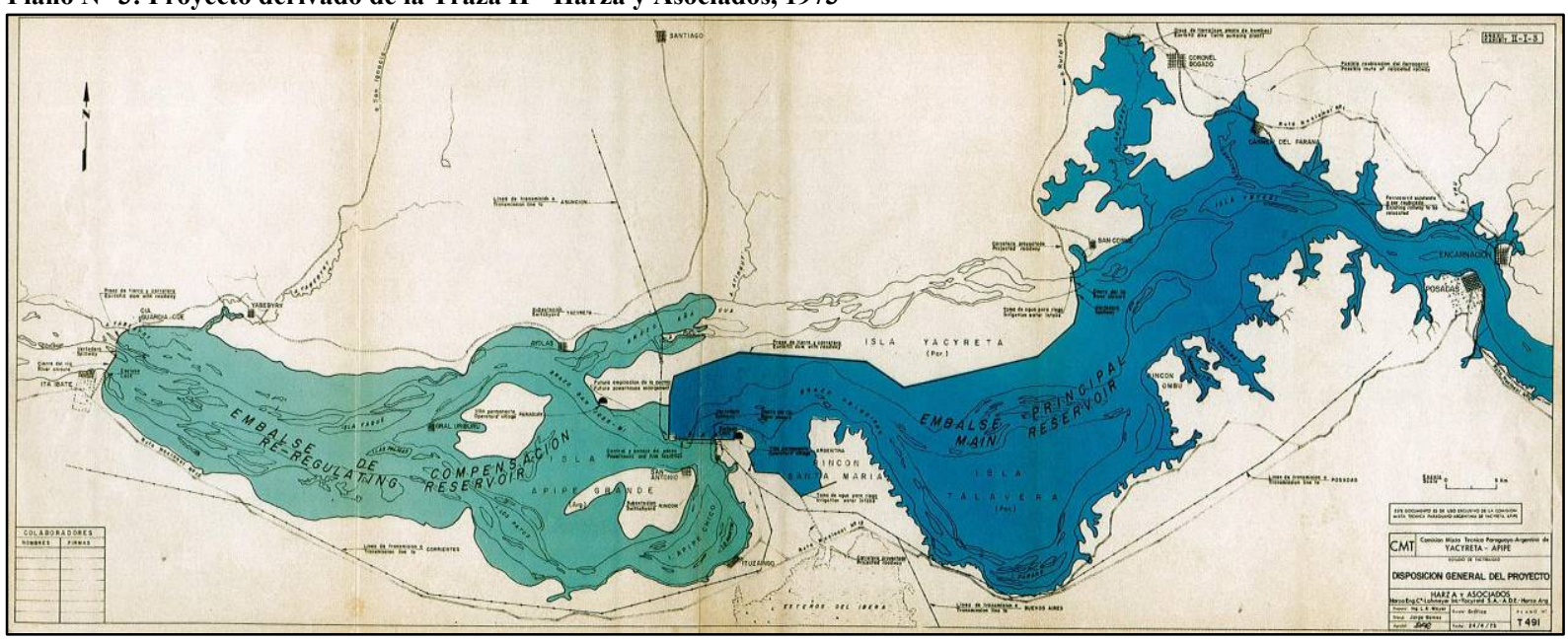

Fuente: Archivo de la Entidad Binacional Yacyretá (Levinton, 2010: 134).

Con este proyecto de gran impacto ambiental, el 3 de diciembre de 1973, se firmaba en Asunción del Paraguay, el Tratado de Yacyretá, ${ }^{68}$ (ver parágrafo I.3.3) que en su Artículo I, establece que:

"Las Altas Partes contratantes realizarán, en común y de acuerdo con lo previsto en el presente Tratado, el aprovechamiento hidroeléctrico, el mejoramiento de las condiciones de navegabilidad del Rio Paraná a la altura de isla Yacyretá y, eventualmente, la atenuación de los efectos depredadores de las inundaciones producidas por crecidas extraordinarias. " (EBY, 1973:5)

${ }^{68}$ El Tratado de Yacyretá, fue aprobado por Ley de la República del Paraguay No 433 del 20/12/1973, y por Ley de la República Argentina № 20.646 sancionada el 06/02/1974 y promulgada el 22/02/1974. La Ley Argentina, resalta además, los avances de la obra de Salto Grande (entre Argentina y Uruguay, concluida en 1979) y consolida la decisión de llevar adelante, entre Argentina y Paraguay, el emprendimiento de Corpus. 
Con la firma del Tratado, se creaba también la Entidad Binacional Yacyretá (EBY), en condiciones igualitarias para ambas partes, a la que se le asignaba la capacidad jurídica y la responsabilidad técnica para realizar los estudios y proyectos de las obras mencionadas, así como, la dirección, ejecución, puesta en marcha y explotación de las mismas.

Sobre finales de 1976 y principios de 1977, debido a una Crecida del río Paraná, se detectó que existía una conexión superficial entre el Brazo Aña Cuá y el Brazo Principal a través del estero llamado Mediodía, en una longitud de 7,5 km. y que el comportamiento del subsistema hidráulico compuesto por el Brazo Aña Cuá - Esteros de la Isla Yacyretá - Brazo Principal; confirmaba el sentido de escurrimiento a través de los esteros y la mecánica de carga y descarga. La Traza II debió recomponerse y el rediseño creó la Traza III.

Plano $\mathrm{N}^{\circ}$ 4: Proyecto derivado de la Traza III - Harza y Asociados, 1977

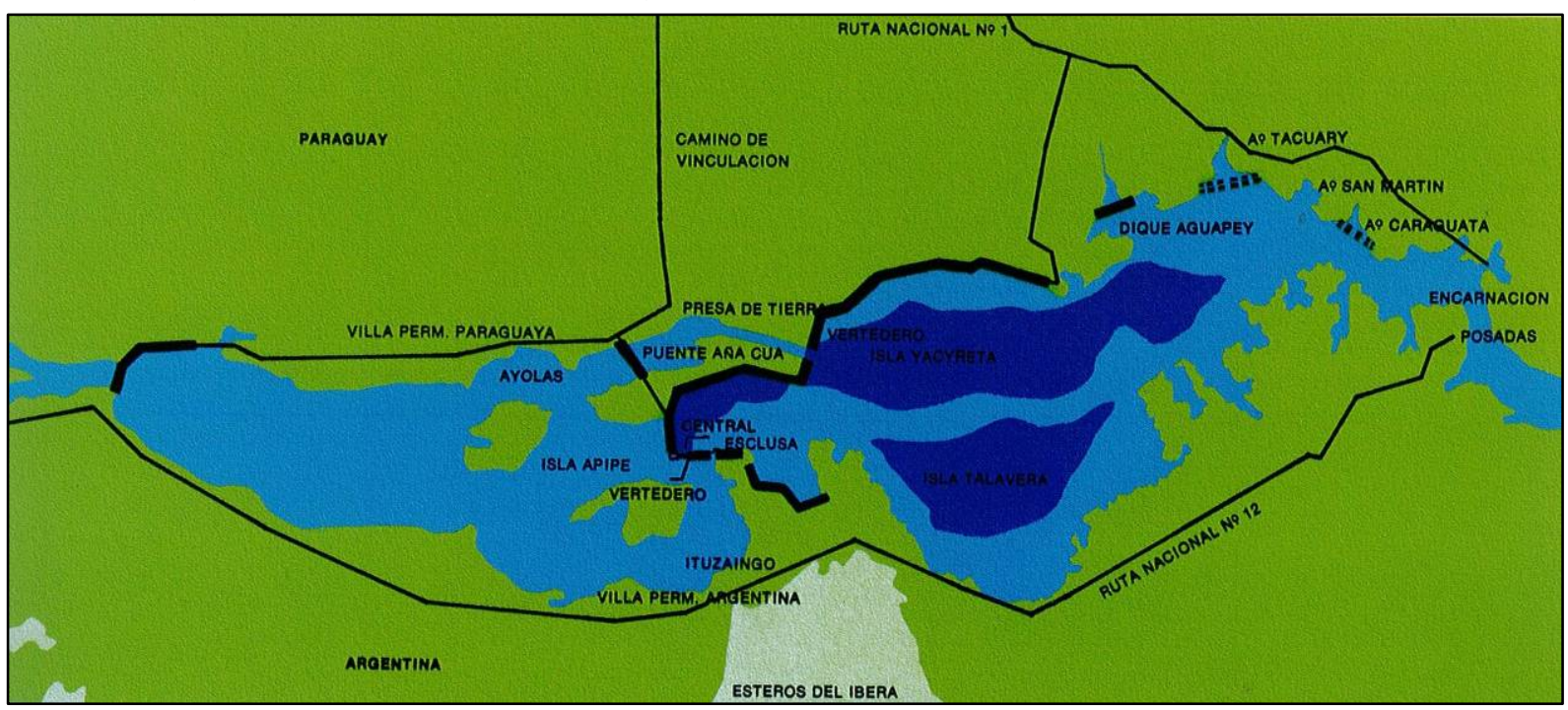

Fuente: Archivo de la Entidad Binacional Yacyretá (Levinton, 2010: 135).

La Memoria y Balance de 1976 de la Entidad Binacional Yacyretá, indicaba en su Disposición General, las siguientes modificaciones:

"[...] la presa del Embalse Principal cruzará el brazo navegable del río Paraná inmediatamente aguas debajo de los rápidos de Apipé, se extenderá río arriba sobre la isla Yacyretá en una longitud de $53 \mathrm{~km}$ para cruzar el Brazo Aña Cuá en las cercanías de San Cosme. En la margen izquierda la presa se extenderá hasta el Rincón Santa María. La longitud total de la presa es de aproximadamente $70 \mathrm{~km}$ que incluye una esclusa de navegación, un vertedero en el Brazo Principal del Paraná, una Central con 20 unidades y previsiones para instalaciones adicionales para 10 unidades más, [...] instalaciones para el pasaje de peces en la estructura de la Central y el Vertedero del Brazo Aña Cuá en el lado norte de la isla Yacyretá. El nivel del agua máximo normal en este embalse quedó establecidos en la cota 82 sobre el nivel medio del mar en Mar del Plata y el lago que se forma tiene una superficie de $1.420 \mathrm{~km}^{2}$ y un volumen de $16.900 \mathrm{Hm}^{3}$ y se extenderá aguas arriba alrededor de $250 \mathrm{~km}$ hasta las cercanías de Corpus. La presa del Embalse de Compensación cruzará el Paraná a la altura de Itá-Ibaté e incluirá 8,6 km de terraplenes, una esclusa de navegación, un vertedero e instalaciones para peces. El nivel del agua variará en este embalse, conforme a las descargas de la Central, entre la cota mínima de $58,5 \mathrm{~m}$ a la máxima de $64 \mathrm{~m}$. El embalse de compensación tendrá una superficie de $600 \mathrm{~km}^{2}$ y un volumen de $2.189 \mathrm{Hm}^{3}$ [...] 
Dique Aguapey: una presa de tierra con coronamiento a cota $86 \mathrm{~m}$. prevendrá contra la extensión del embalse hacia la cuenca de arroyo. El agua almacenada en la zona protegida será transferida al embalse principal mediante una planta de bombeo, conducciones y estructuras de descarga." (Levinton, 2010: 135).

Este proyecto contemplaba además, el endicamiento de los arroyos Tacuary y Caraguatá, evitando de esta manera, una mayor superficie de inundación de territorio paraguayo.

Pero la Traza definitiva de la represa fue establecida tres años después, por las Notas Reversales del 30 de agosto de 1979, que modificaba todo el Anexo 'B' del Tratado de Yacyretá. Las principales modificaciones, al proyecto de 1976, eran el establecimiento de una superficie máxima de inundación de $815 \mathrm{~km}^{2}$ de territorio paraguayo, que motivó la inclusión del cierre o endicamiento del arroyo San Martín, a los ya mencionados en esa misma margen y obras de defensa costera en todo el perímetro del embalse; fijando también, en 30 las unidades generadoras de la Central, en $86 \mathrm{msnm}$, la cota de coronamiento de las presas y ampliando la capacidad de evacuación del Vertedero Aña Cuá a 40.000 $\mathrm{m}^{3} / \mathrm{s}$, con el embalse a cota $84,5 \mathrm{msnm}$, con el objetivo de disminuir en todo lo posible los daños en la costa norte de la parte occidental de la isla Yacyretá.

Plano $N^{\circ}$ 5: Proyecto con Alternativas de Traza y Traza Definitiva [CIO.1, en color rojo] - Harza y Asociados, 1979

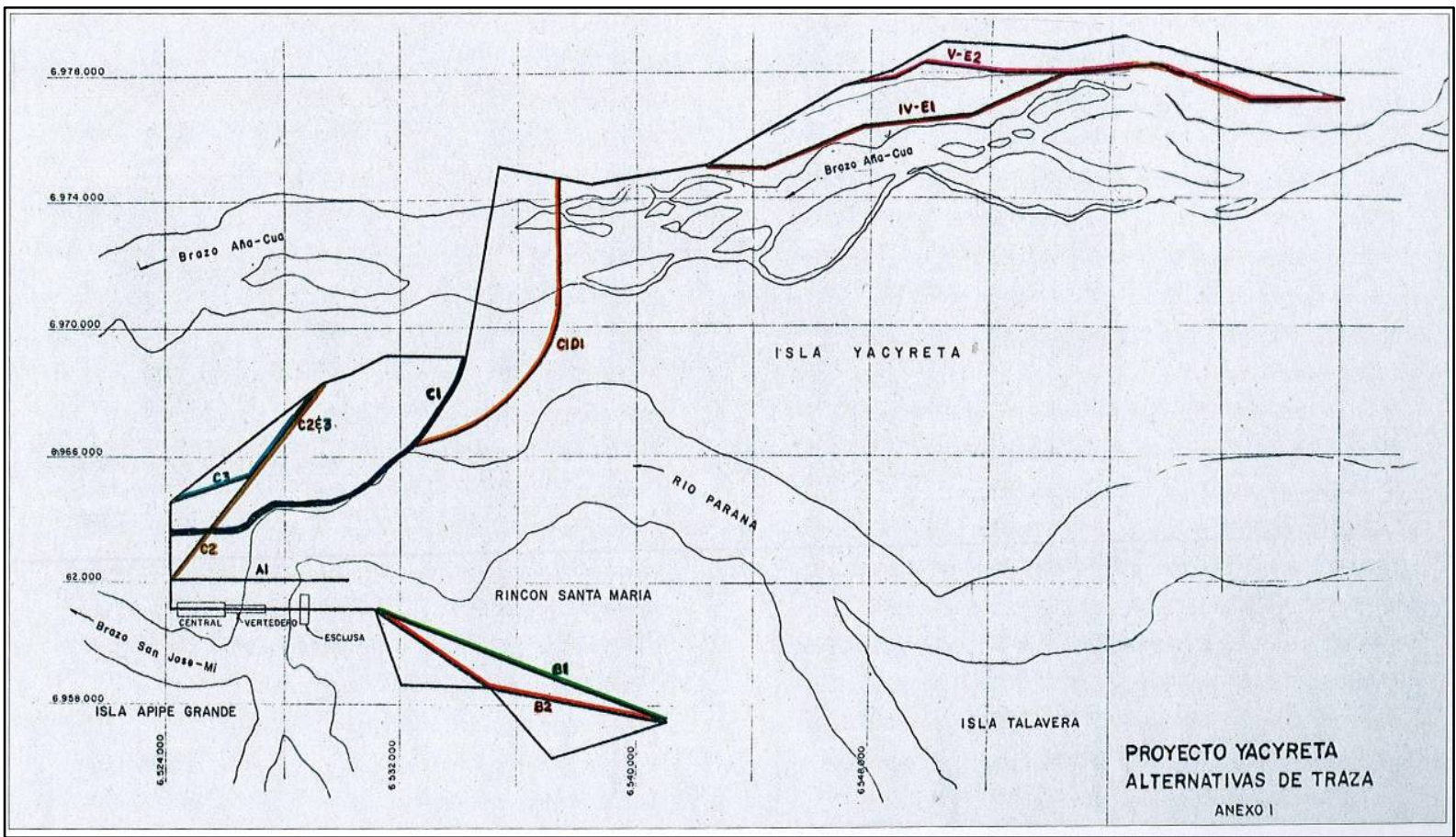

Fuente: Archivo de la Entidad Binacional Yacyretá (Levinton, 2010: 137).

En diciembre de 1979, se realizó el primer Censo de Población afectada por el Proyecto y se dio inicio a la construcción de las Villas permanentes y transitorias de Ayolas (PY) e Ituzaingó (AR), destinadas a los obreros y profesionales que construirían Yacyretá. Estas villas duplicaron la superficie de los cascos urbanos de ambos pueblos, comenzando a vislumbrase de este modo, la primera de las grandes transformaciones de Yacyretá (Lins Ribeiro, 2003). 


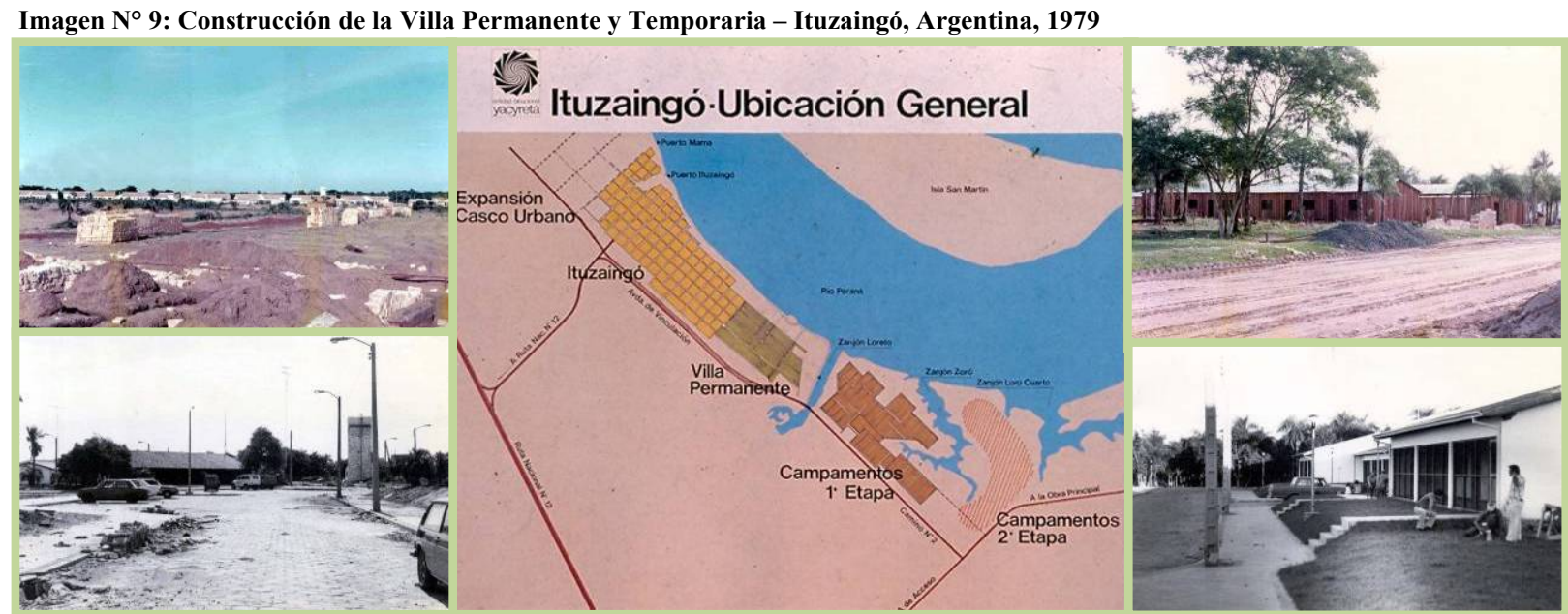

Fuente: Archivo de la Entidad Binacional Yacyretá.

El 2 de junio de 1980, se realizaba la apertura de las ofertas de las 5 empresas preseleccionadas para la Obra Principal (Contrato Y-C1), con un proyecto que ya presentaba al embalse compensador sólo como una posibilidad. En términos de afectación del paisaje, esto representaba no perder $600 \mathrm{~km}^{2}$ de territorio insular y continental, y consecuentemente de biodiversidad, aguas abajo de la Presa Principal.

Plano $N^{\circ}$ 6: Proyecto sin el Embalse Compensador - Harza y Asociados, 1980

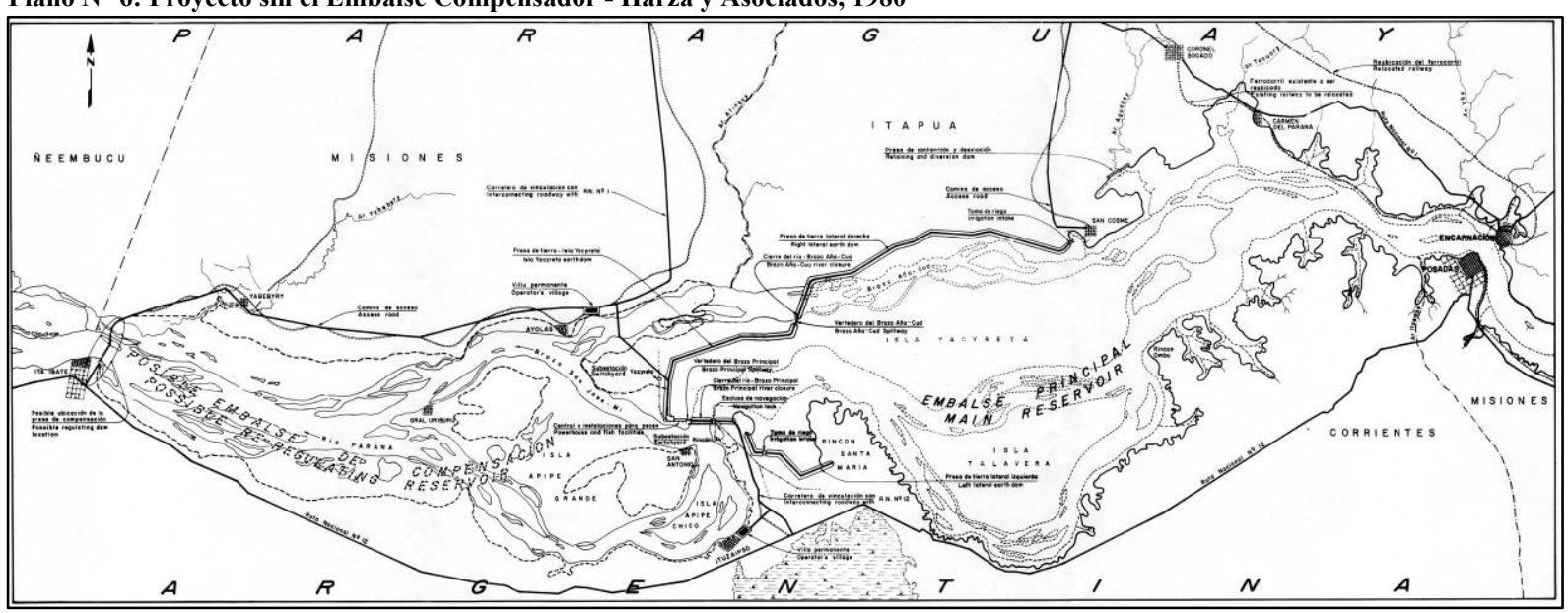

Fuente: Archivo de la Entidad Binacional Yacyretá.

Luego de un largo proceso de contratación, el 20 de octubre de 1983 se firmó el contrato entre la EBY y ERIDAY-UTE y el 3 de diciembre comenzaba la construcción de la Obra Principal (ver parágrafo I.3.4).

El Informe Trimestral de Avance del Proyecto, de diciembre de 1984, modificaba el largo total de la presa fijándolo en $63 \mathrm{~km}$ de longitud; fijaba su coronamiento en la cota 86,75 msnm (4,75 m. por encima del nivel del embalse que lo fijaba en cota $82 \mathrm{msnm}$ ), que la Central contaría con 20 unidades generadoras, con previsión para 10 más; establecía la localización de la esclusa de navegación en el sitio actual, es decir, en Rincón Santa María sobre la margen argentina, reduciendo sus dimensiones a un ancho de $27 \mathrm{~m}$. y una longitud de $237 \mathrm{~m}$. También fijaba las condiciones de operación y los caudales máximos erogables de los Vertederos a los actuales $95.000 \mathrm{~m}^{3} / \mathrm{s}$, para responder al pico de la 
máxima crecida probable; y ya no contemplaba ni el cierre del arroyo San Martín, ni hablaba de las características del embalse compensador.

El plano siguiente, muestra el proyecto con el cual se dio inicio a la ejecución del proyecto, dónde ya no existe al embalse compensador aguas debajo de la represa, así como la Traza adoptada.

Plano $N^{\circ}$ 7: Proyecto Definitivo sin Embalse Compensador - Harza y Asociados, 1984

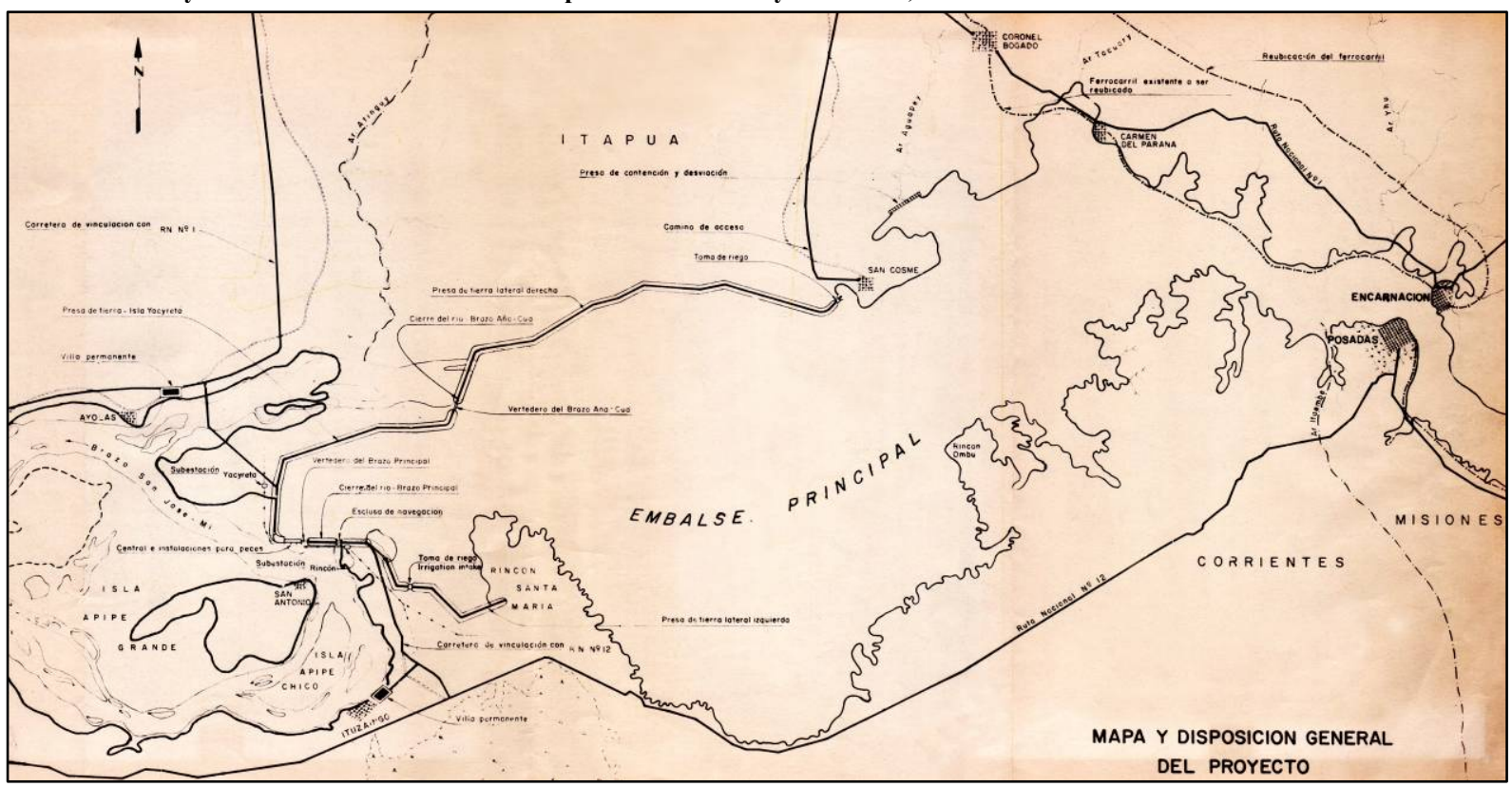

Fuente: Archivo de la Entidad Binacional Yacyretá.

En el mes de mayo de 1985, finalizó la construcción del Puente de Servicio sobre el Brazo Principal del Río Paraná y el 20 de diciembre, se presentaba la Nota-0547 CIDY/ERIDAY, que proponía modificar el ritmo de los trabajos en las Obras Civiles Principales (Levinton, 2010: 116). Con el fin de aliviar el impacto económico que imponía el programa original de la obra en el período de mayor concentración de los trabajos, se decidió solicitar al Contratista la presentación de otra alternativa de Reprogramación postergando desde fin de septiembre de 1990 a febrero de 1993 la puesta en marcha de la primera unidad generadora. Las fechas claves principales que resultaron de dicha reprogramación, fueron las siguientes: a) Inicio del desvío del río: Brazo Principal en abril de 1989 y Brazo Aña Cuá, en abril de 1990; b) Inicio del llenado del embalse, en noviembre de 1992; c) Inicio de generación comercial, en febrero de 1993 (ver parágrafos I.3.4 y I.3.5).

El 22 de octubre de 1986, se formalizó un ajuste al Contrato entre la EBY y CIDY, en el cual desaparecen los Proyectos de Relocalizaciones como objeto del mismo y el 27 de noviembre, se formaliza el Acta de Acuerdo EBY con ERIDAY UTE / Supresión de las Turbinas $\mathrm{N}^{\circ} 21$ a $\mathrm{N}^{\circ} 30$, aprobado por Resoluciones $\mathrm{CE}^{\circ} \mathrm{N}^{\circ}$ 792/86 y CA N 190/86, basadas en el Informe $\mathrm{N}^{\circ}$ I-29-5-005B (Levinton, 2010: 117).

Hacia fines de este año, la traza del Proyecto contemplaba el cierre de tres arroyos en la margen paraguaya: Aguapey, Tacuary y Caraguatá. 


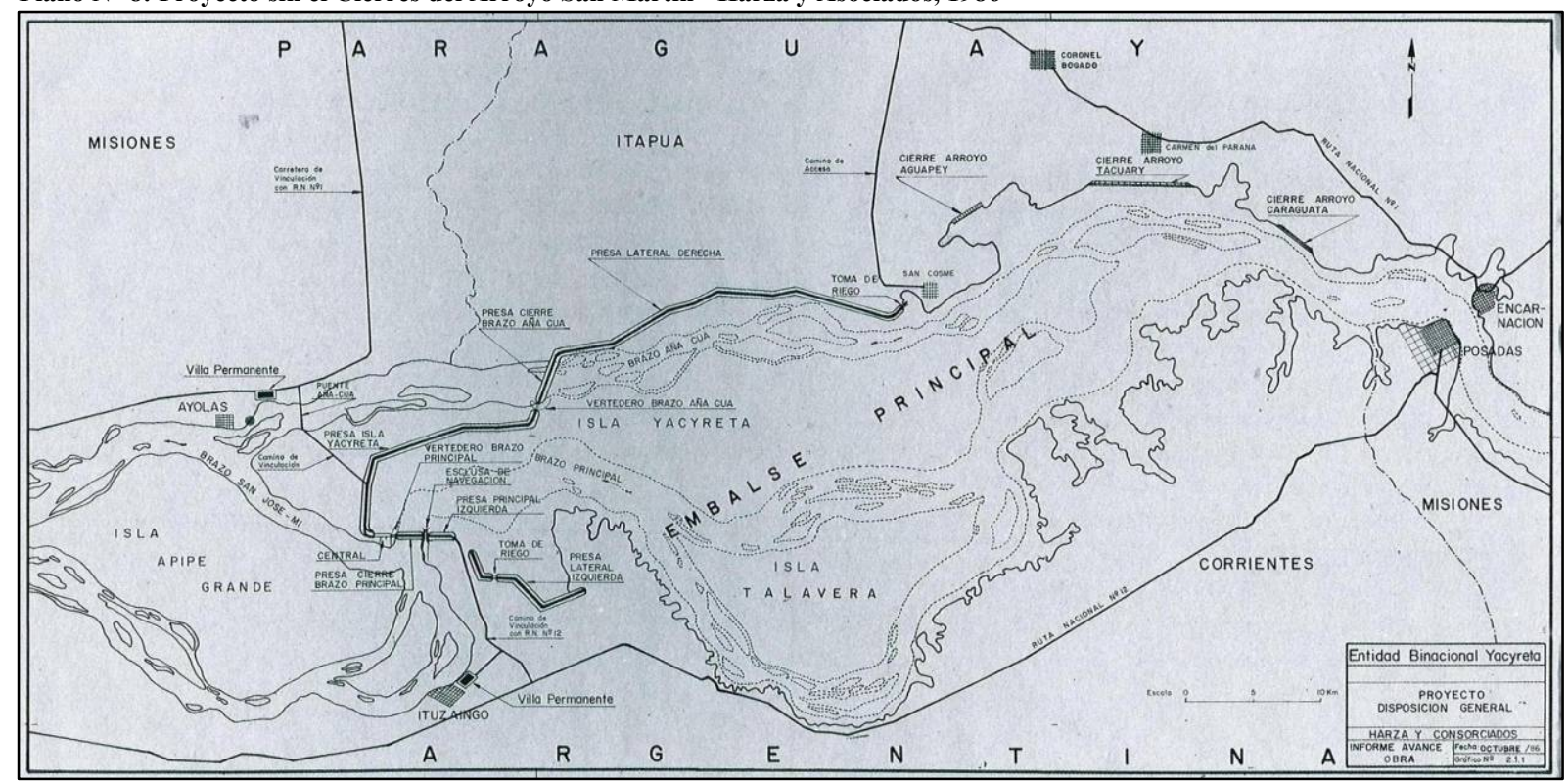

Fuente: Archivo de la Entidad Binacional Yacyretá (Levinton, 2010: 140).

El 26 de marzo de 1987, se firmó el Contrato Y-E1G-Generadores (10 primeros) unidades de generación y el 2 de octubre, se firmaron los Contratos Y-E5-Compuertas para Vertederos y Central y YE15-Equipamiento eléctrico para la Esclusa de Navegación (Levinton, 2010: 117).

En esta época, empieza a estudiarse también, la posibilidad de instalar una Central Hidroeléctrica complementaria en el Brazo Aña Cuá, que además de generar energía, seguiría manteniendo en dicho brazo un caudal de agua de tal manera de evitar su secado y asegurar el equilibrio ecológico del área.

El 5 de abril de 1988, se elabora un nuevo cronograma de las Obras Civiles Principales y el 27 de mayo, por Acta de Acuerdo de la Reprogramación de las Obras Contrato Y-C1 Obras Principales entre la EBY y el Contratista ERIDAY/UTE, se elimina la nave de montaje auxiliar de las unidades 10 y 11 (Levinton, 2010: 117). En julio, se concreta la decisión de llevar la cota del embalse a $83 \mathrm{msnm}$. El 18 de noviembre, se formaliza el denominado "Segundo Convenio de Propietarios", entre los gobiernos de Argentina y Paraguay, con el Banco Mundial. En noviembre, comenzó el montaje de la Cinta Transportadora Rotec en el Puente de Servicio para las tareas de construcción del pre-cierre del Río Paraná y el Director Ejecutivo de la EBY, mediante Nota 5564, define a CIDY el conjunto de Obras de Protección de los valles de los arroyos de la Margen Derecha: Aguapey, Tacuary, Caraguatá y San Martín. En diciembre, se pone en vigencia el Contrato Y-E2-Grúas de la Central / Puentes Grúas y el Contrato Y-E4 Compuertas y Dispositivos para Transferencia de Peces (Levinton, 2010: 118).

En marzo de 1989, comienzan los trabajos para el desvío del Brazo Principal del Río Paraná, en abril se habilita el Vertedero Principal. El 26 de ese mes se firman las Notas Reversales disponiéndose una nueva concepción de protección en el arroyo Aguapey con un cierre frontal mediante una presa y el drenaje de caudales a través de un canal, en el Tacuary con una defensa costera y cancelándose la 
construcción de las defensas de los arroyos Caraguata y San Martín. El 8 de junio se procede al cierre del Brazo Principal del río Paraná (Levinton, 2010: 118/9).

El 2 de abril de 1990, se inaugura el Puente Internacional San Roque González de Santa Cruz entre Posadas y Encarnación, cuya gestión comenzó en 1971 (Levinton, 2010: 119), que representa una gran obra de infraestructura que orientará una profunda transformación del paisaje urbano-costero y del desarrollo de la región, atando definitivamente los destinos de ambas ciudades

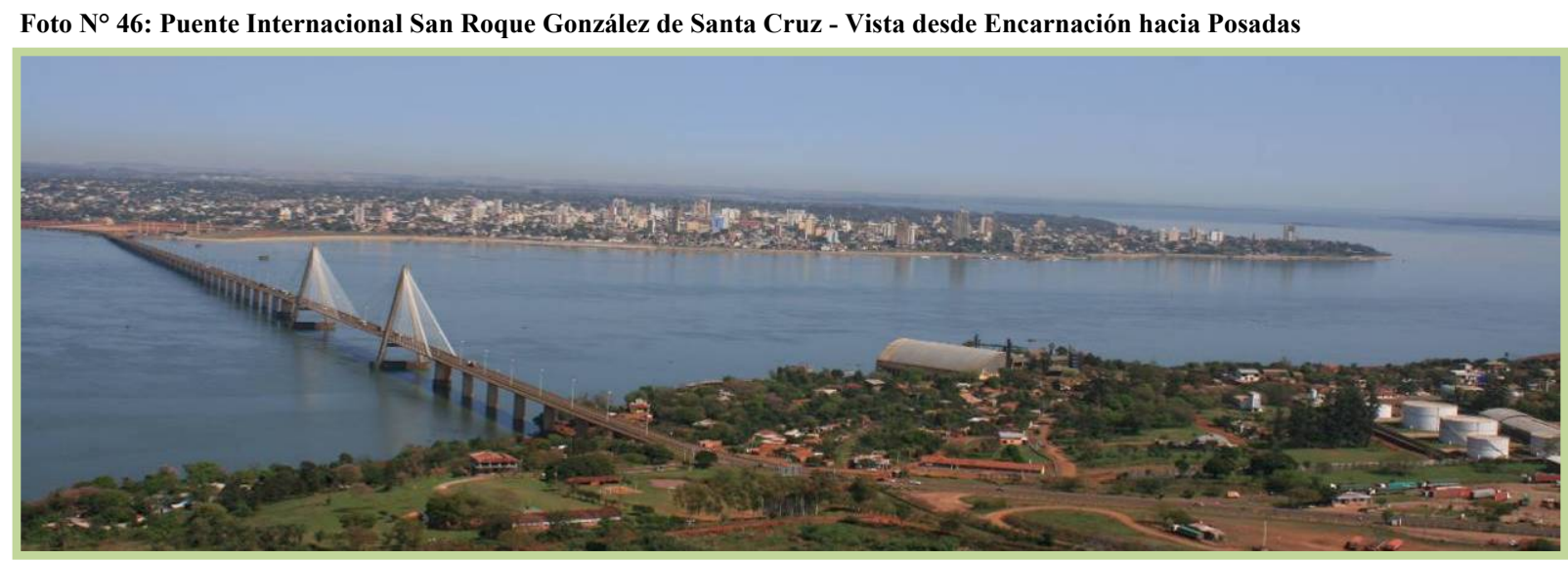

Fuente: Archivo fotográfico de la Entidad Binacional Yacyretá.

El 19 de mayo, se procede habilitar el Vertedero y al cierre del Brazo Aña Cuá. En tanto, hacia fines del año, el gobierno argentino, decide suspender las obras por un lapso de seis meses para encarar su replanteo.

El 7 de diciembre de 1991, el gobierno argentino informa en Ituzaingó (Corrientes AR), la decisión de concluir la construcción de Yacyretá, sustentada en la confirmación de créditos del Banco Mundial, del Eximbank de Japón y del Instituto de Desarrollo Económico del Canadá.

El 9 de enero de 1992, se establece por Notas Reversales un nuevo Cronograma de Obras, con fecha de inicio de operación el $1^{\circ}$ de marzo de 1994 (Levinton, 2010: 119). El $1^{\circ}$ de marzo entra en operación el primer puente grúa destinado a manipular las turbinas y el $1^{\circ}$ de abril la grúa pórtico para el cierre de emergencia de las tomas de la Central. El $1^{\circ}$ de junio se inicia la construcción de la Línea de Transmisión Yacyretá-Resistencia y comienza a analizarse la posibilidad de generar a cota reducida (76 msnm). El 28 de julio, el Acta de Acuerdo entre al EBY y ERIDAY UTE, fija el $1^{\circ}$ de septiembre de 1994 como límite máximo para la puesta en operación de la Unidad Generadora $\mathrm{N}^{\circ} 1$. El $1^{\circ}$ de agosto, se realiza el cierre de las tomas de las unidades generadoras para permitir la remoción de la ataguía de protección y el 4 de septiembre, se formaliza el 'Tercer Convenio de Propietarios' entre los Gobiernos de Argentina y Paraguay con el Banco Mundial, que define las condiciones para la permanencia Prolongada en la Cota 76 msnm. Entre el 9 y 13 de noviembre, se realiza la XI Reunión del Panel de Expertos, donde el Consultor, tomando en consideración la propuesta de una Misión (oct./nov.'92) de los Ingenieros Víctor de Mello y Luis G. DE Mello, presentó tres alternativas de Sección de la Presa para su correspondiente evaluación (Levinton, 2010: 120). 
El primero de junio de 1993, se habilita la Esclusa de Navegación. El 16 de julio, se concreta la privatización del sistema de transporte de energía eléctrica de alta tensión en la Argentina (Transener S.A.) y en diciembre, se efectúa el control de los Vertederos (Principal y Aña Cuá), para la operación del embalse y recrecimiento de las crestas (Levinton, 2010: 121). En tanto que entre el 2 y el 6 de agosto de ese año, se realizó la XII Reunión del Panel de Expertos, donde el Consultor presentó el diseño final del proyecto y el Panel no hizo comentarios sobre el diseño (ver parágrafo I.3.5).

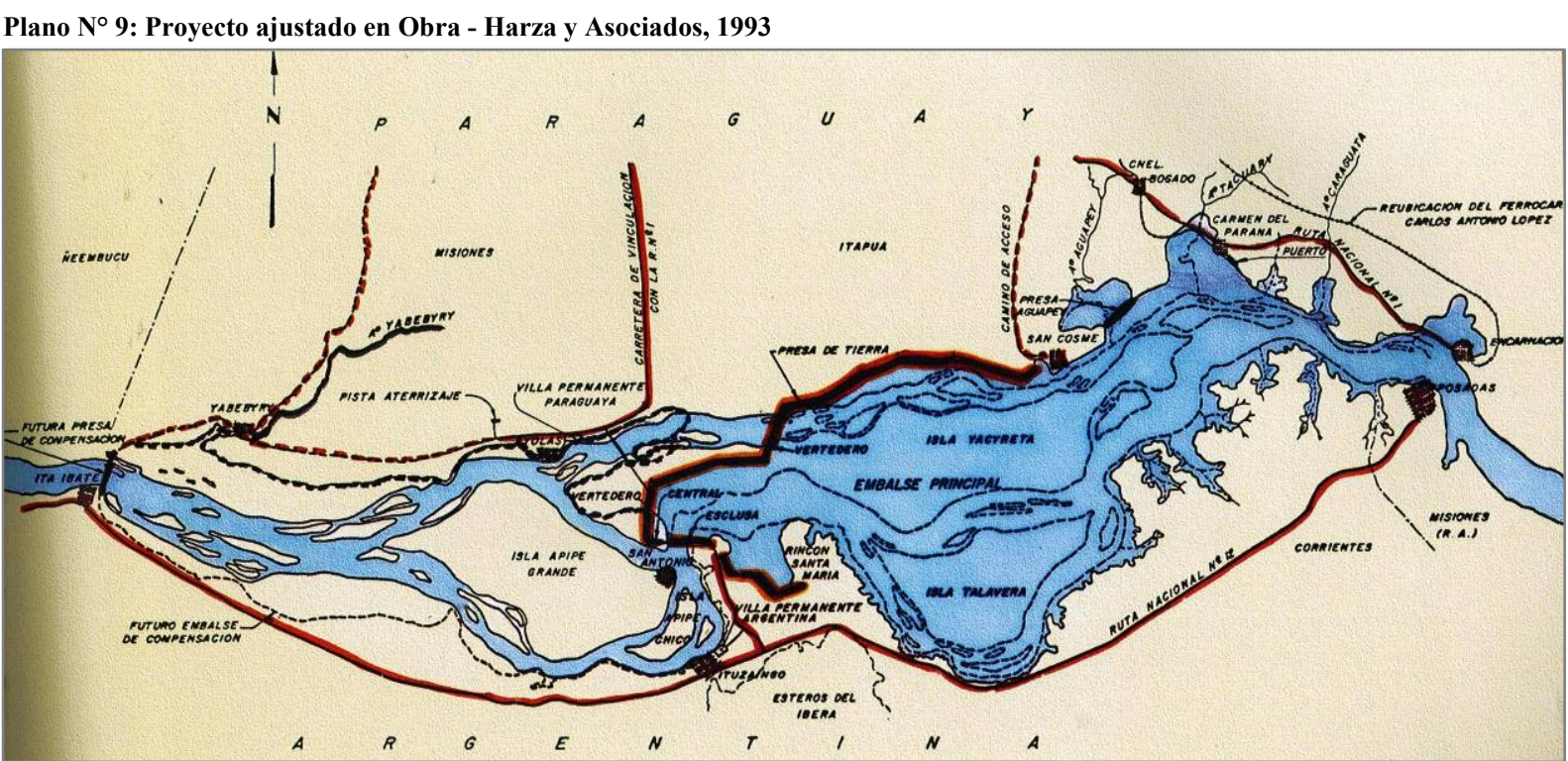

Fuente: Archivo de la Entidad Binacional Yacyretá (Levinton, 2010: 143).

El $1^{\circ}$ de febrero de 1994 se da inicio del recrecimiento de las Crestas de ambos Vertederos; el $1^{\circ}$ de junio comienza el llenado del embalse a Cota $76 \mathrm{msnm}$ para dar inicio a las pruebas de generación de energía; el $1^{\circ}$ de junio se concreta la terminación de las Presas de tierra a cota 86,00 msnm antes del comienzo del llenado del embalse y el 2 de septiembre se inaugura la Central Hidroeléctrica de Yacyretá con la puesta en funcionamiento de la Primera Turbina, o Unidad de Generación (UG No 1), iniciándose así, la generación a cota reducida $(76,00 \mathrm{msnm})$. El 8 de noviembre, se pone en marcha comercial, la UG N² (Levinton, 2010: 122).

El 20 de enero de 1995, se pone en marcha comercial, la UG Nº 3; el 27 de febrero, la UG N 4; el 3 de mayo, la UG No 5 y el 28 de julio, la $\mathrm{UG} \mathrm{N}^{\circ} 6$. En diciembre se desata la crisis financiera de México, con su denominado "Efecto Tequila", que impactará negativamente en la región y también en Yacyretá.

En 1996, el gobierno argentino suspende el financiamiento de las obras complementarias, la EBY acuerda con el Banco Mundial (BIRF) la permanencia prolongada a cota $76 \mathrm{msnm}$, a lo que adhiere posteriormente el Banco Interamericano de Desarrollo (BID), aunque en ese contexto las obras principales continuaron con el cronograma de ejecución, en especial el montaje de las Turbinas.

Como hemos mencionado en el Capítulo I (parágrafo I.3.5), el 7 de julio de 1998, cumpliendo el cronograma, se pusieron en marcha la totalidad de las 20 UG de la Central Hidroeléctrica Yacyretá y en septiembre, se declaran finalizadas las tareas constructivas de la Obra Principal (Levinton, 2010: 122/3). 


$\begin{array}{lll}\text { Rea(25) } & \begin{array}{l}\text { Facultad } \\ \text { de }\end{array} & \begin{array}{l}\text { Universidad } \\ \text { Nacional } \\ \text { Arquitectura } \\ \text { y Urbanismo }\end{array} \\ \text { Pehuen } & \text { La Plata }\end{array}$

\section{III.1.2. Principales elementos que operan la transformación del paisaje}

Yacyretá constituye una gran obra de infraestructura destinada a la generación de energía hidroeléctrica, construida sobre el río Paraná, que conforma la frontera entre la República Argentina y la República del Paraguay, y cuya cuenca, que nace en la República Federativa de Brasil, es una de las más extensas y sistematizadas del mundo (ver parágrafo II.2.3).

Fotos $N^{\circ} 47$ y 48: Proyecto Hidroeléctrico Yacyretá - Obras Principales y Central Hidroeléctrica

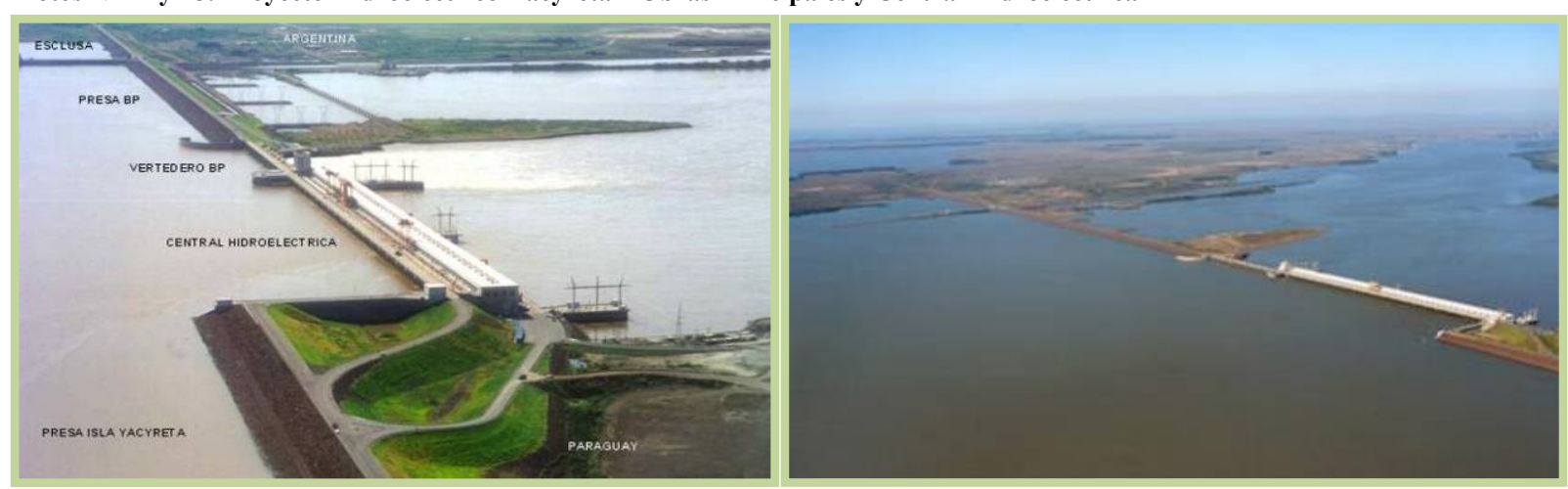

Fuente: Archivo fotográfico de la Entidad Binacional Yacyretá.

La presa fue situada a unos $2 \mathrm{Km}$. aguas abajo de los rápidos del Apipé, frente a las localidades de Ituzaingó (Corrientes, Argentina) y de Ayolas (Misiones, Paraguay); a 70 Km. al O. del eje Posadas (Misiones, Argentina) - Encarnación (Itapúa, Paraguay); a 300 Km. al S-E de Asunción y a 1.000 Km. al N. de Buenos Aires. Los mapas siguientes, muestran la ubicación general del proyecto.

Mapas No 11 y 12: Proyecto Hidroeléctrico Yacyretá - Ubicación General
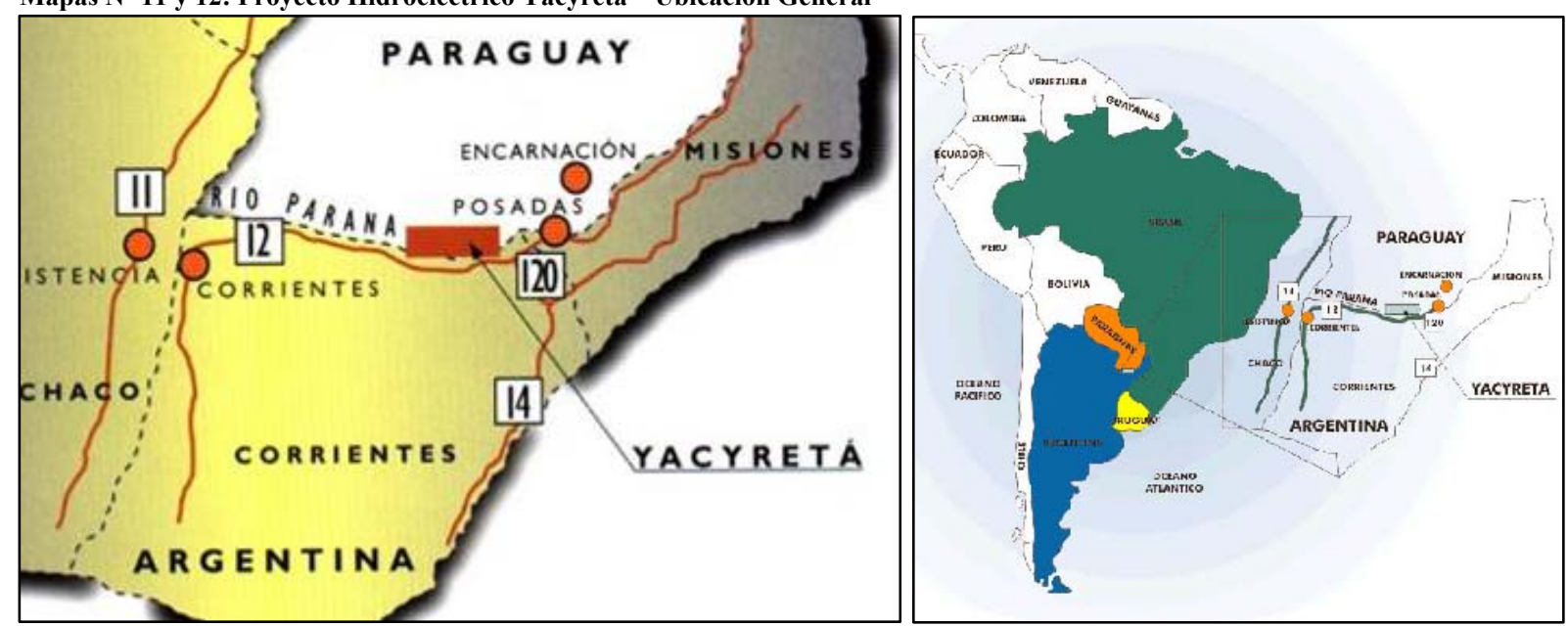

Fuente: Entidad Binacional Yacyretá.

El propósito principal del Proyecto Hidroeléctrico Yacyretá (PHY), cuyas obras principales han sido concluidas en 1994 (ver parágrafo I.3.5), es el aprovechamiento de un recurso natural renovable: las aguas del río Paraná, con el fin de producir energía eléctrica necesaria para cubrir la demanda a mediano plazo del mercado argentino-paraguayo; así como, el mejoramiento de las condiciones de navegabilidad, la eventual atenuación de crecidas y facilitar el desarrollo de riego (EBY, 1992.a: 11). 
Desde otra perspectiva de análisis, Lins Ribeiro presenta este aspecto de la siguiente manera:

"El principal objetivo de Yacyretá es el de proveer energía hidroeléctrica para el sistema energético de la Argentina. También se presenta la represa como un proyecto 'multipropósito', término con que son calificados numerosos proyectos. Es una estrategia común de los promotores de los proyectos de gran escala, destacar los beneficios secundarios [...]. De este modo [...], se da por entendido el impacto de Yacyretá sobre el desarrollo al eliminar los rápidos del Apipé y construir compuertas para la navegación. También supone tener un impacto positivo sobre la agricultura de irrigación, el control de inundaciones, la recreación, el turismo, la pesca, el transporte por tierra (pasará sobre la represa una autopista internacional que conectará Paraguay con la Argentina) y el desarrollo regional en general.

Cualesquiera sean los resultados del esquema multipropósito, el nombre de Yacyretá siempre estará asociado a la producción de energía." (Lins Ribeiro, 2003: 61).

\section{III.1.2.1. Las Obras Civiles Principales}

Las obras civiles principales, conformadas principalmente por la presa de tierra, la central, los vertederos, la esclusa de navegación y las obras de protección de arroyos, se exponen en el Gráfico $\mathrm{N}^{\circ} 2$ y se describen a continuación.

Gráfico No 2: Proyecto Hidroeléctrico Yacyretá - Localización de las Obras Civiles Principales

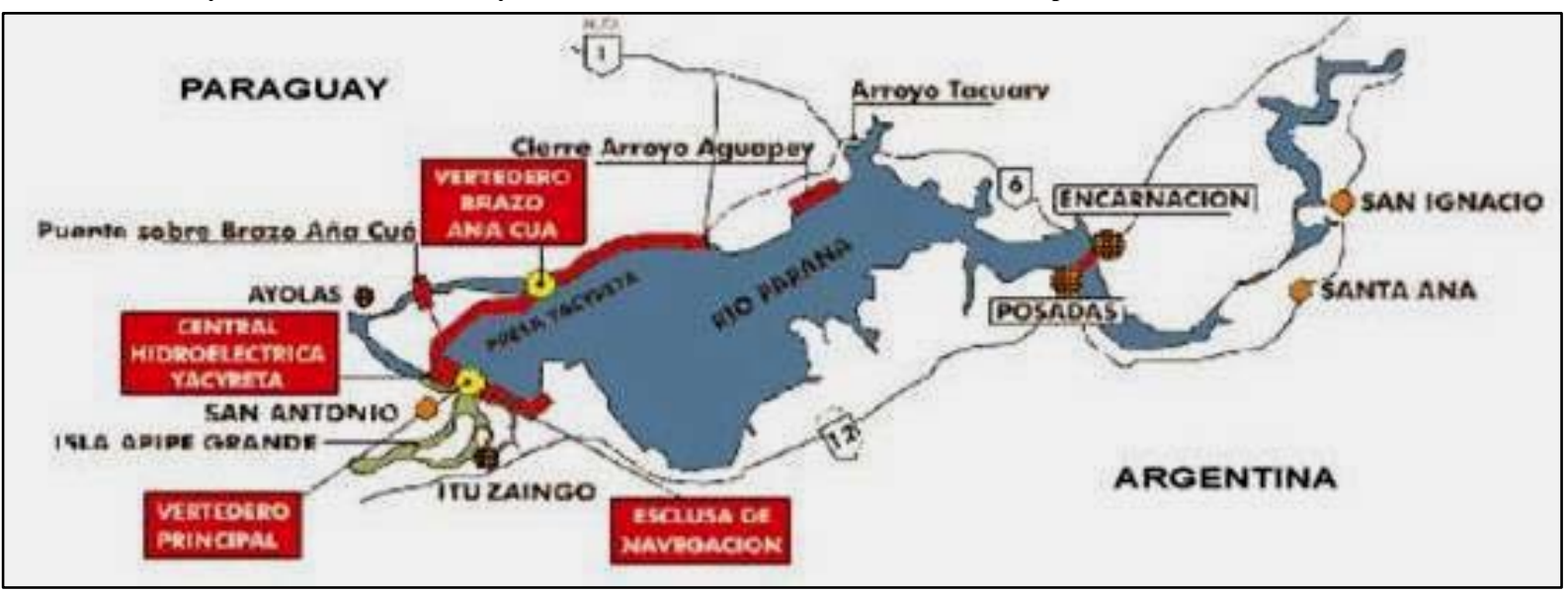

Fuente: Archivos de la Entidad Binacional Yacyretá.

\section{A. Presas de Tierra}

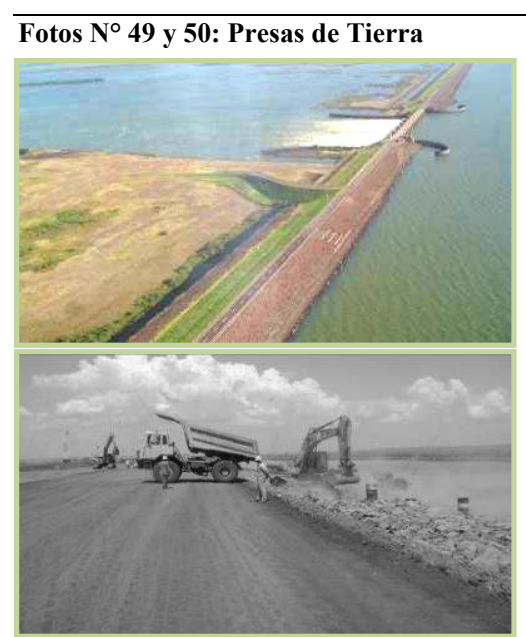

El embalse principal se forma mediante la construcción de varias presas de materiales sueltos, con una longitud de 64,7 kilómetros, y que junto con las estructuras principales de hormigón armado, cierran su perímetro, hasta las zonas más altas de las márgenes argentina y paraguaya.

Estas presas, delimitan un embalse de $1.602 \mathrm{~km}^{2}$, definido por 602 $\mathrm{km}^{2}$ del cauce original del río Paraná y unos $1.000 \mathrm{~km}^{2}$ de tierras inundadas ( $80 \%$ en Paraguay), que se extiende hasta $200 \mathrm{Km}$. aguas arriba del río Paraná.

Fuente: Archivo EBY 


\section{A.1. Carretera de Vinculación}

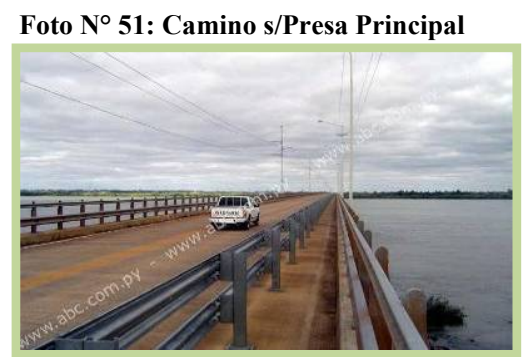

La unión entre la Ruta Nacional No 12 (Argentina) y la Ruta Nacional $\mathrm{N}^{\circ} 1$ (Paraguay), se realiza por una vía de doble trocha sobre el puente del vertedero Brazo Principal, la plataforma de la Central y el tramo de presa Isla Yacyretá, que se une al tramo carretero y al puente sobre el Brazo Aña Cuá.

\section{A.2. Puente sobre el Brazo Aña Cuá}

Foto $N^{\circ}$ 52: Puente hacia Ayolas (PY)

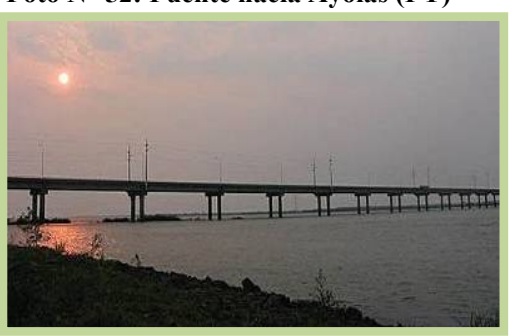

Fuente: Archivo EBY

\section{A.3. Tomas de Riego}

Foto $\mathrm{N}^{\circ}$ 53: Toma de Riego MD

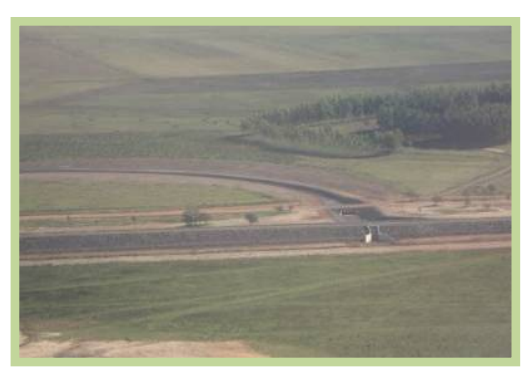

Las dos tomas, de construcción similar, permiten el desarrollo de la agricultura de regadío en ambas márgenes. Una de las tomas está ubicada cerca de San Cosme (Paraguay) y la otra en Rincón Santa María (Argentina).Estos lugares, han sido seleccionados para permitir el riego por gravedad de las tierras aptas adyacentes. El caudal de diseño se ha estimado en $108 \mathrm{~m}^{3} / \mathrm{s}$ en cada toma.

Fuente: Archivo EBY

\section{B. Central Hidroeléctrica}

La estructura y cubierta de la sala de máquinas es de hormigón armado, con una longitud de 808 m. y un ancho de $80 \mathrm{~m}$., dónde se ubican 20 turbinas con sus conductos de agua, un sector de tomas (aguas arriba) y varias galerías de servicio (aguas abajo). El edificio de las oficinas principales se emplaza aguas arriba, totalmente integrado a la misma, en la zona adyacente al Vertedero Principal.

Foto $N^{\circ}$ 54: Central Hidroeléctrica y Vertedero Principal

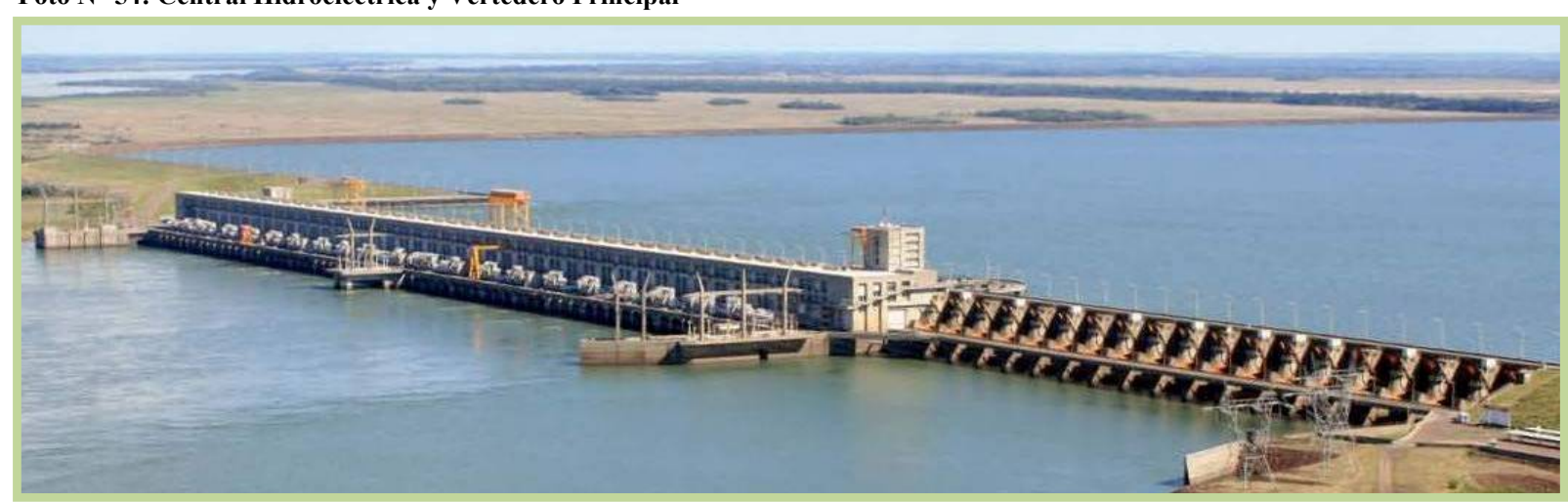

Fuente: Archivo fotográfico de la Entidad Binacional Yacyretá. 
La Central tiene dos Naves de Montaje denominadas Principal y Auxiliar situadas en ambos extremos, con cuatro Puentes Grúa que recorren la Nave de Montaje y la Sala de Generación, dónde se ubican las 20 Turbinas Kaplan de eje vertical, acopladas directamente al generador. Con un salto nominal de 21,30 m. y un caudal máximo turbinable de $16.600 \mathrm{~m}^{3} / \mathrm{segundo}$, a cota de operación definitiva (83 msnm), las 20 turbinas permiten contar con una potencia máxima disponible de unos 3.100 MW y de una energía media anual de unos $20.000 \mathrm{GWh} /$ año.

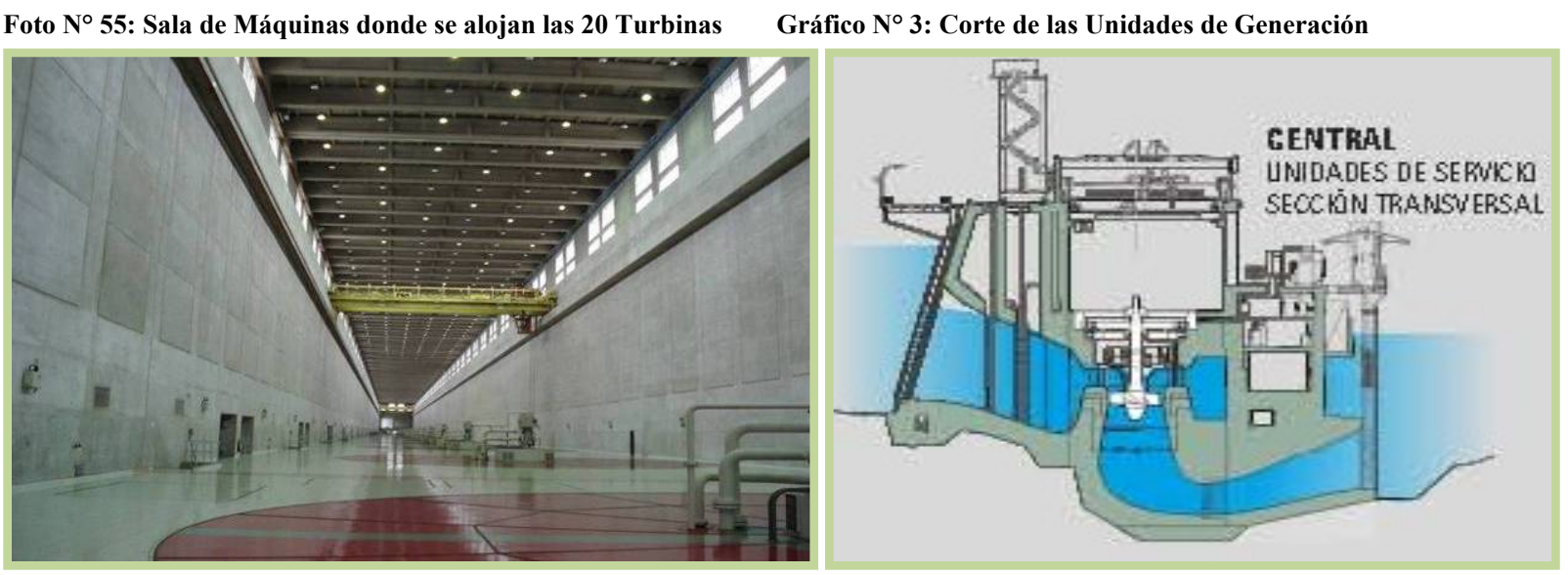

Fuente: Archivo fotográfico y general de la Entidad Binacional Yacyretá.

\section{Estación de Transferencia de Peces}

La Central cuenta, en ambos extremos de la casa de máquinas, con instalaciones para transferencia de peces, que permiten su migración aguas arriba de la Presa. Una a la izquierda -con 2 ascensoresentre la nave y el vertedero principal, y otra a la derecha -también con 2 ascensores- integrada en un monolito con la nave auxiliar de montaje, aguas abajo del muro de cierre lateral derecho. El sistema dispone de tomas de captación que se ubican en la estructura principal y en las Unidades de Generación UG $\mathrm{N}^{\mathrm{o}} 7$ y UG $\mathrm{N}^{\mathrm{o}} 14$, vinculadas entre sí por medio de un canal transversal.

Foto $N^{\circ}$ 56: Ascensor de Peces

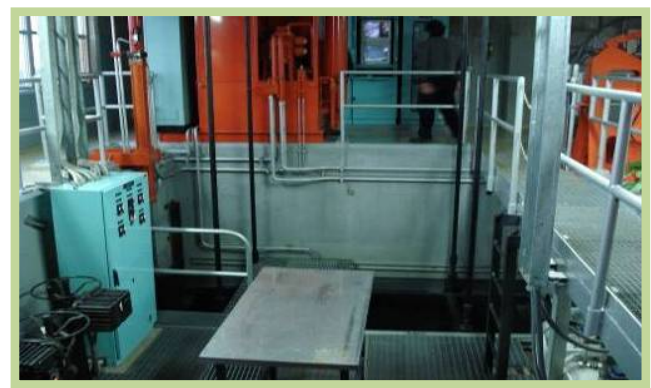

Gráfico $N^{\circ}$ 4: Corte del Sistema de Transferencia

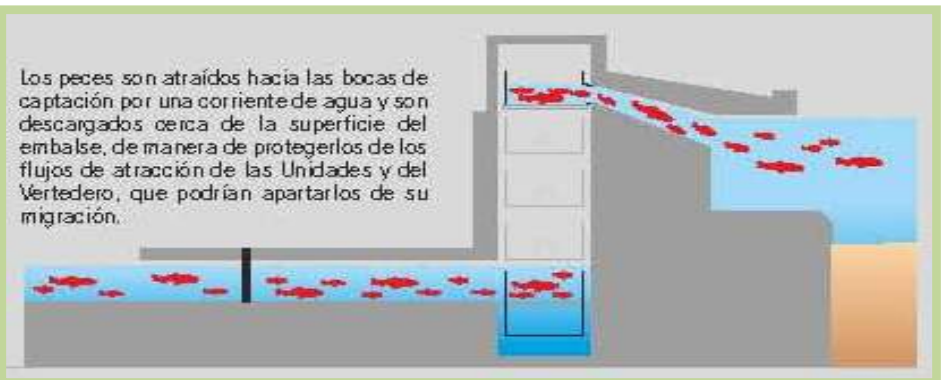

Fuente: Archivo fotográfico y general de la Entidad Binacional Yacyretá.

\section{Vertederos}

El Complejo Yacyretá cuenta con dos vertederos, denominados: Brazo Principal y Brazo Aña Cuá, ubicados ambos en Isla Yacyretá, el primero sobre la margen derecha adyacente a la Central y el segundo en la margen izquierda del Brazo Aña Cuá. En conjunto están diseñados para garantizar una capacidad de descarga de hasta $95.000 \mathrm{~m}^{3} / \mathrm{s}$ que corresponde a la máxima crecida probable, que estadísticamente podría sobrevenir. Son del tipo convencional a lámina guiada, equipados en sus crestas 
con compuertas radiales que se deslizan en guías curvas alojadas en las pilas y deflectores que orientan el flujo para evitar la sobresaturación gaseosa. Sobre las pilas de ambos Vertederos, aguas arriba, se encuentran los puentes que empalman con los caminos de coronamiento de las presas adyacentes.

\section{D.1. Vertedero Brazo Principal}

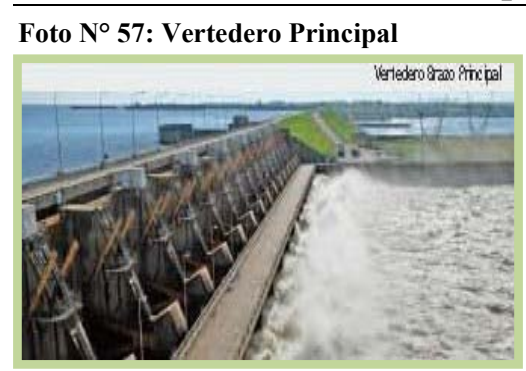

Dotado de 18 compuertas radiales de $15 \mathrm{~m}$. de ancho y $19,50 \mathrm{~m}$. de alto, operadas con servomotores hidráulicos.

La cresta vertedora está a cota $63,5 \mathrm{msnm}$.

La pileta de aquietamiento tiene un ancho de $342 \mathrm{~m}$. y una longitud de $100 \mathrm{~m}$.

Fuente: Archivo EBY

\section{D.2. Vertedero Brazo Aña Cuá}

Foto $N^{\circ}$ 58: Vertedero B. Aña Cuá

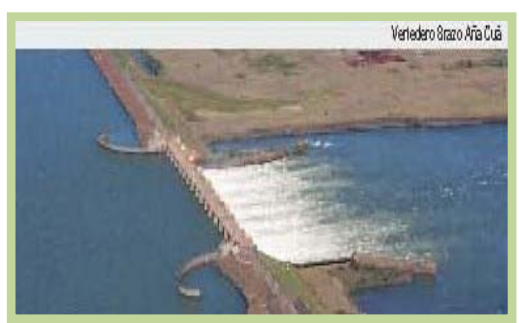

Dotado de 16 compuertas radiales de $15 \mathrm{~m}$ de ancho y $17,30 \mathrm{~m}$ de alto, son también operadas con servomotores hidráulicos.

La cresta vertedora está a cota $66,5 \mathrm{msnm}$.

La pileta de aquietamiento tiene $304 \mathrm{~m}$. de ancho y $90 \mathrm{~m}$. de largo.

Fuente: Archivo EBY

En ambos vertederos, se construyeron deflectores en las rápidas vertedoras de $4 \mathrm{~m}$. de longitud, ubicados a Cotas 57 y 62 msnm, a los efectos de disminuir los niveles de sobresaturación gaseosa aguas abajo.

\section{E. Esclusa de Navegación}

Para mantener la navegación en el río, se construyó una Esclusa, situada en Rincón Santa María, sobre margen argentina, cuyo volumen de hormigón es de $557.000 \mathrm{~m}^{3}$. La Esclusa es operada por la Entidad Binacional Yacyretá, en coordinación con la Prefectura Naval Argentina, con calidad certificada por Norma ISO 9002, en forma gratuita y continua.

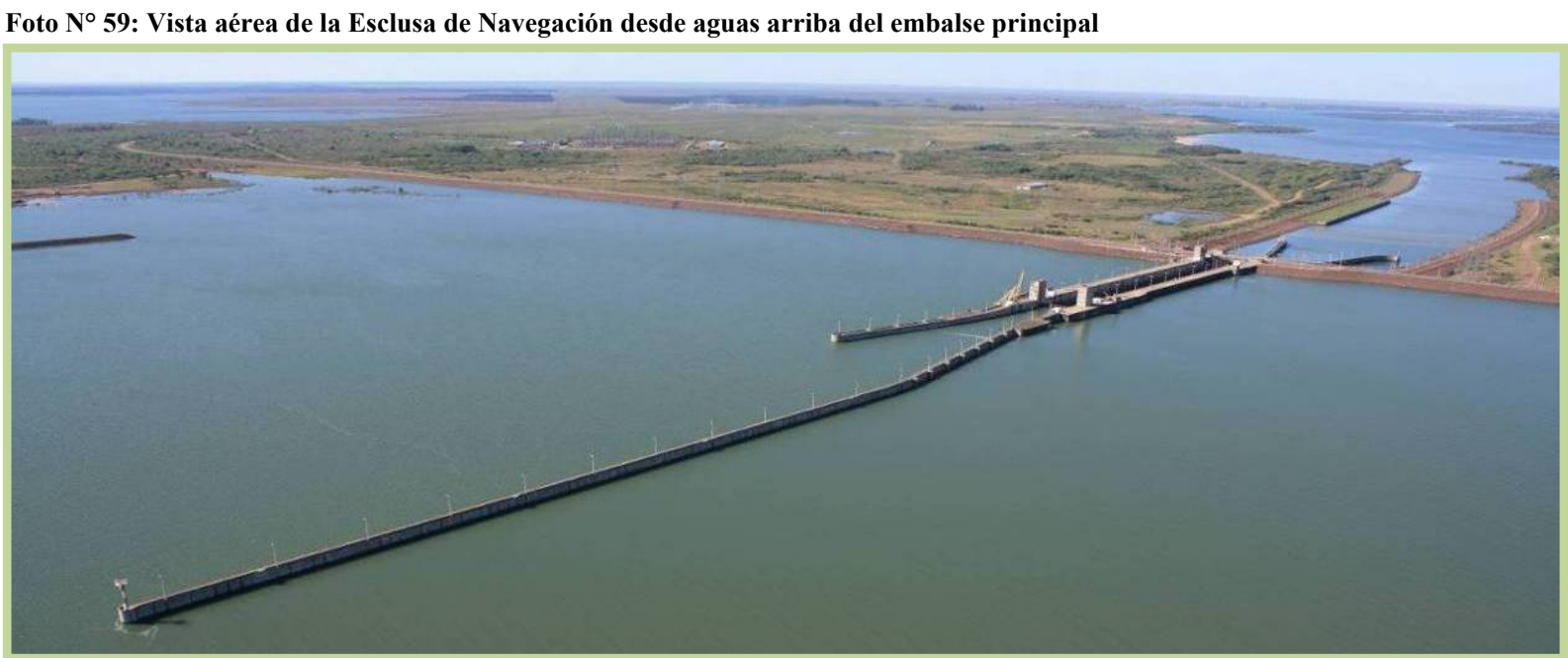

Fuente: Archivo fotográfico de la Entidad Binacional Yacyretá. 
El cuenco tiene una longitud útil de $236 \mathrm{~m}$., su longitud total entre compuertas es de $270 \mathrm{~m}$, un ancho libre de $27 \mathrm{~m}$, una profundidad mínima de agua de $5 \mathrm{~m}$, que con los canales de acceso aguas arriba y abajo de la misma, permite el paso de embarcaciones de hasta 12 pies de calado, con un tiempo de esclusado de 45 minutos. El canal de acceso aguas arriba, tiene un ancho de $100 \mathrm{~m}$., y aguas abajo tiene un ancho de fondo de $120 \mathrm{~m}$. a $140 \mathrm{~m}$., con muros de encauzamiento para las embarcaciones y un muro de amarre y espera de $420 \mathrm{~m}$. de longitud. El coronamiento de los muros laterales se halla a cota $86,00 \mathrm{msnm}$. El cuenco aloja galerías de alimentación y desagüe para operar el sistema, con compuertas radiales que permiten el ingreso o egreso del agua. Durante los cambios de nivel los buques se amarran en bitas (amarraderos) flotantes, que cambian de nivel junto con ellos y los mantienen centrados. Su extremo aguas arriba, está cerrado por una compuerta plana de rodillos de $10 \mathrm{~m}$. de alto y aguas abajo se emplaza una compuerta de dos hojas de $30 \mathrm{~m}$. de alto, operada con pistones hidráulicos. Pose además, diques rompeolas para proteger del oleaje a las embarcaciones y un puente carretero basculante sobre el coronamiento de la Esclusa.

\section{F. Líneas Energéticas}

El transporte y la distribución son funciones que efectúan los sistemas interconectados de ambos países. La estación ubicada en Rincón Santa María (próxima a Ituzaingó) interconecta la Central con el Sistema de Transmisión Argentino y la ubicada en Ayolas con el Sistema de Transmisión Paraguayo.

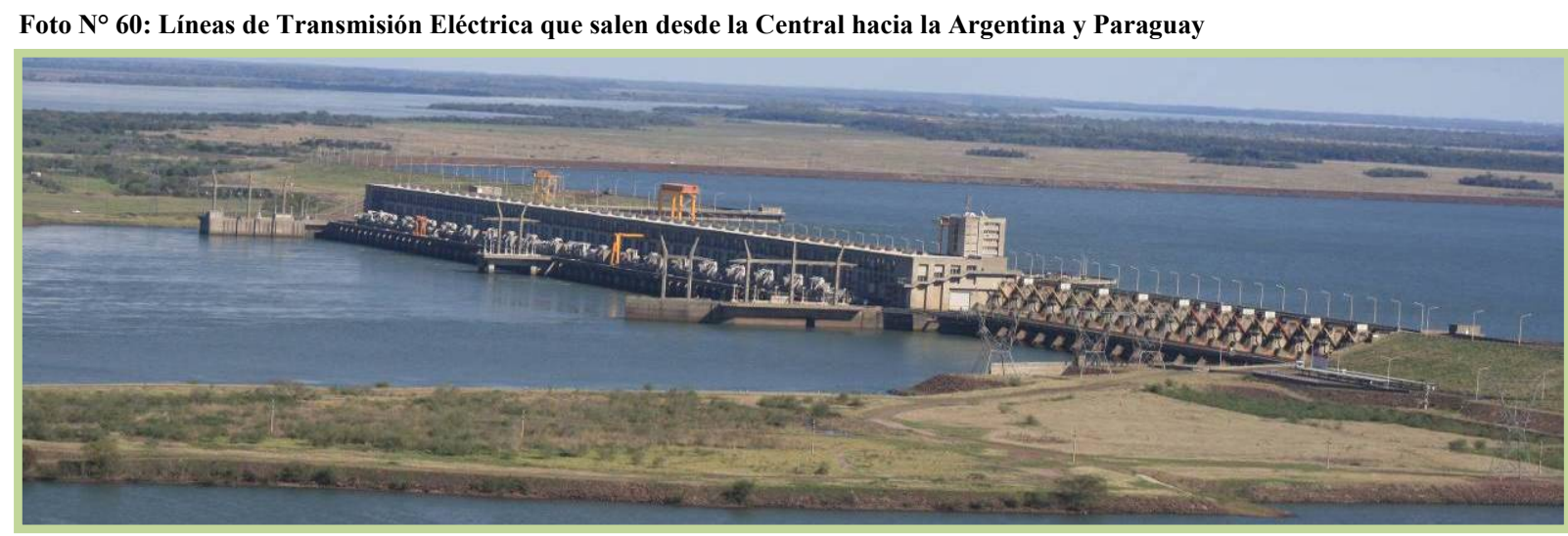

Fuente: Archivo fotográfico de la Entidad Binacional Yacyretá.

La energía de Yacyretá se deriva al sistema argentino a través de 4 líneas de $500 \mathrm{KV}$, que vinculan la Central con el punto de entrega en la estación Rincón de Santa María, y al sistema paraguayo mediante una línea de 220 KV, hasta la subestación Ayolas. Desde la Subestación Rincón Santa María parten cuatro (4) líneas de $500 \mathrm{KV}$, que recorren $2.871 \mathrm{Km}$.: Dos (2), a Resistencia (Chaco, $269 \mathrm{Km}$.), con una vinculación de $80 \mathrm{Km}$. hasta Posadas que alimenta al Sistema Eléctrico de la Provincia de Misiones; una (1) a Santo Tomé (Corrientes) y Rosario (Santa Fe) y otra a Charata (Chaco, 216 Km.), para continuar hasta El Bracho (Tucumán, $422 \mathrm{Km}$.). La otras dos (2) se dirigen a Garabí (Corrientes, $127 \mathrm{Km}$.), para continuar hasta Salto Grande (Entre Ríos, $441 \mathrm{Km}$.), Colonia Elías (Entre Ríos, 160 Km.) y finalizar en Gral. Rodríguez (Buenos Aires, 236 Km.). 


\section{III.1.2.2. Zona de influencia ambiental del Proyecto}

El área del sitio de obra de Yacyretá - un territorio binacional regulado por leyes especiales, cubre $1.600 \mathrm{~km}^{2}$, pero la zona de influencia ambiental del PHY está definida en dos áreas: la de influencia a nivel de cuenca; y la de influencia inmediata.

\section{A. Área de influencia a escala de la Cuenca del Paraná}

Comprende desde el sitio de la presa hasta el embalse de Itaipú (Paraguay y Brasil); aguas abajo, desde el sitio dónde se localiza la presa hasta la confluencia del río Paraguay (Corrientes AR).

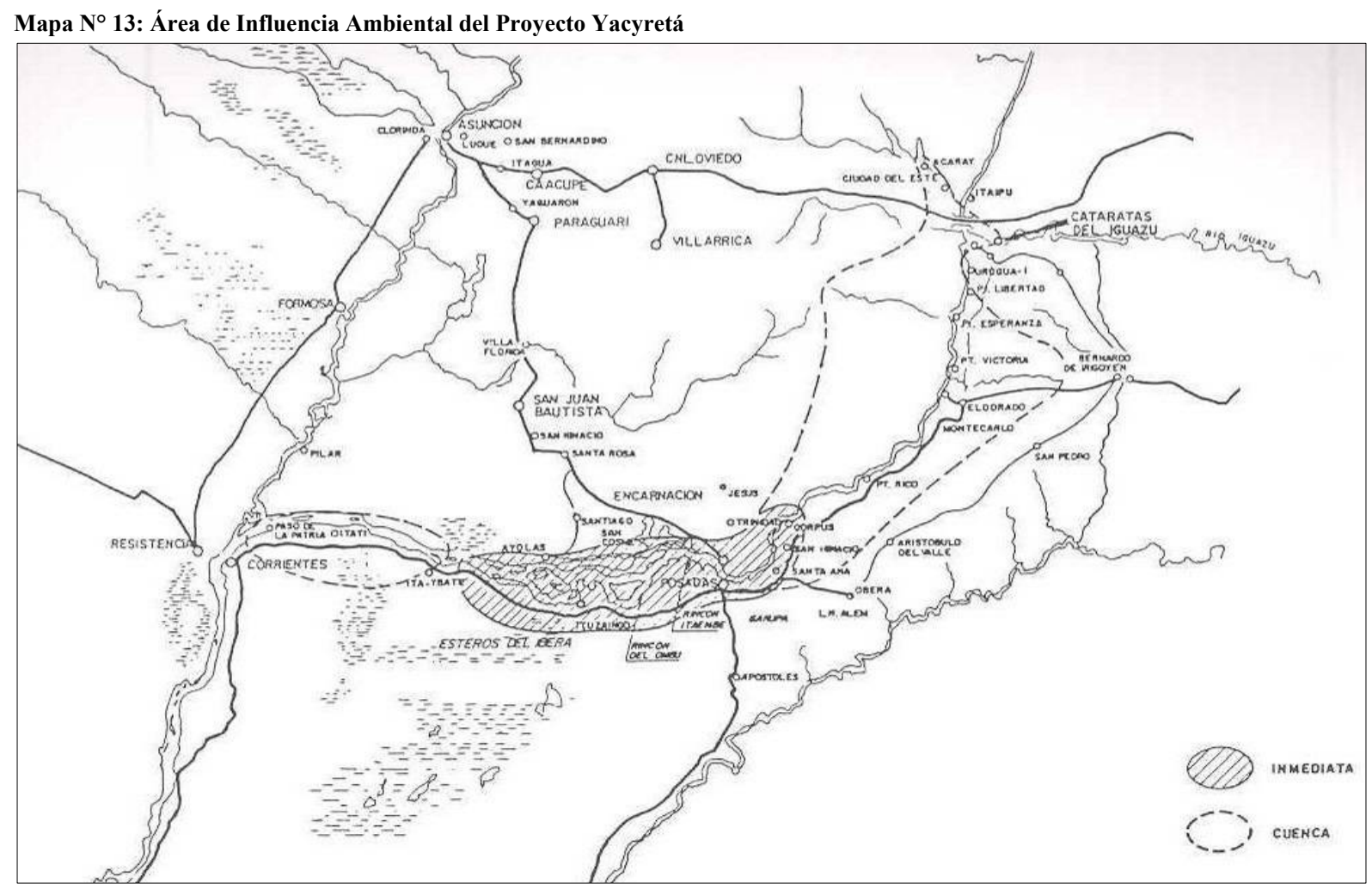

Fuente: Entidad Binacional Yacyretá. Informe de Evaluación Ambiental PHY, 1992: 23.

\section{B. Área de influencia inmediata}

Comprende la zona embalsada hasta la localidad de Corpus (Misiones AR), e inmediatamente aguas abajo de la obra hasta Itá Ibaté (Corrientes, AR). En esta zona es dónde se producen las mayores afectaciones sobre las áreas urbanizadas, aguas abajo y aguas arriba de la presa.

\section{Afectaciones aguas abajo de la Presa}

Estas afectaciones corresponden, principalmente, al periodo previo a la construcción de la infraestructura del proyecto (1978-83), dónde se construyeron las respectivas zonas de apoyo para la construcción de las obras y principalmente, las áreas residenciales en las ciudades de Ituzaingó (Provincia de Corrientes, Argentina) y de Ayolas (Departamento Misiones, Paraguay). 
Fotos $N^{\circ} 61$ y 62: Afectaciones Aguas debajo de la Presa de Yacyretá
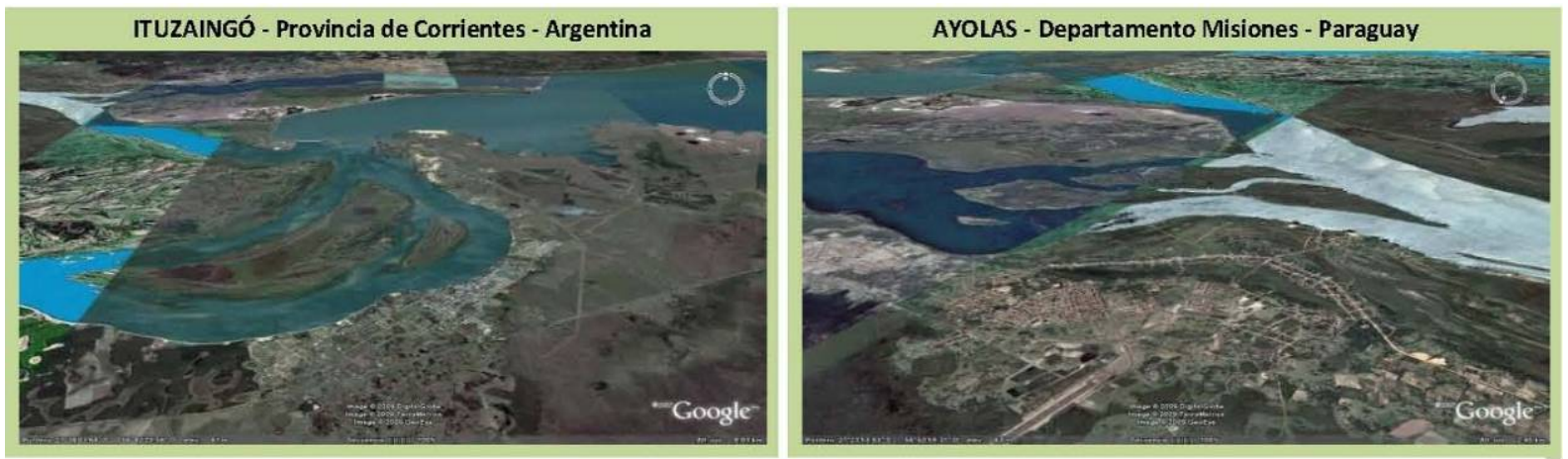

Fuente: Google Earth, 2009, con el embalse a Cota 78 msnm.

\section{Incidencia aguas arriba de la Presa}

A unos $100 \mathrm{Km}$. aguas arriba de la Central Hidroeléctrica, el proyecto afecta a las ciudades de Posadas, Garupá y Candelaria, en la Provincia de Misiones, en Argentina y de Encarnación, Cambyretá, San Juan del Paraná y Carmen del Paraná, en el Departamento de Itapúa, en Paraguay; así como en menor medida, a otros 15 municipios y zonas rurales de ambas márgenes del río Paraná. ${ }^{69}$

Plano $N^{\circ}$ 10: Diseño Tratamiento Costero s/Imagen Landsat Fotos $N^{\circ} 63$ y 64: Tratamientos Costeros - Vista Aérea

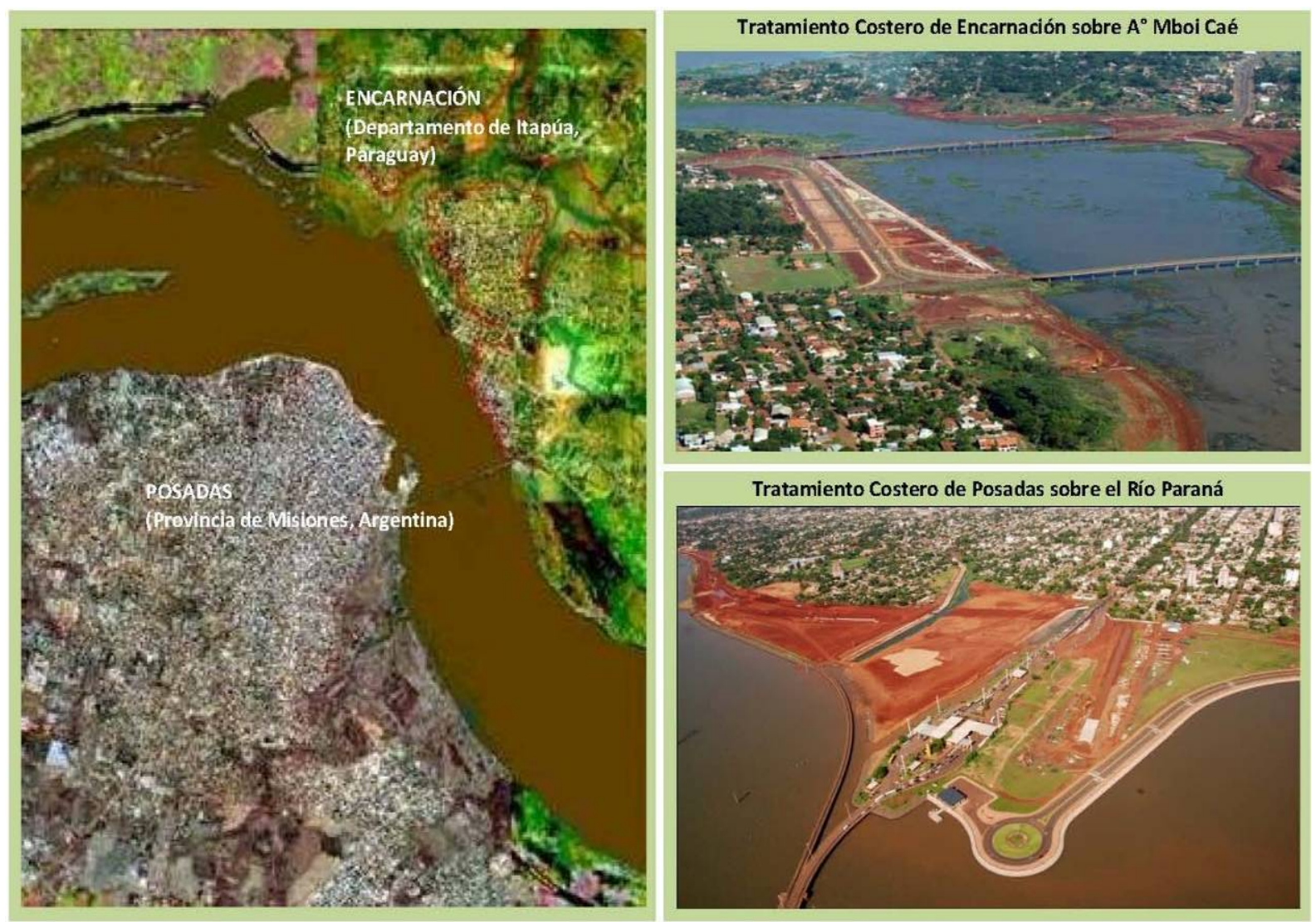

Fuente: Archivo fotográfico y general de la Entidad Binacional Yacyretá. Tratamiento Costero en construcción, 2009.

${ }^{69}$ Esto está generando -además del inmenso lago- una nueva configuración territorial, que será analizada en los dos apartados siguientes (III.2 y III.3) y el cuarto capítulo, en términos de Proyecto Paisaje, en el apartado IV.1. 


\section{III.1.3. La Evaluación Ambiental de Yacyretá (1992)}

Hemos analizado en el Capítulo I, la evolución del proceso de expansión de la construcción de represas para la generación de energía hidroeléctrica, así como, la inserción de estos proyectos en el contexto del debate en torno al vínculo entre medio ambiente y desarrollo que se produjo en las cinco últimas décadas. Hemos analizado también, la cronología de los hechos que definieron la ejecución de Yacyretá cuya concepción se produce en la década de 1920, su definición como proyecto en la década de 1950, su declaración institucional en la década de 1970, el inicio de su construcción en la década de 1980, y la finalización de las 'Obras Principales' en la década de 1990, habiendo quedando pendiente de resolución, los aspectos socio-ambientales, la reposición de diversas obras de infraestructura local y regional y la protección de las ciudades afectadas por la elevación del embalse a su cota de diseño.

Yacyretá, por la fecha de su concepción, no había tenido evaluación ambiental, pero la demora en su ejecución y los cambios sucesivos a nivel mundial que fue sufriendo esa noción de desarrollo y de protección de los recursos naturales han contribuido a que, a principios de la década de 1990, la Entidad Binacional Yacyretá en acuerdo con el Banco Mundial, decidió realizar la Evaluación Ambiental del Proyecto, cuyo Informe fue aprobado el 14 de agosto de 1992 (ver parágrafo I.3.5).

La Evaluación Ambiental de Yacyretá, centró sus principales preocupaciones en los recursos agua (incluyendo calidad del agua, malezas acuáticas y sedimentación), flora y fauna (en especial sobre los recursos ícticos), salud, patrimonio cultural, impacto urbano y desarrollo regional, así como, otros impactos por entonces considerados menores, como los derivados de la construcción de las obras.

Gráfico No 5: Alteraciones Ambientales (reales y potenciales) del Proyecto Hidroeléctrico Yacyretá

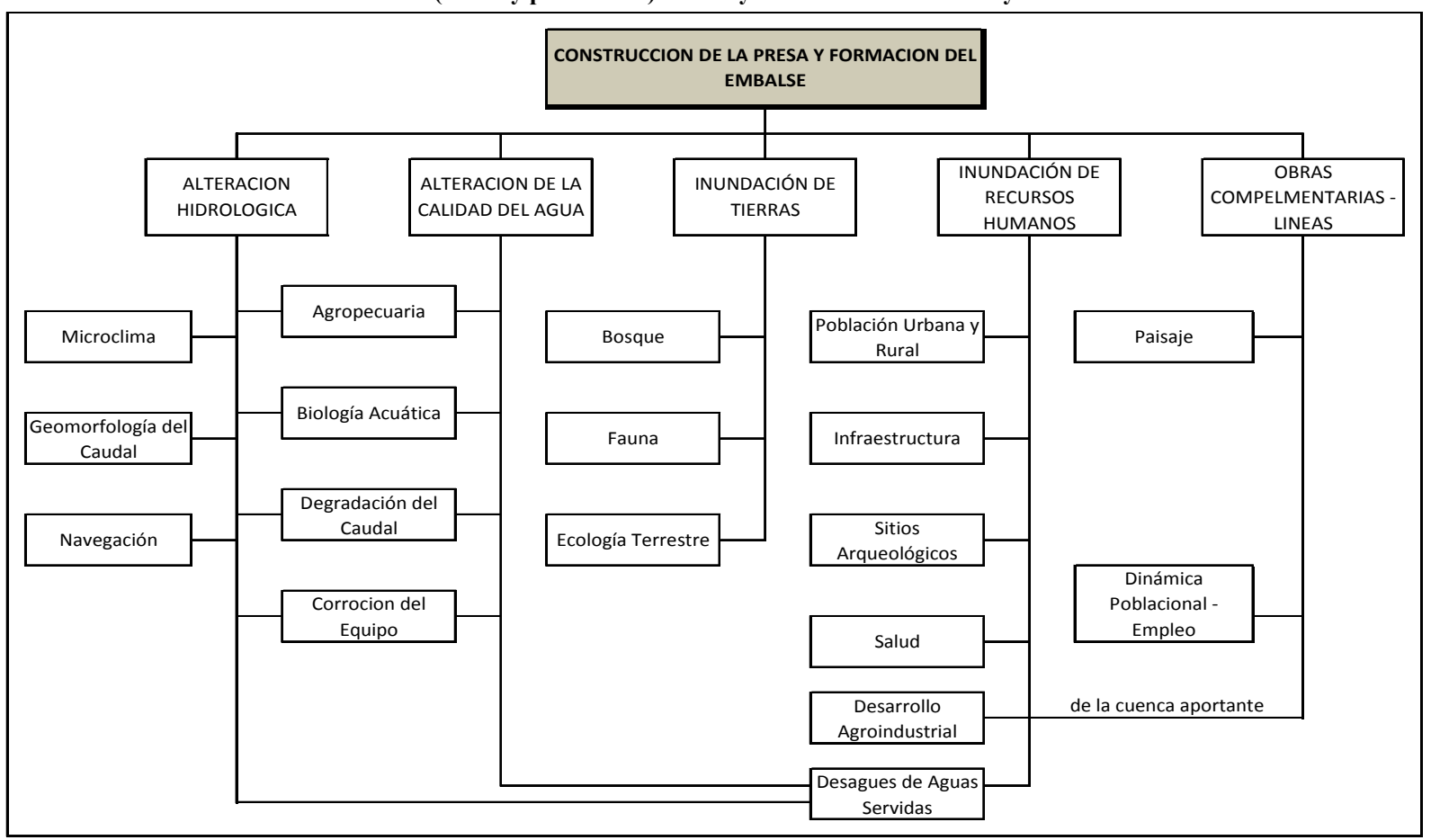

Fuente: Archivo General de la Entidad Binacional Yacyretá. Informe de Evaluación Ambiental PHY (EBY, 1992a: 118) 
El Informe Ambiental, realizó una evaluación de las presas, del embalse y de áreas aguas abajo, indicando que los impactos potenciales más significativos podían agruparse en las siguientes categorías:

a) Conversión de las Áreas de Terreno en Embalse, que implica: la pérdida de bosques terrestres; de vida silvestre, incluyendo especies en vías de extinción; de peces fluviales y de hábitat acuáticos; la reubicación de asentamientos humanos, con pérdida de valores arqueológicos y de infraestructura urbana; cambios sociales y económicos de la población afectada y potenciales problemas de salud en el área de influencia.

b) Alteración de Caudales y Niveles, que implica: la reducción en la dilución y lavado de las corrientes de desechos urbanos; así como de peces / hábitat acuáticos; con bloqueo o reducción de migración de peces; finalmente, marca el desecamiento del Brazo Aña Cuá, que fue posteriormente reconsiderado, derivando en la construcción del vertedero ya descripto, que eroga un caudal denominado ecológico- de aproximadamente $1.500 \mathrm{~m}^{3} / \mathrm{seg}$.

c) Cambios en la Calidad de Agua, que implica: la descomposición de cantidades considerables de biomasa; el crecimiento de malezas acuáticas y la proliferación de vectores; bioacumulación de tóxicos proveniente de la cuenca de aporte; condiciones anóxicas, potencial eutrofización, y la necesidad de controlar la proliferación de malezas acuáticas y de vectores en los subembalses urbanos.

Pero también, la Evaluación Ambiental consideró que la construcción de Yacyretá aportaría impactos directos positivos. Como hemos mencionado en el Capítulo I (parágrafo I.3.1 y I.3.5), estos pueden resumirse en: la producción de energía eléctrica para la región de la cuenca del Paraná y para todo el sistema energético binacional; el incremento en la disponibilidad de agua para uso agrícola; nuevos hábitats para la avifauna; el mejoramiento de la navegabilidad del río; la creación de nuevas oportunidades de empleo regional y local, junto a nuevas condiciones para el desarrollo del potencial turístico de la zona (EBY, 1992.a: 157-158).

De esa Evaluación Ambiental, derivaron como principales medidas de mitigación y compensación, vigentes hasta la fecha, el Plan de Manejo del Medio Ambiente (PMMA) y el Plan de Acción para el Reasentamiento y la Rehabilitación (PARR), que tienen por objetivo proteger el patrimonio histórico y cultural, el ambiente y los recursos naturales y salvaguardar y mejorar la calidad de vida de las poblaciones afectadas del área de influencia del Proyecto Yacyretá.

Sin embargo, estas medidas no fueron suficientes. Las demoras en la ejecución y una no adecuada ponderación de sus efectos sobre las ciudades y el territorio que involucra, principalmente al área de Posadas en Argentina y de Encarnación en Paraguay -que desde la década del 70 hasta hoy, han quintuplicado su población- determinaron la necesidad de un cambio de enfoque por parte de la Entidad Binacional, para enfrentar la terminación de Yacyretá, que es analizado en los apartados siguientes. 
Cuadro No 4: RESUMEN DE IMPACTOS Y MEDIDAS MITIGANTES - PROYECTO YACYRETÁ

\begin{tabular}{|c|c|}
\hline IMPACTO AMBIENTAL & MEDIDAS MITIGANTES / CONTROL / COMPENSACIÓN \\
\hline $\begin{array}{l}\text { > ALTERACION DE LA CALIDAD DEL AGUA EN EMBALSE Y SUBEMBALSES } \\
>\text { DESCOMPOSICION DE LA VEGETACION INUNDADA } \\
>\text { ESTRATIFICACION } \\
>\text { EUTROFICACION } \\
>\text { ACUMULACION PAGUICIDAS Y TOXICOS POR DESARROLLO AGRICOLA } \\
>\text { DESCARGAS DE AGUAS RESIDUALES CLOACALES/INDUSTRIALES } \\
>\text { ACCIDENTES EN TRANSPORTE DE TOXICOS, AGROQUIMICOS Y SUSTANCIAS } \\
\text { PELIGROSAS }\end{array}$ & $\begin{array}{l}\text { > REMOCION DE BIOMASA / ADECUACION SUBEMBALSES } \\
>\text { RECOLECCION Y TRATAMIENTO AGUAS CLOACALES } \\
>\text { MANEJO DE CAUDALES Y NIVELES } \\
>\text { CONTROL DE CONTAMINACION INDUSTRIAL } \\
>\text { ORDENAMIENTO DE USO DEL SUELO } \\
>\text { CONTROL AL USO DE PLAGUICIDAS Y TOXICOS } \\
>\text { MONITOREO } \\
>\text { PLAN DE CONTINGENCIA }\end{array}$ \\
\hline $\begin{array}{l}\text { > DESTRUCCION Y FRAGMENTACION DE HABITATS TERRESTRES, FAUNA EN PELIGRO } \\
\text { DEE XTINCION }\end{array}$ & $\begin{array}{l}\text { > DELIMITACION DE ZONAS PARA RESERVA/REFUGIOS } \\
\text { > SALVAMENTO DE FAUNA } \\
\text { > REFORESTACION } \\
>\text { FOMENTO DE ZOOCRIADEROS } \\
>\text { INVESTIGACION AMBIENTAL }\end{array}$ \\
\hline $\begin{array}{l}\text { > DESTRUCCION DE HABITATS ACUATICOS, INTERRUPCION DE MIGRACIONES DE } \\
\text { PECES, INCREMENTO PESCA ILEGAL, CREACION DE NUEVOS HABITATS PARA } \\
\text { AVIFAUNA. }\end{array}$ & $\begin{array}{l}\text { > ESTACION DE TRANSFERENCIAS } \\
>\text { PROGRAMA DE REPOBLAMIENTO } \\
>\text { ESTACIONES PISCICOLAS } \\
>\text { INVESTIGACION AMBIENTAL } \\
>\text { LEGISLACION } \\
>\text { CONTROL Y VIGILANCIA }\end{array}$ \\
\hline $\begin{array}{l}\text { > MODIFICACION DE CALIDAD Y CANTIDAD DE AGUAS, AGUAS ABAJO, BALANCE } \\
\text { HIDRICO EN BRAZO AÑA CUA, CAMBIOS MORFOLOGICOS EN CANALES, } \\
\text { SALINIZACION DE SUELOS }\end{array}$ & $\begin{array}{l}>\text { REMOCION DE BIOMASA } \\
>\text { MANEJO CAUDALES Y NIVELES } \\
>\text { REGULACION BRAZO AÑA CUA } \\
>\text { MONITOREO } \\
>\text { INVESTIGACION AMBIENTAL }\end{array}$ \\
\hline $\begin{array}{l}\text { > PROLIFERACION DE MALEZAS ACUATICAS QUE PROPICIAN ENFERMEDADES, } \\
\text { MOLESTIAS, IMPACTO SOBRE NAVEGACION ESTETICA, BALANCE HIDRICO. }\end{array}$ & $\begin{array}{l}\text { > REMOCION DE BIOMASA/REMOCION ESPECIFICA } \\
\text { > TRATAMIENTO DE SUBEMBALSES } \\
>\text { RECOLECCION Y TRATAMIENTO DE AGUAS CLOACALES } \\
>\text { CONTROL DE MACROFITAS } \\
>\text { MANEJO DE CAUDALES Y NIVELES } \\
>\text { PROGRAMA DE SALUD Y CONTROL DE VECTORES }\end{array}$ \\
\hline $\begin{aligned}> & \text { INUNDACION DE SITIOS DE INTERES HUMANO, SITIOS ARQUEOLOGICOS, } \\
& \text { HISTORICOS Y RELIGIOSOS }\end{aligned}$ & $\begin{aligned} &> \text { RESCATE ARQUEOLOGICO } \\
&> \text { FORMACION MUSEOS/DOCUMENTACION GRAFICA DE } \\
& \text { MUESTRAS REPRESENTATIVAS } \\
&> \text { INVESTIGACION AMBIENTAL } \\
&\end{aligned}$ \\
\hline $\begin{array}{l}>\text { INUNDACION DE CENTROS URBANOS, POBLACIÓN RURAL, INDIGENA, } \\
\text { INFRAESTRUCTURA URBANA Y DEPOSITOS MINERALES (FUENTES DE EMPLEO) }\end{array}$ & $\begin{array}{l}\text { > RELOCALIZACION DE POBLACIONES } \\
>\text { RECONSTRUCCION INFRAESTRUCTURA } \\
>\text { TRATAMIENTO COSTERO } \\
>\text { ASISTENCIA SOCIAL } \\
>\text { PROGRAMA DE EMPLEO ALTERNO }\end{array}$ \\
\hline $\begin{array}{l}\text { > MODIFICACION MORFOLOGIA NATURAL, FRAGMENTACIÓN DE HÁBITAT, DRENAJE, } \\
\text { MODIFICACIÓN DEL PAISAJE }\end{array}$ & $\begin{array}{l}>\text { RECUPERACION MORFOLOGICA ZONAS DE PRESTAMO } \\
>\text { REFORESTACION } \\
>\text { RECONSTRUCCION DE DRENAJES } \\
>\text { DELIMITACION DE RESERVAS/REFUGIOS }\end{array}$ \\
\hline $\begin{array}{l}>\text { MODIFICACION DE DINAMICA POBLACIONAL, INCREMENTO DE DEMANDA DE } \\
\text { SERVICIOS BASICOS }\end{array}$ & $\begin{array}{l}\text { > APOYO SATISFACCION SERVICIOS BASICOS } \\
>\text { ASISTENCIA SOCIAL }\end{array}$ \\
\hline $\begin{array}{l}>\text { AUMENTO DE LA POBLACION Y/O INGRESO DE NUEVOS VECTORES POR } \\
\text { INUNDACIONES, } \\
>\text { EUTROFICACION, AUMENTO DE CORRIENTES AGUAS ABAJO,EN VERTEDEROS Y } \\
\text { CANALES DE RIEGO } \\
>\text { FORMACION DE POZAS Y ZONAS ANEGADIZAS } \\
>\text { AUMENTO DE MALEZAS ACUÁTICAS } \\
>\text { MIGRACIONES HUMANAS }\end{array}$ & $\begin{array}{l}>\text { MONITOREO } \\
>\text { RELEVAMIENTOS ENTOMOLOGICOS Y MALACOLOGICOS } \\
>\text { REMOCION DE MACROFITAS } \\
>\text { MANEJO DE CAUDALES Y NIVELES } \\
>\text { CONTROL DE ROEDORES Y QUIROPTEROS } \\
>\text { LIMPIEZA DE CANALES } \\
>\text { TRATAMIENTOS PUNTUALES CON BIOSINSECTICIDAS } \\
>\text { TRATAMIENTO DE AREAS DE PRESTAMO } \\
>\text { VIGILANCIA EPIDEMIOLOGICA }\end{array}$ \\
\hline $\begin{array}{l}>\text { PROPAGACION DE ENFERMEDADES POR CONTAMINACION DE AGUA Y SUELO Y } \\
\text { POSIBLES INTOXICACIONES }\end{array}$ & $\begin{array}{l}\text { > SANEAMIENTO BASICO } \\
>\text { PROVISION DE AGUA POTABLE A LA POBLACION DE AREAS URBANAS } \\
>\text { ESTUDIO HIDROGEOLOGICO } \\
>\text { REGULACION Y NORMAS DE VERTIDO DE RESIDUOS INDUSTRIALES } \\
>\text { IMPLEMENTACION DE RED DE MONITOREO DE ARROYOS URBANOS } \\
>\text { TRATAMIENTO DE BASURALES DE POSADAS Y ENCARNACIÓN } \\
>\text { CIUDADES DE POSADAS } \\
>\text { CONTROL DE APLICACION Y NORMAS PARA USO DE AGROQUIMICOS } \\
>\text { MONITOREO DE SALUD EN EL AREA Y ATENCION PRIMARIA }\end{array}$ \\
\hline $\begin{array}{l}>\text { RIESGO DE AUMENTO DE ENFERMEDADES INFECTOCONTAGIOSAS Y DEL INGRESO } \\
\text { DE NUEVAS ENFERMEDADES }\end{array}$ & $\begin{array}{l}\text { > DETECCION Y CONTROL DE EMBARAZADAS } \\
>\text { CONTROL DEL NIÑO SANO } \\
>\text { PREVENCION DE ENFERMEDADES TRANSMISIBLES } \\
>\text { CONTROL DE VECTORES } \\
>\text { INMUNIZACIONES }\end{array}$ \\
\hline > RIESGO DE DESARRAIGO & > ATENCIÓN SOCIOLÓGICA \\
\hline$>$ ALTERACIONES EN EL SISTEMA DE PRESTACION DE SERVICIOS DE SALUD & $>$ COORDINACION A NIVEL DE AREA DE IMPACTO DE LAS ACCIONES DE SALUD \\
\hline > PROBLEMAS EN LA ATENCION MEDICO SANITARIA & $\begin{aligned} & \text { ORGANIZACION DE UN PROGRAMA DE VIGILANCIA EPIDEMIOLOGICA } \\
> & \text { EDUCACION SANITARIA } \\
> & \text { CAPACITACION A PROFESIONALES Y TECNICOS DE LA SALUD } \\
> & \text { ADECUACION DE SERVICIOS Y LABORATORIOS DE DIAGNOSTICO } \\
> & \text { PROGRAMA UNICO DE ATENCION DE LA SALUD A NIVEL BINACIONAL } \\
> & \text { REDIMENSIONAMIENTO DE PLANTA DE PERSONAL E INCORPORACION DE NUEVOS } \\
& \text { PROFESIONALES Y TECNICOS, DEBIDAMENTE CAPACITADOS PARA EL DESARROLLO } \\
& \text { DE PROGRAMAS PUNTUALES }\end{aligned}$ \\
\hline $\begin{aligned}> & \text { PERDIDA DE VIVIENDAS E INFRAESTRUCTURA COMERCIAL POR INUNDACION EN } \\
& \text { ENCARNACION, CARMEN DEL PARANA Y POSADAS }\end{aligned}$ & $\begin{array}{l}>\text { RELOCALIZACION DE POBLADORES } \\
>\text { CONSTRUCCION DE CONJUNTOS DE VIVIENDAS Y/O INDEMNIZACIONES }\end{array}$ \\
\hline $\begin{array}{l}\text { > PERDIDA DE LA FUENTE DE TRABAJO DE LOS TRABAJADORES DE LA INDUSTRIA } \\
\text { CERAMICA }\end{array}$ & $\begin{array}{l}>\text { INDEMNIZACIDNES Y/O RECONVERSION LABORAL, BUSQUEDA DE NUEVOS } \\
\text { YACIMIENTOS, FORMACION DE COOPERATIVAS U OTRAS ALTERNATIVAS PARA SU } \\
\text { EXPLOTACION }\end{array}$ \\
\hline $\begin{array}{l}\text { > } \\
\text { ALTERACION DE LA TRAMA VIAL Y DE LA TRAZA URBANA DE LAS CIUDADES DE } \\
\text { POSADAS, ENCARNACION YCARMEN DEL PARANA Y EN ZONAS RURALES }\end{array}$ & $\begin{array}{l}\text { > TRATAMIENTO COSTERO; RECOMPOSICION DE LA TRAMA URBANA DE } \\
\text { LAS CIUDADES Y DEL RURAL AFECTADA } \\
>\text { TRATAMIENTO PAISAJISTICO DE LAS NUEVAS AREAS A RECUPERAR }\end{array}$ \\
\hline > $>$ ALTERACION DEL COMPORTAMIENTOS OCIAL POR EFECTO DE LAS MIGRAC & $>$ DESARROLLO DE PROGRAMAS EDUCATIVOS Y DE ASISTENCIA SOCIAL \\
\hline$>$ DISMINUCION DE LA PESCA COMERCIAL, RECREATICA Y DE SUBSISTENCIA & $>$ REGLAMENTACION. REGULACION Y CONTROL \\
\hline$>$ ALTERACION DE LA BELLEZA ESCENICA & $>$ RECOMPOSICION Y REFORESTACION DEL PERILAGO \\
\hline$>$ INUNDACION DE ASENTAMIENTOS INDIGENAS & $>$ RELOCALIZACIÓN \\
\hline
\end{tabular}

Fuente: Archivo General de la Entidad Binacional Yacyretá. Informe de Evaluación Ambiental PHY, 1992: 168 a 171. 


\section{III.2. EL PAISAJE EN EL EMBALSE Y EN LAS CUENCAS INTERIORES}

Ya hemos analizado en el Capítulo I, que la creación de un embalse de agua para el funcionamiento de una central hidroeléctrica, conlleva una fuerte transformación en el medio natural que la sustenta y en su entorno cultural, alcanzando incluso dimensión regional, cuando se trata de un emprendimiento a gran escala. Pero además, todo embalse de cualquier represa -incluida Yacyretá-, provoca la formación de pequeños embalses, o subembalses en los cursos de sus afluentes (ríos o arroyos), afectando generalmente a zonas urbanas, periurbanas y rurales de los territorios involucrados en la cuenca.

En consecuencia abordaremos aquí, el análisis específico del embalse y de los subembalses del Proyecto Yacyretá, como elementos del paisaje transformado.

\section{III.2.1. El Embalse de Yacyretá: la transformación del paisaje a escala microregional}

El embalse de Yacyretá representa el principal actor de la modificación del paisaje, dado que para su conformación se inundaron territorios costeros y gran parte de las islas localizadas en el tramo de su formación. Dicho embalse, involucra a su cota final de diseño $(83 \mathrm{msnm})$, una superficie aproximada de $1.600 \mathrm{Km}^{2}$, conformados por los $600 \mathrm{Km}^{2}$ originales de la cuenca del río Paraná, más $1.000 \mathrm{Km}^{2}$ producto de la inundación de territorios insulares y continentales.

"El embalse se llenó en septiembre del año 1994 a la cota de operación 76 msnm, en abril del año 2006 a cota de operación $78 \mathrm{msnm}$, en junio de 2008 a la cota 78,50 msnm y en [noviembre de 2010 a cota 81,5 msnm], siempre en el eje Encarnación - Posadas. La 'cola de embalse' [a esta cota] se encuentra ubicada aproximadamente en el eje Posadas - Encarnación. El tiempo de residencia hidráulico del embalse es de 8 a 9 días. En las vistas que se presentan a continuación se pueden observar imágenes satelitales de los años 1985 y 2009 donde se observa la transformación del área de influencia directa del embalse" (PMMA, IS, 2010: 9-10)
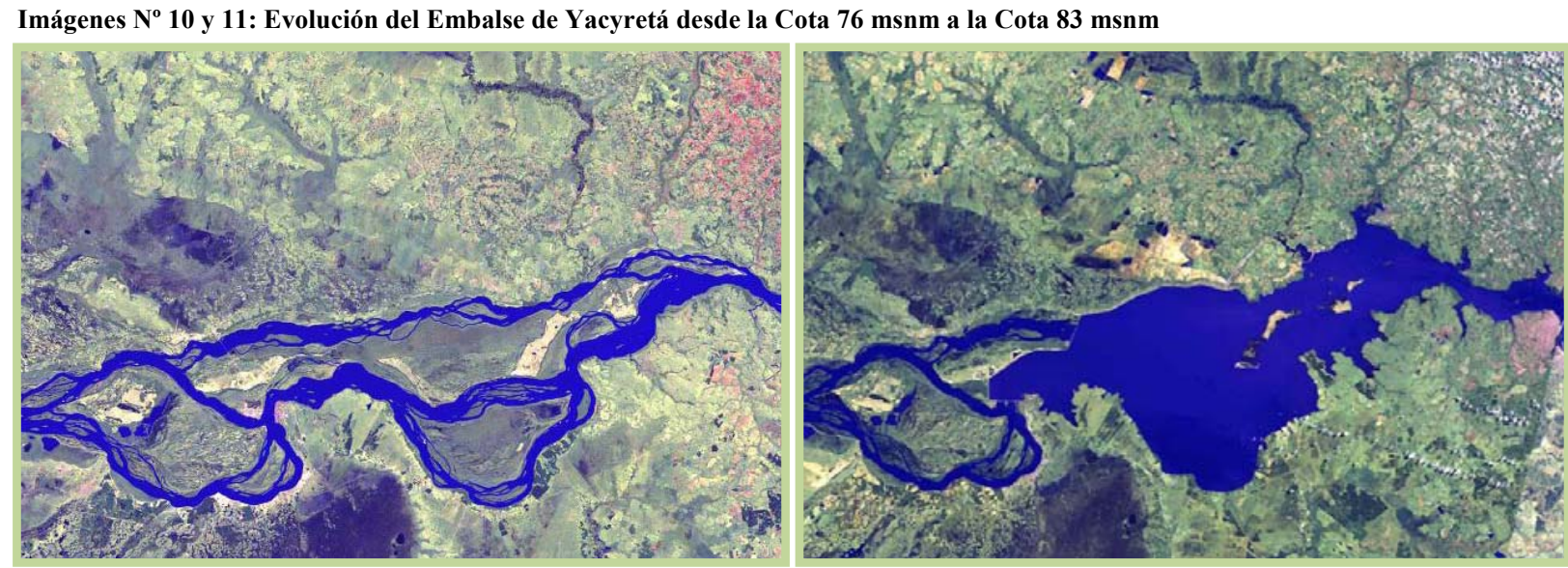

Fuente: Entidad Binacional Yacyretá

Con el llenado del embalse se produjeron las siguientes modificaciones: i) Inundación de territorio insular y continental por la creación del embalse, ii) Interrupción del flujo migratorio de peces por la conformación de la represa, iii) Cambio de las características fluviales del tramo del río Paraná, en el embalse y algunos kilómetros aguas abajo, iv) Inundación de algunos sitios de importancia arqueológica, $v$ ) Necesidad de realizar relocalizaciones rurales y urbanas y obras de infraestructura. (PMMA, IS, 2010: 10-11) 
Un estudio realizado por el Instituto Nacional del Agua de Argentina en 2002, con la cota del embalse a $76 \mathrm{msnm}$, mostraba las siguientes conclusiones:

“[...] i) La información de campo existente al momento de realización de este trabajo permite describir térmicamente al embalse de Yacyretá como un cuerpo de agua bien mezclado durante prácticamente todo el año, al menos hasta las profundidades relevadas; ii) La temperatura del lago sigue una variación estacional marcada, mostrando una amplitud térmica media del orden de los $15^{\circ} C$; [...] vii) Los estudios hidrodinámicos que se desarrollan en forma paralela [...] permiten identificar corredores de flujo bien definidos, dónde las velocidades medias son muy diferentes entre sí. Esto, sumado al hecho de que el vaso hidráulico presenta fuertes variaciones batimétricas, permite inferir que el comportamiento térmico del embalse no sería homogéneo [...]." (INA, 2002: 45-46)

Con relación a la calidad de agua del embalse, el Informe Final de junio de 2010, de la Evaluación Independiente del PMMA, concluye lo siguiente:

De acuerdo con el Informe Final 2007-2009 presentado por la FACEN, correspondiente al periodo total de trabajos 2001-2009, los parámetros In-Situ, contenido iónico, perfiles térmicos y sólidos suspendidos tuvieran los siguientes comportamientos:

Oxígeno Disuelto- poco cambio en el nivel de oxígeno disuelto entre periodos. La tendencia fue no significativa para todas las estaciones del Sistema por todos los datos del periodo 20012009, según el Test de tendencia Kendall.

pH- en el periodo 2001-2009, en el lago, el pH fue estable, con fluctuación entre 6,7 y 7,7 UpH. La tendencia resulto no significativa en todo el Sistema.

Conductividad- estabilidad en las lecturas de conductividad a partir de 2002 hasta la fecha. Tendencia no significativa en todas las estaciones del Sistema.

Turbidez-niveles muy bajos de turbidez en el periodo de 2001-2009.

Tendencia no significativa para todas las estaciones del Sistema.

Composición Iónica- permanece constante en todo el Sistema, con la misma tipología de agua dulce: bicarbonatada-cálcica-clorurada-magnésica.

Estratificación Térmica- no se dieron las condiciones para la estratificación desde la formación del embalse, siendo el resultado la no formación de termoclina.

Sólidos Suspendidos- el tratamiento realizado a los datos recabados entre los años 2001-2009 indica la disminución del ingreso de sólidos al Sistema Yacyretá, con el paso de los años; esto estaría relacionado a la presencia de otros embalses aguas arriba.

Por otro lado, se observó un decrecimiento de sólidos a la salida de los Vertederos, con relación al ingreso al Sistema, por lo que se estaría ante una factible sedimentación de una fracción de los mismos en el centro del embalse. (Ferreira de Camargo et. al., 2010: 13)

Es decir, que desde el punto de vista ambiental, estamos en presencia de un río lentificado por efecto del represamiento generado por el conjunto presa-central hidroeléctrica, cuyas características técnicas de ser un sistema de pasada, permite aprovechar acabadamente la potencia del enorme caudal del río Paraná para generar energía, sin transformar al río aguas arriba de la presa, en un espejo de agua quieto. Esto favorece su auto-purificación y las posibilidades de uso múltiple del agua, que sumado a su gran superficie y a las nuevas configuraciones costeras de ambientes urbanos, periurbanos, rurales y naturales, otorga además, otras posibilidades -desde la perspectiva paisajística- para orientar también una nueva interpretación. 


\section{III.2.2. Subembalses: la transformación del paisaje a escala loca ${ }^{70}$}

Los subembalses, se conforman por el ingreso de agua del embalse principal en los cursos inferiores de los ríos y arroyos que forman parte de la cuenca de aporte del cauce principal del río que ha sido embalsado. Bajo el punto de vista ambiental, “[...] son sistemas abiertos, es decir, intercambian con el entorno materia, energía y diversas formas de vida, que en gran medida son variables externas" (EBY, 2005.a: 9); por lo que la gestión de la temática de los arroyos (futuros subembalses), es de carácter multidisciplinar, en particular de los denominados arroyos urbanos por estar fuertemente influenciados por ciudades importantes en algún sector de sus cuencas (EBY, 2005.a: 7).

\section{Gráfico No 6: SUBEMBALSES - ESQUEMA DE VARIABLES AMBIENTALES}

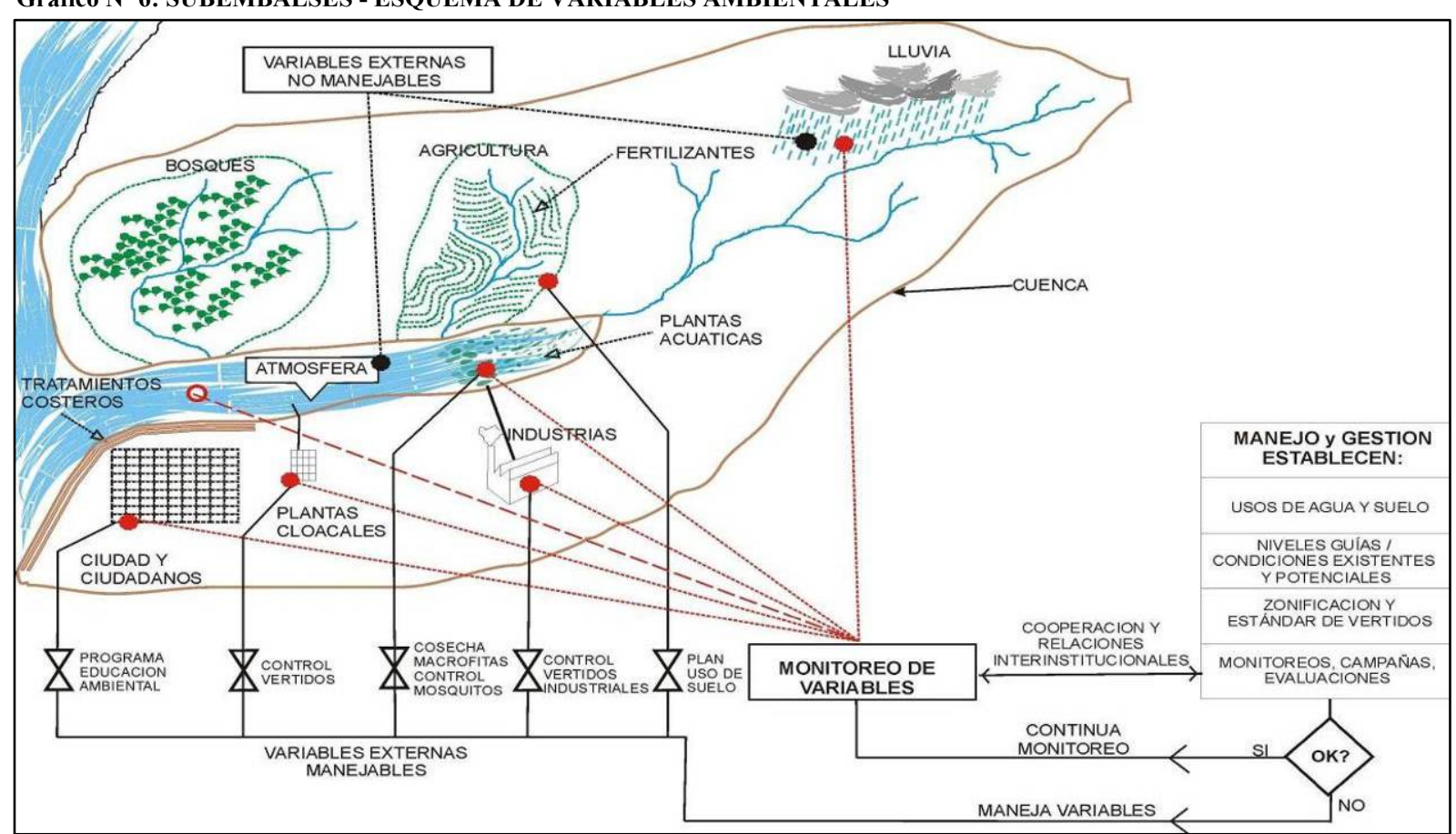

Fuente: Jorgensen \& Volleinweider, Guidelines of Lake Management, Principales, UNEP, 1989 (EBY, 2005:9)

El esquema muestra las variables y el posible mecanismo de manejo y gestión de calidad ambiental de un subembalse y considera: a) el aporte de materia, como elementos simples o complejos, minerales, nutrientes, contaminantes, entre otros (agua, fósforo, nitrógeno, sólidos en suspensión, etc.), derivado de las precipitaciones desde las cuencas, costas, litoral natural o urbanos; b) el intercambio de energía entre el ambiente y el cuerpo de agua, que modifica la temperatura y/o la estratificación térmica y/o la tasa de productividad, entre otras, que a veces suspende materia sedimentada y/o las disuelve disponiéndola para otros ciclos de la materia; c) un determinado estado ambiental, establecido por los ciclos de utilización de materia y energía de las especies de vegetales, animales, hongos, algas que ingresan y/o existen en el cuerpo de agua.(EBY, 2005.a: 9-10)

${ }^{70}$ El presente apartado, expone conceptualmente, los principales elementos de análisis y conclusiones de los estudios sobre Subembalses... (EBY, 2005.a) y sobre Lineamientos de Ordenación y Gestión Territorial... (EBY, 2005.b), realizados por equipos técnicos binacionales, de los cuales ha formado parte el autor. 
El gráfico muestra también, que el estado ambiental de estos cuerpos de agua es dinámico y su calidad depende del manejo adecuado de un conjunto de variables internas y externas. Las primeras están representadas, por ejemplo, por clorofila 'a' (que relaciona los niveles de estados mesotrófico, eutrófico, hipertrófico, etc.); oxígeno disuelto (que satisface la demanda biológica y el sostenimiento de vida acuática); vegetación del ambiente litoral (transformación de nutrientes y energía en materia orgánica y manejo de la calidad del agua); niveles de contaminantes, entre otras variables. En tanto que los vertidos derivados principalmente de la actividad antrópica constituyen las variables externas, que modifican -positiva o negativamente- las variables internas. ${ }^{71}$ Mediante una administración adecuada de variables externas manejables es posible modificar favorablemente la calidad del agua de un subembalse para diversos usos, por ejemplo, estableciendo una zonificación y regulación de la cuenca de aporte; determinando estándares de vertidos; etc., como correcciones que permiten conducir al cuerpo de agua a un estado ambiental adecuado. ${ }^{72}$ (EBY, 2005.a: 10)

De lo expuesto, se deduce que estos subembalses -que son de menor profundidad y de menor velocidad de escurrimiento que el embalse principal- necesitan ser monitoreados para evitar su contaminación y, a mediano y largo plazo, requieren el manejo integral de su cuenca de aporte.

\section{III.2.2.1. Los Subembalses de Yacyretá}

Los principales subembalses de Yacyretá están conformados por las cuencas de una importante cantidad de arroyos que desaguan en el embalse principal, siendo los más significativos, los subembalses de los arroyos urbanos que surcan las ciudades ribereñas: en la margen argentina, los arroyos Mártires y Zaimán en la ciudad de Posadas, y el arroyo Garupá en las ciudades de Candelaria y Garupá; en la margen paraguaya, los arroyos Mboi Caé y Quiteria en Encarnación, Cambyretá y San Juan del Paraná y el arroyo Tacuary en Carmen del Paraná (EBY 2005.a: 8).

Imágenes $N^{\circ} 12$ a 14: Evolución de los Subembalses en el Área de Encarnación - República del Paraguay

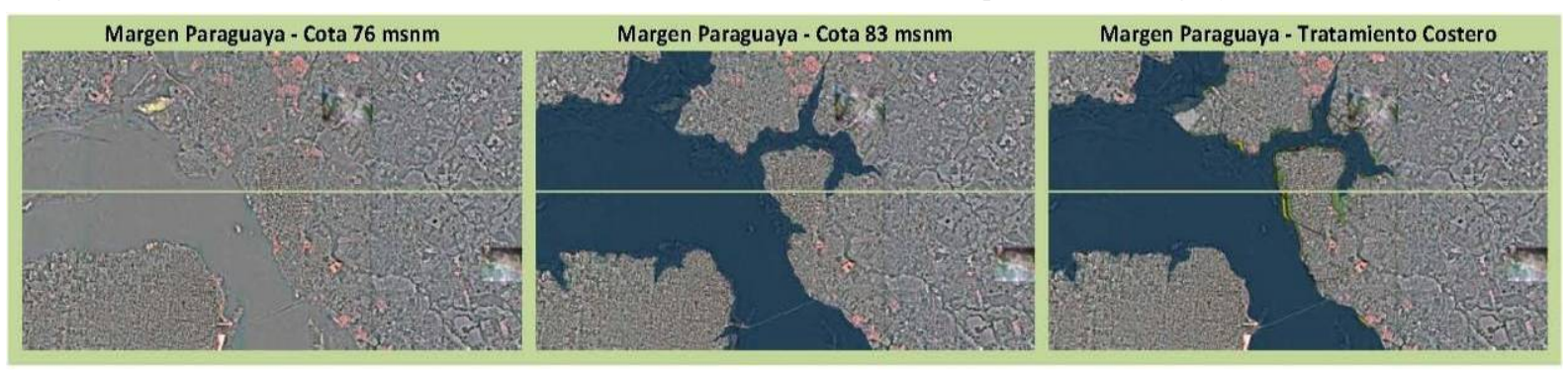

Fuente: Entidad Binacional Yacyretá

71 "La EBY realiza el monitoreo de las variables internas y externas; de calidad de agua, vegetación acuática, mosquitos, salud pública, fauna íctica, entre otros, a través organismos universitarios, científicos y/o públicos, responsables de cada país.” (EBY, 2005.a: 10).

72 "Parte de estos conceptos han sido utilizados por la EBY para la implementación de medidas estructurales como las plantas de tratamiento de efluentes cloacales de Posadas y Encarnación; tratamientos costeros, que incorporaron análisis de funcionamiento hidráulico y de calidad de agua, entre otros aspectos; y medidas no estructurales, como propuestas de control de vertimientos, educación ambiental, entre otros.” (EBY, 2005.a: 11). 
Estas cuencas se dividen, en términos generales, en dos tipos bien diferenciados de áreas: a) la superior: que es el lugar donde se desarrollan y trasladan los aportes hídricos de cada uno de los cauces que conforman el sistema y que se caracteriza por tener una alta pendiente longitudinal, ocupando la mayor parte de la superficie de la cuenca de captación.; b) la inferior: que, con características morfológicas diferenciadas, es la parte de las cuencas donde se forman los subembalses, dado que están asociadas principalmente, al valle de inundación del río Paraná que le impone su dinámica de niveles. Estas áreas tienen distinto grado de desarrollo, definido tanto por las características físicas de cada cuenca de aporte; como por la hidrología de la región -dominada por los abundantes aportes pluviales de la zona (1.600 a $1.800 \mathrm{~mm}$ por año, promedio) que determina que los aportes se caractericen por su alta impermanencia, y especialmente, por el avance de la expansión de los centros urbanos sobre los valles fluviales (EBY 2005.a: 12). Estos aspectos deben ser considerados estratégicos, tanto desde el punto de vista ambiental como en relación con la planificación de dichas urbes, para garantizar, con medidas no estructurales y estructurales, una calidad del agua y del ambiente, de carácter integral y sostenible.

"El estado ambiental que tendrán los subembalses urbanos que se formarán a cota 83 msnm, en [el área de] las ciudades Posadas (Misiones, Argentina] y [e] Encarnación (Itapúa, Paraguay), estarán muy influenciados por las actividades antrópicas que se desarrollen en sus cuencas. En las mismas se construyen asentamientos urbanos, industrias, establecimientos de servicios, dándose en algunos casos actividades agricolas y pecuarias. Estas actividades producen efluentes que se aportan a los cuerpos de agua y determinan su estado ambiental. ${ }^{73}$

En las cuencas de los arroyos Tacuary, Quiteria y Mboi Caé, las actividades agrícolas son importantes. ${ }^{74}$ En este caso la influencia rural es mayor y el peso relativo que tiene la actividad urbana -con relación a los aportes cloacales, contaminantes, sólidos de arrastre (basura) y el análisis de las tendencias de crecimiento de las poblaciones y las transformaciones urbanas-, da una idea sobre las tendencias a largo plazo y los efectos sobre el estado ambiental de los subembalses. Por lo que es posible realizar algunas conclusiones." (EBY, 2005.a: 13).

Imágenes $N^{\circ} 15$ a 17: Evolución de los Subembalses en el Área de Posadas - República Argentina

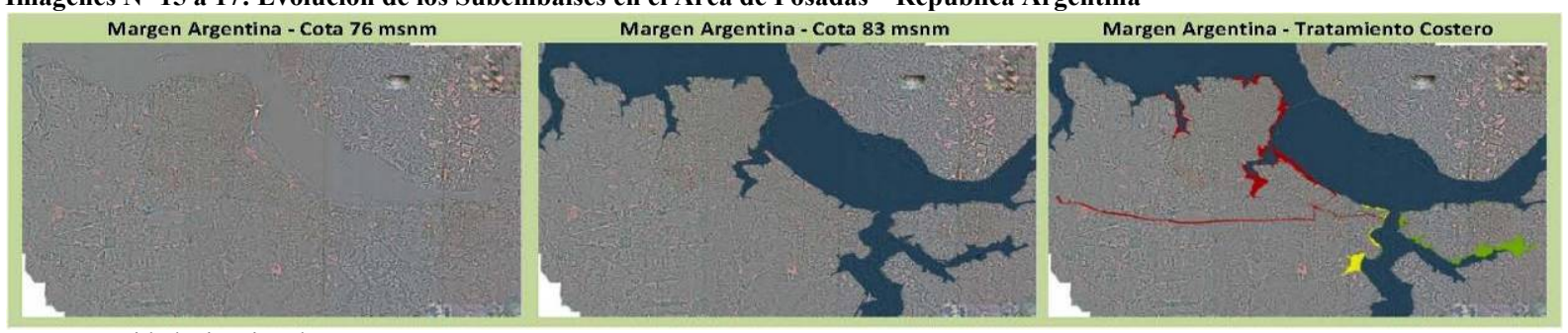

Fuente: Entidad Binacional Yacyretá.

${ }^{73}$ Por ejemplo, de acuerdo al estudio de Manejo de Cuencas Urbanas, Situación y Pronostico a Cota 78, realizado por el Sector Medio Ambiente de la EBY en octubre de 2003, se ha estimado que en la cuenca del $\mathrm{A}^{\circ}$ Mártires (Posadas), el $73 \%$ de las cargas de nutrientes (fósforo total) proviene de las urbanizaciones y solo el $22 \%$ de la actividad agrícola y pasturas y que en la cuenca del $\mathrm{A}^{\circ}$ Mboi Caé (Encarnación), el 58\% de los aportes provienen de la actividad urbana y el $45 \%$ de actividad rural. Comparando la extensión y los usos actuales de cada cuenca, se puede inferir que las cuencas de los arroyos urbanos de Posadas están influenciadas por las actividades netamente urbanas y las actividades rurales y pecuarias no son significativas (EBY, 2005.a: 13)

${ }^{74}$ Según expone la memoria descriptiva del estudio sobre el Tratamiento Costero de Encarnación, realizado por ELECTROMON-IATASA en 2002, el Departamento de Itapúa está en primer lugar en producción de trigo con el $40 \%$ de la superficie productiva; en el segundo lugar en producción de soja con el $38 \%$ de la superficie; en el tercer lugar de producción de maíz con el 16\% de la superficie y en el cuarto lugar en producción de algodón con el 13\% de la superficie (EBY, 2005.a: 13). 


\section{III.2.2.2. El problema del crecimiento urbano}

En las ciudades que forman parte de las áreas metropolitanas de Posadas y Encarnación, la costa del río y los arroyos, han sido condicionantes para el patrón de crecimiento urbano. En el caso de la ciudad de Posadas, los ejes Este / Oeste y Norte / Sur (establecidos en el Plan Posadas de los '80), no hacen más que adoptar estos límites. Actualmente, y bajo la realidad de los emprendimientos habitacionales construidos por el IPRODHA y por la misma EBY, la división del suelo, el mercado inmobiliario, entre otros, el crecimiento tiende hacia la Ruta Provincial № 213, resultado de un esquema de sectores: por ejemplo, la zona oeste de la ciudad, (Villa Cabello) y la zona sur (Villa Lanús) por su densidad, cantidad, servicios, entre otros, son sectores que tienen vida propia, dependiendo poco del centro urbano. Este mismo fenómeno ocurre con los barrios Mboi Caé, de Encarnación y Arroyo Porá, de Cambyretá.

La tasa anual media de crecimiento de Argentina para el periodo 1991/2001 fue del 1,01\%. La provincia de Misiones, en igual periodo, fue del 1,94 \%, siendo la séptima provincia del país de mayor crecimiento. La ciudad de Posadas, en el mismo período creció de 201.663 a 252.981 resultando el 2,29 \%. Para el caso del Paraguay, la tasa anual media de crecimiento del periodo 1992 al 2002 del país ronda el 2,28 \%. La ciudad de Encarnación para similar periodo ha crecido de 69.868 a 98.134 habitantes siendo el 3,46 \%. En el mismo periodo, municipio de Cambyretá ha evolucionado a una tasa anual del 6,76\%.

En América Latina, en la década del 50, la población urbana alcanzó el 41\%, en la década del 90 el $69 \%$ y se espera que para la presente década alcance el $77 \%{ }^{75}$. Esta migración urbana ocurre porque las poblaciones rurales empobrecidas se ven atraídas hacia la ciudad en la búsqueda de trabajo, desarrollo económico, mejor vida, entre otros, sin embargo no siempre ocurre así. Estas migraciones se asientan, en general, en forma irregular, en terrenos privados o públicos, en áreas marginales, inundables, sin servicios, sin acceso a la educación, a la salud y a la vivienda. Otro fenómeno que propicia esta migración interna es la gradual compra de los minifundios por grandes corporaciones o empresas que utilizan el terreno para actividades intensivas y que requiere poca mano de obra por la tecnificación que acompaña a estas inversiones.

En el área de estudio, parte de esa población accede, poco a poco, a una vivienda en los núcleos habitacionales del FONAVI, CONAVI, IPRODHA o EBY con densidades urbana de 100 a 150 hab./ has., o en edificios de departamentos del FONAVI con densidades urbanas de hasta 350 hab./has. En el caso de Posadas, durante los últimos 20 años, el 20\% de las viviendas fueron construidas mediante créditos fiscales, ${ }^{76}$ situación que se ha incrementado por la construcción de viviendas ejecutadas por la EBY, para su Plan de relocalización (PARR) ${ }^{77}$.

A fines de la década del ' 90 , sólo el 20\% del total tenía cloacas por red, el 50\% sistema estático (cámara séptica-pozo absorbente), el 30\% letrinas, el 55\% agua potable por red y el $45 \%$ restante por otros me-

\footnotetext{
${ }^{75}$ Datos de la ONU, citado en Tyller Miller Jr, Ecología y Medio Ambiente, Editorial Iberoamericana, 1992

${ }^{76}$ Código de Planeamiento Urbano de la Ciudad de Posadas, 1998.

${ }^{77}$ De acuerdo a datos del PARR, se afecta en Posadas el 11\% y en Encarnación el 35\% de la población.
} 
$\operatorname{dios}^{78}$. La situación en Encarnación tenía guarismos aún más bajos, 19,8 \% de agua potable y 3,4\% de alcantarillado, siendo la cobertura media de alcantarillado del país el 13,4 \% ${ }^{79}$. Esto está cambiando por la ejecución del préstamo BM No 44840 para Programa de Reforma del Sector Agua Potable y Saneamiento que se ejecuta actualmente vía ENHOSA / SAMSA / Provincia de Misiones en Posadas y la ejecución de la ampliación de la planta potabilizadora de agua, redes de distribución y planta de tratamiento de efluentes cloacales en Encarnación por la EBY. Pero las condiciones de vertidos puntuales aun se mantienen.

Las ciudades, en la medida que crecen, requieren crecientes cantidades de agua de calidad y cantidad suficiente para sus usos, aire limpio, energía, alimentos, que provienen de otras zonas. En el caso de las aguas, una vez utilizadas (o contaminadas) las disponen en su alrededor (arroyos o ríos), salvo el tratamiento que actualmente se realiza. Estos nutrientes, en especial fósforo total (elemento escaso en la naturaleza y limitante del crecimiento de otras especies de vida) son traídos desde otras zonas como alimentos, que luego de utilizarse en consumo humano y excretarse, si no se dispone adecuadamente podrían causar problemas.

En la medida que crecen las superficies impermeabilizadas por cubiertas de techos, pavimentos, solados, etc., los regímenes de escurrimientos naturales de las lluvias se ven modificados aumentando los caudales instantáneos, los arrastres de materiales (tierra, arena, basuras) en las alcantarillas y arroyos, inundando las planicies, entre otros efectos ${ }^{80}$. La generación de basuras domiciliarias en Posadas está en el orden de las 250 ton/día con servicio de recolección y disposición final en un relleno sanitario. Encarnación y Cambyretá produce aproximadamente 130 ton/día, con servicio de recolección y disposición final en un vertedero construido por Yacyretá. El crecimiento de generación es directo con el crecimiento poblacional. En ambas ciudades existe un bajo nivel de educación ambiental urbana. También un porcentaje de las basuras va a parar a la vía pública y en cada lluvia a los arroyos.

Las ciudades que crecen a las tasas mencionadas, con la realidad de las migraciones internas, sin actividades productivas, salvo servicios y administración, tiene pocas probabilidades de ser sustentables y eficientes. Estas migraciones se entrampan en la pobreza y en vez de vivir en una mejora social se ven impelidos a vivir en las calles, pedir limosnas, vivir del trabajo no formal, inclusive aumentando los problemas de seguridad. Para el caso de la ciudad de Posadas, se estima como necesario incrementar los espacios urbanos, restando de los rurales aproximadamente en 70 has/año, incrementando anualmente 10 $\mathrm{Km}$. de calles, 3,5 Km. de avenidas y 44 has de lotes ${ }^{81}$. Es decir que en veinte años se incrementaría en 1400 has, que equivale a aproximadamente a 7 veces el área del microcentro de las cuatro avenidas. Posadas tiene una densidad media de 50 hab./ha, que llega a picos como planes FONAVI hasta 380

\footnotetext{
${ }^{78}$ Código de Planeamiento Urbano de la Ciudad de Posadas, 1998.

${ }^{79}$ Plan de Zonificación de la Municipalidad de Encarnación, 1994.

${ }^{80}$ En el fenómeno meteorológico de "El Niño" de diciembre de 1997, ambas ciudades sufrieron inundaciones inusuales que impulsaron a la EBY a implementar el Programa Desborde de Arroyos (PDA).

${ }^{81}$ Código Planeamiento Urbano de la Ciudad de Posadas, op cit.
} 
hab./has ${ }^{82}$ y medias de conjuntos habitacionales de entre 100 a 150 hab./has. Los Planos VI-01 y VI-02 muestran el crecimiento urbano y las áreas definidas por la Municipalidad de Posadas. En ella se observan que la mayoría de los núcleos habitacionales del FONAVI y EBY se establecen en las cuencas de los arroyos Mártires y El Zaimán y es esperable que las áreas urbanas y periurbanas de ambas ciudades tiendan a aumentar su densidad poblacional, por medio de la inversión pública.

Los problemas de salida de operación de los sistemas cloacales por falta de mantenimiento y preocupación ambiental urbana, tiene una alta probabilidad de ocurrencia. Esto hace que las empresas y agencias de gobierno encargadas del servicio deban encarar nuevas estrategias para garantizar la operación de los mismos. Muchas de las basuras urbanas, a pesar de que existen servicios de recolección, a veces son dispuestas en las calles, veredas, baldíos, arroyos y que en las frecuentes y copiosas lluvias son arrastradas hasta los cuerpos de agua. Si bien en los cuatros subembalses urbanos se han previsto áreas de vegetación litoral que tienen servicios ambientales de protección de calidad de agua, éstos serán sobrepasados, si no existe un cambio de las pautas de conducta de los ciudadanos. Esto será posible mediante el acompañamiento de adecuados planes de educación, dentro de las estructuras formales y curriculares y las gestiones de las agencias de gobierno responsables del cuidado. Existen normas municipales que prohíben y penan este tipo de prácticas. Por otra parte, la actividad agrícola intensiva de la alta cuencas de los arroyos Quiteria y Mboi Caé, en Paraguay, hace necesario planear e implementar adecuados planes de manejo de suelo con las agencias vinculadas a las actividades agrícolas.

Muchos recursos económicos se aplican para atender a estas migraciones internas: nuevas viviendas, servicios de agua, cloacas, salud, educación transporte, recreación, seguridad entre otros. Si estos recursos fueran aplicados en las áreas originales se daría menos motivos para alentar estas migraciones. Debe tenerse presente que en el caso de Posadas la tasa anual de crecimiento es del 22,9 por mil, versus la tasa anual nacional que es de 10,1 por mil. En el caso de Encarnación y Cambyretá son del 34,5 y 67,5 por mil respectivamente versus el 22,9 por mil de la nacional.

"El mantenimiento de la calidad de agua de los arroyos con certeza deberá exigir otras acciones complementarias, pero fundamentales a los cumplimientos de los objetivos establecidos. Así, son ejemplos de estas acciones los planes de manejo de cuencas hidrográficas contribuyentes con énfasis en la calidad de agua y los programas de educación ambiental dirigidos a públicos especificos. Las acciones complementarias no deberán ser desarrollados exclusivamente por la EBY y si de forma interinstitucional (sociedad, poderes públicos y usuarios de agua)." (Ferreira de Camargo et. al., 2010: 18)

El informe plantea como conclusión que, además de las acciones que deben implementarse desde la propia Yacyretá, para garantizar una buena calidad de agua para los subembalses urbanos, por las posibilidades futuras que ofrecerán para usos recreativos y aún para contacto directo, las políticas de planificación urbana y regional debieran, complementariamente, regular, orientar y apoyar la gestión de los gobiernos locales para establecer mecanismos, estrategias, y otros incentivos que tiendan a favorecer las mejoras de calidad de vida de las zonas rurales, de manera que las migraciones internas no sean tentadoras.

\footnotetext{
${ }^{82}$ En Posadas, el Barrio Chacra 32/33 de FONAVI tiene 1.282 viviendas en 16 has.
} 


\section{III.3. EMBALSE, SUBEMBALSES Y CIUDAD: las Zonas Urbano-Costeras}

Con la formación del embalse a su cota final de diseño $(83 \mathrm{msnm})$, se inundan vastas zonas bajas de ciudades en la Provincia de Misiones en Argentina y en los Departamentos de Itapúa y Misiones en Paraguay, que originalmente eran afectadas por las grandes crecientes del río Paraná (aproximadamente una cada 20 años), que incidían directamente sobre los sectores poblacionales de más bajos recursos instalados irregularmente sobre la costa.

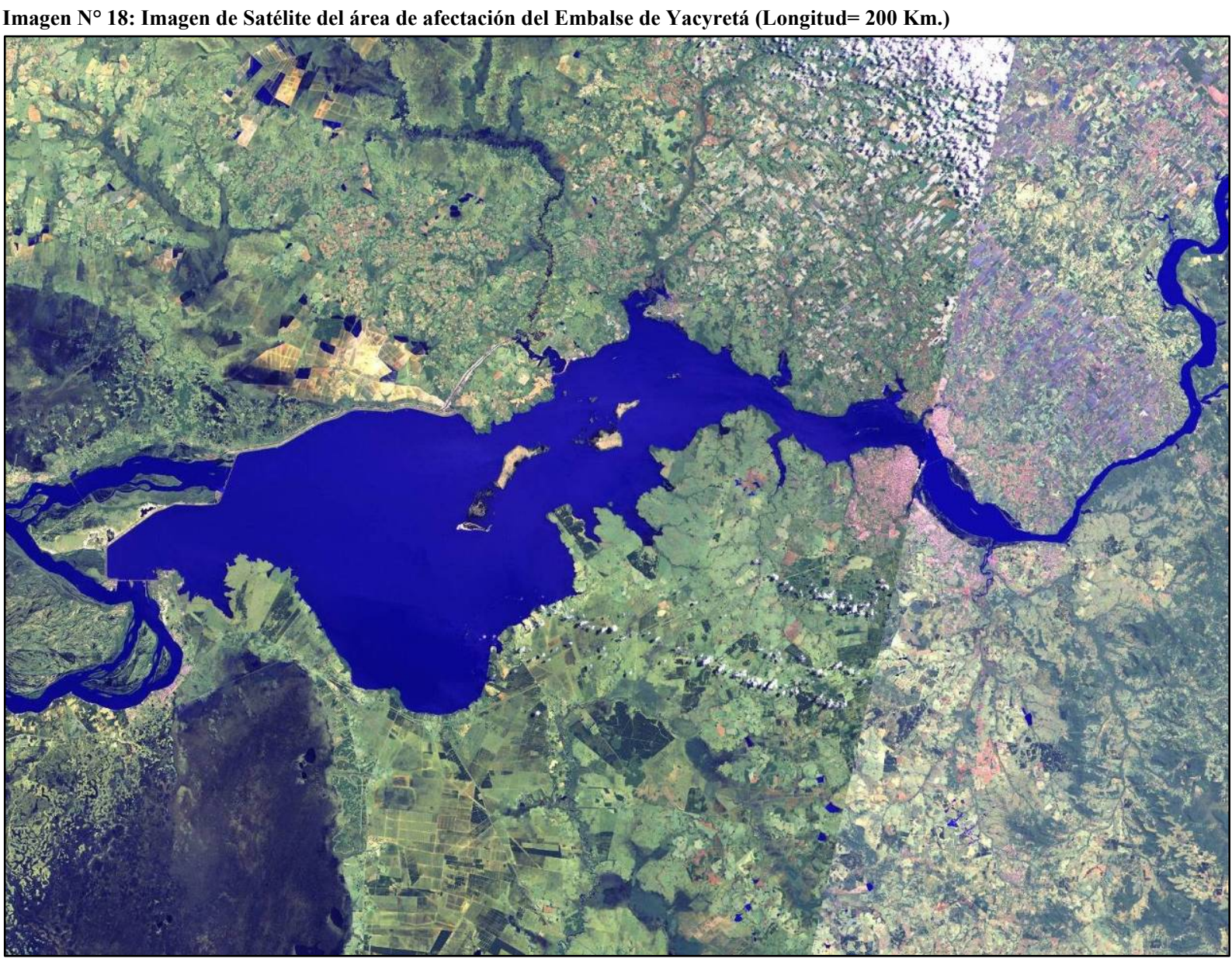

Fuente: Entidad Binacional Yacyretá, 2010

Dentro de estas áreas jurisdiccionales, las de mayor importancia desde la óptica urbana son las de las zonas costeras de las ciudades que conforman las áreas metropolitanas de Posadas y Encarnación.

"Los impactos ambientales directos asociados a la inundación de estas áreas se relacionan con: relocalizaci6n involuntaria de poblaciones y afectaci6n de propiedades e infraestructura. Estos impactos, a su vez, pueden generar repercusiones negativas en las condiciones sociales, económicas y culturales, no sólo de la población directamente afectada, sino de toda la población en general. La infraestructura afectada comprende: puertos fluviales, aeropuertos, vias, caminos, infraestructura ferroviaria, comunicaciones, industrias, comercios y equipamiento urbano." (EBY, 1992.a: 142)

Las ciudades involucradas han sufrido un proceso de crecimiento acelerado y no planificado, con efectos asimilables a los de un área metropolitana dónde, además, el tipo y escala de las inversiones ya realizadas y en ejecución dentro del contexto del Plan de Terminación de Yacyretá (PTY), determinan la existencia de varios temas que han requerido, por parte de la EBY, un enfoque integral. 
De tal forma, las inversiones en materia habitacional y en equipamientos urbanos y comunitarios para concretar el reasentamiento de población y de actividades económico-productivas -dónde se destaca especialmente la relocalización de la Zona Baja Comercial de Encarnación- así como en infraestructura de saneamiento, generan una alta movilidad de población, de recursos y de transformaciones territoriales. Pero existe también otra escala de transformaciones, que se generan a partir de las obras de infraestructura a escala territorial -nuevos puentes, reformas ferroviarias, líneas de transmisión de energía, puertos- y por aquellas localizadas en el entorno de las ciudades que, por ejemplo, han contribuido a devolverle 'la cara al río' a la ciudad de Posadas en Argentina, generando un espacio que ha sido 'apropiado por la comunidad' y que representan nuevas áreas de inversión y aprovechamiento social.

Pero, además, hay que considerar la complejidad que representa ejecutar estas grandes obras en un territorio que tiene sus particularidades. Las principales ciudades, Posadas y Encarnación, están desarrolladas sobre un relieve ondulado que origina marcadas divisorias de aguas y distintos cauces con variaciones de pendientes y donde el tema principal de cada ciudad era la exclusión originada en las diferencias sociales y económicas de su población (Levinton, 2007: 243).

Es decir que, estas transformaciones, que definen una nueva configuración urbano-costera de las ciudades intervenidas, deben ser canalizadas por los distintos actores del territorio, con el desafío de orientar la ordenación y promover el desarrollo de cada ciudad, dónde el principal riesgo está centrado en la inacción. Esto es, el no encauzar un camino donde el involucramiento responsable y el fortalecimiento de las administraciones locales, dificulten la asimilación de esas transformaciones.

\section{III.3.1. El área de Posadas, en Argentina}

El área de la ciudad de Posadas, Capital de la Provincia de Misiones, se caracteriza como un conglomerado urbano conformado por la ciudad capital y las ciudades de Garupá y Candelaria. El Municipio de Garupá forma parte del Departamento Capital pero, desde un enfoque urbanístico, esta ciudad, junto a las de Candelaria y Posadas, conforman lo que puede denominarse como Área Metropolitana de Posadas (AMeP), que por efecto de sus factores intrínsecos de desarrollo y por la presencia de la Capital provincial, representa una zona de alta incidencia regional.

Cuadro $N^{\circ}$ 5: Evolución Demográfica de las Ciudades del Área Metropolitana de Posadas (AMeP)

\begin{tabular}{|l|r|r|r|r|}
\hline \multirow{2}{*}{ CIUDAD } & \multicolumn{4}{|c|}{ POBLACIÓN TOTAL } \\
\cline { 2 - 6 } & Censo 1980 & Censo 1991 & Censo 2001 & Censo 2011 \\
\hline POSADAS & 143.016 & 204.012 & 255.052 & 28.814 \\
\hline GARUPÁ & 7.908 & 14.290 & 32.848 \\
\hline CANDELARIA & 5.872 & 6.798 & 26.713 \\
\hline Total AMeP & $\mathbf{1 5 6 . 7 9 6}$ & $\mathbf{2 2 5 . 1 0 0}$ & $\mathbf{2 9 4 . 9 0 5}$ & $\mathbf{3 5 0 . 3 2 0}$ \\
\hline
\end{tabular}

Fuente: Adaptado de datos del Instituto Nacional de Estadística y Censos (INDEC), República Argentina.

Un análisis expeditivo del área indica que, desde el punto de vista de la inserción en el contexto territorial, cada ciudad sufre los desajustes derivados de la expansión metropolitana (con una proporción del 94\% de población urbana) y de la atracción que ejercen las vías de comunicación provincial y regional. 


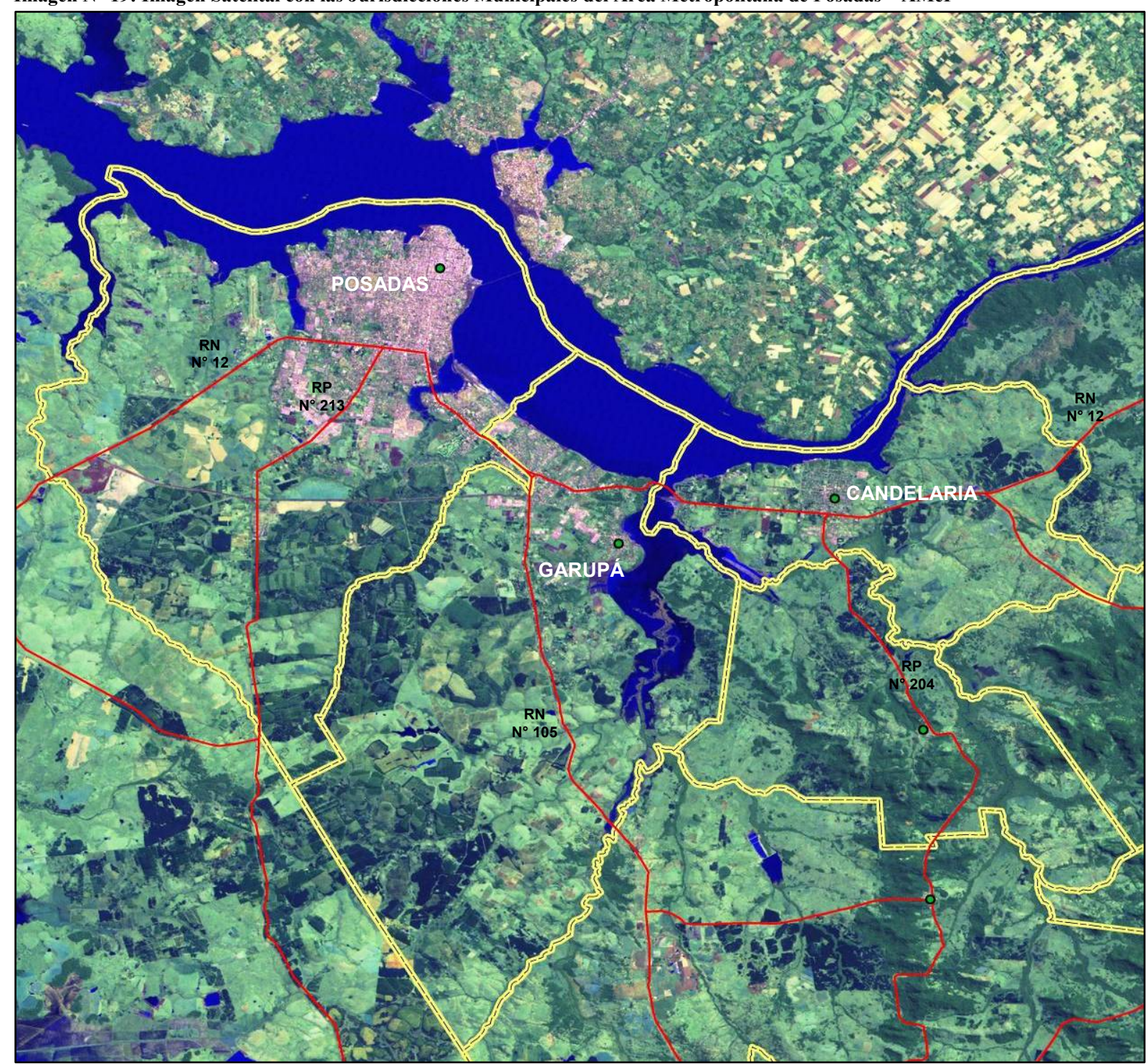

Fuente: Entidad Binacional Yacyretá, 2006.

\section{III.3.1.1. La ciudad de Posadas}

Como hicimos referencia en el Capítulo II (ver parágrafos II.1.3.1 y II.1.4), Posadas, fue fundada el 8 de noviembre de 1870, en el área de emplazamiento de la antigua reducción jesuítico-guaraní de Nuestra Señora de la Anunciación de Itapúa, en proximidades de la laguna San José, sobre la margen izquierda del río Paraná. Originalmente Posadas ocupaba la zona de selva en galería que corre junto al Paraná, pero su crecimiento ha hecho que actualmente abarque tierras ubicadas en las sabanas típicas del sur de Misiones. El relieve es suavemente ondulado, con colinas no muy altas, y con desniveles pocas veces abruptos, salvo en la zona de las barrancas del río. El área urbana ocupa aproximadamente unos 8 kilómetros hacia el sur y 6 hacia el oeste del recodo del río Paraná, y se encuentra asentada sobre un macizo basáltico muy singular, rodeada actualmente por el embalse de Yacyretá, que genera importantes cambios en la fisonomía local, sobre todo en la costa norte y en las desembocaduras de los arroyos urbanos, principalmente los arroyos Itaembé, Mártires, Antonica, Itá, Vicario y Zaimán. 
"El proceso de urbanización de Posadas puede dividirse en tres momentos históricos [...]:

Primer Período:

Del emplazamiento Militar al asentamiento permanente.

Con el asentamiento de tropas paraguayas (1840), se ejecuta la primera instalación física, consistente en una trinchera y campamento de observación denominado 'Trinchera de los Paraguayos'. Este emplazamiento actuó como punto articulador del espacio económico regional, y bisagra en la intersección del río Paraná con la conexión terrestre Itapúa - San Borja; que en una mayor escala, vinculaba Asunción con Porto Alegre (punto de salida al Océano Atlántico).

El asiento del Regimiento 24, durante la guerra de la Triple Alianza, generó el asentamiento espontáneo de vivanderos y proveedores, que continuó con la actividad comercial aún después de finalizada la guerra. Cuando el territorio quedó definitivamente incorporado al dominio de Corrientes y se designó al asentamiento 'Trincheras de San José' como capital del Departamento de Candelaria se consolidó la permanencia de su población que, para entonces, habia extendido sus servicios hacia la actividad dominante, orientada a la extracción de recursos naturales (yerba mate, madera, etc.).

Un asentamiento con vocación urbana: Orden geométrico y organización legal dan consistencia a Posadas, como 'centro' de la actividad extractiva regional. La intensa actividad y la permanencia del asentamiento espontáneo, dan origen al trazado inicial, que a modo de damero abarca un área de $13 \times 14$ manzanas [con dos plazas: la 9 de Julio, frente a la que se sitúan la casa de Gobierno y la Catedral, y la plaza San Martín], y su entorno queda definido por la repetición de chacras [con avenidas situadas cada $400 \mathrm{~m}$.] que como una macro cuadrícula se extiende hasta los límites naturales. Los primeros desbordes del casco céntrico se producen en diferentes direcciones, estimulados por actividades como: el puerto y la Bajada Vieja, el Brete, el cementerio, el matadero municipal, etc. Estos asentamientos dispersos, inducen la temprana extensión del amanzanamiento, fraccionando la traza de chacras, que sin adecuaciones ni previsiones, proyectan la retícula geométrica sobre fuertes condicionantes topográficas.

La designación de la primera junta municipal (1872), da consistencia legal al asentamiento. La comunicación fluvial por el Río Paraná, vía de penetración a toda la región, posiciona a Posadas como ciudad puerto, y última expresión urbana, en la ruta hacia las riquezas naturales.

En 1884 Posadas es designada capital del nuevo Territorio Nacional; su situación política y ubicación estratégica; contribuyen a consolidarla como centro geográfico, político administrativo, y foco de las actividades mercantiles y de la economía extractiva de la región.

Segundo Período:

Posadas, cabecera de la matriz agrícola:

La infraestructura ferro-portuaria abre paso a la ciudad moderna

A fines del siglo XIX se inicia el proceso de inmigración y colonización en la zona centro y sur del territorio, desde donde se expanden las actividades agricolas. Posadas constituye la base de operaciones para la creciente actividad rural.

La presencia de la infraestructura ferro-portuaria en la segunda década del siglo XX constituye un factor de fuerte gravitación en la conformación y consolidación urbana. El ferry-boat (Posadas - Pacú Cuá) articula la conexión Buenos Aires / Asunción, impulsa la economía regional, $y$ afianza el rol de Posadas como centro de intercambio de bienes y servicios para un territorio que trasciende los límites nacionales.

La configuración del borde ribereño como área de trabajo, generó los primeros asentamientos irregulares con características diferentes a la ciudad legal, que con mamposterías, chapas y tejados, se irradia desde la plaza central y se expande por los bordes y acompaña los caminos de acceso al caso céntrico.

El desarrollo de servicios básicos e infraestructura como: telefonía, la primera usina eléctrica, el agua potable, el asfaltado de un grupo de cuadras del centro, junto a la aparición de equipamientos colectivos como el Hospital Regional, el Hotel Savoy, el Banco Nación establecimientos educativos, industriales, Clubes y Asociaciones Civiles, las operaciones de embellecimiento urbano ( bulevar Mitre, Costanera del Parque Paraguayo), y la multiplicación de co- 
mercios y servicios, dan forma y albergan las actividades de un periodo de gran dinámica económica y social de la ciudad.

La mejora de la accesibilidad terrestre, por la Ruta 12 y la Avenida Uruguay, complementariamente con el ferrocarril, paulatinamente reemplazan al río como vía de comunicación y tráfico y se transforman en factores que inducen el crecimiento lineal hacia el sur de la ciudad (la Avenida Uruguay, primero y la Ruta 12, como proceso más reciente.)

La consolidación del casco céntrico con construcciones estables, e infraestructuras y servicios crecientes por un lado, y los desbordes con ocupación y trazado espontáneo de la ribera e internos de chacra, el asentamiento disperso y la baja densidad de población, las expansiones urbanas acompañando los accesos terrestres por el otro, constituyen rasgos urbanísticos de este periodo.

\section{Tercer Período}

Posadas: Capital de la Provincia.

La consolidación de la ciudad moderna.

Posteriormente a la provincialización de Misiones (1953) y designada Posadas como su Capital, la ciudad sufre importantes transformaciones en el marco de una economía provincial signada por la diversificación productiva - proceso este que se corresponde con una paralela diferenciación social - y por las crisis periódicas de sus principales rubros productivos.

Las deficiencias y el tardio desarrollo del sistema viario provincial, potenciaron el rol de la ciudad como centro de consumo y servicios, no sólo para sus propios habitantes sino también para la población del interior. El mejoramiento de la red vial provincial, y la aparición de establecimientos industriales asentados próximos a la producción primaria, generaron nuevos asentamientos urbanos dentro de las zonas productivas, estableciéndose un sistema urbano provincial dentro del cual, Posadas, legitimada en su condición de ciudad capital, sentó una primacía que se mantiene hasta el presente.

Los aires provincialistas traen confianza y deseos de modelar el futuro; en ese contexto tiene lugar la primera planificación de la ciudad: El Plan URBIS (1957). ${ }^{83}$ ". (Borio, 2010: 2-3)

Actualmente es Municipio de $1^{\circ}$ Categoría, cabecera del Departamento Capital y Capital de la Provincia de Misiones. Ocupa una parte urbana más una zona rural ubicada al sur y oeste de la misma, llegando hasta el arroyo Itaembé al Este, límite con la provincia de Corrientes.

En 1971 se elabora el Plan Posadas, que constituye una segunda propuesta de planificación destinada al control urbanistico de la ciudad. Dicho plan considera que la ciudad se caracteriza y debe preparase para ser centro administrativo gubernamental; punto de intercambio de bienes y servicios a nivel regional; nodo de tráfico de transporte, turismo y comercio a nivel internacional. Como idea central los ejes de crecimiento se dirigieron hacia la costa con dos direcciones básicas paralelas al curso del agua, desde el centro hacia el Sur y hacia el Oeste teniendo como marco la desembocadura del Arroyo Zaimán y la del Arroyo Mártires al Sur y Oeste respectivamente. (PEP, 2010: 22).

Si bien su crecimiento tardó en concretarse por ser una de las últimas zonas del territorio argentino en poblarse, es la ciudad más poblada de Misiones y su centro administrativo, comercial y cultural, y una de las ciudades con más actividad y crecimiento de toda la región NEA, a partir del impulso que le otorga las intervenciones de Yacyretá y principalmente el puente internacional San Roque González de Santa Cruz, tendido sobre el río Paraná, que la une a la ciudad de Encarnación, en la República del Paraguay.

${ }^{83}$ El objetivo principal del Plan fue promover el desarrollo y el bienestar ciudadano, regulando el crecimiento físico de la ciudad en forma armónica. Aunque tuvo una aplicación mínima, dicho plan contribuyó a estimular la concreción de muchas obras que comenzaron a transformar la ciudad a inicios de la década del 60; ejemplos de ello son el Anfiteatro, los Barrios Belgrano y 25 de Mayo, el Hotel de Turismo y el Mercado Paraguayo. 
La afectación de Yacyretá alcanza a todo su borde costero sobre el río Paraná y los arroyos urbanos dónde, en las zonas bajas, habitaban unas 6.000 familias y 500 establecimientos de producción artesanal de ladrillos (olerías). Las obras de mitigación y recomposición urbana, en avanzado proceso de ejecución, incluyen cuatro (4) complejos habitacionales (A-1 Yohasá; A-3.2 Nuestra Señora del Rosario; A-4 Nueva Esperanza y San Isidro) con 5.851 viviendas y todos los servicios y equipamientos comunitarios; obras viales costeras y de integración local y regional; así como, obras de protección costera y recomposición de trama urbana, hacia el embalse principal y los subembalses de los arroyos urbanos (Mártires, Antonica, Itá y Zaimán).

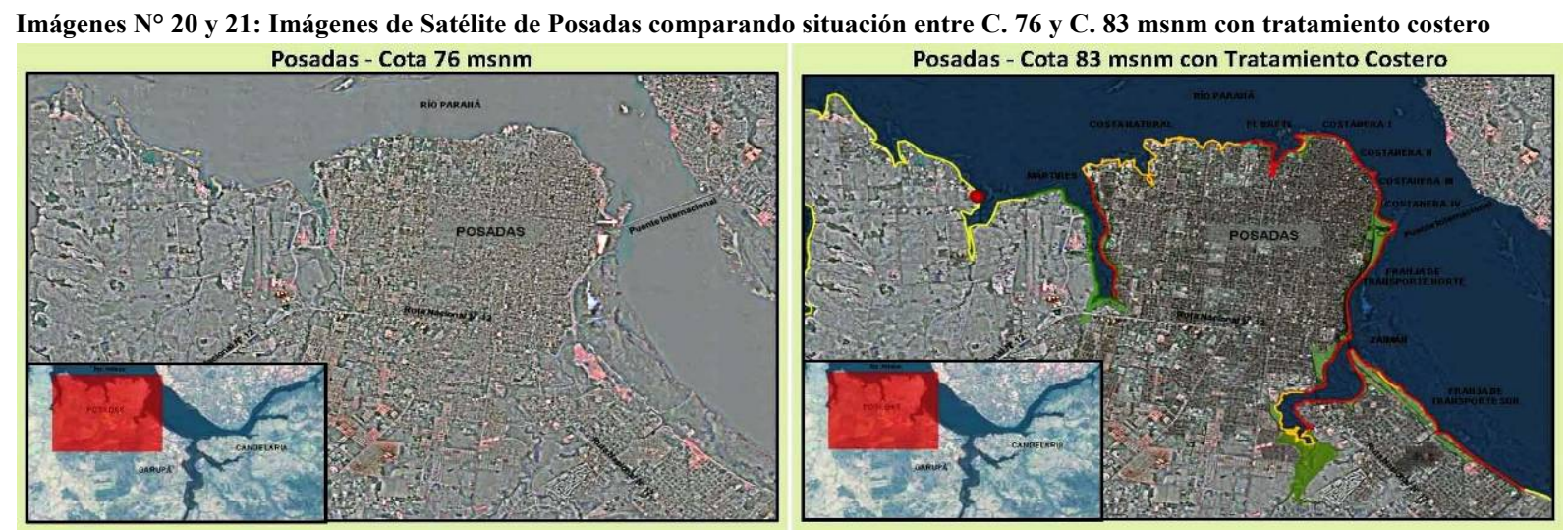

Fuente: Entidad Binacional Yacyretá, 2010

\section{III.3.1.2. La ciudad de Garupá}

Fundada el 15 de octubre de 1957, es una ciudad cuya zona central está localizada sobre el arroyo Pindapoy que, en su confluencia con el arroyo Garupá, desemboca en el río Paraná. Conforma un Municipio de $2^{\circ}$ Categoría de la provincia de Misiones dentro del Departamento Capital, a unos $16 \mathrm{~km}$ del centro de la ciudad de Posadas, a la cual se accede a través de la Ruta Nacional $\mathrm{N}^{\circ} 12$. En su zona central en el entorno de la Estación ferroviaria, existen barrios tradicionales como: Centro, Nu Porá, Santa Inés, Don Santiago, Villalonga, Santa Clara y Santa Elena, en tanto que sus áreas externas, conforman una continuidad del crecimiento periurbano de Posadas.

Garupá viene duplicando su población cada diez años con un crecimiento intercensal de cerca del $70 \% .{ }^{84}$ Esta población provino principalmente del interior provincial en busca de trabajo, y se asentaron en los nuevos barrios de viviendas construidos por el Instituto Provincial de Desarrollo Habitacional (IPRODHA) y en el Complejo Habitacional Virgen de Fátima, construido por la EBY para el proceso de reasentamiento de población que habitaba en la zona de afectación de Yacyretá, dónde se relocalizaron 1.350 familias de Garupá y otras provenientes de distintos barrios de Posadas.

Su cercanía con Posadas determina que la mayor parte de su población se traslade a trabajar en la capital provincial dado que, fuera del circuito económico de Posadas, las actividades económico-

${ }^{84}$ Según datos del INDEC, el Censo de 1980 registra 7.908 habitantes; el Censo de 1991 registra 14.290; el Censo 2001 registra 28.814 y la proyección a 2009 realizada por el Municipio, era de cerca de 50 mil habitantes. 
productivas, están dadas por los aserraderos -que se ubican en Garupá por su rápido acceso a las rutas de donde llega la madera y por la amplitud de los predios-, así como por la presencia de comercios (de insumos para el agro, automotores, etc.) ubicados a la vera de la Ruta Nacional $\mathrm{N}^{\circ} 12$ y algunos pocos y aislados establecimientos industriales.

Desde la óptica urbana, la ciudad presenta tres sectores bien diferenciados. El primero está representado por un pequeño casco urbano con trazado en damero, localizado entra las Rutas Nacionales $\mathrm{N}^{\circ}$ 12 y 105 y la confluencia de los arroyos Pindapoy-Garupá y Negro-Tranquera; el segundo, hacia el N$\mathrm{O}$ y Sur, como periferia urbana con eje sobre la $\mathrm{RN} \mathrm{N}^{\circ} 105$; y el tercero, como expansión urbana de Posadas, con eje sobre la $\mathrm{RN} \mathrm{N}^{\circ} 12$ y el río Paraná.

La afectación de Yacyretá alcanza al borde costero sobre el río Paraná y sobre el arroyo Garupá dónde, en las zonas bajas, habitaban unas 1.000 familias y 100 establecimientos de producción artesanal de ladrillos (olerías). Las obras de mitigación y recomposición urbana, en avanzado proceso de ejecución, incluyen un (a) complejo habitacional (A-3.1 Virgen de Fátima) con 1.366 viviendas, un hospital regional y todos los servicios y equipamientos comunitarios; obras viales costeras y de integración local y regional; un nuevo puente sobre el arroyo homónimo que la vincula con candelaria y el norte provincial; así como obras de protección costera y recomposición de trama urbana, hacia el embalse principal y el subembalse, con reposición del balneario municipal.

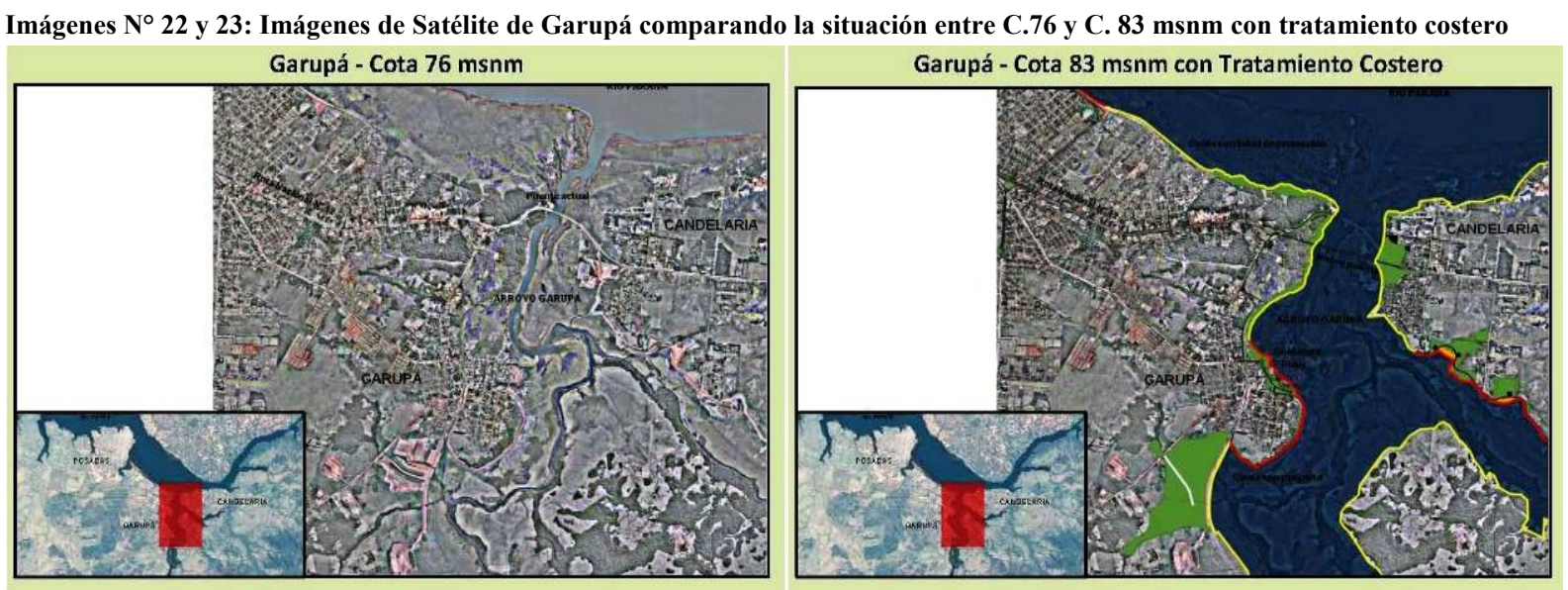

Fuente: Entidad Binacional Yacyretá, 2010

\section{III.3.1.3. La Ciudad de Candelaria}

La actual ciudad de Candelaria, fue -como hemos analizado en el Capítulo II- una importante reducción jesuítica y, después de su fundación como ciudad el 10 de octubre de 1895, fue también la primera capital provincial. Está localizada sobre la costa del río Paraná y, como Municipio de $2^{\circ}$ Categoría, forma parte también del Área Metropolitana de Posadas (AMeP), comunicada a través de la $\mathrm{RN} \mathrm{N}^{\circ} 12$. Por aquella condición de capitalidad, Candelaria posee una zona urbana planificada entre el río Paraná y los arroyos Garupá y San Juan, que tiene una estructura de chacras con avenidas cada 800 m, que conforman una red de macro-manzanas, cuatro de las cuales, poseen un trazado en damero de 8 x 8 man- 
zanas, con una plaza central en la intersección de las avenidas. En el extremo norte del área urbana, cerca del río Paraná, se encuentran las ruinas de la reducción jesuítica.

La afectación de Yacyretá alcanza al borde costero sobre el río Paraná y sobre el arroyo Garupá, cuyo subembalse define un área peninsular coincidente con la zona planificada. En las zonas bajas, habitaban unas 100 familias dedicadas a la producción artesanal de ladrillos (olerías) que fueron apoyadas en su auto-relocalización y compensadas en su actividad. Las obras de mitigación y recomposición urbana, en avanzado proceso de ejecución, incluyen al nuevo puente sobre el arroyo Garupá; defensas costeras, avenida costanera de $400 \mathrm{~m}$ y la reposición del balneario municipal, sobre la costa del río Paraná; obras viales, paseo costero con dos playas y áreas verdes equipadas sobre la margen derecha del arroyo Garupá y una gran reserva natural urbana en la confluencia de este arroyo con el arroyo San Juan.

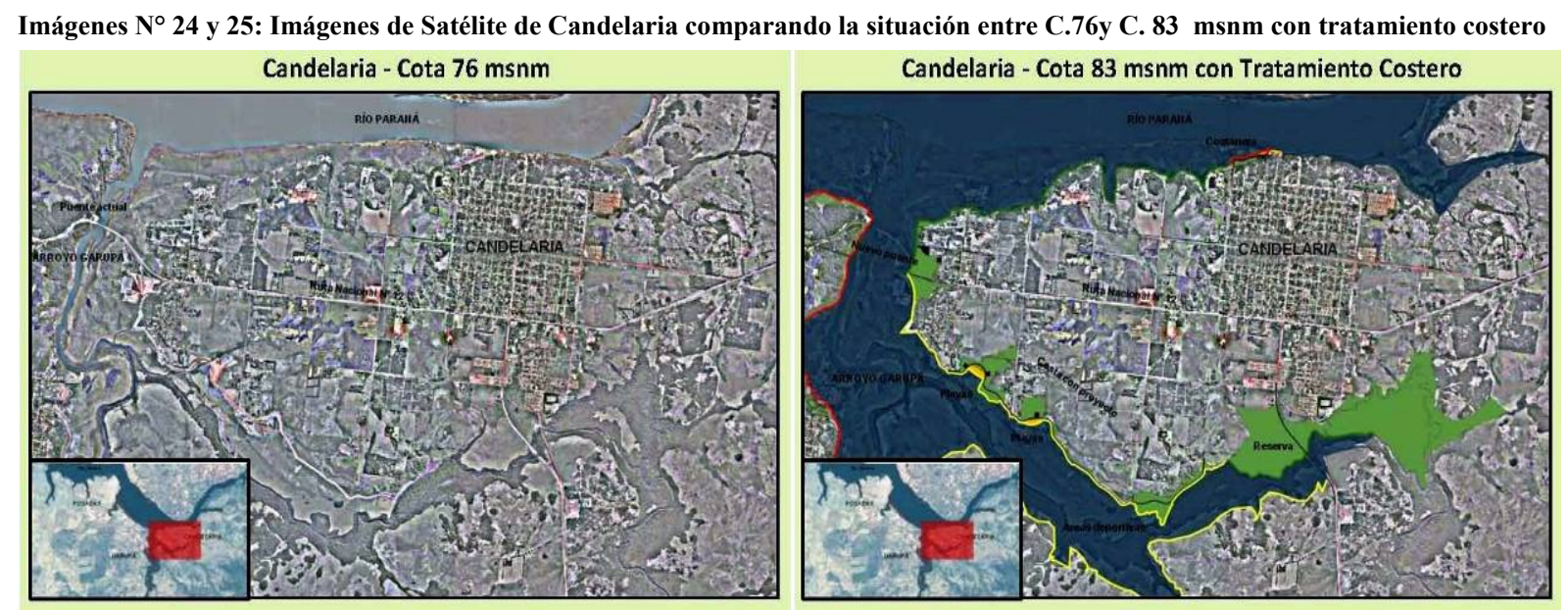

Fuente: Entidad Binacional Yacyretá, 2010

\section{III.3.2. El área de Encarnación, en Paraguay}

Esta área está definida por un 'corredor' de $35 \mathrm{Km}$., que incluye a los Municipios de Encarnación, Cambyretá, San Juan y Carmen del Paraná. Está localizado sobre la Ruta Nacional N ${ }^{\circ} 1$ y es de gran importancia, dado que vincula estas ciudades con la ciudad de Asunción, capital del Paraguay. Este corredor está muy influenciado por la inundación que produce el embalse de Yacyretá a cota final (83 $\mathrm{msnm}$ ), dado que a esa cota del total del área a inundar (aprox. $1.000 \mathrm{Km}^{2}$.), el $80 \%\left(800 \mathrm{Km}^{2}\right.$.), se produce sobre territorio paraguayo. Dicha situación está determinada por las características de la cuenca del Paraná, que es más plana sobre la costa de este país y más abrupta sobre territorio argentino.

Es una zona de gran declive que empieza en la ribera del Río Paraná, unos $80 \mathrm{msnm}$, que va ascendiendo hacia el norte. En la región baja se encuentran Carmen y San Juan del Paraná, Encarnación, Cambyretá y, también, Coronel Bogado. En los ámbitos urbanos, los efectos del embalse y principalmente de los subembalses, son determinantes de una nueva configuración territorial. 


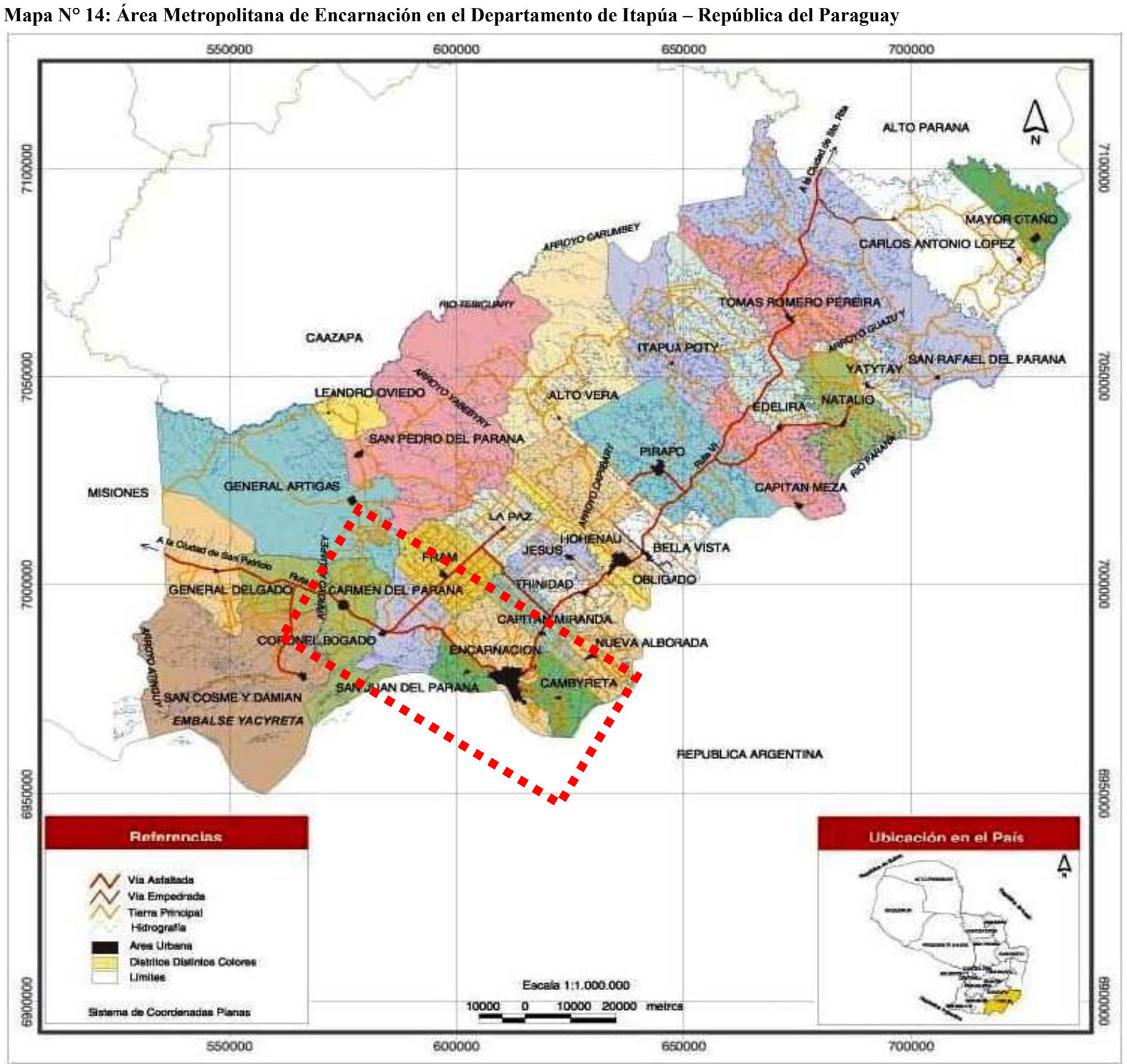

Fuente: Dirección General de Estadística, Encuestas y Censos (DGEEC) del Paraguay, 2001.

\section{III.3.2.1. La Ciudad de Encarnación}

La histórica reducción jesuítica de Nuestra Señora de la Encarnación de Itapúa (ver parágrafos II.1.3; II.1.4 y II.2.4), fue elevado a la categoría de 'Villa' durante el Gobierno de López y desde entonces, según expresa el decreto del 8 de abril de 1.843, se la conoció como 'Villa Encarnación' (Arrúa, 2009: 60).

"Después de la guerra de 1870 la reconstrucción nacional se basó esencialmente en un régimen de privatización de la propiedad de la tierra y en el fomento de la inmigración extranjera. Itapúa fue uno de los primeros departamentos en que se puso en práctica esta política. Desde fines del siglo XIX y principios del siglo XX, las colonias de inmigrantes de origen europeo, especialmente alemanes, eslavos y ucranianos, y más tarde también japoneses, desarrollaron en este departamento la agricultura mediante el cultivo de arroz, tung, soja, trigo y algodón, implantando prácticas agrícolas muy adelantadas" (Atlas de Itapúa, 2002:1) .

La Villa se convirtió en Departamento en 1906, con la primera Ley de División Territorial de la República, pero recién en 1945 recibió el nombre Itapúa, estableciéndose a Encarnación como capital departamental, alcanzando sus actuales límites en 1973, por el Decreto Ley No 426. 
La ciudad moderna se funda con criterio militar, sobre la antigua plaza de la reducción jesuítica (de la que no queda vestigios tangibles), con el nombre de 'Plaza de Armas', en torno a la cual se localizaba el cuartel, la iglesia y el colegio, desarrollando a partir de allí un pequeño trazado en damero y la vinculación con la zona baja portuaria.

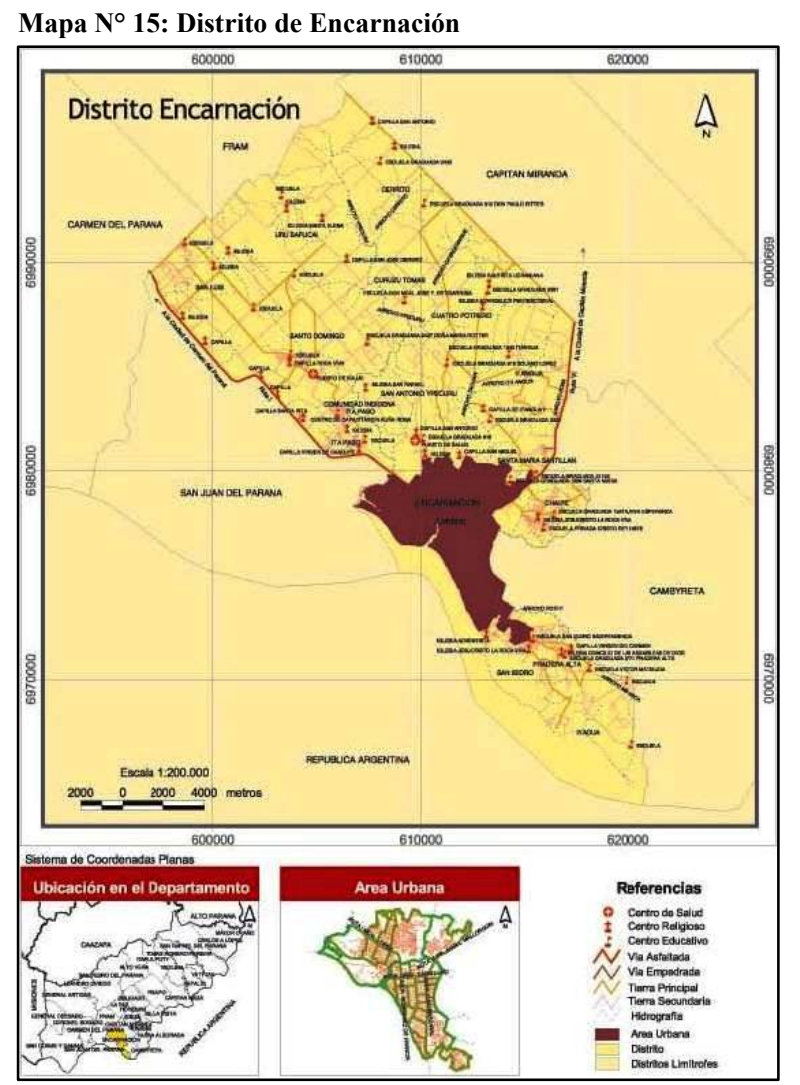

Encarnación es una ciudad costera, cuya zona central está localizada sobre la ribera del río Paraná y la desembocadura del arroyo Mboi Caé. Sobre la zona baja de esta costa, se fue consolidando la actividad portuaria y comercial, reconocida como 'Zona Baja Comercial'.

Estas actividades indujeron la localización de población estable que en las zonas más altas y definieron barrios como Santa Rosa, San Roque y otros pero, en las zonas bajas, favoreció la localización de población de menores recursos que alentados por las expectativas de trabajo que ofrecía Yacyretá y el vínculo con Posadas a través del Puente Internacional- ocuparon en forma precaria estas zonas sin aptitud urbana.

Fuente: DGEEC, Paraguay, 2001

La expansión periurbana -ayudada por las características más planas del territorio- fue análoga a la de otras ciudades latinoamericanas: la 'mancha de aceite' se extendió sin solución de continuidad, aún sobre las mismas planicies de inundación de los arroyos que la surcan y desaguan en el Paraná.

La afectación de Yacyretá alcanza a todo su borde costero sobre el río Paraná y sobre el arroyo Mboi Caé, que define una gran área de subembalse que transforman a la ciudad costera en una suerte de península, que deja escindida del área central a algunos barrios, buena parte de la periferia urbana y su vínculo terrestre con Cambyretá. A esta situación, hay que sumarle la afectación de tradicionales barrios urbanos y toda la ex zona baja comercial que, en conjunto, ha requerido la relocalización de unas 7.000 familias (propietarias y no propietarias), más de 600 establecimientos de producción artesanal de ladrillos (olerías) y tejerías y más de 2.500 locales comerciales con todos sus servicios y equipamientos urbanos, que debió ser contemplada en el proceso de terminación de Yacyretá.

Las obras de mitigación y recomposición urbana, en avanzado proceso de ejecución, incluyen cinco (5) complejos habitacionales (Buena Vista, para familias propietarias con 600 viviendas; Los Arrabales con 25 viviendas; Itá Paso con 674 viviendas, San Pedro con 1.972 viviendas y San Isidro con 
1.662 viviendas), totalizando 4.993 viviendas con todos los servicios y equipamientos comunitarios; cerca de $30 \mathrm{~km}$, de obras de protección costera y avenidas y calles costaneras hacia el embalse principal y los subembalses de los arroyos urbanos (Mboi Caé, Santa María, Poti’y, Yacu Paso y Quiteria) y nuevos accesos viales y puentes de integración local y regional que articulan el área urbana con los barrios al otro lado de los subembalses y el resto del territorio nacional.

\section{III.3.2.2. La Ciudad de Cambyretá}

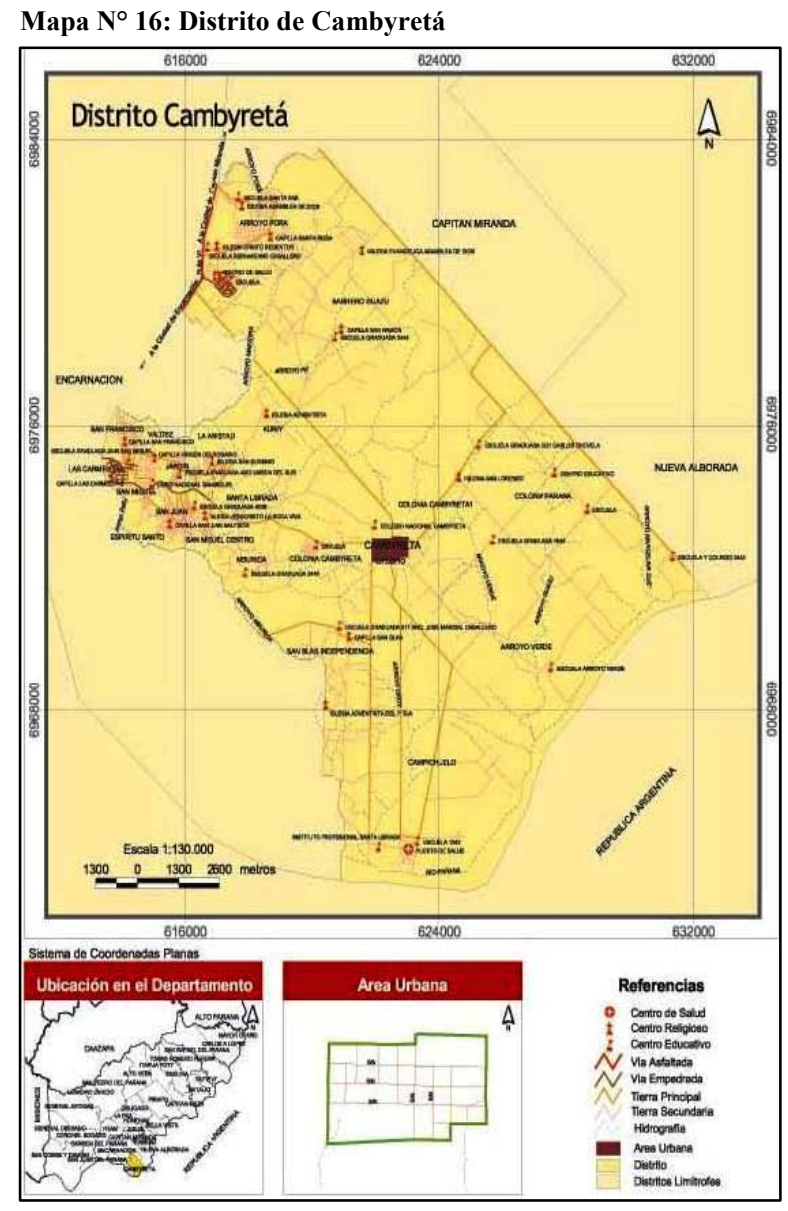

Fuente: DGEEC, Paraguay, 2001.
Históricamente fue un barrio de Encarnación, que ha adquirido el rango de municipio a fines de la década del 80.

"Sin solución de continuidad [con Encarnación] se encuentra Cambyretá. Es una zona de buen poder adquisitivo, reconocida por tener potencialidad de desarrollo semi-autónomo." (Levinton, 2007: 249)

Se trata de una zona dominantemente rural, con un pequeño casco urbano, con una población total al año 2002 de 27.808 habitantes (con un $98 \%$ de población rural).

La afectación de Yacyretá se manifiesta sobre la margen derecha del subembalse del $\mathrm{A}^{\circ}$ Poti'y dónde se ejecutan obras de tratamiento costero y de recomposición de la trama urbana, compuestas por una calle perimetral, áreas parquizadas y dos puentes que, como paseo costero, vinculan Cambyretá con Encarnación.

Las obras de mitigación se complementan con la ejecución 88 viviendas que completan parte del tejido urbano, destinadas a relocalizar familias que habitaban en zona de afectación del barrio San Francisco y hacia el Norte, sobre la Ruta Nacional No 6 que vincula Encarnación y Cambyretá con Ciudad del Este, se ha construido el complejo habitacional Arroyo Porá, en la zona alta lindante con dicho arroyo, compuesto por 1.504 viviendas destinadas a la relocalización de familias no propietarias, asentadas originalmente en zonas inundables del área de Encarnación. Estos conjuntos habitacionales, ya se encuentran totalmente ocupados, poseen todos los servicios y equipamientos comunitarios. 


\section{III.3.2.3. La Ciudad de San Juan del Paraná}

San Juan del Paraná es uno de los 30 Distritos del Departamento de Itapúa. Se localiza sobre el río Paraná y la margen derecha del arroyo Quiteria, al Sur de Encarnación. Fue fundada por el Gobernador Joaquín de Alós y Brú en el año 1789 y alcanzó el rango de municipio en 1988.

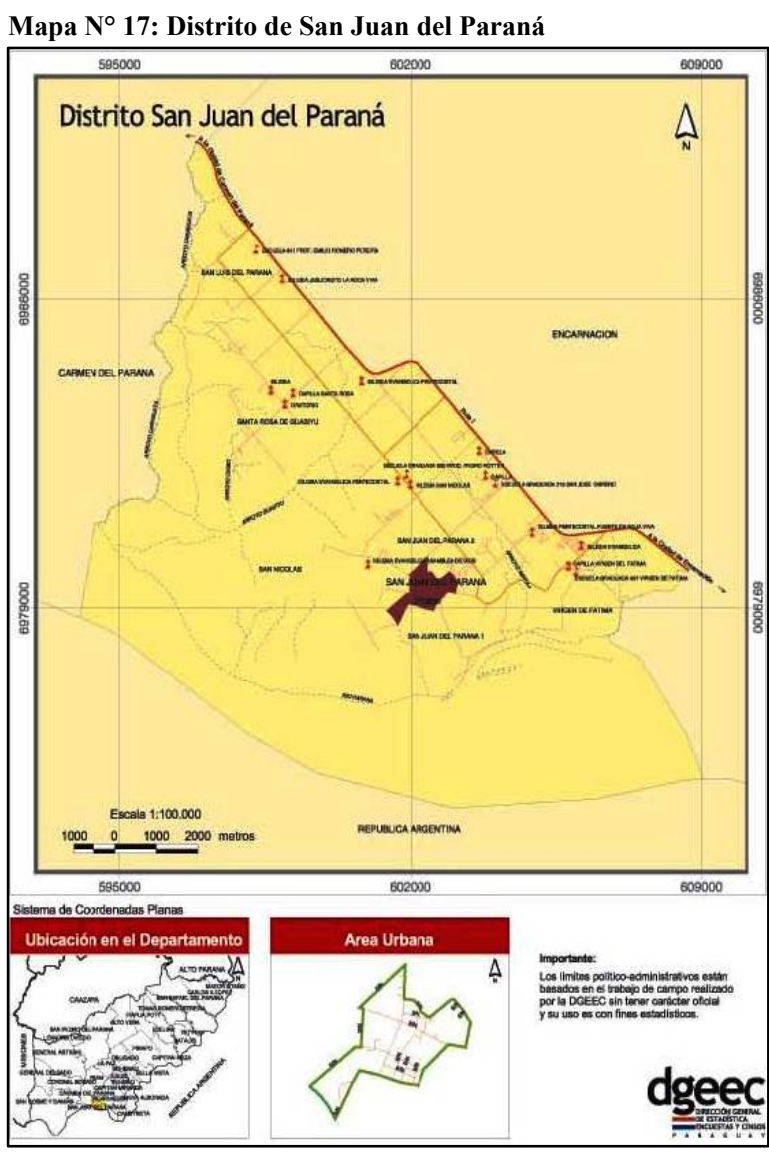

Fuente: DGEEC, Paraguay, 2001
El Distrito tiene una superficie de $250 \mathrm{~km}^{2}$ de extensión territorial, con una población total al año 2002 de 7.091 habitantes (con un $83 \%$ de población rural). Su densidad poblacional es de 29,8 habitantes por $\mathrm{km}^{2}$. Las principales actividades económicas son la agricultura, con cultivos de trigo, soja y otros productos de subsistencia y la actividad ganadera, con vacunos y ovinos; también cuenta con pequeñas industrias madereras y agroindustriales. La comunicación terrestre más importante es el ramal de la $\mathrm{RN} \mathrm{N}^{\mathrm{o}} 1$ Mariscal Francisco Solano López, que lo conecta con Encarnación, Carmen del Paraná y otras localidades, en sentido hacia Asunción. La ciudad ofrece una pequeña zona comercial y es punto de referencia turística para deportes náuticos, con playas sobre el $\mathrm{A}^{\circ}$ Caraguatá, zonas aptas para la pesca deportiva y áreas de monte natural bien conservadas.

La afectación de Yacyretá alcanza a zonas rurales, dónde se conforma un gran subembalse sobre el arroyo Quiteria, que se junta con el embalse principal. En 1993, previo al llenado del embalse a Cota $76 \mathrm{msnm}$, fueron construidos proyectos productivos en el ámbito rural para relocalizar población costera e isleña y, en la fase de terminación, se ha construido un puente de más de $600 \mathrm{~m}$. para el cruce del subembalse, como parte del nuevo acceso vial de la Ruta Nacional $\mathrm{N}^{\circ} 1$ a Encarnación, junto al nuevo Puerto del área metropolitana.

\section{III.3.2.4. La Ciudad de Carmen del Paraná}

Carmen del Paraná es uno de los distritos del Departamento de Itapúa. Se encuentra situado en la región sur del mismo, a 33 km de Encarnación y a 330 km de Asunción, capital de la República del Paraguay. El distrito cuenta con $300 \mathrm{~km}^{2}$ y una densidad poblacional de 23,2 hab./Km². La principal vía hidrográfica es el río Paraná y sus afluentes, siendo los principales, los arroyos Tacuary y Caraguatá. 
Mapa $N^{\circ}$ 18: Distrito de Carmen del Paraná

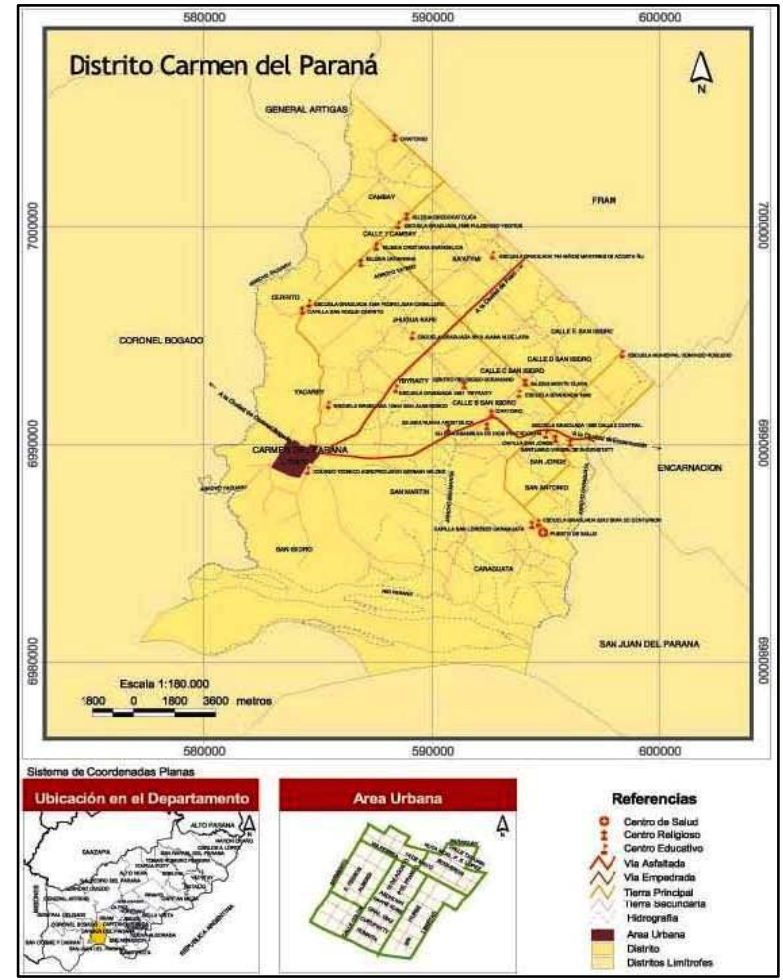

Fuente: DGEEC, 2001
Fue fundado en 1843, durante el gobierno de Carlos Antonio López, en el lugar donde existía un oratorio que motivó la elección del paraje y donde el 9 de marzo de 1811 se había registrado la batalla de Tacuary contra las tropas porteñas lideradas por el Gral. Manuel Belgrano (ver parágrafo II.1.4).

"El pueblo [fue] formado por los antiguos indios misioneros habitantes de Encarnación Itapúa [... dónde] el tiempo ha borrado sus huellas pero la pervivencia de la toponimia alienta a recorrer los lugares más renombrados." (Levinton, 2007: 246).

Después de la Primera Guerra Mundial, gran parte de la población estuvo conformada por inmigrantes extranjeros de diferentes orígenes (rusos, polacos, eslovacos, checos y mayormente ucranianos) que han influido en las costumbres y tradiciones que perduran en la micro cultura local.

"Actualmente es una villa de casas bajas, algunas de antigüedad cercana a principios del siglo XX” (Levinton, 2007: 247)

De acuerdo a datos de la Dirección General de Encuestas Estadísticas y Censo, su población al año 2002 era de 6.165 habitantes (con un 37\% de población rural), con una proyección para el año 2011 de 7.190 habitantes. Las principales actividades económicas son la ganadería y la agricultura, con extensas plantaciones de arroz y cultivos de soja y trigo.

La afectación de Yacyretá alcanza a gran parte de los barrios costeros San Blas, San Roque, Obrero, San Miguel, Loma Clavel y San Isidro, que eran los más poblados de Carmen del Paraná y al arroyo Tacuary, dónde se conforma un gran subembalse que, en forma conjunta con el embalse principal, que se acerca notablemente al área urbana convierten a este pueblo rural en una pequeña península que se inserta entre ambos cuerpos de agua.

Las obras de mitigación y recomposición urbana, ya finalizadas y habilitadas, han incluido una extensión del casco urbano, con 329 viviendas para familias relocalizadas (propietarias y no propietarias), la mejora de los servicios (cloacal, agua y electricidad) y equipamientos comunitarios existentes (Escuelas, Hospital Regional, Destacamento de la Policía Nacional, entre otros); la relocalización de $5,4 \mathrm{~km}$ de la RN $\mathrm{N}^{\circ}$ 1; la construcción de dos nuevos puentes (uno de $25 \mathrm{~m}$. y otro de $175 \mathrm{~m}$. de longitud) y $8,4 \mathrm{~km}$ de protección costera en el entorno del casco urbano hacia el embalse principal y subembalse del arroyo Tacuary, sobre el cual se ha ejecutado una avenida costanera de dos carriles con separador central, iluminación, parquización y la ejecución de tres sectores destinados a playas públicas y la recuperación de 112 has de zonas bajas destinadas a reserva ecológica urbana. 


\section{III.3.3. Las implicancias de la Obra sobre su área de implantación y los instrumentos de} gestión territorial como basamento del proyecto Paisaje

Además del embalse y del sistema presas-puente -que por razones de seguridad internacional aún no puede operar en dicha condición- la situación del área de implantación de Yacyretá estuvo determinada, desde los inicios de la década del 90, por la presencia del Puente Internacional San Roque González de Santa Cruz, que vincula a las ciudades de Posadas y Encarnación y sus áreas de influencia, con los principales corredores del Mercosur. Esta Obra, sumada a la expectativa 'desarrollista' promovida por la ejecución de la hidroeléctrica, han convertido a estas ciudades en un factor de atracción regional binacional, pero el tiempo transcurrido entre esas primeras concreciones y la terminación del proyecto, ha favorecido también su rápido y desordenado crecimiento. Esto fue determinante para la definición del tipo de obras y de gestión que delinearon el Plan de Terminación de Yacyretá.

“[...] La idea esencial, devenida del Plan de Terminación de Yacyretá, es montar una estructura que integre a las ciudades ubicadas sobre ambas márgenes del río Paraná, teniendo el trayecto fluvial como eje. Las ciudades de cada margen, desde Ayolas a Encarnación y a partir de Ituzaingó hasta Garupá, de alguna forma integran un posible recorrido turístico o de intercambio comercial. Por este motivo se puede concebir a las ciudades de las dos márgenes formando lineas paralelas, unidas transversalmente por la represa y los puentes complementarios en un extremo, y por el puente Posadas-Encarnación en el otro." (Levinton, 2007: 243-4)

Esta posibilidad de integración se complementa con el conjunto de nuevos puentes y accesos viales a cada una de las ciudades localizadas sobre ambas márgenes del embalse principal, así como con las obras portuarias y ferro-viales de escala regional, que favorecen la articulación del área con el interior de cada país y entre estos y el resto del Mercosur, que se explican como obras y acciones en el parágrafo III.4 y se analizan en términos de paisaje en el parágrafo IV.1.

De tal forma, este apartado analiza los principales instrumentos de planificación del territorio, que fueron considerados y que están siendo actualizados, conforme el avance de ejecución de las obras de terminación, dentro del contexto de los acuerdos alcanzados entre los gobiernos nacionales (Altas Partes Contratantes) con los gobiernos locales de ambos países y analiza también, los instrumentos de gestión del paisaje que sirven de marco conceptual para el desarrollo del Capítulo IV.

\section{III.3.3.1. Marco de Planificación Territorial}

La planificación territorial -dentro de cuyo marco normativo y de regulación se inscriben las obras del Plan de Terminación de Yacyretá (PTY)- está determinada por las características específicas de la estructura normativa de cada uno de los países. En este sentido, merece mencionarse que mientras que el Paraguay delega esa responsabilidad en los municipios, en la Argentina existe tanto planificación de los gobiernos provinciales como municipales, siendo la situación específica de cada municipio dispar en ambas márgenes, en función de las capacidades operativas de cada unidad de gobierno local. Posadas en Argentina y Encarnación en Paraguay, son los municipios con mayores capacidades de gestión. 


\section{A. La Planificación en la Margen Paraguaya}

El marco legal y normativo está establecido por la Ley Orgánica Municipal N 3.966/10 de la República del Paraguay, que en su Artículo 224 referido a la Planificación Municipal, expresa:

"Las Municipalidades establecerán un sistema de planificación del municipio que constará, como mínimo, de dos instrumentos: el plan de desarrollo sustentable del municipio y el plan de ordenamiento urbano y territorial" (Paraguay, Ley 3.966, 2010: 53).

De todas maneras, sólo el Municipio de Encarnación posee un plexo normativo y de planificación más completo que el resto de los municipios conformado, principalmente, por el Código Urbano y de Edificación -que actualmente está siendo actualizado dentro del marco de un Convenio con la EBY-; por la Ordenanza del Plan Director de Medio Ambiente y por la Resolución Municipal N 493/06 Lineamientos de Ordenamiento Urbano-Territorial y Criterios de Gestión, estos últimos, elaborados por Convenio con la Entidad Binacional.

La normativa municipal se complementa con Leyes y con la intervención de organismos nacionales, dónde merece destacarse a la Secretaría del Ambiente (SEAM), que es el organismo que otorga las Licencias Ambientales de todas las grandes obras a ejecutar en territorio paraguayo, y cuyo propósito es formular políticas y coordinar la supervisión y ejecución de acciones planes, programas y proyectos referidos a la preservación, conservación, recomposición y manejo de los recursos naturales.

\section{B. La Planificación en la Margen Argentina}

En la Argentina se registran dos niveles de gestión: A) Provincial, incluido dentro del Plan Estratégico Territorial nacional; B) Municipal, dónde solamente Posadas posee un instrumento actualizado de planificación que incorpora las obras de terminación de Yacyretá.

\section{B.1. Estrategias Provinciales dentro del Plan Federal}

Plano No 11: Provincia de Misiones - Modelo Deseado

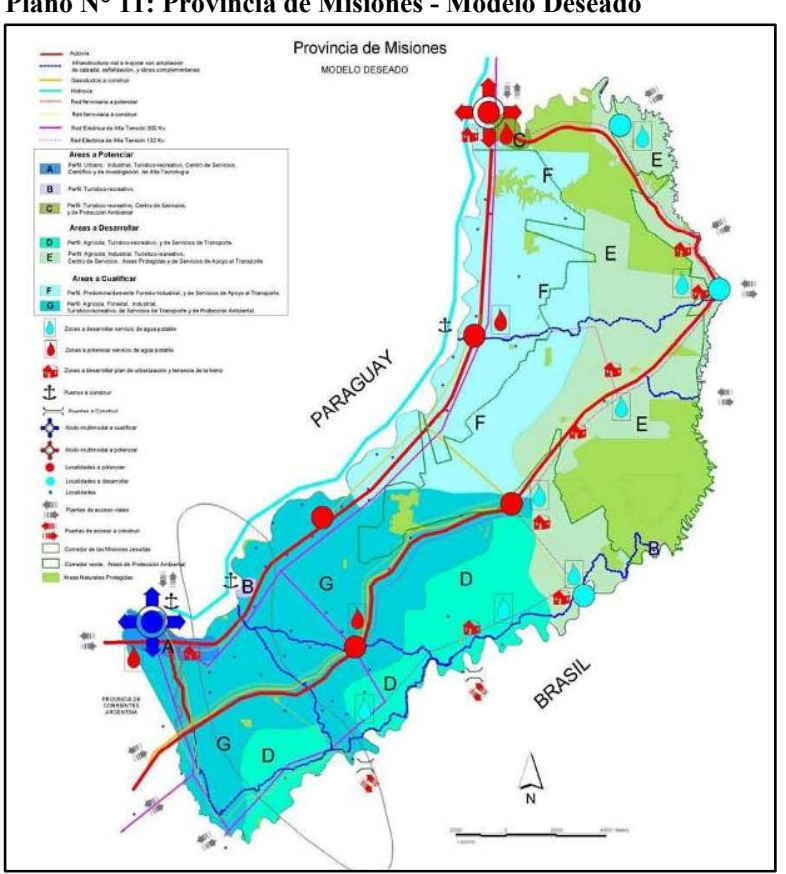

Fuente: Plan Estratégico Territorial, Misiones, 2007: 16
El área de estudio comprende los Departamentos Capital y Candelaria, identificados como Zona 5: Sur dentro de la Provincia de Misiones y el Departamento Ituzaingó dentro de la Provincia de Corrientes.

Esta zona se caracteriza por contar con la mayor proporción de población urbana $(93,7 \%)$, nucleada en un gran centro: la ciudad de Posadas, dónde se concentran los servicios administrativos, comerciales, de salud (hospitales y clínicas) y educativos de nivel terciario y universitario (estatal y privadas), así como, una mayor existencia de infraestructura básica (red de caminos pavimentados, electrificación, agua potable, cloacas). 
En la zona de Corrientes el área limita con los Esteros del Iberá, considerados dentro de las estrategias de conservación natural y cultural ${ }^{85}$ de la provincia con la colaboración de la Entidad Binacional.

Ambas provincias plantean, respectivamente, la integración con los Departamentos de Itapúa y Misiones de la República del Paraguay, a partir de las obras de Yacyretá.

Plano $N^{\circ}$ 12: Provincia de Corrientes - Modelo Deseado

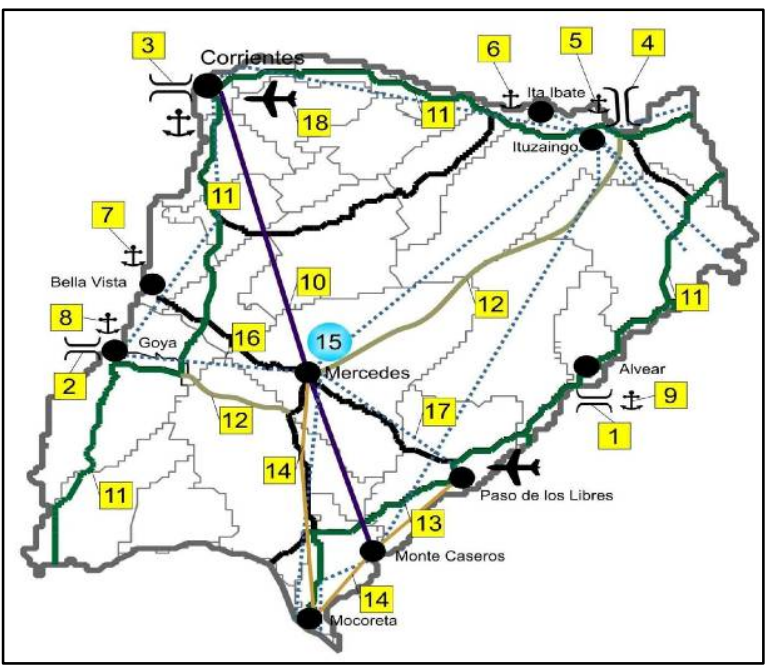

Estas obras están conformadas, principalmente, por el Puente Internacional San Roque González de Santa Cruz, que vincula Posadas y Encarnación; la represa-puente donde se ubica la central hidroeléctrica que une las ciudades de Ituzaingó y Ayolas y los nuevos puertos, construidos por Yacyretá, de Santa Ana y Posadas en la provincia de Misiones, el existente de Ituzaingó en la provincia de Corrientes y el de Encarnación en Paraguay, también construido por Yacyretá.

Fuente: Plan Estratégico Territorial, Corrientes, 2007: 34

A esto se anexan las adecuaciones de las Rutas Nacionales $\mathrm{N}^{\circ} 1$ y $\mathrm{N}^{\circ} 6$ en Paraguay, y de la $\mathrm{RN}$ $\mathrm{N}^{\circ} 12$ en Argentina, que sumado a la reposición del servicio ferroviario que puede vincular Buenos Aires con Asunción, ofrecen nuevas alternativas de articulación a escala del Mercosur.

\section{B.2. $\quad$ Estrategias Municipales de Ordenación}

Las estrategias a esta escala son disímiles entre los grandes y pequeños municipios involucrados dentro del área de proyecto, por lo cual, la EBY apoya las adecuaciones de los respectivos códigos de planeamiento a las nuevas infraestructuras y al proceso de transformación en ejecución.

El Municipio de Posadas, se rige por las Ordenanzas N 917/2002 de Uso del Suelo y la ํㅜ 2.916/ 2011 de Ordenamiento Urbanístico del Frente Fluvial, ambas adecuadas con aporte técnico de la EBY, y desde 2005 está llevando adelante, dentro de la estrategia provincial, el Plan Estratégico Posadas 2022, el cual, “[...] busca contribuir al desarrollo armónico y sustentable de Posadas, a través de una planificación con una concepción integral, generando un núcleo de decisiones que partan de amplios acuerdos de la comunidad" (Plan Posadas, 2010: 12).

En los casos de los municipios de Garupá y Candelaria, este proceso de adecuación se ha comenzado a ejecutar a partir de junio de 2010, con apoyo técnico de la Entidad Binacional Yacyretá.

\footnotetext{
${ }^{85}$ Dentro del área Iberá el gobierno provincial pretende, desde el punto de vista natural, fomentar actividades orientadas a repoblar la reserva a través de la cría de especies en peligro de extinción; desde lo económico, propone fomentar el desarrollo de actividades productivas orgánicas como horticultura, citricultura y granja, y desde lo cultural, las actividades artesanales propias de la zona, como cestería, alfarería, comidas típicas y otras.
} 


\section{III.3.3.2. Marco para el Manejo y la Gestión del Paisaje}

En el área de estudio de esta investigación existen pocos antecedentes en términos de legislaciones nacionales o normativas provinciales y municipales referidas específicamente a la regulación, uso, ordenación o protección del paisaje, pero sí puede verificarse en ambos países, la existencia de normas vinculadas a la protección ambiental, del patrimonio natural y cultural y de promoción de circuitos turísticos, así como la vigencia de convenios y programas internacionales, vinculados principalmente a la protección de recursos naturales y culturales con alto valor de conservación que incluyen implícitamente el concepto de protección de áreas de interés y, por ende, la 'noción de paisaje'. Estos antecedentes son los que se analizan en la primera parte de este parágrafo.

Complementariamente, cabe mencionar que la experiencia de gestión integral sobre la regulación, uso, ordenación o protección del paisaje, está siendo desarrollada principalmente por los países de la Unión Europea, dentro del marco del Convenio Europeo de Paisaje y de leyes sancionadas en los países que conforman la UE, que es lo que se analiza en la segunda parte de este parágrafo.

\section{A. Antecedentes en el Área de Estudio}

\section{A.1. Legislación en Paraguay}

La Constitución Nacional de 1992 se constituye en un hito importante en lo que a derecho ambiental se refiere, dado que introduce un capítulo específico para la Protección del Ambiente, colocándolo en igual rango de importancia que al derecho a la Vida, por sobre la protección de los demás bienes jurídicos protegidos en la propia Constitución Nacional. A partir de ella, el derecho positivo paraguayo engrosó su legislación ambiental -como por ejemplo Ley No 352/94 “Áreas Silvestres Protegidas” que establece regulaciones de Paisajes Protegidos- con la promulgación de normativas que legislan diferentes aspectos relacionados a la preservación, conservación, recomposición y mejoramiento del ambiente, involucrando en la gestión ambiental a Instituciones gubernamentales y no gubernamentales.

\section{A.2. Legislación Argentina}

La norma más vinculada a la noción de paisaje es la Ley 22.351 (PEN del gobierno militar), de Parques Nacionales y Declaración de Reservas, del 12/12/1980, que incorporó modificaciones a las leyes vigentes en la materia, 18.594 y 20.161. La misma especifica que, por su belleza, flora o fauna, o en razón de un interés científico, podrán declararse parques nacionales, reservas nacionales o monumentos naturales, diferentes áreas del territorio de la Republica Argentina,. Establece el dominio público de estas áreas y su condición de 'reserva cerrada'; define cada uno de los términos, sus funciones, la forma de administración, la creación de un fondo de fomento y define 33 áreas integrantes del sistema (17 Parques, 1 Monumento y 14 Reservas), entre las que se encuentra Iguazú (Parque Nacional por Ley 12.103 y modificatorias: Leyes 18.801 y 19.478 y Reserva Nacional por Ley 18.801). 
Dentro del contexto de la legislación vinculada a temas de protección ambiental, se destacan la Ley Nacional 26.331 del 28 de noviembre de 2007, de Presupuestos Mínimos de Protección Ambiental de los Bosques Nativos, que establece presupuestos destinados a la protección ambiental para el enriquecimiento, restauración, conservación, aprovechamiento y manejo sostenible de los bosques nativos, y el proyecto de "Ley de Presupuestos Mínimos Ambientales para la Protección de los Paisajes", que presenta los objetivos, para garantizar: a) la protección de los paisajes para la preservación del patrimonio natural y cultural; b) el libre acceso a los paisajes protegidos de todos los habitantes que deseen hacer uso y goce de los mismos; c) el aprovechamiento sustentable de los paisajes, en el marco de un ordenamiento ambiental del territorio, que no afecte negativamente la calidad de vida de la población, el patrimonio natural y cultural, la conservación de la diversidad biológica, y no altere el equilibrio de los ecosistemas; así como, los servicios turísticos que éstos prestan.

\section{A.2.1. Plan Federal de Turismo en Argentina}

Dentro de una estrategia de puesta en valor del patrimonio natural y cultural de las diferentes regiones y sitios que conforman el territorio argentino, la Secretaría de Turismo de la Nación ha elaborado el Plan Federal Estratégico de Turismo Sustentable, dónde participaron en su elaboración, los sectores públicos, privados y académicos de todo el país.

Concibiendo "[...] al Turismo como uno de los caminos centrales en la construcción de un nuevo modelo de país, atendiendo en este recorrido los principios de sustentabilidad y competitividad que establece el marco nacional e internacional actual" (Secretaría de Turismo, 2005: 14) y con el objetivo de: "Constituirse en el proceso orientador y articulador de actuaciones que, en forma sinérgica, reafirme voluntades, optimice recursos y encamine estos esfuerzos hacia un modelo concertado de desarro1lo turístico sustentable para la República Argentina" (Secretaría de Turismo, 2005: 14), el Plan establece los principales sitios de interés, junto a nuevos escenarios y modalidades, para cada provincia.

En el área de estudio el Plan considera tres corredores de carácter potencial. El primero es el $\underline{\text { Co- }}$ rredor Iguazú-Posadas, , con eje sobre la RN No 12 y el río Paraná, dónde indica que se trata de un corredor de gran atractivo paisajístico, dada la vegetación en contraste con el rojizo de su tierra, señalando como localidades importantes a Santa Ana, Eldorado, Puerto Victoria, Puerto Esperanza y Wanda, además de Posadas y Puerto Iguazú y dentro del cual, localiza al Área de las Misiones Jesuíticas, dónde se destacan las Ruinas de San Ignacio. El segundo es el denominado Circuito Transfronterizo Posadas-Encarnación (referencia 10), que considera la fuerte articulación existente entre ambas ciudades y su situación intermedia entre el primero y el tercer corredor potencial al que denomina Corredor del Alto Paraná, que se extiende también teniendo como eje la RN Nº 12 y al río Paraná, desde Posadas hasta la ciudad de Corrientes, que se articula con Resistencia (Chaco) y considerando a Ituzaingó e Itatí, como sus localidades más importantes. En el área de Ituzaingó (referencia 12) se incluye a la propia ciudad, las islas de Apipé y Yacyretá, la represa de Yacyretá, la presencia de los Esteros del 
Iberá y la pesca deportiva. El caso de Itatí está determinado por que allí se celebra anualmente la fiesta en conmemoración a la Virgen del mismo nombre, patrona de la provincia. (Secretaría de Turismo, Anexo 5, 2005: 91).

Plano $N^{\circ}$ 13: Mapa de Oportunidades del sector Norte de La Región Litoral

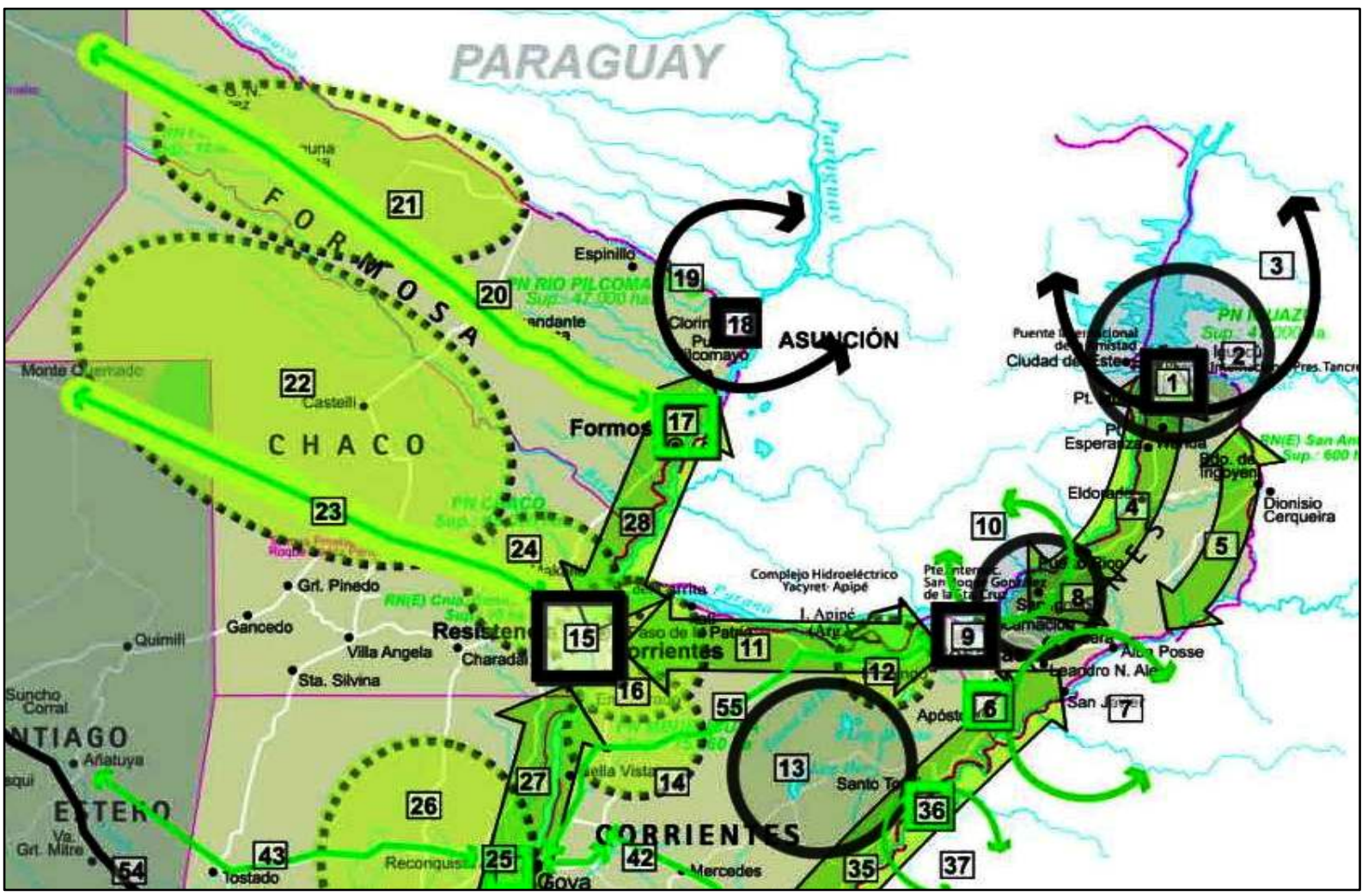

Fuente: Plan Federal Estratégico de Turismo Sustentable. Secretaría de Turismo de la Nación. Anexo 5, $2005: 90$.

\section{B. Antecedentes Internacionales para la Gestión del Paisaje}

A partir de la experiencia de los países germánicos, principalmente de Alemania, donde surgen las primeras ideas acerca del paisaje desde el punto de vista científico -que tuvo su inicio en las concepciones paisajísticas desarrolladas en el siglo XIX por Alexander von Humboldt- actualmente existen en el mundo muchos países que han avanzado en esa interpretación del paisaje como ciencia, a partir de núcleos conformados por universidades y centros de investigación, definidos como Escuelas de Paisaje, que han dado origen a una determinada dirección dentro de la indicada ciencia, sumándose a las líneas de trabajo e investigación ya organizadas y definidas, o bien formando escuelas propias, planteado nuevos problemas y creando nuevos métodos (de Bolós, 1992: 13).

Pero a los fines de esta investigación y de poner en contexto el aspecto vinculado especialmente a las posibilidades de gestión -con el objetivo puesto en la protección y promoción de un ámbito territorial transformado, en términos de paisaje- es que se analizan los instrumentos de gestión que, sin soslayar los aspectos científicos antes mencionados, hemos considerado como términos de referencia valederos para su manejo, que son: el 'Convenio Europeo del Paisaje' y la 'Estrategia Pan-Europea de Diversidad Biológica y del Paisaje', que conforman ejemplos representativos para abordar un proceso de acuerdos y concertación con pautas específicas para la regulación, uso, ordenación y protección del 
paisaje, y a partir de los cuales, se han establecido leyes que regulan dicho accionar, en cada contexto jurisdiccional de los países que conforman la Comunidad Europea, que ha adherido a este proceso.

\section{B.1. Convenio Europeo del Paisaje (CEP, 2000)}

Es un instrumento de gestión que tiene el estatus de tratado internacional abierto a la firma de los países miembro del Consejo de Europa. Fue aprobado el 20 de octubre de 2000 y entró en vigencia el $1^{\circ}$ de marzo de 2004, al cumplirse las primeras diez ratificaciones, aunque sólo está en vigor en aquellos países que lo han firmado y ratificado, y que son los que están desarrollando políticas de paisaje en consonancia con el objetivo del Convenio: “[...] promover la protección, gestión y ordenación del paisaje, así como organizar la cooperación europea en materia de paisaje" (CEP, 2000: 3).

El Convenio Europeo del Paisaje, en su primer artículo, define diversos 'términos' que son utilizados como objetivos de gestión:

- Paisaje, como un área, tal como es percibida por las personas, cuyo aspecto es el resultado de la acción e interacción entre factores naturales y/o humanos.

$\square \quad$ Política de paisaje, como expresión, por parte de las administraciones públicas, de principios, estrategias y directrices que permitan tomar medidas especificas para la protección, gestión y ordenación de los paisajes.

$\square \quad$ Objetivo de calidad del paisaje (para un paisaje específico), como la formulación, por parte de las autoridades públicas competentes, de las aspiraciones de las poblaciones en lo que concierne a las características paisajísticas de su entorno.

$\square \quad$ Protección del paisaje, como las acciones encaminadas a conservar y mantener los aspectos significativos o característicos de un paisaje, justificados por su valor patrimonial derivado de su configuración natural y/o de la actividad humana.

$\square$ Gestión del paisaje, como una actuación, desde la perspectiva del desarrollo sostenible, para asegurar el mantenimiento de un paisaje, con el fin de guiar y armonizar los cambios que sean introducidos por los procesos sociales, económicos y ambientales.

$\square \quad$ Ordenación del paisaje, como las acciones que presenten un carácter prospectivo, con vistas a mejorar, restaurar o crear paisajes.

También plantea diversas 'medidas' y 'objetivos', que pueden resumirse de la siguiente forma:

Reconocer a los paisajes en la legislación, como componentes del entorno de las personas. Una expresión de la diversidad de su patrimonio cultural y natural, y la base de su identidad.

- Establecer y poner en marcha políticas de paisaje para la protección, gestión y ordenación del paisaje, a través de las medidas específicas.

$\square \quad$ Establecer procedimientos para la participación de las instituciones públicas, y de otros agentes en la definición y puesta en marcha de los mecanismos mencionados. 
Integrar el paisaje en la ordenación territorial y el urbanismo, así como en las políticas y actuaciones sectoriales que puedan causar impactos directos o indirectos en el paisaje.

Complementariamente, el Convenio establece un Premio del Paisaje a ser otorgado por el Consejo de Europa, a las instituciones gubernamentales y no gubernamentales que hayan llevado a cabo actuaciones que puedan servir de ejemplo a otras regiones paneuropeas.

De tal forma, podemos indicar que la definición de paisaje establecida en el Convenio como 'cualquier parte del territorio tal como la percibe la población, cuyo carácter sea el resultado de la acción y la interacción de factores naturales y/o humanos', incluye tres dimensiones de interpretación:

- la fisica: el paisaje es el territorio,

- la subjetiva o cultural: el paisaje es una porción de territorio, pero sin olvidar los valores simbólicos que la población le atribuye, y

- la temporal / causal: el paisaje es el resultado de la interacción entre el hombre y la naturaleza.

Además, las propuestas de este acuerdo, se fundamentan en tres estrategias:

- Protección, para paisajes singulares;

- Gestión, a fin de poder gestionar los paisajes ordinarios en un contexto de desarrollo sostenido,

- Ordenación, a fin de actuar con previsión en los nuevos paisajes que exigen atención especial, o en aquellos que han sufrido fuertes transformaciones.

\section{B.2. $\quad$ Estrategia Pan-Europea de Diversidad Biológica y del Paisaje (1995)}

Esta Estrategia define la diversidad del paisaje como la expresión formal de las numerosas relaciones existentes en un periodo dado entre una persona o una sociedad y un territorio definido topográficamente, cuyo aspecto es resultado de la acción, a lo largo del tiempo, de factores naturales y humanos, y la combinación de ambos.

El objetivo general de la Estrategia consiste en asegurar el uso sostenible de la diversidad biológica y del paisaje en el continente europeo en un plazo de 20 años, cuyos objetivos relacionados con el paisaje pueden resumirse en:

Aumentar la capacidad de recuperación o resiliencia de la diversidad del paisaje.

Aumentar la disponibilidad de información, la participación y la concienciación pública en materia de diversidad de paisaje.

$\square \quad$ Integrar los objetivos de uso sostenible y conservación de la diversidad del paisaje en las políticas sectoriales que los afecten.

Mejorar el conocimiento sobre el estado de la diversidad del paisaje.

Los paisajes de prioridad paneuropea que identifica la Estrategia son la tundra, la taiga, las tierras altas (uplands), los bocages, los sistemas de campos abiertos (openfields), las estepas y paisajes áridos, y los paisajes que forman parte del patrimonio cultural. 


\title{
III.4. LAS MEDIDAS DE MITIGACIÓN Y LOS PROYECTOS DE RECONFIGURA- CIÓN TERRITORIAL
}

Si realizamos una suerte de síntesis conceptual de lo expuesto acerca de las implicancias territoriales de Yacyretá, podemos señalar que la concepción del proyecto consideró dos grandes instancias. La primera está compuesta por las denominadas 'obras principales', siendo la construcción de la central hidroeléctrica sobre los Saltos del Apipé, de la presa y la consecuente conformación del embalse en su primera fase de llenado a cota $76 \mathrm{msnm}$, los principales elementos que definen la modificación del ambiente y del paisaje. En tanto que la segunda está conformada por lo que en la evaluación ambiental, se denomina 'obras complementaras', que representan básicamente las medidas de mitigación de los impactos sobre el territorio, que involucran al ambiente y a las poblaciones con sus respectivas actividades económicoproductivas de carácter urbano, periurbano y rural. Sobre esta segunda instancia nos detendremos en este apartado, a fin de comprender las implicancias y trascendencia de su alcance.

Inicialmente y, derivadas de la Evaluación Ambiental de 1992, las dos principales medidas de mitigación estuvieron conformadas por el Plan de Manejo del Medio Ambiente (PMMA) y el Plan de Acción para el Reasentamiento y la Rehabilitación (PARR). Ambos planes formaron parte de los acuerdos de las Altas Partes (Gobiernos de Argentina y Paraguay), con el Banco Mundial o Banco Internacional de Reconstrucción y Fomento (BIRF) y el Banco Interamericano de Desarrollo (BID), siendo éste último el que aportó recursos a través del Préstamo BID 760/OC-RG para su financiamiento. Los alcances conceptuales y metodológicos de estos planes se exponen en la primera parte de este apartado.

Sin embargo, estas medidas no fueron suficientes. Las demoras en la ejecución del proyecto, junto a la ausencia de una adecuada ponderación sus impactos sobre las ciudades y el territorio que involucra, principalmente al área de Posadas en Argentina y de Encarnación en Paraguay -que desde la década del 70 hasta hoy han incrementado en más de cinco veces su población- fueron determinantes para establecerle a la Entidad Binacional, la necesidad de un cambio de enfoque para enfrentar la terminación de Yacyretá. El análisis de este aspecto, conforma la segunda parte del presente apartado.

\begin{abstract}
"Para concluir el emprendimiento, se aprobó el Plan de Terminación de Yacyretá (PTY), a partir de los acuerdos logrados a fines del 2003 entre los Gobiernos de Argentina y Paraguay, a través del cual, se han implementado a partir de mediados del 2004: a) la liberación de las áreas y la compra de tierras afectadas por el embalse, para la construcción de obras de viviendas e infraestructura y para la compensación de áreas a inundar con la implementación de reservas ecológicas; b) la concreción de obras y acciones destinadas a mitigar los efectos sobre el ambiente: presas, caminos, puentes, y otras; c) la construcción de conjuntos habitacionales: 8.300 viviendas con infraestructuras y equipamientos; d) la recomposición de la trama urbana de las ciudades de Encarnación, Cambyretá y Carmen del Paraná (PY) y de Posadas, Garupá y Candelaria (AR), con costaneras, calles, canalización de arroyos, parques urbanos; e) la ejecución de las obras de un canal y una presa para la protección del valle del arroyo de Aguapey en Paraguay, que evitó la inundación de unas 40 mil hectáreas y ha permitido elevar el embalse más allá de la cota 78 msnm; f)la asistencia permanentemente a unas 20.000 familias reasentadas por efectos del emprendimiento, con alimentos, útiles escolares, programas de salud con provisión de medicamentos y capacitación y apoyo a micro-emprendimientos productivos; $g$ ) el fortalecimiento institucional a 15 municipios y 4 gobernaciones en ambas márgenes".(Thomas, 2010.a: 1)
\end{abstract}




\section{III.4.1. La mitigación de los efectos sobre los recursos naturales y culturales}

\section{III.4.1.1. El Plan de Manejo del Medio Ambiente (PMMA)}

El PMMA, creado en 1992 y actualizado en 2002, tiene el objetivo de proporcionar los mecanismos para manejar, minimizar y compensar los impactos ambientales causados a los ecosistemas y comunidades naturales, así como proteger áreas de alto valor ecológico, social y cultural en la zona de influencia del proyecto, generados tanto por la ejecución de las obras, como por el llenado del embalse.

El PMMA incluye la totalidad de las acciones de mitigación, compensación y prevención de los impactos ambientales producidos por el emprendimiento hidroeléctrico Yacyretá, que tienen vigencia durante toda la vida útil del emprendimiento hidroeléctrico y, también, las acciones ambientales que debieron ejecutarse con relación al Plan de Terminación Yacyretá (PTY).

\section{A) Actividades Ambientales Recurrentes del PMMA}

El PMMA se implementa a través de decisiones propias, en los aspectos de responsabilidad de la EBY, y de estrategias interinstitucionales que involucran a Organismos Gubernamentales (OG's) con responsabilidades y competencias específicas, y no Gubernamentales (ONG's) involucrados en las mismas, para acciones que están fuera del alcance y responsabilidad de la EBY. Esta estrategia interinstitucional se complementa con actividades de monitoreo y evaluación, conformadas a través de paneles de expertos, comités de seguimiento y evaluaciones independientes y adopta una estructura orgánico-funcional, que se sustenta sobre los seis Programas Ambientales.

\section{Programa 1: Gerenciamiento Ambiental}

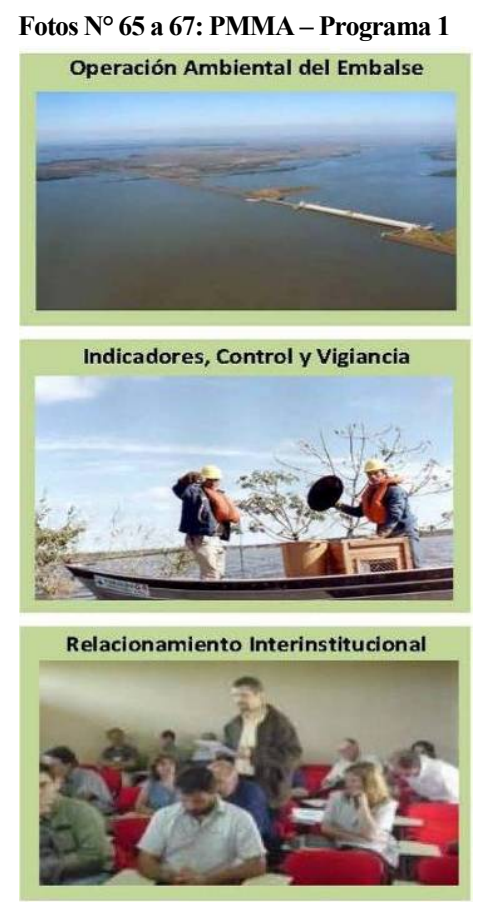

Fuente: Archivo EBY, 2010
Su objetivo es mitigar los impactos garantizando que los criterios ambientales sean considerados en las etapas de proyecto, ejecución, operación y control de las obras y actividades vinculadas a Yacyretá. Incluye tres subprogramas:

1) Operación Ambiental del Embalse, con 7 proyectos: a) manejo de caudales y niveles; b) manejo del embalse y aguas abajo; c) manejo de cuencas; d) erosión costera, hidrogeología urbana y macro regional; e) vegetación acuática; f) manejo del perilago; g) planes de contingencias;

2) Indicadores de Monitoreo y Seguimiento, con dos proyectos: a) indicadores ambientales; b) control y vigilancia ambiental;

3) Relacionamiento Interinstitucional, con 4 proyectos y/o acciones: a) valorización y comunicación de los programas ambientales; b) cooperación y fomento entre organismos; c) educación ambiental; d) capacitación interna. 


\section{Programa 2: Gestión Urbana y Patrimonio Cultural}

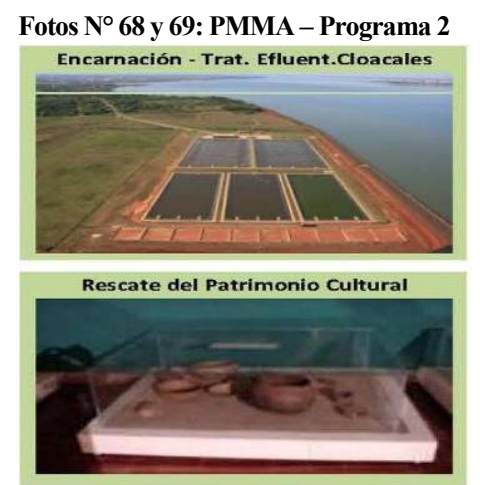

Fuente: archivo EBY, 2010
Integrado por dos subprogramas:

1) Gestión Urbana, con tres proyectos: a) apoyo y asistencia técnica a Municipios; b) tratamiento costero, saneamiento básico y educación ambiental; c) control ambiental de obras;

2) Rescate del Patrimonio Histórico, Cultural y Arqueológico, con dos proyectos: a) rescate o salvamento propiamente dicho; c) divulgación del patrimonio rescatado.

\section{Programa 3: Reservas Naturales y Biodiversidad}

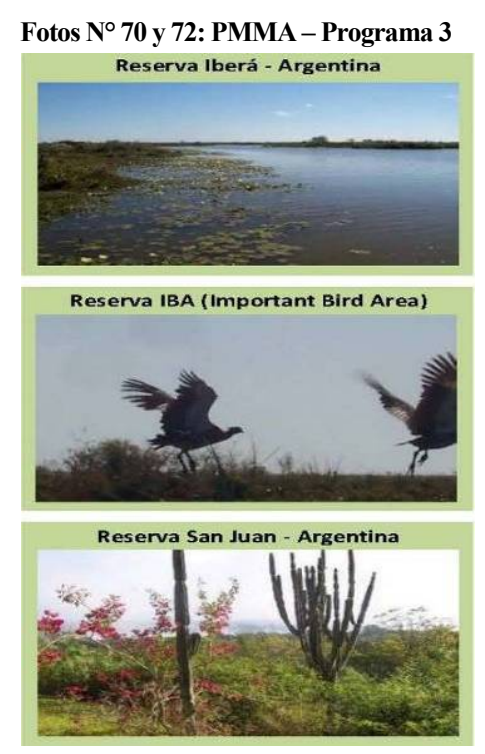

Fuente: Archivo EBY, 2010.

Se implementa, principalmente, mediante el establecimiento de reservas que compensen por los ambientes o ecosistemas perdidos por el llenado del embalse, en una extensión no menor a su superficie total. Se estructura en 4 subprogramas: 1) Recuperación de Ecosistemas, que incluye dos proyectos: a) Investigación de Ecosistemas; b) Reforestación y recuperación de áreas de préstamo; 2) Implantación y Manejo de Reservas, 3) Protección de Especies de Interés, que agrupa dos proyectos: Caracoles acuáticos: en especial del Aylacostoma, que se ejecuta para proteger y reintegrar esta especie y Aves amenazadas: el PMMA incluyó a la Reserva de Isla Yacyretá, como Reserva IBA (Important Bird Area), declarada por la organización Bird Life International; 4) Rescate y Reubicación de Fauna.

\section{Programa 4: Fauna Íctica}

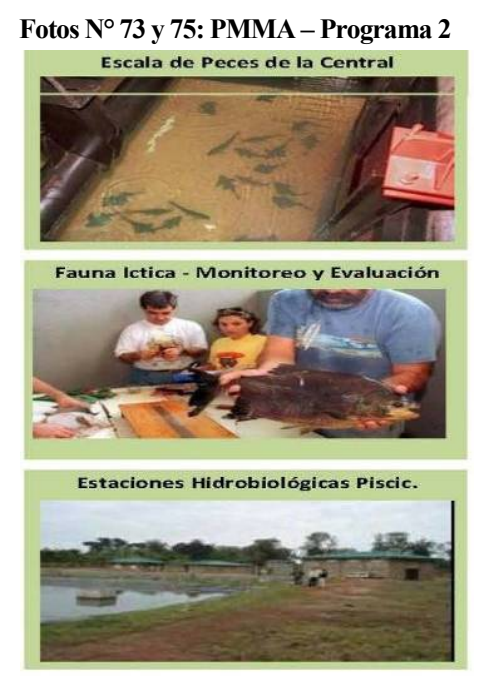

Fuente: Archivo EBY, 2010.
Tiene por objetivo el monitoreo y seguimiento de su evolución en las nuevas condiciones del río y del embalse, con más de 120 especies identificadas. Se integra en 3 subprogramas: 1) Recursos Pesqueros; comprende actividades de ecología acuática y de monitoreo de la pesca comercial, deportiva y de subsistencia; 2) Monitoreo y Evaluación de la Fauna Íctica, comprende actividades de monitoreo y evaluación de la ictiofauna aguas arriba y aguas debajo de la presa; monitoreo de huevos y larvas, que permiten la caracterización de áreas de reproducción y cría; monitoreo del funcionamiento de las 4 instalaciones para peces (IPP), desde el punto de vista biológico; 3) Estaciones Hidrobiológicas y de Piscicultura, una en cada margen. 


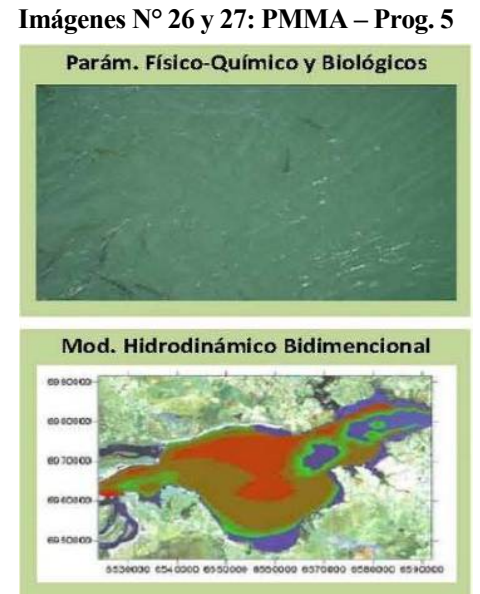

Fuente: Archivo EBY, 2010.
Tiene por objetivo determinar la condición actual, los cambios de las condiciones de base y las tendencias del ecosistema acuático. Se estructura en 2 subprogramas:

1) Monitoreo de parámetros físicos, químicos y biológicos, que se compone 3 proyectos: a) red de monitoreo de estaciones, b) red de monitoreo accesoria, c) red de monitoreos intensivos;

2) Estudios Especiales, que lleva adelante estudios como sobresaturación gaseosa, diseño de modelos y bioensayos (bioacumulación e indicadores).

\section{Programa 6: Salud y Medio Ambiente}

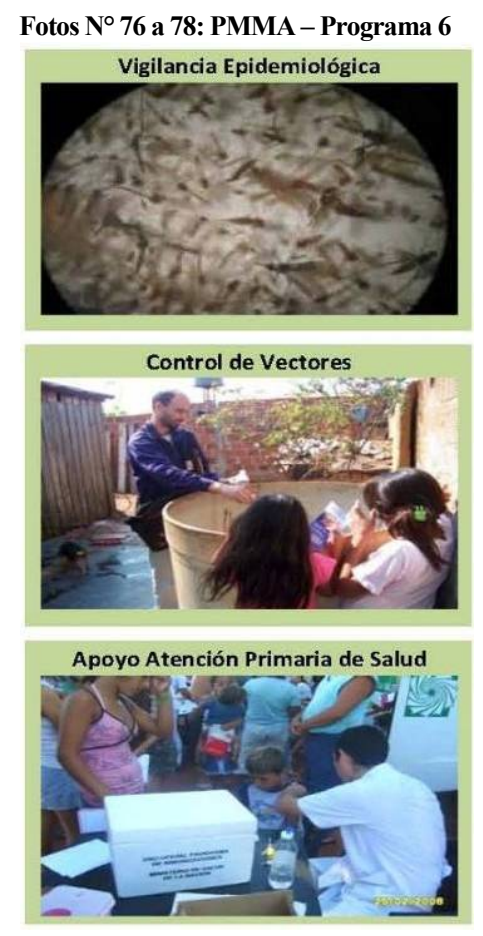

Fuente: Archivo EBY, 2010.
Su objetivo es apoyar a las agencias de salud pública locales en el manejo y prevención de la salud vinculados, principalmente, con los cambios ambientales producidos por el llenado del embalse en el área de influencia. Se desarrolla en tres subprogramas:

1) Vigilancia Epidemiológica,_en el control y sistematización de las morbilidades y el seguimiento epidemiológico de aquellas vinculadas a enfermedades subtropicales;

2) Control de Vectores, a través de a) monitoreo de los vectores hematófagos de interés sanitario en la región; b) otros vectores hídricos, tal el caso de los moluscos biomphalaria y melanoide tubercula$t a$; c) control de roedores urbanos, previo a cada fase de llenado del embalse;

3) Apoyo a la Atención Primaria a la Salud, en conjunto con el Plan de Acción para Reasentamiento y Rehabilitación (PARR).

\section{B) Acciones Ambientales previas a los Llenados Parciales del Embalse}

Una vez reencauzadas las obras y acciones de terminación del Proyecto, fue acordado entre los gobiernos y los Bancos (BIRF y BID), un proceso de liberación de áreas por cotas sucesivas de inundación, que implicaba una serie de acciones ambientales, para concretar cada fase de llenado. De tal forma, las principales acciones previas a cada llenado parcial del embalse, fueron:

i) Evaluación Ecológica Rápida: Es una evaluación ambiental expeditiva, previo a la definición de elementos significativos de fauna y/o flora a ser rescatados. 
ii) Remoción de Biomasa: En ambas márgenes se ejecutan trabajos de remoción de biomasa para el llenado a cota final en toda el área del embalse.

iii) Desratización y Control de Quirópteros: Junto a la remoción de biomasa y previo a cada llenado parcial del embalse, se realizan campañas de control de roedores y quirópteros a fin de minimizar su movilidad hacia otras zonas pobladas.

iv) Rescate Contingente de Flora y Fauna: Previo a cada fase de llenado del embalse, se realizan tareas de rescate de la flora y la fauna, que se identifican por medio del trabajo de la Evaluación Ecológica Rápida, en ambas márgenes.

v) Sellado de Pozos y Letrinas: Se procede al sellado de pozos y letrinas de todas las unidades habitacionales de las familias relocalizadas en ambas márgenes.

Para cada fase de llenado, se cuenta además, con un Plan de Contingencias socio-ambiental que permite dar a los organismos responsables, una alerta temprana ante cualquier eventualidad no planificada, para actuar en forma coordinada y conjunta.

\section{C) Resultados de la ejecución del PMMA}

A manera de síntesis de resultados en la ejecución del PMMA para todo el período de vigencia del Plan (1993-2010) merecen destacarse los siguientes aspectos:

- las aguas del embalse se clasifican como oligo a mesotróficas para el estado trófico y como buenas según índices biológicos (plancton y bentos),

- no se observaron deserciones en la comunidad de peces antes y después del llenado del embalse,

- no se observó ninguna modificación atribuible a la conformación del embalse en lo referente a morbilidades en las poblaciones dentro de la zona de influencia directa,

- no se observan modificaciones (cuali o cuantitativas) en la entomofauna (mosquitos) luego de la conformación del embalse,

- los acuíferos urbanos no han modificado sensiblemente sus niveles hidrométricos estáticos luego del llenado a cotas 76, 78 u $80 \mathrm{msnm}$,

- se crearon más de 100.000 has de reservas naturales compensatorias y se financia su sostenimiento,

- se realizaron y realizan inversiones en materia de saneamiento urbano en las principales ciudades de la zona de influencia directa del embalse (plantas de tratamiento de líquidos cloacales y redes, entrega de camiones recolectores de basura a municipios, sellado y/o traslado de basurales y microbasurales, limpieza de áreas costeras, ampliaciones de Plantas de tratamiento de agua potable, etc.). 


\section{III.4.1.2. El Plan de Acción para el Reasentamiento y la Rehabilitación (PARR)}

"Por su tamaño y la heterogeneidad de las poblaciones afectadas por el Proyecto, el programa de reasentamiento es uno de los más ambiciosos y complejos de América Latina" (BID, 1997: 1).

El PARR, creado en 1992 y actualizado en 2006, ha promovido en ambas márgenes la relocalización de familias urbanas, periurbanas y rurales, y el conjunto de actividades productivas localizadas en las áreas que conformaban la poligonal de expropiación del embalse, junto a las oportunidades de restablecimiento o recomposición de las estrategias de subsistencia de la población afectada. Para cumplir su cometido el PARR organizó su estructura operativa en dos sub planes complementarios:

i) Plan Operacional de Reasentamiento (POR): vinculado con la efectiva desocupación de las áreas de embalse, comprende las tareas de preparación de las familias para el traslado; de implementación efectiva de los traslados y titulación de las viviendas y de recepción de las familias en los nuevos sitios de reasentamiento.
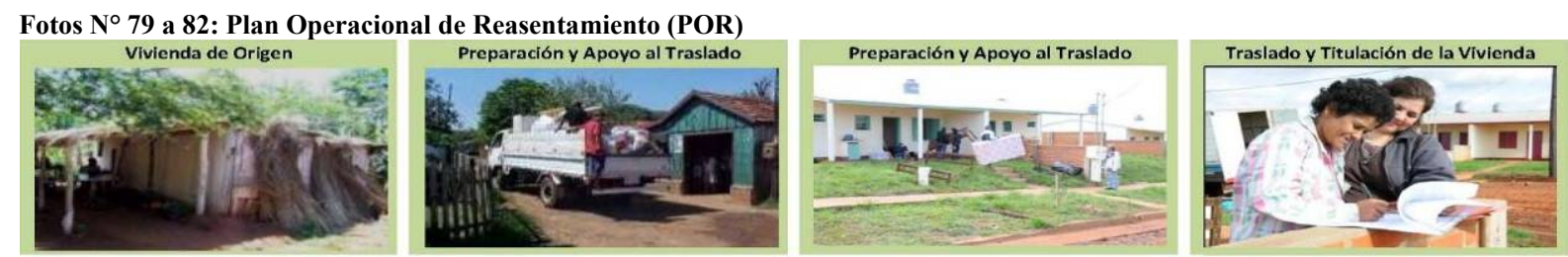

Fuente: Archivo Fotográfico EBY:

ii) Plan de Rehabilitación y Apoyo Social (PRAS): vinculado a la rehabilitación socioorganizativa de las comunidades reasentadas, se desarrollan desde la EBY, con articulación con organizaciones públicas y privadas de la sociedad civil. Las mismas incluyen una primera fase, orientada a la promoción social y organización comunitaria y una segunda fase de capacitación y apoyo al desarrollo de pequeñas iniciativas familiares y comunitarias auto-gestionadas por la propia comunidad.
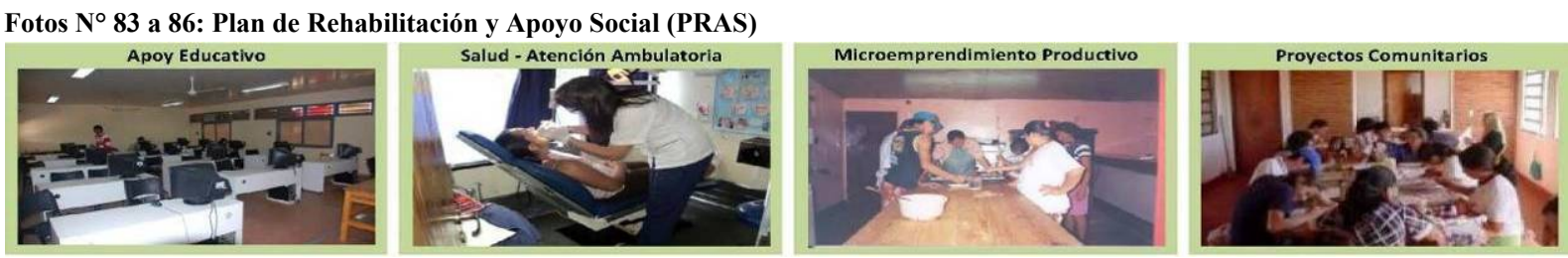

Fuente: Archivo Fotográfico EBY.

\section{A) Las Acciones de Reasentamiento de la Población y Actividades Involucradas}

Desde el primer censo realizado en 1979/80 hasta diciembre de 2010, fecha en la que se concluyó el proceso de reasentamiento por no existir ninguna familia o persona residiendo en las áreas de implantación del embalse a cota final de diseño, el PARR ha atendido un total de 19.214 familias, por las alternativas de reasentamiento aplicadas, incluyendo los no beneficiarios atendidos con apoyo al traslado. De este total 7.656 (40\%) corresponden a la Argentina (MI) y 11.558 (60\%) al Paraguay (MD).

"El cronograma inicial preveía un periodo de seis (6) años para la conclusión de las acciones de reasentamiento, pero este periodo fue avanzando en el tiempo, llegando a prácticamente 20 años de gestión continuada. [...] Este largo periodo de intervención ha generado muchas situaciones conflictivas, que en cierta forma desdibujaron los efectos positivos que el Proyecto fue proporcionando en términos habitacionales, saneamiento e infraestructura urbana, desarrollo regional, mejora ambiental, y sobre todo, de apoyo social a los sectores más marginados de la población involucrada. " (PARR, Informe Semestral $\left.N^{\circ} 4,2010: 4\right)$ 
Considerando los números promedios de personas por grupo familiar registrados en la verificación de 2005 (4,1 personas en MI y 4,4 en MD) el contingente poblacional desplazado por el Proyecto Hidroeléctrico Yacyretá, alcanza a 82.242 personas. ${ }^{86}$

\section{A.1. Las acciones de Reasentamiento en Argentina (MI)}

A.1.1. Población Urbana (MI): Para relocalizar la población urbana de Argentina (MI), la EBY ha construido $\mathbf{7 . 3 9 3}$ viviendas en cinco Conjuntos Habitacionales, con todos los servicios y equipamientos: uno en Garupá, A-3.1 'Virgen de Fátima' con 1.374 viviendas; y 4 en Posadas: Barrio A-1 'Yohasá' con 1.797 viviendas; Barrio A-3.2 'Nuestra Señora del Rosario' con 974 viviendas; Barrio A-4 'Nueva Esperanza' con 1.664 viviendas y Barrio San Isidro con 1.584 viviendas.
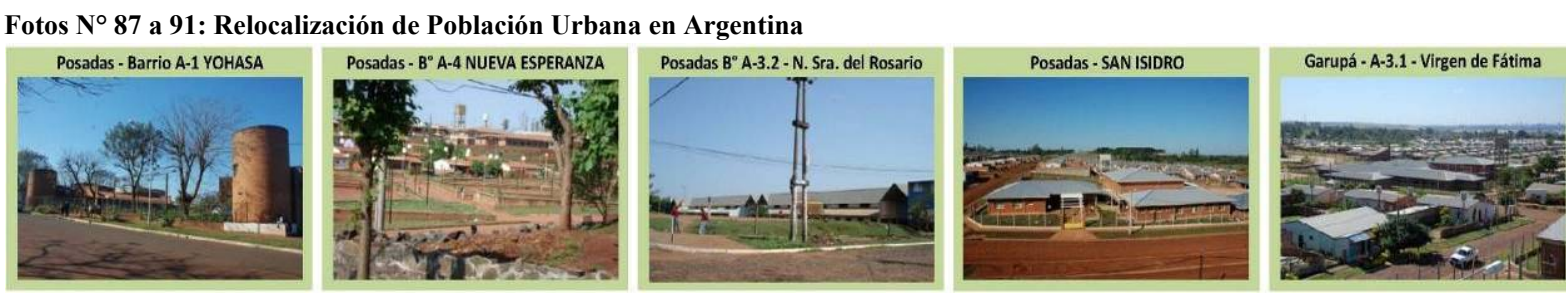

Fuente: Archivo EBY, 2010.

A.1.2. Población Periurbana y Rural (MI): En Argentina (MI) fue realizado un proyecto rural en San Tecla (Provincia de Corrientes) para 15 unidades productivas y 12 olerías y uno para población olera en Nemesio Parma (Posadas, Provincia de Misiones), para 94 olerías. El resto (772 familias rurales) son tratadas por auto-relocalización asistida, a través de montos compensatorios por actividad productiva, cuyo estado de avance es del $90 \%$.
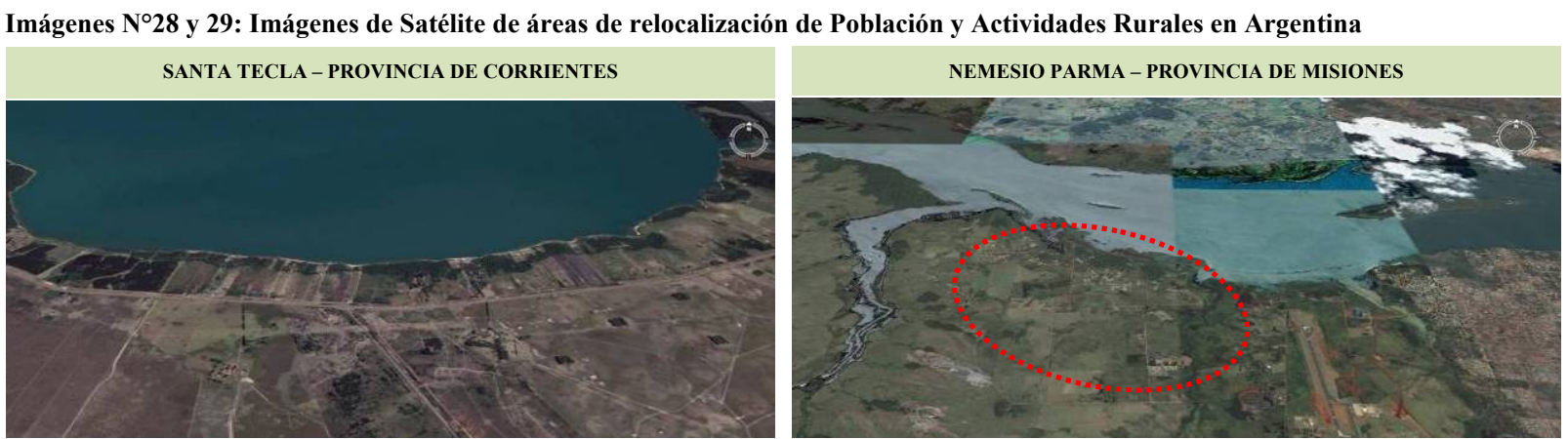

Fuente: Archivo EBY, 2010.

\section{A.2. Las acciones de Reasentamiento en Paraguay (MD)}

A.2.1. Población Urbana (MD): Para relocalizar la población urbana de Paraguay (MD), la EBY ha construido $\mathbf{6 . 8 5 4}$ viviendas en ocho Complejos Habitacionales, con todos los servicios y equipamientos socio-comunitarios: 5 en Encarnación: Buena Vista con 601 viviendas para familias propietarias; Los Arrabales con 25 viviendas, Itá Paso con 674 viviendas, San Pedro con 1.972 vivien-

\footnotetext{
${ }^{86}$ Cabe destacar que las familias de zonas urbanas, eran en general, ocupantes precarios, y una vez relocalizadas, pasan a ser beneficiarias de una vivienda de carácter social otorgadas en propiedad y sin costo, localizadas en trece Conjuntos Habitacionales construidos por la EBY, que totalizan unas 15 mil viviendas, con todos los servicios y equipamientos sociales y recreativo-comunitarios.
} 
das y San Isidro con 1.661 viviendas; 2 en Cambyretá: Arroyo Porá con 1.504 viviendas y San Francisco con 88 viviendas y uno en Carmen del Paraná con 329 viviendas.

Fotos No 92 a 99: Relocalización de Población Urbana en Paraguay
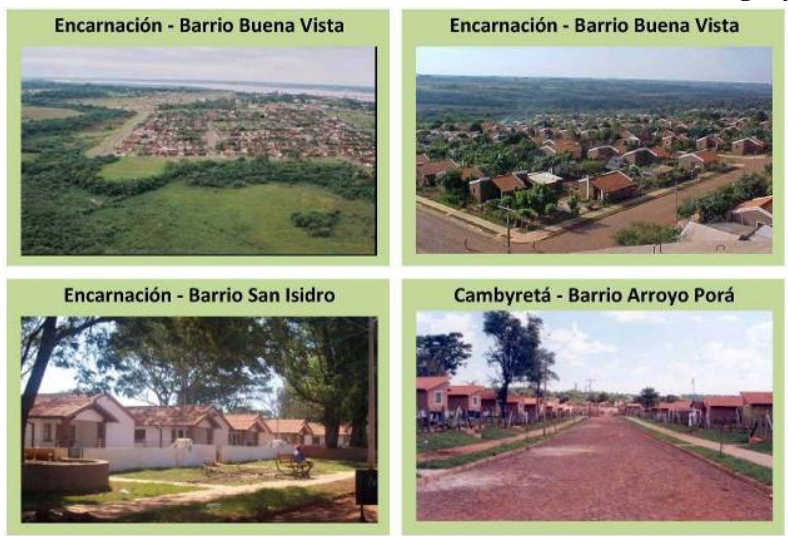
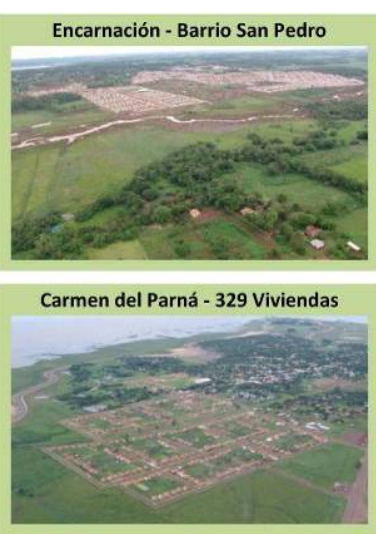
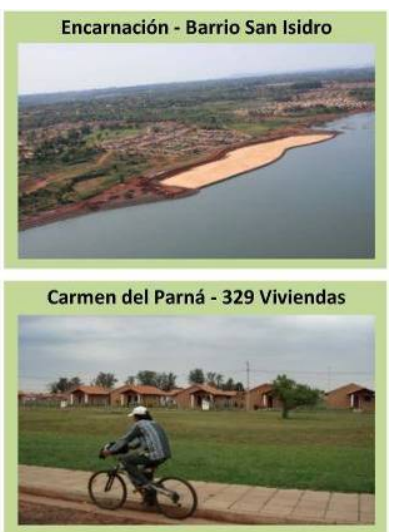

Fuente: Archivo EBY, 2010.

A.2.2. Población Rural (MD): Para el llenado del embalse a cota $76 \mathrm{msnm}$, fueron realizados nueve (9) emprendimientos para población y actividades rurales y dos (2) para oleros y tejeros, que involucraron a 953 familias con sus unidades productivas. Uno de ellos, destinado a población indígena Mbyá-Guaraní, localizado en Pindó (Departamento de Itapúa); dónde se construyeron además, 28 viviendas de dominio comunitario, respetando las características de organización, uso y propiedad, característicos de las comunidades indígenas guaraníes. Para cota final quedan 334 familias, que están siendo apoyadas por la EBY para su auto-reasentamiento y compensadas en su actividad.

Fotos $N^{\circ} 100$ a 103: Relocalización de Población y Actividades Periurbanas y Rurales en Paraguay
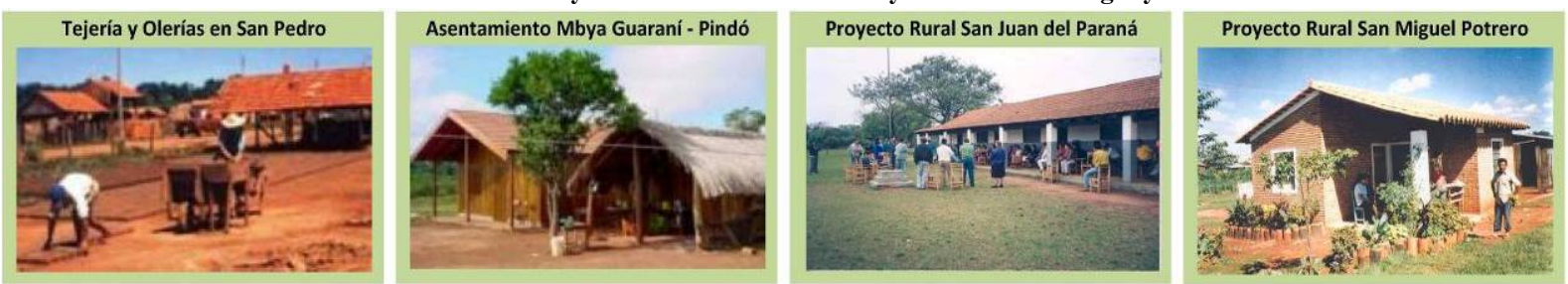

Fuente: Archivo EBY, 2010.

\section{A.2.3. Circuito Comercial de la Zona Baja de Encarnación (MD): Para relocalizar esta im-} portante zona urbana de la ciudad, la EBY ha construido un nuevo Mercado Municipal destinado a unos 300 feriantes y, además, junto al Municipio local, ha planificado y construido toda la infraestructura de servicios y equipamientos urbanos de apoyo, en tres sectores urbanos que consolidan una nueva zona comercial que va desde el Puente Internacional hacia la zona alta de la ciudad. En estos sectores, la EBY apoyó la auto-relocalización de unos 200 propietarios en lotes con servicio y construyó unos 2.500 locales de diverso tipo y dimensiones para no propietarios, mesiteros y casilleros.

Fotos $N^{\circ} 104$ a 107: Relocalización del Circuito Comercial de la Zona Baja de Encarnación
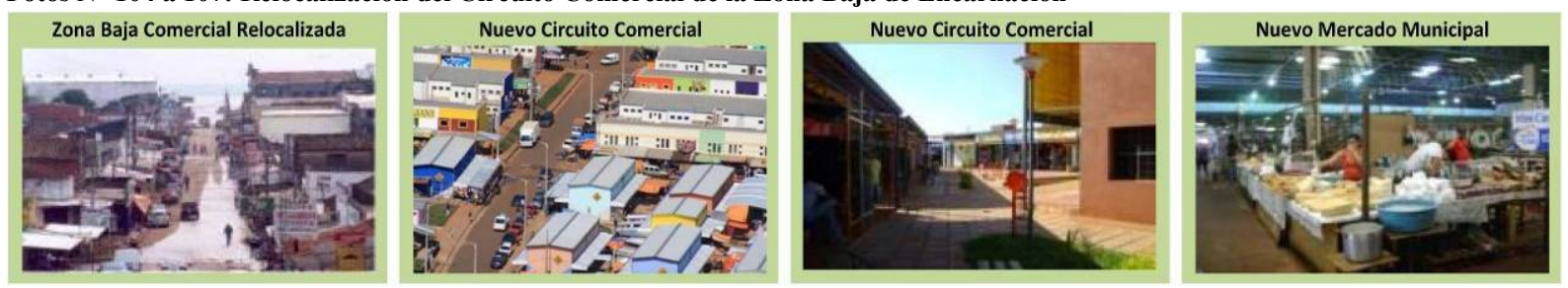

Fuente: Archivo EBY, 2010. 


\section{B. Las Acciones de Rehabilitación Social de la Población Involucrada}

El Plan de Rehabilitación y Apoyo Social (PRAS) reconoce dos fases de intervención organizadas en Programas y Subprogramas:

\section{B.1. $\quad$ Fase de Transición:}

Corresponde a los 24 meses posteriores a la relocalización de la población en los nuevos sitios de reasentamiento. En este periodo, se promueven acciones socio-organizativas destinadas a familias y grupos comunitarios articuladas con los organismos gubernamentales responsables y apoyo transitorio a las instituciones públicas para poder adecuarse a la prestación de los nuevos servicios. Además, la EBY está desarrollando en MI, un Programa de Atención Primaria de la Salud de carácter ambulatorio, a cargo de una Asociación Civil que cuenta con equipo multidisciplinario de profesionales de la salud, equipamiento técnico, tres móviles sanitarios e infraestructura con sede administrativa, laboratorio de análisis clínico, departamento de entomología, farmacia y consultorio fijo.

\section{B.2. $\quad$ Fase de Apoyo a Pequeñas Iniciativas Económico-Productivas}

De carácter familiar y comunitario, promueve oportunidades de inserción económica y laboral, con asistencia técnica y apoyo económico en carácter de subsidio primero y micro-crédito, después. En $\mathrm{MD}$, se ha establecido como prioridad el apoyo a micro-emprendimientos productivos de carácter familiar. En MI, esa prioridad está centrada en apoyar iniciativas grupales y en una relación permanente con las organizaciones gubernamentales, a través de "mesas interactorales", que contribuyen a generar condiciones de organización y desarrollo comunitario.

\section{Fortalecimiento Institucional}

Uno de los aspectos considerados de suma importancia para el proceso de terminación de Yacyretá, está conformado por el Apoyo Interinstitucional que la Entidad Binacional Yacyretá (EBY) presta para operar los nuevos servicios e infraestructuras que se transfieren y para promover la asistencia técnica necesaria para el diseño de estrategias de desarrollo local y regional.

Fotos $N^{\circ} 108$ a 111: Fortalecimiento Institucional
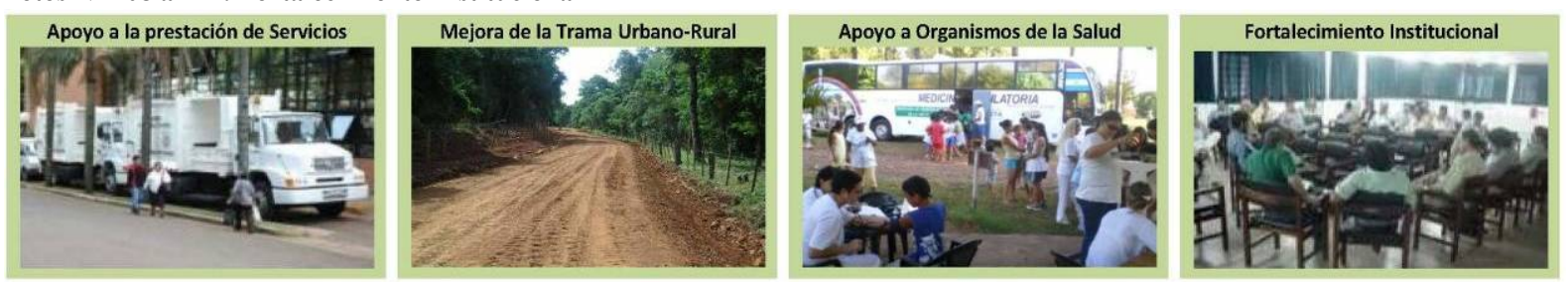

Fuente: Archivo EBY, 2010.

Este accionar, inexistente antes de su institucionalización binacional, se realiza dentro del marco que otorga el Acta de Buenos Aires suscripta el 25/02/2005 con los gobiernos locales de ambos países y, a través del cual, la EBY trabaja con 15 municipios y 4 gobernaciones en ambas márgenes. 


\section{III.4.2. La protección de las ciudades y la articulación territorial}

Para dar respuesta al enorme conjunto de obras e intervenciones urbanas, que hicieron posible elevar en forma parcial el embalse hasta alcanzar su cota de diseño $(83 \mathrm{msnm})$, el Plan de Terminación Yacyretá (PTY), se organizó en cinco grandes Licitaciones Públicas (tres en Argentina y dos en Paraguay), ordenando las grandes obras en cuatro paquetes estructurales, que conceptualmente se describen a continuación.

\section{III.4.2.1. Tratamiento Costero y Recomposición de la Trama Urbana}

Comprende la protección de las zonas urbano-costeras localizadas tanto sobre el embalse principal, como sobre los subembalses de los arroyos que surcan las ciudades. Estos proyectos representan intervenciones a escala urbana, que se ejecutan en diferentes sectores de las ciudades de Encarnación, Cambyretá, San Juan y Carmen del Paraná en la margen paraguaya, y de las ciudades de Posadas (Sectores $\mathrm{A}^{\circ}$ Mártires; Costa Natural; Bahía El Brete; Costanera Centro y A Zaimán), Garupá y Candelaria, en la margen argentina.

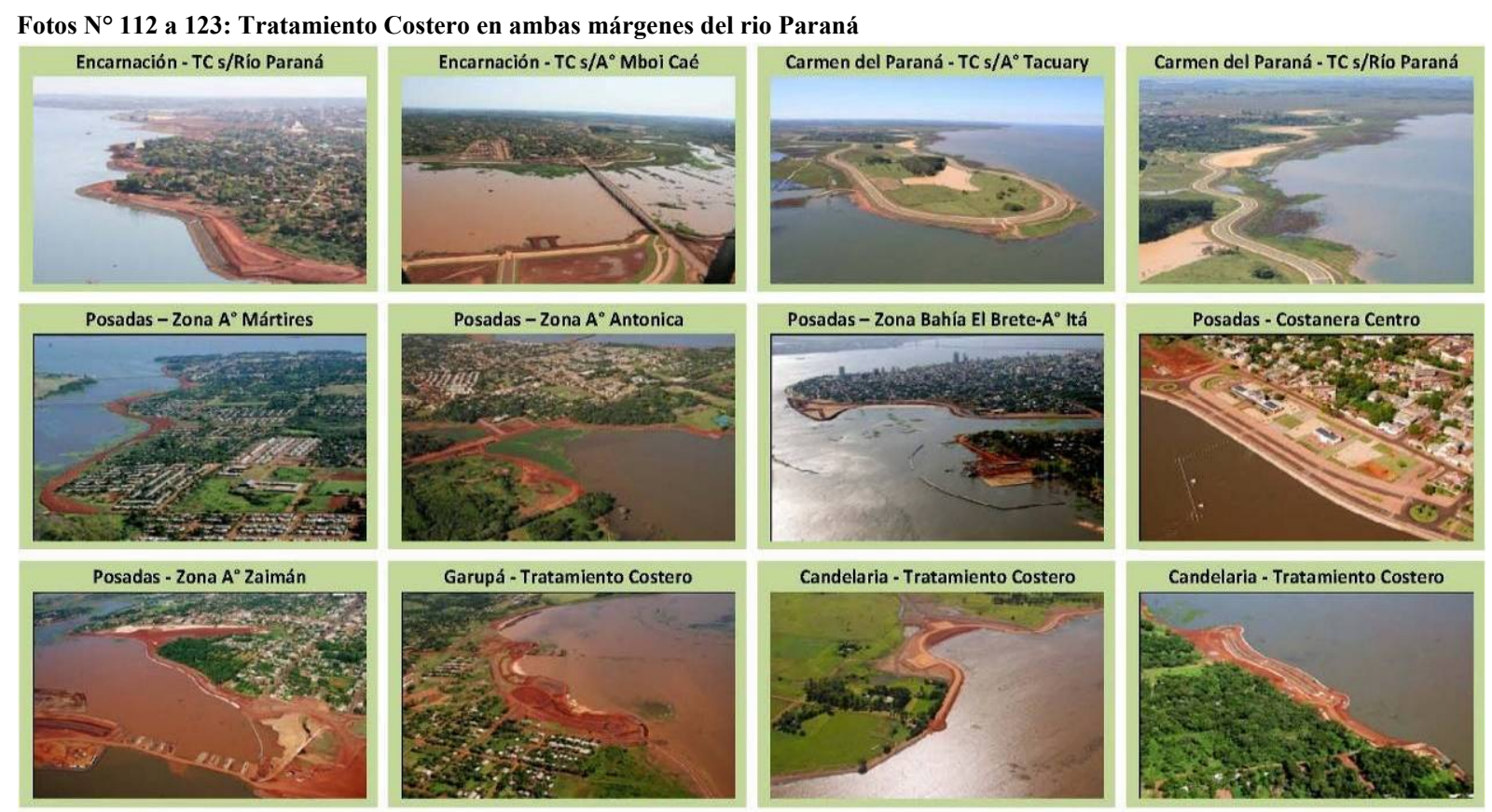

Fuente: Archivo fotográfico EBY

\section{III.4.2.2. Obras Viales de Integración entre Posadas y Encarnación}

Comprende el conjunto de obras que favorecen la articulación dentro de las áreas metropolitanas de Posadas y Encarnación, así como la regional entre ambos países.

En la margen paraguaya, este conjunto de obras, están definidas por diversos puentes y accesos viales de las ciudades involucradas, siendo los más significativos los accesos viales a Encarnación sobre las rutas nacionales $\mathrm{N}^{\circ} 1$, que la vincula con Asunción y $\mathrm{N}^{\circ} 6$ que la vincula con Ciudad del Este, con los respectivos puentes sobre los arroyos Quiteria, Mboi Caé y Santa María; también, la Avenida de Circunvalación y los puentes sobre la Ruta 14, acceso a San Pedro y Yacu Paso en la 
misma ciudad que favorecen, además, la articulación con San Juan del Paraná y Cambyretá; y la relocalización de $5 \mathrm{Km}$. de la Ruta 1 y el puente sobre el $\mathrm{A}^{\circ}$ Tacuary, en Carmen del Paraná.
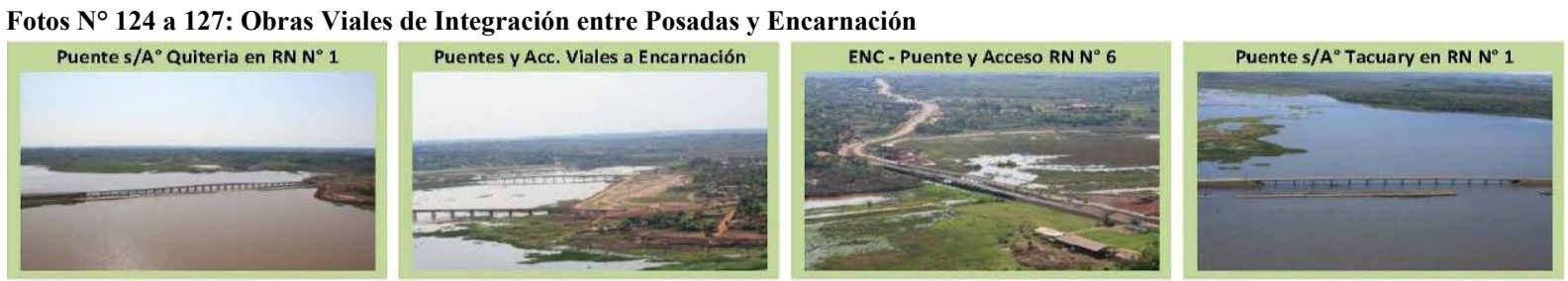

Fuente: Archivo fotográfico EBY

En la margen argentina, comprenden al Acceso Sur y Nodo Vial Garita, con sus adecuaciones urbanas en los tramos denominados Franjas de Transporte Norte y Sur; el By-Pass Arco-Garita, que desvincula el tránsito pasante de la $\mathrm{RN} \mathrm{N}^{\circ} 12$ de la ciudad de Posadas; la Multitrocha de la $\mathrm{RN}^{\circ} \mathrm{N}^{\circ} 12$, con el nuevo acceso a Garupá y el nuevo Puente sobre el arroyo homónimo, que plantea un nuevo vínculo con la ciudad de Candelaria, hasta Iguazú en Argentina y desde allí, con Brasil y Paraguay.

Fotos $N^{\circ} 128$ a 131: Obras Viales de Integración entre Posadas y Encarnación
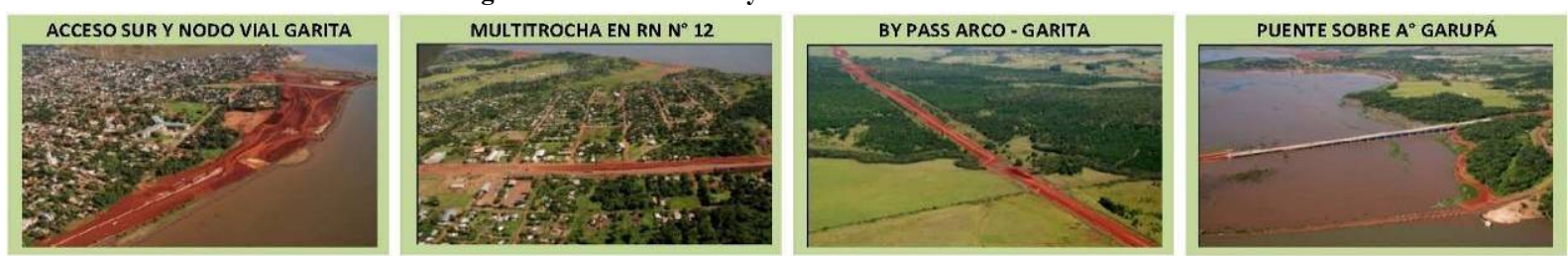

Fuente: Archivo fotográfico EBY

\section{III.4.2.3. Obras Viales en la Provincia de Misiones}

El tercer paquete estructural, está compuesto por el conjunto de catorce (14) obras localizadas sobre rutas nacionales y provinciales: 1) Relocalización $\mathrm{RN} \mathrm{N}^{\circ} 12$ y Puente $\mathrm{s} / \mathrm{A}^{\circ}$ Yaberbiry; 2) Relocalización RP N 204 y Puente s/A Garupá; 3) Relocalización RP N 210 y Puente s/A La Horqueta; 4) Relocalización RP N 210 y Puente s/A El Cazador; 5) Camino y Puente s/A Nacanguazú; 6) Puente s/A ${ }^{\circ}$ Federal; 7) Acceso a Puerto Viejo-San Ignacio; 8) Camino y Puente s/A ${ }^{\circ}$ Curupaity; 9) Camino y Puente entre Corpus y Santo Pipó; 10) Acceso a Piporé y Club Piporé; 11) Acceso a Campamento Yaberbiry; 12) Acceso a Destacamento Nemesio Parma; 13) Relocalización RP N 216 y Puente s/A ${ }^{\circ}$ Yaberbiry; 14) Ex RP No 1 y Puente s/A $\mathrm{A}^{\circ}$ Tranquera. Estas obras, garantizan tanto la movilidad a escala regional, como la accesibilidad para diferentes ciudades del interior provincial.

Fotos $N^{\circ} 132$ a 135: Obras Viales en la Provincia de Misiones
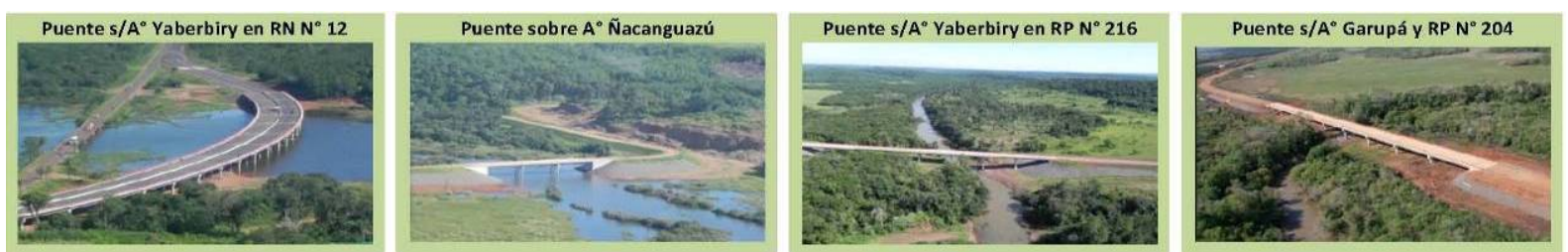

Fuente: Archivo fotográfico EBY

\section{III.4.2.4. Protección Ambiental, Saneamiento y Reposición Funcional:}

Comprende al conjunto de obras que evitan una mayor inundación de diferentes sectores del territorio y/o protegen contra el fenómeno de la erosión; o bien, que construye el saneamiento básico de las 
ciudades involucradas; así como también, reponen obras afectadas por el llenado del embalse y cumple con otras obras comprometidas en el Tratado de Yacyretá.

En la margen paraguaya está compuesto, entre otras, por la protección del valle del arroyo Aguapey, la Planta de Tratamiento de Efluentes Cloacales, Alcantarillado Sanitario, Red de Agua Potable, Edificios Públicos, Puerto y Aeropuerto en la ciudad de Encarnación.

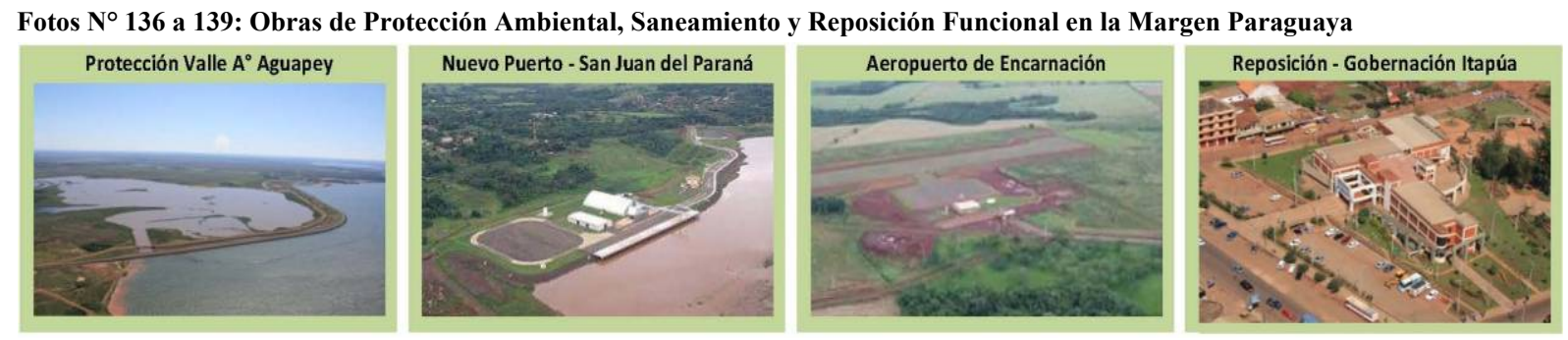

Fuente: Archivo fotográfico de la Entidad Binacional Yacyretá, 2010.

En la margen argentina, comprende la reposición de obras Ferroviarias; una nueva Toma de Agua para Posadas; la recuperación del Patrimonio Cultural: "Villa Cultural La Estación" y rescate y puesta en valor del Ferry ("Presidente Roque Sáenz Peña" o "Ezequiel Ramos Mejía"); reposición del Embarcadero de Lanchas en Posadas y los nuevos Puertos de las ciudades de Posadas y Santa Ana.

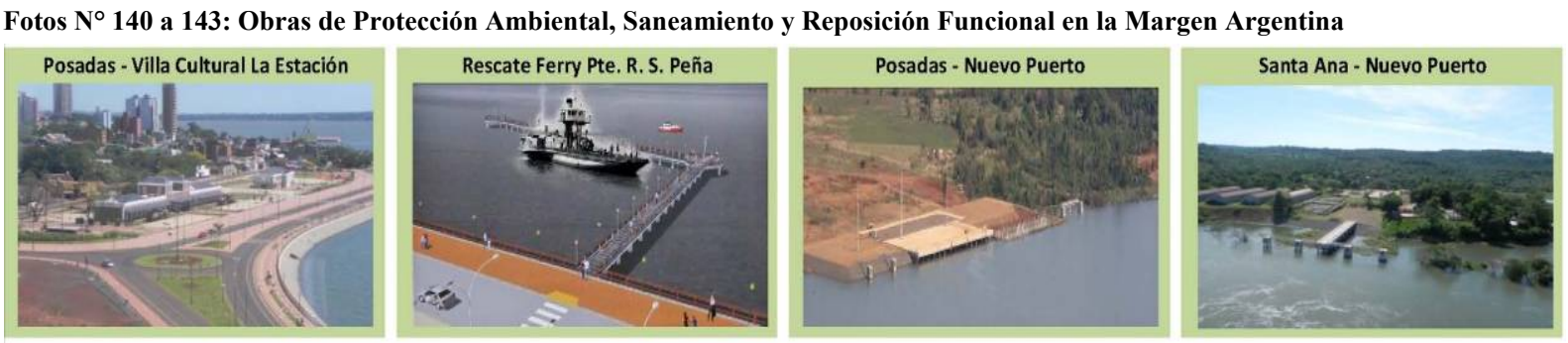

Fuente: Archivo fotográfico de la Entidad Binacional Yacyretá, 2010.

Las Obras representan unos 3 millones de $\mathrm{m}^{3}$ de excavaciones; 24 millones $\mathrm{m}^{3}$ de rellenos y terraplenes; 3 millones de $\mathrm{m}^{3}$ de protecciones en roca; $700 \mathrm{mil} \mathrm{m}^{2}$ de membrana geotextil; $200 \mathrm{mil} \mathrm{m}^{3}$ de hormigones y 15 mil TN de aceros (sin contar las estructuras de hormigón prefabricadas); $150 \mathrm{mil} \mathrm{m}^{3}$ de enripiado y de 1,5 millones de $\mathrm{m}^{2}$ de pavimentos para obras viales de recomposición de trama urbana, paseos públicos, puentes y accesos.

Estos proyectos dejarán, además, un aporte ambiental y recreativo, conformado por más de 6 mil has de lagos, 5 mil metros de playas, 600 has de reservas urbanas y una superficie análoga de espacios verdes equipados, destinados a actividades culturales y recreativas; así como también en nuevas infraestructuras, como plantas de tratamiento de efluentes cloacales, nuevos puertos y nuevos accesos viales, puentes y reposición de edificios públicos, en ambas márgenes.

"Se tratan, en suma, de grandes intervenciones que proponen un nuevo orden urbano que significa devolverle la cara al rio a las ciudades intervenidas y nuevas relaciones sociales, derivadas de los espacios públicos equipados, y territoriales a partir de los nuevos ejes de movilidad, que, como ya puede verificarse en la Costanera de Posadas, promueven nuevas inversiones públicas y privadas, que las convierten en factor decisivo de desarrollo local y regional." (Thomas, 2010.a: 3) 


\section{III.4.3. La planificación como estrategia para la terminación de Yacyretá}

Este aspecto representó el instrumento de gestión a partir del cual la Entidad Binacional Yacyretá, cooperando con los gobiernos locales, fue encuadrando las obras y acciones socio-ambientales, dentro del contexto de los planes de desarrollo urbano de cada municipio directamente involucrado y que, en el Capítulo IV (ver parágrafos IV.1.2, extensiones 2 a 5 inclusive), es analizado como modelo de ordenación del paisaje a escala de área y región metropolitana.

"[...] Uno de los aspectos clave de la instrumentación del PTY está conformado por el Apoyo Interinstitucional que se presta a través de un fortalecimiento para operar los nuevos servicios e infraestructuras que se transfieren y de promover la asistencia técnica necesaria, para el diseño de estrategias de desarrollo local y regional, dentro del marco que otorga el Acta de Buenos Aires suscripta el 25/02/2005 con los gobiernos locales de ambos paises." (Thomas, 2010.a: 6)

De acuerdo con lo establecido en los lineamientos planteados por la Entidad Binacional, la planificación tiene el objetivo de promover la construcción de una política a escala urbana (municipal) y territorial (metropolitana y microregional) a partir del impulso de las obras y acciones de Yacyretá, aprovechando los efectos positivos de las transformaciones que ellas inducen, que están representados por cuatro directrices estratégicas o 'ideas fuerza':

i) Mejoramiento de la Calidad Urbana: completando servicios básicos (agua y cloacas); equipamientos comunitarios y la infraestructura del territorio

ii) Manejo integrado de los espacios abiertos: considerando reservas naturales compensatorias y urbanas; espacios verdes, vacíos urbanos y recursos hídricos y naturales, con asignación de usos compatibles con criterios de calidad ambiental.

iii) Modelo Urbano Compacto: en términos de consolidar las áreas urbanas; cualificar las áreas complementarias y de ampliación urbana y fortalecer los centros externos como nuevas centralidades de equilibrio territorial.

iv) Modelo de Ciudad-Territorio: que auspicie y promueva la diversificación de actividades económico-productivas y el mejoramiento de la oferta de servicios urbanos y turísticos.

Pero en virtud de que dicho proceso de planificación partió de la necesidad de asimilar las transformaciones derivadas de las grandes obras de infraestructura, los lineamientos plantean que su instrumentación operativa debe promover en el mediano plazo, los siguientes aspectos:

a) que las obras y acciones -entendidas como grandes proyectos urbanísticos- sean interpretadas como inductoras del proceso de ordenación y estructuración del territorio;

b) que los procesos de gestión urbana de los Municipios que la integran -en función de adecuar la normativa urbanística- incorporen las transformaciones estructurales;

c) que los acuerdos sobre lo local, metropolitano y regional, se encaucen dentro de una modalidad de gestión interjurisdiccional análoga y concertada. 
La EBY instrumenta los aportes por convenios de cooperación, que contemplan un esquema de trabajo donde la Entidad interviene como promotor de los procesos, pero como un actor más dentro del escenario territorial, promoviendo -conjuntamente con las Universidades y/o con organizaciones públicas y privadas de la sociedad civil de la región- que los Municipios pasen a convertirse en actores principales y conductores de esos procesos. Con esta premisa, la institución logra concertar estudios, normativas y/o medidas destinadas a favorecer el manejo integrado de las áreas territoriales donde se verifican los mayores impactos de las obras y acciones vinculadas con la terminación de Yacyretá.

"Especificamente, esos aportes comprenden, el apoyo técnico para la actualización de los planes de desarrollo urbanístico de los municipios; la formalización de convenios marco y especificos de cooperación (para fortalecimiento institucional y apoyo a la operación y mantenimiento de la infraestructura construida y transferida) y el desarrollo de trabajos especiales vinculados con la evaluación y/o mitigación de los efectos derivados de la ejecución de las obras y acciones de terminación de Yacyretá" (EBY, 2007: 2)

Esta forma de trabajo le ha permitido a la Entidad Binacional, por ejemplo, obtener la viabilidad ambiental de todas las obras en ejecución por parte de los organismos responsables de cada país.

\section{III.4.3.1. En la Margen Paraguaya}

Dentro del marco de un Convenio entre la Municipalidad de Encarnación, la Corporación Antiguo Puerto Madero S.A. y la Entidad Binacional Yacyretá, se elaboraron 'Lineamientos de Ordenación y Gestión Territorial para el Área Metropolitana de Encarnación (AMeE)', que involucran a los Municipios de Encarnación, Cambyretá, San Juan y Carmen del Paraná.

Para el caso del Municipio de Encarnación, esos lineamientos fueron aprobados por la mencionada Resolución Municipal N 493 del 16 de mayo de 2006 (ver punto A del parágrafo III.3.3.1), que además de realizar un aporte para la gestión urbana ha viabilizado, también, la aprobación de:

a) las obras viales y de tratamiento costero sobre el río Paraná y los arroyos urbanos Mboi Caé, Santa María y Poti’y;

b) los proyectos de reconfiguración urbana, que posibilitaron relocalizar el Circuito Comercial de la Zona Baja y adecuar el entorno urbano de la Feria Municipal;

c) los complejos habitacionales destinados a relocalizar la población que habitaba dentro de la poligonal de expropiación del embalse, dentro del ejido urbano de la ciudad.

Para consolidar este proceso en el mediano plazo, Yacyretá ha formalizado, por una parte, un Convenio con la Universidad Católica Nuestra Señora de la Asunción Campus Itapúa y la Municipalidad de Encarnación, en junio de 2010, para actualizar -dentro del marco de la Resolución № 493/06el Código Urbano y de Edificación del Distrito, y ha elevado a la consideración de los gobiernos nacional y municipal, por otra parte, una propuesta de gestión con un plan urbanístico para recuperar las aproximadamente 70 hectáreas que ocupaba la Zona Baja Comercial de la ciudad. 
Imágenes $N^{\circ} 30$ y 31: Encarnación - Lineamientos morfológicos y de gestión para el área urbana recuperada de ex Zona Baja
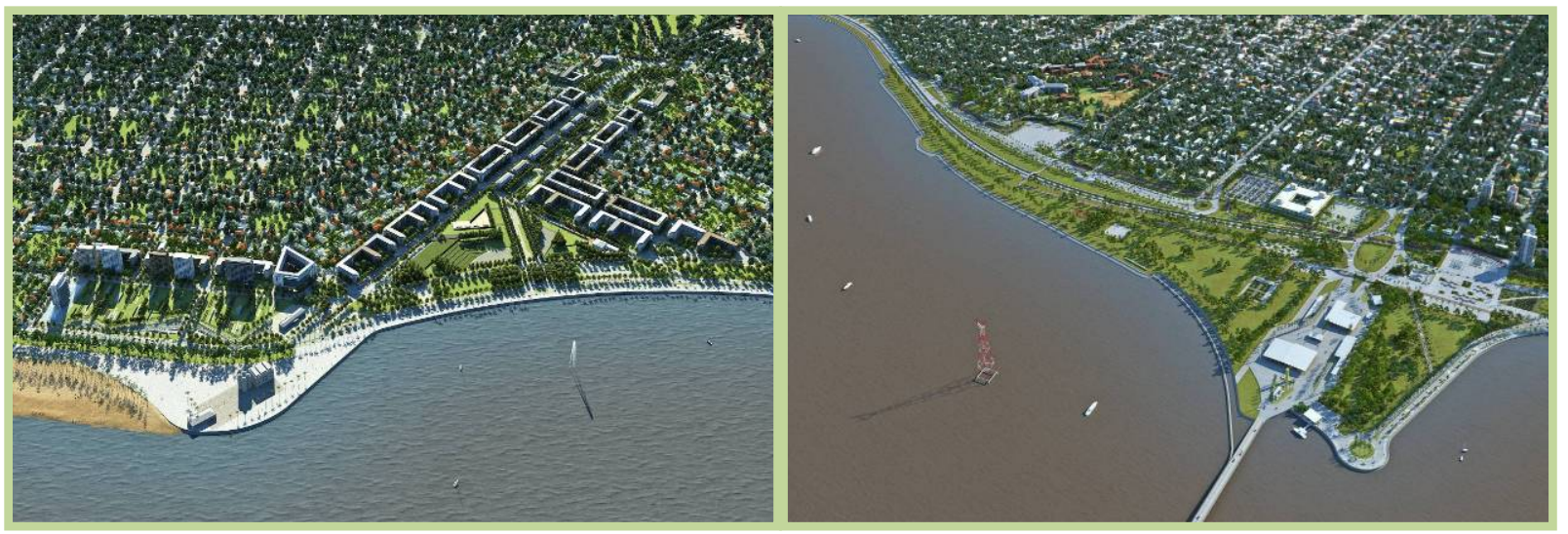

Fuente: Entidad Binacional Yacyretá, 2010.

Esta modalidad de trabajo le ha posibilitado a la EBY encauzar también, otras obras de reposición de importancia regional como la del Puerto Cerealero en San Juan del Paraná o el Aeropuerto en Capitán Miranda, y como en el caso de Carmen del Paraná, dónde ha conseguido concertar a través de un amplio proceso participativo con el Municipio y la población, un plan integral que incluyó obras de tratamiento costero y nuevos puentes, la ampliación urbana para relocalizar 329 familias afectadas por el embalse, la mejora y ampliación de equipamientos comunitarios, educativos y de salud, un parque urbano y nuevos servicios de agua potable y tratamiento de efluentes cloacales para toda la ciudad.

Foto $N^{\circ}$ 144: San Juan del Paraná - Puerto Cerealero

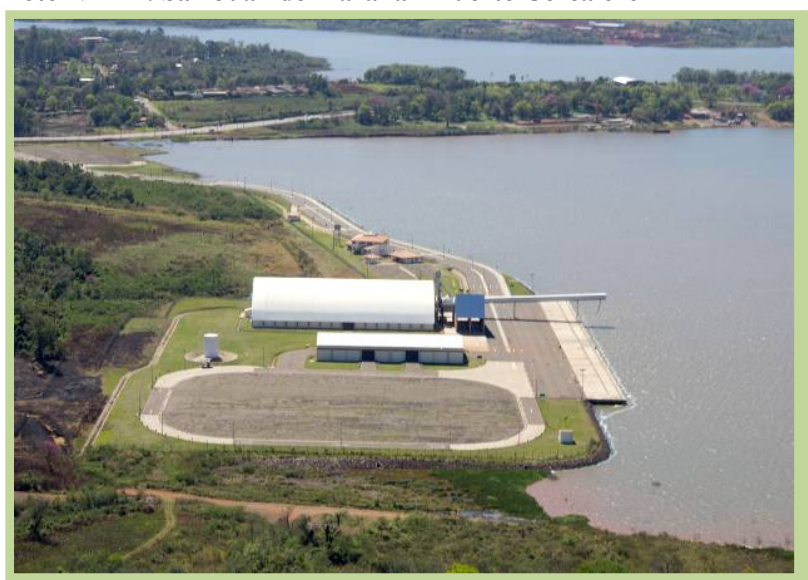

Fuente: Entidad Binacional Yacyretá, 2010
Foto $N^{\circ}$ 145: Carmen del Paraná - Tratamiento Costero

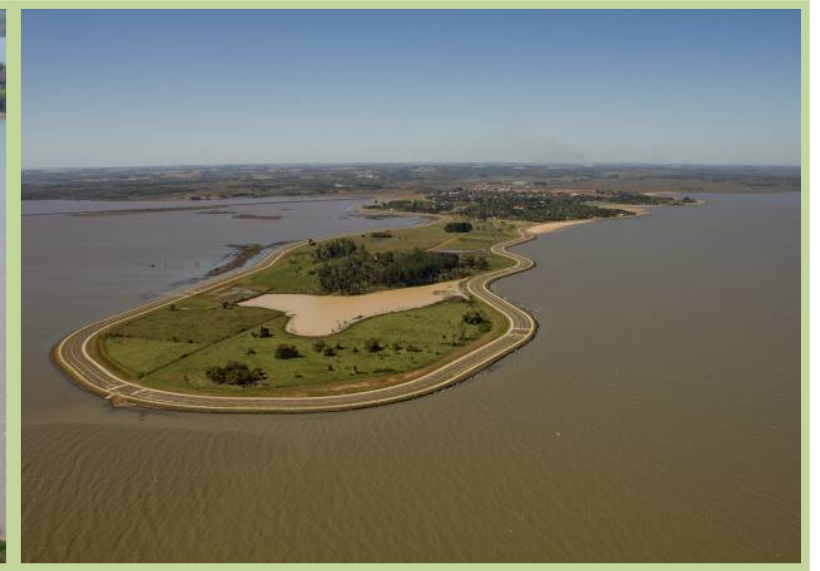

\section{III.4.3.2. En la Margen Argentina}

En esta margen la EBY ha elaborado, también, 'Lineamientos de Ordenación y Gestión Territorial para el Área Metropolitana de Posadas (AMeP)', incluyendo en ella, a los Municipios de Posadas, Garupá y Candelaria, y una zona de influencia delimitada por los municipios de Santa Ana, San Ignacio y Loreto. De forma análoga al área de Encarnación, estos lineamientos aportaron elementos para encauzar las obras y acciones de Yacyretá, dentro del marco de gestión estratégica del gobierno provincial y de los municipios mencionados. 
Para el caso del Municipio de Posadas, los lineamientos que definieron la nueva morfología urbana de las zonas urbano-costeras frente al embalse principal y a los subembalses urbanos, forman parte del mencionado Plan Estratégico y fueron aprobados por la también mencionada Ordenanza $\mathrm{N}^{\circ}$ 2.916/2011 de Ordenamiento Urbanístico del frente Fluvial (ver punto B del parágrafo III.3.3.1),

Plano $N^{\circ}$ 14: Posadas - Plano General de Zonificación de las Zonas Costeras

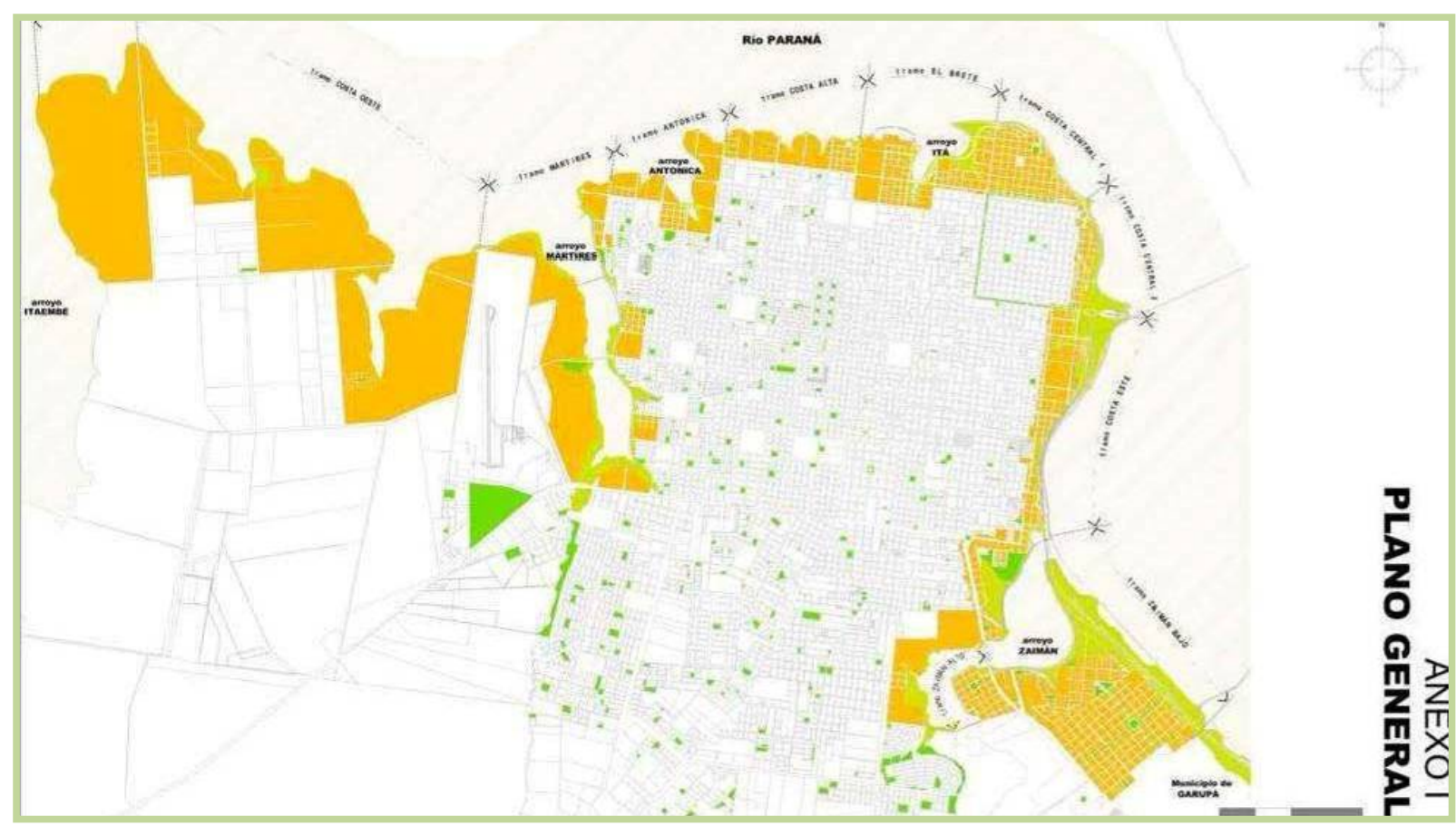

Fuente: Municipalidad de Posadas - Ordenanza N²916/11 (2011: Anexo I: 1)

También en los municipios de Candelaria y Garupá, la Entidad Binacional está colaborando para ajustar la normativa urbanística, sobre la base de delinear y promover el completamiento del tejido urbano-costero, de forma tal que se permita intervenir por Proyectos Urbanos.

Estos proyectos tendrán por objetivo testimoniar una nueva modalidad de ocupación de la costa, revalorizando las visuales tanto hacia el río Paraná, como hacia los subembalses urbanos.

Plano No 15: Candelaria - Jerarquización del Borde Costero

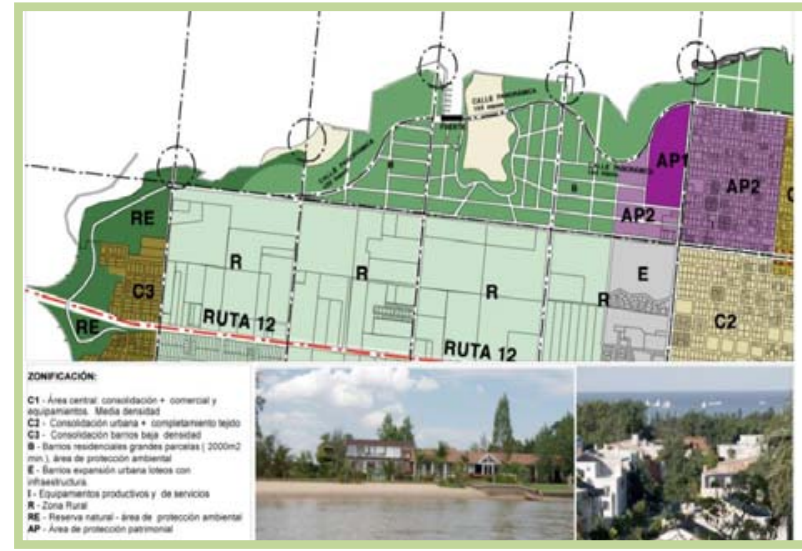

Plano N 16: Garupá - Nuevo Tejido Urbano-Costero

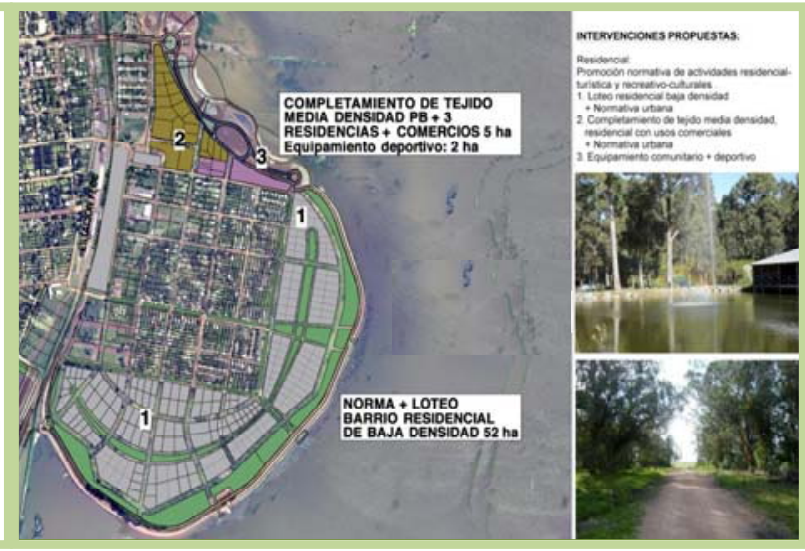

Fuente: Entidad Binacional Yacyretá, 2010. 


\section{CAPÍTULO IV: EL PAISAJE COSTERO Y LAS TRANSFORMACIONES EN LAS CIUDADES INVOLUCRADAS POR YACYRETÁ, ENTRE LOS AÑOS 2005 A 2010}

Lo expuesto en los capítulos anteriores, demuestra que el territorio a escala local y regional, ha sido afectado por diversos procesos de transformación antrópica, en función de hechos significativos acaecidos en sentido histórico, en breves periodos, que son verificables en términos de 'impactos' que han ido transformando el majestuoso y a la vez agresivo ambiente natural, aportando 'nuevos significados' para poder adecuarlo a las necesidades humanas.

De tal forma, hemos podido analizar las 'huellas' de los periodos de conformación de la Región Cultural, y hemos podido reflexionar sobre las características de la más reciente configuración territorial, impulsada por el crecimiento de las ciudades y, particularmente, por la implantación de los grandes proyectos hidroeléctricos construidos en la Cuenca del Plata, profundizando el análisis en las transformaciones generadas por la ejecución de Yacyretá.

En dicho análisis hemos visto que, para asimilar el proceso de transformación derivado de su ejecución, se están sustanciando una importante cantidad de obras y acciones, que tienen por objeto adecuar el territorio y los ámbitos de su área de influencia directa, para concretar el objetivo de su terminación, dónde 'impacto' y 'resignificación', representan dos caras de una misma moneda, a la hora de interpretar el proceso de (re)configuración del paisaje.

Pero, a fin de poder evaluar la validez de esta hipótesis, y considerando que esas transformaciones no fueron pensadas inicialmente en términos de paisaje, nos resulta necesario ensayar una lectura de las mismas en dichos términos, para lo cual en el primer apartado de este Capítulo, se realiza una aproximación a la noción de paisaje a partir de 'la acción' (la obra), incluyendo en ello el análisis de situación del área de estudio en términos: ecológico-ambiental, geográfico-urbanistico; históricocultural, considerando en este análisis a los recursos del paisaje: naturales, culturales, socioeconómicos e institucionales y normativos, y proporcionando además, algunas herramientas de interpretación para valorar elementos identitarios de las zonas urbano-costeras como 'Lugar'.

Esa forma de describir las transformaciones es la que nos permite enfocar, en el segundo apartado del Capítulo, la propuesta de un método alternativo que pueda articularse con los procesos de planificación en marcha y con las inversiones físicas y las acciones concretas, para orientar en el mediano y largo plazo las nuevas relaciones cultura-naturaleza que las mismas suponen.

En la última parte de la Tesis, se incluyen las conclusiones generales que verifican las hipótesis planteadas para esta investigación. 


\section{IV.1. APROXIMACIÓN A LA NOCIÓN DE PAISAJE A PARTIR DE 'LA ACCIÓN'}

Reiterando la consideración acerca de que las transformaciones generadas por la construcción de Yacyretá no fueron pensadas en términos paisajísticos, puede indicarse desde una óptica específica que, en las zonas costeras se manifiestan una serie de conflictos ocasionados tanto por cuestiones propias de su naturaleza, como por otras generadas por el mismo proceso de transformación, que es necesario que sean atendidas en el mediano y largo plazo para su revaloración en virtud de que, estas áreas, pueden adquirir valores naturales, culturales y perceptivos, que potencien su reconocimiento como ordenadoras de la totalidad urbana-territorial, desde su interpretación como 'nuevo paisaje'.

Estas zonas constituyen además la frontera entre dos países, Argentina y Paraguay, que se encuentran unidos por las aguas del Río Paraná y las cuencas interiores, el Complejo Hidroeléctrico-Presa Principal, el nuevo sistema vial, los Puentes sobre el Brazo Aña Cuá y, principalmente, el Puente Internacional San Roque González de Santa Cruz entre Posadas y Encarnación, conformando:

“[...] un escenario paisajístico privilegiado que integra en una sola geografia: aguavegetación y recursos humanos, valores socio-culturales y una historia y experiencias de integración regional. El Tratado de Yacyretá potencia el desafio geopolitico y contribuye a la construcción de un escenario socio-ambiental paralelo y complementado respetando identidades propias, con un territorio amplio como espejo del lago de Yacyretá que canalizan las aguas de las cuencas hacia la generación energética. El Plan de Gestión de las Cuencas debe constituirse en el hilo conductor de la rica experiencia del emprendimiento hidroeléctrico Yacyretá que dinamiza la relación de las cuencas con la producción energética, contribuye a normalizar la administración de recursos hídricos cumpliendo normas internacionales, tratados y leyes nacionales vigentes. (Global Consultores, 2008: 35)

De tal forma, esta primera parte del Capítulo, aborda esa gran transformación desde una visión que interpreta al área de intervención como paisaje, orientando una valoración de las acciones a partir de tres dimensiones o escalas de análisis, que aluden a la clasificación del Sistema de Inventario del Patrimonio Mundial (TASEO): ${ }^{87}$ i) La macro-escala o escala Territorio; ii) La escala intermedia, que abraca las áreas de influencia de las ciudades de Posadas y Encarnación, considerada como Área; iii) La escala urbana y de las zonas específicas de intervención, consideradas como Sitio (o Lugar), que incluyen también, las otras dos escalas de clasificación: Edificio (o Monumento) y Objeto.

Esta mirada incluye un análisis de situación de los 'recursos del paisaje', que permite reconocer a priori valores paisajísticos en ciertas porciones del territorio, que aporten una mirada estética, apuntalada en la diversidad y sectorialidad propia de su configuración física y cultural, a partir de tres dimensiones de análisis: a) ecológica-ambiental, a fin de reconocer los problemas y valores naturales del área como potencial paisajístico, con la identificación de espacios a proteger y ordenar, por existir en todos o parte de ellos, recursos naturales vitales y escasos de ecosistemas frágiles de gran valor, por su contribución al mantenimiento de la biodiversidad y calidad ambiental; b) geográfico-urbanistica, desde una perspectiva

${ }^{87}$ El Sistema de Inventario del Patrimonio Mundial, reconoce cinco escalas de relevamiento: Territorio, Área, Sitio (Lugar), Edificio (o Monumento) y Objeto, denominada por la sigla: TASEO 
que permita entender el impacto del emprendimiento hidroeléctrico, su propia configuración, y las oportunidades que ofrece esa modificación cultural; c) histórico-cultural que permite identificar y describir 'lugares' en los que se encierran los principios y tradiciones que han dado origen a la conciencia colectiva y entender, además, la forma en la que preexisten ciertos valores tangibles e intangibles del área y de la región de pertenencia, que sean merecedores de su conservación y transmisión a las generaciones venideras, respetando y afianzando lo que puede denominarse como la identidad del lugar.

\section{IV.1.1. Interpretación del Proyecto como Paisaje a escala 'Territorio'}

La carretera-puente conformada por el sistema de presas y central hidroeléctrica, y el puente internacional Posadas-Encarnación, ofrecen alternativas de interconexión entre ambas márgenes del proyecto y, consecuentemente, una nueva posibilidad de recorrido y percepción de cada ámbito del territorio modificado que, en términos de paisaje, presenta la necesidad de enfrentar su planificación territorial, como Área de Manejo Integrado, sobre la base de la ordenación de cada ámbito jurisdiccional.

Plano $N^{\circ}$ 17: Territorio involucrado por el Proyecto Hidroeléctrico

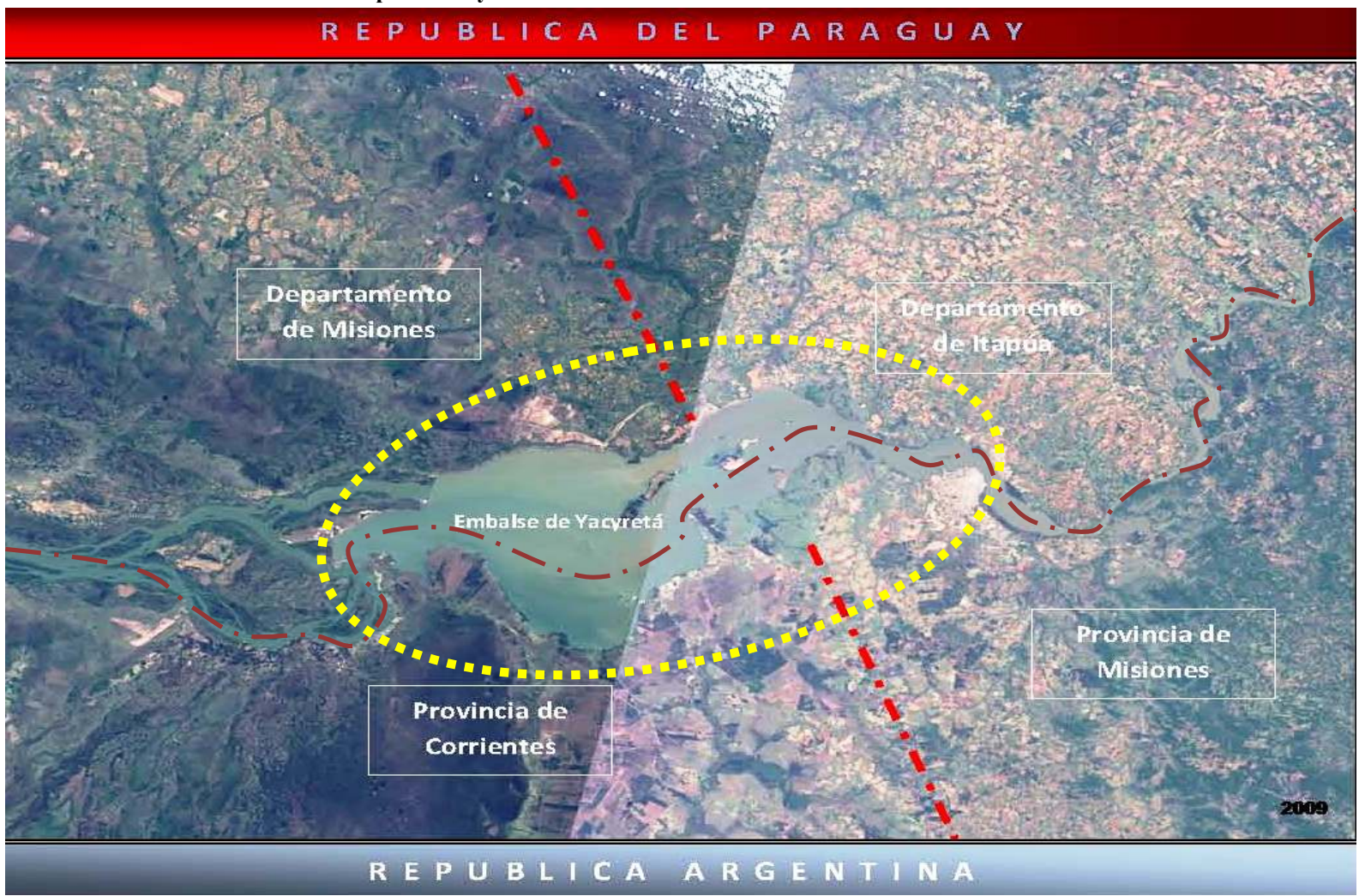

Fuente: Elaboración propia.

A esta escala, las prioridades de gestión debieran estar puestas en aquellos aspectos relacionados con un manejo integrado de: a) los espacios abiertos, b) los vacíos territoriales y urbanos; c) las cuencas hídricas; d) los grandes espacios naturales protegidos. En general, pueden ser incluidos en:

- las áreas de ribera sobre el río Paraná, afectadas por el recrecimiento del embalse y las cuencas y áreas de borde de los arroyos y subembalses (calidad del agua y ambiental);

- los espacios naturales protegidos y los abiertos de uso público (de equilibrio territorial); 
- el ámbito rural y los vacios urbanos, que constituyen áreas de riesgo de periferización producto de los efectos derivados de la consolidación de ejes de movilidad territorial, que sin medidas preventivas, inducen urbanización en las tierras vacantes de usos.

Estos ámbitos son en esencia de carácter interjurisdiccional -dado que corresponden, en general, a áreas de borde entre municipios diferentes, o entre el espacio urbano y periurbano, o entre éste y el espacio rural- y es por ello que merecen especial atención, y dónde su manejo integrado -con una asignación de usos compatibles con criterios de calidad ambiental- debe procurar la concertación de medidas de mitigación y normativas sustancialmente análogas, en las jurisdicciones involucradas.

\section{IV.1.1.1. Análisis Ecológico-Ambiental a escala Territorio}

La zona de implantación de Yacyretá representa, desde este punto de vista, un gran ecotono o interfase ecológica-ambiental, dado que se ubica en el límite de las zonas del Curso Superior del río Paraná (ver parágrafo II.3.2.1), reconocidas como Alto Paraná y Porción Inferior del Alto Paraná.

\section{A. Aspectos Ambientales}

Desde la óptica ambiental, merecen destacarse las características básicas de los dos sistemas dominantes del área de implantación de Yacyretá, conformado por el Alto Paraná Encajonado (APE) y la Porción Inferior del Alto Paraná (PIAP).

\section{A.1. Alto Paraná Encajonado (APE)}

El APE se extiende unos $280 \mathrm{Km}$ desde Posadas hasta Puerto Iguazú en la Argentina y desde Encarnación a Ciudad del Este en Paraguay. Dentro del tercio inferior de esta área se localiza la cola del embalse de Yacyretá, en una extensión aproximada a $100 \mathrm{Km}$., que va desde el eje Posadas-Encarnación hasta el Departamento San Ignacio en Argentina y la parte norte del Departamento de Itapúa, en Paraguay.

El rasgo más importante del paisaje del APE es la presencia de dos pediplanos que abarcan una franja de unos cincuenta kilómetros de ancho, de los cuales $15 \mathrm{~km}$. corresponden a territorio argentino, sobre la provincia de Misiones y $35 \mathrm{~km}$. se ubican en territorio paraguayo, entre los que se encuentra el valle encajonado del río Paraná. Las barrancas de este colector principal superan los 80 metros y su altura media es de 60 metros sobre los cerros locales (Morello et al., 2004:13).

A escala regional, esta zona presenta ecosistemas de selvas ribereñas, cañaverales o pajonaltacural, sabanas sumergidas y de tierra firme de arenales y, a escala local, existen ecosistemas de neblina de las cascadas, de corredores de cauces y rupestres asentados en paredones de basalto. "Estos tipos de vegetación proporcionan conectividad entre hábitats semejantes o complementarios, en ecosistemas selváticos distintos o similares, y son de importancia por su papel de corredores biológicos y por ser los tipos de vegetación menos estudiados de la Selva Paranaense, en la Argentina y en Paraguay." (Placci, 2002, citado en Morello et al., 2004: 18). 
En el APE hay una gran variedad de tipos estructurales y fisonómicos de formaciones vegetales, representados en dos ecorregiones: Selva Paranaense -la más extensa, con dos tipos: selva ribereña y las de tierras altas que nunca se inundan-, y los Campos y Malezales -en la porción sur del APE, cuya formación característica es la de sabana o campo cerrado; junto al ecotono entre ambas -caracterizado por una unidad fitogeográfica identificada como montes de urunday-, que sin ser una ecorregión, es de gran importancia en su extensión, funcionamiento y rol ecológico (Morello et al., 2004: 33 a 36).

\section{A.2. Porción Inferior del Alto Paraná (PIAP)}

En la Porción Inferior del Alto Paraná -que abarca la zona comprendida entre el eje PosadasEncarnación hasta Confluencia, en el encuentro de los ríos Paraná y Paraguay, en una extensión análoga a la anterior- es dónde se ubica el embalse principal. Aguas abajo de la represa de Yacyretá el río presenta una dirección hacia el oeste, ensanchándose progresivamente y ramificándose en varios canales que forman una gran cantidad de islas fluviales hasta unirse con el río Paraguay, frente a Paso de la Patria (Provincia de Corrientes, Argentina).

El cauce del río Paraná presenta en este sector un amplio valle de inundación que define ambientes con fisonomía de esteros, arroyos, y frecuentes lagunas y madrejones interconectados con la dinámica fluvial, que forman ecosistemas de camalotes y embalsados; sistema de islas y en las zonas costeras, suelos arenosos, arcillosos y orgánicos (histisoles) con tipos de vegetación vinculados a anegamiento (suzales, tacurales, carrizales, totorales, etc.) y selvas de albardón y ribereña (Morello et al., 2004: 27).

La presencia de esos tipos de suelos ha sido determinante para la localización, en las periferias de las ciudades, de pequeños establecimientos dedicados a la elaboración artesanal de ladrillos (olerías) y de medianas industrias de tejería que, en el entorno del área de estudio, fueron relocalizados en el año 1993, previo a la elevación del embalse a la cota 76 msnm, realizada entre junio y septiembre de 1994.

\section{B. Aspectos Ecológicos}

Desde una perspectiva regional "los tres grandes sistemas ecológicos del Alto Paraná son el fluvial-insular, la selva y la sabana" (Morello et al., 2004: 27), presentes aguas arriba y aguas abajo del embalse de Yacyretá, que junto al gran avance de la urbanización de las dos principales ciudades de su entorno (Posadas y Encarnación), han afectado esencialmente al primero de ellos y los usos periurbanos y agrícolas, a los otros dos. Desde esta perspectiva, puede decirse que actualmente estamos en presencia de un ambiente particularmente antropizado:

"[...] un territorio diseñado por el ser humano sobre una matriz de selvas, sabanas y humedales de las que todavía quedan fragmentos importantes [...] un territorio litoral [dónde] los ecosistemas naturales desempeñan un papel importante en el control de la contaminación de las aguas del río, la erosión de sus costas y el enturbiamiento del agua por dicha erosión, [siendo] a su vez, un área de alto riesgo, por la tasa creciente de conversión de tierras naturales en cultivos y plantaciones a consecuencias, entre otras cosas, de su contacto con una vía importante de transporte: la vía fluvial." (Morello et al., 2004: 71). 


\section{IV.1.1.2. Análisis Geográfico-Urbanístico a escala Territorio}

Podemos señalar, en este sentido, que las zonas costeras están ubicadas en una trama regional de suma importancia. En las zonas libres de urbanización, existe un gradiente de conversión de ecosistemas naturales a usos agrícolas (más marcado en la margen paraguaya), que constituye un ecotono entre un sistema natural y un sistema convertido a la agricultura que conserva características del primero, que pueden ser de importancia para la planificación del uso del suelo o para su manejo en un programa de restauración. Se ha verificado que la matriz provee conectividad al fragmento en todas direcciones, lo que facilita tanto la circulación de organismos como la reposición de biodiversidad específica a los sitios actualmente ocupados (Morello et al., 2004: 87), empleando a los arroyos como corredores aptos para recomponer gran parte de la biodiversidad perdida.

En tanto que, en las áreas urbanizadas, las zonas costeras adquieren el carácter de interfase urbana, como grandes espacios públicos equipados, que se articulan con espacios verdes y parques urbanos en las cabeceras de los subembalses. Más allá de las periferias de las ciudades, que tienen la potencialidad de convertirse en nuevas centralidades urbanas, se verifica aquel gradiente de conversión que va desde los usos agrícolas intensivos, a una agricultura de bajo impacto, dónde las cuencas de los arroyos urbanos que finalizan en subembalses adaptados al uso público, se convierten, por razones sanitarias, en las zonas de mayor cuidado para garantizar la calidad del agua de los mismos.

Desde esta óptica, las zonas urbano-costeras, representan una respuesta específicamente urbana al tratamiento costero de todo el perímetro del embalse, que pueden convertirse en un factor de ordenación del paisaje de toda el área de perilago, como vínculo entre el resto de los sectores:

a) De la periferia urbana:

Como factor de consolidación de nuevas centralidades, desde unas respuestas complementarias y análogas a éstas.

b) De la producción primaria intensiva y de lo rural:

Como factor de control de la periferización, a partir del tratamiento diferenciado de los subembalses de los arroyos que circundan estas zonas, como áreas especiales de manejo, en términos de corredores de biodiversidad.

c) De las áreas de amortiguación a escala territorial y urbana:

Conformadas por las áreas libres de usos, por las más de 140 mil hectáreas de reservas naturales compensatorias creadas a partir de la mitigación de los ambientes perdidos, por la red aún potencial de zonas de reserva y recreativas vinculadas con los subembalses rurales; y por la red de espacios abiertos compuestos por más de 600 hectáreas de áreas públicas, parques urbanos y áreas de reserva de las cabeceras de esos subembalses. 


\section{IV.1.1.3. Análisis Histórico-Cultural a escala Territorio}

Es a escala Territorio, donde los aspectos histórico-culturales deben servir como orientación para una gestión del área en términos de Paisaje, dado que lo cultural surge gradualmente como una expresión de las actuaciones de la sociedad humana articulada con su tecnología sobre la naturaleza, en un territorio concreto, cuyos componentes identificativos son: a) el sustrato natural (orografía, suelo, vegetación, agua); b) la acción humana, modificación y/o alteración de los elementos naturales y construcciones para una finalidad concreta; c) las actividades desarrolladas, en términos de componente funcional en relación con la economía, formas de vida y creencias.

Es decir que, el paisaje cultural es una realidad compleja, integrada por componentes naturales y culturales, tangibles e intangibles, cuya combinación configura el carácter que lo identifica como tal; por ello debe abordarse desde diferentes perspectivas.

Tipos de Paisajes Culturales:

- Paisaje claramente definido, creado y diseñado intencionadamente por el ser humano. Se trata de paisajes ajardinados y parques, construidos por razones estéticas que generalmente, aunque no siempre, se encuentran asociados a edificios religiosos o monumentos de otra índole.

- Paisaje evolucionado orgánicamente, debido a un imperativo inicial de carácter social, económico, administrativo y/o religioso, y que ha evolucionado hasta su forma actual como respuesta a la adecuación a su entorno natural. Este proceso se refleja de formas diferentes, por lo que se establecen dos subtipos:

- Paisaje vestigio (o fósil), es aquel en el que su proceso evolutivo concluyó en algún momento del pasado, pero sus rasgos característicos son todavía visibles materialmente.

- Paisaje activo, es el que conserva un papel social activo en la sociedad contemporánea asociado con el modo de vida tradicional, y cuyo proceso de evolución sigue activo.

- Paisajes culturales asociativos son aquellos en los que existen poderosas asociaciones, religiosas, artísticas o culturales con el medio natural, en lugar de pruebas culturales materiales, que pueden ser inexistentes o poco significativas.

Clasificación de los paisajes culturales: urbanos, rurales y arqueológicos. (UNESCO, Convención del Patrimonio Mundial).

Es decir que, los contenidos culturales intangibles involucran el horizonte 'simbólico cognitivo', y del sistema de valores de los actores -representados por los pobladores del lugar, del entorno urbano y de los usuarios, así como de las organizaciones gubernamentales (OG) y no gubernamentales (ONG)-, que en conjunto y dentro del contexto de evolución histórica de la región configuran la 'identidad' del lugar. En tanto que, los contenidos culturales tangibles o construidos, involucran elementos de valor cultural y patrimonial, producto del rescate arqueológico y de la resignificación de edificios, monumentos o lugares efectuados durante el mismo proceso de construcción de Yacyretá.

Es por ello, que resulta de fundamental importancia abordar el reconocimiento de la interpretación cultural de los principales 'elementos' (naturales y construidos) que estructuran el paisaje regional, como aspectos intangibles que ayudan a identificar la identidad del área, y como tangibles o testimonios construidos de esa identidad. 


\section{A. El Agua: el río y el embalse, los arroyos y los subembalses}

Es el elemento determinante para conseguir el objetivo de la acción, que es su aprovechamiento hidroenergético. Pero, como puede observarse en el desarrollo de esta investigación, el agua significa mucho más: el río transformado en lago y los arroyos afluentes en lagos interiores, requieren un permanente control para garantizar la calidad del agua en toda la cuenca, y presentan la alta potencialidad de nuevos usos, para riego, consumo humano, transporte y recreación.

Volcando estos conceptos a nuestro caso de estudio, nos permite observar que 'el río' ha sido para la cultura guaraní el elemento primordial de su existencia, de igual forma que los arroyos afluentes, que conformaron un elemento esencial para la localización de las aldeas y pueblos. Ríos y arroyos, también fueron determinantes para la instalación de las ciudades hispánicas, de los pueblos-ciudad de las misiones jesuíticas y para el posterior desarrollo de las actuales ciudades y centros rurales y, también, para su aprovechamiento hidroeléctrico.

Vemos así que -parafraseando a Cambas- tanto para 'los indios de ayer y los hombres de ahora', el río, por su connotación histórica y presente de límite, frontera, comunicación, aprovechamiento y aún, para 'encontrar horas plácidas de esparcimiento', representa un elemento esencial para el desarrollo de la región y de las poblaciones que en su entorno se localizan (Cambas 1962: 7).

Hoy esa relación con el agua debe ser reinterpretada: el tramo del río transformado en un gran lago, y los arroyos en lagos interiores, suponen que será necesaria una nueva mediación para que el elemento agua siga siendo interpretado culturalmente como esencial para el desarrollo de los pueblos, con el desafío de realizar desde la noción de paisaje, un aporte ético y estético para encauzar su (re)significación.
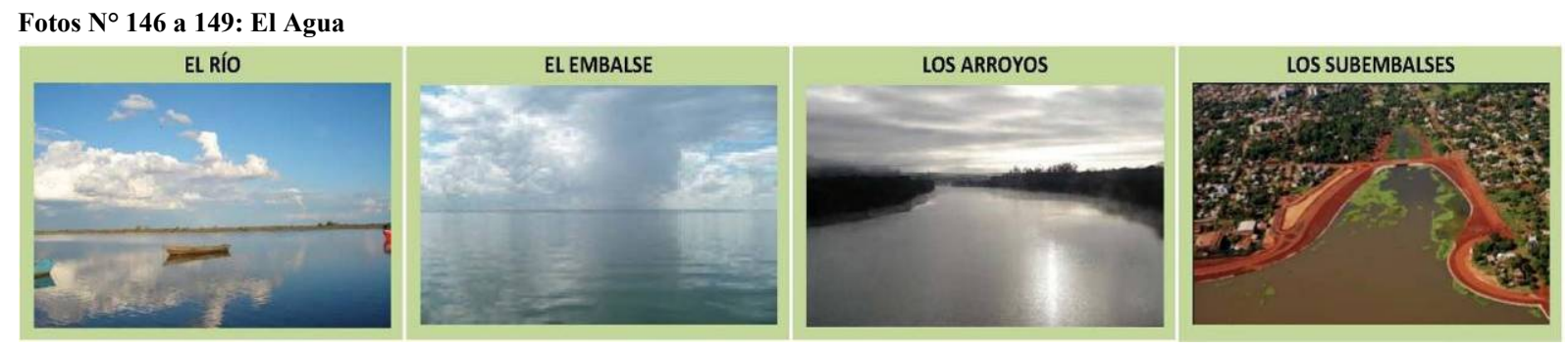

Fuente: Archivo fotográfico EBY

\section{B. Los Rápidos: 'itú' o arrecifes}

Estos accidentes naturales tienen un alto significado en la conformación del paisaje regional, su belleza natural alcanza hoy valor Patrimonial a escala mundial (Patrimonio Mundial de la Humani$d a d)$, como lo demuestra el caso de las Cataratas del Iguazú.

Desde el punto de vista del desarrollo cultural de la región, los itú o arrecifes, tuvieron además un alto significado simbólico y valor defensivo para las poblaciones originarias, conformándose en verdaderos límites para el avance de la conquista española y portuguesa, fundamentalmente los Saltos del Guaira y del Apipé sobre el río Paraná y el Salto Grande sobre el río Uruguay. 
"Esto le permitió a los grupos étnicos habitantes del hinterland ubicado entre los arrecifes mantenerse por un tiempo, sin ser sojuzgados por los españoles y portugueses. Sólo los jesuitas pudieron ingresar por tierra a las áreas dominadas por estos indígenas que desde las islas cercanas a los saltos contenían a los invasores. [...] sólo la naturaleza quedó como un obstáculo para remontar aguas arriba el río Paraná. [...] La cuestión sin resolución definitiva siguió siendo por mucho tiempo el pasaje por los 'itú' o arrecifes." (Levinton, 2010: 83)

En la actualidad, esos saltos han desaparecido por la presencia de las centrales hidroeléctricas de Itaipú, Yacyretá y Salto Grande, respectivamente. Sólo Yacyretá posee una esclusa que permite la navegación e Itaipú tiene una en estudio. Por eso es clave determinar el concepto a partir del cual debe interpretarse la obra dentro del proceso de resignificación de ese paisaje.
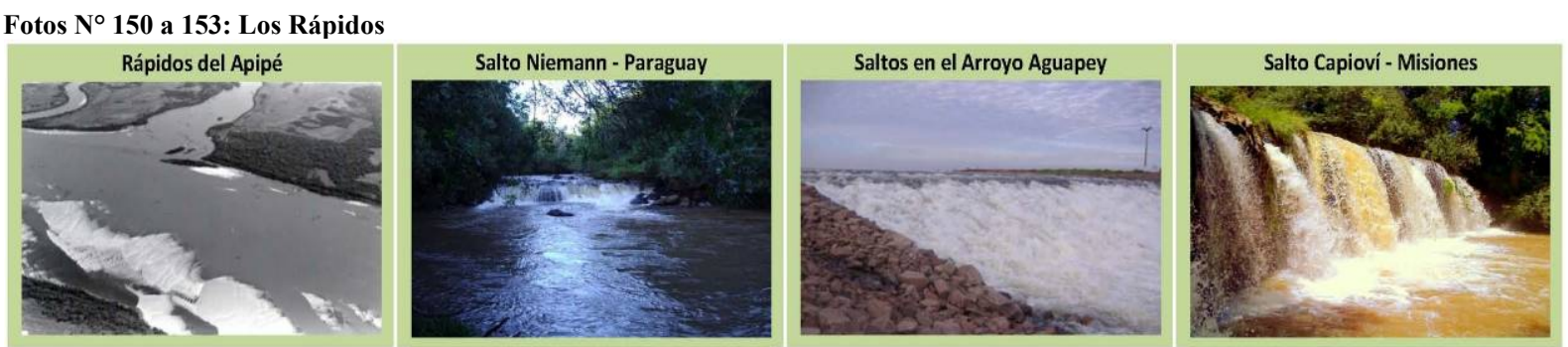

Fuente: Archivo fotográfico EBY.

\section{La Tierra: las islas y las zonas costeras}

La interpretación cultural del elemento 'tierra', también resulta de suma importancia para la modificación y reinterpretación del paisaje, en particular, las zonas costeras que son las inicialmente afectadas por este tipo de proyectos hidroeléctricos. Se manifiestan allí, la pérdida de humedales, la alteración de zonas de esteros, la desaparición de áreas de selva ribereña o de monte y la pérdida de sitios que han sido históricamente esenciales para el asentamiento de pueblos y ciudades.
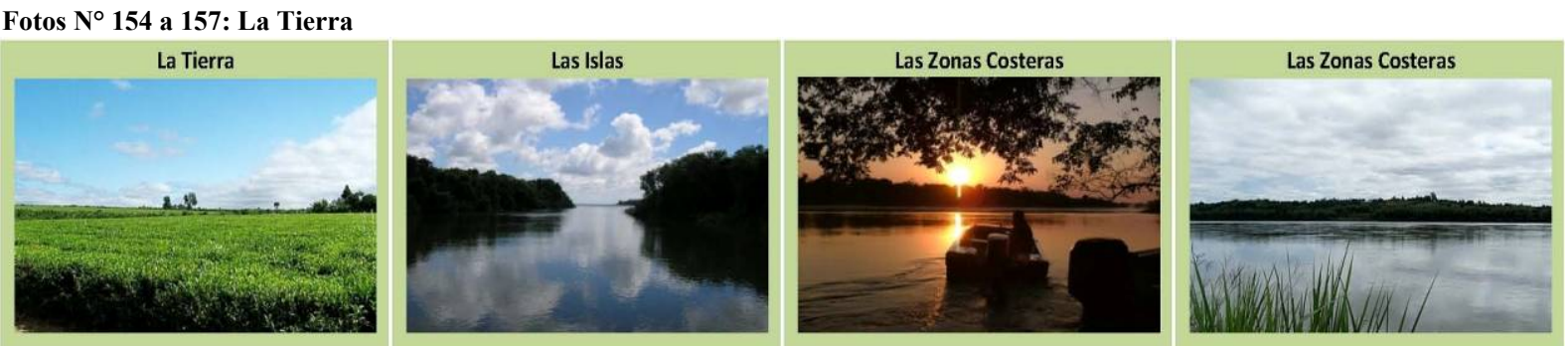

Fuente: Archivo fotográfico EBY.

Hablar de las zonas costeras, es hablar de la historia de la ciudad: "el gran invento de la humanidad, junto al lenguaje", según Lewis Mumford (1960). Los bordes fluviales y marítimos fueron asiento de la ciudad y eran interpretadas, según el contexto histórico, como de vinculación y complementariedad entre pueblos vecinos en tiempos de paz; o como puntos de expansión o zonas de frontera defensiva en tiempos de guerra; mientras que, el agua -un elemento fundamental para el desarrollo de los seres vivos y para la vida de una ciudad- adquirió para las antiguas culturas, también, un sentido religioso (entre otros, el Nilo, el Ganges, incluso el Paraná).

Por esos factores de disponibilidad de recursos, de dominación y aún de veneración, el hombre eligió las zonas costeras para asentarse, conformando verdaderas interfases que sintetizan la relación histórica cultura-naturaleza. La noción de interfase es superadora de las de límite o borde; así como, de las de nexo, 
o punto de convergencia; y aún, de espacio abierto o verde (público o privado). Esta noción proviene de la ecología urbana, ${ }^{88}$ que la describe como "[...] el punto de contacto (área y factor de integración) entre dos o más sistemas, representando así, el sitio de mayor intercambio de materia, energía e información entre esos sistemas” (Pesci, 1999: 52). “[...] Por eso puede indicarse que "[...] Si se detectan las interfases, se atiende lo esencial de los sistemas en interacción. Entrando por las interfases se está más cerca de reconocer prontamente la identidad y la complejidad de esos sistemas. Proyectar las interfases es proyectar lo esencial, el ADN de un territorio o de una ciudad" (Pesci, 2007: 32); y adentrarse en su análisis como archivo histórico de la relación cultura-naturaleza, es también consustancial a la noción paisaje.

En el área de estudio, hemos analizado en el capítulo II (ver parágrafo II.1.1), el significado que, para el pueblo guaraní, ha tenido este elemento natural, desde su interpretación cultural. Partiendo de la mítica 'Tierra sin Mal' (Yvy maraey) que “[...] acompaña siempre, o incluso sigue como una sombra, a los Guaraníes [...que] -con sus diversos avatares: el dramatismo exótico, el místico, el político, el ecológico- campea en los dos polos de un temario Guaraní que siempre parece repartido entre cuestiones territoriales y religiosas" (Calavia Sáez, 2004: 11); hasta las zonas urbano-costeras de los nuevos pueblos y ciudades, que han consolidado el vínculo con el río y a partir de él con la región.

En ese recorrido histórico, los espacios costeros del río Paraná y de sus arroyos afluentes, han conformado -desde la Cultura Guaraní hasta nuestros días- un paisaje caracterizado por áreas naturales de alta singularidad y culturales con fuerte identidad, dónde una intervención de la escala de Yacyretá, ha implicado una gran distorsión, que justifica una reflexión sobre sus efectos y sus significados.

Por otra parte, podemos señalar que cuando las modificaciones del territorio y del paisaje se producen no como producto de la decantación histórica del desarrollo de una determinada cultura, sino que se hacen en forma abrupta y con escasas posibilidades de asimilación por parte de los pueblos involucrados, aparece entonces el conflicto y también el desafío de reflexionar sobre las alternativas de cómo recomponer esas relaciones entre el hombre (cultura) y su medio (naturaleza), que delinearon un paisaje modificado en aras de intereses -nacionales y regionales; geopolíticos y de desarrollo- que exceden inicialmente su comprensión desde lo local.

Por eso la hipótesis de esta investigación parte de reconocer a las zonas costeras como interfases, es decir, como los lugares de mayor diversidad -biológica, económica y social- lo que nos permite abordar la conflictualidad de las modificaciones provocadas por la obra; y al hacerlo en términos de paisaje -incorporando la dimensión histórica y su significado- podemos, además, aproximarnos a la potencialidad de su resignificación.

\footnotetext{
${ }^{88}$ El concepto de interfase fue definido por Valerio Giacomini (1980/83) para Roma, en el marco del Programa MaB, UNESCO y desarrollado por la Fundación CEPA, para el Proyecto de Ecología Urbana del Sistema Urbano Pampeano para UNESCO, (CEPA 1983/85) y aplicado también por el autor, en tres proyectos en la Provincia de Río Negro (CFI-Fulco [Dir.] et al, 1993/96).
} 


\section{La Selva o 'el Monte'}

También se ha analizado la importancia de la selva o 'el monte', que según Crivos y Martínez (2000), para los Mbyá-Guaraní aparece como un escenario que condensa lo relativo al mundo natural.

"Tiempo y espacio míticos se actualizan en las actividades de las poblaciones Mbyá contemporáneas. La nostalgia del monte instalada en la memoria grupal, orienta los desplazamientos hacia un espacio todavía posible aunque cada vez más distante, que condensa aspectos materiales y simbólicos esenciales a la vida del grupo." (Crivos y Martínez, 2000: 1.269)

Fotos $N^{\circ} 158$ a 161: La Selva
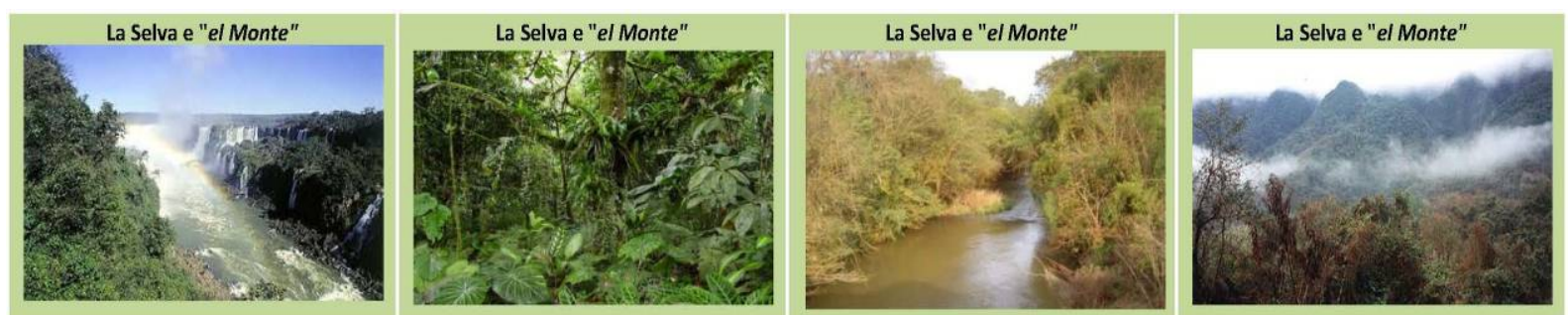

Fuente: Archivo fotográfico EBY.

Pero, este enorme espacio que domina el territorio, nunca fue un lugar prístino donde no interviene la acción transformadora del hombre. Desde lo tangible constituyó, en los lugares accesibles a orillas de ríos y arroyos, un ámbito ligado fundamentalmente al sentido de supervivencia y, desde lo intangible, alcanzó un sentido mítico que, en cierto modo, aún para las pequeñas comunidades aborígenes actuales, como componente esencial de las referencias a la 'tierra sin mal'.

\section{E. Los Esteros}

El paisaje de esteros está determinado generalmente, por una morfología de terreno plana, con una pendiente de llanura, la presencia de cuerpos de agua como una lámina permanente y sistemas de lagunas, cuya caracterización ecológica está determinada principalmente por una vegetación cerrada siempre verde y asociada a los complejos húmedos de laguna y una muy alta diversidad de aves y fauna terrestre y acuática. Son, en general, sitios de difícil accesibilidad, pero se caracterizan por tener usos antrópicos determinados principalmente por diversas haciendas para cría de ganado y caseríos costeros que se distribuyen por el conjunto de la unidad de ambiente y paisaje.

Fotos $N^{\circ} 162$ a 165: Los Esteros
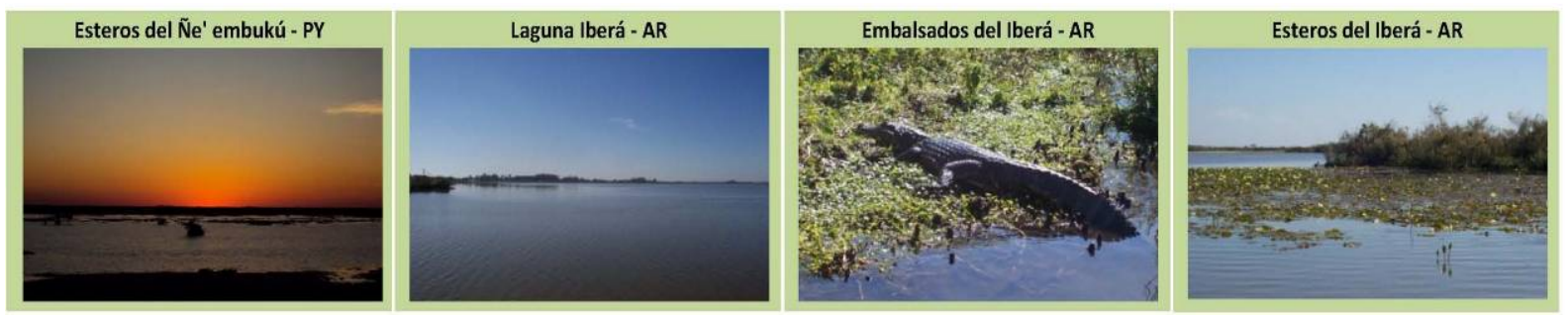

Fuente: Archivo fotográfico EBY.

En el área de estudio, existen zonas de esteros en ambas márgenes del río Paraná, dónde Yacyretá adquirió y estableció áreas con status de conservación en concepto de reservas compensatorias por territorio inundado, que cuentan con planes de manejo y han sido transferidos a los organismos públicos competentes. Siendo el área de mayor significación los Esteros del Iberá en la Provincia de Corrientes, 
con cinco unidades de conservación implementadas por Yacyretá y dónde, además, un área de 24.500 hectáreas centrada en la Laguna Iberá fue designada Sitio Ramsar en 2002. Tanto el Iberá como los demás esteros representan cauces abandonados del río Paraná, tallados y remodelados por éste en tiempos remotos, que poseen cordones arenosos que se formaron con materiales de arrastre aluvial del río. ${ }^{89}$

\section{F. La Ruina}

Son los elementos culturales que como fragmentos de pueblos o ciudades del pasado -junto a las muestras etnográficas que son rescatadas y puestas en valor durante la ejecución de este tipo de emprendimientos- conforman testimonios tangibles de gran valor como rescate de lo intangible o 'memoria' colectiva de los pueblos que, traducido en términos de paisaje, representan un placer que, como sostuvo Simmel: "[...] consiste en el hecho de que una obra del hombre va sentida en sustancia como un producto de la naturaleza [...]. La ruina, dice Simmel, se inserta en el paisaje circundante, se adapta como el árbol y la piedra." (Milani, 2007: 194).

En nuestro caso de estudio, 'la ruina' es el testimonio tangible de la cultura de la región histórica, representada por la red de reducciones jesuíticas que fueron abandonadas por los indígenas en las primeras décadas del siglo XIX, producto de los proyectos de colonización derivados del proceso de creación del Territorio Nacional de Misiones en el año 1881, que hizo surgir "[...] nuevos caminos y nuevos pueblos, al costado de los cuales quedaron mudos los pueblos viejos convertidos oficialmente en 'ruinas jesuiticas' [...]” (Snihur, 2007: 232) y que, tal como lo describe Armani:

"Desiertas, cayeron en una rápida degradación. La selva subtropical, derrotada antes por los misioneros y los guaranies, volvió por sus fueros sobre la obra de los hombres; se adosó a los muros de las iglesias, edificios públicos y casas, y los envolvió hasta destruirlos” (Armani, 1998: 210).

Estas Ruinas, junto a la importante muestra etnográfica diseminada y rescatada en todo este territorio, son los testimonios tangibles de mayor valor que perviven de ese período de contacto de la Cultura Guaraní con las misiones jesuíticas.

\footnotetext{
${ }^{89}$ La vegetación propia de los diferentes ambientes de la eco-región presenta comunidades de pirí (pirizales) y vegetación palustre arraigada; embalsados con camalotes y otros vegetales que forman islas flotantes a la deriva; pajonales en cañadas y bañados; prados anegadizos en bancos de arena; isletas (llamadas en la región 'mogotes') de bosque constituido por especies de la Selva Paranaense, como timbó, lapacho y laureles; y palmares de yatay. La riqueza faunística de la eco-región es alta, compartiendo especies paranaenses y chaqueñas. Entre los reptiles existen poblaciones importantes de yacaré ñato (u overo) y negro; varias tortugas acuáticas; ofidios coma la boa curiyú y la ñacaniná de bañado. Las aves ligadas a los esteros y ámbitos palustres son numerosas, debiendo mencionarse las siguientes: el yabiyú, cigüeña común, tuyuyú, cuervillos de cañada, espátula rosada, carau, garzas, diversos patos, gallaretas, gallinetas, pollas de agua y el chajá. Entre las diferentes especies de pájaros palustres se encuentran los varilleros negros, congo, federal, dragones y los capuchinos. En las zonas altas se encuentra el ñandú, colorada, coludo grande y cachilo ceja amarilla; en las zonas bajas, el coludo chico y el cachilo canela. Las rapaces están representadas por el caracolero, aguilucho pampa, gavilán planeador y aguilucho alas largas. El guacamayo celeste, que habitaba los palmares de yatay, se ha extinguido. Entre los mamíferos se hallan poblaciones de especies amenazadas como el aguará-guazú y el ciervo de los pantanos. Otras especies características de la región son, lobito de río, zorro pampa, hurón mediano, carpincho, coipo, zorro del monte, guazuncho o birá y el mono carayá. Subsisten, aunque disminuidas, poblaciones de gato montés, gato moro y tamandúa (u oso melero).
} 
“[...] Hoy, los restos de las Reducciones paraguayas se han convertido en reliquias arqueológicas, testimonio de la singular historia del 'Estado' jesuita de los guaranies” (Armani, 1988: 210).

Estos restos de urbanismo jesuita-guaraní, inspiran hoy un respeto que está siendo apoyado por UNESCO para su recuperación. A este testimonio tangible se le suma también lo intangible, derivado del imaginario colectivo creado por aquellos primeros pobladores inmigrantes europeos del mencionado proceso de colonización del territorio misionero.

"[...] Este nuevo poblador desconocía la historia de la región [...] Entonces, el vacio se completaba con el componente fantástico y mágico [...] dónde las ruinas de los pueblos y el territorio adquirieron un matiz surrealista. La explicación popular se volvió así fantástica y las ruinas jesuiticas pasaron a ser un lugar mágico, un universo paralelo ubicado al costado del camino moderno de los pueblos nuevos [...]. Las ruinas eran -y son- un sitio que despierta cierto temor y reverencia, del que puede surgir la bendición o alguna terrible maldición. Han surgido de ese modo, como creación del imaginario colectivo popular, un gran acervo cultural consistente en mitos y leyendas fantásticas [...] muy distante de la lectura y discursos académicos, pero no menos real en cuanto manifestación socio-cultural." (Snihur, 2007: 235).

Fotos No 166 a 169: La Ruina
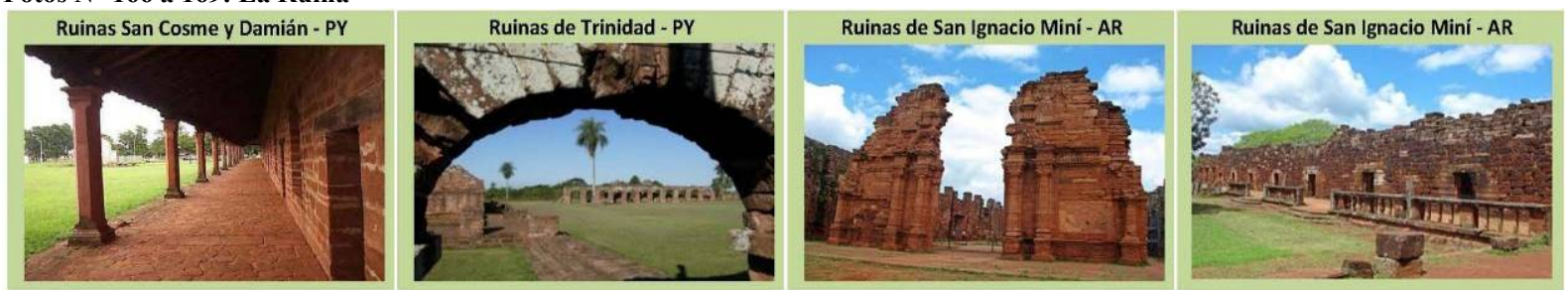

Fuente: Archivo fotográfico EBY.

\section{G. La Obra}

En un emprendimiento hidroeléctrico a gran escala, 'la Obra' está representada por el conjunto de construcciones que la conforman: la central de generación, la presa, los nuevos puentes y caminos, las obras de protección costera y de recomposición urbano-ambiental de pueblos y ciudades en el entorno del proyecto. Como hemos analizado en el tercer Capítulo de esta investigación, esto representa una gran transformación del paisaje a escala local y regional, planteando nuevas relaciones y, consecuentemente, nuevos significados en el territorio.

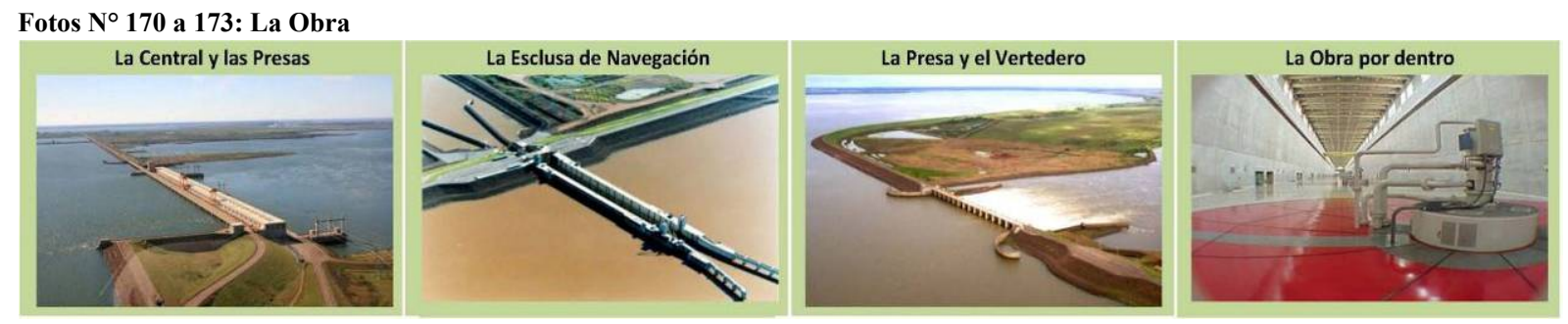

Fuente: Archivo fotográfico EBY.

\section{H. Las Infraestructuras: el puente, las rutas, caminos y los accesos, los puertos}

Puentes, caminos, puertos, han adquirido gran significación histórica, en un territorio caracterizado por una accidentada topografía, selvas y caudalosos ríos y arroyos. Este tipo de infraestructuras también son claves en un emprendimiento hidroeléctrico a gran escala, porque su concreción implica profundizar esas limitantes de base y, consecuentemente, conlleva la necesidad de su reinserción en unas escalas y proporciones que orientan una nueva significación. 


\section{H.1. Puentes, Caminos y Accesos}

Los puentes adquirieron importancia ya desde el período jesuítico, aún cuando fueron excepcionales dado que, en la mayoría de los casos, los arroyos eran cruzados por los sitios menos profundos.

"Uno de los más relevantes fue el construido sobre el arroyo Chimiray, permitiendo la comunicación de los pueblos de Apóstoles, Concepción, Santa María la Mayor, Mártires y San Javier, con las estancias que poseían en la cuenca del río Aguapey. Sus restos aún persistían a principios del siglo XX, momento en que fueron relevados minuciosamente por Leopoldo Lugones, quedando plasmada la descripción en 'El Imperio Jesuítico'. La madera era el elemento utilizado para la construcción de puentes, mientras que las piedras eran utilizadas para los muros de contención de los terraplenes de acceso. Como excepción cabe mencionarse el puente construido integramente en piedra sobre el curso del río Igarupá [...]." (Snihur, 2007: 113).

En la actualidad los puentes -articulados con los caminos y rutas derivados de la consolidación moderna de los antiguos “[...] 'caminos reales' [que] permitían la comunicación de los pueblos o reducciones entre sí” (Snihur, 2007: 108)- son los únicos que permiten la comunicación terrestre de toda esta región, integrada por Paraguay y parte de la Argentina y Brasil.

El mismo proyecto Yacyretá ha construido y está construyendo más de cuarenta puentes, con sus caminos rurales, rutas provinciales y nacionales y accesos viales y/o ferroviales a los pueblos y ciudades localizadas dentro de su área de incidencia. Aún el conjunto de grandes obras conformado por la misma central hidroeléctrica, esclusa, sistema de presas y puentes secundarios, constituyen una especie de 'gran puente' que une los territorios de los dos países.

Quizás, el de mayor significación histórica, estética y funcional es el 'Puente Internacional San Roque González de Santa Cruz' ${ }^{90}$, que es un puente ferro-vial construido sobre el río Paraná, que comunica a las ciudades de Posadas (AR) y Encarnación (PY) y que tiene una longitud total de $2.550 \mathrm{~m}$., con un puente central de $579 \mathrm{~m}$. El mismo fue inaugurado en 1990, obteniendo el premio internacional "Puente de Alcántara" a la obra pública más destacada del período (1989-1990) y que desde lo intangible, puede ser reinterpretado como nuevo símbolo de integración.

\section{H.2. Los Puertos}

Ya desde el periodo jesuítico, “[...] en los pueblos ribereños del río Paraná, prevalecía la comunicación fluvial. [...] las reducciones de Candelaria, San Ana, Loreto, San Ignacio, Corpus, Itapúa, Trinidad y Jesús tuvieron cada una sus respectivos puertos [...] El río Paraná unía [además] a las reducciones guaraníes con las ciudades de Corrientes, Santa Fe y Buenos Aires [...]" (Snihur, 2007: 108), empleándose complementariamente, una ruta terrestre que bordeaba el río, para salvar los Rápidos del Apipé. Posteriormente, con el avance de la consolidación de los caminos y puentes internos, sumado a las históricas dificultades que para la navegación representaban los mencionados rápidos, varios de estos puertos, quedaron reducidos a un transporte entre comunidades vecinas. Solo los puertos de San-

${ }^{90}$ El nombre del puente se debe al Padre jesuita, fundador de varias reducciones, entre ellas, la de Encarnación, que hoy corresponde a las actuales ciudades de Posadas y de Encarnación. 
ta Ana y Posadas, sobre la margen izquierda y el de Encarnación, sobre la margen derecha, mantuvieron cierta relevancia, y son los que han sido repuestos por Yacyretá.

Fotos $N^{\circ} 174$ a 177: Las Infraestructuras
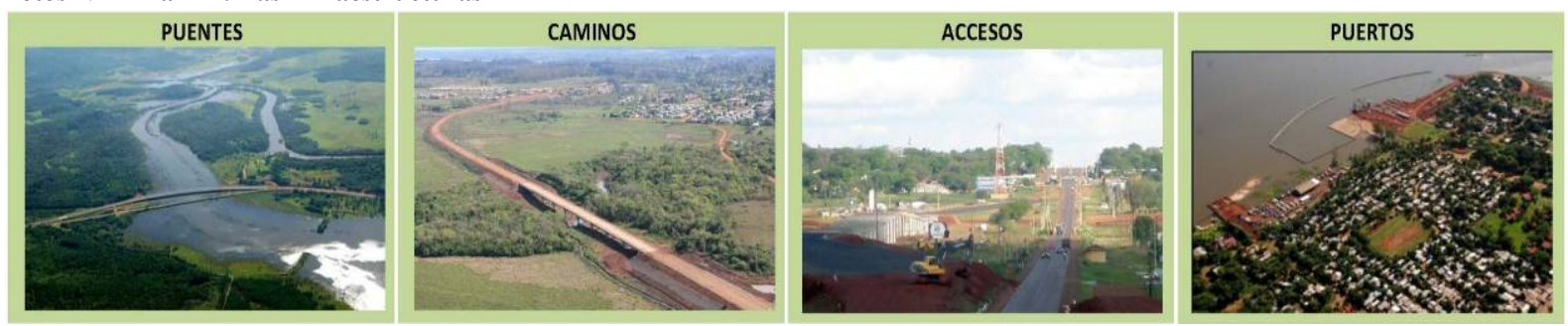

Fuente: Archivo fotográfico EBY.

\section{El Hábitat Humano: las ciudades, los pueblos, el entorno rural}

Desde el punto de vista del análisis de impactos, son las poblaciones costeras las principalmente afectadas por estos proyectos, ya sea en su estructura económica-productiva, habitacional y social, cultural, en sentido amplio. Al respecto, Garnier propone que esta suerte de desestructuración del territorio y de la ciudad debe ser analizada bajo su doble aspecto funcional y formal, y sostiene que:

"[...] El análisis de la evolución de la imagen urbana [...] hace necesaria, pues, una descomposición en sus elementos morfológicos, según métodos utilizados, por ejemplo, por Kevin Lynch. Este último descompone la imagen de la ciudad en cinco tipos de elementos: las trayectorias, los bordes, los barrios, los nudos y los hitos. Nos inspiraremos en este tipo de procedimientos para entender los mecanismos de desestructuración de la ciudad [...], aún cuando lectura de Lynch no permite, por sí misma, descubrir los motivos sociales y económicos de las transformaciones espaciales. Nuestro enfoque será, pues, esencialmente empírico." (Garnier: 1994: 102).

Dentro del contexto de una gran obra de infraestructura como Yacyretá, ello incluye, además, un profundo proceso de resignificación de sitios históricos (como la Bajada Vieja o Bahía El Brete, en Posadas); de edificios y monumentos (como las estaciones ferroviarias de Posadas y Encarnación, y del Soldado Desconocido en Encarnación); de rescate de la memoria (como la realizada para edificios y la Zona Baja Comercial de Encarnación).

Fotos $N^{\circ} 178$ a 181: EI Hábitat Humano
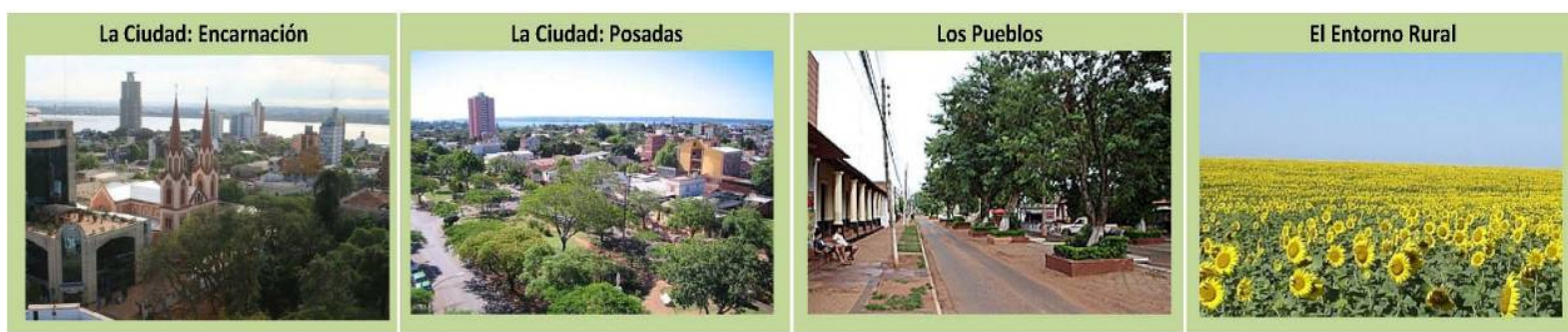

Fuente: Archivo fotográfico EBY.

Pero además, las nuevas relaciones que aporta la articulación fluvial (nuevos puertos y esclusa de navegación), con la terrestre (carretera internacional conformada por el conjunto de presas y las nuevas infraestructuras ferro-viales), puede generar nuevas condiciones de desarrollo sobre la base de la exportación de productos primarios -soja y madera- y del turismo, aportando desde esas nuevas relaciones una nueva escala de significación para el territorio, las ciudades y los barrios. 


\section{IV.1.2. Interpretación del Proyecto como Paisaje a escala 'Área'}

Las características generales del área de estudio a escala 'Territorio', permiten delinear diferentes Áreas de gestión paisajística, que pueden ser interpretadas con esa finalidad, como Unidades de Ambiente y Paisaje (UAP), dónde el recorrido y la percepción otorgan sentido a la noción de 'unidad'.

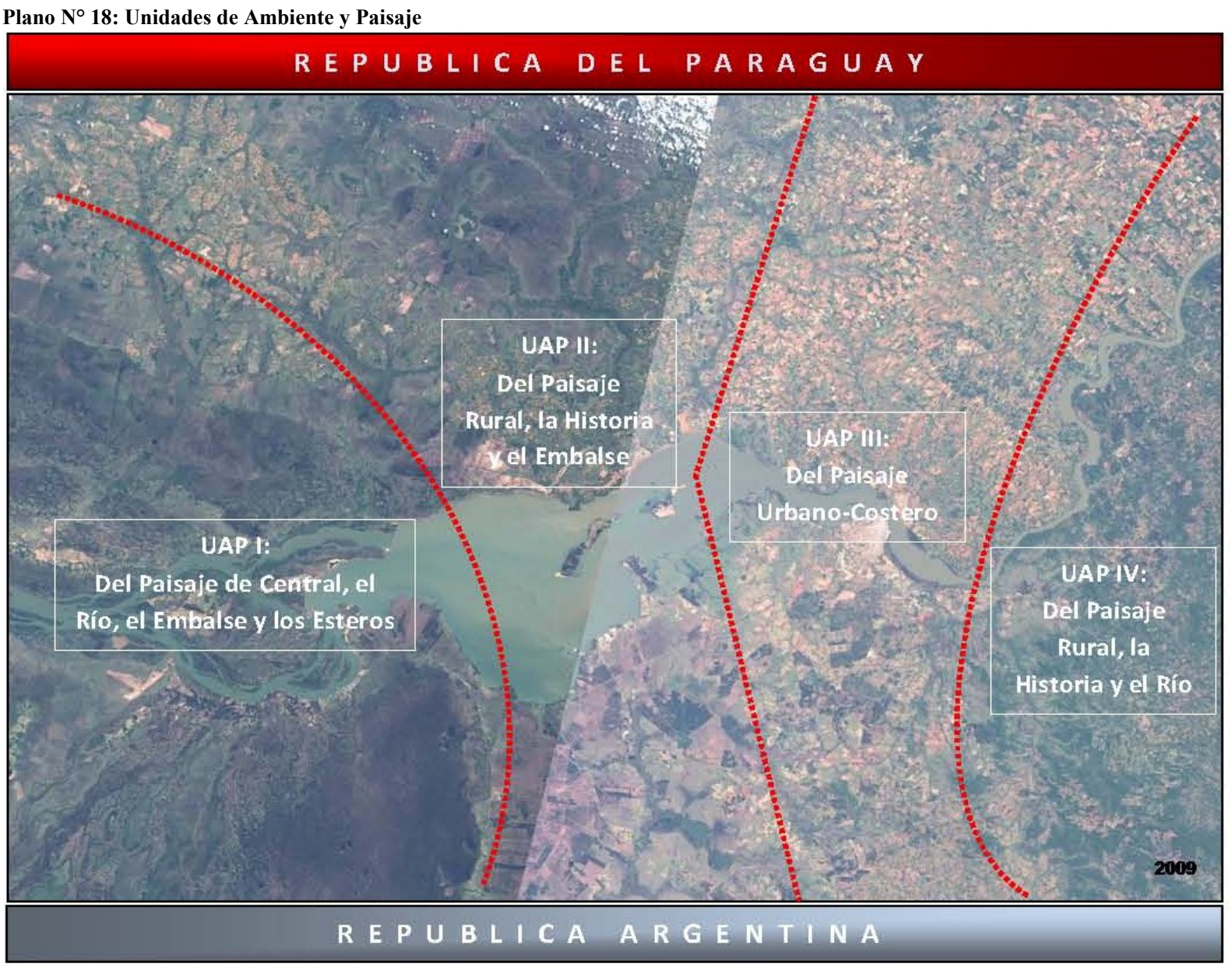

Fuente: Elaboración propia.

El gráfico muestra que una zonificación a esta escala de interpretación, permite identificar cuatro áreas caracterizadas de índole binacional, que actúan como matrices de paisaje.

\section{UAP I: Área del Paisaje de la Represa}

Con el sistema presa-puente como vínculo, en esta Unidad de Ambiente y Paisaje, pueden identificarse cinco conjuntos de elementos que definen el sentido de unidad: 1) el conjunto conformado por la central hidroeléctrica, las presas, la esclusa de navegación y los puentes, que actúan como vínculo entre ambas márgenes; 2) las ciudades aguas abajo de la represa: Ayolas, en Paraguay, e Ituzaingó en Argentina, con sus playas y su historia de ocupación y transformación; 3) el lago (aguas arriba), el río (aguas abajo) y los arroyos; 4) el sistema de reservas naturales, las islas y los esteros; 5 ) la costa y la selva ribereña. Los cuatro últimos, verificables en ambas márgenes. 


\section{UAP II: $\quad$ Área del Paisaje Rural, la Historia y el Embalse}

Con el lago como vínculo, pueden identificarse en cada margen de esta UAP, cinco conjuntos de elementos que definen el sentido de unidad. Los tres primeros en la margen paraguaya: 1) el conjunto de obras de protección del valle del arroyo Aguapey, el arroyo, el campo, la selva, las áreas recuperadas y las áreas de reserva; 2) las ruinas de San Cosme y Damián, la iglesia jesuítica; 3) la reserva indígena de Pindó. Los dos conjuntos restantes, en ambas márgenes: 4) los pueblos rurales, la zona rural, las rutas y los caminos; 5) el embalse, la selva, los arroyos, las costas, playas y dunas.

\section{UAP III: $\quad$ Área del Paisaje Urbano-Costero}

Con el Puente Internacional y el agua como vínculo binacional, esta UAP representa el objeto específico de estudio de esta investigación, dónde pueden identificarse cuatro conjuntos de elementos que definen el sentido de unidad: 1) las ciudades con sus nuevas zonas costeras, espacios públicos, puertos, zonas comerciales, nuevos barrios, sitios y monumentos históricos; 2) el embalse, los subembalses, los bosques en galería y las reservas o parques urbanos; 3) los nuevos accesos ferro-viales, rutas y puentes; 4) el entorno periurbano y rural.

\section{UAP IV: $\quad$ Área del Paisaje Rural, la Historia y el Río}

Con el río Paraná como vínculo binacional, en esta UAP, se identifican cinco conjuntos de elementos que definen el sentido de unidad: 1) los pueblos y ciudades del interior, los nuevos puentes, las rutas, caminos y accesos; 2) la red de ruinas jesuíticas; 3) las áreas rurales, parte del sistema de áreas de reserva natural; 4) el río, el puerto de Santa Ana (AR) y los arroyos; 5) la selva paranaense, los bosques en galería y la serranía.

Todos o parte de los conjuntos de elementos que definen el sentido de cada Unidad de Ambiente y Paisaje, pueden ser verificados en cada ámbito territorial específico, que al sumarle la presencia del paisano, como integrante del país, otorgan a los mismos el sentido antropológico de 'Lugar'. Esta es la verificación que se realiza en la tercera parte de esta interpretación del Proyecto en términos de Paisaje, en las ciudades intervenidas, que son las que conforman las áreas metropolitanas de Posadas y Encarnación.

De todas maneras, antes de efectuar dicha verificación, se presentan a continuación unos catálogos síntesis de cada UAP, y en el parágrafo IV.1.2.2 del presente apartado, se describe la potencialidad de desarrollo de la UAP III, desde una visión integral del ordenamiento territorial realizada para insertar los proyectos urbanos del Plan de Terminación de Yacyretá (PTY), que incluye las tres dimensiones de análisis: ecológica-ambiental; geográfico-urbanístico; histórico-cultural 


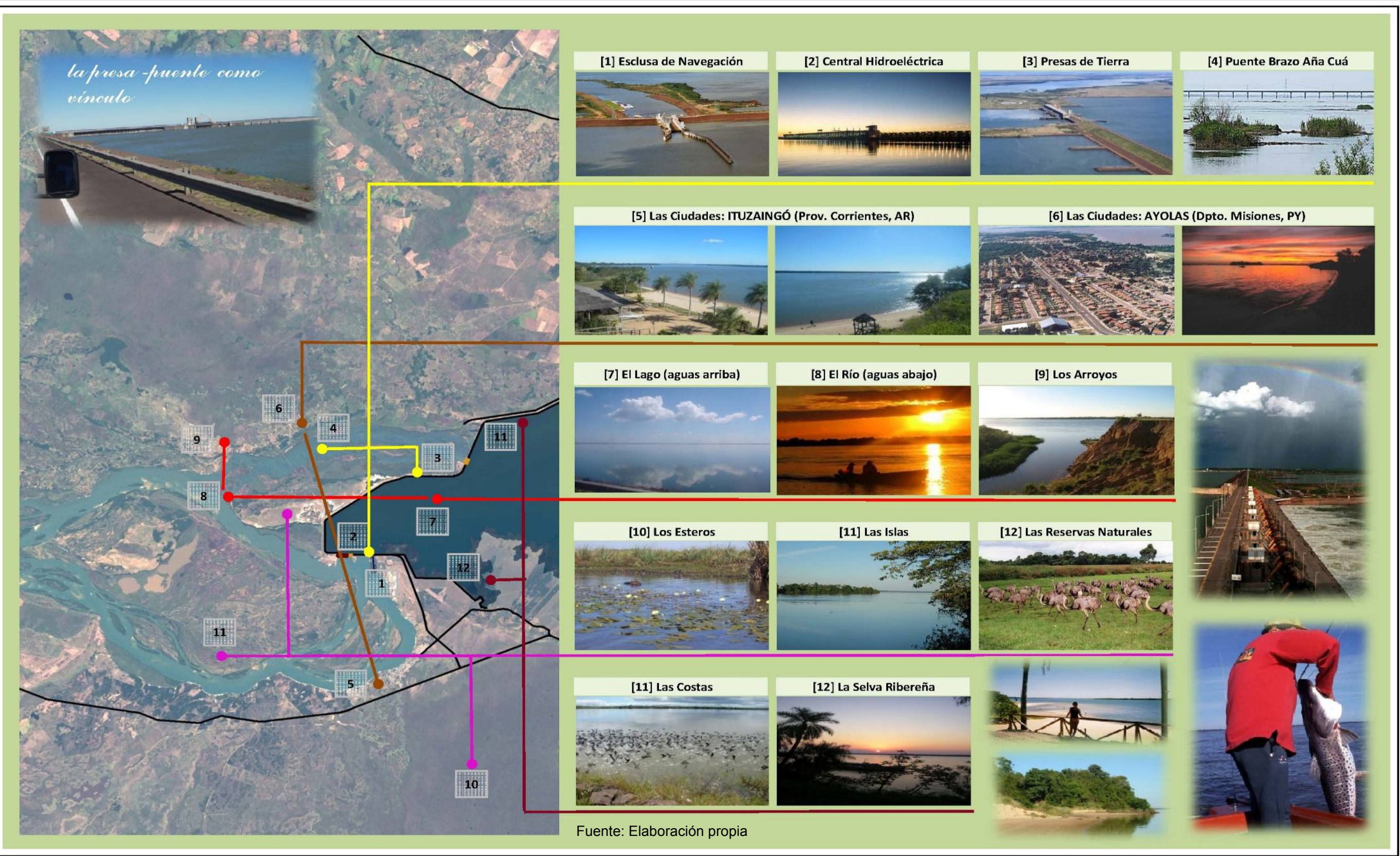




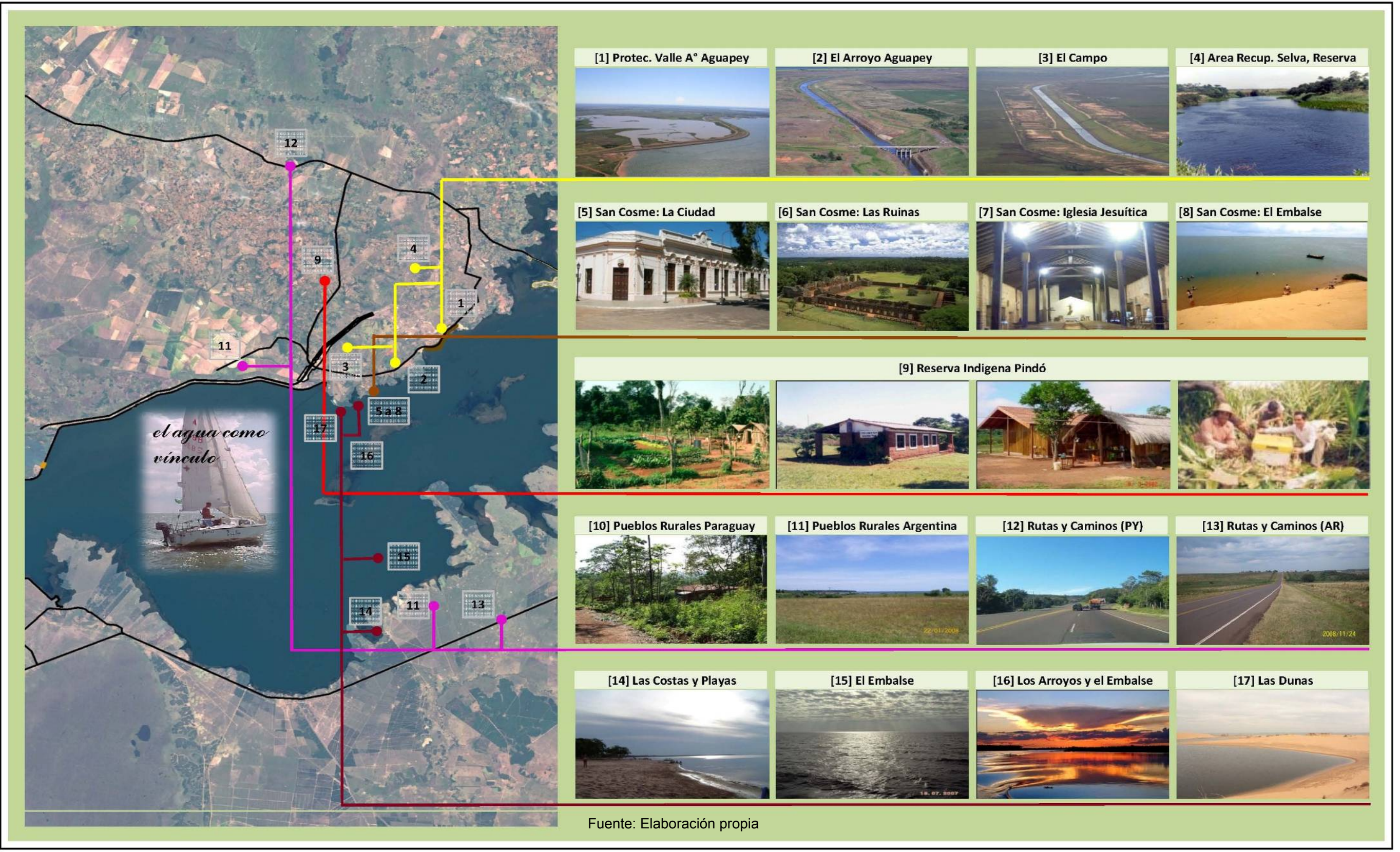




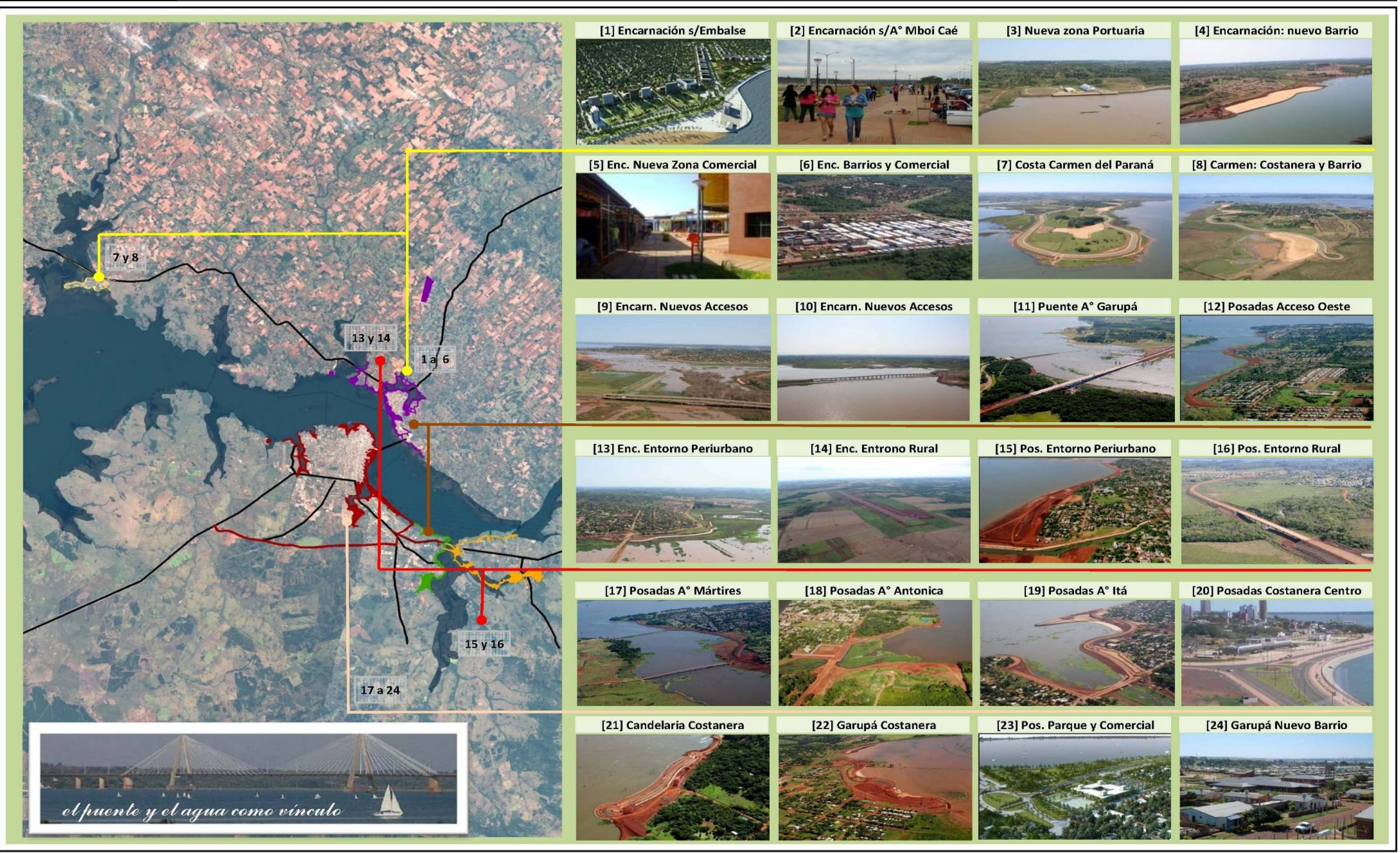

Fuente: Elaboración propia 


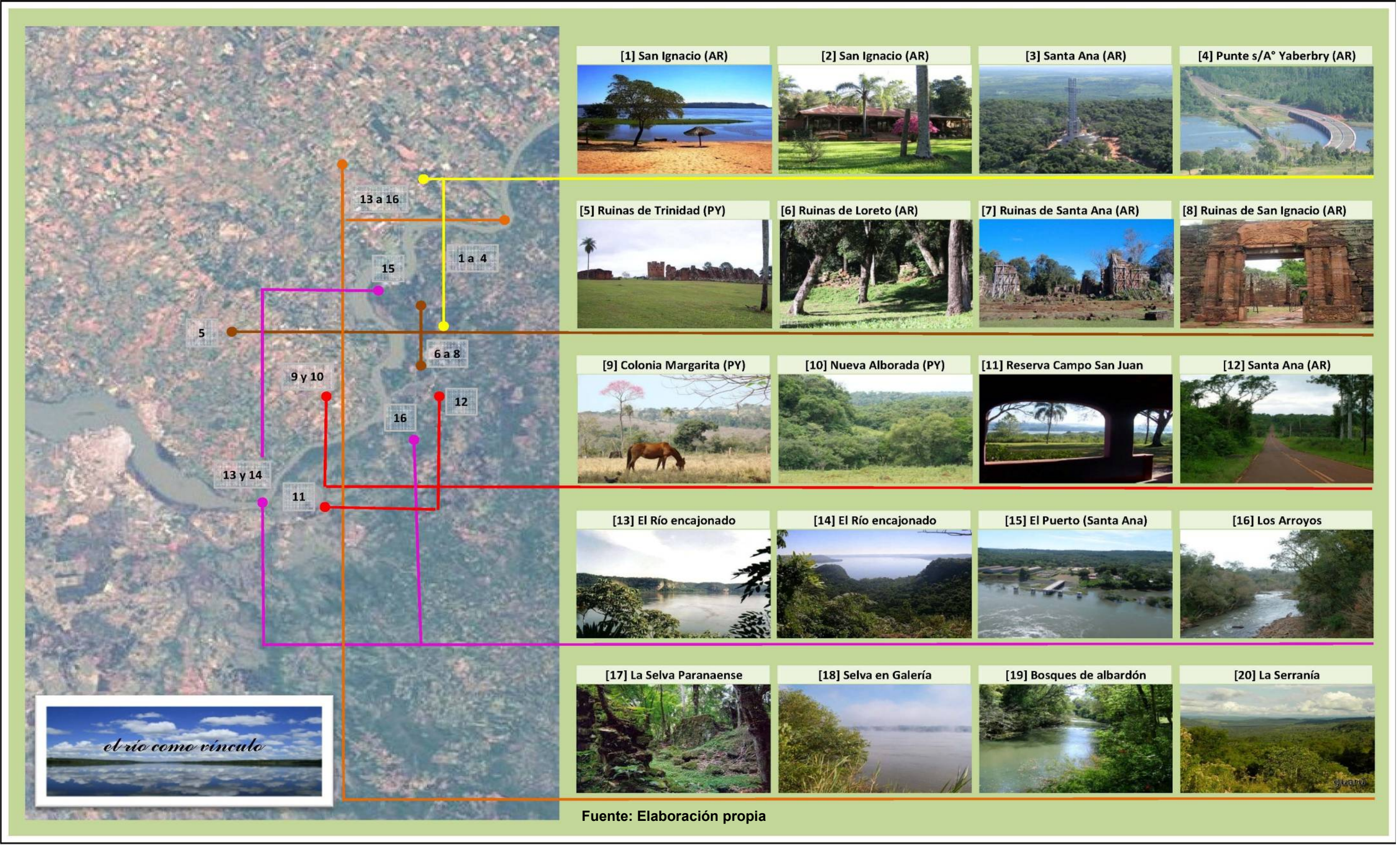




\section{IV.1.2.1. Las Zonas Urbano-Costeras desde la perspectiva Metropolitana}

El sistema de asentamientos urbanos de las áreas metropolitanas de Posadas (Provincia de Misiones, República Argentina) y de Encarnación (Departamento de Itapúa, República del Paraguay), ofrecen la posibilidad de pensar en un territorio integrado, a partir de consolidar un modelo de ordenación que contemple el crecimiento diferenciado de esas áreas, tanto en función de sus propios procesos de urbanización dónde "[...] en Argentina el 11 por ciento del territorio está urbanizado o en proceso de urbanización, [y] en Paraguay ese valor es solo del 3 por ciento" (Morello et al., 2004: 99), como por las características intrínsecas del área geográfica de sus respectivas implantaciones.

\section{A. El Área Metropolitana de Posadas (AMeP)}

El área del gran Posadas, de mayor altura respecto del nivel del río Paraná que el área de Encarnación, favoreció la consolidación de los sectores urbanos en torno a la costa del río, sobre el eje definido por la Ruta Nacional $N^{\circ} 12$, hacia el norte, incluyendo en su proceso de 'metropolización' a barrios externos como el caso de Miguel Lanús o el complejo habitacional de Yacyretá, Nuestra Señora del Rosario (A-3.2, con 974 viviendas) y a las ciudades de Garupá, incluyendo al complejo habitacional Fátima de Yacyretá (A-3.1, con 1.374 viviendas) y Candelaria.

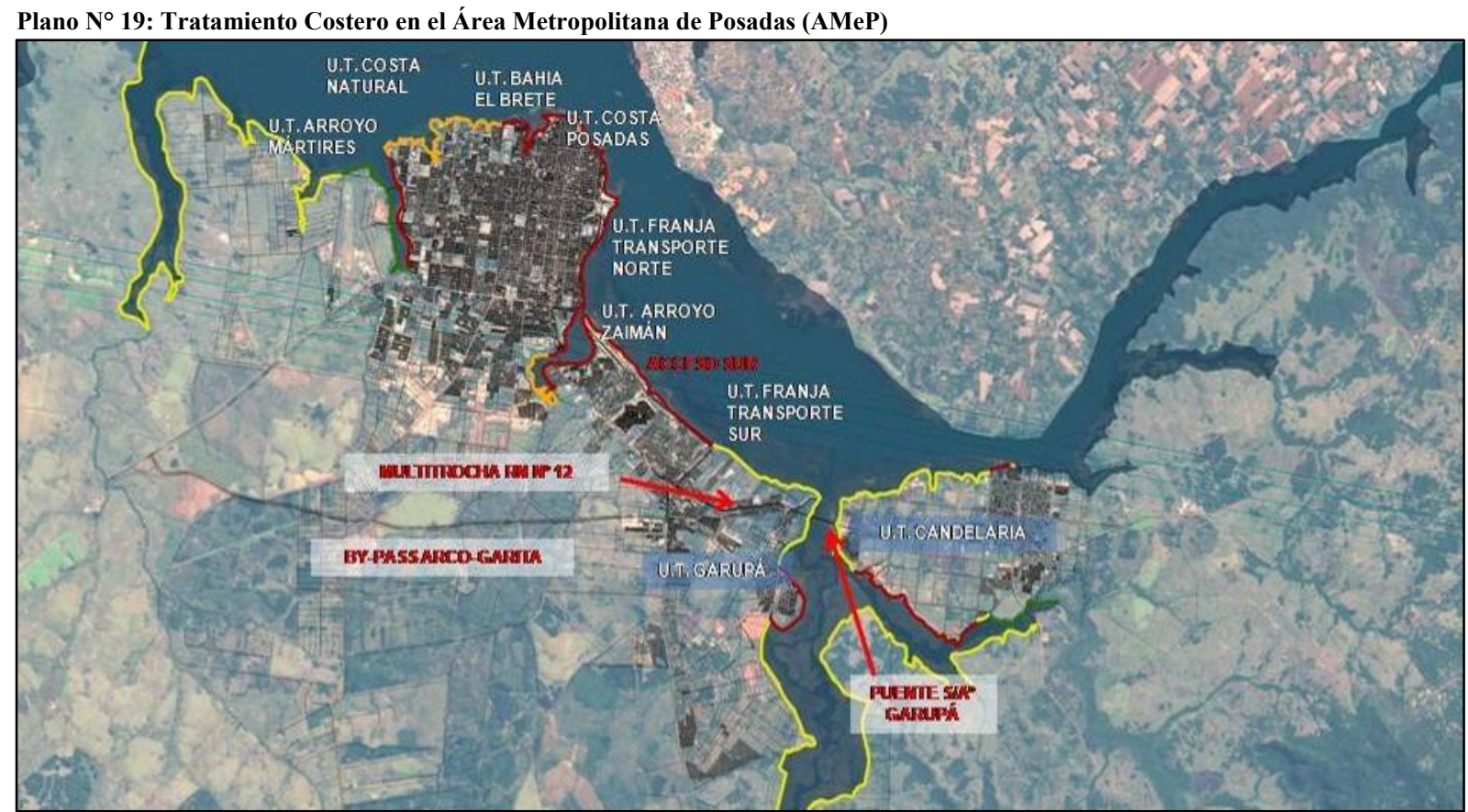

Fuente: Entidad Binacional Yacyretá, 2010.

En su última fase de crecimiento, durante la primera década de 2000, la periferia urbana ha avanzado como 'mancha de aceite' hacia el sur, favorecido por diferentes barrios con más de seis mil viviendas construidas por el Instituto Provincial de Desarrollo Habitacional de la Provincia de Misiones (IPRODHA) y también por Yacyretá, con sus complejos habitacionales Nueva Esperanza (A-4, con 
1.664 viviendas) y San Isidro (con 1.584 viviendas), ocupando tierras antes destinadas a la actividad hortícola, rural y forestal.

El sistema urbano-costero de incidencia de Yacyretá, en territorio misionero, se completa con tres pequeñas ciudades localizadas hacia el norte, que tienen carácter de centros externos históricoproductivos: Santa Ana, San Ignacio y Loreto, que poseen puerto e importantes ruinas jesuíticas.

\section{B. El Área Metropolitana de Encarnación (AMeE)}

El área de Encarnación, con una planta urbana cinco veces menor que la del gran Posadas, se localiza sobre la margen derecha del río Paraná, en zonas más bajas y sujetas históricamente a inundaciones periódicas, que fueron determinando su crecimiento sobre dos ejes.

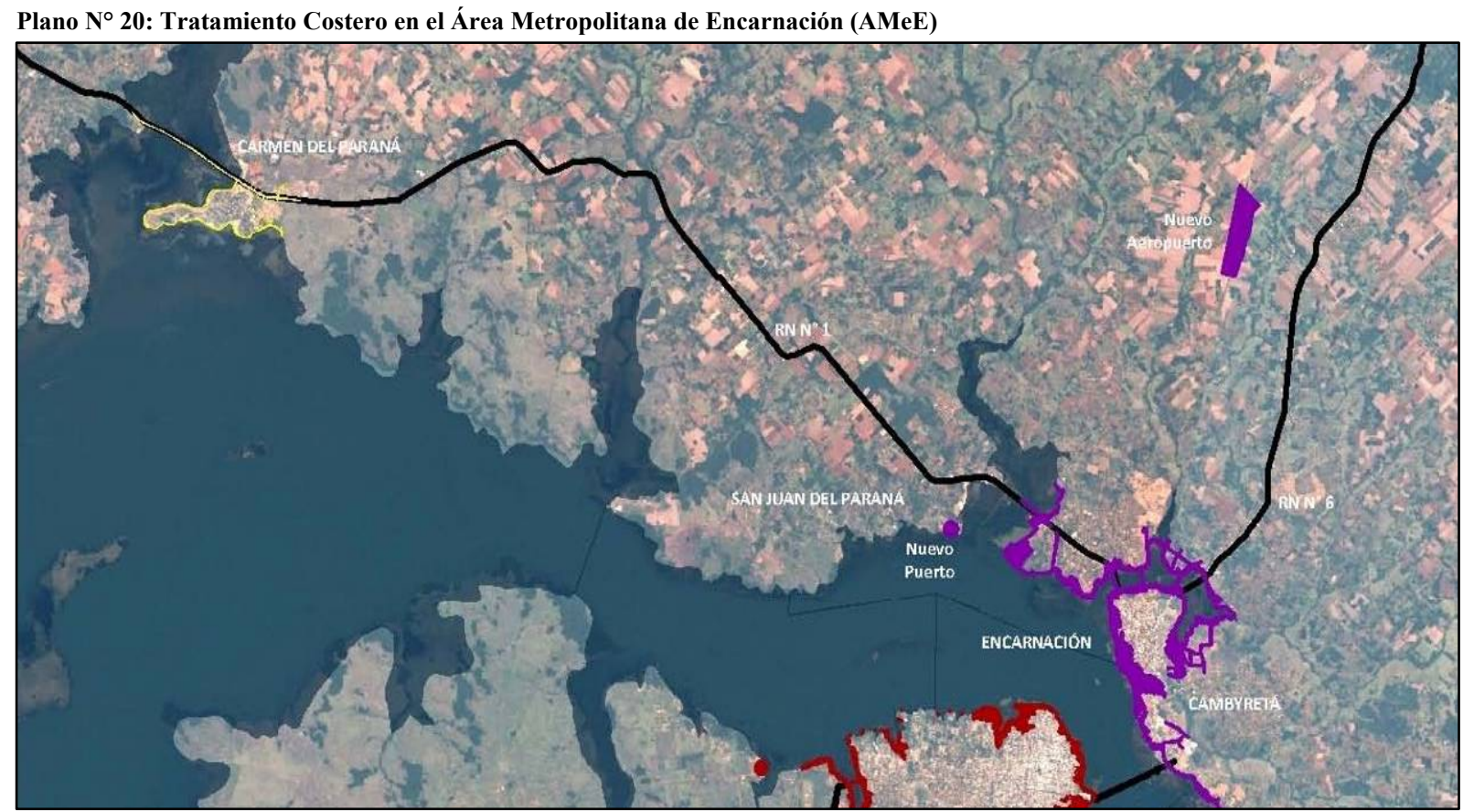

Fuente: Entidad Binacional Yacyretá, 2010

El primero, con centros urbanos más alejados de la costa, sobre la Ruta Nacional $N^{\circ} 1$ en sentido hacia Asunción (Capital del Paraguay), incluye a barrios externos de Encarnación como Mboi Caé Norte e Itá Paso (incluyendo al barrio homónimo de 674 viviendas construidas por Yacyretá), y a las ciudades de San Juan y Carmen del Paraná, localizada a 33 kilómetros de Encarnación.

El segundo eje se desarrolló hacia el interior en sentido Norte y en torno a la Ruta Nacional $\mathrm{N}^{\circ} 6$, hacia Ciudad del Este, en zonas más altas y en torno a los numerosos arroyos que surcan el territorio paraguayo, incluyendo barrios externos de Encarnación, como Santa María y a la ciudad de Cambyretá, incluyendo los complejos habitacionales de San Francisco (88 viviendas) y Arroyo Porá (1.544 viviendas), construidos por Yacyretá. 


\section{IV.1.2.2. Lineamientos para el Área Metropolitana de Posadas (AMeP)}

El aporte para esta zona se realiza en términos de Lineamientos de Ordenación y Gestión Territorial que abarca a la denominada Área Metropolitana de Posadas (AMeP), e involucra a las ciudades y municipios de Posadas, Garupá y Candelaria.

Estos Lineamientos proponen elementos para analizar la construcción de una política urbana para ese territorio, a partir del impulso de las obras y acciones de la EBY y en función de aprovechar los efectos positivos de las transformaciones urbano-territoriales que las mismas inducen $y$, en este sentido, representan "disparadores" en términos de directrices estratégicas de desarrollo sustentable para la gestión, tanto a escala municipal, como metropolitana y microregional. ${ }^{91}$

Plano $\mathrm{N}^{\circ}$ 21: Lineamientos para el Área Metropolitana de Posadas (AMeP)

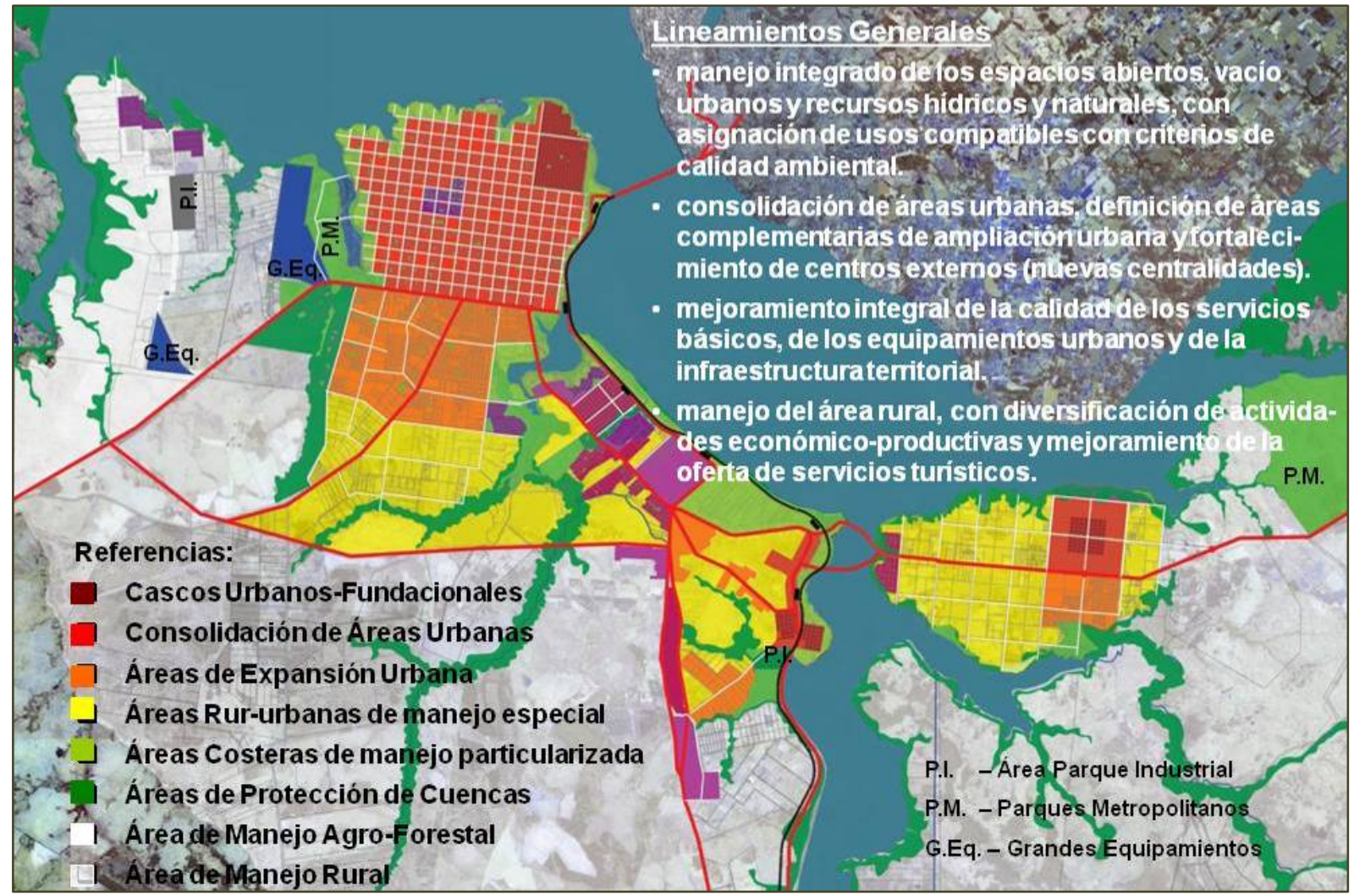

Fuente: Elaboración propia para la Entidad Binacional Yacyretá, 2006.

\section{A. Ideas Fuerza para la Gestión del AMeP}

En esta mirada los Lineamientos hacen un aporte en términos de "Ideas Fuerza" para ordenar y orientar los temas de discusión del Área Metropolitana de Posadas (AMeP) en general y de las ciudades y municipios de Posadas, Garupá y Candelaria, en particular.

${ }^{91}$ Esta escala incorpora una visión sobre los Municipios de Santa Ana, San Ignacio y Loreto, que en esta instancia, no forman parte de las prioridades de gestión. 


\begin{tabular}{|c|c|c|}
\hline ed (1925 & $\begin{array}{l}\text { Facultad } \\
\text { de } \\
\text { Arquitectura } \\
\text { y Urbanismo }\end{array}$ & $\begin{array}{l}\text { Universidad } \\
\text { Nacional } \\
\text { de } \\
\text { La Plata }\end{array}$ \\
\hline
\end{tabular}

MANEJO INTEGRADO DE LOS ESPACIOS ABIERTOS, VACÍOS URBANOS Y RECURSOS HÍDRICOS Y NATURALES, CON ASIGNACIÓN DE USOS COMPATIBLES CON CRITERIOS DE CALIDAD AMBIENTAL.

Esta idea-fuerza, identifica las siguientes áreas de atención:

a. Las nuevas áreas de ribera sobre el río Paraná, como una nueva relación de los barrios, de las ciudades y del territorio con el río.

b. Las áreas de borde de los arroyos y subembalses urbanos (calidad del agua y ambiental).

c. Los vacíos urbanos con usos no compatibles, o sin asignación actual de usos, como áreas de riesgo de periferización.

d. Los espacios abiertos de uso público o privado (equilibrio territorial).

Plano $N^{\circ}$ 22: Lineamientos de Espacios Abiertos Metropolitanos

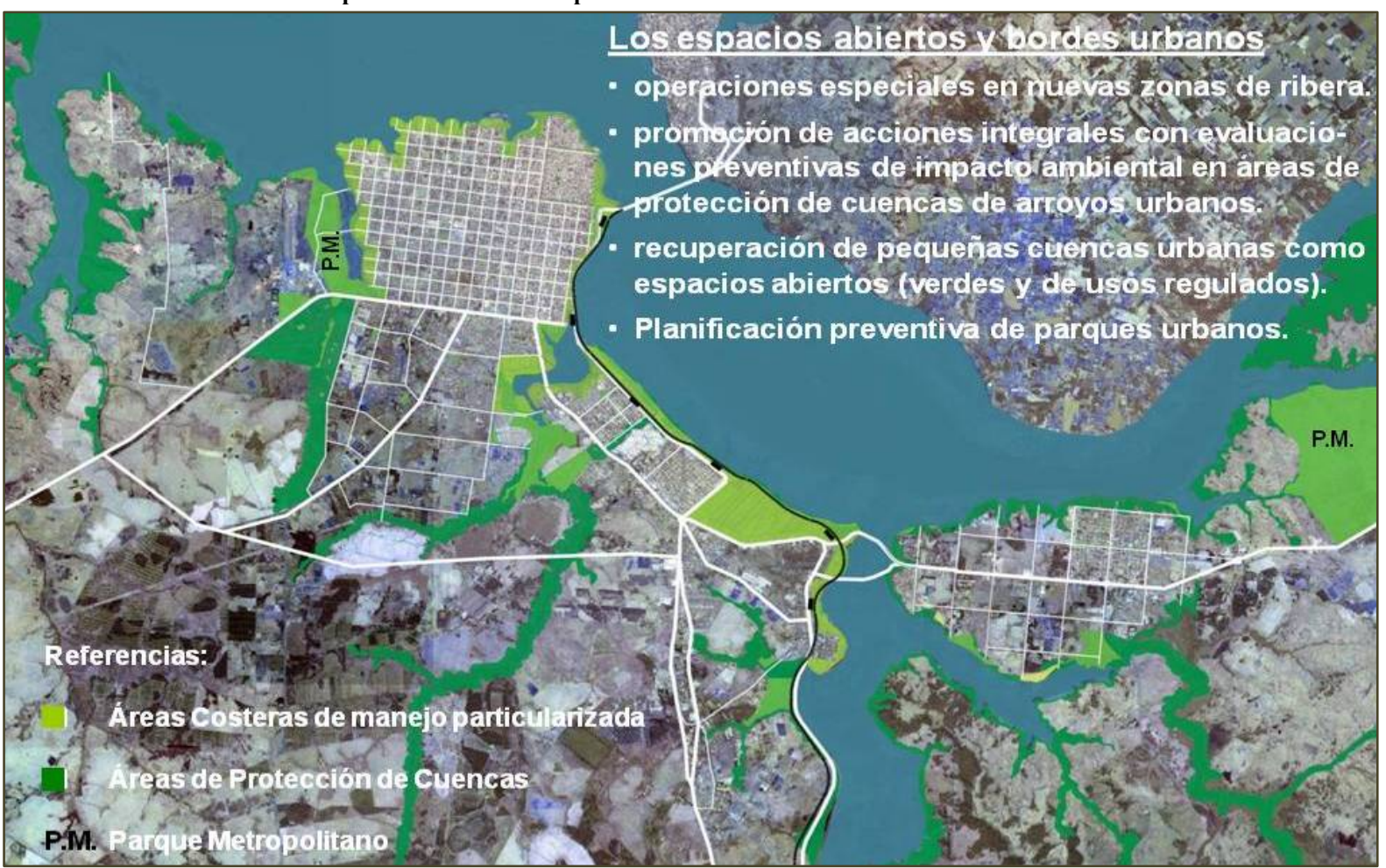

Fuente: Elaboración propia para la Entidad Binacional Yacyretá, 2006

La aplicación de esta idea-fuerza puede implicar, por ejemplo:

$\checkmark$ El diseño e implantación de operaciones especiales en nuevas zonas de ribera.

$\checkmark$ La promoción de acciones integrales con evaluaciones preventivas de impacto ambiental en áreas de protección de cuencas de arroyos urbanos.

$\checkmark$ La recuperación de pequeñas cuencas urbanas como espacios abiertos (verdes y usos regulados).

$\checkmark$ Una planificación preventiva de parques urbanos.

Fotos $N^{\circ} 182$ a 184: Manejo Integrado de los Espacios Abiertos
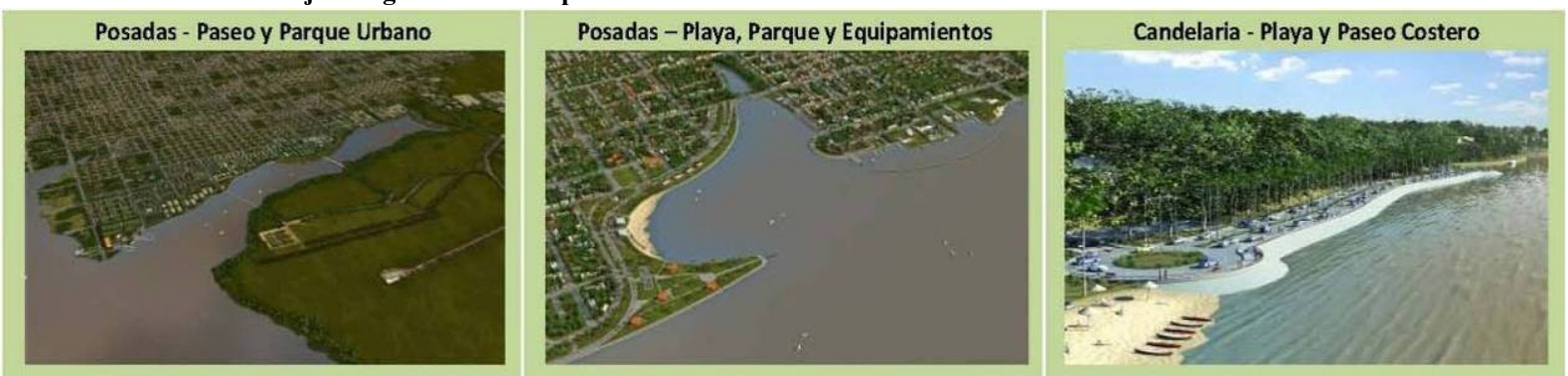

Fuente: Archivo fotográfico EBY

El PAisaje COSTERo COMO FACTOR DE INTEgRACión

EL PROYECTO HIDROELÉCTRICO YACYRETÁ Y LAS TRANSFORMACIONES DE LAS ZONAS URBANO-COSTERAS

DE LAS CIUDADES INVOLUCRADAS, EN EL PERIODO 2005 - 2010 


\section{CONSOLIDACIÓN DE LAS ÁREAS URBANAS, DEFINICIÓN DE ÁREAS COMPLEMENTARIAS Y DE AM-} PLIACIÓN URBANA Y FORTALECIMIENTO DE CENTROS EXTERNOS (NUEVAS CENTRALIDADES).

Esta idea-fuerza identifica las siguientes áreas de atención:

a. Los cascos urbano-fundacionales (consolidación y puesta en valor).

b. Las áreas complementarias y de expansión urbana (resignificación).

c. Las áreas con potencialidad de desarrollo semi-autónomo (fortalecimiento).

d. Las áreas de entorno de grandes equipamientos urbanos -Terminal de ómnibus, aeropuerto, estaciones de transferencia ferroviaria, centros multimodales, etc. (pautas de manejo).

Plano $N^{\circ}$ 23: Lineamientos de Consolidación Urbana

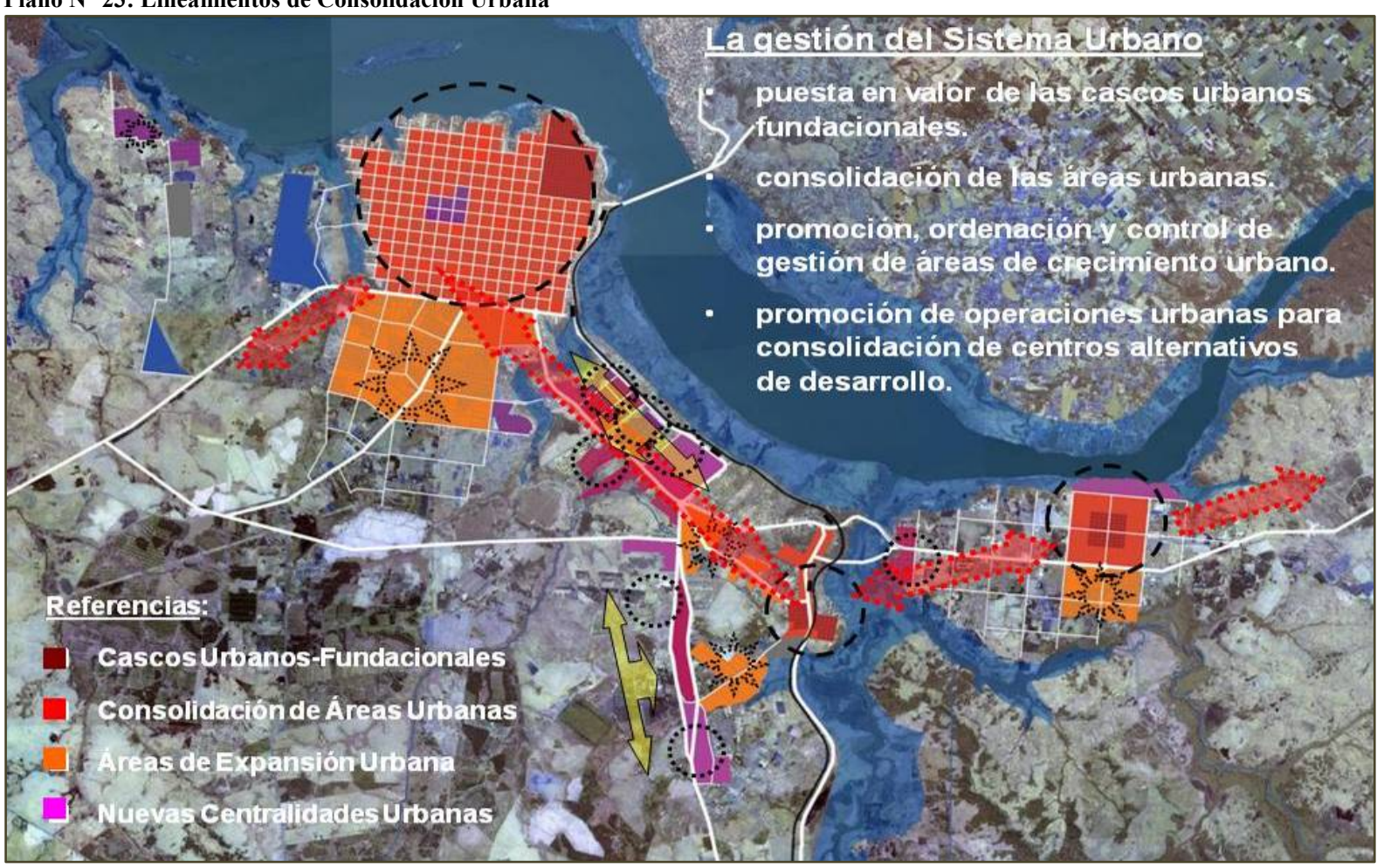

Fuente: Elaboración propia para la Entidad Binacional Yacyretá, 2006.

La aplicación de esta idea-fuerza puede implicar la definición de metodologías de trabajo y de promoción de, por ejemplo:

$\checkmark$ Consolidar modelos de ciudades compactas, a partir de inversiones y promoción de la inversión privada para la puesta en valor de las áreas urbanas.

$\checkmark$ Acciones de ordenación, promoción de acciones especiales y control de gestión, de áreas de crecimiento urbano.

$\checkmark$ Promoción de operaciones urbanas e inversiones productivas, destinadas a favorecer la consolidación de áreas periurbanas, como centros alternativos de desarrollo local.

Fotos No 185 a 187: Consolidación de Áreas Urbanas
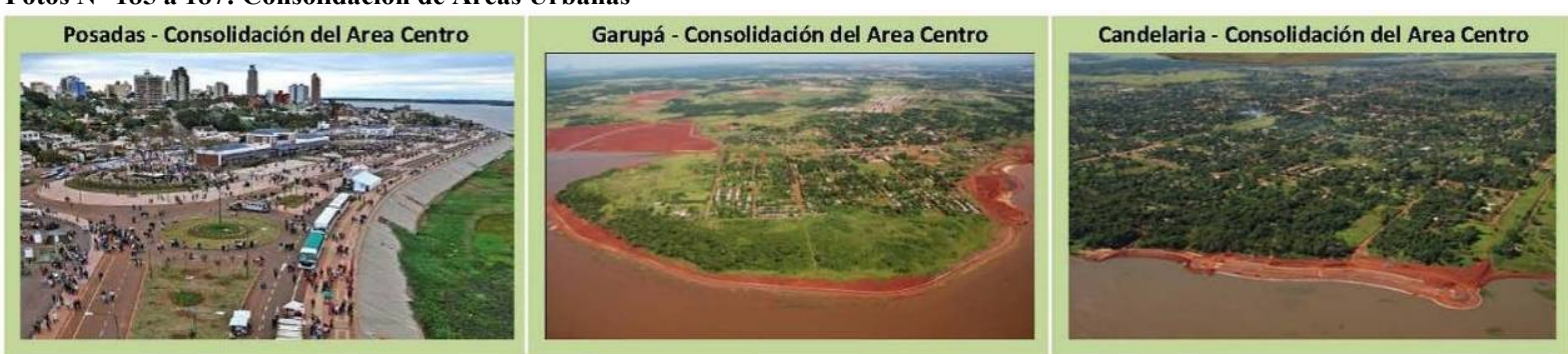

Fuente: Archivo fotográfico EBY. 


$\begin{array}{lll}\text { Red } & \begin{array}{l}\text { Facultad } \\ \text { de }\end{array} & \begin{array}{l}\text { Universidad } \\ \text { Arquitectura } \\ \text { de } \\ \text { yehal }\end{array} \\ \text { Pehuen } & \begin{array}{l}\text { de } \\ \text { La Plata }\end{array}\end{array}$

MEJORAMIENTO INTEGRAL DE LA CALIDAd DE LOS SERVICIOS BÁSICOS (AGUA Y CLOACAS), DE LOS EQUIPAMIENTOS COMUNITARIOS Y DE LA INFRAESTRUCTURA DEL TERRITORIO.

Esta idea-fuerza identifica aspectos interjurisdiccionales de gestión para:

a. El manejo integrado a escala metropolitana de los sistemas de saneamiento, salud, educación y recreación.

b. El manejo sustentable de áreas de borde urbano, con los ejes de movilidad.

c. La consolidación de una red ferro-vial, de características tramada y selectiva.

d. El manejo integrado y complementario de los servicios y del transporte metropolitano.

Plano No 24: Lineamientos de Infraestructura Territorial

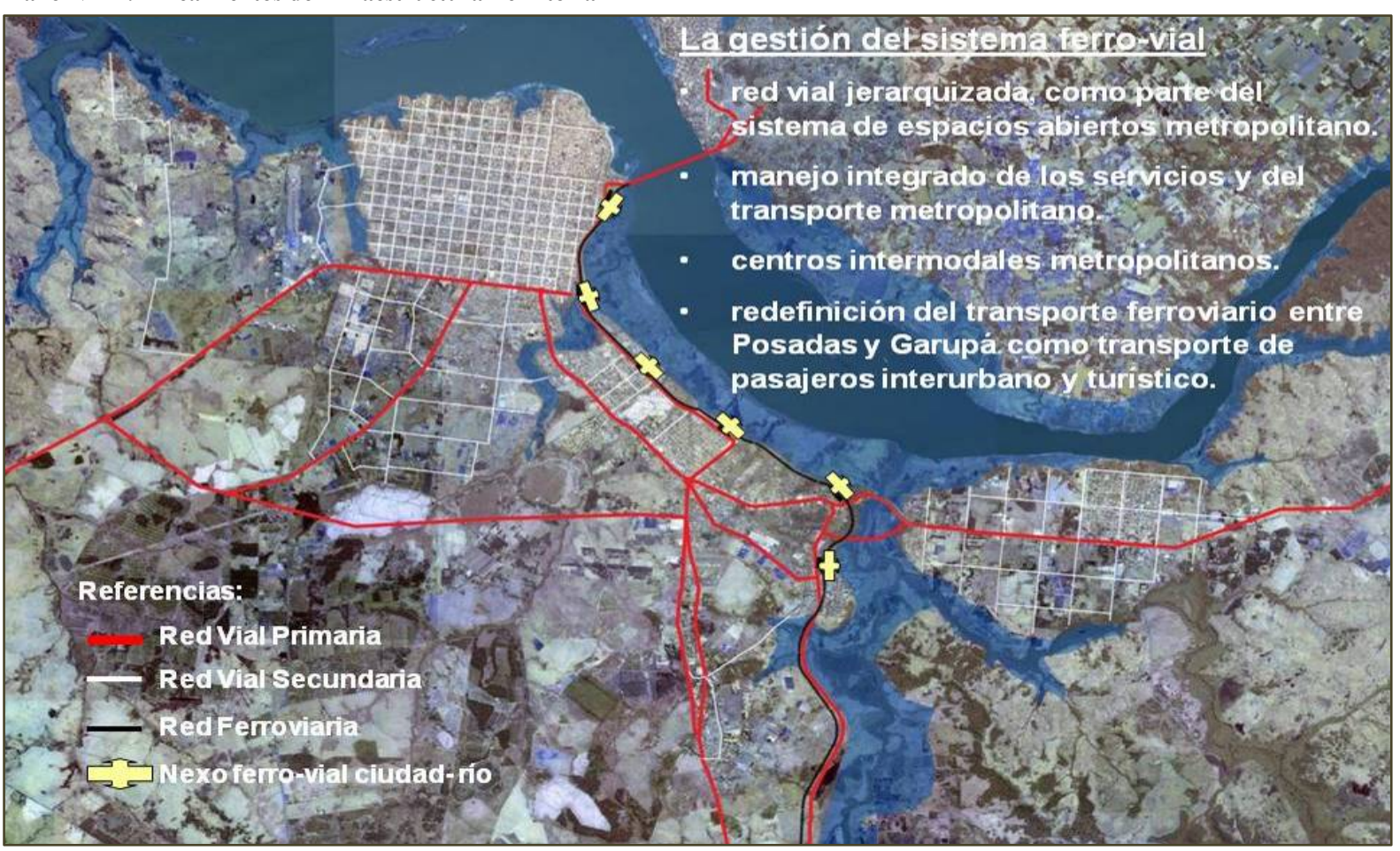

Fuente: Elaboración propia para la Entidad Binacional Yacyretá, 2006.

La aplicación de esta idea-fuerza puede implicar la definición de metodologías de trabajo y de promoción de, por ejemplo:

$\checkmark$ El manejo integrado de sistemas de tratamiento de efluentes cloacales; régimen de control de efluentes industriales; residuos sólidos; ampliación de redes domiciliarias de agua potable.

$\checkmark$ La readecuación a escala metropolitana, de centros de salud, educacionales y/o recreativos.

$\checkmark$ La implantación de acciones complementarias que favorezcan el uso y comprensión de la red vial como parte de un sistema de espacios abiertos metropolitano.

$\checkmark$ La posibilidad de redefinir el transporte ferroviario entre Garupá y Posadas, y aún Encarnación, como transporte alternativo interurbano de pasajeros y turístico, junto a la consolidación de centros de servicio de ruta y centros intermodales metropolitanos.

Fotos $N^{\circ} 188$ a 190: Infraestructura Territorial

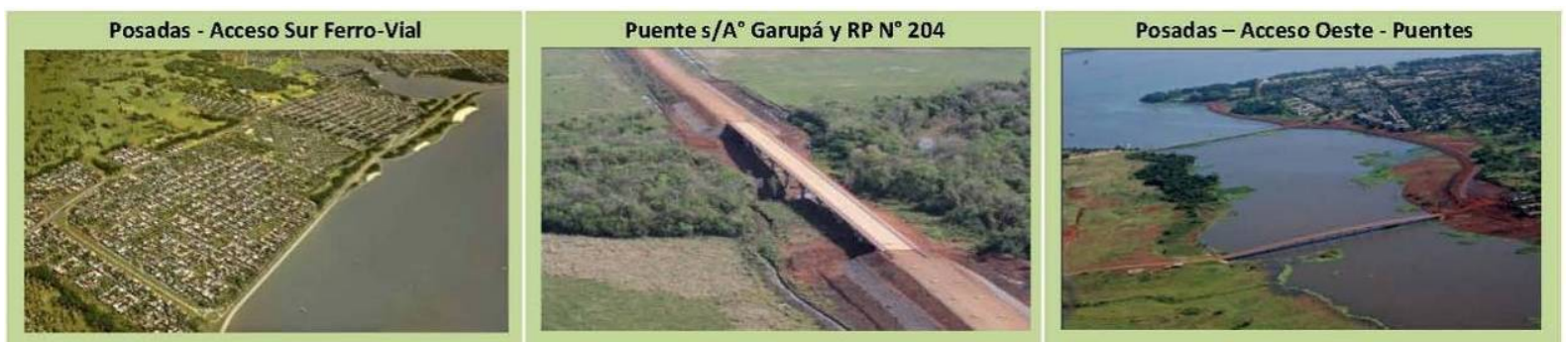

Fuente: Archivo fotográfico EBY.

El PAisaje Costero Como FaCtor de InTEgraCión

EL PROYECTO HIDROELÉCTRICO YACYRETÁ Y LAS TRANSFORMACIONES DE LAS ZONAS URBANO-COSTERAS

DE LAS CIUDADES INVOLUCRADAS, EN EL PERIODO 2005 - 2010 


\section{DIVERSIFICACIÓN DE LAS ACTIVIDADES ECONÓMICO-PRODUCTIVAS Y MEJORAMIENTO DE LA OFERTA DE SERVICIOS TURÍSTICOS.}

Esta idea-fuerza identifica aspectos jurisdiccionales e interjurisdiccionales de gestión para:

a. La asignación de usos para grandes fracciones y para el área rural, compatibles con criterios de manejo sostenible del recurso suelo y del recurso hídrico.

b. La definición y aplicación de medidas promocionales para la instalación de áreas de explotación forestal, áreas recreativas, clubes de campo (que resuelvan autónomamente la provisión y tratamiento de todos sus servicios básicos), entre otras.

c. La gestión de áreas particularizadas, para la localización de nueva hotelería y nuevos servicios orientados a los sectores productivos, empresariales y turísticos.

Plano $N^{\circ}$ 25: Lineamientos de Diversificación Económico-Productiva

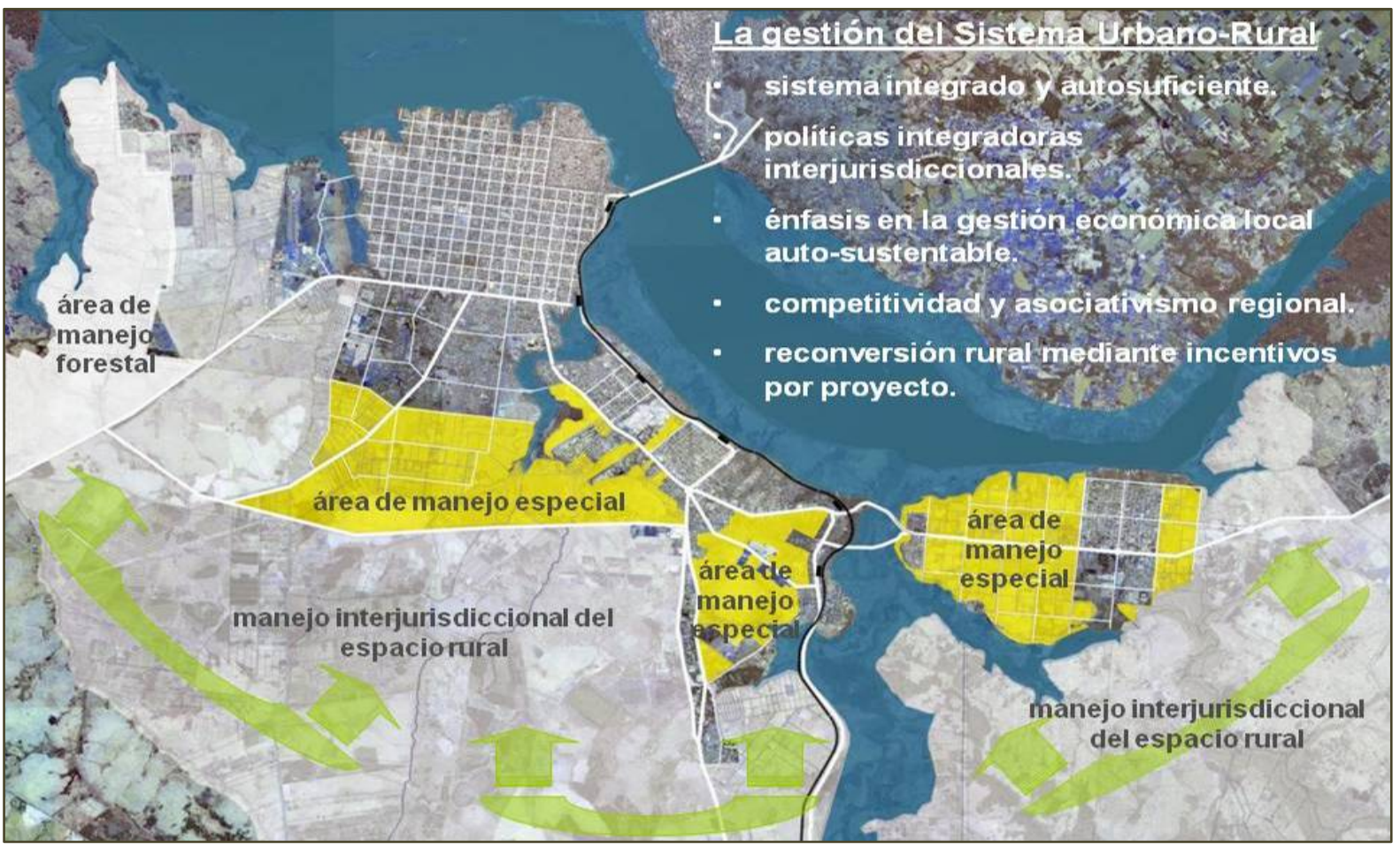

Fuente: Elaboración propia para la Entidad Binacional Yacyretá, 2006.

La gestión integral del Sistema Urbano-Rural permitiría consolidar a mediano y largo plazo, un sistema rural-urbano integrado y autosuficiente a partir de, por ejemplo:

$\checkmark$ Políticas integradoras interjurisdiccionales.

$\checkmark$ Mecanismos de promoción con énfasis en la gestión económica local auto-sustentable.

$\checkmark$ La aplicación de créditos y acciones que promuevan condiciones de competitividad y asociativismo regional.

$\checkmark$ La reconversión de las actividades rurales mediante incentivos por proyecto.

Fotos No 191 a 193: Diversificación Económico-Productiva

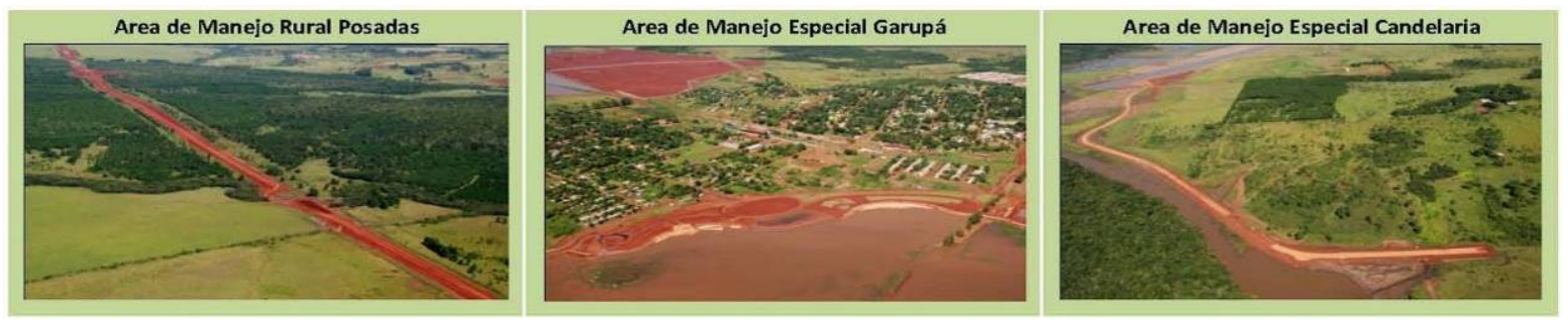

Fuente: Archivo fotográfico EBY. 


\section{B. Ideas Fuerza para la Gestión Urbana - Escala Municipal}

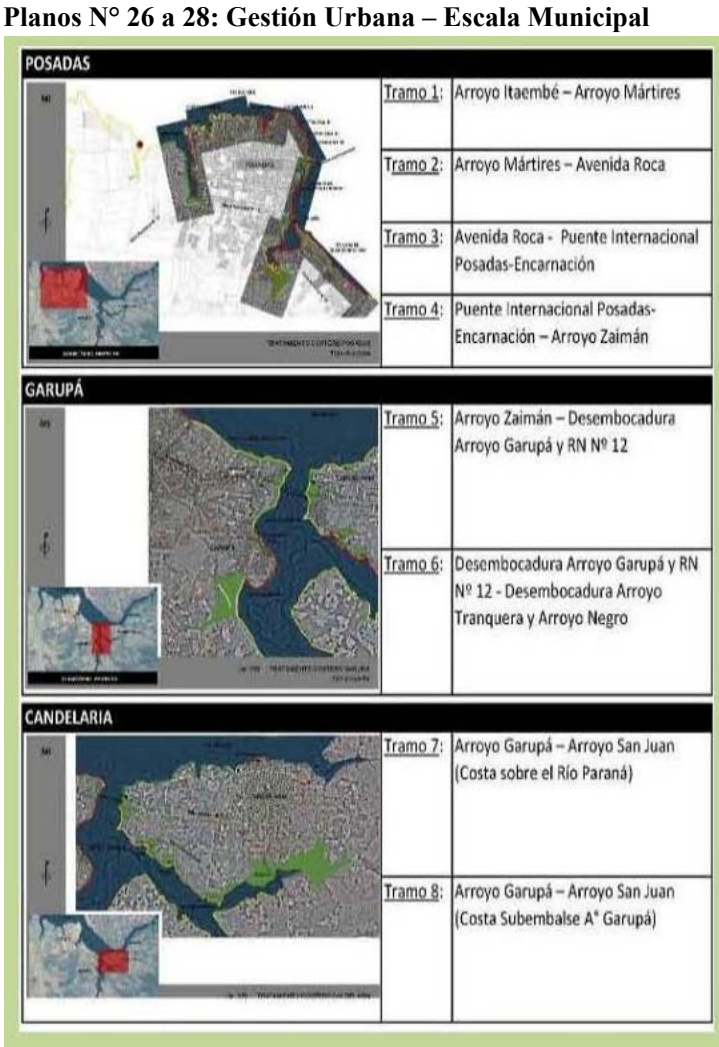

Fuente: Elaboración propia para la EBY
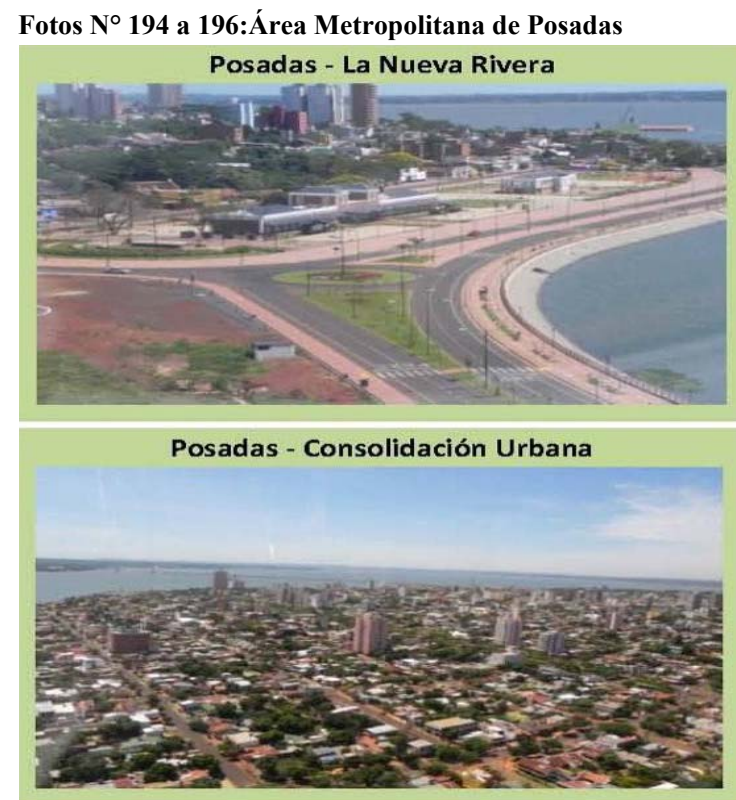

Posadas - Entorno Urbano

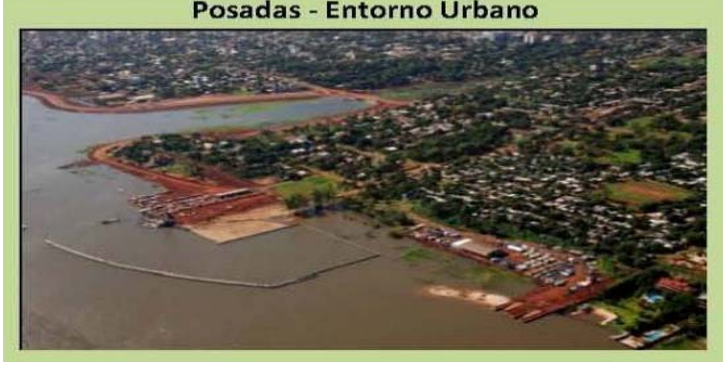

Fuente: Archivo Fotográfico EBY.
La estrategia de intervención supone combinar distintas líneas de acción para tres áreas caracterizadas de ordenación, dónde Yacyretá está ejecutando obras de tratamiento costero, articulación vial y recomposición, protección y mejoras de la trama urbana-costera de las ciudades de Posada, Garupá y Candelaria.

\section{B.1. La Nueva Ribera}

Comprende el reconocimiento de nuevas piezas urbanas como espacios de oportunidad (proyecto urbano) que oriente las expectativas de inversión, en las siguientes zonas y tramos urbanos:

\section{B.2. Consolidación Urbana}

El criterio de consolidación es aplicable a las áreas urbanas de las ciudades involucradas, donde el concepto de 'manejo' está orientado a promover la producción de intervenciones de pequeña a mediana escala, definidas como: a) Jerarquización de cascos históricos urbano-fundacionales; b) Puesta en valor de áreas, sitios y edificios de valor patrimonial; c) Ordenamiento y consolidación de áreas centrales; d) Reconfiguración de áreas costeras de río y arroyos.

\section{B.3. Entorno Urbano}

Orienta la ordenación de las áreas complementarias y de crecimiento de las ciudades (donde se insertan, principalmente en Posadas, los sitios de reasentamiento poblacional de Yacyretá). Aplica criterios de manejo de áreas particularizadas en los siguientes tópicos: a) Resignificación de Áreas Complementarias (ampliación urbana; nuevas centralidades); b) Áreas Particularizadas (bordes de rutas, entorno de grandes equipamientos urbano,; grandes vacíos urbanos o áreas de riesgo de periferización); c) Áreas de Protección de Cuencas de arroyos urbanos. 


\section{Ideas Fuerza para la gestión Microregional}

Plano $N^{\circ}$ 29: Lineamientos de articulación Territorial

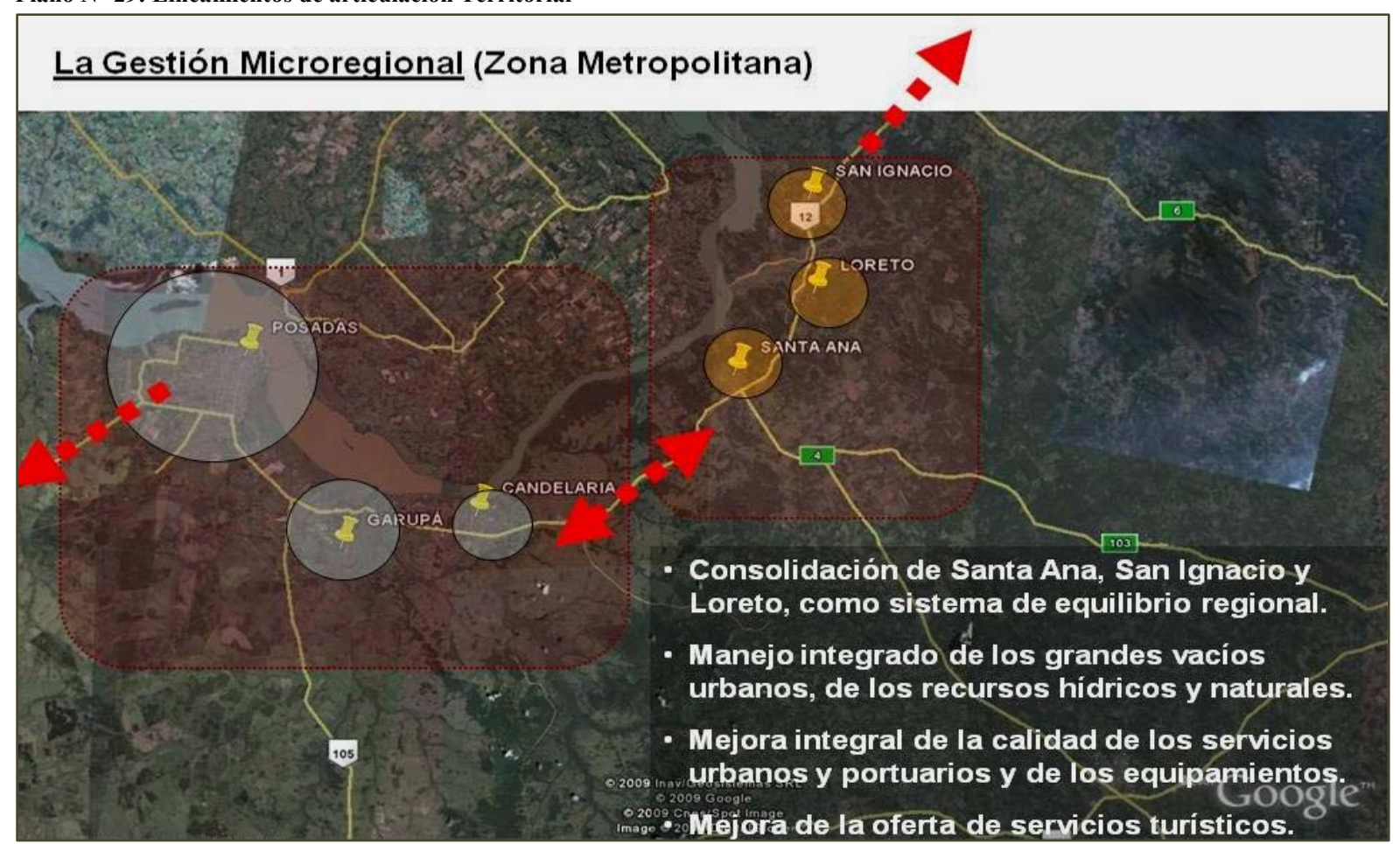

Fuente: Elaboración propia para la Entidad Binacional Yacyretá, 2006.

Los lineamientos a esta escala, pueden contener aspectos de gestión, tales como:

$\checkmark$ Consolidación de Santa Ana, San Ignacio y Loreto como sistema de equilibrio territorial: centros histórico-turísticos y agro-productivos de equilibrio metropolitano.

Incluye:

$\square \quad$ Puesta en valor de cascos urbano-fundacionales.

$\square \quad$ Resignificación de áreas complementarias y de expansión urbana.

$\square \quad$ Fortalecimiento de áreas con potencialidad de desarrollo semi-autónomo.

$\square \quad$ Jerarquización de áreas de interés histórico-patrimonial.

$\checkmark$ Manejo integrado de los grandes vacíos urbanos y de los recursos hídricos y naturales. Incluye:

$\square \quad$ El área de ribera sobre el río Paraná entre $\mathrm{A}^{\circ}$ San Juan y San Ignacio.

$\square \quad$ El manejo de cuenca de los arroyos y subembalses.

$\square \quad$ El manejo del gran vació urbano entre Candelaria y San Ana.

$\checkmark$ Mejoramiento integral de la calidad de los servicios básicos, de los equipamientos comunitarios y de la oferta de servicios turísticos.

Fotos N 197 a 199: Gestión Microregional
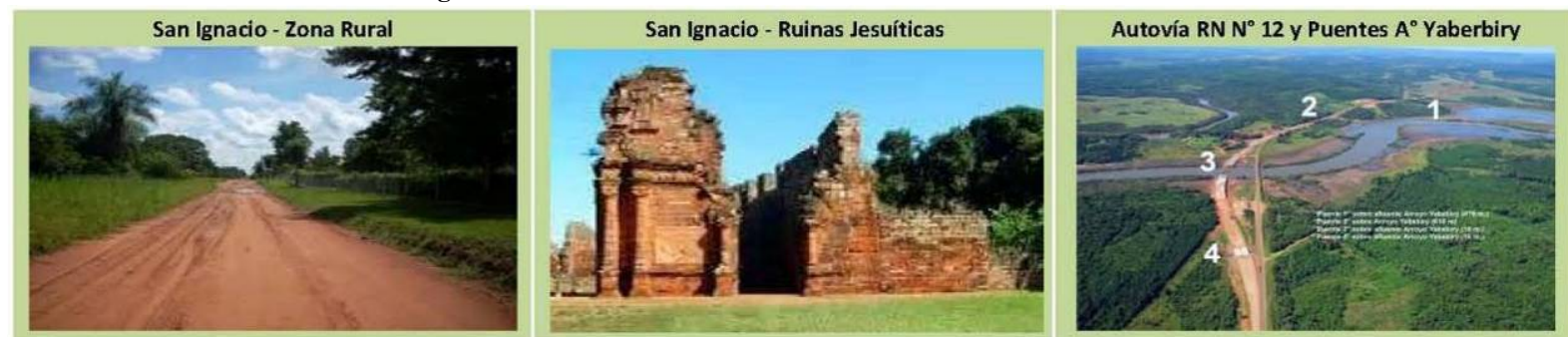

Fuente: Archivo fotográfico EBY 


\section{IV.1.2.3. Lineamientos para el Área Metropolitana de Encarnación (AMeE)}

Actualmente se están encauzando tareas conducentes a actualizar el Código Urbano y de Edificación -que se enmarcan en la Resolución № 493/06 de Lineamientos de Ordenamiento UrbanoTerritorial y Criterios de Gestión para el Municipio de Encarnación- aprobados por la Junta Municipal.

Estos Lineamientos ${ }^{92}$ establecen criterios básicos de ordenación y gestión que orientan el modelo urbano, derivado de las transformaciones en el territorio a partir de la ejecución de las obras de terminación de Yacyretá, proponiendo un enfoque integral para enfrentar esas transformaciones con una visión positiva del desarrollo urbano y ambiental, para Encarnación, y para el Corredor de $35 \mathrm{Km}$. que incluye a éste Municipio y a los de Cambyretá, San Juan del Paraná y Carmen del Paraná. Los criterios de ordenación abarcan tres escalas de intervención:

La aprobación de este marco normativo otorga un aval a las realizaciones, y da seguridad jurídica e institucional a las obras y acciones que se están implementando a través de la ejecución del PTY y a los trabajos que permitan profundizar estos lineamientos y criterios, para convertirlos en una concreta herramienta de ordenamiento territorial y uso del suelo.

La Resolución contiene los criterios de ordenamiento para el Municipio de Encarnación y, dada la influencia de esta ciudad sobre su entorno territorial, considera también los criterios para abordar una temática análoga de gestión en los otros Municipios que conforman la región. En tal sentido, los criterios de ordenación abarcan tres escalas de intervención:

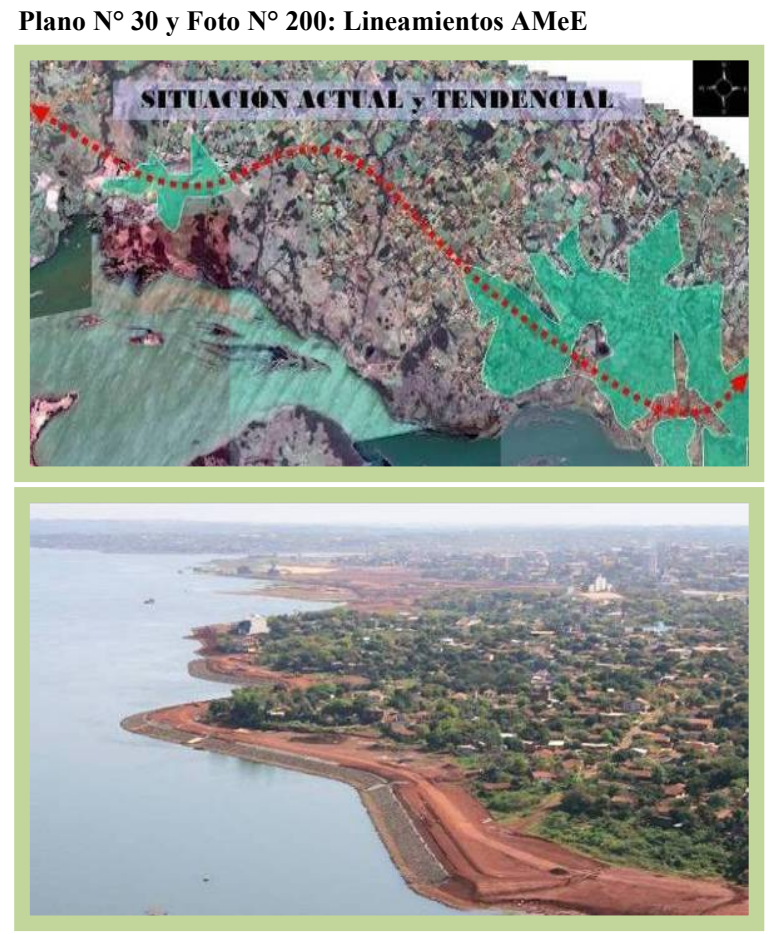

Fuente: Resolución 493/06. Municipalidad de Encarnación.
La Microurbana: incorporando la incidencia de las transformaciones que orientan las obras y acciones de la EBY y de otras operaciones urbanísticas a promover en el área de Encarnación.

La Urbana: como estrategia que complemente las operaciones urbanísticas a escala micro-urbana abarcando, en este caso, a la jurisdicción municipal como elemento de gestión.

La Territorial: o microregional, a fin de favorecer el desarrollo de cada componente del Corredor que, sobre la $\mathrm{RN} \mathrm{N} \mathrm{N}^{\mathrm{o}}$ 1, incluye a los Municipios antes mencionados.

\footnotetext{
${ }^{92}$ Los criterios de gestión desarrollados para esta escala en el Municipio de Encarnación, pueden ser entendidos como "principios rectores", que como tales, pueden ser transferidos para la gestión del resto de las áreas urbanas a consolidar.
} 


\section{A. Lineamientos para la escala Microurbana}

La estrategia para esta escala de intervención, incorpora las transformaciones que orientan las obras de Yacyretá y otras operaciones urbanísticas a promover, en tres áreas caracterizadas:

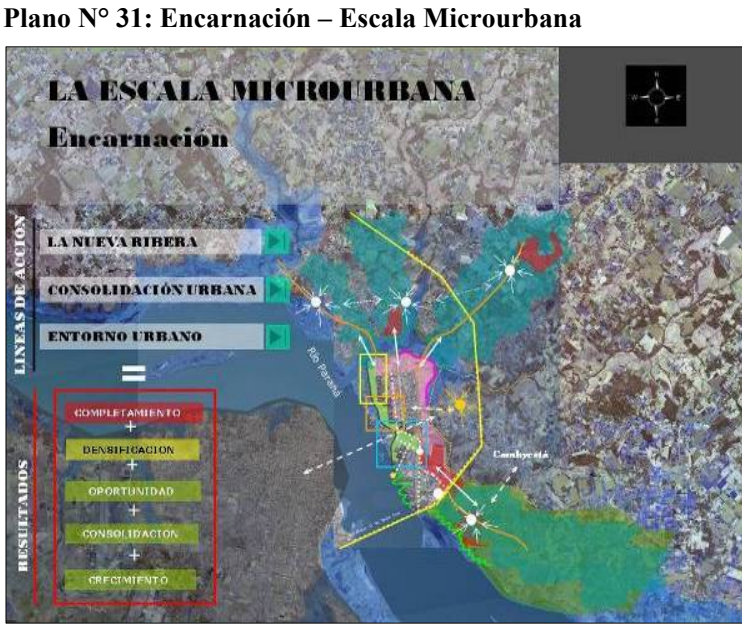

Fuente: Resolución 493/06. Municipalidad de Encarnación.
Nueva Ribera: comprende la futura zona costera de Encarnación, dónde se propone una operación de gran escala, que permita insertar esta nueva pieza urbana como un espacio de oportunidad -en términos de proyecto urbano-, que oriente las expectativas de inversión.

El Área Urbana Central: Orientando la producción de pequeña y mediana escala en sectores urbanos o barrios centrales, con el propósito de desencadenar efectos de transformación que aproximen al escenario buscado de consolidación.

Entorno Urbano: orientando la ordenación de la actual periferia urbana como "nuevas centralidades" de equilibrio territorial aprovechando, inicialmente, los conjuntos habitacionales, los servicios, obras de saneamiento y equipamientos construidos por la EBY.

Esta forma de intervención "desde la ciudad hacia el territorio", auspicia un modelo de desarrollo urbano que busca: aprovechar un área de oportunidad que le devuelva "la cara al río" a la ciudad; consolidar el área urbana central (zona alta) y reconfigurar los barrios que la delimitan y finalmente, favorecer el desarrollo del entorno cercano como centros alternativos de desarrollo, o nuevas centralidades urbanas, aprovechando la nueva configuración territorial.

\section{A.1. La Nueva Ribera}

Representa un 'área de oportunidad', proyectada sobre la base de conceptos urbanísticos contemporáneos que posibilitará generar nuevos productos inmobiliarios y una sinergia que prestigie el área costera resignificada, donde el espacio público actúa como ordenador y articulador de un nuevo paisaje urbano, y de nuevas relaciones de continuidad con la ciudad actual reforzando, así, la identidad ciudadana.

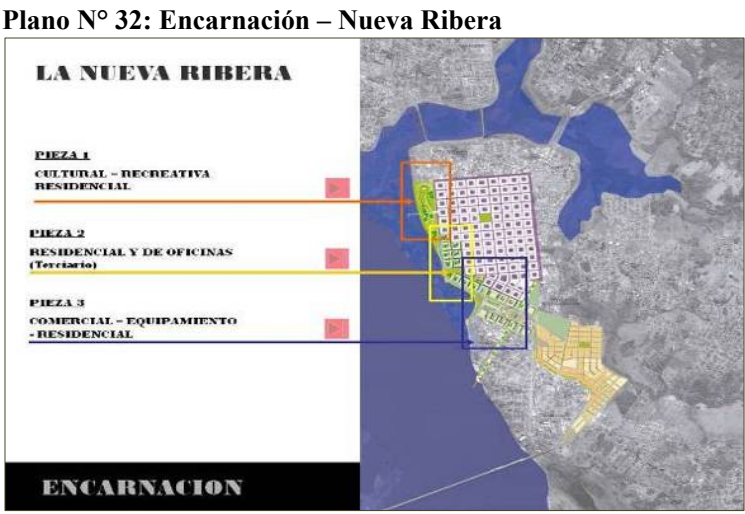

Fuente: Resolución 493/06. Municipalidad de Encarnación.
La Nueva Ribera se concibe como una unidad articulada en tres piezas, definidas desde los atributos que determinan su especificidad, de las formas de interacción entre ellas y de su contribución al funcionamiento del sector urbano en especial y de la ciudad.

En este nuevo ámbito urbano, se propicia una combinación de usos (residencia, comercial, servicios), en un balance adecuado con áreas públicas, como espacios verdes, de uso cultural y de esparcimiento, con promoción de la inversión pública y privada.

Dentro de este enfoque, esta nueva área de oportunidad se encuentra integrada por tres piezas urbanas de diferente carácter: 1) CUltural-ReCreativo-RESIDENCIAL; 2) RESIDENCIAL-TERCiARIO;

\section{3) COMERCIAL -EQUIPAMIENTO-RESIDENCIAL.}


Estas piezas producen la articulación entre "la ciudad antigua" y "la ciudad nueva", generando una nueva relación Ciudad-Río, con acceso franco a la ribera y con el rescate y resignificación de sitios y edificios de valor cultural y patrimonial.

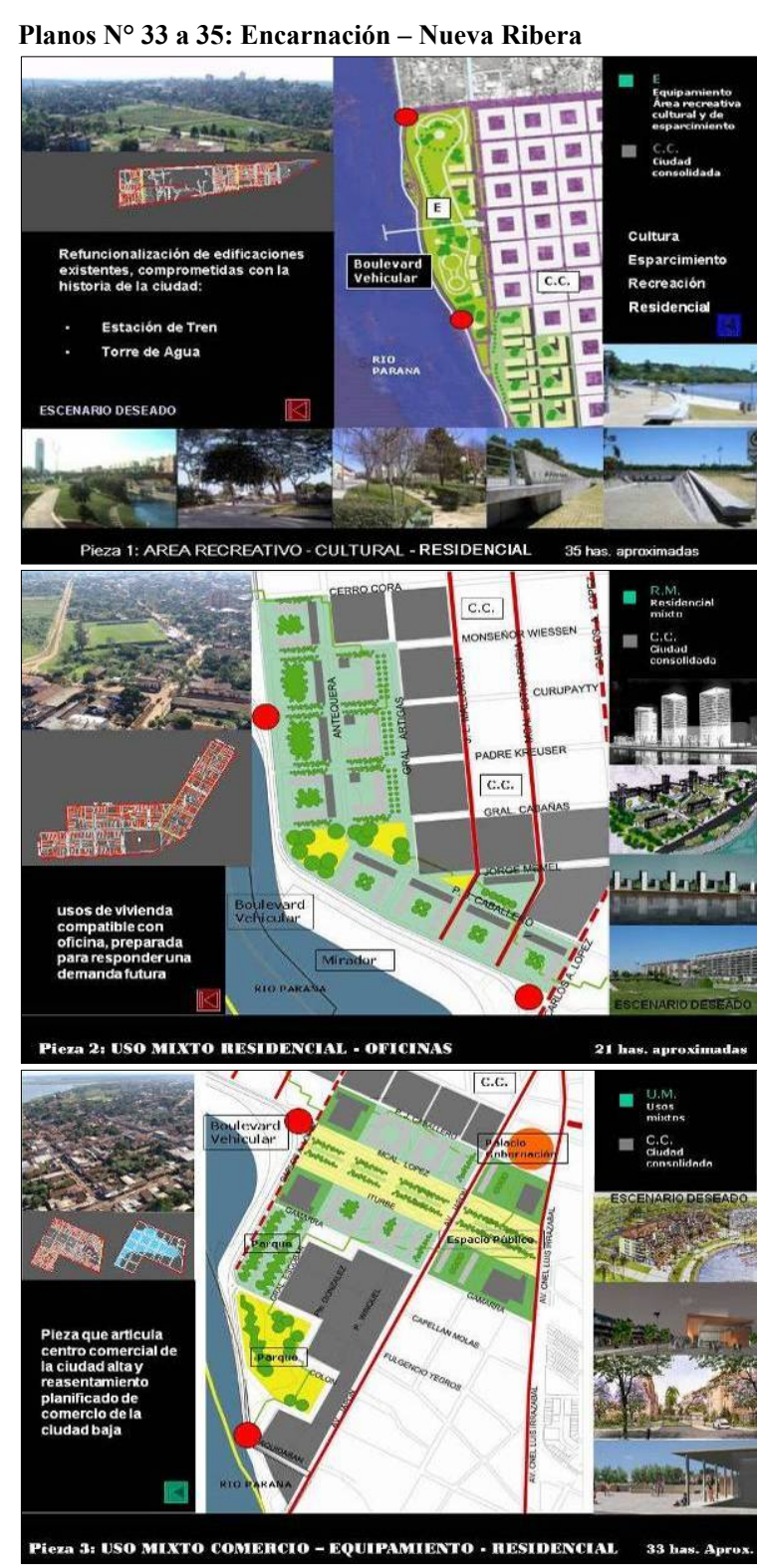

Fuente: Resolución 493/06. Municipalidad de Encarnación.

\section{Pieza 1: Cultural - Recreativo - Residencial}

Comprende unas 35 has, entre Av. B. Caballero al N; calle Cerro Corá al S; Av. Gaspar Rodríguez de Francia al E y la ribera del río Paraná al O. Para este sector se busca promocionar inversiones públicas y privadas comprometidas con la cultura urbana, esparcimiento y recreación, junto a inversiones de carácter residencial y otras que favorezcan la refuncionalización de edificios de interés histórico como la Estación del FFCC y la Torre de Agua.

\section{Pieza 2: Residencial - Terciario}

Comprende unas 20 has., dónde la construcción del boulevard costero (al O), resalta su condición de 'nexo' por su ubicación entre las otras 2 piezas, permitiendo repensar la intensidad de usos del suelo (mayor FOT, FOS y Densidad), con una división parcelaria diferenciada, con la capacidad de recrear usos de vivienda compatible con oficina, para responder a una demanda futura.

\section{Pieza 3: Comercial - Equipamiento - Residencial}

Esta pieza tiene unas 33 has., delimitadas entre la calle Pedro J. Caballero al N, la Av. Cnel. Luis Irrazábal al E, la calle Gamarra al S y la traza del boulevard costero al Oeste.

La misma representa una oportunidad para resignificar valores ciudadanos y para articular la vieja y la nueva ciudad, a través de una operación que conjugue el rescate histórico con una estrategia de usos flexibles, donde se integren la zona comercial existente, sectores tradicionales de la ciudad, la zona de Buena Vista y la del nuevo Circuito Comercial.

Cabe mencionar que la a propuesta de gestión para la Nueva Ribera, es análoga a la que la Corporación Puerto Madero ha desarrollada en esa zona de la ciudad de Buenos Aires. Esto es, a través de un ente autárquico que desarrolle y promueva el área de inversión, en forma descentralizada. 


\section{A.2. Consolidación Urbana}

Este criterio es aplicable al sector urbano de Encarnación, que se encuentra comprendido entre la Nueva Ribera al O; los arroyos Mboi Caé y Santa María al N; el arroyo Poti'y al E y la prolongación del acceso del Puente Internacional al S.

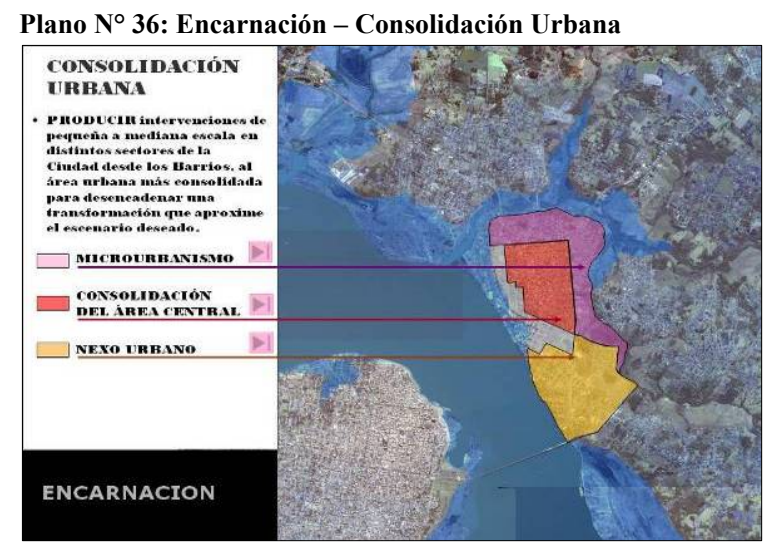

Fuente: Resolución 493/06. Municipalidad de Encarnación.
Tiene por objetivo desencadenar una transformación que aproxime el escenario de consolidación deseado, se propone la producción de intervenciones de pequeña a mediana escala, definidas como: a) de microurbanismo en los barrios que limitan con los arroyos urbanos; b) de consolidación del área urbana central; c) de ordenación en la zona $\mathrm{S}$, donde se registra el mayor nivel de intervención de la EBY (zona “nexo”).

\section{a) Microurbanismo: "de los barrios"}

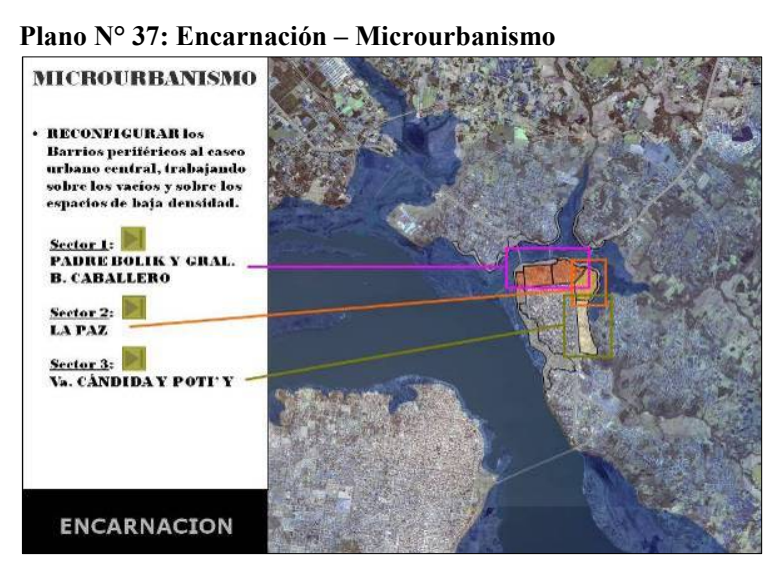

Fuente: Resolución 493/06. Municipalidad de Encarnación.

\section{Sector 1: Padre Bolik-Gral. B. Caballero}

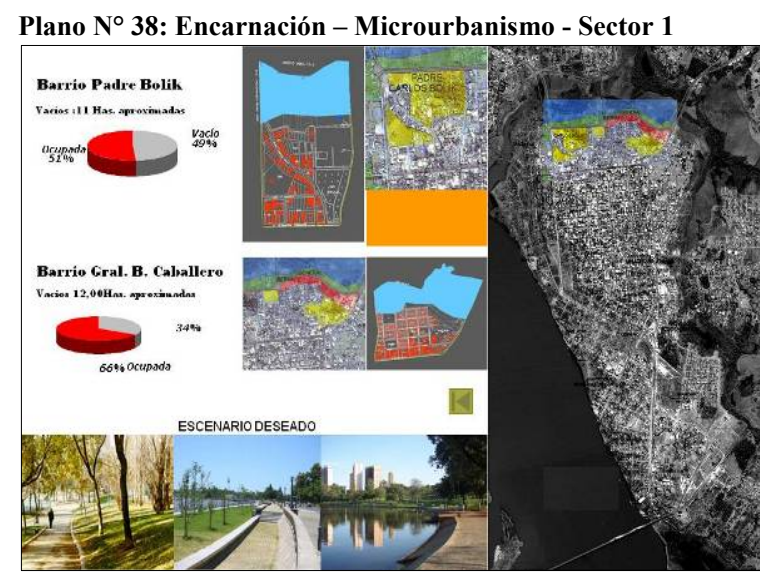

Fuente: Resolución 493/06. Municipalidad de Encarnación.
Comprende los Barrios que contornan al casco urbano central y limitan, en la zona $\mathrm{N}$ y E, con los arroyos Mboi Caé, Santa María y Poti'y, donde se propone un proceso de re-configuración, trabajando en 3 sectores sobre sus vacíos y espacios de baja densidad, que aportan unas 67 has, de superficie, que pueden inducir nuevos procesos de inversión que contribuyan a consolidar el área urbana de Encarnación.

Es el sector $\mathrm{N}$ del casco urbano, donde se localizan los Barrios Padre Bolik y Gral. B. Caballero, que limitan con el $\mathrm{A}^{\circ}$ Mboi Caé al N; la desembocadura del mismo sobre el río Paraná al O; la Av. Caballero al S y la RN No 6 al E. En este sector se busca consolidar una imagen comercial s/Av. Caballero y residencial con dominio de espacio verde en las áreas vacantes de uso. Sobre la zona costera, el uso peatonal y recreativo domina s/el vehicular. 


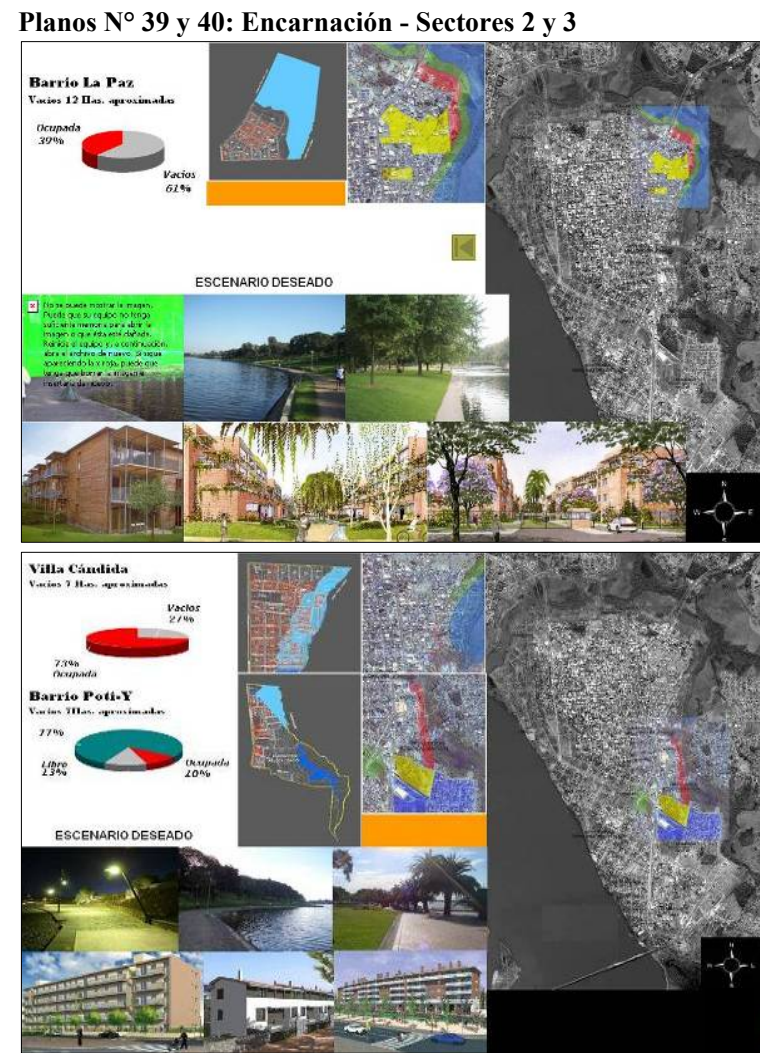

Fuente: Resolución 493/06. Municipalidad de Encarnación.

\section{b) Consolidación: "del área central"}

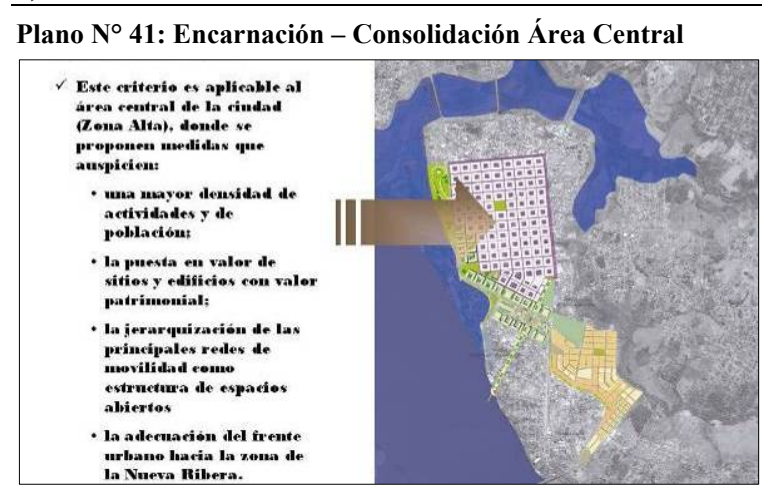

Fuente: Resolución 493/06. Municipalidad de Encarnación.

\section{c) Ordenación: "del nexo urbano"}

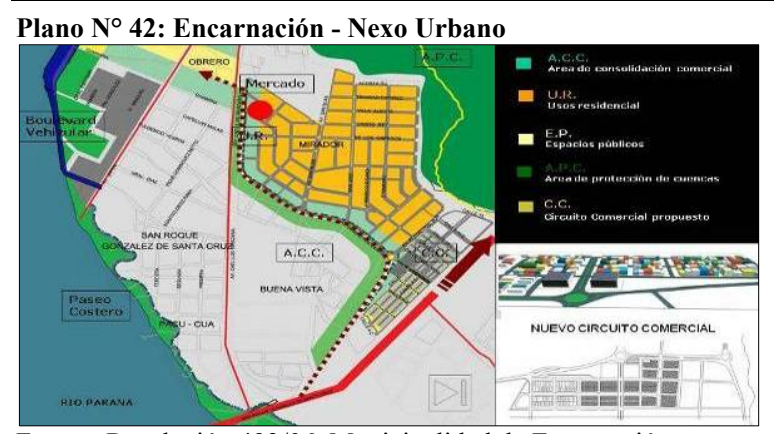

Fuente: Resolución 493/06. Municipalidad de Encarnación.

\section{Sector 2: La Paz}

Comprende al $\mathrm{B}^{\circ} \mathrm{La}$ Paz, al N-E del casco urbano. Representa una zona de baja densidad con grandes residencias privadas, dónde se auspicia una imagen de consolidación con dominio residencial de alta densidad, promocionando la unificación de parcelas para que prevalezca el espacio verde sobre el construido. Sobre la zona costera se plantea como dominante el uso peatonal y recreativo.

\section{Sector 3: Villa Cándida - Poti’y}

Al Este del casco urbano, limita con $\mathrm{B}^{\circ} \mathrm{La} \mathrm{Paz}$ al N; la Av. Irrazábal al O; el Puente de Ruta 14 al S y el arroyo Poti'y al E, comprendiendo al barrio homónimo y Va. Cándida. Por su cercanía al área central, se propicia su consolidación con una imagen urbana, con presencia de espacios verdes y uso recreativo-peatonal en la zona costera.

Este criterio, aplicable al área central de la ciudad (Zona Alta), propone medidas que auspician mayor densidad de actividades y población; puesta en valor de sitios, lugares y edificios con valor patrimonial; jerarquización de la red de movilidad como estructura de espacios abiertos y medidas para adecuar el frente urbano que limitará con la Nueva Ribera sobre el río Paraná.

Comprende al sector urbano en proceso de consolidación a partir de distintas intervenciones de la EBY: zona residencial Buena Vista; área de relocalización de la Zona Baja Comercial; nueva Feria Municipal y el eje de movilidad que vincula a Encarnación con el Puente Internacional y con Cambyretá en su continuidad como Av. Circunvalación.

Esta zona tiene una alta potencialidad comercial y actúa como nexo binacional y como área de transición con el distrito de Cambyretá, junto con la zona de protección de cuenca del arroyo Poti’y. 


\section{A.3. Entorno Urbano}
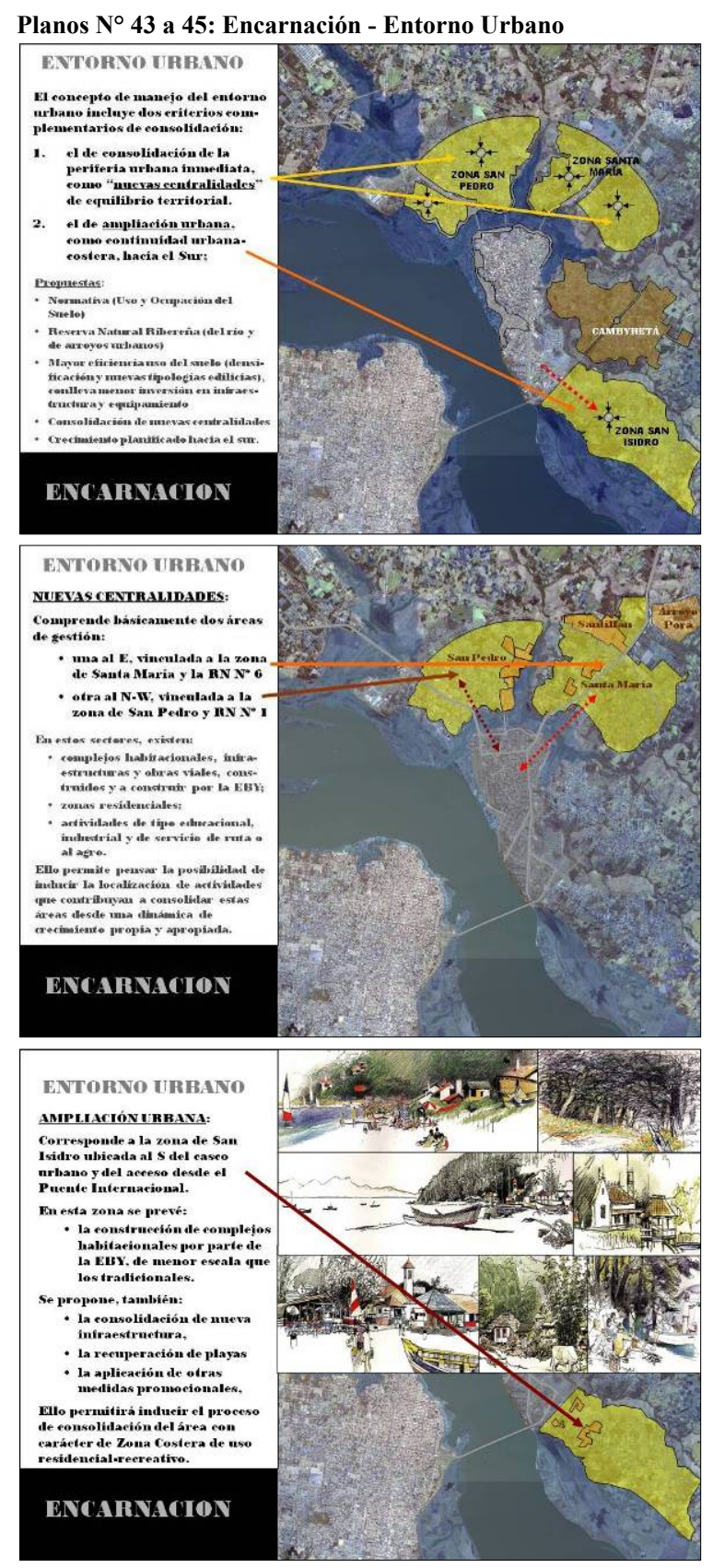

Fuente: Resolución 493/06. Municipalidad de Encarnación.

Foto $\mathrm{N}^{\circ}$ 201: $\mathrm{B}^{\circ}$ San Isidro - Tratamiento Costero y Playa

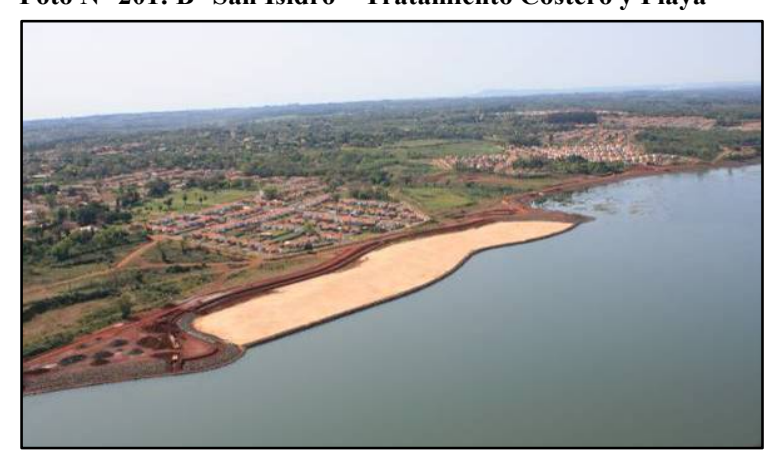

Fuente: Archivo fotográfico EBY
El concepto de manejo de entorno urbano incluye 2 criterios complementarios de consolidación: a) de ampliación urbana, como continuidad urbanocostera, hacia el Sur; b) de la periferia urbana inmediata, como 'nuevas centralidades' de equilibrio territorial. Esta zona se encuentra delimitada entre los subembalses y la traza de la Av. Circunvalación, donde se desarrollan actividades complementarias a las comerciales y de servicio del área central, que le otorgan potencialidad para su reconversión.

\section{a) Ampliación Urbana}

Corresponde a la zona de San Isidro, ubicada al S del casco urbano y del acceso desde el Puente Internacional, donde la construcción del Complejo Habitacional San Isidro en forma difusa por parte de la EBY, junto a la consolidación de nueva infraestructura urbana, la recuperación de playas y la aplicación de otras medidas promocionales, permitirán inducir el proceso de consolidación del área con carácter de Zona Costera de uso mixto Residencial - Recreativo, sobre el río Paraná.

\section{b) Consolidación de la Periferia}

Comprende básicamente dos áreas de gestión: una al E, vinculada a la zona de Santa María y la RN No 6 y otra al N-W, vinculada a la zona de San Pedro y a la RN No 1.

En estos sectores existen complejos habitacionales, infraestructuras y obras viales, construidos y a construir por la EBY, junto a zonas residenciales y otras actividades de tipo educacional, industrial y de servicio de ruta o al agro, que permiten pensar en la posibilidad de inducir la localización de actividades que contribuyan a consolidar estas áreas desde una dinámica de crecimiento propia y apropiada. 


\section{B. Lineamientos para la escala Urbana}

En esta escala las inversiones de la EBY abarcan aspectos residenciales y de equipamientos comunitarios; infraestructura de saneamiento, infraestructura vial, obras de defensa costera y otras obras de reposición física, como el puerto y el aeropuerto. Ello determina la necesidad de proponer medidas promocionales de uso del suelo y de ordenamiento territorial que complementen la visión microurbana y orienten inversiones, que contribuyan a consolidar el área urbana y las nuevas centralidades.
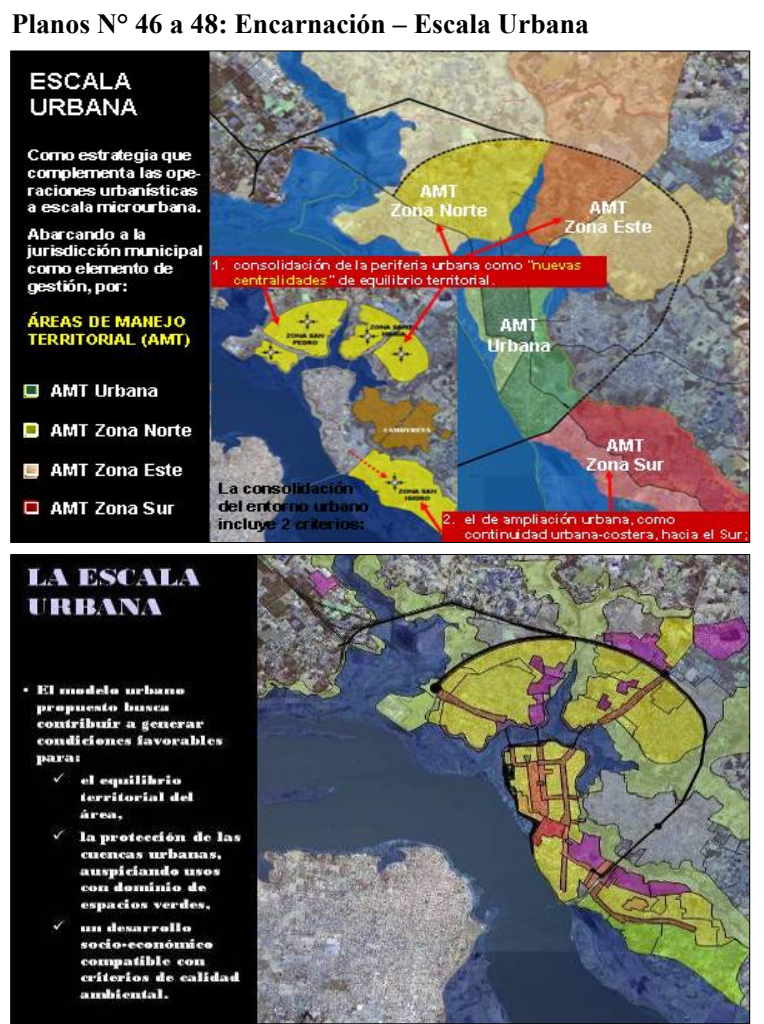

Esta estrategia propone alternativas de manejo en las siguientes áreas de gestión:

Rurales y Periurbanas:- Zona Norte y Sta. María y sectores vinculados a los ejes de movilidad territorial (ejes de rutas)- auspiciando actividades compatibles con el criterio de consolidación de centros externos de equilibrio territorial;

De Ampliación Urbana:-San Isidro y Buena Vista- que contribuyan a delinear nuevos límites de la ciudad.

Naturales de Equilibrio:-sistemas de espacios abiertos y del territorio-, incluyendo las zonas costeras al río Paraná y las de subembalses.

Este accionar propicia la consolidación de un "modelo de desarrollo" urbano que busca contribuir al equilibrio territorial; a un desarrollo socioeconómico compatible y a la protección de las cuencas urbanas, en este caso, para garantizar que sobre las áreas de protección de cuencas se desarrollen actividades que mejoren el paisaje urbano y no afecten la calidad de agua de los subembalses urbanos.

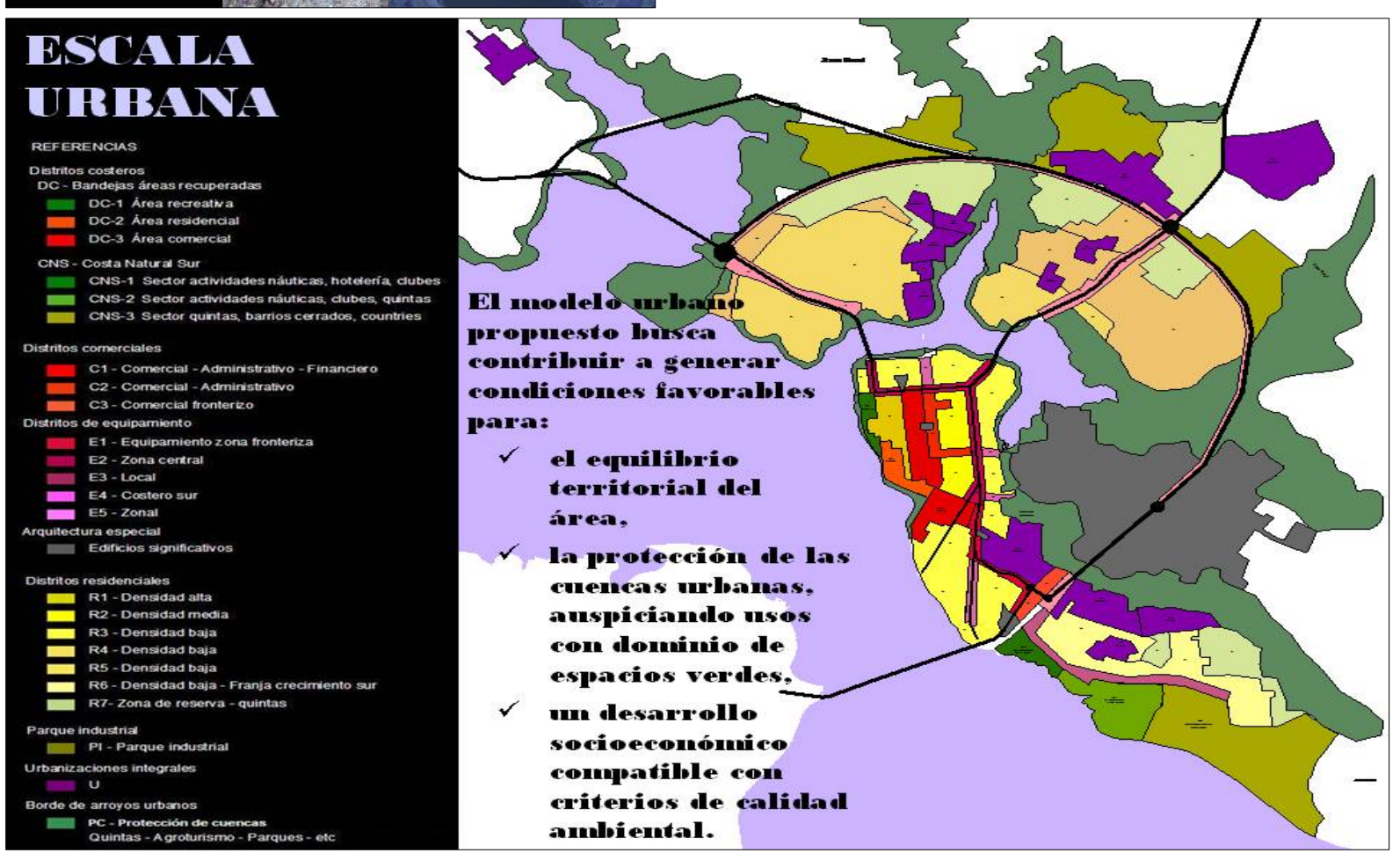

Fuente: Resolución 493/06. Municipalidad de Encarnación. 


\section{Lineamientos para la escala Territorial (o microregional)}

En la escala microregional o del territorio, se destacan inversiones de la EBY de alta incidencia en el Corredor que incluye a los Municipio de Encarnación, Cambyretá, San Juan del Paraná y Carmen del Paraná (éstos últimos, sobre la Ruta Nacional No 1, hacia Asunción).

Por ello, las orientaciones de gestión en esta escala de intervención, buscan favorecer el desarrollo de los Municipios de dicho Corredor, a partir de un manejo por áreas de gestión que promueva:

- la consolidación y especialización de las áreas urbanas -i.e.: Encarnación, como centro comercial y de servicios; Cambyretá como de servicio rural; San Juan del Paraná, agro-portuario y Carmen del Paraná, agro-turístico local y regional-;

- la calificación de otros sitios de menor rango y de las áreas periurbanas -como centros de equilibrio donde se promocionen actividades compatibles con las características del entorno urbano y rural-;

- el manejo adecuado de las actividades productivas del entorno rural, como siembra directa, producción orgánica, asistencia técnica, manejo forestal, entre otras y,

- la consolidación, creación y manejo de áreas naturales de equilibrio territorial -cuencas urbanas y suburbanas, parques urbanos, áreas costeras, etc.-

En este sentido se apunta, entonces, a favorecer el nivel de organización y complementariedad estructural del territorio -limitado en la división política-administrativa vigente- incluyendo esta visión al proceso en marcha en Encarnación y Carmen del Paraná, a fin de poder abordar campos de actuación estratégicos en la escala microregional.

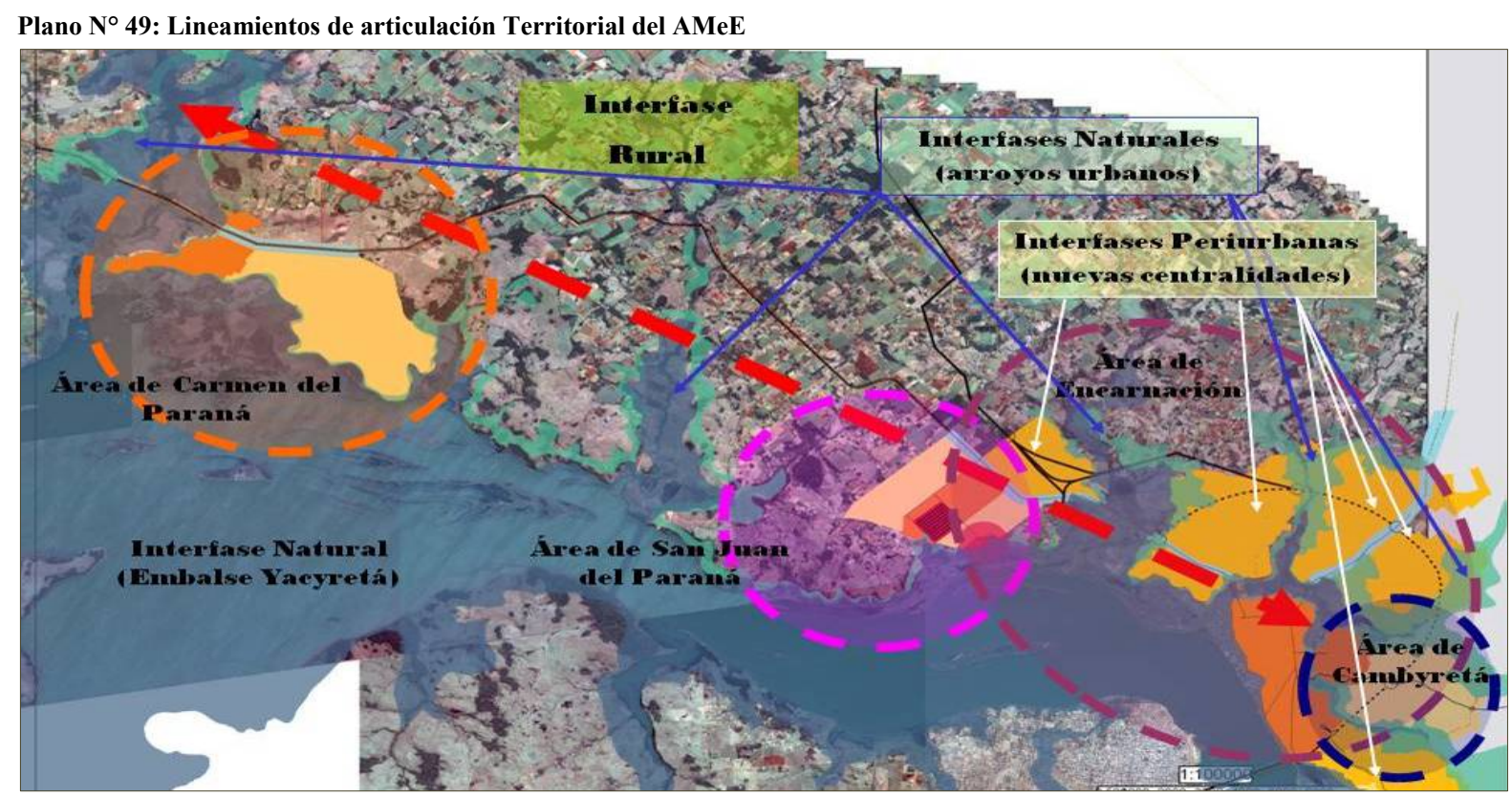

Fuente: Resolución 493/06. Municipalidad de Encarnación.

En la escala territorial, las acciones deben promover oportunidades para restablecer un desarrollo descentralizado, un cuidado de las zonas más frágiles y un manejo responsable de sus recursos, poniendo en valor sus paisajes culturales y naturales. 


\section{IV.1.2.4. Lineamientos para un Enfoque Regional}

Los lineamientos expuestos para las áreas metropolitanas de Posadas y Encarnación, parten de la premisa que gobernabilidad y buen planeamiento son hoy sinónimos de sustentabilidad socioambiental, considerando que las ciudades operan en un escenario diferente donde lo local-regional cobra otra dimensión y dónde la gestión urbana debe aportar soluciones al soporte económico, las infraestructuras de servicio, la calidad de vida y la equidad social.

En el caso de ciudades intermedias como las que integran estas áreas, que -en forma análoga a otras ciudades de similares características en los países latinoamericanos- están siendo afectadas por un crecimiento rápido determinado por migraciones internas y por estar insertas en un contexto de discontinuidad de políticas y de recursos, la acción concreta o proyecto urbano, como instrumento operativo de un plan, puede contribuir decididamente a fortalecerlas como "[...] organizadoras de una trama o red urbana-territorial, que establezca la gobernabilidad de la interacción entre lo urbano y lo rural y entre lo natural y construido, como una de las bases de la sustentabilidad" (Pesci, 2001: 52).

En esta línea de pensamiento, el urbanista español Josep María LLop, sostiene -desde su concreta experiencia en Lérida, España- que el urbanismo en este tipo de ciudades, en función de la superficie de sus espacios urbano y rural y de la dimensión sociológica, es más formalizable a escala de proyecto urbano, donde la zonificación es más proyectual y menos normativa.

Desde esta óptica los proyectos urbanísticos, arquitectónicos, ambientales o paisajísticos, insertos en un plan, adquieren una doble dimensión estratégica: una constructiva o de intervención y la otra, como pieza de estructuración del territorio. Estas dos dimensiones deben ser utilizadas a favor de la transformación de los métodos de planificación y de intervención, apoyadas más directamente en las condiciones del medio físico y social.

La visión que se propone sigue esta hipótesis, dónde un 'plan' debe entenderse como un instrumento de 'gobernabilidad' concebido a partir de una política de desarrollo, representada por una serie de intervenciones a diferentes escalas, para lugares concretos y en un contexto determinado (obras y acciones), donde los problemas y las potencialidades se convierten en campo de trabajo y donde la ingeniería, la arquitectura y el urbanismo se leen como elementos para el desarrollo de las ciudades donde se interviene.

De esta forma "[...] se puede acercar el modelo (una teorización técnica), al lugar (un espacio físico) y al contexto (unas condiciones socioculturales y políticas determinadas)". En los términos planteados por Jaime Lerner "[...] recuperando la capacidad de gestión para formalizar el urbanismo a escala de proyecto urbano, atendiendo la dimensión social y donde la zonificación sea más proyectual y menos normativa [...]." (Lerner, 2004. Curitiba, Brasil). 
Lo expuesto muestra la importancia de considerar la articulación de ambas áreas metropolitanas dentro del concepto de región, dado que la existencia de la Represa y del Puente Internacional, no sólo las comunica sino que las articula dentro del contexto territorial, socioeconómico y cultural.

Plano $\mathrm{N}^{\circ}$ 50: Lineamientos de articulación Regional

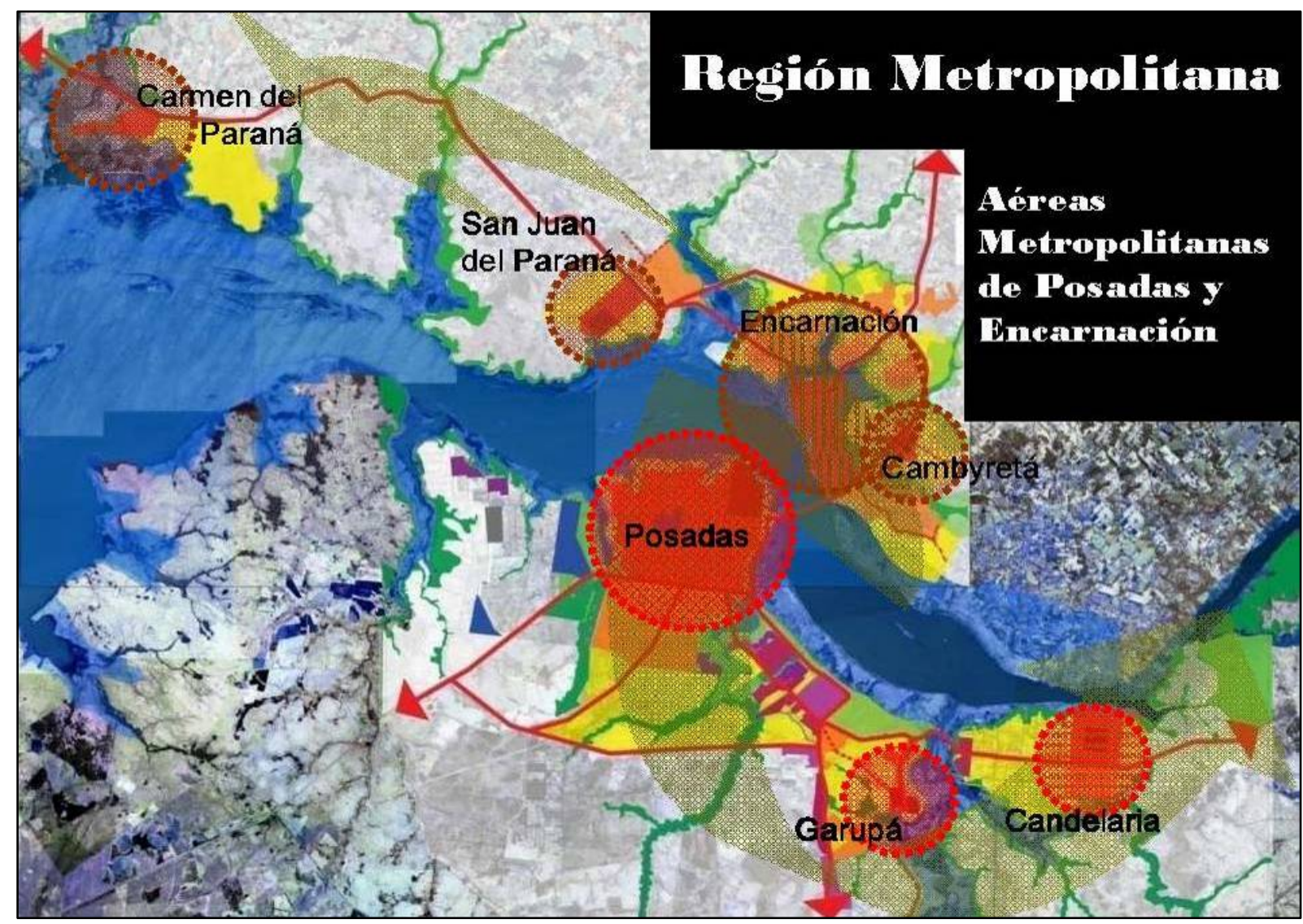

Fuente: Resolución 493/06. Municipalidad de Encarnación.

Es desde esta perspectiva, que el proceso de terminación de Yacyretá, puede contribuir como factor de desarrollo local y regional. Y por esto es que la EBY está realizando y/o financiando trabajos de apoyo técnico que permitan insertar estas transformaciones, en el marco de planes urbanos específicos, sin perder el contexto de inserción regional.

En forma análoga a lo expuesto para la escala territorial, las acciones a escala regional deben también orientar espacios de oportunidad para restablecer un desarrollo descentralizado ('multipolar'), ${ }^{93}$ un cuidado de las zonas más frágiles y un manejo responsable de sus recursos, poniendo en valor sus paisajes culturales y naturales. "El territorio no es un vacio, sólo para la extracción, la acumulación de desechos y la progresiva emigración de la población rural”.

${ }^{93}$ Trasladar al plano del territorio este enfoque se asocia al concepto desarrollado por Rubén Pesci de multipolaridad. Este concepto se basa en la idea de crear o reforzar interfases sociales como "nodos de una red" que permite la asociación de muchos y pequeños centros con "condición de ciudad", dentro de una gran ciudad; dentro de un contexto territorial más amplio; o dentro de un particular contexto socioeconómico y cultural. Ello contribuye a aumentar la "diversidad" de oferta y demanda, haciendo más segura su "sustentabilidad". 


\section{IV.1.3. Interpretación del Proyecto como Paisaje a escala 'Lugar'}

Si las características generales del área de estudio a escala 'Territorio' favorecen alternativas de interconexión entre ambas márgenes del proyecto y, consecuentemente, una nueva posibilidad de recorrido y percepción de cada ámbito del territorio modificado y, a escala Área pueden ser interpretadas como Unidades de Ambiente y Paisaje (UAP), es en la escala de 'Lugar', dónde ese recorrido le permite al usuario y/o visitante, aprehender desde el conocimiento y la percepción la noción de 'unidad'.

\section{IV.1.3.1. Análisis Ecológico-Ambiental a escala Lugar}

Para esta escala de interpretación, podemos señalar que las zonas urbano-costeras se localizan en un área de transición entre lo natural y lo urbano, que les otorga especiales características, que pueden explicarse conceptualmente desde las siguientes condiciones específicas: a) son áreas de interfase construida entre el elemento agua y la ciudad; b) son áreas con valor ecológico y cultural de alta singularidad que le otorgan valor paisajístico.

\section{A. Las Zonas Urbano-Costeras como Interfase Natural}

Estas áreas o unidades territoriales y los diferentes ambientes que la conformaban, estaban definidas como un gran ecotono (o interfase), por constituirse en el punto de encuentro y superposición de distintos sistemas: el ambiental (fluvial -de ríos y arroyos-) y el territorial (urbano-rural).

Estas áreas de contacto suelo-agua o de ribera, pueden ser caracterizadas, además, en función de la conformación de la vegetación característica que originalmente se desarrollaba en cinco estratos.

Gráfico No $7: \quad$ ESTRATOS DE VEGETACIÓN

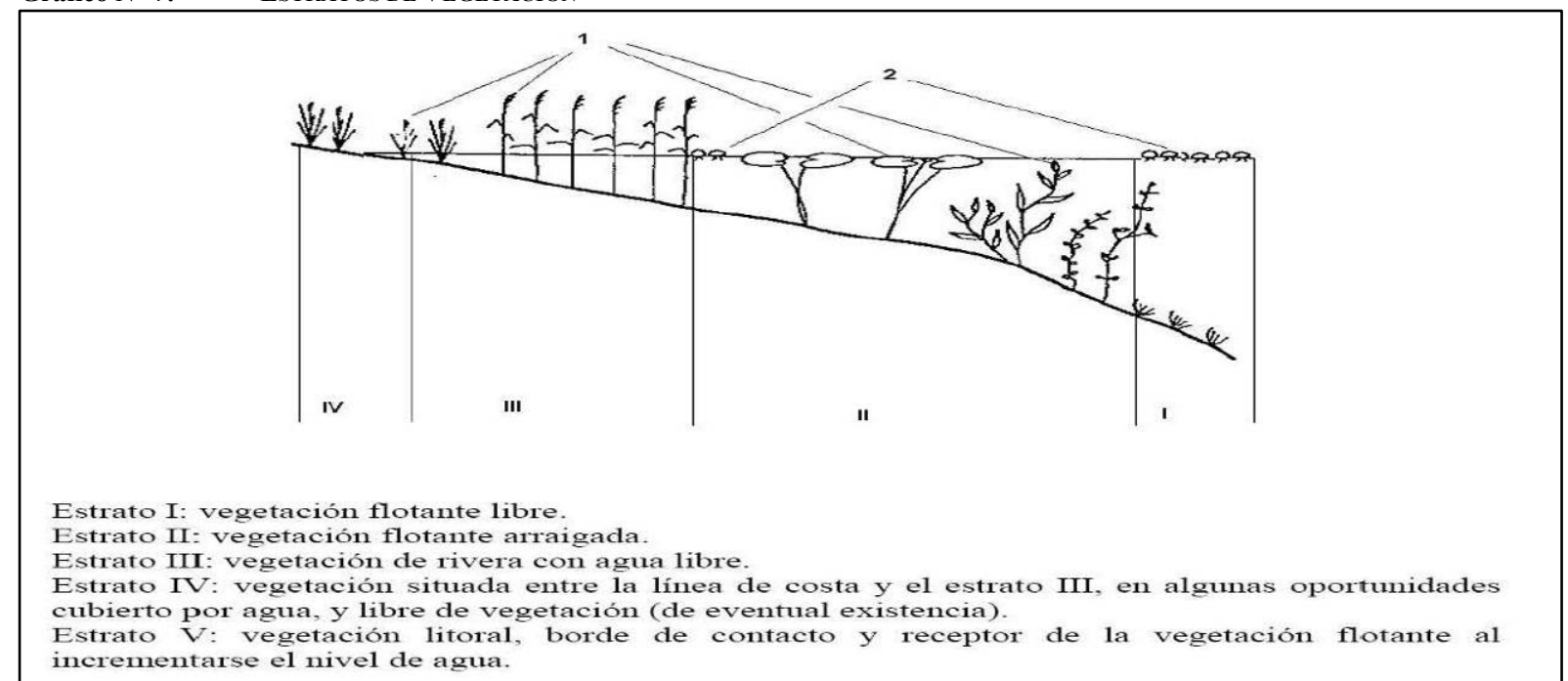

Fuente: EBY - PMMA, 2008.

En ese contacto, estas zonas bajas estaban originalmente sometidas a una serie de 'problemas', que pueden ser clasificados como: a) naturales: por efecto de las periódicas inundaciones; b) biológicos: como hábitat propicio para la cría y reproducción de vectores transmisores de enfermedades tropicales peligrosos para el ser humano; c) antrópicos: derivados de la libre disposición para ser ocupadas por la 
población lugareña, tanto para residencia como para trabajo (producción de ladrillos artesanales) y de procesos de contaminación provocados por las actividades productivas primarias y secundarias y por la ausencia de obras de saneamiento básico en las ciudades costeras. Factores estos, que determinaban su conformación como áreas de alto riesgo para la población urbana en general.

\section{B. Las Zonas Urbano-Costeras como Paisaje construido}

La nueva configuración costera, en el contacto entre sectores urbanos con el embalse principal sobre el río Paraná y con los arroyos que surcan las ciudades afectadas, están definiendo una interfase urbana que puede describirse dentro de los mismos parámetros anteriormente mencionados: a) naturales: dónde los bajos han sido inundados y en parte se han rellenado, recuperando amplios sectores como espacios públicos equipados, con áreas aptas para la inversión privada; además, las zonas de humedales perdidas en el entorno de las ciudades han sido compensadas con áreas de reserva protegidas y con planes de manejo en superficies análogas a las perdidas; b) biológicas: la desaparición de los bajos-inundables reduce los ambientes propicios para la proliferación de vectores de interés sanitario; c) antrópicos: la población ha sido relocalizada en zonas altas, en complejos habitacionales con todos los servicios básicos y equipamientos socio-comunitarios y las actividades económicas, han sido también relocalizadas y/o compensadas en su actividad.

Con las obras de tratamiento costero, los perfiles característicos de la zona cambian en la forma en la que se indica en el esquema adjunto:

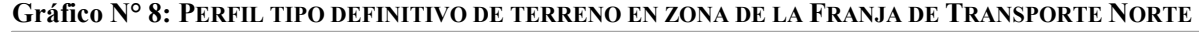

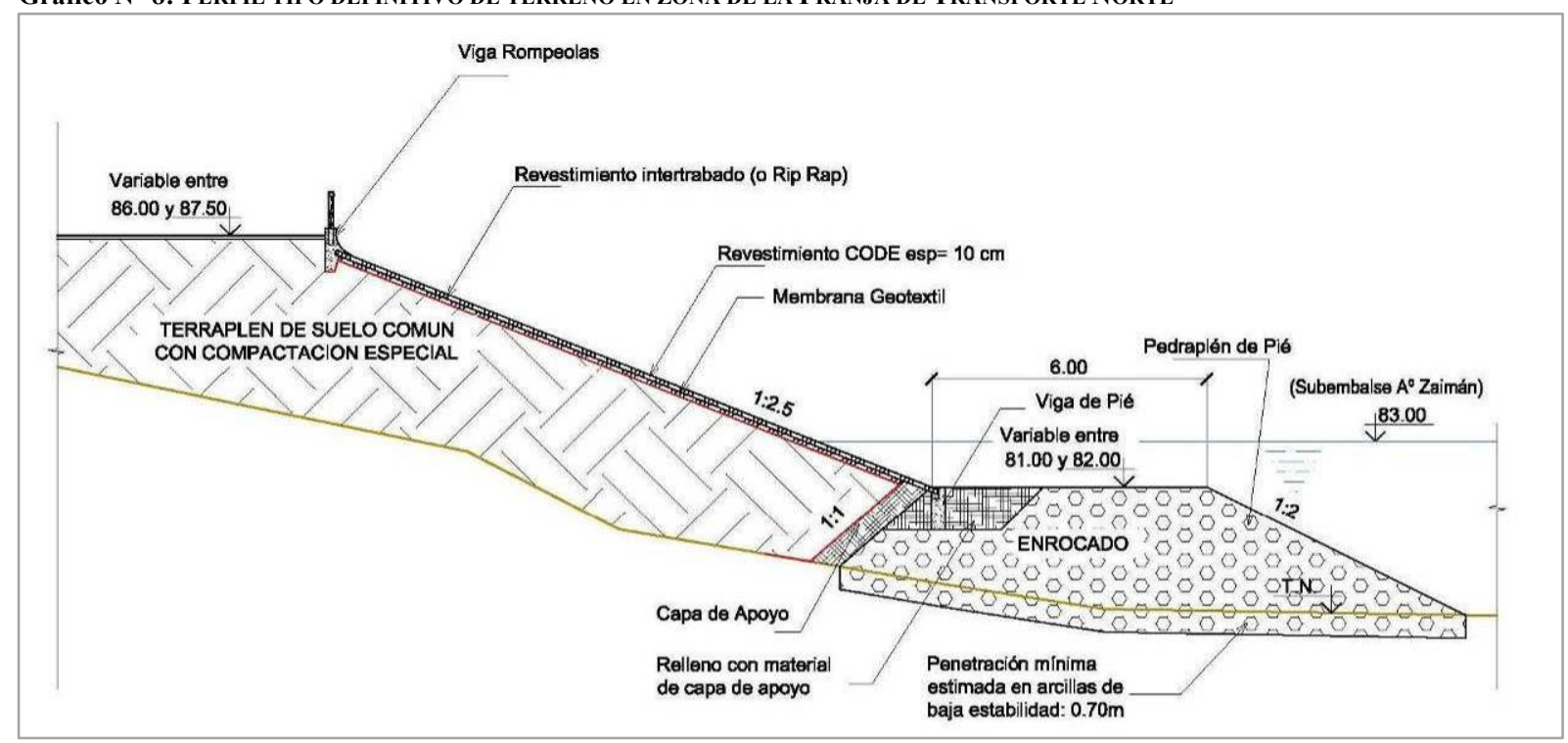

Fuente: EBY - PMMA, 2008.

En suma, el perfil típico, muestra el pase desde una línea de borde natural a la nueva conformación costera, que minimiza la formación de vegetación acuática, potencia los usos recreativos y de esparcimiento, reduce los ambientes propicios para la proliferación de vectores de interés sanitario y establece un límite estable entre el suelo y el agua; es decir, plantea nuevas relaciones río-ciudad. 


\section{IV.1.3.2. Análisis Histórico-Cultural y Geográfico-Urbanístico a escala Lugar}

Las Zonas Urbano-Costeras representan, desde este punto de vista, un factor de ordenación del nuevo Paisaje construido, que puede ser explicado realizando un análisis y reconocimiento de estas Zonas, a partir de ser interpretadas como 'Lugares' caracterizados y definidos por la potencialidad que presenta su problemática de transformación y sectorización, representada por tres niveles:

1. El primer nivel está definido por la nueva configuración costera sobre el embalse principal, que presenta ámbitos antes inexistentes, que tienen la conflictualidad de la memoria sobre lo perdido y la potencialidad de nuevas relaciones entre la ciudad y el río-embalse.

2. Un segundo nivel, en sentido longitudinal, está representado por el tratamiento de los antiguos arroyos, hoy transformados en subembalses urbanos, que tiene la conflictualidad de haber perdido sus albardones de ribera y de sectorizar los también antiguos barrios, y la potencialidad de aportar una valoración estética desde los nuevos ámbitos urbanizados y de recreación, y un valor ambiental, desde la conservación de sus áreas de cabecera con reservas o parques urbanos que, en conjunto, otorgan carácter a cada sector urbano (Lugar).

3. Un tercer nivel está determinado por las diferentes modalidades en que se desarrollan las actividades urbanas, a partir de los ejes de circulación urbana y metropolitana, representados por las vías de comunicación ferro-viales de cada ciudad y área metropolitana de cada país, y por el Puente Internacional que las vincula, que presentan la problemática de sectorización y la potencialidad de integración urbana, metropolitana y regional.

De otra forma, puede expresarse que el problema (conflicto) de fondo no son las respuestas de transformación urbana ni las actividades que se desarrollan en la ciudad (nivel físico-construido), sino las relaciones (nivel relacional) que definen las modalidades de usos entre los elementos (significantes) que conforman estas Zonas y entre éstas y su entorno físico y humano inmediato. Pero, como todo conflicto, puede ser analizado además desde su potencialidad, podemos decir también, que estos grados de sectorización, permiten identificar lugares que -no exentos de situaciones negativas-, poseen características intrínsecas que le otorgan singularidad. Esa singularidad está determinada por la presencia de matrices de ambiente y paisaje (potencialidad), que articulan naturaleza y cultura, en un ámbito propicio para ser gestionado concertadamente y ser reconocidos y revalorizados así, por el conjunto de la sociedad. Para que ello sea posible, es necesario comprender la situación de cada 'Lugar', a fin de poder identificar posteriormente las potencialidades que ofrecen para una gestión paisajística, que aporte nuevos significados al paisaje urbano y regional.

Desde esta perspectiva, e integrando estos criterios que articulan conflicto y potencialidad, pueden reconocerse dentro de cada área metropolitana, los siguientes 'Lugares' o ámbitos de ambiente y paisaje: 


\section{A. Lugares en el Área Metropolitana de Posadas (AMeP)}

En coincidencia con los distintos tramos y modalidades de intervención del área urbano-costera, se reconocen ocho (8) Lugares:

Plano $N^{\circ}$ 51: Interpretación de las Zonas Urbano-Costeras en la Margen Argentina como Lugares

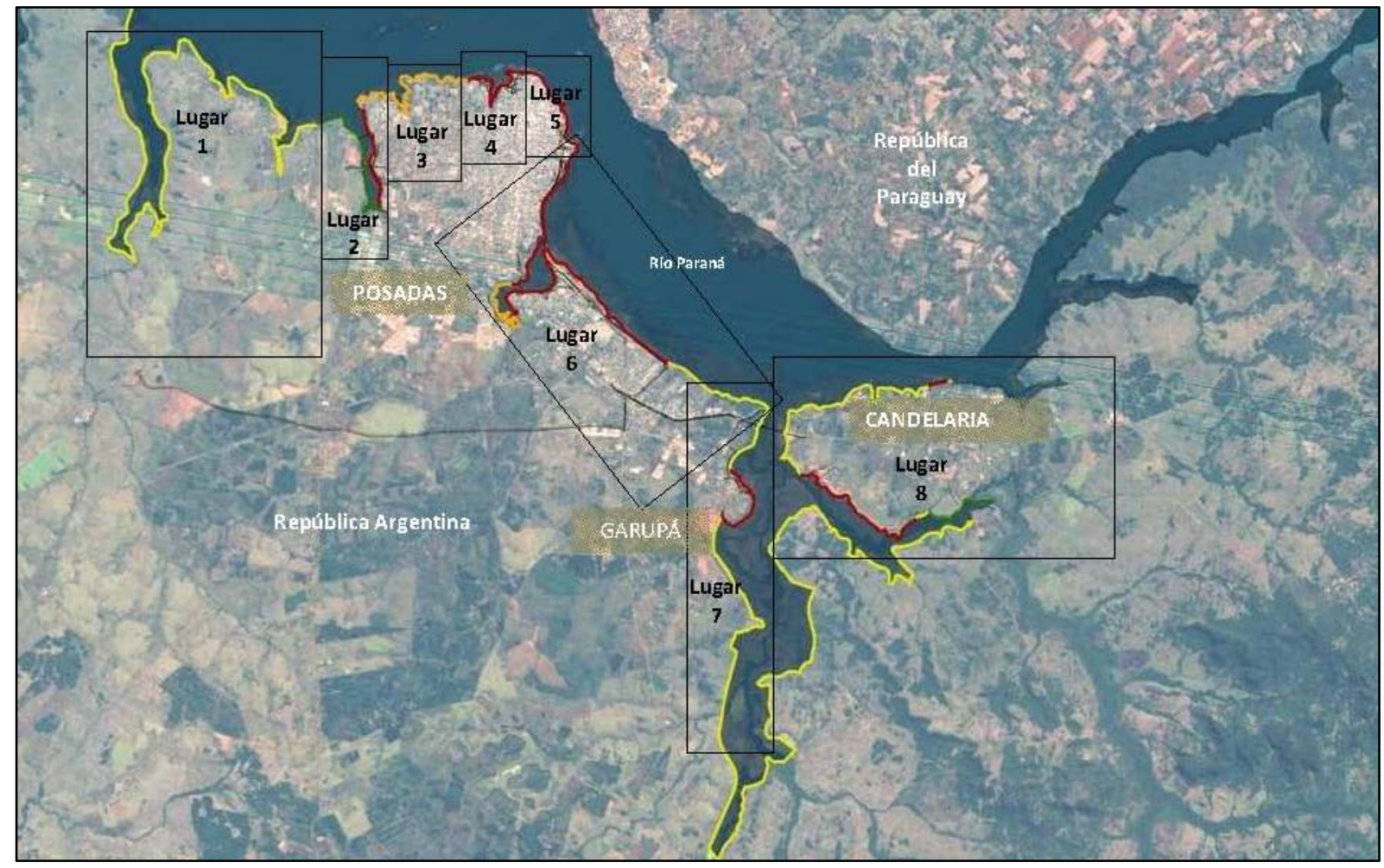

Fuente: Elaboración Propia, en base a información EBY

\section{Lugar 1: Del PAisAJE DEL ARROYo ITAembÉ DE PosADAS}

Definido por la Costa del río Paraná al N, el subembalse rural del A Itaembé (límite entre las provincias de Misiones y Corrientes) al N-O; la margen izquierda del subembalse urbano del $\mathrm{A}^{\circ}$ Mártires al S-E y el entorno de la Ruta Nacional $N^{\circ} 12\left(\mathrm{RN}^{\circ} 12\right)$ al Sur.

El Lugar, al que se accede desde la $\mathrm{RN} \mathrm{N}^{\circ} 12$, se corresponde con un área complementaria urbana de la ciudad de Posadas, dónde se localizan barrios residenciales de baja densidad y una zona de reserva del IPRODHA para la construcción de un barrio-parque de 2.000 viviendas, con zonas dedicadas a la producción forestal y otras pequeñas industrias de ladrillos y extractivas, y grandes equipamientos urbanos, como el Aeropuerto Internacional, los nuevos Puerto y Parque Tecnológico Industrial, la Planta de Tratamiento de Efluentes Cloacales, el Centro del Conocimiento, hotelería internacional y el Parque de la Ciudad.

Las principales componentes del paisaje del Lugar son: a) El Subembalse del A Itaembé; b) El Tratamiento de la Costa Natural sobre el Embalse Principal; c) El Área Complementaria Urbana entre el río y la $\mathrm{RN}^{\circ}$ 12; d) La Periferia Urbana, al Sur de la $\mathrm{RN} \mathrm{N}^{\circ} 12$. 


\section{Figura ${ }^{\circ}$ 8: LUgAR 1 - DEL PAISAJE DEL ARROYO ITAEMBÉ}

Se localiza en la zona Oeste de la ciudad de Posadas y representa un área complementaria urbana, dónde el arroyo Itambé se constituye como límite entre las Provincias de Corrientes y Misiones.

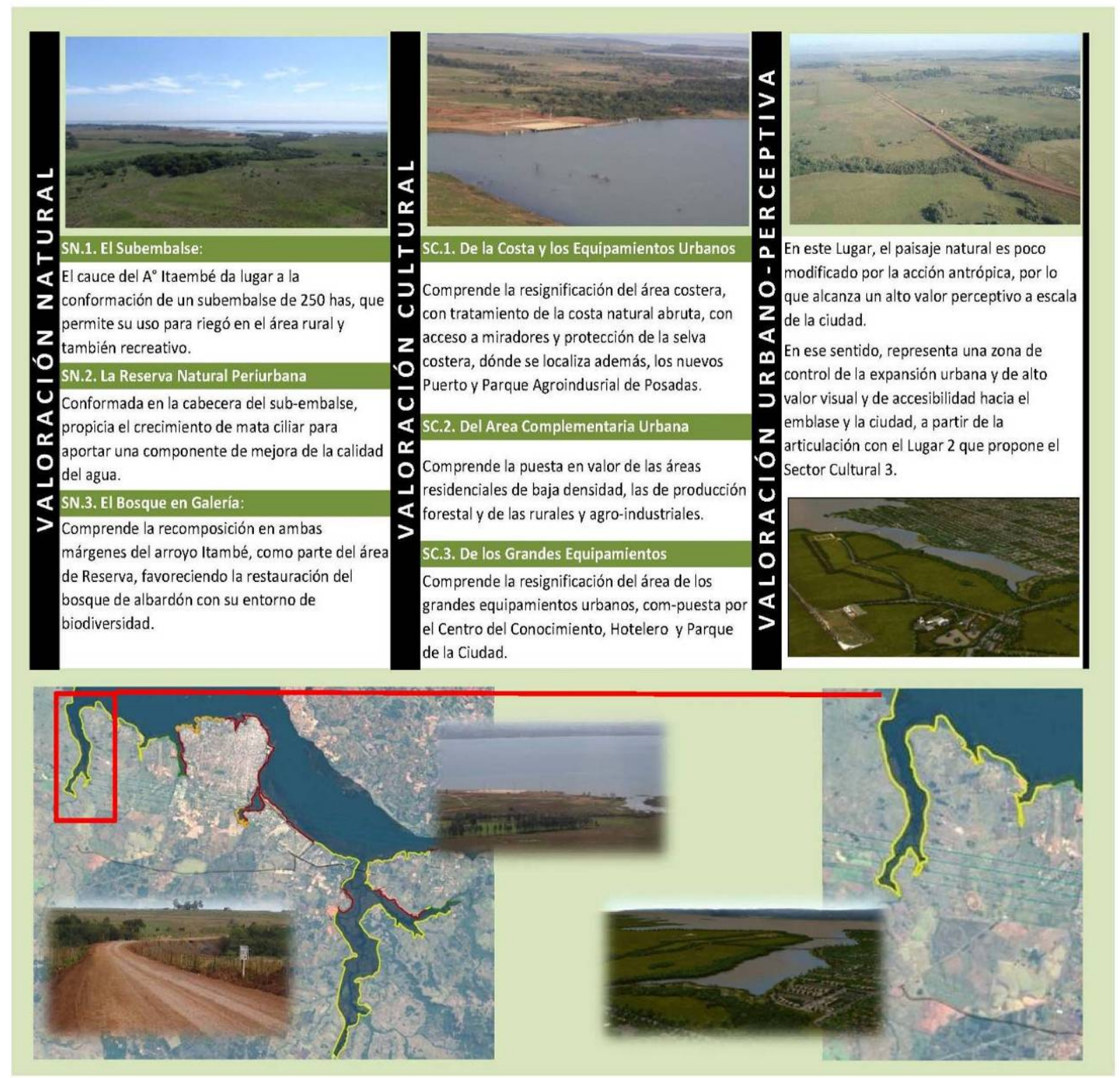

Fuente: Elaboración propia.

\section{LUGAR 2: DEL PAISAJE DEL ARROYO MÁRTIRES DE POSADAS}

Definido por el entorno urbano del subembalse del arroyo Mártires, el Lugar, al que se accede desde la ciudad y desde la $\mathrm{RN}^{\circ} 12$, constituye un límite natural, ahora potenciado por el subembalse, entre el área urbana y la complementaria-urbana de la ciudad de Posadas.

Las componentes principales del paisaje del Lugar son: a) El Subembalse del $\mathrm{A}^{\circ}$ Mártires; b) El Tratamiento Urbano-Costero de la margen derecha del subembalse; c) El Tratamiento Natural, como área de conservación, de la margen izquierda del subembalse; d) Los Puentes, que vinculan las áreas urbanas y complementaria-urbana de la ciudad; e) La Reserva o Parque Natural Urbano de la cabecera del subembalse y la periferia urbana-sur. 


\section{Figura N $^{\circ}$ 9: LugAR 2 - DEL PAISAJE DEL ARROYO MÁRTIRES}

Se localiza en la zona Oeste de la ciudad de Posadas y representa el límite entre el casco urbano y la zona complementaria urbana, dónde se localizan el Nuevo Puerto, el Aeropuerto Internacional, el Centro de Convenciones y el Parque de la Ciudad.

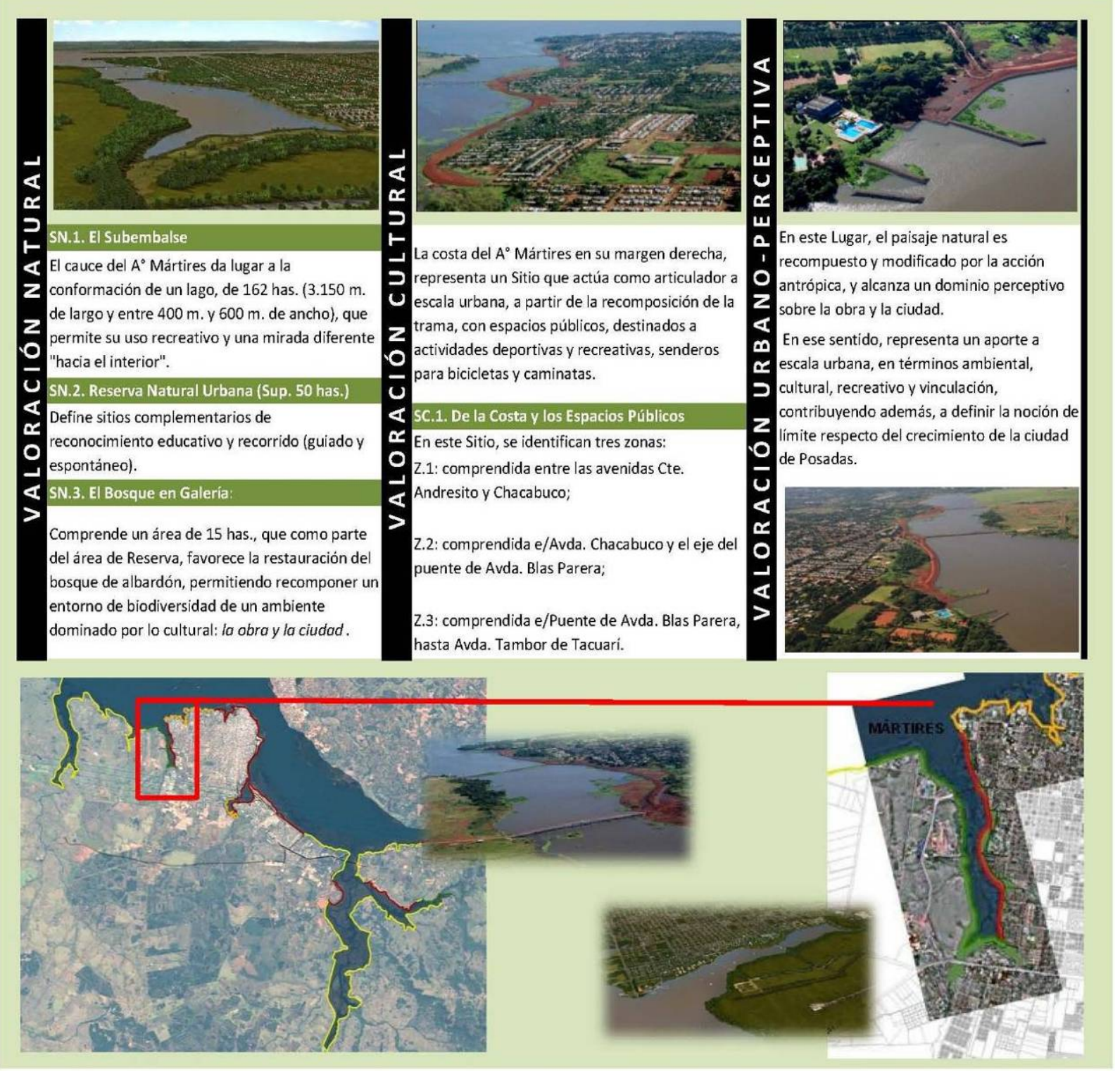

Fuente: Elaboración propia.

\section{LUGAR 3: DEL PAISAJE DEL ARROYO ANTONICA Y DE LA COSTA NATURAL DE PosAdAS}

Definido por el entorno urbano del subembalse del $\mathrm{A}^{\circ}$ Antonica y la Costa Natural Alta localizada entre los arroyos Mártires al N-O e Itá al S-E. El Lugar, al que se accede desde la ciudad y desde la $\mathrm{RN} \mathrm{N}^{\circ} 12$, constituye un mirador hacia el embalse principal, determinado por la altura que, respecto de éste, tiene este sector urbano de la ciudad de Posadas.

Las componentes principales del paisaje del Lugar son: a) El Subembalse del $\mathrm{A}^{\circ}$ Antonica; b) El Tratamiento de la Costa Natural; c) El Entrono Urbano, con el nuevo Puente, sobre avenida Centenario y arroyo Antonica, que articula dicho entrono con la ciudad; d) La Reserva o Parque Natural Urbano de la cabecera del subembalse y la periferia urbana-sur. 


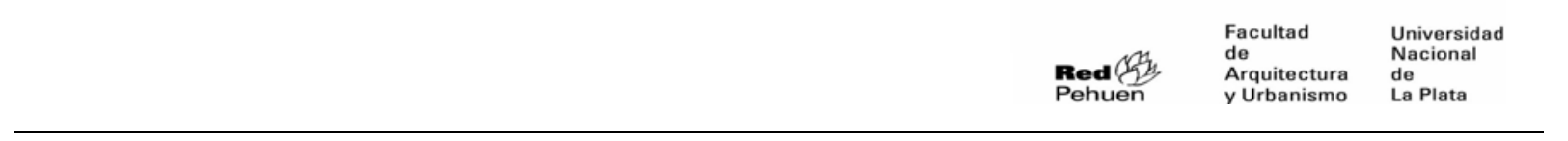

\section{Figura N $^{\circ}$ 10: Lugar 3 - DEL PAISAJE DEL ARROYO ANTONICA Y DE LA COSTA NATURAL}

Se localiza en la zona Noroeste de la ciudad, sobre el embalse del río Paraná, desde la desembocadura del A Mártires hasta la in-tersección de la linea de ribera con la Av. Aguado, dónde se vincula con el Lugar 4.

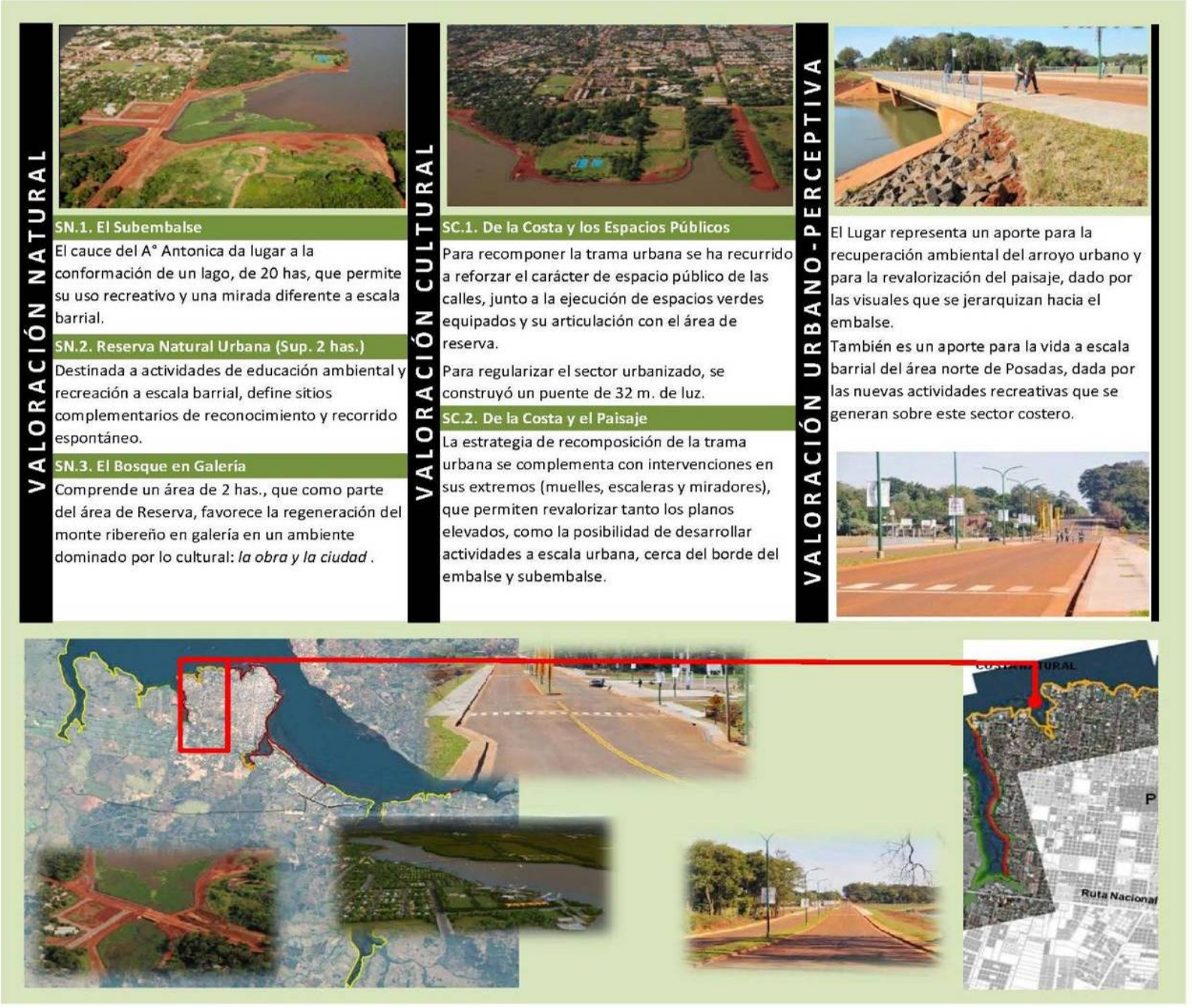

Fuente: Elaboración propia.

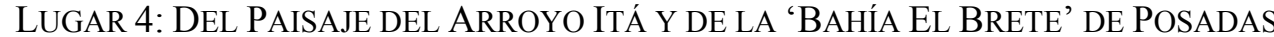

Definido por el entorno urbano del subembalse del $\mathrm{A}^{\circ}$ Itá, este Lugar, constituye el límite natural del Casco Urbano Fundacional de la ciudad de Posadas al que se accede, como continuidad urbana, desde la Costanera Centro de la ciudad y desde la Avenida Urquiza.

Las componentes principales del paisaje del Lugar, que otorgan un nuevo carácter a barrios tradicionales de la ciudad, son: a) El Subembalse del A Itá; b) El Tratamiento Urbano-Costero de la margen derecha del subembalse, con Avenida Costanera, amplias zonas públicas equipadas y la recuperación del tradicional 'Balneario El Brete'; b) El Tratamiento Urbano-Costero de la margen izquierda del subembalse, con su expansión hacia el embalse principal, con sectores destinados a clubes de canotaje y náuticos; c) El Entorno Urbano, con el nuevo Puente sobre Av. Urquiza y A ${ }^{\circ}$ Itá, como continuidad de la Avenida Costanera; d) La Reserva o Parque Natural Urbano de la cabecera del subembalse y su entorno urbano. 


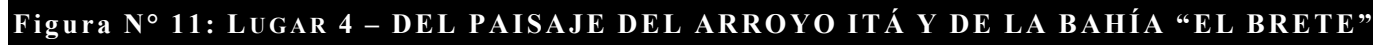

Se localiza en la zona Noroeste de la ciudad, en el límite entre la nueva costanera (paseo público) y el área destinada a clubes de la costa natural (más privada), que convierte a este sector en el remate de la Avenida Costanera de Posadas (Lugar 5).

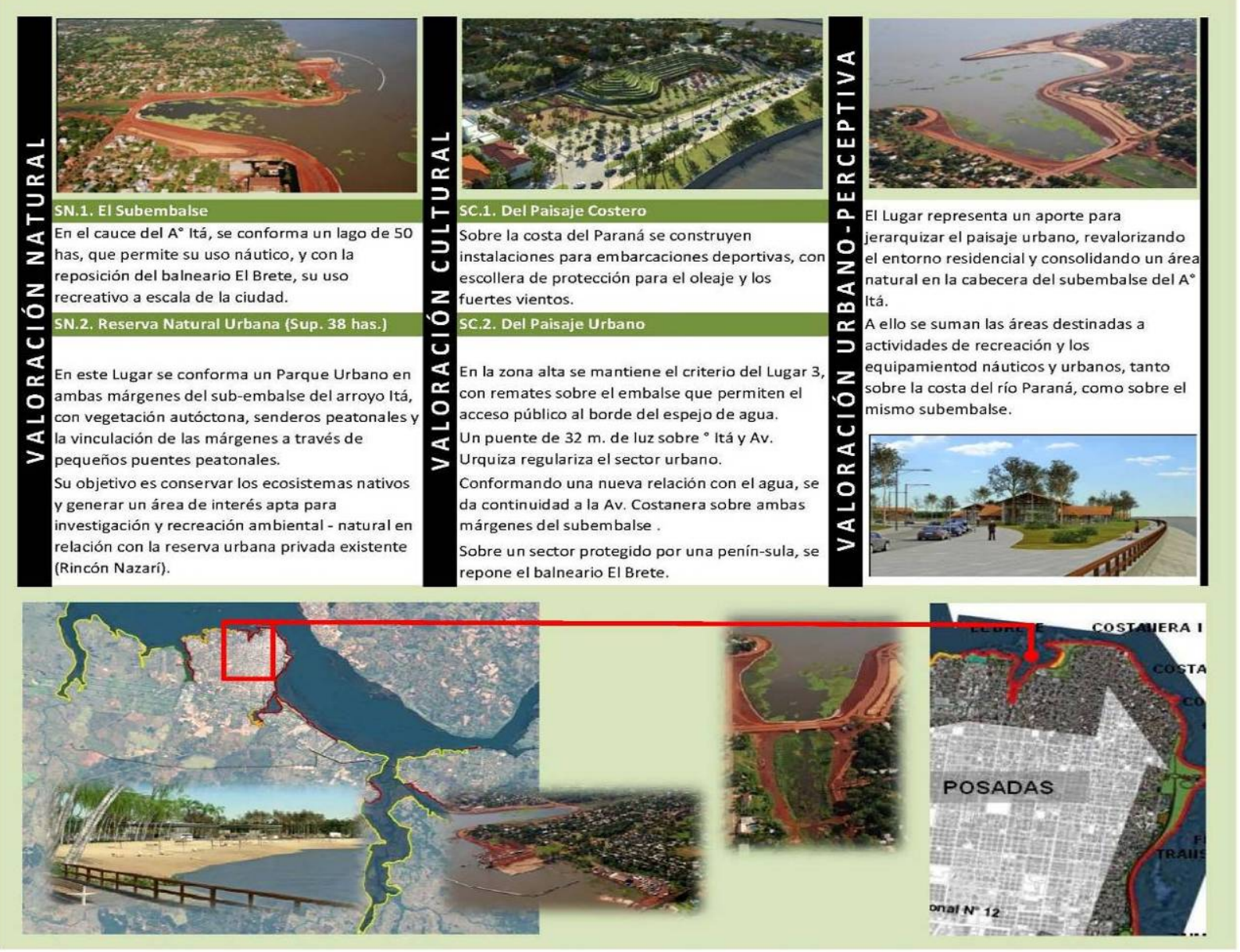

Fuente: Elaboración propia.

\section{Lugar 5: Del Paisaje Urbano-Costero del Casco Fundacional de Posadas}

Definido por la Costanera de Posadas, se localiza sobre el embalse principal del río Paraná, entre la prolongación de la Av. Roca, en el límite con el Lugar 5, hacia el Norte; el Puente Internacional al Sur y el área urbana centro de Posadas al Oeste.

Las componentes principales del paisaje del Lugar, que otorgan un nuevo carácter urbano al casco fundacional de la ciudad, está conformado por: a) El Entorno Residencial y de Servicios de los tres primeros Tramos de la Costanera; b) La Recuperación del Patrimonio Urbano-Ambiental del cuarto Tramo, con la 'Villa Cultural La Estación' (compuesta por Plaza Cultural de 3,5 has., Edificio Cultural de $1.750 \mathrm{~m}^{2}$, Edificio de Artesanos de $700 \mathrm{~m}^{2}$ y Museo Ferroviario, Teatro al aire libre y fuente histórica, de $1.500 \mathrm{~m}^{2}$ ); el rescate del Ferry ('Presidente Roque Sáenz Peña' o 'Ezequiel Ramos Mejía'), con infraestructura de amarre y pasarelas para peatones y pescadores; el Centro de Fronteras Argentino - Paraguayo con $2.500 \mathrm{~m}^{2}$ destinados a reponer el Embarcadero e instalaciones de apoyo (con boleterías, Prefectura, Migraciones, Aduana, Administración de Puertos, estacionamiento y espacio verde) y de un Parque Urbano de 12,5 has, en el límite con la cabecera del Puente Internacional. 


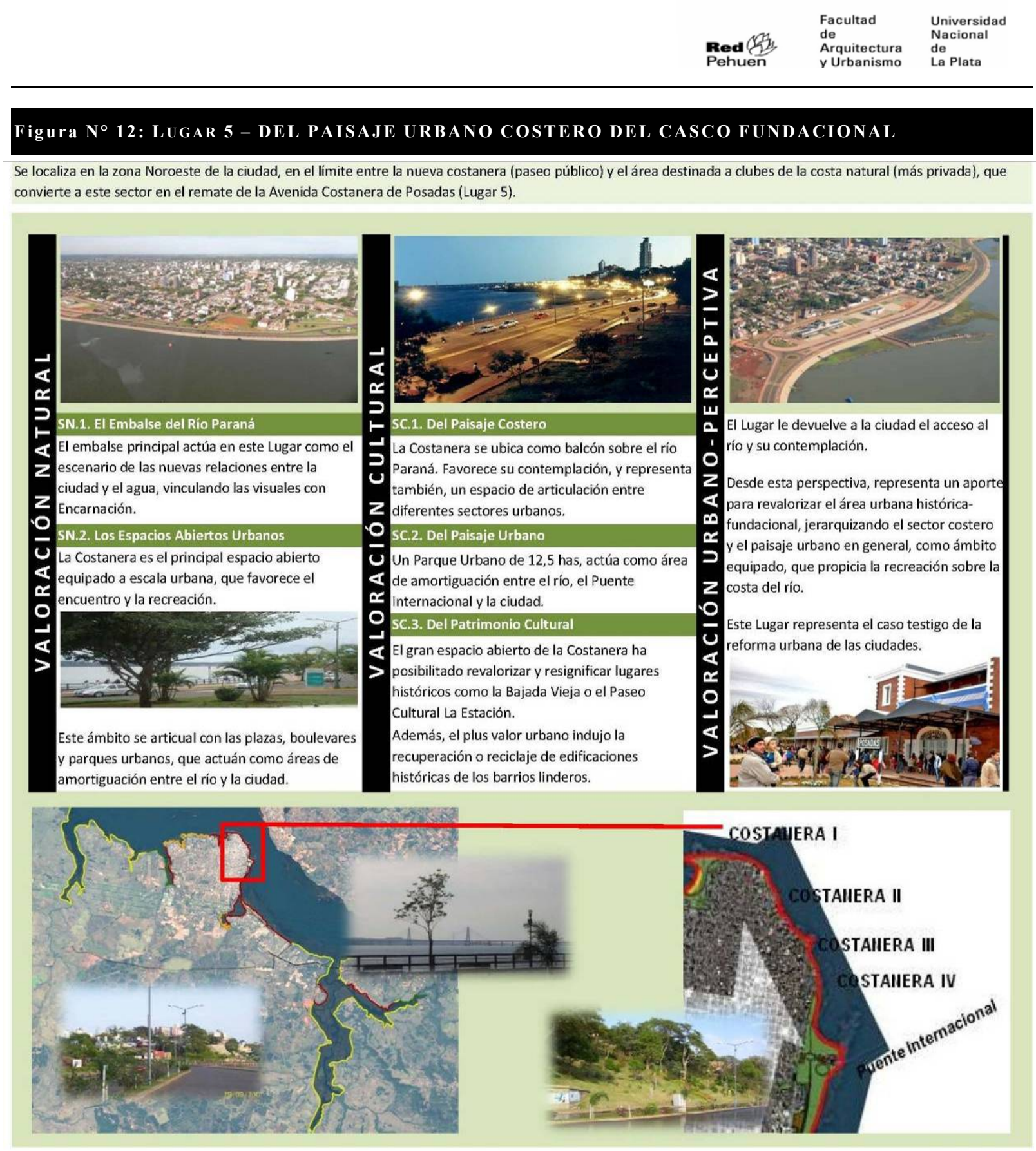

Fuente: Elaboración propia.

\section{LUGAR 6: DEl ARROYo ZAIMÁN y DEL ACCESO SUR, ENTRE POSADAS Y GARUPÁ}

Definido por el área comprometida por el nuevo Acceso Sur a Posadas y el área de subembalse del arroyo Zaimán, limitando con el Puente Internacional, al Norte; el embalse principal del río Paraná, al Este; el entorno de la RN No 12, al Oeste y la desembocadura del arroyo Garupá, al Sur.

Este Lugar constituye una amplia interfase periurbana entre las ciudades de Posadas y Garupá, cuyas principales componentes paisajísticas, son: a) El tratamiento costero y el entorno periurbano de la Franja de Transporte Norte del Acceso Sur; b) El Tratamiento Urbano-Costero del subembalse del arroyo Zaimán; c) El tratamiento costero y el entorno periurbano de la Franja de Transporte Sur del Acceso Sur; d) El entorno periurbano de Garupá en el área del Nodo Vial Garita del Acceso Sur y de la Multitrocha de la $\mathrm{RN}^{\circ}$ 12; e) La Zona Costera de Garupá sobre el embalse principal. 


\section{Figura ${ }^{\circ}$ 13: Lugar 6 - DEL PAISAJE Del ARROYO ZAIMÁn Y DEL ACCESO SUR A POSADAS}

Se localiza en la zona Sur de la ciudad de Posadas, en una franja de 7,5 Km. sobre la costa del río Paraná, desde el Puente Internacional Posadas-Encarnación y el kilómetro 10 de la RN № 12, en la zona de la Garita.

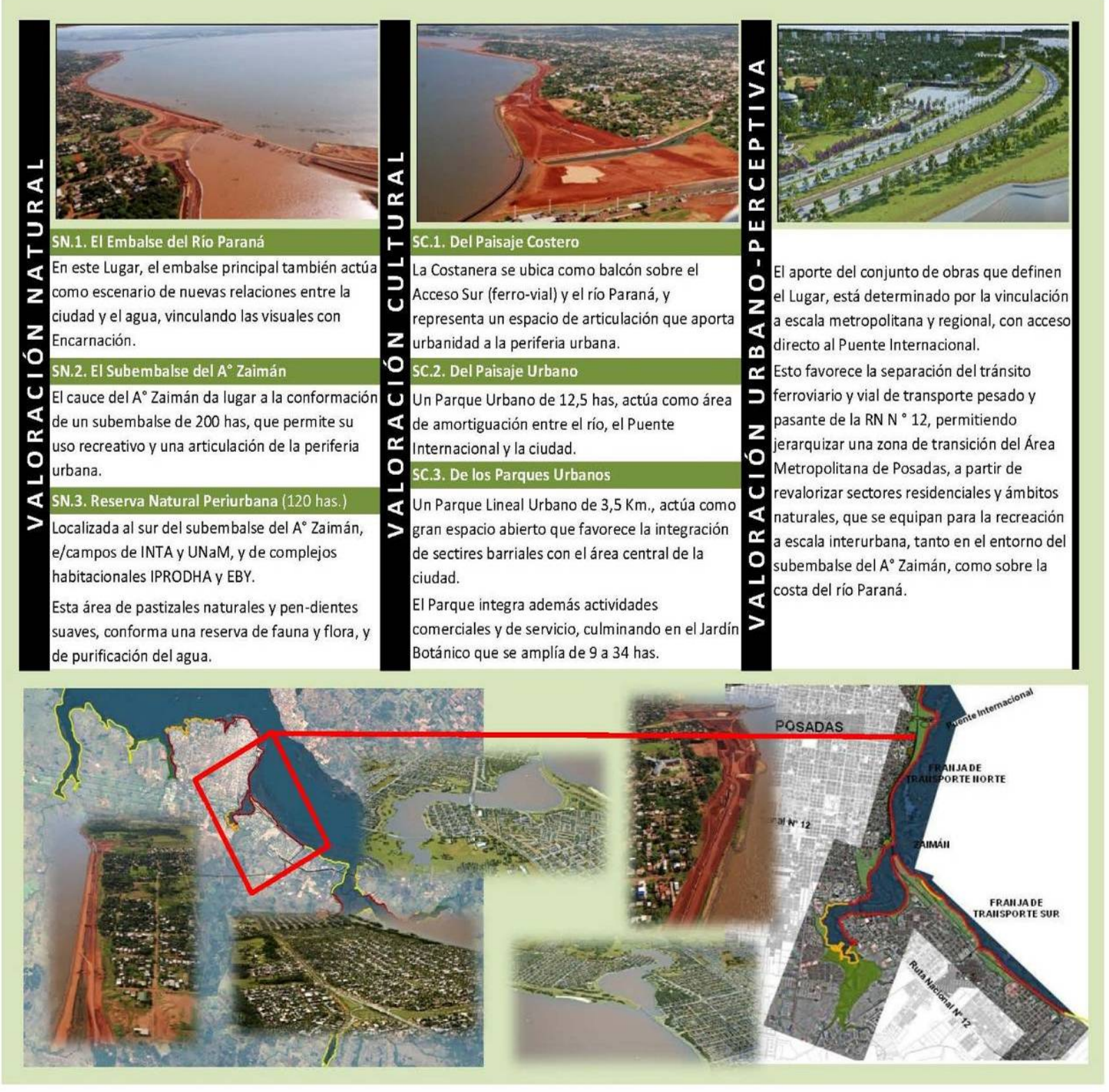

Fuente: Elaboración propia.

\section{LUGAR 7: DEL ARROYo GARUPÁ Y DE LA COSTA URBANA DE LA CIUDAD}

Definido por el área urbana de la ciudad de Garupá, localizada sobre la margen derecha del arroyo homónimo, este Lugar, constituye una zona de recomposición urbanística de dicha ciudad, cuyas principales componentes paisajísticas son: a) El tratamiento urbano-costero, con la nueva Avenida Costanera, la jerarquización del casco urbano fundacional, la Estación Ferroviaria y la reposición del Balneario Municipal; b) La Costa Natural, en el desembocadura del arroyo en el embalse principal; c) La Reserva Urbana y el entorno periurbano en la zona de confluencia de los arroyos Negro y Tranquera; d) El Puente sobre el arroyo Garupá, que la vincula con Candelaria y el norte misionero. 


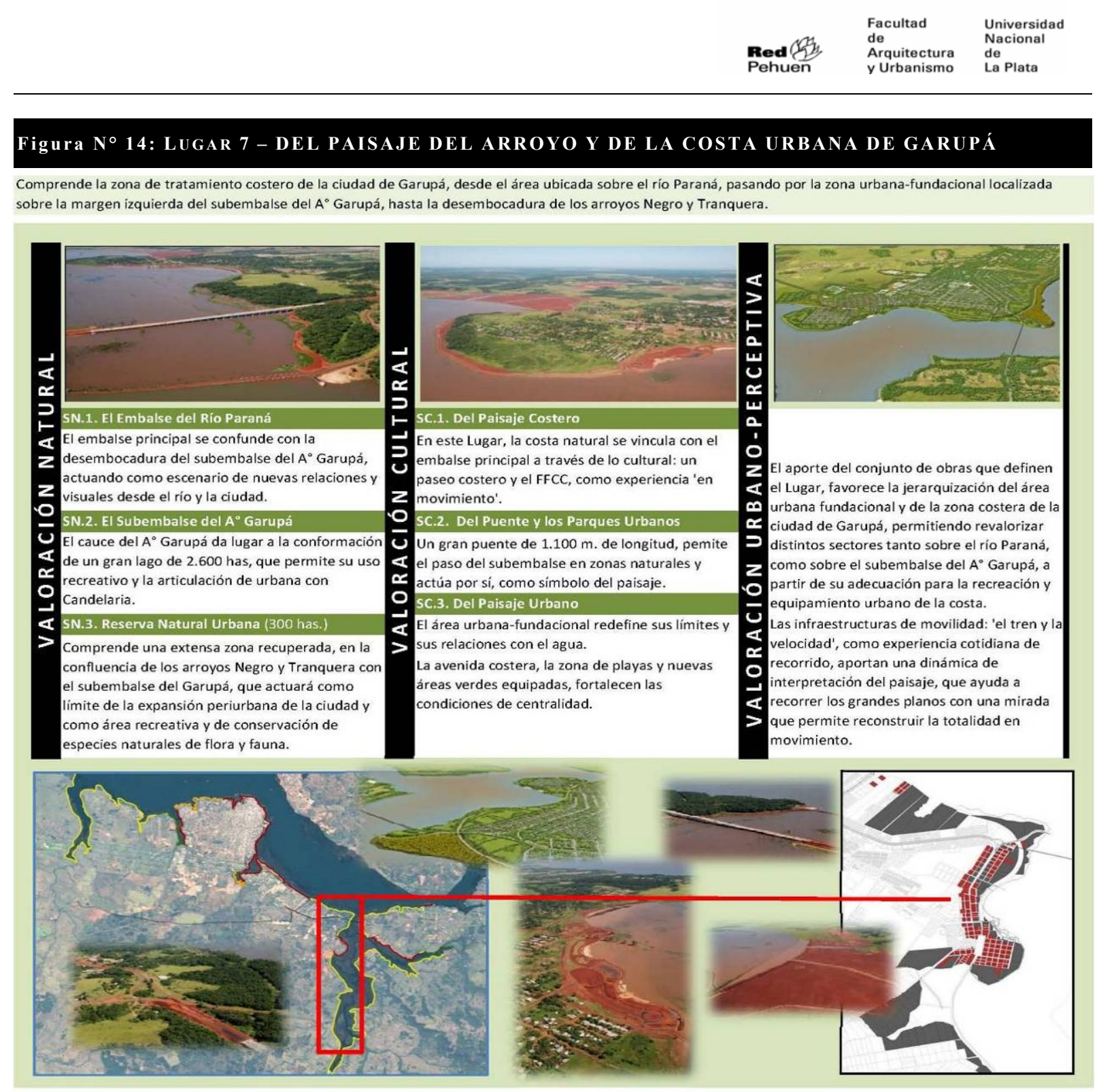

Fuente: Elaboración propia.

\section{LUGAR 8: Del ARRoyo GARUPÁ Y DE LA COSTA URBANA DE LA CIUDAD DE CANDELARIA}

Definido por el área urbana de la ciudad de Candelaria, localizada sobre el embalse principal del río Paraná, al Este; sobre la margen izquierda del subembalse del arroyo Garupá, al Norte y Oeste y con el arroyo San Juan y Reserva Ecológica Compensatoria 'Campo San Juan', al Sur.

Este Lugar constituye una zona de jerarquización urbanística de dicha ciudad, cuyas principales componentes paisajísticas son: a) La zona urbano-costera con el embalse principal, con la nueva Avenida Costanera, la reposición del Balneario Municipal, la jerarquización del casco urbano fundacional y del área de las Ruinas Jesuíticas; b) La zona de costa natural, sobre el embalse principal y la desembocadura del arroyo en el embalse, con el Puente sobre el arroyo Garupá que la vincula con esa ciudad y con Posadas, y con el norte misionero; c) La zona urbano-costera con el subembalse del arroyo Garupá, con su paseo costero, playas y parques y áreas públicas equipadas; d) La Zona de Reserva Natural Urbana de la cabecera del subembalse; c) El entorno periurbano y rural, con al Puente sobre el arroyo Garupá en la Ruta Provincial Nº 204. 


\section{Figura N 15: Lugar 8 - DEL PAISAJE DEL ARROYO GARUPÁ Y DE LA COSTA URBANA DE CANDELARIA}

Comprende a toda la zona de tratamiento costero de la ciudad de Candelaria, que como una península, se ubica entre el río Paraná y el subembalse del arroyo Garupá.
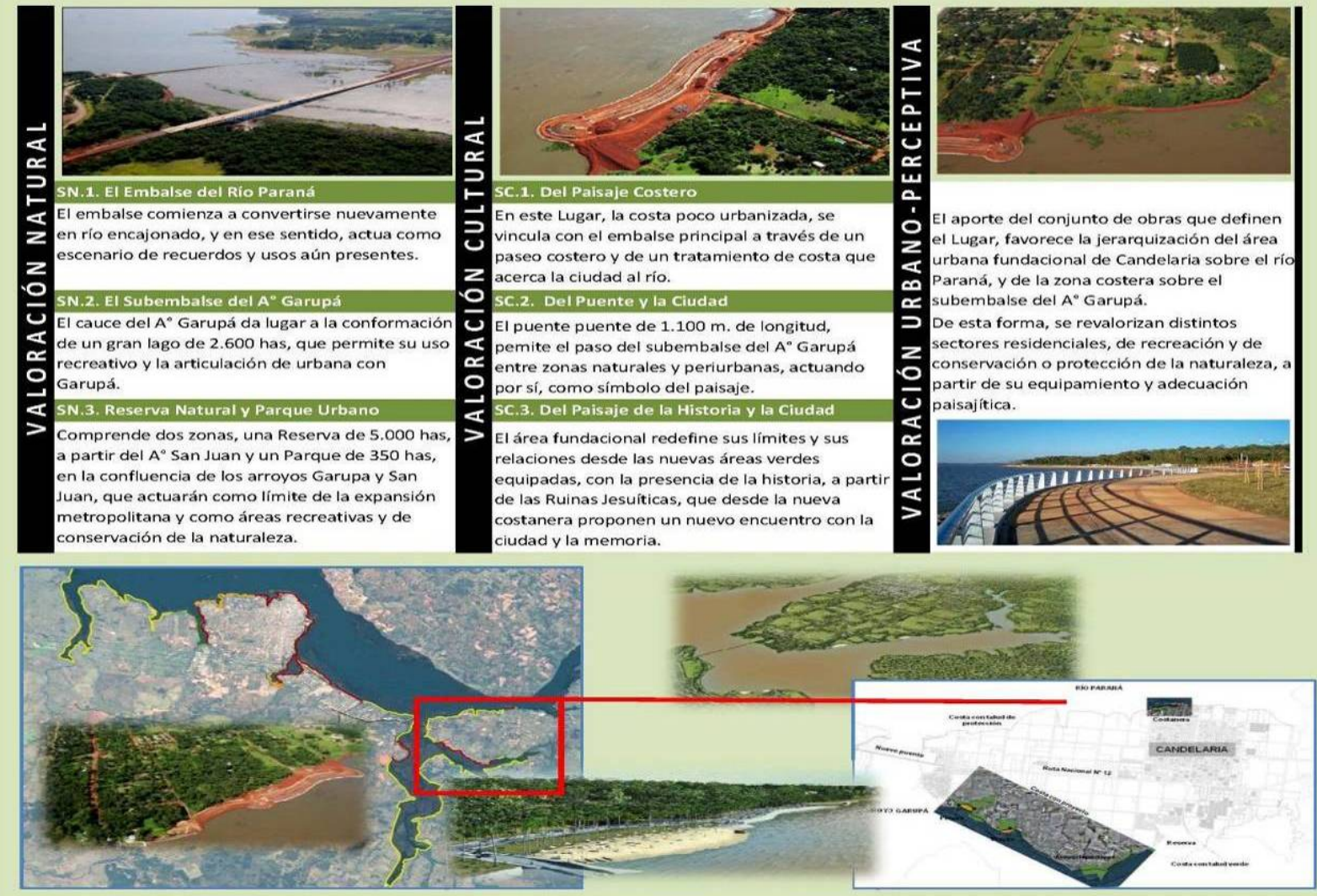

Fuente: Elaboración propia.

\section{B. Lugares en el Área Metropolitana de Encarnación (AMeE)}

En coincidencia con los distintos tramos y modalidades de intervención del área urbano-costera, se reconocen seis (6) Lugares:

Plano $N^{\circ}$ 52: Interpretación de las Zonas Urbano-Costeras en la Margen Paraguaya como Lugares

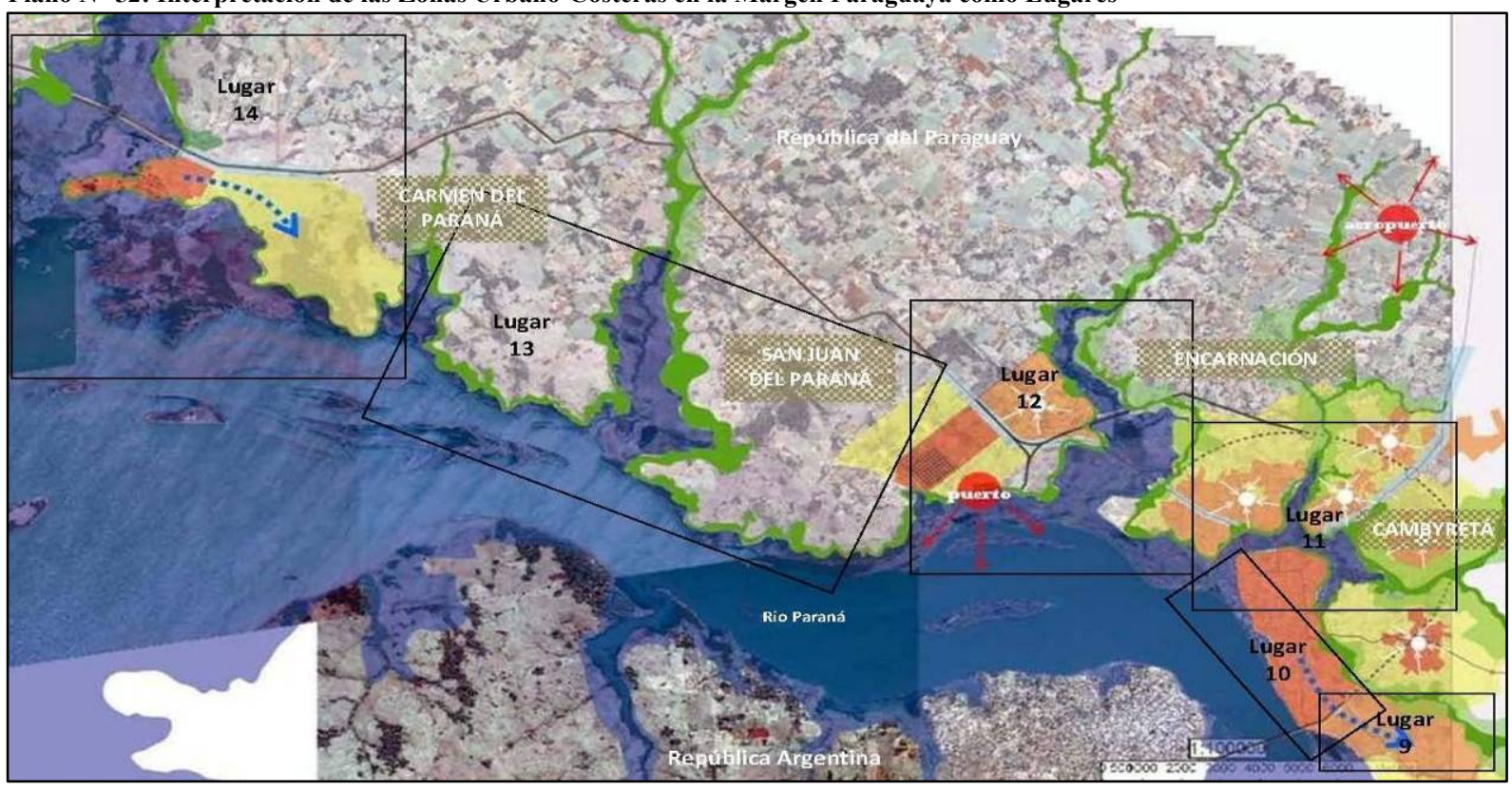

Fuente: Elaboración Propia, en base a información EBY 
LUGAR 9: DE LA COSTA SUR DE ENCARNACIÓN Y EL ENTORNO RURAL

Definido por el área de expansión urbana de la ciudad de Encarnación, localizada sobre el embalse principal del río Paraná, al Oeste; la margen izquierda del arroyo Poti’y en su tramo Sur; y el área del FFCC y nuevo Circuito Comercial de Encarnación, al Norte.

Este Lugar constituye una zona de consolidación como nueva centralidad urbano-residencial, a partir de las propias intervenciones de Yacyretá, cuyos principales componentes paisajísticos son:

a) La zona urbano-costera con el embalse principal, con el nuevo Paseo Costero, la reposición del Balneario Municipal, los espacios públicos equipados y la zona residencial de San Isidro;

b) La zona de protección ambiental del arroyo Poti’y, en su tramo Sur;

c) El entorno Rural.

\section{Figura N $^{\circ}$ 16: LUGAR 9 - DEL PAISAJE COSTERO DE ENCARNACIÓN Y DEL ENTORNO RURAL}

Se localiza en la zona Sur de Encarnación sobre el río Paraná, desde el Puente Internacional hasta unos $2.500 \mathrm{~m}$. al sureste del puente, abarcando toda la zona costera del barrio San Isidro construido por Yacyretá.

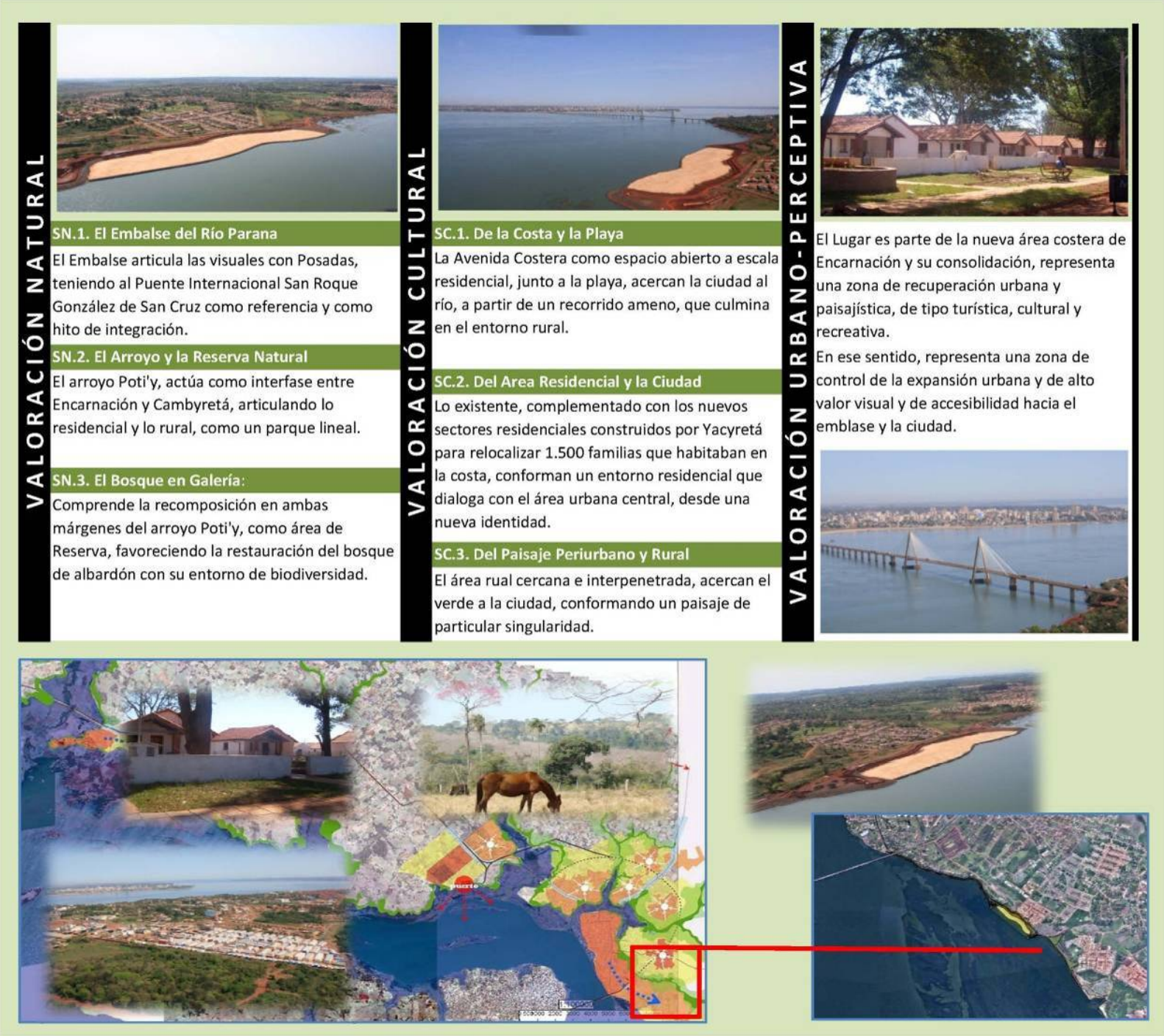

Fuente: Elaboración propia. 


\section{LUGAR 10: DE LA COSTANERA DE ENCARNACIÓN SOBRE EL EMBALSE PRINCIPAL}

Definido por la Costanera del casco urbano fundacional de Encarnación, se localiza sobre embalse principal del río Paraná al Oeste; el Puente Internacional al Sur; el área urbana central al Este y el subembalse del arroyo Mboi Caé, al Norte.

Los principales componentes del paisaje del Lugar, que otorgan un nuevo carácter urbano al casco urbano fundacional de la ciudad, está conformado por:

d) El Entorno Residencial y de Servicios del área de Pacú Cuá, desde el Puente Internacional hasta la Avenida Japón;

e) La Zona de Recuperación Urbana Centro, comprendida entre la Av. Japón y la calle Curupaity, con el área de la ex Zona Baja Comercial y el entorno urbano existente;

f) La Zona de Recuperación Urbana Norte, con el área urbana costera-central, los edificios y monumentos históricos, espacios públicos equipados y parques urbanos y el área de cabecera del puente sobre la Ruta Nacional $N^{\circ} 1$.

\section{Figura N $^{\circ}$ 17: Lugar 10 - Del PAISAJE COSTERO De ENCARNACIÓN SOBRE EL EMBALSE}

Comprende los $4.800 \mathrm{~m}$ de frente urbano de la ciudad Encarnación sobre el río Paraná, desde el Puente Internacional al Sur, hasta la desembocadura del subembalse del arroyo Mboi Tesá sobre dicho embalse principal, al Norte.

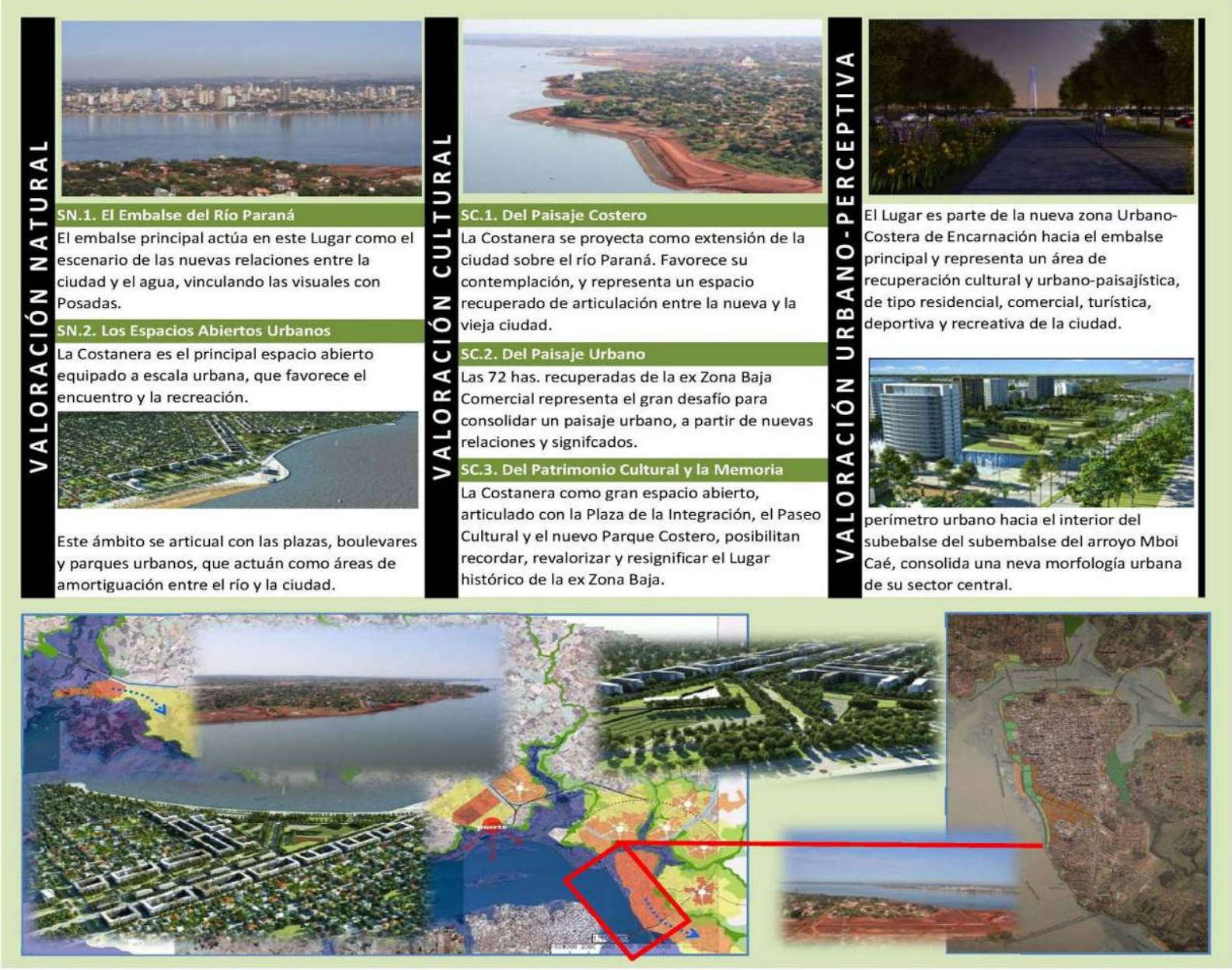

Fuente: Elaboración propia. 


\section{LugAR 11: De LA CuENCA DEL ARROYo MBOI CAÉ}

Comprende un amplio sector urbanizado, conformado por la cuenca inferior del arroyo Mboi Caé, cuyo subembalse incluye a los arroyos Tacuapí, Santa María y Poti'y. Los principales componentes del paisaje del Lugar son: a) La Zona Urbano-Costera del $\mathrm{A}^{\circ}$ Mboi Caé (MI), con la Av. Costanera, los espacios públicos y el entorno Residencial de los Barrios Sta. Rosa, Padre Bolik y Bernardino Caballero; b) La Zona Costera del $\mathrm{A}^{\circ}$ Mboi Caé (MD), e/Puente $\mathrm{RN}^{\circ} 1$ y la desembocadura del subembalse del $\mathrm{A}^{\circ}$ Quiteria en el embalse principal, con el entorno residencial Mboi Caé Norte, la zona de playa y espacios públicos; c) La Zona Urbano-Costera del $\mathrm{A}^{\circ}$ Mboi Caé (MD), e/Puente $\mathrm{RN} \mathrm{N}^{\circ}$ 1, el entorno residencial y de servicios de San Pedro y el rural sobre A $^{\circ}$ Tacuapí; d) La Zona Urbano-Costera del subembalse del A Poti’y (MI) con el paseo costero, espacios públicos y el entrono urbano-residencial de los Barrios La Paz, Villa Cándida y Poti'y; e) La Zona Residencial-Costera del A Poti’y (MD) y del A Santa María (MI) con el entrono residencial del Barrio homónimo, paseo costero y espacios públicos; f) La Zona Urbano-Costera Media del $A^{\circ}$ Poti'y, con el Parque Urbano del arroyo, entorno residencial, comercial y de servicios de Buena Vista, sobre su margen izquierda y el entorno rural de Cambyretá, sobre su margen derecha; g) Los nuevos Puentes y Accesos Viales, s/RN N 1 y 6, y los de vinculación urbana, con San Pedro, Yacu Paso, Santa María, Curupaity, y la Ruta 14, que vincula Encarnación con Cambyretá.

\section{Figura ${ }^{\circ}$ 18: Lugar 11 - DEL PAISAJE DE LA CUENCA DEL ARROYO MBoi CAé}

Comprende un amplio frente urbano de la zona Norte de la ciudad de Encarnación, localizado sobre ambas márgenes del subembasle del arroyo Mboi Caé, que incluye a los arroyos Tacuapi, Santa María y Potíy.

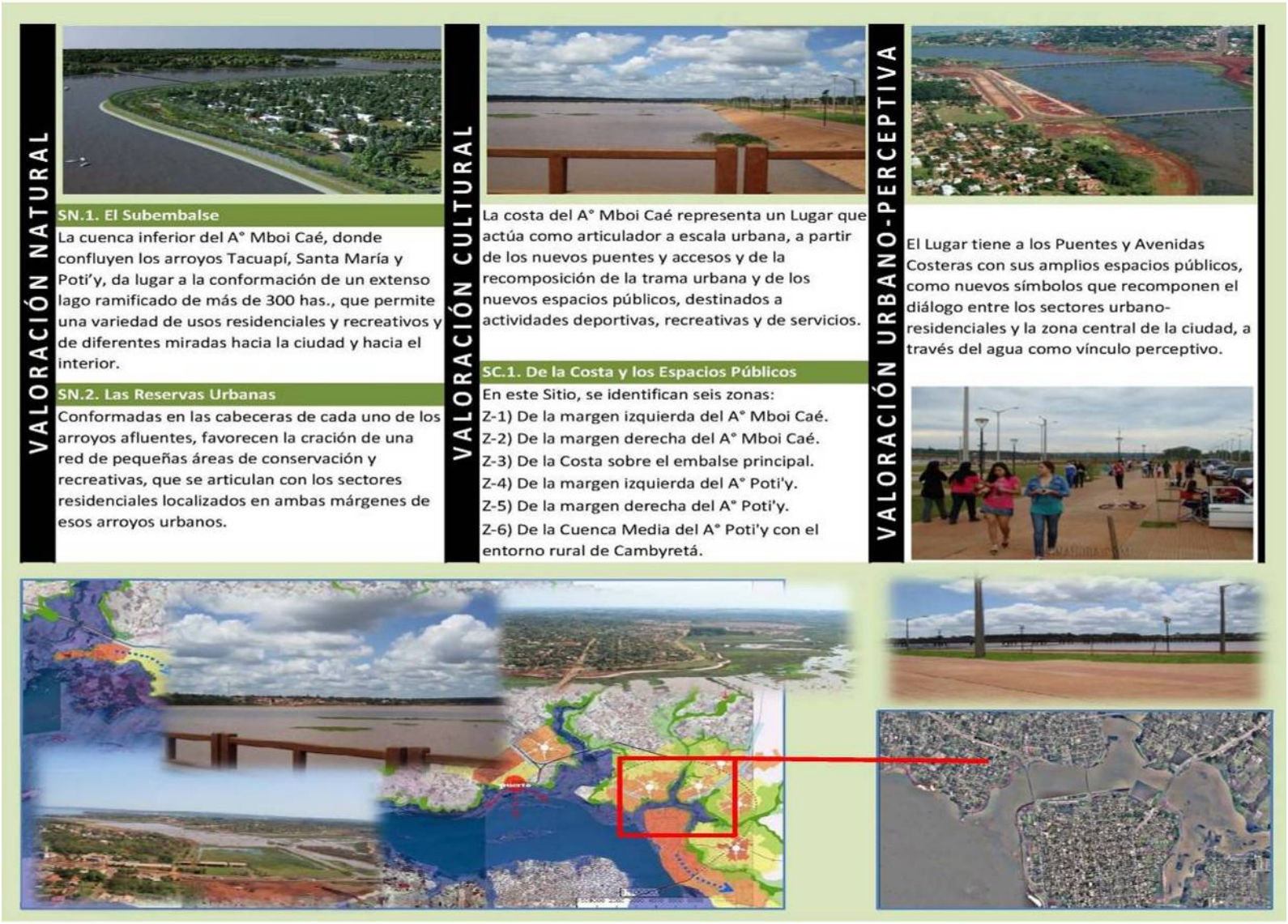

Fuente: Elaboración propia 


\section{LUGAR 12: DE LA CUENCA DEL ARROYO QUITERIA}

Comprende el área de transición entre los Municipios de Encarnación, sobre la margen izquierda del $\mathrm{A}^{\circ}$ Quiteria, y de San Juan del Paraná, sobre la margen derecha del mismo, dónde los principales componentes del paisaje del Lugar, están conformados por:

a) La Residencial-Costera de la margen izquierda del subembalse del arroyo Quiteria, con el Paseo Costero, los espacios públicos equipados, el área de la Planta de Tratamiento de Efluentes Cloacales de Encarnación con su área de reserva forestada, el entorno Residencial de los Barrios La Esperanza y Quiteria y la nueva zona del basural;

b) La Zona Costera de la margen derecha del arroyo Quiteria, con el nuevo Puerto Cerealero, en la desembocadura del subembalse sobre el embalse principal, con el entorno residencial de San Juan del Paraná y de Itá Paso (Encarnación) y la costa natural del arroyo;

c) El Entorno Rural de la cabecera del subembalse;

d) El nuevo Acceso Vial a Encarnación y el Puente sobre $\mathrm{RN}^{\circ} \mathrm{N}^{\circ}$, en su cruce con el subembalse del arroyo Quiteria.

\section{Figura N $^{\circ}$ 19: Lugar 12 - Del PAISAJE DE LA CUENCA DEL ARROYO QUITERIA}

Se localiza sobre la Ruta Nacional $N^{\circ} 1$, al Norte de Encarnación, abarcando la cuenca inferior del arroyo Quiteria, que es el límite entre esa gran ciudad y la pequeña San Juan del Paraná.

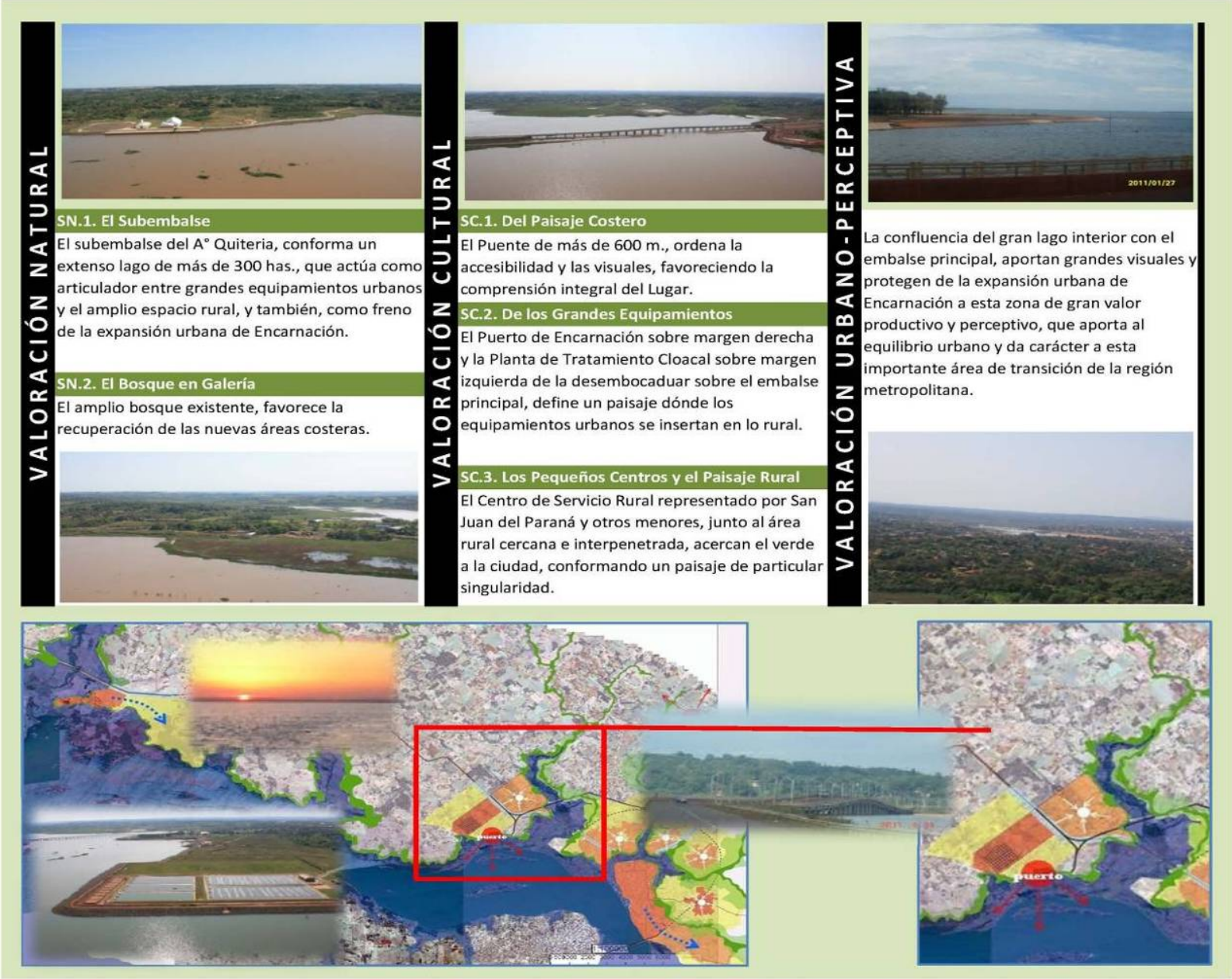

Fuente: Elaboración propia 


\section{LUGAR 13: DE LA COSTA Y EL ENTORNO RURAL ENTRE SAN JUAN Y CARMEN DEL PARANÁ}

Comprende el área de transición entre los centros de servicio rural, conformados por las pequeñas ciudades de San Juan y Carmen del Paraná, que tiene la potencialidad de convertirse en una gran interfase natural-costera a escala metropolitana, a partir del cuidado de los subembalses de los arroyos que la circundan, dónde se destaca el Caraguatá, junto a la revalorización de los pequeños centros poblados y de un manejo adecuado de las actividades rurales, así como de la inclusión de actividades turístico-recreativas que incorporen valor agregado a esas actividades.

Los principales componentes del paisaje del Lugar son:

a) La Zona Rural y los arroyos, dónde la $\mathrm{RN}^{\circ} 1$ actúa como eje de articulación;

b) La Zona Costera sobre el embalse, dónde un caminos costero permitiría articular nuevos usos y relaciones en toda la interfase costera;

c) El subembalse y la selva en galería del $\mathrm{A}^{\circ}$ Caraguatá y otros arroyos menores, que pueden actuar como corredores de biodiversidad transversales al embalse principal.

\section{Figura $\mathrm{N}^{\circ}$ 20: Lugar 13 - DeL PAISAJE DE LA COSTA Y EL ENTORNO RURAL}

Comprende la zona rural y la costera sobre el río Paraná, ubicada al Norte de Encarnación, entre las ciudades de San Juan del Paraná y Carmen del Paraná, sobre el eje de la Ruta Nacional $N^{\circ} 1$.

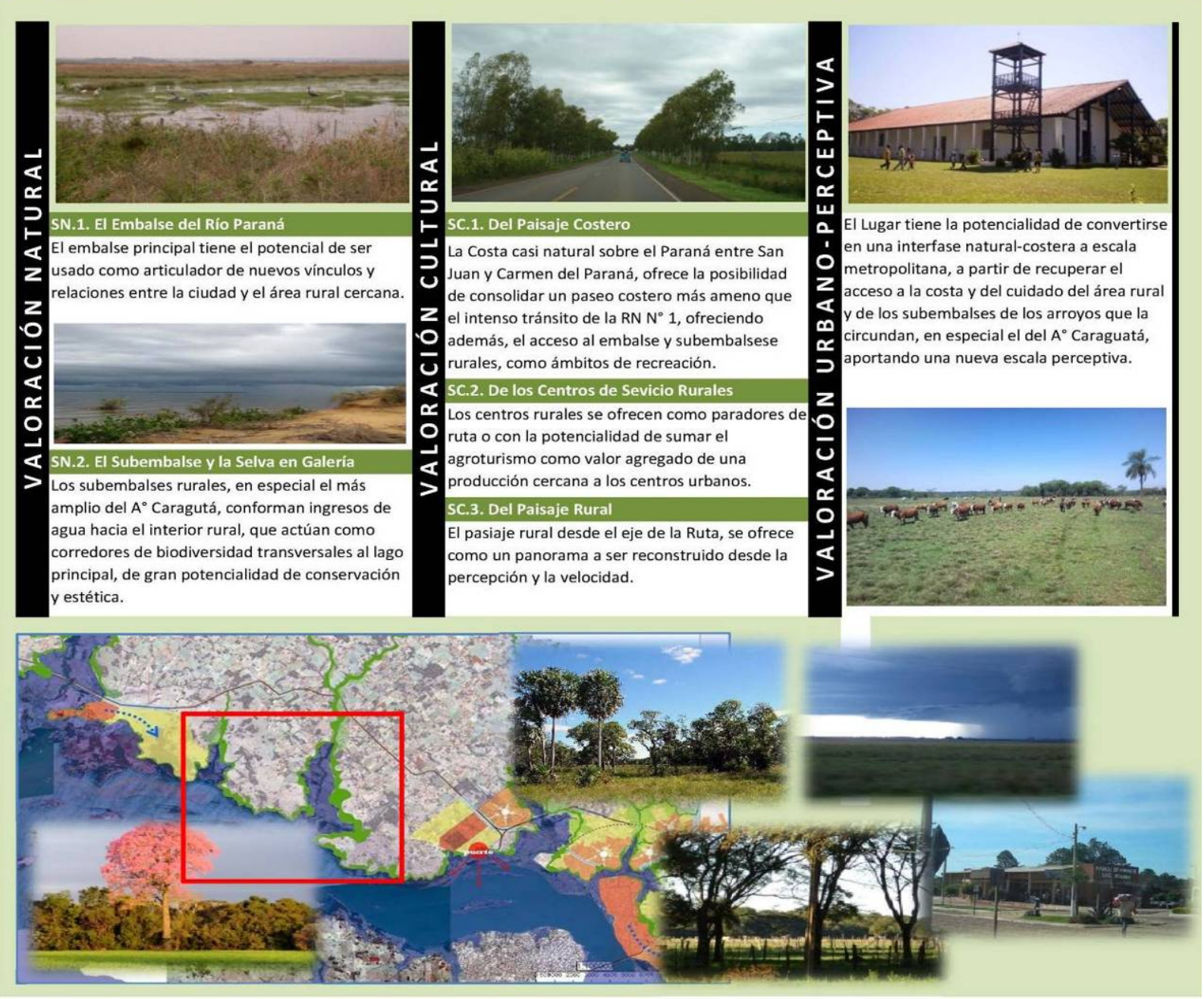

Fuente Elaboración propia. 


\section{Lugar 14: Del Arroyo TACuARY y de la Costa de CARMen del ParanÁ}

Comprende todo el tratamiento de adecuación de la ciudad de Carmen del Paraná, a las condiciones de elevación del embalse de Yacyretá a su cota de diseño.

Los principales componentes del paisaje del Lugar son:

a) La Zona Urbano-Costera del perímetro del casco urbano fundacional en contacto con el embalse principal, con la Avenida Costanera, las playas, los espacios públicos equipados y el entorno Residencial del área urbana, incluido el nuevo Barrios construido por Yacyretá;

b) La Zona Urbano-Costera del perímetro del casco urbano fundacional en contacto con el subembalse del arroyo Tacuary, con la Avenida Costanera, los espacios públicos equipados, la Reserva o Parque Urbano y el entorno residencial del área urbana;

c) El nuevo Acceso Vial y Puente sobre la $\mathrm{RN} \mathrm{N}^{\circ} 1$ y subembalse del arroyo Tacuary, y el entorno rural.

\section{Figura $N^{\circ}$ 21: LUgAR 14 - DEL PAISAJE DEL A ${ }^{\circ}$ TACUARY Y DE LA COSTA DE CARMEN DEL PARANÁ}

Comprende al centro de servicio rural de carmen del Paraná, que se localiza a $33 \mathrm{Km}$ al Norte de Encarnación, sobre la Ruta Nacional $\mathrm{N}^{\circ} 1$, en un entorno rural principalmente dedicado al cultivo de arroz, que forma parte del Area Metroplitana de Encarnación (AMeE).

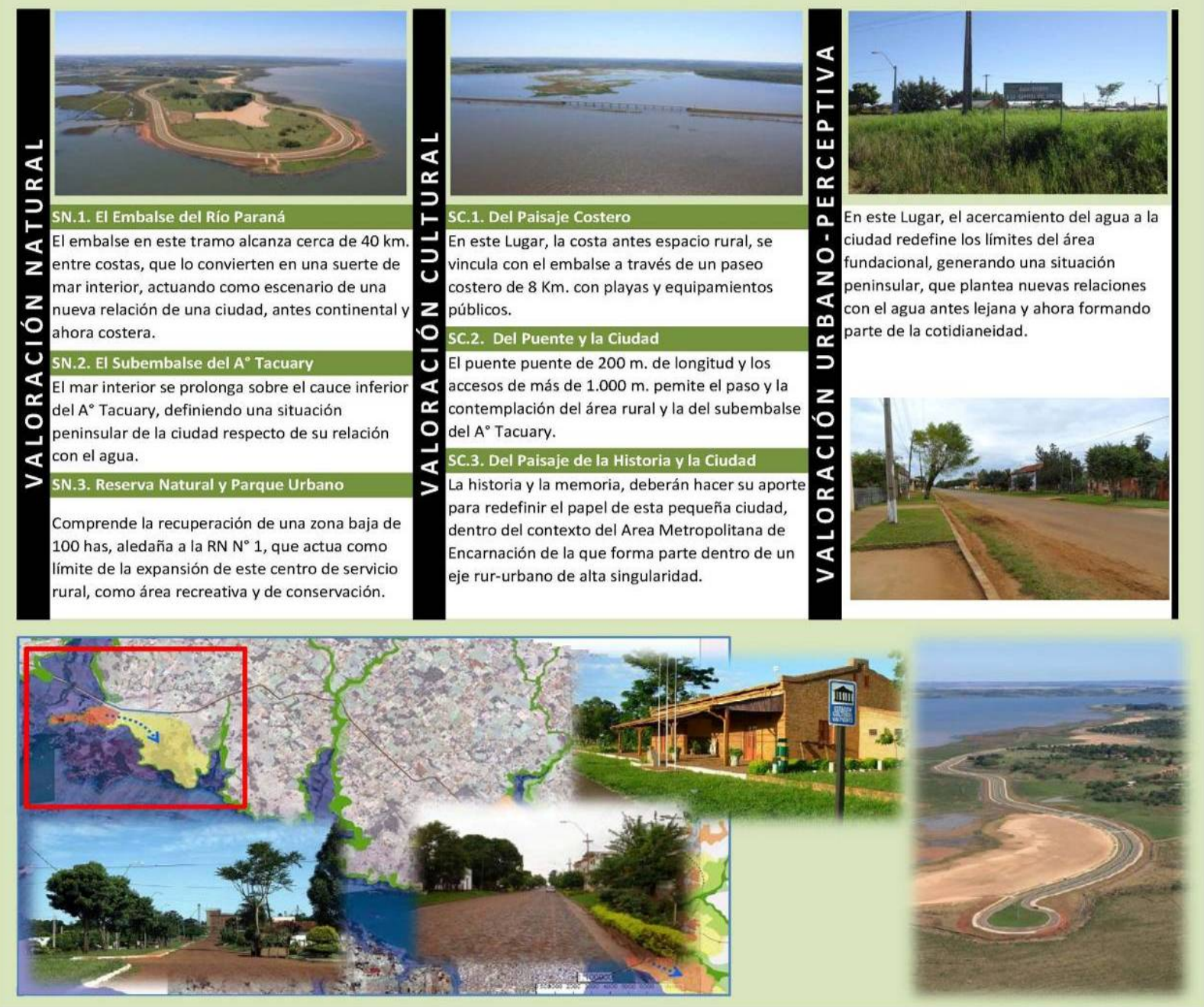

Fuente: Elaboración propia. 


\section{IV.2. DEL PROYECTO A LA REFLEXIÓN: Hacia un Modelo de Gestión del Paisaje}

El análisis empírico realizado en la primera parte de este Capítulo, sobre las transformaciones generadas por la ejecución de una gran obra de infraestructura hidroeléctrica como Yacyretá en términos paisajísticos nos ha permitido demostrar que el paisaje está ligado a la subjetividad, pues es precisamente la mediación establecida a través de la mirada, el ingrediente que convierte al territorio en paisaje.

Pero esa lectura, aún sin haber sido pensado en esos términos, representa una suerte de ensayo de lo que podría ser y, consecuentemente, un desafío para encauzar, a partir de la terminación del proyecto hidroeléctrico, un proceso proyectual y de gestión que complemente los procesos de planificación territorial en marcha, orientando la interpretación de las distintas miradas que sobre este tipo de obras van teniendo los diferentes actores del territorio con sus lógicas.

Este desafío, tanto para el caso de estudio como para otros emprendimientos futuros, debiera incluir necesariamente la noción actual de paisaje, que implica su reconocimiento como un recurso y un patrimonio ambiental, cultural, social, histórico y de desarrollo económico, que ha ido adquiriendo una consideración creciente en el conjunto de los valores ambientales que demanda la sociedad y que otorga además, un papel principal a las poblaciones locales y a sus aspiraciones, pues se considera que el paisaje es una porción del territorio, pero tal como es percibida por sus habitantes y los que la visitan.

En este sentido, los objetivos de calidad paisajística para un determinado territorio o porción de él, pueden ser asimilables, entonces, a los de una estrategia de conservación de la biodiversidad, reflejando también, las aspiraciones de la ciudadanía con relación al entorno en el que desarrolla su vida.

Por eso podemos coincidir para nuestro caso de estudio que "[...] toda estrategia de conservación de la biodiversidad [y del paisaje] debe tener en cuenta las complejas y diversas necesidades de la vida silvestre $[\ldots]$. Por sobre todo, $[\ldots]$ las necesidades de la sociedad, desde el campesino de subsistencia al empresario forestador y al productor de yerba mate.” (Morello, et. al., 2004: 117).

Desde el punto de vista metodológico debemos señalar que la evolución de esta noción de paisaje sobre todo en los últimos doscientos años- hace que hoy sea considerada como una ciencia, por lo que es posible entonces, analizar y describir sus componentes de forma eminentemente objetiva y que, junto a concretos instrumentos de gestión adecuados a cada contexto de intervención, pueden contribuir a hacer viable el reconocimiento del paisaje como un recurso y un patrimonio ambiental, cultural, social, histórico y de desarrollo económico.

Es decir que "[...] como todas las ciencias actuales, tiene planteado el reto de la metodología [y que] a causa de la complejidad natural de los paisajes, los estudios que pueden realizarse son diversos $\mathrm{y}$, por tanto, son varias las metodologías útiles en cada caso, lo que hace difícil hablar de la metodología del paisaje" (Bovet Pla y Ribas Vilas, en de Bolós, 1992: 124). 
Es por eso que señalamos que, una metodología para la gestión del paisaje, puede ser asimilable a un proceso de planificación estratégica, cuyos lineamientos estratégicos para su aplicación, pueden ser complementados con la aplicación de una modalidad de valoración y un instrumento de catalogación.

Principios éstos que están establecidos sobre la base de criterios estéticos, que deben permitir abordar el análisis e identificación de ámbitos paisajísticos, y de criterios éticos, que induzcan factores de desarrollo de las comunidades locales involucradas, pensando en los problemas y potencialidades actuales y en las generaciones futuras y que, en forma análoga a lo descripto, lleva implícito cierto grado de subjetividad, que consideramos equivalente al de cualquier otro proceso que incluya la valoración o ponderación de diversos factores o atributos de un determinado ámbito territorial.

Por estas razones es que esta nueva dimensión del paisaje, como recurso y como aspecto esencial de la calidad de vida, implica que será necesario encauzar su gestión dentro del marco del desarrollo sostenible, para su protección, restauración y/o mejora, allá donde se puedan haber dado procesos de degradación y/o de pérdida de calidad ambiental.

Es decir, que “[...] la 'gestión del paisaje’ comprende la dirección, planificación y realización de medidas al servicio de la utilización y de la conservación de los recursos naturales, del desarrollo y de las modificaciones del paisaje. [... representando] un campo interdisciplinario que requiere combinar las experiencias de las ciencias naturales, sociales y técnicas (Ribas Vilas, en de Bolós, 1992: 259)

Es sobre la base de este marco conceptual que, en este segundo apartado del Capítulo, se exponen los principios metodológicos que nos resultan importantes no dejar de lado a la hora de pensar en el paisaje como objeto de gestión, en nuestro contexto latinoamericano.

En lo específico, representa la etapa operativa de un modelo de planificación integral, ${ }^{94}$ cuyas metas están centradas en tres aspectos:

a) Determinar objetivos alcanzables (objetivo de desarrollo e instrumentales);

b) Plantear el cómo podemos llegar (estrategia), como momento donde se define el modelo de actuación fundado en el conocimiento pleno de la realidad; y,

c) Qué hacemos para llegar (gestión y creatividad, dentro del marco de participación corresponsable), que debe acompañar todo el ciclo de proyecto, procurando conjugar las aspiraciones del cuerpo social involucrado.

\footnotetext{
${ }^{94}$ Este marco conceptual y las herramientas de gestión metodológicas que se explican a continuación, sirven para seleccionar aquellos aspectos más relevantes de un determinado sector territorial que orientan un cierto modelo de gestión. Las mismas han sido adoptadas por el autor de esta investigación para ser aplicada en diversos trabajos, en especial, en los procesos de 'Ordenamiento Integral de la Infraestructura de Servicios de San Carlos de Bariloche' (CFI, 1993); 'Ordenamiento Ambiental de la Ciudad de San Carlos de Bariloche' (CFI, 1995) y 'Estrategias de Gestión Territorial en Áreas Protegidas, Departamento Bariloche, Eje Andino Patagónico Bariloche - El Bolsón' (CFI, 1996), dónde el Paisaje como objeto de uso y contemplación a través del turismo, representa el eje sobre el cual se sustenta el desarrollo de esta parte de la región andino-patagónica argentina.
} 


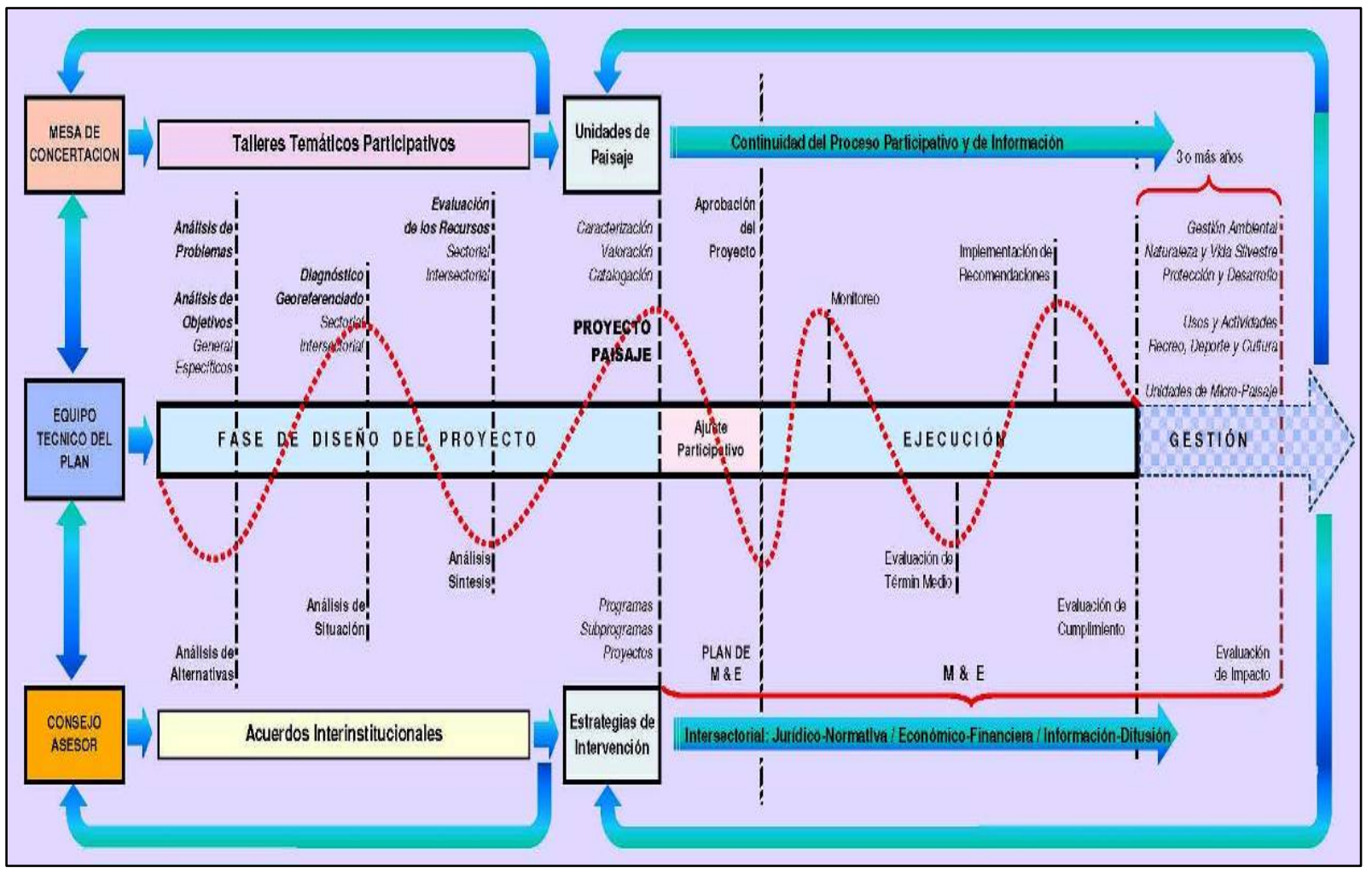

Fuente: Elaboración Propia.

El gráfico muestra que el desafío radica en delinear un 'modelo de actuación' que “[...] se trata, en primer lugar, de una mentalidad antes que de un método" (Ribas Vilas, en de Bolós, 1992: 260), y que como modalidad de intervención, debe ser presentada como una hipótesis de trabajo cuyo planteo se verifica y ajusta al confrontarlo con la realidad institucional -organismos municipales, departamentales y nacionales- junto con las organizaciones de la comunidad y con la población organizada; en tanto que su proceso de ejecución debe admitir, además, modalidades de actuación abiertas que, dentro de un plan de monitoreo y evaluación, puedan ser discutidas en forma participativa, probándolas experimentalmente en la realidad, y realizando así, los ajustes que el uso concreto aconseje.

\section{IV.2.1. Acerca de los Objetivos del Proyecto Paisaje}

En general, puede decirse que la gestión de paisajes debería atender a uno o varios de los siguientes objetivos: a) conservación y mantenimiento de la naturaleza del paisaje existente; b) mejora, mediante la introducción de nuevos elementos o la gestión diferente de elementos existentes; c) restauración; d) creación de una identidad nueva, o aceleración de los procesos de cambio que lleven a una nueva identidad del paisaje, en el caso de paisajes banalizados o fuertemente transformados; e) preservación, en el caso de los hitos o monumentos paisajísticos, como medida de gestión orientada a buscar la conservación del elemento principal de un paisaje según su configuración actual. 
Podemos considerar así, que la concepción del 'proyecto paisaje' como estrategia de gestión, debiera asumir complementariamente, la noción de tutela ambiental, ${ }^{95}$ entendida como modalidad de actuación socio-institucional para alcanzar el objetivo de desarrollo sostenible. Y para que ello sea posible, puede plantearse inicialmente, una modalidad de reconocimiento y evaluación de la situación de los recursos naturales y culturales; la clasificación de las áreas donde debe intervenirse y la definición de estrategias que permitan abordar los conflictos y potencialidades del espacio, para su ordenación y valoración.

La metodología articula así un enfoque holístico y multidimensional, que se estructura en tres fases operativas: análisis y evaluación de los recursos como oferta del paisaje; desarrollo de un modelo de gestión; y verificación (monitoreo y evaluación) de las estrategias planteadas.

"Para articular estos factores (múltiples y diversos), hacerlos formar parte de un mismo universo y evolucionar de manera sinérgica y solidaria, resulta imprescindible conocer el estado de situación del área y sus tendencias; como base para fundamentar las decisiones, los objetivos comunes y las prioridades de gestión. En suma, con un plan y una estrategia para llevarlo adelante." (Tauber, 1999: 23)

Si analizamos con detenimiento el contenido de estos supuestos podemos coincidir que más que un desafío técnico, el rescate de la noción de paisaje en el contexto de procesos de desarrollo local y regional, encierra un desafío político y social, con responsabilidades compartidas.

Por eso la propuesta de planificar con visión estratégica, debe enfatizar tanto los aspectos relacionados con la capacidad de interacción de la gestión público-privada como la de superar la visión sectorial de los problemas (enfoque holístico). Debe además, admitir nuevas tendencias, discontinuidades y superposiciones focalizando alternativas y caminos para aprovechar oportunidades. Pero debe también hacer hincapié en acciones integradas, destinadas a orientar cambios de naturaleza estructural, con alto compromiso institucional. Y es en este sentido, que el Proyecto apunta a determinar el nivel de organización y de complejidad estructural del territorio, incluyendo al proceso de ejecución de las obras de Yacyretá y de planificación urbana, abordando campos de actuación estratégicos a escala de las zonas costeras, de la ciudad y de la región.

En tal sentido, debiera tenerse en cuenta además, que esta mirada a partir de un sector del territorio permite el doble enfoque de las 'Reservas de Biosfera': uno propio del proyecto, para responder a los objetivos y metas específicas del mismo y el otro, como ejemplo demostrativo, en términos de modelo de gestión, cuyos resultados puedan ser transferidos al resto del territorio a la que pertenece el área de proyecto. En este marco, el ordenamiento del paisaje aunado al del territorio, puede convertirse en una herramienta de planificación a largo plazo, que organice la toma de decisiones a corto y mediano plazo y que disminuya o evite los riesgos ambientales inherentes a un manejo del territorio no planificado.

\footnotetext{
${ }^{95}$ La noción de ‘tutela ambiental como forma del desarrollo' está vinculada a los esfuerzos por el uso de tecnologías apropiadas, para un desarrollo armónico sociedad-naturaleza; ratificada por los trabajos de las ONG, en la Conferencia ECO '92 de Río de Janeiro, Brasil.
} 
El objetivo de un plan de estas características puede estar centrado, además, en la identificación de factores de complementariedad y competitividad regional (cultura e identidad, asociada al territorio), para abordar un proceso integrador ${ }^{96}$ que considere los recursos del paisaje en términos de oferta natural y cultural; el manejo perceptivo y participativo del ambiente y el inicio de procesos de coordinación y concertación interinstitucional e intersectorial que orienten acciones en el territorio.

$\mathrm{Al}$ respecto, pueden ser de gran utilidad recurrir a orientaciones estratégicas, como las del Programa $\mathrm{MaB}$ (El Hombre y la Biosfera de UNESCO) y, en consecuencia, podría plantearse un criterio de paisaje como área protegida, con los siguientes objetivos específicos:

- Propiciar un desarrollo genuino de los asentamientos humanos, basado en estrategias de uso adaptado, del patrimonio natural y cultural, que estructuren el desarrollo territorial en un marco de preservación de recursos paisajísticos.

- Alentar el desarrollo de proyectos piloto integrados, que enfrenten en forma holística los complejos problemas de las relaciones entre los aspectos socioeconómicos, físicos y biológicos del territorio, que mejoren la calidad ambiental y de vida general.

- Propender a la expansión de los beneficios de un área natural y culturalmente protegida al resto del territorio, como modalidad de desarrollo incluyendo actividades de formación e investigación, como estrategia para reforzar los recursos humanos necesarios para llevar a cabo la actuación de mediano y largo plazo, su gestión y aplicación.

\section{IV.2.2. Aspectos Técnicos del Proyecto Paisaje}

Para alcanzar un objetivo de desarrollo y consolidación de un territorio en términos de paisaje dentro del contexto de un plan de acción, deberá encauzarse la resolución técnico-metodológica que permita resolver el abordaje de una temática particular como la paisajística que, como hemos señalado con antelación, no registra antecedentes específicos en la región de análisis de esta investigación.

De tal forma, en el primer acápite del presenta apartado, se plantea la necesidad de realizar el análisis de situación o diagnóstico estratégico georeferenciado del área de estudio en términos: ecológicoambiental, geográfico-urbanístico, histórico-cultural, incluyendo en ello, a los recursos del paisaje: naturales, culturales, socioeconómicos e institucionales y normativos, proporcionando las herramientas para valorar elementos identitarios de zonas específicas como 'Lugar'.

\footnotetext{
${ }^{96}$ Dada la vinculación física entre los territorios de ambos países y la influencia que ejercen las áreas metropolitanas de Posadas y Encarnación, sobre su entorno en la resolución y previsión de conflictos, resulta fundamental aplicar la 'noción de proyecto' como herramienta de manejo de ese territorio, dado que esta noción permite -en un marco global- adecuar las decisiones a las necesidades de la sociedad en función de los resultados que se vayan obteniendo, completando los procesos de verificación y control, que aseguren la búsqueda sostenida de los objetivos de inicio. En este sentido, es que resulta importante atender la necesidad de complementar el ciclo de proyecto de la planificación urbana-regional ya iniciado, con un enfoque alternativo que otorgue 'cualidad' a los ámbitos propicios para su contemplación y uso controlado.
} 
El segundo aspecto considerado relevante, está centrado en la posibilidad de encauzar una evaluación y valoración -sectorial e intersectorial- de conflictos y potencialidades de los recursos del paisaje, que permitan extraer conclusiones que, desde una cierta perspectiva de proyecto y de gestión, orienten el cambio de los aspectos negativos, induciendo efectos positivos sobre el ambiente y el paisaje.

Estas conclusiones permitirán abordar la tercera instancia del proceso de construcción del proyecto paisaje, vinculada con la identificación de escenarios de intervención y de criterios de actuación (en términos de programas; subprogramas y proyectos emergentes), que definen un cierto modelo de gestión que se articula con la ordenación del territorio y de las ciudades y que, como 'modelo', haga tangibles aquellos objetivos específicos de mejora, preservación y/o consolidación de un determinado paisaje.

Finalmente, la cuarta instancia de esta parte de los aspectos metodológicos, analiza los instrumentos que permiten instaurar dentro del proceso proyectual, medidas de monitoreo y evaluación para la revisión de resultados, garantizando el aporte a los objetivos de desarrollo trazados en el proyecto.

Esta forma de análisis representa una manera de agrupar las variables que, en términos de aproximaciones sucesivas, permiten describir el territorio en términos de paisaje, así como, analizar las modalidades o intensiones de su utilización. Y representa, además, una mirada que incluye una perspectiva socioeconómica, que identifica espacios a consolidar, promocionar y desarrollar, por la potencialidad de sus recursos y por la situación de su población, recuperando condiciones de equilibrio territorial con equidad social, asociadas al paisaje y una socio-institucional, como forma de aplicación de una política efectiva que oriente un modo de gestión flexible del paisaje, con activa participación de los actores sociales y con permanencia en el tiempo para las generaciones futuras (desarrollo sustentable).

\section{IV.2.2.1. Análisis de Situación o Diagnóstico Estratégico}

Representa el nivel analítico/deductivo del proceso proyectual, que tiene un carácter técnicocientífico, que debe iniciarse a partir de producir información actualizable a diversas escalas, con el objetivo de identificar, dimensionar y localizar déficit, potencialidades y ofertas del territorio. Un proceso de análisis de situación de estas características, permite convertir la información en un tipo de conocimiento que debe orientar la discusión de prioridades ambientales, paisajísticas y socioeconómicas, para generar y profundizar los instrumentos de ordenación y promoción de las acciones. El análisis de situación o diagnóstico estratégico, es la instancia de identificación de prioridades y de diseño de instrumentos de diagnosis, para que estos datos puedan ser utilizados en forma inmediata por aquellos que deben tomar decisiones permanentes dentro de la realidad local y regional.

En la actualidad, es conveniente que este tipo de análisis se implemente a través de herramientas informáticas basadas en un sistema de información geográfica (GIS), que permita manejar la complejidad de las variables que se analizan; diagnosticar en tiempo real e implementar mecanismos para actualizar en forma permanente esa información. Esto posibilita medir la evolución de indicadores de diversa índole (ambientales, urbanísticos, de calidad de vida, etc.), ya que esta tecnología admite la 
construcción de bases de datos que tienen como característica principal que el empleo de la información espacial y alfanumérica se realiza en forma integrada, pudiendo abordarse de este modo aspectos de alta complejidad relacional. Esta tecnología permite transformar la información en conocimiento, que para una gestión territorial significa poder abordar el proceso de toma de decisiones con una dinámica acorde a los cambios y exigencias que la realidad impone, facilitando la identificación del camino más corto para alcanzar objetivos instrumentales. A partir de esta información básica, podrán generarse diagnósticos sectoriales, de tipo físico-territorial productivo y normativo; así como, análisis de tipo intersectorial del sistema territorial.

\section{A. Diagnósticos Sectoriales}

Permiten realizar una caracterización de la realidad ambiental, socioeconómica y urbanística del área en estudio, a partir del análisis de su evolución histórica y su inserción regional; la población; la vivienda; los servicios de infraestructura; los servicios sociales, como educación, salud y seguridad; así como su caracterización económica, a través de la evaluación del estado de los sectores comercial, de servicios, industrial y agropecuario; la conformación y evolución del Producto Bruto Interno; la situación ocupacional y las posibilidades de orientar un rol para el área en el contexto regional.

Como hemos visto empíricamente en la primera parte de este Capítulo, la fase de análisis de situación de los 'recursos del paisaje' tiene por objetivo reconocer, a priori, valores paisajísticos en ciertas porciones del territorio, que aporten una mirada estética, apuntalada en la diversidad y sectorialidad propia de su configuración física y cultural. Este análisis aborda una visión estratégica del área de intervención como paisaje, a fin de orientar una valoración del territorio a partir, por ejemplo, de las tres dimensiones de análisis, con sus respectivas aproximaciones, empleadas en esa interpretación: i) ecológica-ambiental, por su contribución al mantenimiento de la biodiversidad y calidad ambiental; ii) geográfico-urbanistica, para entender la configuración urbano-territorial; iii) histórico-cultural que permita identificar los principios y tradiciones que han dado origen a la conciencia colectiva y entender la forma en la que preexisten valores intangibles y tangibles del área y de la región de pertenencia.

Estas dimensiones de análisis representan una manera de agrupar las variables que, junto a la delimitación por escalas espaciales y temporales del área territorial que se va a analizar (Bovet Pla y Ribas Vila, en de Bolos, 1992: 132), permiten tanto describir y analizar esa porción de territorio en términos de paisaje, como identificar las modalidades e intensiones de su utilización.

\section{B. Análisis Intersectorial del Sistema Territorial}

Comprende la verificación de las potencialidades del sistema territorial, para definir una serie de criterios de manejo particularizado desde un análisis de variables definidas por interacción sistémica de varios indicadores (como grado de interacción asociativa-comunitaria, incidencia pobreza-deterioro ambiental, etc.) y funciones de valor ambiental, definidas por interacción de las variables antes mencionadas, para obtener resultados tales como estratificación socioeconómica-urbanística, etc. 
Ello permite identificar y delinear áreas de gestión; o grandes componentes de intervención, que sinteticen aspectos específicos de carácter socio-territorial, tales como:

a) Componente Natural: para la caracterización de unidades homogéneas y su posible tratamiento, en función de la capacidad de soporte; definición de pautas de recuperación de áreas degradadas; aspectos normativos; áreas de amortiguación ecológica; interfases urbano-rurales-naturales, etc.

b) Componente Físico-Construido: analizando ocupación y usos de las distintas áreas (residenciales, turísticos, recreativos, industriales, comerciales, etc.); condiciones de urbanidad; patrones de asentamiento (espacios abiertos - espacios cerrados); unidades morfológicas; estructura de movilidad, transporte e infraestructura de servicios.

c) Componente Socioeconómico -Productivo: que considere segmentos productivos con base en las actividades predominantes de áreas caracterizadas; perfil de la población; potencial productivo; valor de la tierra; investigación de mercado; identificación de proyectos de inversión; etc.

d) Componente Institucional y Normativo: para orientar la gestión institucional, jurisdiccional e interjurisdiccional.

Esta agrupación de temas sectoriales y críticos, permite definir campos estratégicos de actuación, así como, escenarios de intervención.

\section{IV.2.2.2. Evaluación de los Recursos como oferta del Paisaje}

A fin de poder encauzar el proyecto paisaje en términos de gestión, una forma posible de abordar esta fase del proyecto, es efectuar un análisis jerárquico en términos de 'conflictos' o temas-problema del área objeto de estudio y de 'potencialidades' del contexto que orienten la solución de los mismos. La instancia de evaluación comprende tres fases operativas: ${ }^{97}$

La primera fase plantea una identificación, clasificación y posterior evaluación de los conflictos del área de intervención denominada sectorial, que se presenta en matrices síntesis de interacción organizadas según las tres aproximaciones de análisis: a) ecológica-ambiental; b) geográfico-urbanístico; c) histórico-cultural (intangible y tangible). A través de esas matrices de interacción, se priorizan conflictos denominados 'decisores', que son aquellos sobre los cuales deben orientarse las prioridades de actuación, para modificar las tendencias negativas que operan sobre el paisaje y el territorio.

Desde esta perspectiva de análisis sectorial, se pasa a una segunda instancia de evaluación denominada intersectorial, definiendo así aquellas ‘cuestiones' que involucran aspectos del paisaje, vincu-

\footnotetext{
${ }^{97}$ Esta metodología de evaluación ha sido desarrollada por la Fundación CEPA (Centro de Estudios y Proyectos del Ambiente. La Plata, Argentina) sobre la base de la aplicación del método basado en la Matriz de Leopold (United States Geological Survey, 1971), y ha sido adaptada por el autor de esta investigación para ser aplicada a diversos trabajos profesionales, vinculados con la gestión urbana y regional, y ha sido adecuada además, junto al equipo conformado para el proyecto "Valores Identitarios. Parque Pereyra Iraola: hacia un modelo alternativo de desarrollo del paisaje' (FAU-UNLP, 2008), realizado en el Taller de aplicación y experimentación de la Maestría Paisaje, Medio Ambiente y Ciudad. Antecedentes estos, citados en la Bibliografía.
} 
lados con la estructura territorial y relacional entre centros urbanos, áreas rurales y naturales (protegidas o no). La inclusión de esta visión intersectorial es la que permite observar de qué forma los conflictos sectoriales juegan en el contexto de la evaluación de un sistema territorial, que es objeto de una determinada acción proyectual.

La tercera instancia de evaluación comprende una fase de interpretación subjetiva de los conflictos y potencialidades de los recursos del paisaje, que representa una suerte de conclusión, o conclusiones síntesis, derivadas de la evaluación intersectorial de conflictos, que articula conceptualmente al territorio, al ambiente y al paisaje.

El análisis conclusivo al que se arriba luego de estas aproximaciones, permite desarrollar una valoración del área objeto de estudio, a fin de orientar el proyecto paisaje y un escenario para su gestión.

\section{A. Evaluación Sectorial por Recursos del Paisaje}

La evaluación sectorial se organiza en función de los análisis de los aspectos ecológicoambientales, geográfico-urbanísticos y los histórico-culturales (intangible y tangible), descriptos en el apartado anterior, que son entendidos como recursos del paisaje. Esta evaluación comprende tres fases, para cada recurso del paisaje: i) identificación de conflictos y potencialidades; ii) evaluación sectorial; iii) interpretación sectorial.

\section{A.1. Identificación de Conflictos y Potencialidades}

Consiste en elaborar una planilla que ordena el proceso de discusión que debe ser planteado inicialmente por el equipo de proyecto y que, posteriormente, es recomendable que pueda extenderse al conjunto de actores dentro de un proceso de difusión, comunicación y participación, que identifica y expone los principales conflictos (amenazas o debilidades, que representan incompatibilidades entre la necesidad y la realidad, y/o intereses encontrados) y su potencialidad (fortalezas y oportunidades existentes, que representan alternativas de utilidad para la solución de los conflictos, o el desarrollo de nuevas posibilidades). ${ }^{98}$

\section{A.2. Evaluación Sectorial}

Comprende un proceso de evaluación de los conflictos identificados, a través de la aplicación de una matriz de interacción de doble entrada, como método técnico que permite establecer las relaciones entre los componentes del subsistema analizado. Este método matricial permite obtener una primera "radiografía' de los problemas en cuestión y se implementa a los efectos de definir grupos de conflictos con su correspondiente caracterización y valoración. Dicha matriz permite establecer una valoración en el sentido de las filas, de aquellos aspectos sectoriales más conflictivos. El sentido de la relación es horizontal y la evaluación establecida es si el elemento analizado encabezando las filas, 'afecta' al elemento vertical

\footnotetext{
${ }^{98}$ Esta fase metodológica es sustancialmente análoga a la utilizada por el Banco Interamericano de Desarrollo, para definir el árbol de problemas (conflictos) y objetivos (potencialidades), en la instrumentación del Sistema de Marco Lógico, que permite delinear la Matriz de Marco Lógico de sus programas y proyectos de inversión.
} 
que encabeza cada columna. Para determinar cual elemento afecta directamente a otro y en qué medida, se establece un rango en la relación a factores de influencia. ${ }^{99}$ Se obtiene entonces una SUMA ACTIVA (SA), en sentido HORIZONTAL o de las FILAS, que define una valoración para cada conflicto o problema identificado, que determina cuál elemento afecta a otros en mayor medida.

\section{A.3. Interpretación de la Matriz de Evaluación Sectorial}

Esta modalidad de valoración permite determinar el ELEMENTO ACTIVO, denominado CONFLICTO DECISOR representado por aquel conflicto que afecta y define la existencia del resto. Posteriormente a esa definición se realiza una nueva discusión, para interpretar esa incidencia, para explicarla y orientar desde cada potencialidad, escenarios de intervención sectorial, que contribuyan a solucionar en parte o totalmente, los efectos de esa conflictualidad. Esta fase de interpretación permite además, reagrupar aquellos conflictos que son causa-efecto de procesos análogos, definiendo de este modo, cuáles de esos temas-problema, deben ser considerados en el proceso de evaluación intersectorial.

\section{B. Evaluación Intersectorial de los Recursos del Paisaje}

Las reflexiones de carácter sectorial, permiten extraer conclusiones sobre aquellas cuestiones que no constituyen fenómenos visibles pero que, por efecto de un determinado comportamiento sociocomunitario e institucional, definen ciertas condiciones 'tangibles' de un determinado lugar.

Pero es necesario, además, entender que esto no es suficiente para comprender las complejas relaciones que determinan las condiciones de calidad urbana, ambiental y paisajística de una cierta porción del territorio que adquiere valores singulares para la sociedad; y es por ello, que resulta necesario encauzar un análisis más complejo que permita identificar primero, de qué manera interactúan las diversas problemáticas que operan sobre ese territorio, a fin de poder inferir, simultáneamente o después, su potencialidad en términos de metas alcanzables y escenarios posibles de intervención, que puedan ser analizados y ajustados, dentro de un proceso de interacción con esa sociedad.

Para ello resulta de utilidad aplicar un proceso de evaluación de tipo intersectorial utilizando, por ejemplo, una tabla o matriz de interacción, como método para establecer las relaciones entre los componentes del sistema, en término de evaluación cuantitativa de impactos entre conflictos.

\section{a) Aplicación de Factores de Influencia}

En dicha matriz se presenta una valoración de los conflictos considerados más significativos en términos de Paisaje, conforme los siguientes factores de influencia: $\mathbf{0}=$ factor $\sin$ influencia; $\mathbf{1}=$ factor con influencia leve; $\mathbf{2}$ = factor con influencia media $; \mathbf{3}=$ factor con influencia alta .

Para la evaluación, se establece un tipo de relación horizontal (en sentido de las filas) y vertical (en sentido de las columnas), a fin de determinar cual elemento afecta directamente a otro, y en qué medida. Es decir,

\footnotetext{
${ }^{99}$ Esto se realiza de acuerdo a una escala de valoración, como por ejemplo: $0=$ factor sin influencia; $1=$ factor con influencia leve; 2 = factor con influencia media; $3=$ factor con influencia alta.
} 
se calcula la suma de los elementos en dos sentidos: Suma Activa (SA), en sentido horizontal o de las filas; Suma Pasiva (SP), en sentido vertical o de las columnas.

\section{b) Definición de Elementos Determinantes}

Una vez efectuado el paso anterior, se determinan los elementos determinantes o conflictos principales del sistema evaluado, que se obtiene de la forma siguiente:

\section{b.1.) Valoración para las Columnas}

El resultado de esta valoración de conflictos está representado por el cociente "Q", entre la Suma Activa y la Suma Pasiva. De esta forma se determinan los siguientes elementos:

Elemento Activo (Q máximo): Es el que se obtiene en coincidencia con el mayor valor obtenido en la ecuación, representando al conflicto decisor del sistema, que es el que ejerce una gran influencia sobre los demás, siendo el menos influenciable por el resto.

Elemento Pasivo (Q mínimo): Es el que se obtiene en coincidencia con el menor valor obtenido en la ecuación; y se lo entiende como el conflicto pasivo, que es el más afectado o influenciado por el resto.

\section{b.2.) Valoración para las Filas}

El resultado de la valoración de conflictos en este sentido está representado por el producto 'P' entre la Suma Activa (SA) y la Suma Pasiva (SP). De esta forma se determinan los siguientes elementos:

Elemento Crítico (P máximo): Es el que se obtiene en coincidencia con el mayor valor obtenido en la ecuación, que corresponde al conflicto crítico, que es el que ejerce más influencia sobre el resto y es simultáneamente afectado por los demás.

Elemento Intermedio (P mínimo): Es el que se obtiene en coincidencia con el menor valor obtenido en la ecuación, que representa al conflicto intermedio, porque es el menos influenciable y porque ejerce a su vez menos influencia sobre los demás.

\section{c) Jerarquización e Interpretación de Elementos o Conflictos Determinantes}

El tercer aspecto de la evaluación intersectorial comprende una interpretación de los denominados ‘elementos determinantes' del sistema, dónde se efectúa una explicación de la jerarquización obtenida en el cálculo matricial, de acuerdo a la conceptualización explicada anteriormente.

\section{Análisis Síntesis de Conflictos y Potencialidades de los Recursos del Paisaje}

Esta fase de la valoración subjetiva de los conflictos y potencialidades de los recursos del paisaje, representa una suerte de conclusión o conclusiones síntesis, derivada de la evaluación intersectorial de conflictos, que articula los conceptos de territorio-ambiente-paisaje.

Estas conclusiones pueden ser explicadas también desde su potencialidad; es decir, tratando de orientar el cambio de las cuestiones 'claves' que, desde una cierta perspectiva de proyecto y de gestión, puedan inducir efectos positivos sobre las demás.

Así entonces, podemos entender que el paisaje puede contener los parámetros para articular adecuadamente el accionar de los diversos organismos públicos y de los actores privados, orientados des- 
de un cierto modelo de gestión que se articule con la ordenación urbano-territorial y que, como 'modelo', haga tangibles aquellos objetivos específicos de mejora, preservación y/o consolidación paisajística.

En suma, esta forma de evaluación, pone en evidencia que todos los elementos o conflictos tienen un peso relativo sobre un determinado sistema territorial objeto de estudio, por lo que su importancia radica en la posibilidad de poder establecer el tipo de interacción o, en otras palabras, su 'estructura relacional', dónde el 'proyecto paisaje'-parafraseando a Pierre Donadieu- deberá orientar la reivindicación de factores de identidad, a través de una nueva lógica -patrimonial o cultural, económica, ambiental, territorial- de articulación socio-institucional (Donadieu, 2006: 60).

\section{IV.2.2.3. Formulación e implementación de un Proyecto Paisaje}

Para orientar el camino de la gestión temporal de un proyecto que desde el paisaje oriente condiciones de desarrollo local y regional, habrá que definir un 'plan de acción', que no debe ser un producto, sino un proceso abierto que asuma los cambios, ya sea por factores exógenos (del entorno) o endógenos (propios del plan), o por efecto de objetivos de corto plazo alcanzados en su aplicación. El mismo debe representar una concreta forma de intervención o 'modelo de actuación', que se construya en forma concertada, a través de la permanente interacción de las siguientes instancias: a) La definición de Unidades de Paisaje, como objetos instrumentales de gestión; b) La determinación de las estrategias y campos de actuación, integrales y prioritarios; c) La definición concertada de la forma de actuación para la efectiva implementación del Plan.

En términos generales, puede señalarse que es la etapa operativa dentro de un modelo de planificación integral, cuya meta es determinar objetivos alcanzables (de desarrollo e instrumentales); plantear el cómo podemos llegar (estrategia) y qué hacemos para llegar (gestión y creatividad, dentro de un marco de participación corresponsable). Es el momento donde se define una modalidad de actuación fundada en el conocimiento pleno de la realidad y en las aspiraciones de la sociedad directa e indirectamente involucrada.

\section{A. Definición de Unidades de Paisaje}

Una vez descripto, analizado y evaluado el territorio objeto de estudio, será necesario definir un marco de referencia para la gestión del paisaje, que deberá ser fruto de la constatación de las oportunidades y potenciales ventajas competitivas del área en cuestión.

En lo específico, está conformado por la definición de Unidades de Paisajes a partir de tres instancias de estudio, en función del grado de subjetividad implícito en el proceso:

\section{A.1. Caracterización}

Consiste en identificar, describir y evaluar tipos y unidades de paisaje, que estarán conformados por las distintas combinaciones de los principales factores que definen las características paisajísticas del área de estudio, así como por los elementos singulares o hitos de una determinada porción de territorio. Esta ins- 
tancia está relacionada con los apartados de caracterización de los paisajes y de elaboración de la base cartográfica en el proceso de confección de un Catálogo, que puede considerarse libre de subjetividad.

\section{A.2. Valoración}

Consiste en la aplicación de una serie de valores que se decidan adscribir a cada tipo o unidad de paisaje resultante de la fase anterior. En este caso, la subjetividad proviene de la decisión de tomar como referencia, para establecer el valor de cada tipo de paisaje, la opinión técnica que permita someter a posteriori a la opinión de los ciudadanos sobre los mismos.

Esta tarea puede realizarse a partir de la construcción de 'matrices de valoración' que permitan articular los principales aspectos que fueron analizados y evaluados a través de las perspectivas de análisis aplicadas para interpretar el territorio (ecológica-ambiental, geográfico-urbanistica, históricocultural) considerando por ejemplo: a) características: nivel de calidad o degradación, rareza, representatividad, diversidad, singularidad, pertenencia y complejidad; b) percepción: color, contraste, textura, densidad, auditivo, olores, visual y táctil; c) modalidades posibles de reconocimiento : accesibilidad, medios de movilidad, potencial de vista, capacidad de carga y amplitud.

\section{A.3. Catalogación}

La principal función de los catálogos de paisaje es la incorporación de directrices paisajísticas en la ordenación territorial y concretamente en los planes territoriales parciales. Es por este motivo que su alcance territorial se corresponde con el de cada uno de los ámbitos de aplicación de estos planes.

Los catálogos de paisaje son unos documentos de carácter técnico que, en forma análoga a los aplicados en la Unión Europea, pueden ser concebidos como herramientas para la ordenación y la gestión del paisaje desde la perspectiva del planeamiento territorial. Determinan la tipología de los paisajes, sus valores -presentes y latentes- y el estado de conservación, los objetivos de calidad que deben cumplir y las medidas para conseguirlo. Son, por lo tanto, de suma utilidad para la definición e implementación de políticas de paisaje, especialmente orientadas a la integración de objetivos paisajísticos en las estrategias territoriales, con la participación activa de todos los agentes sociales que intervienen en el territorio, en la gestión y planificación de su propio paisaje.

\section{B. Determinación de la estrategia de intervención}

Se refiere a la identificación de líneas de acción estratégicas que permitan orientar una concreta posibilidad de gestión del paisaje, donde los campos de actuación se verifican en un marco de relación institucional para abordar los conflictos del territorio partiendo de 'lineamientos generales o campos de actuación’ y ‘formas de gestión o actuación específicas', que permitan alcanzar los objetivos trazados a través de la definición de subproyectos emergentes del medio natural y/o cultural; de la necesidad de equipamientos y servicios; de la actuación institucional y normativa. Es decir, que las 'cuestiones' derivadas del análisis de los recursos son las que posibilitan definir 'campos estratégicos de ac- 
tuación' cuya resolución constituye el marco que permite definir Programas, Subprogramas y Proyectos que dan forma al 'modelo de gestión' a implantar. ${ }^{100}$

Este modelo representa así, una estrategia de gestión que se construye por la articulación de dos fases interactuantes: los 'campos' y la 'forma de actuación'. ${ }^{101}$

\section{B.1. Los Campos de Actuación}

Los ejes estratégicos devienen y contienen al objetivo de desarrollo y surgen de la situación de base o situación actual, indicando las tendencias de mayor relevancia para alcanzar ese objetivo, conformando las ideas fuerza que resuelven un conjunto de problemas (expresión conjunta de conflictos) y el horizonte que orienta todas las acciones, para pasar de una situación actual deficiente a una situación futura deseada. A su vez, cada eje estratégico presenta objetivos instrumentales a alcanzar; así como, los mecanismos para verificar los impactos (positivos y negativos) que pueden derivarse de ese accionar y deben articular además, aquellos aportes de ideas, trabajos e iniciativas de inversión, que surjan del proceso de articulación de los actores sociales y que ayudarán a construir la fase de puesta en marcha, en el corto, mediano y largo plazo. Pero también deben incluir aquellas iniciativas postergadas o en ejecución, o bien, las que surjan del proceso de interacción, ya sea para atender necesidades comunitarias, productivas, culturales o de cuidado ambiental, que deberán ser parte en su debida dimensión del plan de acción. De esta forma, podrán definirse objetivos específicos de corto y mediano plazo para cada estrategia, como medios para atender al objetivo central o de desarrollo. Estos substancian en positivo, lo que se pretende alcanzar para dar respuesta a los problemas identificados.

Esta interpretación permite formular los campos de actuación prioritarios, que predefinen aquellas cuestiones sobre las que se considera de fundamental importancia intervenir para corregir los conflictos que afectan el paisaje. Por eso, representan áreas temáticas englobantes o totalizadoras de una serie de cuestiones de raíz común, que deben ser abordadas desde una determinada óptica.

Es decir, son los temas clave del territorio, que contienen acciones que engloban o totalizan una serie de 'cuestiones' relevantes sobre las cuales debe existir una suerte de consenso generalizado, que debe construirse con base en la permanente articulación social e institucional, que implica el proceso de gestión, y que deben ser abordados desde una determinada óptica. Es el QUE hay que hacer, repre-

\footnotetext{
${ }^{100}$ Para su definición resulta importante considerar las Pautas de Selección y Funciones de las Reservas de Biosfera (Programa MaB de UNESCO), como "principios rectores" para definir subproyectos según las siguientes consideraciones: a) fortalecer la conservación de la diversidad biológica, los recursos genéticos y los ecosistemas (función de conservación); b) consolidar una base operacional y facilitar la investigación y supervisión, con actividades de formación y educación ambiental (función logística); c) asociar la protección ambiental y el desarrollo de los recursos como principio rector de las actividades de investigación, educación y demostración (función de desarrollo).

${ }^{101}$ El concepto de 'modelo aplicado al proyecto' no es un concepto rígido ni preestablecido. El mismo admite una familia de tipos de amplia variedad. "Es un prefiguración genérica, parangonable a... Conociendo el modelo, se pueden detectar los tipos o soluciones específicas, rescatando los valores de ese modelo y descartando su transculturación." (De Carlo, Giancarlo. Instituto de Cultura Itálica, 1985).
} 
sentando el nivel de decisión político-técnico, que surge de una interpretación de los temas críticos, y se definen en función del objetivo trazado para el proyecto.

\section{B.2. Definición de la Forma de Actuación}

La resolución de las 'cuestiones' que definen los ejes estratégicos o campos de actuación, genera la necesidad de encontrar respuestas específicas sobre temas prioritarios, concretando acciones multipropósito que produzcan efectos positivos que retroalimenten el proceso de planificación, para su ajuste y adecuación. Es el 'cómo', el 'dónde' y 'con quienes' hay que hacerlo, representando el nivel técnico y de gestión operativa para abordar la conflictualidad del sistema territorial.

Este conjunto de 'cuestiones' se reflejan en lo que pueden denominarse como 'patrones de comportamiento y espacio' (eco-comportamentales) ${ }^{102}$ que se relacionan con ciertas pautas de comportamiento físico-espaciales (patrones de asentamiento), relacionadas con ciertas características socioeconómicas y de gestión.

Sobre la base de esos patrones se define una modalidad de gestión específica, que recupere la importancia de la acción concreta y la promoción de las actividades como método de cambio. Bajo este concepto, se puede superar la instancia de la norma abstracta de carácter sectorial y coercitivo, que en general, se muestra ineficaz para conservar, preserva y/o mejorar los ecosistemas humanos.

Esta modalidad de intervención se puede presentar a partir de la integración de: programas, subprogramas o acciones y proyectos prioritarios.

\section{B.2.1. Programas:}

Son grandes líneas de actuación de tipo general, que operan como herramientas político-técnicas que deben ser implementadas para alcanzar en forma integral una o varias estrategias, orientando la generación de proyectos para dar cumplimiento a uno o varios objetivos estratégicos y por lo tanto garantizando la ejecución del plan. Estos programas (sus objetivos generales e institucionales) pueden no corresponderse con las actuales capacidades de gestión, de recursos humanos, financieros, físicos, de información diagnóstica actualizada y actualizable, etc., de las instituciones que deben implementarlos. En este caso deben guiar el camino (a largo plazo), para alcanzar la maduración necesaria y la generación de recursos institucionales, humanos y económicos.

102 Alexdander, C. en "El Lenguaje de Patrones" (1978) dice al respecto, que “... podemos definir un patrón como un principio general del diseño y del planeamiento a través del cual se formula un problema concreto que puede presentarse repetidas veces en cualquier proceso de diseño. Además, delimita el tipo de contextos en el cual el problema puede ocurrir y muestra las características esenciales que ha de poseer por ejemplo, cualquier edificio. En este sentido, podemos afirmar que un patrón es un imperativo empírico que formula las condiciones mínimas necesarias para conseguir la salud individual y colectiva de una comunidad". De otro modo, "los patrones son configuraciones estables que asumen los fenómenos: el modo en que se repite una cierta manera de agruparse, de actuar, de construir, de acumular, de distribuir; una cierta manera de disponerse los elementos característicos de un sistema o de una parte de él”. Pesci, R. (1995). 


\section{B.2.2. Subprogramas 0 Acciones}

Son la garantía de ejecución del Plan y se manifiestan como medidas que pueden agrupar proyectos o instrumentos de gestión público-privada, que deben ser implementados para alcanzar los objetivos de cada estrategia, compuestos por acciones específicas, que abarcan distintas escalas de actuación y plazos, y que surgen de requerimientos del diagnóstico o de iniciativas o prioridades del sector público, del sector privado o del sector social.

\section{B.2.3. Proyectos Prioritarios o de actuación particularizada}

Son acciones específicas que surgen de cada subprograma y brindan la posibilidad de aplicar soluciones en el corto plazo que atienden, desde el punto de vista social, aquellas cuestiones insoslayables o urgentes y, desde el punto de vista técnico, retroalimentan el proceso de planificación, posibilitando su ajuste y clarificando el planteo general. Se actúa así en forma demostrativa y se logra confianza para aquellas acciones de mediano y largo plazo a desarrollar en el contexto del Plan. Los proyectos pueden alcanzar distintos niveles de desenvolvimiento, pudiendo incluirse a cada estrategia proyectos nuevos; tanto de inversión, como de mejoramiento social y/o ambiental.

Este accionar puede incluir, además, la ejecución de pruebas piloto a escala real, que tengan por finalidad corroborar el impacto de las acciones transformadoras, poniendo en marcha alguna actividad multipropósito de corto plazo que proponga efectos multiplicadores y una alta participación social, que atiendan objetivos particulares y requerimientos de uno o más ejes estratégicos de actuación. Esta actividad aportará al diseño definitivo del plan de acción, a partir de la definición de formas de promoción, formulación y evaluación de proyectos y, también, a la determinación y verificación de indicadores de impacto (social, económico y ambiental).

En suma, podemos indicar que esta modalidad de intervención permite encauzar acciones que enfrenten aquellas cuestiones en que se considera de fundamental importancia intervenir para modificar las tendencias del sistema territorial y, permite también, 'orientar' el proceso de gestión, porque ofrece pautas para corregir conflictos tanto de orden estético (valoración y/o mejora), como ético (de carácter ambiental o socioeconómico), que puedan incidir en las condiciones de desarrollo local o regional.

Representa conceptualmente, un proceso jurídico-normativo que incluye una perspectiva socioeconómica, porque identifica espacios a consolidar, promocionar y desarrollar, recuperando condiciones de equilibrio territorial con equidad social asociadas al paisaje, al reconocer la potencialidad de los recursos y la situación de su población y, una socio-institucional, como forma de aplicación de una política efectiva que oriente un modo de gestión flexible del paisaje, con activa participación de los actores sociales y con permanencia en el tiempo para las generaciones futuras (desarrollo sustentable). 


\section{IV.2.2.4. Monitoreo y Evaluación}

En vista de que los proyectos deben constituirse en el medio fundamental para lograr la efectividad o el impacto deseado, es importante preparar planes apropiados de Monitoreo y Evaluación (M\&E) ${ }^{103}$ en la etapa de diseño, a fin de que puedan ser implementados durante la etapa de ejecución, para aumentar la probabilidad de que los proyectos tengan un desempeño efectivo. En términos generales, los buenos sistemas de $M \& E$ de proyectos generan productos para: a) mejorar el desempeño de proyectos nuevos y en ejecución; b) obtener información sobre lecciones aprendidas y mejorar prácticas en un campo determinado; c) mejorar la sostenibilidad y efectividad en el desarrollo de los proyectos.

Gráfico N 10: El M\&E en el Ciclo de Proyectos

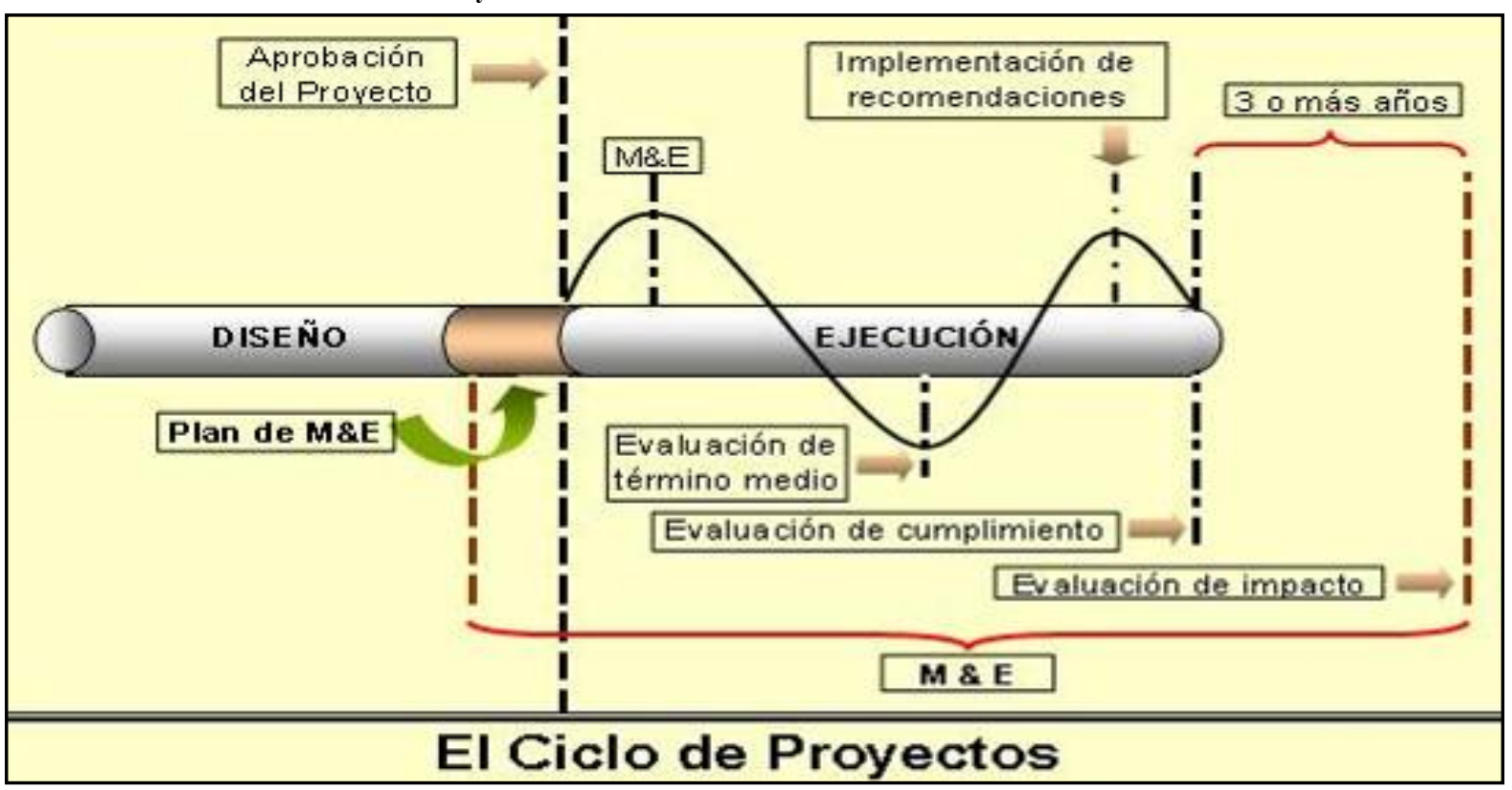

Fuente: BID, 2005. Curso de Monitoreo y Evaluación de Proyectos

\section{A. El Monitoreo de Proyectos}

El Monitoreo es un procedimiento sistemático empleado para comprobar la efectividad y eficiencia del proceso de ejecución de un proyecto para identificar los logros y debilidades y recomendar medidas correctivas para optimizar los resultados deseados.

Sistemático: porque tiene que ver con el establecimiento de un sistema planificado, cuya implementación permita: a) determinar el progreso en la ejecución del proyecto; b) dar retroalimentación a los involucrados; c) recomendar acciones correctivas para abordar problemas que afectan al proyecto.

Eficiencia: es la medida en que los insumos del proyecto han sido suministrados y administrados, y las 'actividades' han sido organizadas de manera más apropiada, al menor costo, para producir los 'componentes' necesarios.

${ }^{103}$ El contenido de este acápite representa una síntesis conceptual de los apuntes del Curso de Sistema de Marco Lógico y de Monitoreo y Evaluación de Programas y Proyectos del Banco Interamericano de Desarrollo (BID), que el autor de esta Tesis realizó en el BID, en el año 2005. 
Efectividad: se refiere a la medida en que el proyecto produce -en términos del marco lógico- los componentes (productos) planeados; se está logrando el propósito (efecto directo); y, está contribuyendo significativamente al logro del fin (impacto / efectividad en el objetivo de desarrollo).

Considerando que el monitoreo se efectúa durante la etapa de ejecución de un proyecto y no en otras etapas del ciclo de proyecto, y que estas actividades pueden ser ejecutadas por el equipo de diseño en un proceso para consolidar un proyecto de paisaje, podría tomar la forma de un 'Observatorio de Calidad del Paisaje', que pueda: a) medir la evolución de indicadores de calidad; b) sacar conclusiones y recomendar prioridades; c) difundir y transferir esa información a empresas y organizaciones de la comunidad.

\section{B. La Evaluación de Proyectos}

Evaluación es una apreciación y valoración sistemática y objetiva sobre el diseño, la ejecución, la eficiencia, la efectividad, los procesos y los resultados de un proyecto en ejecución o completado y se realiza normalmente durante todo el ciclo de proyectos, incluyendo varios años después de completada la ejecución, en el caso de evaluaciones de impacto o sostenibilidad.

En la evaluación se pregunta si un proyecto está 'funcionando' satisfactoriamente, en particular, a la luz de los resultados planificados o ya obtenidos. Por lo tanto, requiere asignar tiempo y recursos para que se pueda realizar un trabajo especial que, normalmente, involucra la participación de profesionales especializados no asignados (externos) al proyecto. Algunos ejemplos de evaluación de proyectos son: anuales, de término medio y ex-post, pero las evaluaciones se clasifican, en general, en dos tipos: formativa y sumativa.

\section{B.1. Evaluación Formativa}

Es aquella que establece medidas que permiten el aprendizaje y realizar modificaciones durante las etapas de preparación y ejecución del proyecto. Afecta al proyecto durante la preparación y la ejecución y, por lo tanto, puede ser considerada parte integral del proceso de monitoreo durante la ejecución, teniendo impacto sobre un proyecto en marcha. La evaluación formativa se lleva a cabo para mejorar el desempeño de un proyecto en ejecución y el énfasis está dado en la retroalimentación para mejorar el producto final. Ejemplo de esto son las evaluaciones anuales, o la evaluación de término medio, que se realizan en la etapa de ejecución.

\section{B.2. $\quad$ Evaluación Sumativa}

Se realiza normalmente cuando termina la ejecución del proyecto o varios años después, en el caso de evaluaciones ex-post o de impacto, y se utiliza para determinar hasta qué punto los resultados planificados fueron producidos o logrados, así como para mejorar otros proyectos o programas en ejecución o futuros, a través de sistematizar las lecciones aprendidas. 


\section{Diferencias entre Monitoreo y Evaluación}

El monitoreo, es un proceso continuo; ocurre todos los días, semanas, meses en la ejecución del proyecto; es un proceso continuo de análisis, observación y sugerencias de ajustes para asegurar que el proyecto esté encarrilado para alcanzar sus resultados planificados. En tanto que, la evaluación, es periódica. Consiste en formular conclusiones acerca de lo que se observa a una escala mayor, considerando aspectos tales como el diseño del proyecto y sus impactos, tanto los previstos como los no previstos.

En tal sentido, el monitoreo y la evaluación formativa de proyectos son similares y, los principales elementos de un buen Plan de M\&E son los siguientes:

1) Sistemático: Significa que el M\&E debe ser planeado cuidadosamente e integrado plenamente en todo el ciclo del proyecto.

2) Participativo: Los involucrados importantes forman parte del diseño y de la ejecución de $M \& E$ desde el comienzo. Significa que 'todos' los que contribuyen al proyecto, o que son afectados por el proyecto, entienden 'quién' es responsable por hacer 'qué'.

3) Centrado en el desempeño: Para examinar que los resultados están de acuerdo con el Propósito del proyecto. El concentrarse en el desempeño significa que es necesario identificar áreas de débil desempeño para realizar ajustes tan pronto como sea posible.

4) Dirigido al aprendizaje: El mensaje principal (central) de M\&E, es convertir las experiencias en lecciones aprendidas. Se extraen lecciones aprendidas para mejorar este proyecto así como otros futuros.

5) Orientado hacia la toma de decisiones: Eso se cumple cuando la información suministrada por M\&E ayuda para tomar decisiones informadas de continuar o cambiar actividades del proyecto. M\&E de alta calidad va más allá del 'qué' al 'y qué'.

Hacerlo de manera participativa y con buen trabajo de equipo es importante en M\&E, porque siempre hay muchas ideas de cómo lograr una determinada meta. Una variedad de puntos de vista nos puede ayudar a preparar un mejor proyecto. Tenemos tres resultados importantes de la participación:

- Los involucrados pueden llegar a acuerdos en cuanto a los parámetros de los resultados, así como en la forma de reconocer un desempeño apropiado.

- Ello tiende a aumentar el sentido de "pertenencia" del proyecto por parte de los involucrados, así como la corresponsabilidad.

- También puede fomentar el compromiso por parte de los involucrados en cuanto a los objetivos del proyecto, lo cual podría proteger al proyecto cuando se atraviese un momento o situación difícil.

Hay dos aspectos importantes que deben ser incluidos en un Plan de M\&E:

1. Parámetros del Proyecto: El primer requisito de un Plan de M\&E es incluir los parámetros para el monitoreo del proyecto: qué se espera del proyecto; Indicadores del Propósito y de los Componen- 
tes y sus correspondientes Medios de Verificación. En pocas palabras, se tiene que incluir la Matriz de Marco Lógico (MML) del proyecto.

2. Arreglos para M\&E: Los arreglos importantes para incluir en un Plan de M\&E, son los siguientes: a) para recoger o administrar la información y los documentos requeridos por el proyecto; b) Institucionales, para llevar a cabo M\&E y recoger, analizar y reportar sobre los resultados; c) mecanismos para incluir a los involucrados en la toma de decisiones oportuna; d) Presupuesto para financiar M\&E, incluido en el plan financiero del proyecto.

Como resumen, un Plan de M\&E debe ser planificado desde el momento en que el proyecto está en la etapa de identificación y diseño y, a partir de ahí, será necesario ser riguroso y exigente en la implementación de las actividades de M\&E en la etapa de ejecución.

\section{IV.2.3. Aspectos de Gestión del Proyecto Paisaje}

Como hemos analizado en el Capítulo I (ver parágrafos I.1 y I.2), la noción de paisaje dentro del contexto de una gran obra de infraestructura está ligada a su construcción y a las nuevas relaciones que esta establece con el entorno de su implantación. Por eso, si resulta viable la interpretación realizada en el primer apartado de este Capítulo sobre el Proyecto Hidroeléctrico Yacyretá en términos de paisaje, al incluir estos conceptos dentro de instrumentos de planificación, deberá tenerse en cuenta que será necesario definir además un plan de gestión que acompañe todo el ciclo de proyecto, promoviendo la articulación de los principales actores del territorio y " [...] un conjunto de acciones para poder desarrollar los propósitos que éste establece y para convertir en realidad el proyecto paisaje, controlarlo, dirigirlo y encauzarlo hacia el logro de los objetivos previstos.” (Salvador Palomo, 2003: 295).

\section{IV.2.3.1. De la Articulación de los Actores Socio-Institucionales}

\section{A. Aspectos Conceptuales}

Se ha indicado que las posibilidades de éxito en lograr metas de desarrollo, se basan en la generación y sostenimiento de ventajas competitivas y que ello se logra con el esfuerzo corresponsable entre el sector público y el sector privado. Ese esfuerzo debe estar orientado a optimizar el propio potencial del territorio, sumado a una participación de recursos e impulsos externos, dentro del marco del 'sistema de actores' (Arocena, 1995) que opera el contexto territorial en el que se desarrollan.

En tal sentido, esta Fase se sustenta en la aplicación de actividades que buscan indagar sobre los diferentes puntos de vista y lógicas de los distintos sectores de la comunidad, destinado a construir un plan de acción sobre la base de 'cuestiones comunes' sobre las cuales profundizar, permitiendo instaurar un proceso de 'concertación de intereses'. 


\section{B. Aspectos Metodológicos}

Es la instancia que permite consolidar la ‘cooperación' entre el Sector Público y el Privado, con la meta de concertar socialmente los objetivos del Plan, e identificar y comprometer recursos humanos y materiales que hagan factible la implementación de sus Fases operativas. Dicha cooperación supone la recreación de espacios de concertación público-privada, para construir una lógica territorial horizontal en torno a un conjunto de problemas considerados prioritarios. Esto conlleva una mecánica de trabajo social que representa un nivel analítico-inductivo, enfocado en temas críticos comprehensivos, que abarquen las condiciones actuales y las posibilidades futuras, a fin de delinear 'escenarios de actuación integrales' para su análisis y evaluación socio-institucional. La misma debe permitir, además, captar en forma sistemática la percepción de la comunidad acerca de la aplicación de políticas sectoriales, o de programas y proyectos específicos en el territorio.

En términos de aplicación de este método, los temas críticos decantados y priorizados a través del trabajo perceptivo y participativo, deben ser objeto de verificación y profundización durante la elaboración del análisis de situación. Esto significa vincular el proceso técnico/científico con un proceso de sensibilización, formación y consulta, que articule las visiones técnicas, las político-institucionales y las de la comunidad organizada, según la estructura de participación que surja de la experiencia a desarrollar en esta Fase. Estas acciones están orientadas a organizar 'espacios de articulación' que permitan conformar, al menos, un equipo técnico del plan junto a instancias institucionales representativas, como un consejo asesor y una estructura de participación socio-institucional, que haga viable la concertación social.

Cuadro $\mathrm{N}^{\circ}$ 6: Ejemplo de Espacios de Articulación Socio-Institucional Integrados a un Plan

\begin{tabular}{|l|l|}
\hline Tipo de Espacio & Misiones y Funciones \\
\hline EQUIPO & $\begin{array}{l}\text { Responsable de la coordinación técnica del plan. Puede integrarse con profesionales provenientes del Sector } \\
\text { Público, de Organizaciones Privadas y expertos seleccionados. }\end{array}$ \\
\hline $\begin{array}{l}\text { CONSEJO } \\
\text { ASESOR }\end{array}$ & $\begin{array}{l}\text { Responsable de, por ejemplo: a) planificar nuevas estrategias, acciones o proyectos basándose en el conocimiento } \\
\text { que genere, por ejemplo, un Observatorio de Calidad del Paisaje y en los objetivos y prioridades identificados en } \\
\text { la Mesa de Concertación; b) plantear los caminos más convenientes para alcanzar los objetivos; c) ejecutar y } \\
\text { coordinar acciones y programas públicos y/o privados, verificando sus impactos y orientando su rumbo. } \\
\text { Integrado por referentes institucionales con prestigio profesional y/o empresarial, actuando a modo de una 'agen- } \\
\text { cia de desarrollo local'. }\end{array}$ \\
\hline $\begin{array}{l}\text { Responsable de: a) articular la relación de funcionarios y técnicos con los distintos sectores de la comunidad; b) } \\
\text { recoger e intercambiar información, inquietudes y preocupaciones; c) debatir y acordar objetivos y prioridades, } \\
\text { que serán objeto de análisis dentro del esquema participativo que propone el mismo proceso de planificación. } \\
\text { Integrada por representantes de organizaciones empresariales, productivas, gremiales, profesionales, sociales, } \\
\text { culturales, políticas y religiosas, junto a una representación de los poderes ejecutivo y legislativo locales. } \\
\text { Constituye una estructura de participación socio-institucional, que articula participación directa, probando diversas } \\
\text { modalidades flexibles de organización, como por ejemplo: por barrios, por cuencas hídricas, por áreas ambienta- } \\
\text { les, por familias afectadas por situaciones críticas, etc., y participación indirecta, a través de medios tecnológicos, } \\
\text { para favorecer la visión externa; que en conjunto, deben permitir y facilitar el análisis de temas críticos y el trata- } \\
\text { miento de las estrategias de intervención. }\end{array}$ \\
\hline
\end{tabular}

Fuente: Elaboración propia.

Estos espacios representan formas democráticas de asumir la diversidad del ambiente humano, que deben servir para legitimar las decisiones, incorporando las necesidades y aspiraciones del cuerpo social, recuperando así la idea de cultura local. Se trata de espacios que deben integrar las diferencias, exaltando la diversidad y evolución de la comunidad, ejercitando formas de gobierno basadas en procesos de coordinación, comunicación y gestión concertada, en aras del bien común, que permitan orientar la construc- 
ción (o reconstrucción) de una nueva ética social, a través del desarrollo de capacidades y destrezas en la población que (en nuestro contexto latinoamericano) representa un desafío esencial para enfrentar las exigencias actuales. En especial cuando se trate de sectores sociales con alto índice de necesidades básicas insatisfechas, que supone operar, junto con estos preceptos, la necesaria y muchas veces urgente atención de la emergencia social; y también porque coincidiendo con José Arocena, "el desarrollo local se produce cuando existe capacidad de negociación y de juego entre actores buscando una articulación de intereses que desemboque en beneficios para las sociedades locales" (Arocena, 1995: 38).

\section{IV.2.3.2. De la Gestión por escalas de intervención}

Salvador Palomo (2003: 296 a 307), reconoce que para desarrollar un plan verde en ciudades, debe contarse con instrumentos de gestión ambiental, jurídico-normativa, económico-financiera, de usos y actividades, de paisaje (entendido como códigos de calidad de los espacios verdes urbanos y agrícolas), de la naturaleza y la vida silvestre, informativa y de difusión, de protección y desarrollo, y de recreo, deporte y cultura. Estos instrumentos, que abarcan todos los aspectos de la gestión de un plan, pueden organizarse tomando como ejemplo el caso de estudio, conforme las diversas escalas de intervención analizadas.

\section{A. Para la escala Territorial}

Para ordenar la gestión a esta escala, se contemplan como prioridad los aspectos de:

Gestión Ambiental, que “[...] abarca cuestiones como los riesgos y estrategias ambientales (Agenda 21), la formulación de modelos de buena práctica, la elaboración y utilización de indicadores de confort, sostenibilidad y calidad ambiental y la información al público del estado ambiental [...]" (Salvador Palomo, 2003: 296) de los diferentes Lugares, en términos de Cartas de Gestión.

Gestión de la Naturaleza y la Vida Silvestre, que favorezca la consolidación de tipos de hábitats, en términos de corredores verdes y/o de biodiversidad, parques y lugares de importancia regional, metropolitana y urbana (Salvador Palomo, 2003: 301).

Gestión Protección y Desarrollo, que incluye el impulso de proyectos demostrativos para, por ejemplo, fomentar la forestación urbana; la agricultura urbana para mejorar el paisaje periurbano; o la integración ciudad-campo (Salvador Palomo, 2003: 304 a 306).

\section{B. Para la escala Metropolitana}

En lo que respecta a la ordenación de la gestión a escala urbana y metropolitana, podrían considerarse como prioridad aquellos aspectos vinculados con:

Gestión de usos y actividades, que "[...] interviene en la repercusión territorial de los documentos de planificación, la decisión para áreas abandonadas, baldías o en desuso, y su integración en ciertos espacios. Aborda también las actividades en diferentes espacios, como bosques, playas, áreas agrícolas periurbanas, así como las regulaciones que afectan a las calificaciones urbanas, las protecciones [...], así como los aspectos de recreo y esparcimiento urbano." (Salvador Palomo, 2003: 298). 
Gestión de recreo, deporte y cultura, que "[...] supone una rentabilización de espacios de inmediato interés para la sociedad: la componente de ocio activo, turismo rural, rutas agrícolas, etc., que son actividades que integran a la población del núcleo habitado y su entorno periurbano.” (Salvador Palomo, 2003: 306).

\section{Para la escala Urbana}

En lo que se refiere a la gestión en la escala urbana y de micro-lugares, podrían considerarse como prioridad aquellos aspectos vinculados con:

Gestión de las unidades de micro-paisaje, en términos de códigos de calidad de diferentes ámbitos o espacios, como por ejemplo, de los espacios verdes urbanos, de los paisajes periurbanos, de los paisajes agrícolas y de los paisajes rurales (Salvador Palomo, 2003: 300).

\section{IV.2.3.2. La Gestión Intersectorial}

Atender la gestión desde este punto de vista, significa reconocer la necesidad de contar con un marco normativo que proyecte esquemas de actuación que aseguren la viabilidad del proceso, ya sea utilizando normas y formas asociativas existentes, o propiciando otras que consoliden un contexto con el grado de flexibilidad necesario para su adaptación a la realidad, que irá cambiando con la implementación del plan de acciones del Proyecto Paisaje.

En lo que se relaciona con la gestión horizontal o transversal a todas las escalas físicas de intervención, son de utilidad los instrumentos de:

Gestión Jurídico-Normativa, que actúa en cuestiones como la propiedad, las relaciones con las administraciones, las disposiciones reguladoras, la legislación y su interpretación, que se traducen por ejemplo, en términos de Leyes y Ordenanzas para Catálogos de Paisaje y de Unidades Protegidas (Salvador Palomo, 2003: 297).

Gestión Económico-Financiera, que son acciones relativas al manejo y control de fondos específicos para ejecutar el plan de gestión (Salvador Palomo, 2003: 298).

Gestión Informativa y de Difusión, que representa "[...] uno de los objetivos del desarrollo sostenible, especialmente en el medio urbano [...]" (Salvador Palomo, 2003: 303), como una manera de convencer a los habitantes y visitantes acerca de la necesidad de no deteriorar el ambiente.

De esta forma el territorio podrá ofrecerse como un ámbito de concertación de políticas públicas y privadas para la integración, coordinación y complementación de acciones que posibiliten desarrollo con equidad social y procesos participativos responsables, que permitan aprovechar las fortalezas propias y las oportunidades del contexto, trabajando sobre las debilidades que permitan minimizar los riesgos que conlleva toda acción orientada a valorizar un determinado entorno territorial dentro de un contexto de desarrollo. Tanto porque las políticas destinadas a este fin deben involucrar a la comunidad en su conjunto; como por que la verdadera noción de desarrollo, debe leerse en una cantidad cre- 
ciente de gente 'incluida' entre los beneficiarios del sistema (Tauber, 1999: 48). Es decir, un tipo de desarrollo que contemple el crecimiento económico, el medio social al que sirve (o debería servir) y, fundamentalmente, el soporte paisajístico-ambiental sobre el que se asienta y pretende revalorizar.

En síntesis, se trata de institucionalizar un territorio con valores éticos y estéticos, en el marco de un proceso de desarrollo sustentable, cuya implicancia social es satisfacer las necesidades del presente sin comprometer las posibilidades de las generaciones futuras.

En este contexto, el análisis de recursos institucionales y normativos, permite plantear el marco a partir del cual puede inferirse una definición legal del área de estudio en el ordenamiento jurídico vigente, que debe permitir construir el proceso de planificación y gestión sobre bases que -al menos inicialmente- signifiquen la menor fricción posible con la legislación existente. Ello permitirá proponer formas de coordinación y regulación, para el accionar de los diversos organismos y niveles de administración y para los particulares involucrados, al cumplimiento de normas y dictámenes que se establezcan en dicha planificación, revalorizando de este modo el rol de la gestión a escala municipal.

De acuerdo con esta premisa es que debe profundizarse, en esta instancia, el análisis de los siguientes aspectos:

Los jurídicos y legales, considerando la definición del marco de regulación y manejo de las actividades que surgen del modelo de gestión.

Los institucionales y administrativos, para consolidar los roles de los distintos organismos de administración y su injerencia en la gestión del paisaje y del desarrollo a escala local y regional.

Los de organización social, identificando concretas posibilidades para institucionalizar la modalidad de gestión participativa a aplicar.

Este tipo de análisis y evaluación permitirá organizar lineamientos para orientar la coordinación jurisdiccional y para aplicar medidas adecuadas de planificación y gestión. En tal sentido, se considera de suma importancia para dotar de efectividad a ese proceso, el reconocimiento de un marco legal efectivo para, entre otras: a) reconocer al área de proyecto como una entidad jurídica, dentro de un marco del ordenamiento territorial; b) reconocer la validez legal de las delimitaciones, zonificaciones o áreas de manejo que se propongan, al efecto del régimen de usos y aprovechamiento de los recursos del paisaje y del territorio; c) Determinar las relaciones de compatibilidad entre esta ordenación y otras tipologías de ordenación territorial y sectorial; d) Consolidar jurídicamente un mecanismo de participación y de apoyo institucional para facilitar el cumplimiento del objetivo de desarrollo trazado.

Esta instancia tiene una alta implicancia técnica, política, social e institucional, porque representa la garantía de gerenciamiento del Proyecto para su concreta aplicación. Por ello -en lo que atañe a la implementación de programas, subprogramas o proyectos- desde este punto de vista jurídico aparece como particularmente relevante que esta Fase acompañe todo el proceso del ciclo planteado, a fin de poder evaluar y consolidar progresivamente los distintos aspectos de implementación. 


\section{IV.3. CONCLUSIONES}

Las últimas cinco décadas han mostrado el crecimiento de la conciencia ambiental en el conjunto de la sociedad mundial, junto a un también creciente avance teórico y práctico de la aplicación de la noción de paisaje, como forma de mantener, recuperar y planificar determinadas porciones del territorio con criterios estéticos de contemplación y éticos de valoración del hecho específico y del entorno. Esa nueva conciencia ambiental ha permitido desarrollar, además, un creciente posicionamiento contrario a la construcción de grandes obras de infraestructura, en particular de las hidroeléctricas, que generan importantes impactos negativos sobre el ambiente, muchos de ellos de carácter irreversibles, o de lenta y dificultosa reversibilidad. Aún siendo estas grandes obras, las que han contribuido a resolver necesidades básicas de las grandes aglomeraciones urbanas donde habita más del $80 \%$ de la población mundial, vinculadas con el transporte, la articulación territorial, la provisión de agua para consumo, para la producción o para la generación de energía eléctrica.

Precisar la posición de un conjunto de variables conceptuales como paisaje, entorno y sustentabilidad o desarrollo sostenible, y ponerlas en relación a una gran obra de infraestructura, descubriendo la coincidencia y convergencia de su evolución hacia un estado de la cuestión, ha dado el marco necesario para ubicar en un determinado contexto teórico-conceptual el objeto de estudio.

1. Para aproximarse al concepto de paisaje reflexionando sobre la acción, resultó necesario considerar lo que Aguiló -coincidiendo con Maderuelo- presenta como dos rasgos fundamentales de la relación del hombre con el paisaje: el momento sensorial o perceptivo que es consustancial a la idea de paisaje y el momento que recoge lo actuado por el hombre a lo largo del tiempo (Aguiló, en Maderuelo, 2006: 213). Para el primer momento -de características intangibles- Aguiló indica que frente a la idea de país, el paisaje surge como resultado de la consideración desde fuera de esa realidad. De otra forma, Graciela Silvestri y Fernando Aliata plantean que la noción de paisaje representa hoy una mirada estética, que indica una conexión inescindible entre forma percibida y sentido (Silvestri y Aliata, 2001: 11), pero alertando que también constituye una 'postura ética', como camino alternativo para pensar las relaciones entre los artefactos humanos y la naturaleza (Silvestri y Aliata, 2001: 12).

Por eso, a la noción respecto de que el paisaje es un producto histórico de la cultura del que mira (Le Dantec, 2007); ${ }^{104}$ ha resultado importante introducir el segundo rasgo o momento -de características tangibles- planteado por Aguiló, referido a que el paisaje funciona como un archivo histórico de la acción del hombre, siendo a su vez producto de una particular significación referida a un territorio (País) y al que lo habita (Paisano); porque si bien es cierto lo expuesto por Le Dantec que si no hay País, no hay Paisaje, también hay que señalar que 'no hay País sin Paisanos' qué son quiénes pertene-

${ }^{104}$ Nos referimos a la noción de paisaje expuesta por Jean Pierre Le Dantec, en el Seminario País y Paisaje: historia y teoría (inédito). Maestría Paisaje, Medio Ambiente y Ciudad, 2007. UNLP. La Plata. Argentina. 
cen y 'hacen' a ese País. Con este enfoque, y retomando algunas enseñanzas de la geógrafa argentina Elena Chiozza, es que hemos considerado al 'paisaje' como la asunción cultural y artística (ética y estética) que de ciertas porciones de ese País hacen sus Paisanos y quiénes lo visitan (Chiozza, 1983), ${ }^{105}$ es decir, que no hay hombre sin paisaje, ni paisaje sin hombre.

"[...] No hay paisaje sin hombre porque la ubicuidad humana ha llevado nuestra huella hasta casi todos los lugares, pero además porque es únicamente la mirada del hombre la que cualifica como 'paisaje', la que vuelve paisaje lo que naturalmente es territorio. $Y$ no hay hombre sin paisaje porque estamos hechos de él, en reciprocidad vital [...] un territorio interpretado culturalmente (Martínez de Pisón, en Maderuelo, 2006: 132).

En este sentido, puede afirmarse así que la constatación de lo tangible e intangible tiene el valor añadido de destacar la raíz cultural de todo paisaje (Aguiló, en Maderuelo, 2006: 213), y puede concluirse, por otra parte, que la noción de paisaje deriva de país, en el sentido de región o territorio y se distingue de este, en que es una visualización de esa realidad, dónde país sería más el contenido y paisaje, la expresión sensible de esas relaciones entre el hombre y el medio que conforman la cultura, como resultado comprensivo de toda la actividad sensorial del hombre frente a un medio que contiene el poso de la cultura. De acuerdo con ello el paisaje adquiere, de esta forma, un valor operativo fundamental que lo vincula decididamente a la acción. (Aguiló, en Maderuelo, 2006: 214).

Pero además, si el paisaje puede interpretarse como un producto social. Cuando el paisaje originario 'desaparece', es 'reemplazado' por otro y la población es desplazada a otro ambiente no necesariamente análogo al de origen, pareciera importante dejar abierta entonces una ventana para reflexionar sobre lo que Carmen Pena denomina "paisajes del recuerdo y el olvido...", dónde se conjugan los paisajes de partida (en nuestro caso, las islas, la costa del río Paraná, la casa ribereña, lo rural vinculado al río, la selva...), y los de llegada (la ciudad, la periferia urbana, lo rural...). En suma, dónde “[...] el recuerdo y la necesidad de olvidar son caras de una misma moneda. Su dualidad y esquizofrenia, símbolo universal de la emigración y de la compleja construcción social de un paisaje vivido y recordado" (Pena, en Nogué, 2007: 125). Sin ser objeto específico de esta investigación, no puede soslayarse que este aspecto puede constituir una de las claves a descifrar en el nuevo escenario dominado por 'la transformación', dónde resulta prudente coincidir con la idea de que paisaje es donde se vive y sobrevive y ello conlleva tanto la utilidad como la calidad y más en estos casos, donde pareciera ser que el verdadero problema está en conducir el cambio de modo que el desarrollo no se pague excluyentemente en cultura (Martínez de Pisón, en Nogué 2007: 328).

Estas aproximaciones nos permiten reforzar la 'noción de paisaje', definida en el Convenio Europeo de Paisaje, como cualquier parte del territorio tal como la percibe la población, cuyo carácter es el resultado de la interacción de factores naturales y/o humanos, en el sentido de que no sólo está definido por

${ }^{105}$ Nos referimos a la noción de paisaje expuesta por Elena Chiozza, en su Seminario (inédito). 1983, Maestría Proyectación Ambiental, Universidad de Belgrano. Buenos Aires. Argentina. 
quién lo percibe, sino también por aquel que lo 'aprehende' por habitarlo; ${ }^{106}$ incorporando la idea de que paisaje no es sólo percepción, sino también conocimiento (Silvestri y Aliata, 2001: 104).

Pero además, para trasladar estos conceptos a nuestro contexto latinoamericano, nos resulta imprescindible indicar que la noción de paisaje debiera contribuir a preservar el patrimonio natural y cultural -en sus vertientes de lo tangible o construido y de lo intangible- con criterios de gestión que configuren un aporte a la mejora de la calidad de vida de las poblaciones involucradas.

2. La noción de paisaje, como construcción cultural, es abarcativa de lo tangible e intangible de esa 'encrucijada' entre la naturaleza y la cultura, porque permite conjugar en una misma mirada los aspectos físicos, históricos, simbólicos, míticos, sensoriales, que una persona puede obtener al posicionarse desde su experiencia, frente a un espacio determinado. Y en "[...] esa relación esencial del hombre con la naturaleza que es el construir" (Aguiló, 1999: 13), un concepto que nos ha resultado válido para encauzar el análisis de las relaciones entre una gran obra de infraestructura y un determinado ámbito territorial, es la necesidad de aproximarse a la obra (la acción) desde la reflexión, incorporando en esa discusión, el contraste de los criterios de eficiencia, equidad y sostenibilidad.

La incidencia de las obras de infraestructura sobre el entorno, se mide en términos de impactos (negativos y positivos) sobre el medio físico natural y socioeconómico y cultural, en especial los hidroeléctricos, que tienen el potencial para causar impactos negativos importantes, en virtud de lo cual, ha aumentado la crítica a los mismos, en particular en las últimas cinco décadas. Los críticos más severos reclaman que como los beneficios valen menos que los costos sociales, ambientales y económicos, es injustificable construir grandes represas. Pero otros sostienen que se puede evitar o reducir los costos ambientales y sociales a un nivel aceptable, al evaluar cuidadosamente los problemas potenciales y la implementación de las medidas correctivas, que además de contribuir a mitigar los impactos negativos de la obra, impulsen la conformación de nuevos ámbitos (naturales, sociales y culturales), que pueden favorecer el desarrollo de nuevas relaciones en diversas escalas de interpretación y que, a través de 'la mediación de la mirada', pueden contribuir también a construir una nueva 'noción de paisaje'.

Es decir que, cualquier reflexión sobre los efectos de una obra de infraestructura, debe considerar si se utilizan bien los recursos del paisaje, si existe una compensación adecuada de sus efectos positivos o negativos y sobre cuáles serían las medidas a seguir, o bien, si se puede seguir actuando de esa forma en el futuro. "[...] Sólo por esa vía permitiría superar el arrinconamiento de la reflexión en un reducto de negatividad, proporcionando oportunidades a la acción reflexiva." (Aguiló, en Maderuelo, 2006: 212).

${ }^{106}$ El mismo Preámbulo reconoce que el paisaje es un elemento importante de la calidad de vida de las poblaciones en todas partes: en los medios urbanos y rurales, en las zonas degradadas y de gran calidad, en los espacios de reconocida belleza excepcional y en los más cotidianos (Convenio Europeo de Paisaje, 2000: 1). 
3. Siguiendo el sentido de nuestra argumentación, el acercamiento desde las modalidades de la acción para recoger lo actuado por el hombre sobre su mundo, constituye el segundo rasgo para explicar contextualmente esa relación del hombre con el paisaje (Aguiló, en Maderuelo, 2006: 216). Es por ello que, para comprender el significado de una determinada acción del hombre sobre el territorio, nos ha resultado necesario analizar de qué forma ha evolucionado, en las cinco últimas décadas, el concepto de desarrollo y su implicancia sobre el ambiente, analizando los paradigmas y los imperativos dominantes de cada década, que han permitido, complementariamente, explicar y entender 'el porqué' de las adecuaciones del proyecto Yacyretá, en su largo período de ejecución, que ha pasado por un complejo proceso de adaptación a situaciones propias del proyecto y del área de implantación; así como, por situaciones derivadas del contexto internacional que incidieron en los países involucrados y en la región.

Poner en contexto el estado de la cuestión significa entender que la idea de construir proyectos hidroeléctricos en las cuencas de los ríos Uruguay y Paraná (entre ellos Yacyretá), que preveían las necesidades de abastecimiento energético para la región, nace a fines de siglo XIX, y la mayoría de los cuales fueron concretados durante el siglo XX. Yacyretá fue formalmente concebido en la década de 1920; tomó forma institucional hacia finales de la década de 1950 “[... en que primaba la concepción del medio ambiente como un conjunto ilimitado de recursos o 'bienes libres', que podían ser explotados indiscriminadamente" (Pichs Madruga, 2004: 4); se consolidó en 1973, a partir de la firma del Tratado, década considerada por Kathleen Murphy como la del 'desarrollo de macro proyectos en el Tercer Mundo', en la que se iniciaron más de 900 emprendimientos y por lo menos 600 más se encontraban en etapa de diseño (Murphy, 1982: xv), dónde [...] las inversiones representaron más de 500 mil millones de dólares, y cada proyecto empleó más de 10 mil personas (Murphy, 1983: VII, XV).” (Lins Ribeiro, 2003: 46), y su efectiva construcción tuvo su inicio en la década de 1980, dónde el tema ambiental internalizado en la década del 60 y puesto de relieve en la década del 70-, comenzaba a ocupar en muchos países un lugar central, tanto en el plano teórico como en el proceso de toma de decisiones.

"Desde mediados de ese decenio se asiste a un proceso de internacionalización del debate en torno al vínculo entre medio ambiente y desarrollo, que tiene importantes dimensiones politicas, económicas, tecnológicas, sociales, ambientales y humanas. Este proceso de internacionalización tiene sus antecedentes en la evolución de la corriente ecologista desde la década de 1960." (Pichs Madruga, 2004: 4).

La ejecución de Yacyretá pasó también por la década de 1990, que estuvo caracterizada por la evolución del conocimiento respecto de los problemas ambientales que aquejaban y aún aquejan al mundo, como la pobreza y la contaminación; por la consolidación de la idea de alcanzar un desarrollo sostenible con justicia social, y por los movimientos sociales y organizaciones no gubernamentales, que comenzaron a manifestarse en pos de la preservación del planeta y de una mejor calidad de vida para la comunidad mundial y en contra de muchas iniciativas de desarrollo, entre ellas, la construcción de grandes represas. En tanto que, su fase de terminación se ha sustanciado durante la primera década del tercer milenio, dónde el desafío está centrado en encontrar respuestas a los serios problemas 
económicos, sociales y ambientales que enfrenta la humanidad, sobre la base de estrategias de desarrollo sostenibles y participativas que, con alta presencia estatal, busquen superar la dicotomía planteada entre conservación o desarrollo.

“[...] El planeamiento participativo y el Estado -como agente regulador-ganan relevancia, asumen nuevos papeles y se tornan en una necesidad vital en la medida en que la sociedad se orienta hacia un nuevo estilo de desarrollo que busca que la conservación ambiental y la biodiversidad, el crecimiento económico y la equidad social, ya no sean 'categorías autónomas, como si cada una de ellas estuviera desligada o pudiera analizarse al margen del problema central del desarrollo' (Uranga, 2000: 17) y en donde el progreso duradero dependa del respeto de los derechos humanos y de la articulación efectiva de los ciudadanos en los asuntos públicos." (Tauber, 2008: 55-56)

Dentro de este contexto de intervención, la noción de sustentabilidad o sostenibilidad introduce un concepto complementario de la noción de desarrollo, necesariamente endógeno, que lo justifica y fortalece en tanto su evolución no destruya el medio en el que se lo promueve, consolidando una idea de desarrollo 'que satisface las necesidades del presente sin menoscabar las capacidades de las futuras generaciones para satisfacer sus propias necesidades' (Brundtland, 1987). Es así que la sustentabilidad adquiere una condición de par y al igual que el desarrollo, es social, cultural, política, económica y medioambiental (Tauber, 2008: 56). Ello representa una visión estructural que está induciendo, también, una nueva mirada a nivel mundial sobre las obras de infraestructura a gran escala, en especial las hidroeléctricas que, bajo este enfoque implica la necesidad de analizar integralmente los escenarios de intervención para delinear escenarios de gestión que contemplen el objetivo de desarrollo sustentable.

Pero, además, asumiendo que las nuevas tecnologías que promueven una significativa economía del uso de energía y recursos naturales en los productos de las economías modernas (Tauber, 2008: 56) no pueden satisfacer aún las demandas energéticas a gran escala de nuestras sociedades, en la región de análisis de esta investigación, junto a las 'lecciones aprendidas' de la ejecución de Yacyretá, debiera contemplarse necesariamente esta visión para los emprendimientos hidroeléctricos contenidos en la agenda conjunta de Argentina, Brasil y Paraguay.

"[...] el enfoque para el desarrollo de la región, puede estar centrado en la puesta en valor de los recursos históricos y culturales que otorgan identidad regional y de un prudente aprovechamiento turístico y energético-productivo de los recursos naturales. En este sentido, cabe destacar las iniciativas hidroenergéticas que se están trabajando tanto con Brasil como con Paraguay, que bajo un nuevo enfoque, proponen realizar primero las inversiones en materia de vinculación y adecuación urbana de las ciudades involucradas, asegurando además, un plus energético para la región, que -sumado a la disponibilidad de gas natural que aportará el Gasoducto del Noreste- permitirían consolidar una nueva matriz de desarrollo, con sustentabilidad económica y responsabilidad socio-ambiental." (Thomas, 2010b: 7)

Es decir que, como agenda de desarrollo, debieran incluirse por lo menos tres aspectos: el o los modelos de desarrollo que se ponen en juego, la producción y concentración del conocimiento que acompaña a los mismos, y la idea de participación como criterio de sustentabilidad (Uranga, 2006: 16, en Tauber, 2008: 57) 
4. En síntesis, la evolución de las variables contextuales analizadas, como las nociones de paisaje, entorno y sustentabilidad, puestas en relación con una gran obra de infraestructura y a nuestro contexto latinoamericano, nos permiten observar que:

- La aplicación de la 'noción de paisaje' con relación a un determinado contexto territorial está dominada en occidente, por una visión principalmente europea orientada a poner en valor los recursos naturales y los ambientes modelados por el hombre, a partir de políticas concertadas a escala de país y de la región, que orientan y definen procesos que tienden a rescatar aquellos valores naturales y culturales, tangibles e intangibles, en territorios dónde esos valores mantienen pervivencia y una cierta calidad de vida de las poblaciones que lo habitan.

- Cuando esa noción de paisaje pretende ser aplicada a contextos como el latinoamericano, los valores naturales de exuberante belleza y escala que poseen estos países, conviven, en general, con intervenciones humanas que modifican o deterioran el ambiente, y con poblaciones que sufren necesidades básicas insatisfechas, muchas de ellas en situación de pobreza estructural, dónde esta nueva noción deberá aportar soluciones novedosas, orientadas a definir criterios de gestión que conjuguen la mirada estética con una postura ética de justicia social, como camino alternativo que permita repensar la compleja relación cultura-naturaleza en ámbitos determinados.

- La necesidad de construir grandes obras de infraestructura de transporte vial o ferroviaria para salvar obstáculos naturales y cubrir las grandes distancias de nuestro continente, así como para abastecer de energía, principalmente destinada al desarrollo industrial y consumo de esas comunidades, obligan a repensar no ya la posibilidad de construirlas o no sino, más bien, la forma o modalidad en que esas grandes obras deben enraizarse en su entorno, contribuyendo a solucionar el problema que les da origen sin destruir el medio en el que se asienta; es decir, reduciendo los costos ambientales y sociales a un nivel aceptable (sentido ético), y aportando a la construcción de nuevas relaciones y percepciones de su área de implantación (sentido estético).

- De tal forma, como señalamos en el capítulo I (ver parágrafo I.2.1), cuando esa mirada de la obra sobre su entorno se convierte en positiva, sucede que en la misma dirección de las obras del Land Art, estas grandes obras pueden representar hitos en donde el entorno no sólo es su enclave, su sitio específico, sino que es incorporada como parte de la obra de arte, despertando interés y actuando como un imán en el paisaje, fomentando su apreciación en un doble sentido: perfeccionando las cualidades estéticas de la naturaleza y mejorando las éticas (Marchán Fiz, en Maderuelo, 2006:43).

- Las variables seleccionadas para establecer el estado de la cuestión muestran un origen, coincidente en la década del sesenta, con los efectos de la consolidación del paradigma de expansión de la frontera económica y uso irrestricto de los recursos que favorecieron el financiamiento y, con ello, la expansión de grandes obras de infraestructura, principalmente las hidroeléctricas, por los avances tecnológicos y la demanda producida por el crecimiento demográfico descontrolado, que fue motivando 
una paralela y progresiva aceleración de su evolución reactiva, que alcanza su apogeo en la década del noventa y que continúa aún en el período dónde se sitúa nuestro objeto de estudio.

- En este contexto de fuerte debate sobre la existencia e implementación de estas grandes obras, deberán articularse estas nociones de paisaje, entorno y sustentabilidad, con un proceso de desarrollo que haga converger la política, la planificación, la gestión y la comunicación, en una relación sinérgica entre la cuestión socio-cultural, el empoderamiento social y la participación como método (Tauber, 2008: 678), en la forma de un proceso de verificación y ajuste necesario para la retroalimentación del ciclo y para orientar condiciones de sustentabilidad dentro del contexto histórico en el que se inserte.

Seguramente, el nivel de éxito de este tipo de proceso, dependerá de la capacidad de organización de los actores sociales, culturales, políticos, económicos, en su ámbito cultural y territorial, ${ }^{107} \mathrm{y}$ dependerá también, de la generación de negociaciones distintas con los agentes o actores externos (empresas, instituciones o diferentes niveles del Estado), con la finalidad de crear y fortalecer la institucionalidad propia, e introducir diferentes tipos de consensos, para mejorar las condiciones del entorno socio-ambiental (Tauber, 2008: 57).

Para situar en su medio nuestro objeto de estudio, la investigación ha analizado el proceso histórico de estructuración del territorio y la evolución del paisaje en el contexto regional dónde se inserta Yacyretá, y ha explicado desde las variables paisaje e infraestructura, los alcances contemporáneos de la inserción de obras de infraestructura hidroeléctrica a gran escala, describiendo y analizando las principales variables afectadas por este tipo de proyecto, las preocupaciones sobre el tema y sus desafíos, así como, sus conflictos determinantes y las potencialidades derivadas de su transformación, considerando en este análisis, las 'huellas' ${ }^{108}$ ecológicas y culturales de esos procesos sobre la región históri$c a$, e identificando, en ese marco de referencia, los principales compontes del paisaje regional.

5. El área de implantación de Yacyretá ha sido afectada por diversos procesos de transformación antrópica, en función de hechos significativos acaecidos en breves periodos, vistos en términos históricos, que son verificables en términos de 'impactos' que han ido transformando el majestuoso y a la vez agresivo ambiente natural, aportando 'nuevos significados' para poder adecuarlo a las necesidades humanas; estos hechos, se manifiestan como 'huellas culturales' derivadas del proceso de ocupación del territorio a escala regional, que pueden ser clasificados en tres grandes periodos:

${ }^{107}$ Al respecto, Tauber incluye la siguiente acotación, que resulta apropiada a nuestro caso de estudio: "Adoptamos la definición de territorio que establece que 'El territorio no es un hecho meramente físico sino también temporal. Este espacio-tiempo está cargado con la historia misma de quiénes lo habitan, expresada en múltiples intereses. Aquí es donde se produce un nuevo mapa, el de las relaciones sociales, quizás más difícil de establecer por su intangibilidad o quizá por su permanente movimiento' (Zingoni, 2003:5)".

${ }^{108}$ La huella equivale a deuda y constituye por eso un excelente indicador para repartir la responsabilidad que cada uno tiene en el desarrollo global (Doménech Quesada, 2007:1). 
5.1. Conformación de la 'región histórica' (Levinton 2007): determinado a partir de la irrupción de los pueblos guaraníes, pasando por la implantación de las ciudades del periodo de la conquista hispánica junto a las reducciones de la Encomienda y de la red de pueblos-ciudad jesuíticos, que representan fases de ese proceso de consolidación de la región histórica. Los pueblos guaraníes no fundaron ciudades, fueron avanzando en la ocupación del territorio a partir de la técnica del 'rozado' de vastos sectores vinculados a las costas de ríos y arroyos. Esta técnica -que aún hoy es empleada por las pequeñas comunidades rurales- permitía el asentamiento de pequeños clanes en sitios dónde la presencia del agua proveía de la pesca, la comunicación y aún la recreación, y dónde la riqueza de la tierra favorecía su cultivo para cubrir necesidades alimenticias. Estos sitios eran ocupados hasta que la tierra agotara su capacidad productiva ( 3 a 5 años), mudándose luego a otros con análogas características a las abandonadas. La conquista hispánica, además de la típica implantación de ciudades, estuvo caracterizada por un proceso de sedentarización de esos clanes seminómades, a través de reducciones indígenas. Este proceso se efectuó, inicialmente, por el denominado método de 'la Encomienda' para pasar luego por pequeñas reducciones conducidas por padres franciscanos, hasta la consolidación de un verdadero sistema de 'pueblos-ciudad' del período jesuítico, que conformaron la base de la actual ocupación del territorio. Las transformaciones no fueron menores, pero el impacto de los posteriores períodos de ocupación del territorio, y el propio poder de la naturaleza, en particular del avance de la selva, fueron progresivamente ocultando la 'huella cultural' de este periodo.

5.2. Conformación del los Territorios Nacionales: el segundo periodo estuvo determinado por un proceso de abandono progresivo de esos pueblos-ciudad, definido a partir del proceso de consolidación de los territorios nacionales con sus diversas guerras, en especial las de la Triple Alianza y del Chaco, que tuvieron un efecto casi devastador sobre territorio paraguayo. La posterior consolidación de esos territorios nacionales, estuvo caracterizado por el crecimiento de las ciudades existentes, por la expansión de nuevas ciudades refundadas mayormente sobre los mismos pueblos jesuíticos, y por la promoción y localización de colonias agrícolas destinadas a inmigrantes europeos que -junto al desarrollo subsidiado de la producción industrial de la yerba mate, el té y el tabaco, sumado a las posteriores actividades forestales y ganaderas- fueron afectando importantes superficies de selva y cursos de agua, con un gran impacto sobre la naturaleza y la cultura local, que fueron configurando un paisaje con predominio de lo cultural, en un contexto antes dominado por lo natural.

5.3. La expansión rural, las aglomeraciones urbanas y las represas hidroeléctricas: más contemporáneamente, un tercer período de transformación (o reconfiguración) del territorio ha estado impulsado por el gran crecimiento de las ciudades, principalmente las capitales de provincias y departamentos localizadas a la vera de los principales ríos: Paraná, Paraguay y Uruguay; por la expansión de la frontera agrícola (principalmente sojera) y del desarrollo de la actividad forestal con aprovechamiento de especies nativas primero y por la implantación de especies exógenas después, que eliminaron enormes superficies de selva; y particularmente, por la implantación de más de sesenta grandes 
proyectos hidroeléctricos en toda la Cuenca del Plata (principalmente en Brasil), incluyendo Yacyretá, que han definido la reconfiguración territorial de la región histórica, a partir de unas nuevas relaciones de una cultura que ha dominado decididamente a la naturaleza.

6. Complementariamente, el análisis e interpretación de las huellas culturales relacionadas con la evolución histórica de la región a partir de aplicar los criterios paisajísticos de Berque (1995), ha demostrado que a pesar de no cumplir acabadamente la taxonomía aplicada para esa interpretación, la cultura guaraní tenía una relación con el entorno que puede considerarse 'paisajística' (Donadieu, 2006: 21). Como hemos señalado con antelación, de ese primer período sólo se rescatan costumbres, testimonios orales y las ruinas del periodo jesuítico, que en la actualidad forman parte del sistema turístico y de rescate cultural de la región. Articular estos testimonios al conjunto de las nuevas relaciones cultura-naturaleza -que propone la nueva configuración territorial derivada de los procesos de conformación de los territorios nacionales, junto a las nuevas actividades productivas, al desarrollo de las ciudades y las transformación generadas por la construcción de grandes obras de infraestructura hidroeléctrica- presentan el desafío de ser reinterpretados por el conjunto social 'en tanto que paisaje' (Berque, 2006), y para que ello sea posible parece necesario considerar, en estas nuevas relaciones, el conjunto de imágenes que están unidas a las cuatro categorías de procesos: patrimoniales, económicas, ambientales y territoriales, que corresponden a las cuatro dualidades de valores sociales: memoria/amnesia, riqueza/pobreza, seguridad/peligro, urbanismo/exclusión" (Donadieu, 2006: 60 a 62).

7. En síntesis, la evolución de las variables contextuales analizadas -como los conceptos de impacto y resignificación- puestas en relación con el proceso histórico de estructuración del territorio y la evolución del paisaje en el contexto regional por efecto de una gran obra de infraestructura hidroeléctrica como Yacyretá, permiten observar que:

- Si bien no han quedado vestigios tangibles de los primeros asentamientos guaraníes en la región, los misioneros eligieron, en general, las aldeas (tekoha) de los Caciques más importantes como lugares de asentamiento de las nuevas reducciones: "Lo que parece diferenciar cualitativamente a la aldea de la reducción no es sólo el tamaño de la concentración humana sino también el carácter de las leyes de convivencia, que harían del asentamiento misional esa incipiente ciudad (civis). El teko pyahu, entonces, designará la idea de la existencia guaraní en un sistema nuevo" (Levinton, 2009.a: 150). Se trata de 'huellas', que perviven hasta hoy como patrimonio tangible, conformado por 'la ruina' y restos arqueológicos, e intangible, conformado por los escritos de época y por la pervivencia del idioma, mitos, leyendas y costumbres en los pueblos de la región.

- Pero además, el análisis de los acontecimientos históricos, vinculado a la conformación de ciudades en los territorios nacionales en formación, permite afirmar que las trazas de los pueblos- ciudad y de las aldeas-capilla de la época jesuítica-guaraní fueron utilizadas por las diferentes políticas de reorganización del territorio misionero paraguayo-argentino, aprovechando la localización estratégica 
de cada emplazamiento, con relación a la altitud respecto de su área circundante, así como a la íntima relación que tenían con los ríos y arroyos, los caminos construidos para su interconexión y la proximidad a los yerbales (Levinton, 2007: 120), configurando un paisaje regional de ciudades-puerto, que siguieron teniendo al río como la posibilidad más importante de intercambio para la región, dado que el territorio, de accidentada geografía, plagado de cursos de agua y carente de infraestructura regional, resultaba complicado para el progreso.

- Por otra parte, la irrupción en la Cuenca del Plata de los emprendimientos hidroeléctricos, ha traído enormes controversias; basta la sola mención de que en marzo de 1997, se firmaba la Declaración de Curitiba (Brasil) declarándose al 14 de Marzo como el 'Día Mundial de Acción contra las Represas y por los Ríos, el Agua y la Vida' en el marco del '1er. Encuentro Internacional de Afectados por Represas'; pero es necesario reconocer también que han aportado al desarrollo de la región, tanto en su razón de ser: la producción de energía eléctrica que, por ejemplo, en Brasil representa más del $80 \%$ de su matriz energética, como en facilitar la navegación, en el aporte de nuevas infraestructuras de saneamiento en las ciudades, y de movilidad a escala regional, así como, en la sistematización de la cuenca, que permite regular los grandes caudales de sus ríos, minimizando los efectos de las históricas, traumáticas y periódicas inundaciones que sufría la región, con la consecuente afectación de las poblaciones costeras que, como en el caso de Yacyretá, representaba el 92\% de las cerca de 20 mil familias (unas 100 mil personas) que han sido relocalizadas y que habitaba en forma irregular en ámbitos costeros inundables, ambientalmente degradados, sin servicios y sin equipamientos socio-comunitarios.

"En esta mirada es fundamental uno de los conceptos escasamente trabajados en la limitada historiografía existente: el de impacto regional. El Megaproyecto Yacyretá no sólo ha sido una obra nacional para producir electricidad. Si entendemos el espacio de la implantación del Proyecto Yacyretá como una región histórica la cuestión de impacto se vincula con problemáticas especificas de la Argentina y del Paraguay a escala de la macro y micro región. En este sentido nos referimos a los Departamentos de Misiones e Itapúa (Paraguay) así como a las Provincias de Misiones y Corrientes (Argentina).”(Levinton 2010: 19).

Es por ello que el paisaje -desde una visión integral y a través del aprovechamiento para la generación de energía hidroeléctrica de dos de sus principales componentes: el agua y los saltos o arrecifesseguirá siendo, probablemente, protagonista del desarrollo de la región, dónde las controversias deberán ser reencauzadas dentro de un contexto de gestión socio-institucional corresponsable.

Como hemos mencionado con antelación, la inserción de Yacyretá en su entorno local y regional, ha pasado por un largo proceso de 'adaptación' a situaciones propias del proyecto y del área de implantación y, en ese trayecto, ha tenido que adecuarse a las también analizadas situaciones derivadas del contexto internacional, que incidieron en los países involucrados, en la región y en el propio diseño del proyecto que, en conjunto, definieron su ejecución y, con ello, las diversas posibilidades de 'transformación' y reconfiguración' del paisaje. 
8. El análisis de las circunstancias históricas que definen la ejecución de Yacyretá, nos permite afirmar que existe una directa relación entre el proceso de decisiones de su concepción y las variaciones del proyecto junto a los impactos de su construcción sobre la naturaleza y la cultura.

Las adaptaciones del proyecto giraban en torno a las discusiones sobre las diversas trazas posibles para el cierre del río Paraná que implicaban directamente la cantidad de territorio a ser inundado en cada margen, principalmente en la República del Paraguay. El Informe Técnico-EconómicoFinanciero del Anteproyecto realizado en 1964 por la CMT, consideraba que la construcción de las obras insumirían unos 8 años, estimándose que podrían iniciarse en 1972. Pero recién el 3 de diciembre de 1973 se firmaba en Asunción del Paraguay el Tratado de Yacyretá, con un proyecto de gran impacto ambiental, ya que generaba una gran superficie de territorio a ser inundado, por efecto de un embalse compensador localizado en zona de llanura (con alta afectación de territorio insular) y con una superficie equivalente al 50\% de la del embalse principal, dónde se preveía adicionalmente, ejecutar una central hidroeléctrica y una esclusa de navegación. Por estas discusiones la obra se inicio en 1983, ya sin considerar el embalse compensador. Luego de varias crisis financieras, finalmente el 7 de diciembre de 1991, el gobierno argentino informa en Ituzaingó (Provincia de Corrientes, Argentina), la decisión de construir Yacyretá en un periodo de 4 años a partir de 1994.

Efectivamente, el llenado a cota 76 fue realizado en 1994 y las obras principales concluyeron en 1998 con la puesta en operación comercial de la vigésima turbina. Pero quedaron pendientes los aspectos socio-ambientales y la protección de las ciudades aguas arriba de la presa. Recién en 2003 se reinició el proceso de terminación y, a medida que se fueron cumpliendo los compromisos sociales y ambientales, se fue alcanzando progresivamente la cota de diseño $(83 \mathrm{msnm})$, que se alcanzó en febrero de 2011. En este largo proceso, Yacyretá debió asumir, además de los mencionados pasivos propios de su ejecución, los cambios de visión del mundo sobre este tipo de proyectos y sobre los nuevos paradigmas de desarrollo.

9. El análisis de los principales elementos que definen su funcionamiento y, principalmente, la transformación del paisaje, nos ha mostrado que el principal impacto de Yacyretá está determinado por el embalse de $1.600 \mathrm{~km}^{2}$-definido por los $600 \mathrm{~km}^{2}$ del cauce original del río Paraná y los 1.000 $\mathrm{km}^{2}$ de tierras insulares y continentales inundadas- más los cerca de $200 \mathrm{~km}^{2}$ adicionales de subembalses -que se conforman por el ingreso de agua del embalse principal en los cursos inferiores de los ríos y arroyos que forman parte de la cuenca de aporte del cauce principal del río embalsado- El 80\% de la superficie afectada pertenecía a la República del Paraguay y se extiende hasta 200 kilómetros aguas arriba del río Paraná, dónde se localizan 15 municipios en ambas márgenes del río que, por directa consecuencia de la demora en su ejecución, ha representado una afectación de unas 20 mil familias (un horizonte poblacional de más de 100 mil habitantes) y más de 5 mil unidades productivas, urbanas, periurbanas y rurales -incluida la totalidad de la Zona Baja Comercial de Encarnación-, que representa un $150 \%$ más de la afectación originalmente considerada en su planificación, a lo que deben sumarse 
edificios públicos, redes de transmisión eléctrica y de otros servicios, vías férreas, rutas y accesos de orden local y regional.

10. Si a estos factores se incluye una no adecuada ponderación de los impactos de Yacyretá sobre las ciudades y el territorio que involucra, principalmente en el área de Posadas en Argentina y de Encarnación en Paraguay -que desde la década del 70 hasta hoy han quintuplicado su población-, vemos el por qué de la afirmación acerca de que los instrumentos de gestión socio-ambientales derivados de la evaluación ambiental del Proyecto realizada en 1992, nueve años después de iniciada su ejecución que fueron los Planes de Manejo del Medio Ambiente (PMMA) y de Acción para el Reasentamiento y la Rehabilitación (PARR)- no fueron suficientes; justificando en consecuencia, la necesidad de definir un cambio de enfoque para enfrentar la terminación de Yacyretá, como proceso de reconfiguración integral del territorio afectado, articulando los criterios de reposición funcional y de desarrollo urbanoterritorial (Thomas, 2010.a: 5).

11. En síntesis, la evolución cronológica de los hechos que definieron la ejecución de Yacyretá, puestas en relación con las variables analizadas, como las nociones de adaptación, transformación y reconfiguración del paisaje, nos permiten observar que:

- El principal problema de Yacyretá ha sido su prolongado tiempo de ejecución. "Durante este periodo fueron desarrollados varios planes de intervención manteniendo operativo el PARR y el PMMA. Esta situación obligó al Proyecto a absorber varias consecuencias del contexto externo que fueron 'confundidas' o aprovechadas como si fueran parte de sus efectos. También el largo tiempo conlleva el crecimiento vegetativo de la población y facilita los intereses especulativos, lo que ha aumentado considerablemente el contingente poblacional atendido por el Proyecto y, consecuentemente, los costos del tratamiento de los impactos socioeconómicos" (EBY, 2009.a: 187).

- La culminación en 1998 de las Obras Principales, 25 años después de la firma del Tratado, y su posterior paralización retomada 5 años después, en 2003 ha contribuido a generar una visión negativa sobre el proyecto, minimizando sus logros: "Cualesquiera sean los resultados del esquema multipropósito, el nombre de Yacyretá siempre estará asociado a la producción de energía.” (Lins Ribeiro, 2003: 61).

- Sin embargo, la ejecución del PMMA, a través de sus programas de gerenciamiento ambiental y del PARR, a partir de haber cumplido el proceso relocalizatorio y ejecutando las acciones de rehabilitación social de la población relocalizada -como medidas de mitigación ambiental y social, respectivamente- han sido muy bien consideradas por los organismos multilaterales que apoyaron en buena parte el financiamiento del proyecto, conformándose tanto en el sustento técnico de base para alcanzar el objetivo de recrecimiento del embalse de Yacyretá a su cota final de diseño, como para revisar y actualizar sus políticas operacionales.

- Por otra parte, el tratamiento prioritario de los principales subembalses está determinado por la posibilidad de establecer nuevas condiciones de uso y de significado, en el proceso de reconfiguración 
que representan estas lenguas de agua en el interior del territorio. De tal forma, la protección del valle del arroyo Aguapey en territorio paraguayo, además de proteger de la inundación a más de 40 mil hectáreas, permiten establecer un plan de manejo de desarrollo sustentable de las mismas, como áreas de producción controlada y como área de reserva protegida (sentido ético), dónde el mismo canal y presa de cierre de más de 20 kilómetros de longitud, conforman además una gran obra de infraestructura que aporta condiciones para establecer una nueva mediación a través de la mirada (sentido estético). También las obras de saneamiento, como las plantas de tratamiento de efluentes cloacales, contribuyen a evitar la emisión de vertidos contaminantes a estos cuerpos de aguas y sus áreas de protección ambiental se integran al ambiente natural circundante. Y finalmente, los $54 \mathrm{~km}$. de tratamiento urbanocostero y de recomposición de la trama urbana de las ciudades en torno al embalse principal y a los subembalses de los arroyos urbanos, está contribuyendo a aportar unas 600 hectáreas de lagos interiores, con calidad de agua apta para su uso recreativo, aportando además, nuevas relaciones de los barrios y de la ciudad con el agua y, consecuentemente, una nueva configuración del paisaje urbano.

- Además, el conjunto de obras conformado por más de 50 kilómetros de rutas, puentes y accesos viales que integran nacional y binacionalmente a las ciudades involucradas dentro del área del proyecto -dónde se destacan el Puente Internacional San Roque González de Santa Cruz que une las ciudades de Posadas y Encarnación y la misma ruta consolidada sobre la represa que 100 kilómetros aguas abajo del Puente une las localidades de Ituzaingó (AR) con Ayolas (PY)- junto a los mencionados 54 kilómetros de avenidas costaneras que devuelven a las ciudades su acceso al río y su contemplación; a la reposición del sistema ferroviario en ambas márgenes; a los nuevos complejos habitacionales con todos los servicios y equipamientos urbanos -que con más de 15 mil viviendas se utilizaron para reasentar a la población que sin esos beneficios habitaba en la costa inundable del río y arroyos; así como a la reforma urbanística integral de Carmen del Paraná y la urbana de Encarnación dónde se relocalizó el Circuito Comercial de la Zona Baja y los edificios públicos afectados de la ciudad- y las cerca de 150 mil hectáreas de áreas de reservas protegidas, parques urbanos, plazas, paseos y espacios públicos equipados y la reforestación del peri-lago, conforman un gran circuito regional que, a partir de su resignificación, permite pensar en la integración, con nuevas relaciones de producción, intercambio y turismo, sobre la base de alcanzar objetivos locales y regionales de desarrollo sustentable.

- Hemos analizado también que, para encauzar esas obras y acciones dentro de cada contexto territorial, el organismo ejecutor de Yacyretá ha impulsado una estrategia de planificación a escala local, urbana y regional, dónde la acción concreta o proyecto urbano, como instrumento operativo del plan, puede contribuir a fortalecer la gestión del desarrollo a nivel de las administraciones locales, como "[...] organizadoras de una trama o red urbana-territorial, que establezca la gobernabilidad de la interacción entre lo urbano y lo rural y entre lo natural y construido, como una de las bases de la sustentabilidad" (Pesci, R, 2001: 22). De tal forma, los impactos y las transformaciones derivadas de ese accionar, representan tanto medidas de mitigación de la ejecución del proyecto, como un aporte al sa- 
neamiento y crecimiento de las ciudades, que pueden leerse como una 'amenaza' o como una 'oportunidad' para encauzar un desarrollo con equidad y sustentabilidad, donde la nueva configuración territorial a partir de la transformación de las zonas costeras represente, también, un nuevo paisaje en las mismas escalas de instrumentación del plan: el barrio, la ciudad, el territorio.

En suma, el análisis de estas variables ha permitido verificar que puede encauzarse una gestión del paisaje a partir de sus interfases costeras, principalmente de los arroyos urbanos, dónde la planificación y gestión participativa como proceso, se muestra como una componente del discurso reciente de marcada vigencia, y como un insumo indispensable para orientar la '(re)conciliación' entre la cultura y la naturaleza como objetivo, y con el horizonte el desarrollo sustentable como meta a alcanzar, en un contexto de corresponsabilidad socio-institucional.

El paisaje como proyecto en las zonas urbano-costeras de las ciudades involucradas en el caso de Yacyretá, en el quinquenio comprendido entre el mes de junio de 2005 al mes de julio de 2010, se abordó desde un enfoque metodológico que incluye un análisis de situación a partir de tres componentes: ecológico-ambiental, histórico-cultural y geográfico-urbanístico, que representa una manera de agrupar las escalas de intervención y las variables territoriales y socioeconómicas, para describirlas y evaluarlas como recursos del paisaje, y desde la aplicación de una forma de valoración, identificación de lineamientos estratégicos y catalogación, como un instrumento para su gestión.

12. Dado que el interés de esta investigación se ha centrado en esa conjunción de lo natural y lo construido, no se ha profundizado el estudio de la naturaleza que en forma salvaje o prístina, que es cada vez más difícil de encontrar, ni tampoco a lo exclusivamente urbano, dado que ambos extremos son objeto de disciplinas específicas (la biología, la geografía o la arquitectura y la ingeniería); sino que se abordó como un problema de cómo el hombre se ha hecho presente en un sector determinado del mundo, profundizando sobre el concepto de 'lugar', entendido como producto de esa relación.

13. Las zonas costeras, principalmente las urbano-costeras, tanto en el embalse del río Paraná como en los subembalses de los arroyos -que están siendo modificadas con el objetivo de alcanzar la cota de diseño de Yacyretá ( $83 \mathrm{msnm})$, con la consecuente necesidad de haber tenido que relocalizar población y actividades económicas, productivas y de servicio- como los antiguos puertos de Posadas y Santa Ana en Argentina y de Encarnación en Paraguay así como la totalidad del Circuito Comercial de la denominada Zona Baja de esa ciudad, y zonas residenciales tradicionales que dieron origen e identidad a 'la ciudad', representan una trama de espacios abiertos de características únicas en la región, que aportan una nueva significación en su relación con 'el agua' de las siete ciudades más impactadas de ambas márgenes del río Paraná. 
14. Ello demuestra la certeza de lo señalado en la justificación de esta investigación acerca de qué, hablar de las zonas costeras -que son las inicialmente afectadas por este tipo de proyectos- es hablar de la historia de la ciudad, así como, a lo señalado respecto de que cuando las alteraciones urbanas se producen no como producto de la decantación histórica del desarrollo de una cultura, sino que se hacen en forma abrupta y con escasas posibilidades de asimilación por parte de las poblaciones afectadas, aparece el conflicto y también, el desafío de reflexionar sobre las alternativas de cómo recomponer esas relaciones 'cultura-naturaleza', que delinearon un paisaje que es modificado en aras de otros intereses (nacionales y regionales; geopolíticos y de desarrollo), que exceden lo local.

15. Desde esta perspectiva, el proyecto paisaje ha recurrido a una estrategia de gestión de sus interfases costeras (Giacomini, 1980/83), como "teatro de experimentación para el desarrollo sustentable" (Halffter; 1994), actuando como inductor de nuevas relaciones de integración entre naturaleza y cultura del territorio modificado. Esto es, proponiendo una reflexión sobre 'los bordes' más significativos de esta intervención, que se materializa en el paisaje de las zonas costeras del río Paraná (embalsado) y de las cuencas de los arroyos que surcan el territorio y desaguan en él, analizando las posibilidades de la resignificación de estos espacios que históricamente han sido concebidos como de articulación entre los pueblos, identificando claves para una nueva articulación entre espacio, sociedad y naturaleza, en el área comprendida por las áreas metropolitanas de Posadas, en Argentina y de Encarnación, en Paraguay, que permiten aportar elementos para afirmar que es posible resignificar la configuración del nuevo paisaje, a partir de recomponer la fractura de la relación naturaleza-cultura, provocada por la construcción de una gran obra de infraestructura hidroeléctrica, que es uno de las principales preguntas fundantes de esta investigación.

16. En síntesis, la noción de paisaje aplicada como metodología de proyecto para interpretar las transformaciones de Yacyretá sobre su entorno, en particular, sobre las zonas urbano-costeras de las ciudades involucradas, nos permite observar que:

- Este enfoque metodológico ha permitido avanzar hacia una forma de interpretación del territorio modificado, que analiza los impactos e identifica las potencialidades del mismo para su ordenación, considerando un criterio de 'doble articulación': artealización in situ e in visu, por una parte, y país y paisaje, por otra (Roger, 2007), avanzando en el concepto de paisaje -a escalas 'territorio', 'área' y 'lugar'- con un enfoque multidimensional y transdisciplinario, que procura aportar el basamento conceptual para la construcción del concepto de resignificación de los espacios transformados que plantea la hipótesis general de esta investigación.

- Pero además, esta mirada sobre las interfases urbano-costeras, analizadas en el contexto urbano, territorial y socio-ambiental, verifica asimismo en líneas generales, la hipótesis de que el territorio transformado por la construcción de un proyecto hidroeléctrico a gran escala como Yacyretá, implica una gran distorsión ambiental, que tiene la potencialidad de constituirse en matrices de un nuevo Pai- 
saje y, desde este enfoque, ha permitido revisar con precisión sus aspectos más específicos, entender su desarrollo y su comportamiento, reconociendo la necesidad de articular estrategias de intervención, nivelando el desarrollo de las variables ambientales y culturales, formulando criterios convergentes que orientan el desarrollo de una nueva noción del territorio en términos de paisaje, que ha sido concebida como una herramientas de gestión que permite una producción transversal y sinérgica, que desde una gestión holística puede orientar una moderna concepción del desarrollo, articulada en planes, programas, proyectos y procesos de gestión que revaloricen la naturaleza y la cultura de ese 'nuevo paisaje' que debe ser aprehendido por el conjunto social.

- Como hemos señalado en la introducción de la investigación, este aporte tiene un doble alcance: uno teórico, como reflexión sobre las implicancias (ecológicas, económicas y sociales) que sobre el desarrollo local (Arocena, 1995) tiene una enorme transformación como la generada por Yacyretá; otro proyectual, como instrumento de valoración y de ordenación a escala territorial, que permita orientar un proceso de construcción social del paisaje (Nogué, 2007), en forma sustentable y transferible a otros territorios involucrados por proyectos de estas características, configurando un modelo de actuación, que se presenta como una hipótesis de trabajo, cuyo planteo deberá ser verificado y ajustado al confrontarlo con la realidad institucional -organismos municipales, departamentales y nacionales- junto con las organizaciones de la sociedad civil, y con la población organizada.

En tanto que su proceso de ejecución debe admitir, además, modalidades de actuación abiertas a fin de poder discutirlas en forma participativa, probándolas en forma experimental en la realidad y realizando los ajustes que el uso concreto aconseje.

Habida cuenta que la investigación estuvo orientada a identificar, diagnosticar y explicar las relaciones urbano-territoriales que surgen de la repercusión ambiental que experimenta el sistema territorial y el paisaje -como consecuencia de la construcción de un proyecto de infraestructura hidroeléctrica a gran escala, como es el caso de Yacyretá- resultó necesario enfrentar esa relación entre lo natural y lo construido a partir de una mirada alternativa.

Dicha mirada, permitió abordar los efectos de este tipo de proyectos sobre los que, como hemos visto, existe una vasta bibliografía y posturas internacionales, ya sea contrarias, así como otras que recomiendan hacerlas con alto respeto ambiental, en función de los impactos que este tipo de obras generan sobre el territorio y sobre el desarrollo de las comunidades locales involucradas.

Por eso, para cerrar estas conclusiones en sus aspectos teórico-conceptuales y metodológicos, se aporta el conjunto de pautas y puntos de referencia que conformaron las preguntas fundantes profundizadas en la investigación. 
17. La 'mirada' sobre el paisaje desde una perspectiva de 'desarrollo sustentable' se explica cómo postura ética dirigida a un territorio que ha sido fuertemente transformado desde unos intereses que, parafraseando a José Arocena, son de una 'lógica cultural' diferente a la 'lógica de lo local' (Arocena, 1995, op.cit) que justifica las reflexiones efectuadas sobre sus efectos y sobre el proceso cultural que como desafío de gestión deberá encauzarse en sentido a su resignificación.

"Nadie pone en duda que en el Paraguay el futuro del país pasa por el cabal aprovechamiento de la enorme cantidad de energía hidráulica que Dios puso a su disposición. Pocos, sin embargo, se detienen a pensar que tal aprovechamiento depende de que la energía se convierta en industria, la industria dinamice el comercio, el comercio la infraestructura, la infraestructura facilite la productividad, y ésta, el bienestar que favorezca la gobernabilidad. Pocos perciben que todos estos procesos de transformación dependen de la capacidad de la población para realizarlos. Es decir, de su educación". Y añado: No estamos hablando de cualquier educación, sino de aquella directamente orientada a producir ese cambio." (Díaz Bordenave, 2010:1)

18. Pensar la relación 'cultura-naturaleza' como potencialidad (paisaje) y no como ruptura, reconoce la mutua interdependencia de contenido-continente, que el hombre ha creado a lo largo de la historia: hábitat para perdurar y amoldar en él sus requerimientos, inquietudes y contradicciones; en suma, su cultura. En el caso de estudio, el área de proyecto está inserta en lo que Norberto Levinton denomina región histórica de la cultura guaraní (Levinton, 2007: 21 a 28), donde aún antes del encuentro entre esta cultura con las misiones jesuíticas, el río Paraná representaba la columna vertebral que articulaba las poblaciones establecidas en sus márgenes y en las islas; y donde los cursos menores (otros ríos y arroyos), representaban -por las dificultades que presentaba la topografía- los principales medios de circulación, comunicación y articulación entre estas poblaciones. Luego de los diversos y complejos vaivenes de la historia, el río se convirtió en límite entre dos países (Argentina y Paraguay), constituyéndose en algunas pocas oportunidades en 'barrera infranqueable' y, mayormente, en un factor de integración entre pueblos de un mismo origen. Con el devenir del desarrollo histórico, esas 'fracturas' territoriales fueron superadas, pero el caudaloso Paraná siguió siendo punto de referencia de esta región; sin embargo, la sistematización de su cuenca para su aprovechamiento hidroeléctrico, desde el Brasil hasta la Argentina, aportó nuevas 'fracturas' que han conformado una nueva relación entre la cultura y la naturaleza y, en consecuencia, un nuevo paisaje regional.

19. Calificar las zonas costeras como 'interfase', ha permitido superar las nociones de límite o borde; así como, las de nexo o punto de convergencia; y aún, de espacio abierto o verde (público o privado), para entenderlas como el punto de contacto (área y factor de integración) entre dos o más sistemas, representando así, el sitio de mayor intercambio de materia, energía e información entre esos sistemas, es decir, como las zonas de mayor diversidad biológica, económica y social (Pesci, 1999: 52). Ello ha permitido enfocar lo esencial de los sistemas en interacción, reconociendo desde las interfases su identidad y complejidad: “[...] Proyectar las interfases es proyectar lo esencial, el ADN de un territorio o 
de una ciudad" (Pesci, 2007: 32). Y hacerlo en términos de paisaje implica, además, aproximarse a la potencialidad de su resignificación.

20. De todas maneras, en esa potencialidad que presenta el 'hecho consumado' no podemos soslayar la existencia de otras miradas que no aceptan la posibilidad de esa nueva resignificación:

\section{"Yacyretá...lugar donde llora la luna}

[...] Hace unos años escribi acerca de Yacyretá, haciendo referencia al lugar 'donde brilla la luna', recordando fue lugar de poesias, canciones, donde vivian pueblos originarios y donde los rápidos del Apipé dibujaron sonrisas a miles de pescadores desde siempre, entre tantas otras cosas que hacen a la vida normal de la gente del río. Hace tres décadas es parte de una triste historia donde la sumatoria de tiempo, algunos medios de prensa, funcionarios de turno y la mirada esquiva, indiferente [...], jugaron en contra del río, de la gente de alli [...] que sufren el calvario que toda gran represa hidroeléctrica trae consigo, transformando lo hermoso en paisaje de horror. [...] Acostumbrándose a que hablar de reclamos de familias forzosamente afectadas, fraudes, corrupción, improvisaciones, daños ambientales, sea cosa de todos los días. La despreocupación de una gran parte fue tal que el gran ruidoso río fue silenciándose, transformándose en un espejo inmenso de aguas quietas, como la misma sociedad que recién cuando el agua le llegó al patio de sus casas comenzó a darse cuenta que más abajo hay una inmensa represa [...] ¿Qué sucedió para tanta indiferencia generalizada?

[...] Lo que quedó bajo el agua o en las orillas pero a varios kilómetros en barrios hacinados, donde no está el fresco del río, la sombra para el mate y la siesta o los vecinos que mensualmente forman parte de las filas para retirar bolsas de ayuda y antes tenían un trabajo digno, no conmueve a muchos y es la postal diaria de la resignación de algunos, la impotencia de tantos cada vez más. [...]La destrucción del patrimonio cultural -aquello imposible de poner preciocon la pérdida de sitios arqueológicos, de áreas de valor cultural, arquitectónico, histórico, como el deterioro ambiental, con la contaminación del rio, pérdida de calidad de agua, zonas de alta calidad ambiental y productiva quedaron de por vida sepultadas bajo el agua, provocando la desaparición y muerte de especies aún desconocidas, dramática disminución de la fauna íctica y la destrucción de hábitats únicos en el mundo, son apenas parte del saldo negativo de esta obra [...] La expulsión de comunidades Mbyá Guaranies de su territorio tradicional [... y] los residuos de la ciudad, [...] sacando provecho de esto los especuladores inmobiliarios, hoy 'dueños' de las tierras que 'valían poco' y ahora cuestan fortuna [...]

Con algunas suntuosas obras tratan de parchar el cáncer que es la hidroeléctrica para poblados argentinos y paraguayos. La costanera posadeña es una de ellas, la realidad más palpable que ha hecho notar aún más la indiferencia ciudadana para con el río. Esta es más la vidriera de una elite que un lugar de encuentro de toda la sociedad, como los balnearios y playitas públicas de antes. Es una obra que hasta ahora excluye [...Pero] debería haber un trabajo social para que la misma sea de todos, hasta del paisaje.

[...] Hoy somos todos afectados, salgamos del letargo, porque muy a pesar de Yacyretá cerca, la insistencia de otras grandes represas no justifica ante el hambre de energía brasileño, que vivamos otra vez todos, el calvario por Corpus Christi, Garabi, Roncador, Panambi o como se llamen las hidroeléctricas planeadas, pero no consumadas. Misiones [...]”"

(Bregagnolo, 2011, http://www.misionesonline.net/opinion/leer/1636) ${ }^{10}$

No es objeto de esta investigación discutir los impactos que plantean este tipo de miradas, pero sí lo es el de hurgar por algunas ventanas que la misma crítica -fundada en algunos aspectos y no en otros- deja abierta, como cuando habla sobre la Costanera de Posadas, indicando que si bien desde su

${ }^{109}$ Rulo Bregagnolo, es coordinador de la campaña Mega Represas Nunca Más, del Grupo Ecologista Cuña Pirú. 
óptica hoy "es una obra que excluye", la misma crítica plantea que "debería haber un trabajo social para que la misma sea de todos, hasta del paisaje"; es decir que, vemos que aún desde una posición sustancialmente antagónica a la transformación, es posible ese camino de la resignificación.

21. Es por ello, que si bien "[...] ahora parece más natural pensar que paisaje e infraestructura forman parte de único diseño" (CITRAC, 2003: 15), un proceso corresponsable no puede excluir esas 'miradas'. De tal forma: 1) infraestructura como paisaje y paisaje como infraestructura; 2) aceptación de la noción de paisaje como proyecto; 3) menos territorio y más paisaje; 4) gobernar la transformación; 5) intervenir ex-ante; 6) balance costo/beneficio en términos ambientales; 7) interacciones innovadoras; 8) la correcta auscultación del lugar de implantación, comprendiendo y respetando los factores de identidad; 9) la preservación ambiental; 10) un accionar que favorezca la calidad del proyecto paisaje (CITRAC, 2003: 103 a 107), representan diez aspectos no excluyentes para encauzar la percepción, clasificación, intuición e inflexión del proceso de evolución del lugar de implantación de una gran obra de infraestructura.

22. Llevar estos conceptos a nuestro caso de estudio, para ser trasladados a otros proyectos en vías de ejecución, ${ }^{110}$ permite vislumbrar que el verdadero desafío radica en encauzar un proceso que en términos de desarrollo económico permita mantener y operar adecuadamente las infraestructuras; que en términos de desarrollo ambiental, garanticen la calidad ambiental general y la calidad del agua del embalse y de los subembalses, en particular; y que en términos de desarrollo social, se operen alternativas de crecimiento económico y cultural para las poblaciones involucradas, en un camino que en forma análoga a su concreción y/o terminación y a pesar de la gran transformación, haga tangible el objetivo de desarrollo sostenible.

El proyecto paisaje representará así un modelo de actuación integral, donde, la infraestructura enraizada en su entorno territorial, se convierte en portadora de un mensaje cultural que 'esculpe' el soporte natural originario y lo ofrece transformado para una nueva mediación, 'dando voz' en cierta forma, al paisaje dominantemente natural que la contiene y circunda.

${ }^{110}$ Hablamos específicamente de las Represas de Corpus (a ser ejecutada entre Paraguay Argentina), localizada entre Itaipú y Yacyretá, sobre el río Paraná, y las de Panambí y Garabí (a ser construidas entre Brasil y Argentina) localizadas sobre el río Uruguay. 



\section{BIBLIOGRAFÍA}

ADORNO, Theodor W., 1990 (1ºd. en alemán, 1969). Teoría Estética. Akal, Madrid, España.

AGUILÓ, Miguel, 1999. El Paisaje Construido: una aproximación a la idea de lugar. Colegio de Ingenieros de Caminos, Canales y Puertos. Madrid, España.

ARGENTINA y PARAGUAY, 1973. Tratado de Yacyretá. Buenos Aires, Asunción: HMSO.

ARMANI, Alberto, 1988 (1977). Ciudad de Dios y Ciudad del Sol: El “Estado” jesuita de los guaranies (16091768). Fondo de Cultura Económica. Encuadernación Progres S.A. México (2da. Edición corregida). Título original: Cittá di Dío e cittá del sole. Lo "Stato" jesuita del Guaraní (1609-1768). Vita Nova, SPA Edizioni Studium, Roma, Italia.

AROCENA, José, 1995. El Desarrollo Local: un desafio contemporáneo. CLAEH Universidad Católica del Uruguay. Editorial Nueva Sociedad.

AUGUÉ, Marc, 2005 (1992). Los no-lugares. Espacios del anonimato. Una antropología de la sobremodernidad. Título original: Non-lieux. Introduction a une anthropologie de la surmodernité, Édition du Seuil, París, Francia. Versión castellana, trad. Margarita Mizraji, Editorial Gedisa S.A., Barcelona, España. Impreso Artes Gráficas Piscis S.R.L., Buenos Aires, Argentina.

ARRÚA, Griselda A., 2009. Encarnación: una mirada histórica. Edit. Entidad Binacional Yacyretá. Encarnación, Departamento de Itapúa, República del Paraguay.

BANCO INTERAMERICANO DE DESARROLlO, 1994. "Programa de Medio Ambiente y Reasentamiento". Contrato de Préstamo entre la Entidad Binacional Yacyretá y el Banco Interamericano de Desarrollo. C.C. EBY. miento del PHY. C.C. EBY. , 1997. "Panel de Revisión". Informe sobre el estado de ejecución del Plan de Reasenta2001. "Reasentamiento Involuntario". OP-710.

, 2005. "Política de Medio Ambiente y Cumplimiento de Salvaguardas". OP-703.

BANCO MUNDIAL, 1991. "Pueblos Indígenas”. OD 4.20, OP 4.10, BP 4.10.

1999a. "Evaluación Ambiental”. OP 4.01, BP 4.01; BP 4.02.

, 1999b. "Bienes Culturales". OPN 4.11.

2001a. "Hábitats Naturales". OP 4.04, BP 4.04.

2001b. "Reasentamiento Involuntario". OP 4.12 y Anexo A, BP 4.12.

BARTOLOMÉ, Leopoldo J., 1982. Colonias y Colonizadores en Misiones. Universidad Nacional de Misiones, Posadas, Argentina.

1985. Relocalizados: Antropología Social de las Poblaciones Desplazadas. Colección Hombre y Sociedad, Ediciones del IDES, Buenos Aires, Argentina.

BARTOLOMÉ, Miguel A. 1992. "Presas y Relocalizaciones de Indígenas en América Latina". En ALTERIDADES $\mathrm{N}^{\circ} 2$, pp. 17 a 28.

BERQUE, Agustín, 1995. Les Raisons du paysage. De la Chine antique aux environnements de synthèse. Hazan, París, Francia.

, 2004. "La grotte et le Land Rover L'histoire de la ville-nature en Asie orientale n'est-elle qu'orientale ?”. Conferencia en Colloque La ville-nature contemporaine Institut d'urbanisme de Grenoble, 5 y 6 de febrero.

2005. "Cosmophanie et paysage moderne". Conférencier en Colloque International Paysage \& modernité(s), CNRS / Université Paris III, 10 a 12 de marxo.

, 2006. "Trayección y Realidad del Paisaje”. Conferencia en Girona, Fundació Espais Jornades hibrids, 3 al 5 de julio.

, 2007. "Paisaje y Ecúmeno". Conferencia en Maestría Paisaje, Medio Ambiente y Ciudad, FAU/UNLP, 7 al 9 de agosto, La Plata, Argentina.

BOISIER, Sergio, 1993. "Postmodernismo Territorial y Globalización: Regiones Pivotales y Regiones Virtuales" (mimeo). Instituto Latinoamericano y del Caribe de Planificación Económica y Social (ILPES). Santiago de Chile.

BOLÓS, María de (Dir.), 1992. Manual de Ciencias del Paisaje: teoría, métodos y aplicaciones. Masson, S.A. Colección de Geografía. Barcelona España. 
BORIO, Carlos A. 2010. “¿Quo Vadis Posadas? Reseña sobre la Evolución Urbanística de la Ciudad de Posadas”. Universidad Católica de Santa Fe, sede Posadas, Misiones, Argentina

BORJA, Jordi y CASTELLS, Manuel, 1997. Local y Global: la gestión de las ciudades en la era de la información. Taurus Pensamiento. United Nations for Human Settlements (Habitat). Madrid, España.

BREGAGNOLO, Rulo. 2011. "Yacyretá...lugar donde llora la luna". http://www.misionesonline.net/opinion/leer/1636

CALAVIA SÁEZ, Óscar, 2004. "La Persistencia Guaraní". Revista de Indias, vol. LXIV, núm. 230, pp., 9 a 14, ISSN: 0034-8341. Universidad Federal de Santa Catarina, Brasil.

CAMBAS, Aníbal, 1962. Los Antiguos Guaranies del Alto Paraná. Artes Gráficas de Gendarmería Nacional, Buenos Aires, Argentina.

CÉSAR, Julio Ramón de, 2002. Noticias del Paraguay. Asunción, Union Académique Internationale / Academia Paraguaya de la Historia.

CHIOZZA, Elena, 1983. "País, Paisaje y Paisanos". Seminario de la Maestría Proyectación Ambiental. Universidad de Belgrano. Buenos Aires Argentina.

CITRAC (Circolo Trentino per l' Architettura Contemporanea), 2003. Nuove infraestrutture per nuovi paesaggi. Skira editore. Provincia Autónoma di Trento. Milano. Italy.

COCCO, Giuseppe (org.), et. al., 2001. A Cidade Estratégica. Novas e velhas práticas no planejamento do Rio de Janeiro: a impostura do Porto de Sepetiba. DP\&A editora. Rio de Janeiro, Brasil.

COMIP, 1992. Aprovechamiento Energético del Alto Paraná. Documentos y Tratados. Buenos Aires, Argentina.

COMITÉ INTERGUBERNAMENTAL COORDINADOR DE LOS PAÍSES DE LA CUENCA DEL PLATA (CIC), 1969. Tratado de la Cuenca del Plata. Publicado en http://www.cicplata.org/Buenos Aires, Argentina.

COMISIÓN MUNDIAL DE REPRESAS, 2000. "Represas y Desarrollo: Un Nuevo Marco para la Toma de Decisiones". Informe de la Comisión, 16/11/2000, http://www.dams.org/report/wcd informe.htm

------, 1998. "Sistema de Información sobre Calidad del Agua para el Alerta Hidrológico de la Cuenca del Río de la Plata: Primera Etapa Diagnóstico y Prediseño". Buenos Aires, Argentina.

CONSEJO DE EUROPA, 2000. Convenio Europeo del Paisaje. Comunidad Económica Europea. Florencia, Italia.

CORTIÑAS, Juan C., 2000. Argentina y Paraguay: hacia una integración activa. Ediciones al Margen. La Plata, Argentina.

CRIVOS, MARTA Y MARTÍNEZ, MARÍA R., 2000. "Historias culturales-historias naturales. Movilidad y paisaje en la narrativa Mbyá-Guaraní”: Facultad de Ciencias Naturales y Museo de la Universidad Nacional de La Plata. Ponencia a la XI Conferencia Internacional de Historia Oral. Estambul, Turquía. Publicado en: Proceedings, Tomo III, pp. 1265-1269.

CULLEN, Gordon, 1981 (1971). El Paisaje Urbano, tratado de estética urbanistica. Título original: Townscape, Architectural Press, Londres. Trad. $6^{\circ}$ ed., por José Mª Aymamí. Ed. castellana, Edit. Blume, Barcelona, España (1974). Impr. Gráficas L' Alzina, S.A.

DANKLMAIER, Christine, 2001. "Impactos selectivos y adaptación al medio: los desplazados por Yacyretá". En Estudios Regionales. Año 10. № 19. Posadas, Argentina.

DE BARROS TOMÉ MACHADO, Marcello, 2008. A Modernidade no Rio de Janeiro: construção de um cenário para o turismo. Prefeitura do Rio/Culturas. Coleção Biblioteca Carioca, Vol. 51. Rio de Janeiro, Brasil.

DELVALLE, Alberto. 1998. Pueblos de Itapúa. Datos Históricos. Editado por la Universidad Católica, Sede Regional Itapúa, Encarnación, Paraguay.

DÍAZ BORDENAVE, Juan, 2010. "Más importante que Itaipú y Yacyretá". http://www.ultimahora.com/notas/

DONADIEU, Pierre, 2006. La Sociedad Paisajista. Editorial de la Universidad Nacional de La Plata, Argentina.

DUCROT, Oswald / TODOROV, Tzveta. 2003 (1972). Diccionario Enciclopédico de las Ciencias del Lenguaje. Editorial Siglo XXI, Buenos Aires, Argentina.

ENTIDAD BINACIONAL YACYRETÁ (EBY), 1992a. "Informe de Evaluación Ambiental Proyecto Hidroeléctrico Yacyretá." Informe Final. C.C. EBY.

1992b y 2002a (Actualización). "Plan de Manejo Medio Ambiente (PMMA)". Informes Finales Aprobados. C.C. EBY. 
1992c y 2006 (Actualización). "Plan de Acción para el Reasentamiento y la Rehabilitación (PARR)": Informes Finales Aprobados. C.C. EBY.

- , 2001. "Plan de Infraestructura Social y Medioambiental para culminar el llenado del embalse de Yacyretá (PISMA)”. Informe Final Aprobado. C.C. EBY.

(PEY’ 2002)”. Informe Final Aprobado. C.C. EBY.

2002b. "Plan Estratégico Yacyretá, para le terminación del proyecto , 2003. "Informe sobre la Solicitud de Inspección al Mecanismo de Investigación Independiente del BID. Reclamaciones presentadas por la Federación de Afectados por Yacyretá de Itapúa y Misiones (FEDAYIM)”. Informe del Ejecutor. C.C. EBY.

2004. "Plan de Terminación de Yacyretá (PTY)". C.C. EBY.

(Informe Final Grupo de Trabajo). C.C. EBY.

, 2005a. "Subembalses: arroyos Mártires, Zaimán, Mboi Caé y Quiteria" , 2005b. "Lineamientos de Ordenación y Gestión Territorial para la Región Metropolitana de Posadas y Encarnación.” Informe Final del Grupo de Trabajo Binacional. C.C. EBY.

-, 2006. "Programa de Calidad de Agua del Embalse Yacyretá". Informe Anual año 204-2005. Convenio Centro Regional de Investigación y Desarrollo (CONICET), Facultad de Ciencias Exactas, Químicas y Naturales (UNaM), Entidad Binacional Yacyretá. C.C. EBY.

2007. “Apoyo al Desarrollo Municipal. Municipios de Argentina y Paraguay”. Informe para el Banco Interamericano de Desarrollo. C.C. EBY.

, 2009a. "Programa de Medio Ambiente Reasentamiento: Informe de Cierre del Préstamo BID 760/OC-RG”. Informe del Ejecutor. C.C. EBY.

-, 2009 b. "Programa de Calidad de Agua del Embalse Yacyretá". Informe Anual: periodo 2008-2009. Sector Medio Ambiente EBY. Convenio Marco Entidad Binacional Yacyretá, Universidad Nacional de Misiones, Facultad de Ciencias Exactas, Químicas y Naturales. C.C. EBY.

ción a septiembre de 2009." Informe de Actualización Trimestral. C.C. EBY. , 2009c. "El Plan de Terminación de Yacyretá (PTY), estado de ejecu2010. “El Proyecto Hidroeléctrico Yacyretá”. http://www.yacyreta.org.ar/

ETORENA, Alba Celina / FREAZA, José Carlos, 2010. "Memorias de la ciudad, sus orígenes y protagonistas". Entrevista sobre la presentación del libro Historia de Posadas. Primera Edición, domingo 16 de mayo de 2010, pág. 10-11. Posadas, Misiones, Argentina.

FERREIRA DE CAMARGO, Fernando; FRANÇA, Antonio Carlos; DA SILVA NOFFS, Paulo, 2010. "Evaluación Ambiental Independiente: Informe Final” PMMA, C.C. Entidad Binacional Yacyretá, Argentina-Paraguay.

FLORES, López y Albert A. 1995. La contaminación y sus efectos en la salud y el ambiente. Centro de Ecología y Desarrollo AC., México.

FONTANARI, Enrico, 2007. "Paisaje y Planificación”, Seminario de la Maestría Paisaje, Medio Ambiente y Ciudad, FAU/UNLP, marzo, La Plata, Argentina.

FUNDACIÓN CEPA, 1985. "Ecología Urbana del Sistema Urbano Pampeano”, Proyecto 11/ MAB, UNESCO. Fondo Editorial CEPA, La Plata, Argentina.

1992. "Tecnologías Apropiadas: la vuelta a las energías limpias, el futuro de Yacyretá", Revista A/MBIENTE N ${ }^{\circ}$ 74, pp. 13 a 16. Editorial A/MBIENTE, La Plata, Argentina.

compilación), 2005. “La Sustentabilidad Hoy”, Fondo Editorial CEPA, La Plata, Argentina.

FUNDACIÓN CEPA y FLACAM, 1995. “Asunción 2000: Desarrollo Urbano y Sustentabilidad”, Documento Ambiente No 3. Serie: "Construcción de la Ciudad”, La Plata, Argentina.

FUNDACIÓN PROTEGER, 2010. “Crece el Reclamo Mundial contra las Represas”. Publicado en http://www.proteger.org.ar/doc25.html

FULCO, Carlos (Dir.)... [et $a$ ], 1993. “Ordenamiento Integral de la Infraestructura de Servicios de San Carlos de Bariloche". Consejo Federal de Inversiones (CFI), Buenos Aires, Argentina.

-, 1995. "Ordenamiento Ambiental de la Ciudad de San Carlos de Bariloche”. Consejo

Federal de Inversiones (CFI), Buenos Aires, Argentina. 1996. "Estrategias de Gestión Territorial en Áreas Protegidas, Departamento Bariloche, Eje Andino Patagónico Bariloche - El Bolsón”. Consejo Federal de Inversiones (CFI), Buenos Aires, Argentina. 
FULCO, Carlos, Blanco, Paola, Romero, Alcira, Cárcamo, Javier. 2008. "Valores Identitarios. Parque Pereyra Iraola: hacia un modelo alternativo de desarrollo del paisaje”. Taller de aplicación y experimentación. Maestría Paisaje, Medio Ambiente y Ciudad. Facultad de Arquitectura y UNLP (inédito). La Plata, Argentina.

GARCÍA CANCLINI, Néstor, 1989. Culturas Hibridas Estrategias para entrar y salir de la modernidad. Ed. Grijalbo. México D.F.

$1^{\circ}$ Reimp. Buenos Aires, Argentina.

2007. Imaginarios Urbanos. EUDEBA Universidad de Buenos Aires, $3^{\circ}$ Edic.

GARCÍA DELGADO Daniel, et al, 1997. Hacia un Nuevo Modelo de Gestión Local: Municipio y Sociedad Civil en Argentina. FLACSO, UBA y UCC. Buenos Aires, Argentina.

bral del tercer milenio. Espasa Calpe/Ariel 1998.

GARNIER, Alan, 1994. El Cuadrado Roto: Sueños y Realidades de La Plata. La Plata, Argentina. Talleres Gráficos de "Los Tilos" Cooperativa de Trabajo Ltda. Edición original (1989), Departamento de Arquitectura, Escuela Politécnica Federal, Lausana, Suiza.

GIACOMINI, Valerio, 1983. “Roma”. Programa MaB, UNESCO.

GIMÉNEZ, Ramón, 1988. Esto es Itapúa. Encarnación, Paraguay.

GLOBAL CONSULTORES, 2008. "Plan de Gestión Integrado de las Cuencas de los arroyos Quiteria y Mboi Caé.” Informe Final. C.C. Entidad Binacional Yacyretá, Argentina-Paraguay.

GOBIERNO DE ESPAÑA, 2000. “Guías Metodológicas para la elaboración de Estudios de Impacto Ambiental de Grandes Presas”. Serie Monografías, Secretaría de Medio Ambiente, Centro de Publicaciones de la Secretaría General Técnica, Ministerio de Medio Ambiente, Madrid, España.

GOBIERNOS DE LAS REPÚBLICAS DE ARGENTINA, BOLIVIA, BRASIL, PARAGUAY Y URUGUAY, 1969. "Tratado De La Cuenca Del Plata”. Brasilia, República Federativa de Brasil.

GÓMEZ, Jorge R. 2010. “La Lengua Guaraní.” Publicado en http://www.educar.org/Kunumi/

GONZÁLEZ, Natalicio, 1988. Proceso y formación de la cultura paraguaya. Edición Cuadernos Republicanos. Asunción del Paraguay.

1997 (1964). Geografia del Paraguay. CEERRE. Asunción del Paraguay.

GORELIK, Adrián, 2004. Miradas sobre Buenos Aires: historia cultural y crítica urbana. Siglo XXI Editores Argentina S.A.

GROPPA, Octavio, 2006. "Aproximaciones al desarrollo: Primera Parte”, en Revista Valores en la Sociedad Industrial, año XXIV, $\mathrm{N}^{\circ} 65$, pp. 35-44, Universidad de La Rioja, Argentina.

HARZA Y CONSORCIADOS, Consultores Internacionales de Yacyretá (CIDY), 2002. "Plan de Control Ambiental: Obras de Protección de los Arroyos Aguapey y Tacuary”. Informe Final. C.C. Entidad Binacional Yacyretá, Argentina-Paraguay.

INSTITUTO NACIONAL DEL AGUA, 2002. "Simulación Numérica de la Estratificación Térmica en el Embalse de Yacyretá.” Proyecto LHA-INA. Laboratorio del Agua. Inédito. Buenos Aires, Argentina. C.C. EBY.

INSTITUTO PROVINCIAL DE ESTADÍSTICA Y CENSOS (IPEC), 2008. Anuario Estadístico de Misiones. IPEC, Posadas, Provincia de Misiones, Argentina.

INTERNATIONAL HYDROPOWER ASSOCIATION, 2010. Recomenmended Final Draft Hydropower Sustainability Assessment Protocol. Background Document. Early Stage, Preparation, Implementation and Operation Assessment Tool. Edition, IHA.

ISOLA, Aimaro (ricerche coordinatte), 2002. Forme Insediative e Infrastrutture. Politecnico di Torino, Dipartimento di progettazione architettonica. Editoriale Marsilio Editori s.p.a., Italia.

KIELY, Gerard., 1999.INGENIERÍA AMBIENTAL. Fundamentos, entornos, tecnologías y sistemas de gestión. Título original: Environmental Engineering. Traducción coordinada por José Miguel Veza. Derechos Reservados por McGraw-Hill/Interamericana de España, S.A.U. Edit. Antonio García Brage. Impreso en Impresos y Revistas, S.A. (Impresa), Madrid, España.

KROEBER, Clifton B., 1967. La navegación de los ríos en la historia argentina, 1794-1860. PAIDOS, Buenos Aires, Argentina. 
LE DANTEC, Jean Pierre, 2007. "País y Paisaje, historia y teoría". Seminario de la Maestría Paisaje, Medio Ambiente y Ciudad, 26 al 28 de marzo. FAU, UNLP. La Plata. Argentina

LEVINTON, Norberto, 2007. YACYRETÁ. Una Nueva Significación. La Relación entre el espacio y sociedad como consecuencia de la implantación de un megaproyecto. Entidad Binacional Yacyretá. Edit. Goleen Company SRL. Casano Gráfica S.A. Buenos Aires, Argentina.

,2009a. El espacio jesuítico-guaraní: la formación de una región cultural. Colección Bicentenario. Centro de Estudios Antropológicos de la Universidad Católica (CEDUC). Biblioteca de Estudios Paraguayos - Volumen 80. Editora Litocolor SRL, Asunción, Paraguay.

2009b. San Ignacio Miní: La identidad arquitectónica. Colección Arquitectura y Patrimonio. Contratiempo Ediciones. Buenos Aires, Argentina.

-, 2009c. "Antecedentes misioneros jesuítico-guaraníes en el área de Ituzaingó y Ayolas. Los puertos del Itú." Mimeo, inédito. Buenos Aires, Argentina.

, 2010. "Yacyretá: El fin de la historia. La influencia de los Gobiernos argentinos y paraguayos en el Tratado, en el proyecto y en la construcción." Entidad Binacional Yacyretá. Edit. Contratiempo Ediciones. Buenos Aires, Argentina.

LINS RIBEIRO, Gustavo, 2003 (1999). Capitalismo transnacional y política hidroenergética en la Argentina: la Represa de Yacyretá. Editorial Universitaria de Misiones, Posadas, Argentina.

LYNCH, Kevin, 2008 (1984). La Imagen de la Ciudad. Título original: The Image of the City. Editorial Gustavo Gil, SL, Barcelona, España.

MADERUELO, Javier (Dir.)... [et. al.], 2006. Paisaje y Pensamiento, ABADA Editores S.L., Madrid, España.

MAEDER, Ernesto J. A., 1992. Misiones del Paraguay, conflicto y disolución de la sociedad guaraní, Editorial MAPFRE, Madrid, España.

MALDONADO, Tomás, 1999 (1990). Hacia una Racionalidad Ecológica. Título original: Cultura, democrazia, ambiente. Saggi sul mutamento, Feltrinelli, Milán, Italia. Versión castellana: Lomónaco, Alexandra Ediciones Infinito, Buenos Aires, Argentina.

MARTÍNEZ ESTRADA, Ezequiel, 2007 (1934). Radiografia de la Pampa. $1^{\circ}$ Ed.: Losada, Bs. As., Argentina.

MELIÁ, Bartomeu, 1988. El guaraní conquistado y reducido. Universidad Católica de Asunción. Paraguay.

MICÓ, Tomás, 1975. Antecedentes históricos de Encarnación de Itapúa, (s.d.). Asunción del Paraguay.

MILANI, Raffaelle, 2007 (2005). El arte del paisaje. Título original: L'arte del paessaggio, Società editrice Il Mulino, Italia. Versión castellana: Edición de Federico López Silvestre. Paisaje y Teoría, Editorial Biblioteca Nueva, S.L., Madrid, España.

MILLER, George Tyler Jr., 1994 (1992). Ecología y medio ambiente. Title original: Living in Environmental An Introduction to Environmental Science, Wadsworth Publishing Company, EEUU. Edición castellana: Trad. Irma de León Rodríguez y Virgilio González Velázquez - Coord. Francisco Panlagua Bocanegra. Grupo Editorial Iberoamérica, México DF.

MINISTERIO DE ECONOMÍA Y OBRAS PÚBLICAS DE LA PROVINCIA DE MISIONES, 1957. "URBIS: Plan Regulador de la Ciudad de Posadas". Archivo General de la Gobernación. Posadas, Misiones, Argentina.

MINISTRO DE PLANIFICACIÓN FEDERAL, INVERSIÓN PÚBLICA Y SERVICIOS, 2008. Plan Estratégico Territorial: 1816-2016 Argentina del Bicentenario. Oporto, Graciela Rubén (Coord. Técnica). Editado por Impresora Alloni SRL, Buenos Aires, Argentina.

MOGUER, Magnus. Actividades políticas y económicas de los jesuitas en el Río de la Plata. 1985 (1953). Hyspamérica, Buenos Aires, Argentina.

MONSALVE MORALES, Lorena L. 2008. "Patrimonio Cultural y Material y su Salvaguardia: apuntes sobre su tratamiento en América Latina". Boletín Gestión Cultural N 17: Gestión del Patrimonio Inmaterial. Septiembre de 2008 ISSN: 1697-073X. CRESPIAL, Lima, Perú.

MORELLO, Jorge H. / MATTEUCCI, Silvia D. / RODRÍGUEZ, Andrea F. / MENDOZA, Nora E. 2004. El Alto Paraná Encajonado argentino-paraguayo: mosaico de paisajes y conservación regional. $1^{\circ}$ ed. Ediciones FADU, UNESCO (Colección Encuadres), Buenos Aires., Argentina.

MUMFORD, Lewis, 1960. La cultura de las ciudades. Editorial Infinito, Buenos Aires, Argentina. 
MUNICIPALIDAD DE ENCARNACIÓN, 2006. "Resolución Municipal N 493/06: Lineamientos de Ordenamiento Urbano-Territorial y Criterios de Gestión para el Municipio de Encarnación”. Encarnación, Paraguay.

MUNICIPALIDAD DE GARUPÁ, 2010. Plan Urbano-Ambiental. Plan Estratégico Garupá 2025. Inédito.

MUNICIPALIDAD DE POSADAS, 2002. “Ordenanza N 917/02: Código Urbano y Zonificación”. Posadas, Misiones, Argentina.

2010. "Plan Estratégico Posadas 2022". Posadas, Misiones, Argentina.

2011. “Ordenanza No 2916/11: Ordenamiento Urbanístico del Frente

Fluvial de la Ciudad de Posadas". Posadas, Misiones, Argentina.

NOGUÉ, Joan (ed.), et. al., 2007. La Construcción Social del Paisaje. Paisaje y Teoría, Editorial Biblioteca Nueva, S. L., Madrid, España.

PASTORE, Carlos. La lucha por la tierra en el Paraguay, 1972. Editorial Antequera, Montevideo, República Oriental del Uruguay.

PESCI, Rubén / PÉREZ, Jorge (Comp.), et. al., 1995. Proyectación Ambiental. Documento Ambiente $\mathrm{N}^{\circ}$ 2. Serie Desarrollo Sustentable. Foro Latinoamericano de Ciencias Ambientales (FLACAM), La Plata, Argentina.

PESCI, Rubén, 1985. La Ciudad In-urbana. Editorial CEPA. Talleres Gráficos Litodar, Buenos Aires, Argentina. , 1992. "Confiabilidad crediticia global y el futuro de Yacyretá", en A/MBIENTE No 74, pp. 26 a 27. Editorial A/MBIENTE, La Plata, Argentina.

1999. La Ciudad de la Urbanidad. Fundación CEPA. Editado por Artes Gráficas Sifer SRL, Buenos Aires, Argentina.

, 2007. AMBITECTURA, Hacia Un tratado de arquitectura, ciudad y ambiente. Editorial CEPA y Ediciones al Margen, La Plata Argentina.

PICHS MADRUGA, Ramón, 2004. "Medio Ambiente y Desarrollo (1964-2004)", en "Los últimos 40 años de la economía mundial". Centro de Investigaciones de la Economía Mundial-CIEM-, Documento de Trabajo 09/04, Vol. II, pp. 4-23, La Habana, Cuba.

RAVELLA, Olga, 2001. La Planificación Urbana Regional. Origen, presente y Futuro. Editorial de la Universidad Nacional de La Plata, La Plata, Argentina.

RAVELLA, Olga / VARELA, Leonardo (Comp.), et. al., 2008, Diseñando el Paisaje: Trabajos del taller de proyectos. Maestría Paisaje, Medio Ambiente y Ciudad, UNLP, Prometeo Libros, Buenos Aires, Argentina.

REHO, Matelda, 2007. "El Manejo de las Transformaciones del Paisaje", Seminario de la Maestría Paisaje, Medio Ambiente y Ciudad, FAU/UNLP, 4 al 7 septiembre, La Plata, Argentina.

REVERCHÓN, Ramón Enrique, 2009. "Encarnación, ciudad con historia" Universidad Nacional de Itapúa, Encarnación, Paraguay.

ROCCATAGLIATA, Juan A., 1998. "Los Territorios del Futuro: una renovación conceptual en la ordenación del territorio”, en Revista Ambiente N ${ }^{\circ} 77$, La Plata, Argentina.

ROGER, Alain, 2007 (1997). Breve Tratado del Paisaje. Título original: Court traité du paysage, Éditiones Gallimard, París, Francia. Versión castellana: Edición de Javier Maderuelo. Paisaje y Teoría, Editorial Biblioteca Nueva, S.L., Madrid, España.

RUBIANI, Jorge. 2001. "Paraguay de Antes". http://www.meucat.com/. Basado en la obra "Postales de La Asunción de Antaño".

SALVADOR PALOMO, Pedro J., 2003. La Planificación Verde en las Ciudades. Editorial Gustavo Gili, SA, Barcelona, España.

SÁNCHEZ QUELL, Hipólito. 1981 (6 edición): Estructura y Función del Paraguay Colonial. Editores Casa América y Librería Comuneros, Asunción del Paraguay.

SANTOS, Milton, 1965. A Cidade nos países subdesenvolvidos. Editora Civilização. Rio de Janeiro, Brasil. , 2000 (1997). La naturaleza del espacio Técnica y Tiempo. Razón y Emoción. Editorial Ariel S.A. Barcelona, España.

SECRETARÍA DE TURISMO DE LA NACIÓN, 2005. TURISMO 2016: Argentina, Plan Federal Estratégico de Turismo Sustentable. Rubén (Coord. Técnico). Consejo Federal de Inversiones. Editado por Centro de Comunicación de la Fundación CEPA (FLACAM), La Plata, Buenos Aires, Argentina. 
SEPP, Antonio, 1973 (1709). Relación de viaje a las Misiones Jesuíticas. Buenos Aires, EUDEBA.

SERIÉ, Pedro. 1935. "Una Excursión Científica por los ríos Paraguay, Alto Paraná e Iguazú, en 1892”. Revista Geográfica Americana $\mathrm{N}^{\circ}$ 27. http://www.histarmar.com.ar/InfHistorica/ExpCientParaguay1892.htm

SILVESTRI, Graciela y ALIATA, Fernando, 2001. El Paisaje como cifra de armonía. Ediciones Nueva Visión, Buenos Aires, Argentina.

SNIHUR, Esteban A., 2007. El Universo Misionero Guaraní: un territorio y un patrimonio. Programa Misiones Jesuíticas, Ministerio de Ecología, Recursos Naturales Renovables y Turismo, Gobierno de la Provincia de Misiones, Entidad Binacional Yacyretá. Golden Company SRL, Buenos Aires, Argentina.

SOLÀ-MORALES, Ignasi de, 2002. Territorios. Editorial Gustavo Gili, S.A., Barcelona, España.

SUAREZ, M., FRANCO, R. y COHEN, E. (Comp.), 1984 Efectos Sociales de las Grandes Represas en América Latina, CIDES (OEA), ILPES (ONU), Buenos Aires, Argentina.

TAUBER, Fernando, 1999. Municipio y Desarrollo: el nuevo desafio. Editorial de la Universidad Nacional de La Plata - IRO S.A. Buenos Aires, Argentina.

2008. "La Comunicación en la Planificación y Gestión para el Desarrollo de las Instituciones Universitarias Públicas Argentinas. Universidad Nacional de La Plata en el trienio junio 2004 - mayo 2008”. Tesis Doctoral. Director Martín Becerra. UNLP, inédito. La Plata, Argentina.

TAUBER, Fernando, et. al., 2006. La Planificación Estratégica Participativa: para el desarrollo urbano y regional. Impreso en los Talleres Gráficos de la DIEBO, La Plata, Argentina

THOMAS, Oscar A. 2010.a. "YACYRETÁ: un aporte hacia la construcción de una agenda de desarrollo regional". Disertación en las Jornadas sobre Aprovechamientos Hidroeléctricos y Desarrollo Regional. Universidad Nacional de Misiones, Argentina y Universidad Nacional de Itapúa, Paraguay. Posadas, Misiones, Argentina.

2010. b. "La Costanera de Posadas y el Plan de Terminación de Yacyretá". Entrevista para la Revista Constructor Urbano: la revista del Mercosur. Posadas, Misiones, Argentina.

UNESCO, 1986. Sistema de Inventario y Registro Automatizado de Monumentos y Sitios (TASEO). Consejo Internacional de Monumentos y Sitios. Pub. ICOMOS/SIRAMS, Buenos Aires, Argentina.

-, 1987. “Estrategias Ecológicas para Ciudades Habitables". Seminario Regional. Programa 11 MAB (El Hombre y la Biosfera). Pub. UNESCO/ROSTLAC. Montevideo, Uruguay.

2006 (1972). Textos Básicos de la Convención del Patrimonio Mundial de 1972. Centro del Patrimonio Mundial de UNESCO. Organización de las Naciones Unidas para la Educación, la Ciencia y la Cultura. París, Francia.

UNITED NATIONS ENVIRONMENT PROGRAMME (UNEP), 1992. "Declaración de la Conferencia de las Naciones Unidas sobre el Medio Humano": http://www.unep.org

VELÁSQUEZ, Rafael E., 1972. La Población del Paraguay en 1682, Asunción, Centro Paraguayo de Estudios Sociológicos, Asunción del Paraguay.

-, 1981. "Indígenas y españoles en la formación del pueblo Paraguayo", en Suplemento Antropológico. Vol. XVI N² 2, Asunción del Paraguay.

VITALONE, Cristina / ZIVANO, Graciela / FULCO, Carlos, 1996. La Región Capital, en el escenario de procesos de desarrollo del litoral bonaerense. Proyecto Región Capital, Jerarquización de la Ciudad de La Plata y Región Capital. Secretaría de Asuntos Municipales e Institucionales de la Provincia de Buenos Aires, La Plata, Argentina.

1998. "Área Costera Sur del Río de la Plata: consideraciones de base para la institucionalización de un proceso integrado de planificación y gestión. Componente Jerarquización de La Plata y Región Capital”. Proyecto PNUD Arg. 95/013. Edit. Centro de Documentación e Información del Programa de Fortalecimiento Institucional, Secretaría de Asuntos Municipales e Institucionales de la Provincia de Buenos Aires. La Plata, Argentina.

WATSUJI, Tetsuro, 2006. ANTROPOLOGÍA DEL PAISAJE "climas, culturas y religiones". Ediciones SIGUEME, Salamanca, España.

WHIGHAM, Thomas y COONEY, Jerry (Edit.), 2006. Campo y frontera. El Paraguay al fin de la era colonial. Servilibro, Asunción del Paraguay.

WIKILIBROS, 2008. "Impactos Ambientales de las Presas Hidráulicas", http://es.wikibooks.org/wiki/ Impactos ambientales/ resa hidr\%C3\%Alulica 